\title{
Final Report: Pilot-scale Cross-flow Filtration Test - Envelope A + Entrained Solids
}

by

M. R. Duignan

Westinghouse Savannah River Company

Savannah River Site

Aiken, South Carolina 29808

B. Skwarek

Point of Contact $-5-9038$

DOE Contract No. DE-AC09-96SR18500

This paper was prepared in connection with work done under the above contract number with the U.S.

Department of Energy. By acceptance of this paper, the publisher and/or recipient acknowledges the U.S.

Government's right to retain a nonexclusive, royalty-free license in and to any copyright covering this paper, along with the right to reproduce and to authorize others to reproduce all or part of the copyrighted paper. 
Final Report: Pilot-scale Cross-flow Ultrafiltration Test Using a Hanford Site Tank 241-AN-105 Waste Simulant - Envelope A + Entrained Solids

February 23,2000

M. R. Duignan, 786-5A

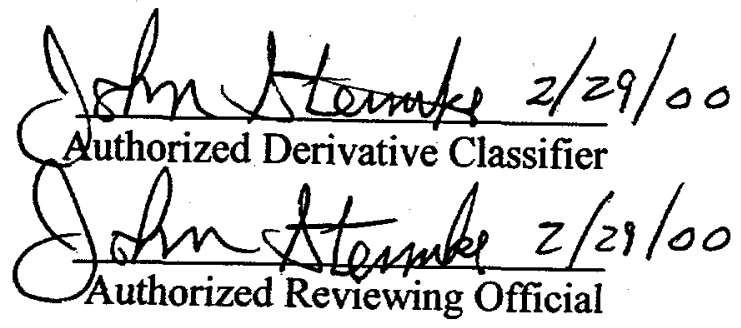

DISCLAIMER

This report was prepared as an account of work sponsored by an agency of the United States Government. Neither the United States Government nor any agency thereof, nor any of their employees, makes any warranty, express or implied, or assumes any legal liability or responsibility for the accuracy, completeness, or usefulness of any information, apparatus, product or process disclosed, or represents that its use would not infringe privately owned rights. Reference herein to any specific commercial product, process or service by trade name, trademark, manufacturer, or otherwise does not necessarily constitute or imply its endorsement, recommendation, or favoring by the United States Government or any agency thereof. The views and opinions of authors expressed herein do not necessarily state or reflect those of the United States Government or any agency thereof.

This report has been reproduced directly from the best available copy.

Available for sale to the public, in paper, from: U.S. Department of Commerce, National Technical Information Service, 5285 Port Royal Road, Springfield, VA 22161, phone: (800) 553-6847

fax: (703) 605-6900

email: orders@ntis.fedworld.gov

online ordering: http://www.ntis.gov/ordering.htm

Available electronically at http://www.doe.gov/bridge

Available for a processing fee to U.S. Department of Energy and its contractors, in paper, from: U.S. Department of Energy, Office of Scientific and Technical Information, P.O. Box 62, Oak Ridge, TN 37831-0062, phone: (865) 576-8401

fax: (865) 576-5728

email: reports@adonis.osti.gov 


\section{TABLE OF CONTENTS}

Summary

Acknowledgments

Nomenclature

List of Figures

Introduction

Experimental

Results and Discussion

Conclusions

Recommendations

Approvals

References

Appendix A: Experimental Data - Water and Cleaning

Appendix B: Experimental Data - Low Solids Concentration

Áppendix C: Experimental Data - High Solids Concentration

Appendix D: Experimental Data - Washing

Appendix E: Analytical Data

Appendix F: Measurement Uncertainty

Distribution

\section{Page}

4

5

5

6

7

8

25

47

48

49

49

51

66

134

145

166

202

226 


\section{DISCLAIMER}

Portions of this document may be illegible in electronic image products. Images are produced from the best available original document. 


\section{SUMMARY}

This report discusses the results of the operation of a cross-flow filter in a pilot-scale experimental facility that was designed, built, and run by the Experimental Thermal Fluids Laboratory of the Savannah River Technology Center of the Westinghouse Savannah River Company. This filter technology was evaluated for its inclusion in the pretreatment section of the nuclear waste stabilization plant being designed by BNFL, Inc. The plant will be built at the U.S. Department of Energy's Hanford Site as part of the River Protection Project.

The filter element under study was recommended by BNFL, Inc. and it was manufactured by the Mott Metallurgical Corporation in Connecticut. The filter unit contained seven 316 stainless steel sintered metal tubes. Each tube had an inside diameter of 0.375 inch, an outside diameter of 0.5 inch, a porous length of 40 inches, and a filter pore size that is classified as a nominal rated 0.1 micron. These dimensions give an active filter surface area of $2.29 \mathrm{ft}^{2}$. At the time of this task these aforementioned dimensions were given as prototypic, therefore each filter tube was considered full size to the filter, which would be built for the plant. Only the number of tubes was expected to change.

The filter was tested with a simulated nuclear waste of Tank 241-AN-105, which is referred to as envelope $A$ waste. The recipe for the simulant was developed by Waste Process Technology section of SRTC and the simulant was made by TFL personnel specifically for this task. The supernatant portion of the simulant was non-organic, alkalinic, $\mathrm{pH}>14$, and had molarities of sodium, nitrates, and nitrites, of approximately 5 $\mathrm{M}, 1.4 \mathrm{M}$, and 1.2 M, respectively. To the supernatant insoluble solids were added to simulate those in the real waste. The solids loading began at $0.5 \mathrm{wt} \%$ and then was eventually raised to about $16 \mathrm{wt} \%$ during the test. The particle sizes ranged from 0.5 to 5 microns by design. At $25^{\circ} \mathrm{C}$, and a solids loading of $0.5 \mathrm{wt} \%$, this slurry had a density of approximately $1.23 \mathrm{~g} / \mathrm{mL}$, a viscosity of $3 \mathrm{cP}$, and Newtonian rheological characteristics. However, as the solids loading increased a yield stress was present, but it dropped very fast to revert to a Newtonian fluid while in motion. The flow conditions for the test varied: Axial slurry velocities ranged from $3 \mathrm{ft} / \mathrm{s}$ to $15 \mathrm{ft} / \mathrm{s}(1 \mathrm{~m} / \mathrm{s}$ to $4.6 \mathrm{~m} / \mathrm{s})$ and transmembrane pressures ranged from 15 psid to 70 psid $(100 \mathrm{kPa}$ to $480 \mathrm{kPa})$ at a temperature of $25^{\circ} \mathrm{C}$.

The results showed a good filtrate flux and separation. Under the optimum flow conditions of a slurry velocity of $12.4 \mathrm{ft} / \mathrm{s}$ and a transmembrane pressure of $42 \mathrm{psid}(3.8$ $\mathrm{m} / \mathrm{s}$ and $300 \mathrm{kPa}$ ), the observed filtrate flux was consistently greater than $0.10 \mathrm{gpm} / \mathrm{ft}^{2}$ $\left(4.1 \mathrm{lpm} / \mathrm{m}^{2}\right)$, even without backpulsing for more than 7 hours. However, a backpulse frequency of 30 minutes would increase the flux to $0.16 \mathrm{gpm} / \mathrm{ft}^{2}\left(6.5 \mathrm{lpm} / \mathrm{m}^{2}\right)$. A filtrate flux could be maintained above $0.10 \mathrm{gpm} / \mathrm{ft}^{2}$ as the insoluble solids loading increased to $16 \mathrm{wt} \%$ and at no time did the filter plug from a slurry cake build up. To free the filter surface of the slurry cake, a volume of only $0.036 \mathrm{gal} / \mathrm{ft}^{2}\left(1.17 \mathrm{liters} / \mathrm{m}^{2}\right)$ was needed. This backpulse volume leads to a lost flux of $0.0012 \mathrm{gpm} / \mathrm{ft}^{2}\left(0.05 \mathrm{lpm} / \mathrm{m}^{2}\right)$ for a backpulse frequency of 30 minutes. Finally, for all test runs the measurable amount of insoluble solids was insignificant in the filtrate. 


\section{ACKNOWLEDGMENTS}

The author would like to thank all that were involved in this task. Andy Foreman's care and dedication in running this experiment allowed it to be successfully completed. Support from the other Experimental Thermal Fluids Laboratory personnel: Mike Armstrong, Vern Bush, Jimmy Mills, and Jerry Corbett was instrumental in keeping the experiment on track and maintaining the test rig ready, from instrumental calibration to last minute changes that were needed due to unforeseen difficulties. The Lab supervisor, Susan Hatcher, is to be commended for keeping us safe, even when things seemed to be the most hectic. A special thanks is in order to all those individuals just mentioned for the long hours they invested in the experiment, which at times disrupted their family life. I would also like to thank Charles Nash and John Steimke for their help in planning the test from their expertise and past work in filtration. The management of both Dan Burns and Martha Ebra made this task's successful completion a sure thing. Thanks to Hector Guerrero who had the unenviable task of reviewing this report, and to Gwen Watts, who would probably want to forget all the cutting and pasting. Finally, I would like to thank both my SRS customer, Steve Wach, and my BNFL customers, Paul Townson and Mike Johnson, for their support and insight, which made this work possible.

\section{NOMENCLATURE}

$\begin{array}{ll}\text { BNFL } & \text { BNFL, Inc. } \\ \text { DIF } & \text { Deionized and Filtered (0.2 micron) Water } \\ \text { i.d. } & \text { Inside Diameter } \\ \text { LAW } & \text { Low Activity Waste } \\ \text { nominal } & \text { The word "nominal" for a filter rating is a vague term because its meaning } \\ & \text { is manufacturer depend. Further, a "nominal" rating does not give an } \\ & \text { exact size to a filter medium; but rather an approximation to the expected } \\ & \text { performance of a filter. In the case of Mott, a nominal rated } 0.1-\mu \mathrm{m} \text { filter } \\ & \text { means that approximately 95\% of particles greater than } 0.1 \mu \mathrm{m} \text { will not } \\ & \text { pass the filter. } \\ \text { RPP } & \text { River Protection Project } \\ \text { o.d. } & \text { Outside Diameter } \\ \text { SRTC } & \text { Savannah River Technology Center } \\ \text { TMP } & \text { Transmembrane Pressure (the average pressure drop across the thickness } \\ & \text { of the filter medium - perpendicular to the slurry flow.) } \\ \text { TR } & \text { Test Rig } \\ \text { TTR } & \text { Technical Task Request } \\ \text { V } & \text { Velocity of the slurry flow along the length of the filter tubes } \\ \text { WPT } & \text { Waste Processing Technology } \\ \text { WSRC } & \text { Westinghouse Savannah River Company } \\ \text { XF } & \text { Cross-flow Filter }\end{array}$




\section{LIST OF FIGURES}

This list only includes those figures in the body of this report. The figures in each of the appendices are listed at the beginning of each appendix.

Figure 1. Schematic of the Pilot-scale Cross Flow Ultrafiltration Test Facility

Figure 2. Pilot-scale Cross Flow Ultrafiltration Test Facility

Figure 3a. 7-tube bundle of nominal rated 0.1 micron filter, 3/8" i.d., 1/2" o.d., 40" long

Figure $3 \mathrm{~b}$. Upstream view of the seven-tube bundle

Figure 3c. Support plate at the mid-section of the seven-tube bundle

Figure 4. Cross-flow Filter Housing

Figure 5. Cross-flow Filter in Test Rig

Figure 6. Main Mixing Tank for the Experiment

Figure 7. Envelope A Simulant: Supernate Only

Figure 8. Envelope A Simulant: Solids Only - 0.5 wt $\%$

Figure 9. Insoluble Solids Distribution

Figure 10. Filtrate flux immediate following a backpulse

Figure 11. Axial pressure drop vs. axial velocity of water in the cross-flow filter

Figure 12. Filtrate flux Vs. axial velocity of water in the cross-flow filter

Figure 13. Reynolds Vs. axial velocity of water in the cross-flow filter

Figure 14. Normalized TMP vs. filtrate velocity in the cross-flow filter

Figure 15. Test matrix as stated in the test specification (3)

Figure 16. Particle size based on a volume distribution

Figure 17. Particle size based on a number distribution

Figure 18. Reduction of sodium with successive washings

Figure 19. Filtrate density vs. sodium during washing

Figure 20. Filtrate viscosity vs. sodium during washing

Figure 21. Oxalate changes in the filtrate during the test

Figure 22. Water Runs before and after the Env. A test

Figure 23. Cleaning run

Figure 24. Water Run at higher TMP using flowmeter Q3

Figure 25. Composite of all 17 low solids concentration test runs

Figure 26. Effect of time on filtrate flow

Figure $27 \mathrm{a}$. Effect of TMP at a slurry velocity of $6.5 \mathrm{ft} / \mathrm{s}$

Figure 27b. Effect of TMP at a slurry velocity of $9 \mathrm{ft} / \mathrm{s}$

Figure 27c. Effect of TMP at a slurry velocity of $12 \mathrm{ft} / \mathrm{s}$

Figure 27d. Effect of TMP at a slurry velocity of $12 \mathrm{ft} / \mathrm{s}$

Figure 28a. Effect of axial slurry velocity at a TMP of $20 \mathrm{psid}$

Figure $28 \mathrm{~b}$. Effect of axial slurry velocity at a TMP of 42 psid

Figure 28c. Effect of axial slurry velocity at a TMP of 71 psid

Figure 29. Long term filter operation between backpulses

Figure 30. Filter operation with an increasing backpulse frequency

Figure 31. Run 2.14: 7 wt\% insoluble solids; 26 wt\% total solids

Figure 32. Run 2.14b: 8 wt\% insoluble solids; 36 wt\% total solids

Figure 33. Typical wash test run

Figure 34. Dewatering/Plugging test run

Figure 35. Dewatering/Plugging test run with post-washed slurry

One table: Table 1. Insoluble solids in the slurry and the filtrate throughout the test 


\section{INTRODUCTION}

BNFL, Inc. (BNFL) has been contracted by the Department of Energy to design a facility to stabilize liquid radioactive waste that is stored at the Hanford Site. Because of its experience with radioactive waste stabilization, the Savannah River Technology Center (SRTC) of the Westinghouse Savannah River Company is working with BNFL to help design and test certain parts of the waste treatment facility. One part of the process is the separation of radioactive solids from the liquid wastes by cross-flow filtration. This task tested a cross-flow filter with a simulated radioactive waste, made to prototypically represent the waste chemical and physical characteristics.

This technical baseline research and development work was initiated by a Technical Task Request (TTR) (1) that was issued in October of 1998. This TTR came about from the BNFL specifications $(2,3)$ to design and test a pilot scale cross-flow filtration system. With initial documentation in place $(4,5,6)$ the task began by defining a slurry to be filtered. A recipe for a low activity waste (LAW) slurry simulant, which would contain entrained solids, was developed by the Waste Process Technology section of SRTC to represent the waste in Hanford Tank 241-AN-105 $(7,8)$. This waste is referred to as Envelope A waste. At the beginning of this task the exact composition of the complex slurry was not completely defined, however, enough information did exist to begin work by modifying an existing test rig and getting the appropriate approvals to insure its safe operation $(9,10,11)$. Previous work $(12,13,14)$ assisted in guiding the plan of this task.

Envelope A simulant was the first in a series of two that would be used in this task. This report deals solely with this first simulant to evaluate a cross-flow filter. The chosen filter was manufactured by the Mott Metallurgical Corporation to meet the required specification $(2,3)$ :

7 filter tubes with each having an inside diameter of 0.375 inch

40-inch porous length for each filter tube and made of stainless steel

Nominal rated 0.1 micron filter element (the Nomenclature explains 'nominal')

and the test rig was modified to meet the required specification $(2,3)$ :

Maximum recirculation flow of $5 \mathrm{~m} / \mathrm{s}(16 \mathrm{ft} / \mathrm{s})$

Maximum transmembrane pressure (TMP) of 80 psid

Maximum recirculation flow to be achievable at the maximum TMP

Instrumentation to monitor the recirculation flow rate, the filtrate flow rate, the

TMP, and the slurry temperature

All materials to be compatible with $1 \mathrm{M}$ nitric acid solution

All specifications were met or exceeded. A short history of task activities is:

Arrival of the filter from Mott - February 19, 1999

Shakedown activities began - March 1, 1999

Envelope A simulant was defined - March 2, 1999

Simulant was made - April 16, 1999

Permission was received from BNFL to begin testing - May 12, 1999

Test was completed - July 26, 1999

Preliminary data were sent to BNFL on November 9, 1999 (15) 


\section{EXPERIMENTAL}

Equipment

In general, the equipment assembled for this task was done to conform to the Test Specification $(2,3)$. To facilitate understanding of the experimental equipment an explanation of the salient features follows.

Test Rig

Figure 1 is a schematic of the entire Test Rig (TR) and Fig. 2 is a photograph of the same. It stood approximately 25 -feet tall and was serviced by a two-level mezzanine. The TR was much taller than the 3-foot tall filter element because it originally was used to test a 10-foot tall filter in 1994 (12). Several modifications were made in order to install the meter-long cross-flow filter. The entire TR was made of 300 series stainless steel with the majority being of 304 stainless steel.
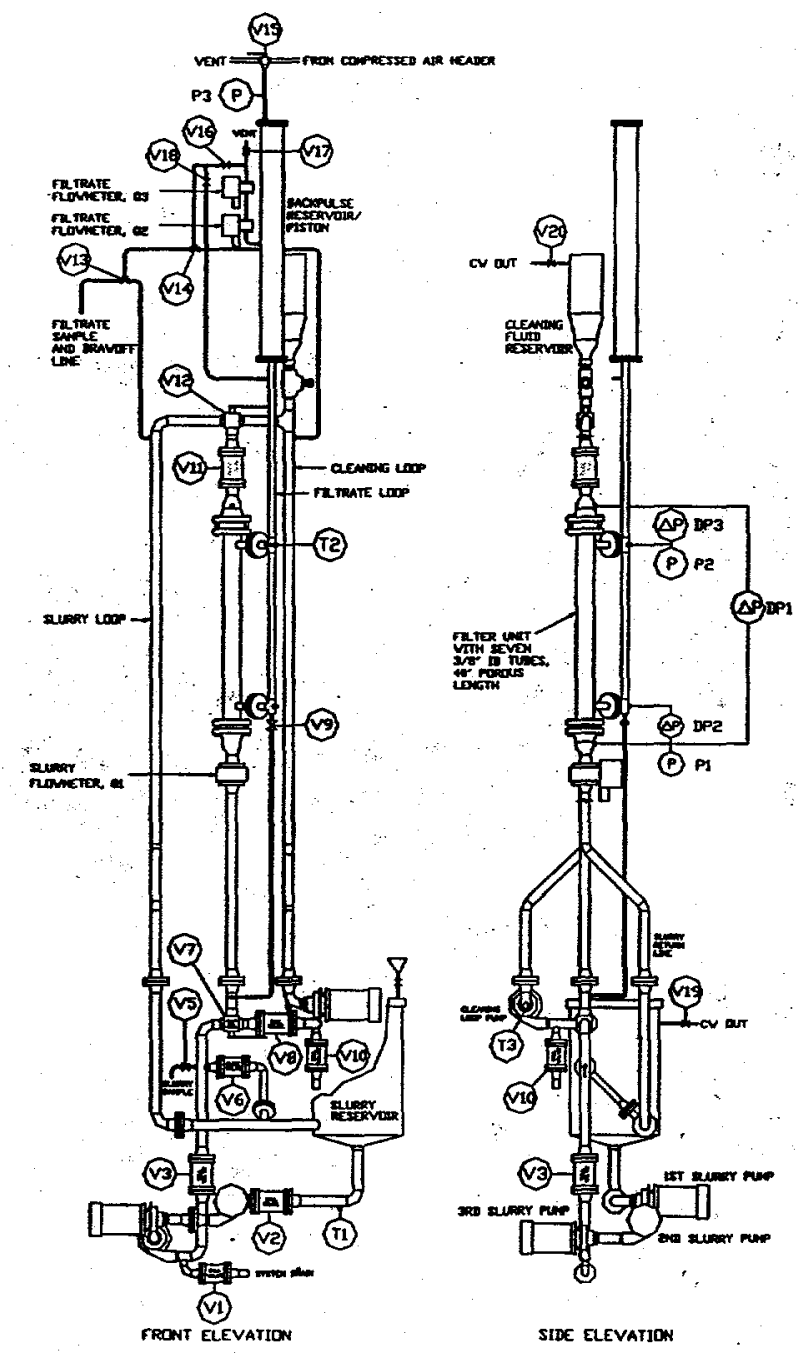

Figure 1. Schematic of the Pilot-scale Cross Flow Ultrafiltration Test Facility 


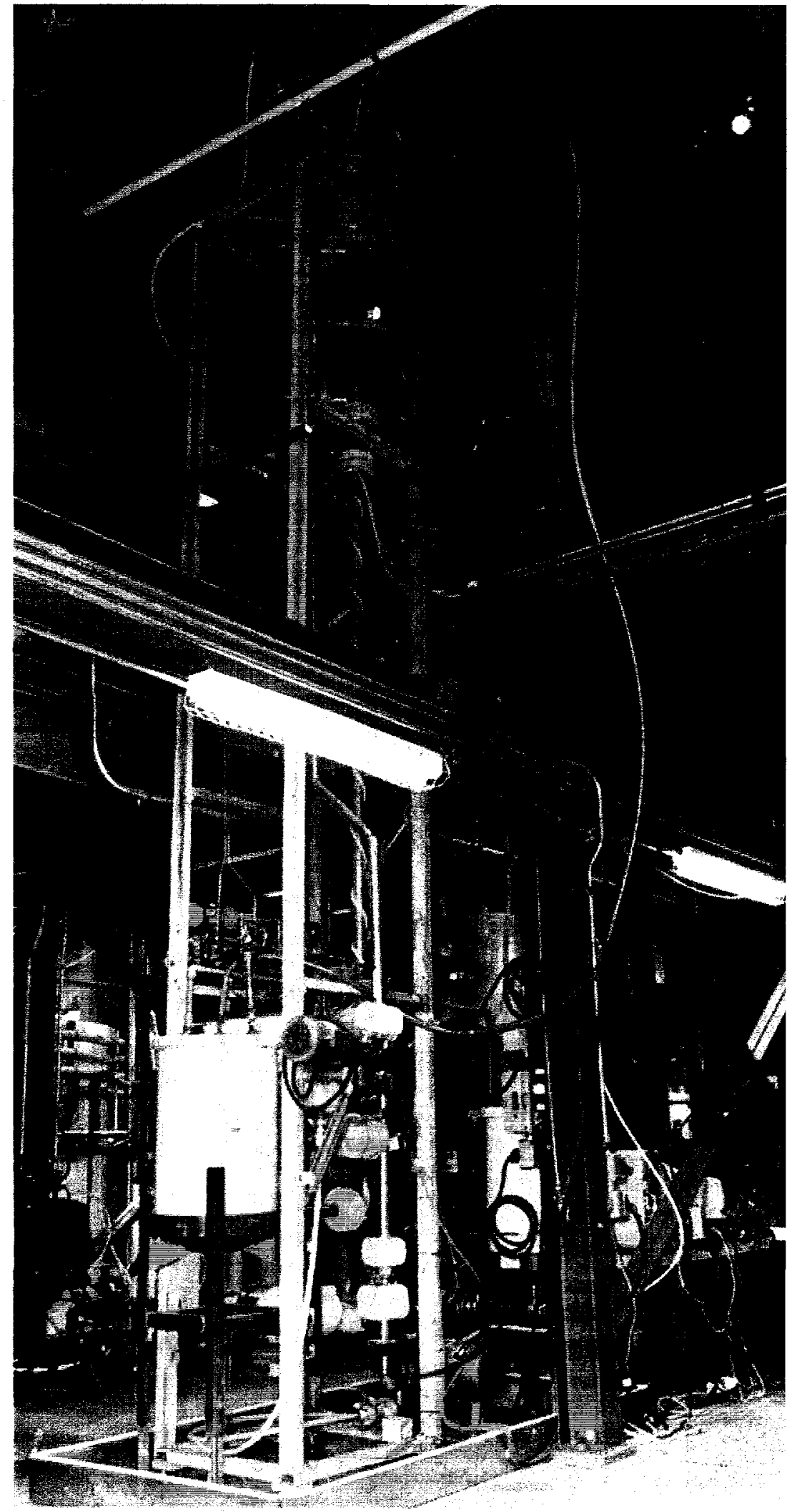

Figure 2. Pilot-scale Cross Flow Ultrafiltration Test Facility 
The TR is made up of three basic flow loops:

1. Slurry loop, which contains the filter and its housing and serves as the primary flow path for circulating slurries. This loop has an internal volume of approximately 20 liters, excluding the reservoir tank.

2. Filtrate loop, which begins at the filter housing and allows the separated filtrate liquid to flow up through the backpulse piston before returning to the top of the slurry loop to close the circuit. This loop has an internal volume of approximately 6 liters.

3. Cleaning loop, which enables cleaning of the filter in place without having to remove the slurry from the test rig by correctly orienting two 3-way valves. This loop has an internal volume of approximately 15 liters.

Two other flow circuits that are subsections of the other loops are the backpulse and the recirculations loops:

1. The backpulse loop is part of the filtrate loop and stands ready to reverse the flow of filtrate. A pulse forces filtrate back through the seven filter elements in order to knock off built-up slurry cake on the inside diameter of the porous tubes. [The backpulse piston assembly controls the amount of filtrate used for a backpulse. The maximum piston travel was 2 inches, but it was initially set at $3 / 4$ inch to inject 0.041 gallon back through the filter (the piston housing inside diameter is 4.026 inches) to attain a $0.018 \mathrm{gal} / \mathrm{ft} 2$ (the filter inside surface area was $2.29 \mathrm{ft} 2$ ), as was found in a previous filtration test (12). However, starting with test run 2.09 on 5/20/99 the injection volume was doubled to $0.036 \mathrm{gal} / \mathrm{ft} 2$ because it showed a considerable improvement in the filtrate flux recovery. Even with this volume, a backpulse frequency of 30 minutes would cause an insignificant reduction in the mean filtrate flux of $0.0012 \mathrm{gpm} / \mathrm{ft} 2$.]

2. The recirculation loop is part of the slurry loop (by using valve V6). This loop is used to: better control the slurry flow, increase mixing, and keeps the slurry wellmixed when the flow through the filter needs to be stopped.

The TR is controlled through a series of valves, which are described below:

V1: Drains slurry from the test rig

V2: Isolates the slurry reservoir from the pumps

V3: Controls the slurry (cleaning fluid) flow upstream of the filter and isolates the slurry loop from the pump

V4: Allows liquid to be introduced to the slurry reservoir

V5: Allows slurry to be samples (not used for this test)

V6: Recirculates slurry to the reservoir

V7: Directs either slurry (cleaning fluid) to the filter; 3-way valve

V8: Used for the same functions as V3 but for the cleaning loop

V9: Drains the filtrate loop

V10: Drains the cleaning loop

V11: Controls the slurry (cleaning fluid) flow downstream of the filter

V12: Directs either slurry (cleaning fluid) from the filter; 3-way valve 
V13: Directs filtrate to the sample port or back to the slurry loop; 3-way valve

V14: Directs filtrate to the to the slurry loop or to the cleaning loop; 3-way valve

V15: Allows air to pressurize the backpulse piston

V16: Shuts filtrate flow from the backpulse piston

V13: Directs either filtrate to the sample port or back to the slurry loop; 3-way valve

V17: Vents the test rig

V18: Allows filtrate to bypass the backpulse piston

V19: Allows coolant flow to the cooling coil in the slurry reservoir

V20: Allows coolant flow through the cooling coil in the cleaning fluid reservoir

To circulate slurries and liquids the test rig and mixing tank were serviced by five TEEL stainless steel centrifugal pumps:

Materials

\begin{tabular}{|c|c|c|c|c|c|}
\hline Location & Model hp & Housing & \multicolumn{2}{|c|}{ Shaft Impeller-Sleeve } & Seals \\
\hline 1.Slurry Loop & $2 \mathrm{P} 3923$ & $304 S S$ & 304SS & $303 S S$ & Graphite/Ceramic/Viton \\
\hline 2.Slurry Loop & 2P392 3 & 304SS & 304SS & 303SS & Graphite/Ceramic/Viton \\
\hline 3.Slurry Loop & $2 P 3923$ & 304SS & 304SS & 303SS & Graphite/Ceramic/Viton \\
\hline 4.CleaningLoop & $2 \mathrm{P} 3923$ & 304SS & 304SS & 303SS & Graphite/Ceramic/Viton \\
\hline 5.Mixing Tank 1 & 1P701B $3 / 4$ & 304SS & 304SS & 416SS & Graphite/Ceramic/Viton \\
\hline
\end{tabular}

Three $3 \mathrm{hp}$ pumps were used in series on the slurry loop to attain the head of $80 \mathrm{psig}$ at 40 $\mathrm{gpm}(-5 \mathrm{~m} / \mathrm{s})$ since one pump is able to produce about $28 \mathrm{psi}$ at $40 \mathrm{gpm}$ with water.

\section{Cross Flow Filter}

The heart of this entire experimental task was the cross-flow filter element that was to be tested to define its operational characteristics under required flow conditions. There were several candidates that could have been used for this test but due to availability and past experience in robust designs a Mott Filter was chosen. The specifications for the filter unit were:

Material:

Porosity:

Length:

Diameter:

Number:

\author{
316 stainless steel (sintered metal) \\ nominal rated 0.1 micron \\ 40 inches \\ 3/8-inch I.D., 1/2-inch O.D. \\ 7 tubes
}

The unit which was received from Mott met the requirements, see Figs. 3, 4, and 5. The 40-inch length was made from two 20 -inch lengths that were welded together at the center. [When subtracting the weldments at the end and middle of the tubes, the actual active porous length was $393 / 4$ inches (1.01 meter)]. The 7 tubes were welded together with the tube sheets and extra support was made with a central stabilizing plate and supporting solid metal 1/4-inch rods which ran the length of the tube bundle, Fig. 3c. From the figures it is possible to see that some of the porous surfaces were slightly marred. Because of the large surface area this marring was not expected to affect results and no effects were notice during testing. The tube housing, Figs. 4 and 5, was made 
from a 3-inch schedule 10 pipe with two pipes connected at either end to remove filtrate. For this test the filter unit was oriented vertically in the test rig, see Figs. 1, 2, and 5. The tube bundle sat in the housing such that the large tube sheet (right side of Fig. 3a) was secured to the top flange of the housing; this tube sheet also supported the weight of the assembly. The smaller, lower, tube sheet (foreground in Fig. 3b) was able to pass through the housing and separated the slurry side of the flow channel from the filtrate side with an "O" ring between the outer perimeter of the lower tube sheet and the inside diameter of the filter housing.

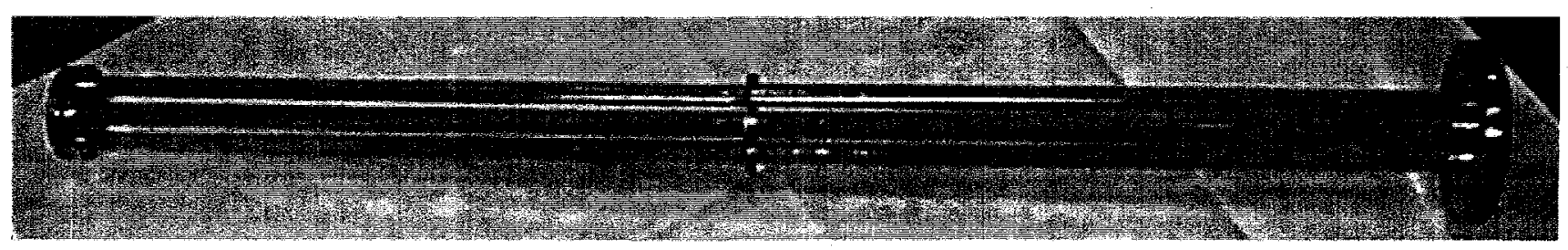

Figure 3a. 7-tube bundle of nominal rated 0.1 micron filter, $3 / 8$ " i.d., $1 / 2$ " o.d., 40 " long

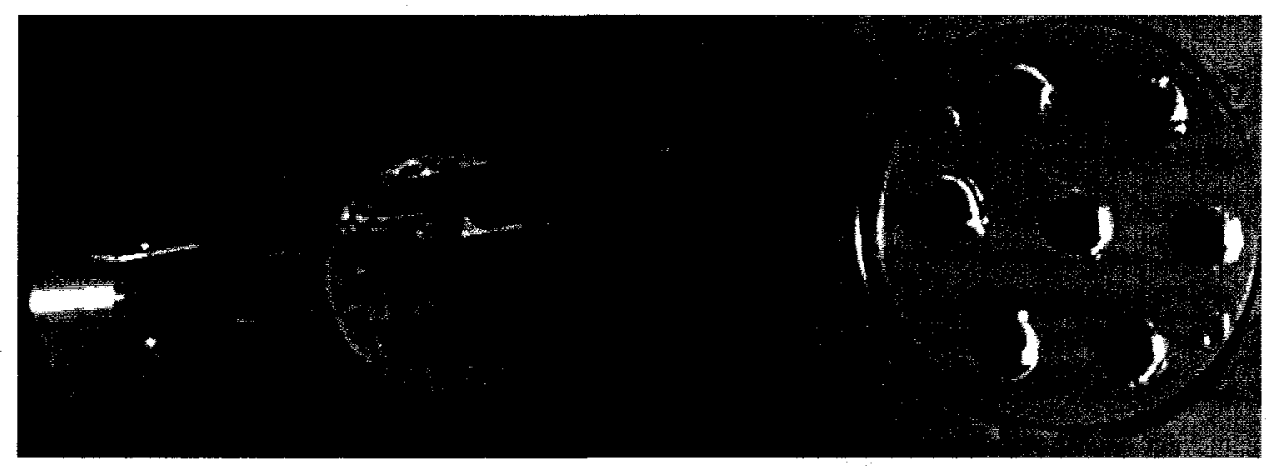

Figure 3b. Upstream view of the seven-tube bundle

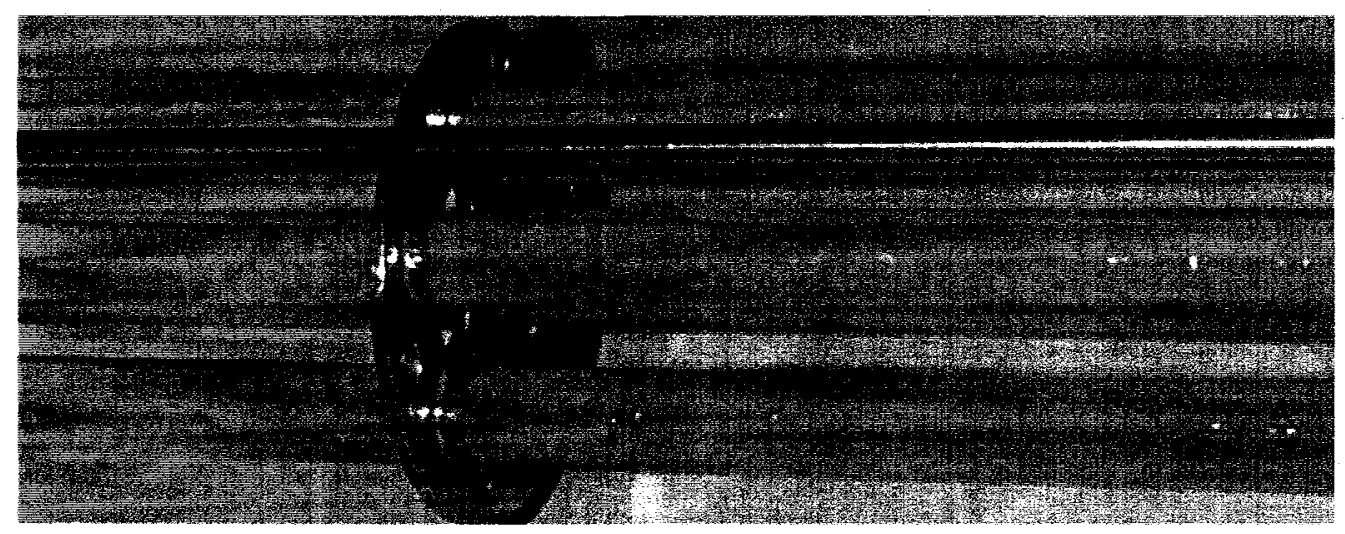

Figure 3c. Support plate at the mid-section of the seven-tube bundle 


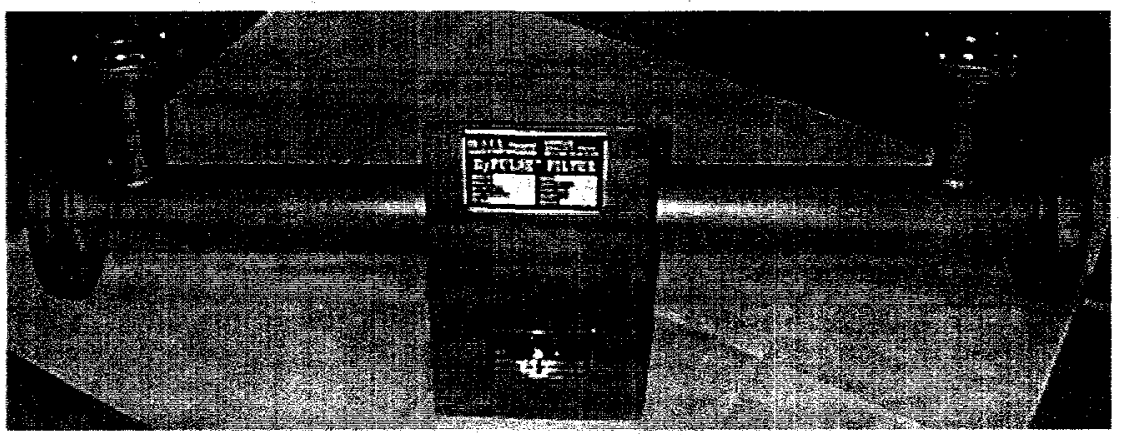

Figure 4. Cross-flow Filter Housing

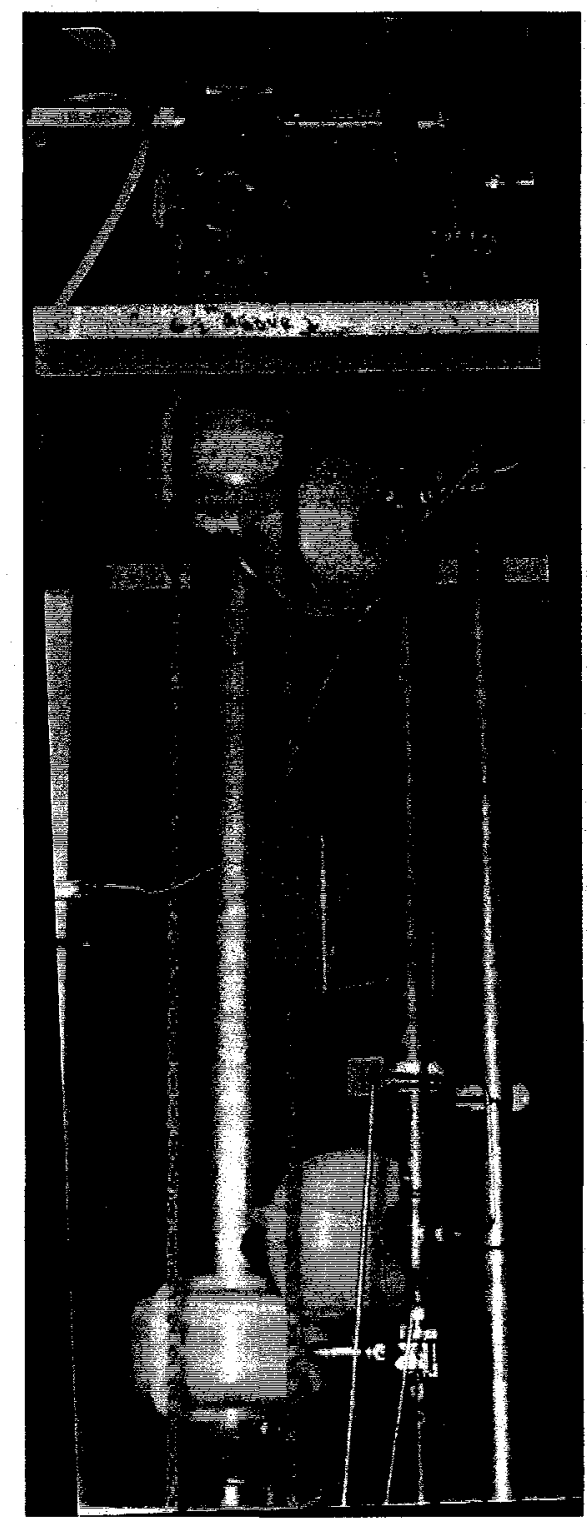

Figure 5. Cross-flow Filter in Test Rig 


\section{Mixing Tanks}

There were two main tanks used for mixing and preparing the slurry solutions:

1. The slurry reservoir was a 110-liter plastic tank that primarily served as the Test Rig reservoir. It was also used (along with the recirculation loop) as a mixing tank when solids had to be added to the slurry and was the location from where slurry samples were taken. Mixing was accomplished with the recirculation loop by using valve V6. [The slurry reservoir is shown in Fig. 1 and is the large white tank in the foreground of Fig. 2.]

2. The mixing tank (MT) was a separate 110-liter plastic tank. It served to make the 75liter batch of simulant supernate before the solids were added to complete the slurry. Since it was hard-piped to the slurry reservoir it was also used to make the cleaning fluid (1 $\mathrm{M}$ nitric acid) as well as the cleaning solution used to clean the entire test rig during shakedown activities (1\% Alconox solution - phosphate). Mixing was accomplished with the recirculation loop by using valve V23. [Figure 6 is a schematic of this tank and can be found in Fig. 2 as the lower white tank behind the vertical Ibeam at the lower right side of the photograph.]

The MT is controlled through a series of valves, which are described below:

V21: Contols the flow to the pump

V22: Drains the MT

V23: Recirculates the contents of the MT

V24: Allows the mixed contents to enter the slurry reservoir

V25: Allows liquid to be introduced into the MT

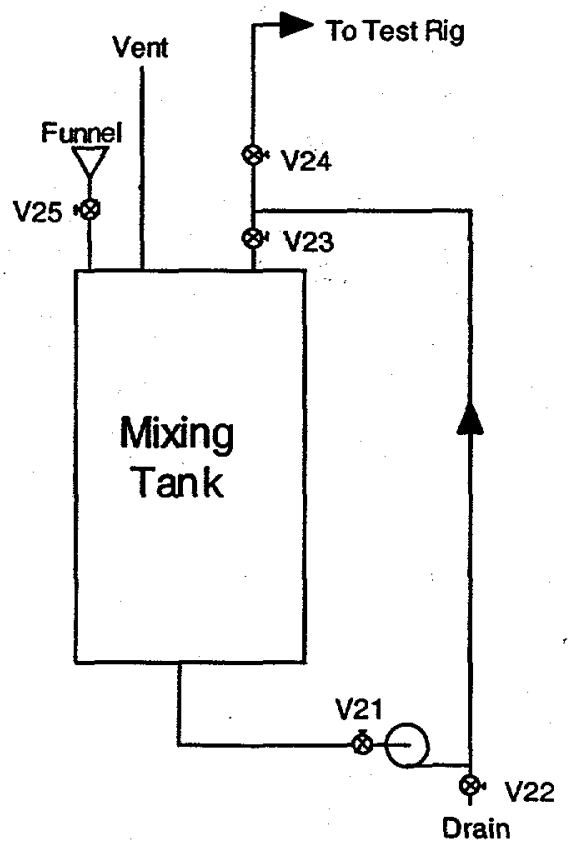

Figure 6. Main Mixing Tank for the Experiment 


\section{Instrumentation}

The measurement equipment used for this experiment was:

5 Type $\mathrm{E}$ thermocouples with accuracies from* 1.0 to $1.5^{\circ} \mathrm{C}$, 6 Variable capacitance pressure transducers with accuracies from* 0.02 to $0.38 \mathrm{psi}$, and 3 Magnetic flow meters with accuracies from* 0.005 to $0.19 \mathrm{gpm}$.

*accuracies are a function of the instrument and calibration. The uncertainty introduced through the use of the 16-bit data acquisition system was insignificant $(<0.1 \%$ reading) and was not included in the values above.

Figure F1, Appendix F, shows two tables which list all the instruments and data acquisition system (DAS) channels for each of the non-thermocouple instruments. The thermocouples had their own dedicated computer card to interface and convert the temperatures properly. The calibration of the DAS was checked and that information can also be found in Fig. F1, which includes tables and graphs that show the results and the transfer functions used for each channel.

Two instrument changes were made during this task:

1. On $3 / 24 / 99$, the pressure transducer used for $\mathrm{dP} 2$ (No. TR-00532). was recalibrated to reduce the calibrated pressure range so that the measurement uncertainty was reduced to 0.13 psid from 0.42 psid. Even though the actual experiment did not begin until May of 1999 , the pre-3/24/99 calibration was used in obtaining certain shakedown data for water and thus it is included for completeness.

2. On 7/14/99, another filtrate flowmeter was added (Q3; No. TR-03562). By this date the experiment was complete, except for the final water run 2.22. This new flow meter increased the measurable range for filtrate flow from a maximum of $1.2 \mathrm{gpm}$ to $5 \mathrm{gpm}$, or the flux from $0.52 \mathrm{gpm} / \mathrm{ft}^{2}$ to $2.18 \mathrm{gpm} / \mathrm{ft}^{2}$, respectively. However, the measurement uncertainty for the larger filtrate flow rate was larger by a factor of four. This new meter was only necessary for the water runs, since with slurry, the filtrate fluxes were always below $0.5 \mathrm{gpm} / \mathrm{ft}^{2}$.

From Figs. 1, F1, and F2 the location and the usage of each instrument can be determined, however the following list will better describe the placement and usage of all the measurement instruments:

T1 - A thermocouple located in the exit pipe of the slurry reservoir to measure the slurry temperature on its way to the filter.

T2 - A thermocouple located in the filtrate line at the end of the upper filter housing filtrate exit pipe to measure the filtrate temperature as it leaves the filter housing. T3 - A thermocouple located in the cleaning loop at the exit of the cleaning loop pump. T4 - A thermocouple located at the top of the test rig near valve V13 to measure ambient temperature.

T5 - A thermocouple located at the bottom of the test rig near valve V5 to measure ambient temperature. 
For the 6 pressure transducers also refer to Fig. F2, which indicates, pressure-line locations as well as their heights.

P1 - A gauge pressure transducer located at the beginning of the filter housing to measure the pressure of the slurry just before entering the filter tubes.

P2 - A gauge pressure transducer located in the filtrate line at the end of the upper filter housing filtrate exit pipe to measure the pressure of the filtrate as it leaves the filter housing.

P3 - A gauge pressure transducer located at the air side of the backpulse piston to measure the pressure applied to produce a backpulse.

dP1 - A differential pressure transducer located across the slurry side of the filter to measure the drop in pressure along the filter tubes.

dP2 - A differential pressure transducer located across filter and housing at the filter entrance to measure the transmembrane pressure at the beginning of the filter.

dP3 - A differential pressure transducer located across filter and housing at the filter exit to measure the transmembrane pressure at the end of the filter.

[The transmembrane pressure is determined from the average of dP2 and dP3.]

Q1 - A magnetic flowmeter located at the entrance of the filter to measure the slurry flowrate.

Q2 - A magnetic flowmeter located at the filtrate line between the exit of the backpulse piston and valve V16 to measure the filtrate flowrate.

Q3 - A magnetic flowmeter located at the filtrate line between the exit of the backpulse piston and valve V16 to measure the filtrate flowrate.

\section{Measurement Uncertainty}

Appendix $\mathrm{F}$ has all the pertinent information on the uncertainties. The measurement uncertainties (at a 95\% confidence level) for the important calculated quantities are:

$\begin{array}{llll}\text { Slurry Velocity in a Filter Tube } & = & \mathrm{V} & \pm 8.16 \% \\ \text { Transmembrane Pressure } & = & \text { TMP } & \pm 1.07 \% \\ \text { Temperature Corrected Filtrate Flux } & = & \text { Fc } & \pm 6.72 \% \\ \text { Permeability } & = & P & \pm 6.80 \%\end{array}$

These numbers are based on pre- and post-test calibrations of the instruments.

\section{Simulated Waste Slurry}

Beside the cross-flow filter, the most important aspect of this experiment was the slurry used to simulate a Hanford Site waste. The waste that was simulated is referred to as Envelope A + ES. The Envelope A components include soluble radioactive wastes in tank 241-AN-105 from the Handford Site and the ES refers to the insoluble Entrained Solids from that tank. The simulant used for this task was cold (non-radioactive), but made chemically equivalent to actual waste. The actual simulant development is beyond the scope of this task and not elaborated here. A recipe for the simulant supernate, Fig. 7, 


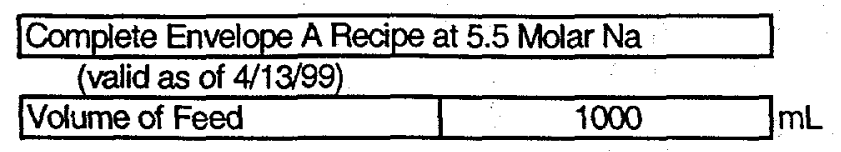

Transition Metals and Complexing agents

\begin{tabular}{|c|c|c|c|c|}
\hline Compounds & Formula & Conc., PPM & $\mathbf{M}$ & grams \\
\hline Boric Acid & $\mathrm{H} 3 \mathrm{BO} 3$ & 126 & $2.43 E-03$ & 0.150 \\
\hline Calcium Nitrate & $\mathrm{Ca}(\mathrm{NO}) 2.4 \mathrm{H} 2 \mathrm{O}$ & 102 & $5.13 \mathrm{E}-04$ & 0.121 \\
\hline Cesium Nitrate & CsNO3 & 10 & $6.27 \mathrm{E}-05$ & 0.012 \\
\hline Magnesium Nitrate & $\mathrm{Mg}(\mathrm{NO} 3) 2.6 \mathrm{H} 2 \mathrm{O}$ & 25 & $1.14 \mathrm{E}-04$ & 0.029 \\
\hline Potassium Nitrate & KNO3 & 8302 & $9.77 \mathrm{E}-02$ & 9.880 \\
\hline Zinc Nitrate & $\mathrm{Zn}(\mathrm{NO} 3) 2.6 \mathrm{H} 2 \mathrm{O}$ & 20 & 7.94E-05 & 0.024 \\
\hline Glycolic Acid & $\mathrm{HOCH} 2 \mathrm{COOH}, 70 \mathrm{wt} \%$ & 719 & $7.88 \mathrm{E}-03$ & 0.856 \\
\hline Sodium Chloride & $\mathrm{NaCl}$ & 6472 & $1.32 \mathrm{E}-01$ & 7.702 \\
\hline Sodium Fluoride & $\mathrm{NaF}$ & 181 & $5.14 \mathrm{E}-03$ & 0.216 \\
\hline Sodium Sulfate & $\mathrm{Na2SO4}$ & 492 & 4.13E-03 & 0.586 \\
\hline Potassium Molybdate & $\mathrm{K} 2 \mathrm{MOO} 4$ & 88 & $4.39 \mathrm{E}-04$ & 0.105 \\
\hline Ammonium Acetate & $\mathrm{CH} 3 \mathrm{COONH}_{4}$ & 221 & $3.42 E-03$ & 0.264 \\
\hline
\end{tabular}

In a separate container mix the following

Fill the container with water

grams

\begin{tabular}{|c|c|c|c|c|}
\hline Compounds & Formula & Conc., PPM & $\mathbf{M}$ & grams \\
\hline Aluminum Trihydroxide & $\mathrm{A} \mid(\mathrm{OH}) 3$ & 49574 & $7.56 \mathrm{E}-01$ & 58.993 \\
\hline Sodium Hydroxide & $\mathrm{NaOH}$ & 84956 & $2.53 E+\infty$ & 101.098 \\
\hline Sodium meta-silicate & Na2SiO3.9H2O & 922 & $3.86 \mathrm{E}-03$ & 1.097 \\
\hline Sodium Acetate & $\mathrm{NaCH} 3 \mathrm{COO} .3 \mathrm{H} 2 \mathrm{O}$ & 1670 & $1.46 E-02$ & 1.987 \\
\hline Sodium Formate & HCOONa & 1879 & $3.29 \mathrm{E}-02$ & 2.236 \\
\hline Sodium Oxalate & $\sqrt{\mathrm{Na}_{2} \mathrm{C} 2 \mathrm{O} 4}$ & 401 & $3.56 E-03$ & 0.477 \\
\hline Sodium Phosphate & $\mathrm{Na} 3 \mathrm{PO} 4.12 \mathrm{H} 2 \mathrm{O}$ & 985 & $3.09 \mathrm{E}-03$ & 1.173 \\
\hline
\end{tabular}

Mix thoroughly. Then add this solution to the first solution. Then

\begin{tabular}{|l|l|c|c|c|c|}
\cline { 2 - 6 } Add & Formula & Conc., PPM & M & & grams \\
\cline { 2 - 6 } & Sodium Carbonate & 9567 & $1.07 \mathrm{E}-01$ & & 11.385 \\
\hline
\end{tabular}

Mix thoroughly. Then

\begin{tabular}{|l|l|c|c|c|c|}
\cline { 2 - 5 } Add & Formula & Conc., PPM & M & & grams \\
\hline Sodium Nitrate & NaNO3 & 90607 & $1.27 \mathrm{E}+00$ & & 107.822 \\
\hline Sodium Nitrite & NaNO2 & 71911 & $1.24 \mathrm{E}+00$ & & 85.574 \\
\hline
\end{tabular}

Mix thoroughly and dilute to the mark.

The final addition of water would be, needed $=\frac{298.2}{\text { based upon a density of } 1.25 \mathrm{~g} / \mathrm{mL}}$ Needed grams \begin{tabular}{l|r} 
Final Weight & 1250 \\
\hline
\end{tabular}

Figure 7. Envelope A Simulant: Supernate Only 
and one for the simulant solids, Fig. 8, were obtained from the WSRC Waste Processing Technology group.

\begin{tabular}{|c|c|c|}
\hline Approximate Supernate Volume & 1000.0 & $\mathrm{~mL}$ \\
\hline Approximate Supernate Density & 1.25 & $\mathrm{~g} / \mathrm{mL}$ \\
\hline Approximate Supernate Mass & 1250.0 & grams \\
\hline At $0.5 w t \%$ solids loading & 6.28 & grams \\
\hline Total Mass Supernate + Solids & 1256.3 & grams \\
\hline
\end{tabular}

$\begin{array}{llrc}\begin{array}{llc}\text { Compound } \\ \text { Name }\end{array} & \begin{array}{l}\text { Compound } \\ \text { Formula }\end{array} & \begin{array}{c}\text { Concentration } \\ \text { g/100g solids }\end{array} & \begin{array}{c}\text { Needed } \\ \text { grams }\end{array} \\ \text { Alumina } & \mathrm{Al} 2 \mathrm{O} 3 & 9.20 \% & 0.58 \\ \text { Calcium Oxalate } & \mathrm{CaC} 2 \mathrm{O} 4 & 5.00 \% & 0.31 \\ \text { Chromium Oxide } & \mathrm{Cr} 2 \mathrm{O} 3 & 26.00 \% & 1.63 \\ \text { Ferric Oxide } & \mathrm{Fe} 2 \mathrm{O} 3 & 1.10 \% & 0.07 \\ \text { Manganese Oxide } & \mathrm{MnO} 2 & 0.30 \% & 0.02 \\ \text { Sodium Oxalate } & \mathrm{Na} 2 \mathrm{C} 2 \mathrm{O} 4 & 52.40 \% & 3.29 \\ \text { Nickel Oxide } & \mathrm{NiO} & 0.50 \% & 0.03 \\ \text { Silicon Oxide } & \mathrm{SiO} 2 & 5.40 \% & 0.34 \\ & & & \\ & \text { Total } & 99.90 \% & 6.28\end{array}$

\section{${ }^{*}$ All compounds should be sized between 0.5 and 5 microns}

Figure 8. Envelope A Simulant: Solids Only $-0.5 \mathrm{wt} \%$

Each recipe is shown on a per-liter basis. The test required a batch of 75 liters, therefore the quantities shown in both recipes were increased accordingly. (A volume of 75 liters was chosen to fill the slurry reservoir to the half-way mark, since the test rig proper held approximately 25 liters and the reservoir tank held 110 liters. The extra space was needed for foaming if it had occurred.) Along with the recipe for the solids, Fig. 8, the particle size distribution was specified: all particle should be between 0.5 and 5 microns based on the actual waste sampling, Fig. 9a. Therefore, all the solids indicated in Fig. 8 were purchased to that specification. Before adding the solids to the 75 liters of supernate the customer requested to evaluate the actual solids distribution. It was important to know if the purchased solids were of the correct size, as well as, what the distribution would be after the simulant was prepared. On 4/16/99 the 75 liters of supernate was made. On $4 / 19 / 99$ a sample of $250 \mathrm{~mL}$ of the supernate was taken and 
enough solids were added to obtain $0.5 \mathrm{wt} \%$. Then the sample was submitted to determine the solids distribution. The distribution was obtained by Microtrac, Fig. 9b, on $5 / 12 / 99$ and sent to the customer by facsimile transmission. On the same day the approval to begin testing was obtained. Both the actual waste and the simulant show a relatively small number of particles greater than 20 microns. In fact, for the simulant the large particles (thought to be soft sodium oxalate) eventually were broken up and do not show up in later distributions. Run 2.00 (water) began the following day and the simulant was finalized.
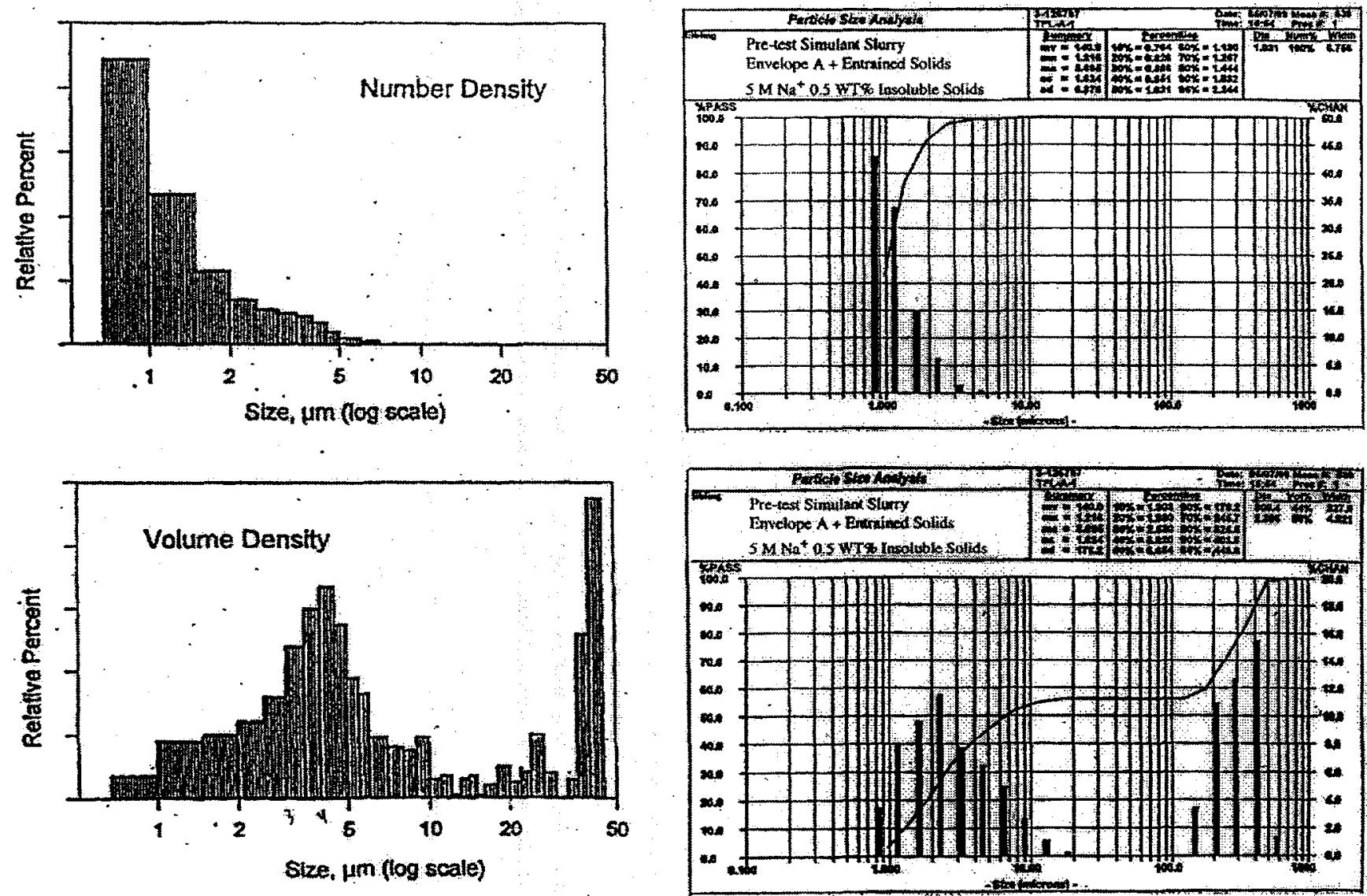

(a) Solids Distribution in Actual Waste Sample

(b) Solids Distribution in Waste Simulant

Figure 9. Insoluble Solids Distribution

Specifics about the simulant can be found in Appendix E: Analytical Data, but some general properties at $25^{\circ} \mathrm{C}$ were:

Slurry Density: $\quad \sim 1.23 \mathrm{~g} / \mathrm{mL}$ at $0.5 \mathrm{wt} \%$ insoluble solids and $30 \mathrm{wt} \%$ total solids Slurry Density: $\quad \sim 1.28 \mathrm{~g} / \mathrm{mL}$ at $8 \mathrm{wt} \%$ insoluble solids and $36 \mathrm{wt} \%$ total solids Slurry Viscosity: $\quad-3 \mathrm{cP}$ at $0.5 \mathrm{wt} \%$ insoluble solids and $30 \mathrm{wt} \%$ total solids Slurry Viscosity (washed): $\quad \sim 2 \mathrm{cP}$ at $12 \mathrm{wt} \%$ insoluble solids and $14 \mathrm{wt} \%$ total solids 
Slurry Rheology $\quad \sim$ Newtonian (at high insoluble solids loadings Bingham plastic characteristics are present, i.e., yield stress. See Figs, E2 and E3)

Supernate Density: $\quad \sim 1.21 \mathrm{~g} / \mathrm{mL}$ at $36 \mathrm{wt} \%$ soluble solids

Supernate Viscosity: $\sim 1.8 \mathrm{cP}$ at $36 \mathrm{wt} \%$ soluble solids

Sodium $\left[\mathrm{Na}^{+}\right]$Conc: $\sim 5 \mathrm{M}$

\section{Test Procedure/Matrix}

Details of the test matrix and test execution can be found in the Test Procedure (16) and the accompanying Operational Instructions (17), which are also listed in the task notebook (4). However, to facilitate understanding of the test's general operation, the procedural steps are summarized below:

Daily pre-test activities -

1. Equipment is turned on to warm up if not already on.

2. The equipment was checked for functionality and after each of the four liquid-filled pressure sensing lines (see Fig. F2; Appendix F) were purged with $5 \mathrm{ml}$ of distilled and filtered water, the transducers were checked at their zeroes for drift. The zeroes are recorded for 2 to 3 minutes by the DAS. Those data are included in each day's data sheets.

Daily testing activities for constant solids runs (low and high concentrations) -

3. Begin circulating the slurry in the recirculation loop until the temperature reached $25^{\circ} \mathrm{C}$.

4. Turn on the reservoir cooling coil.

5. Allow the slurry to flow through the cross-flow filter.

6. Set the appropriate flow conditions as per the test procedure by iterating between valves V3 and V1.

7. When the slurry and filtrate loops establish steady flows adjust the backpulse piston pressure to at least $30 \mathrm{psi}$ over the slurry pressure in the filter.

8. Set the DAS to read every minute.

9. Backpulse the filter, hold the piston down for $\mathbf{1 0}$ seconds, then allow the filtrate flow to return. (At times this step had to be repeated so that the flow parameters could be set correctly. Also, because the filtrate had to refill the backpulse piston plenum, the filtrate-flow return-time was a function of the filtrate flux. As mentioned in "backpulse loop" description of the Test Rig section, the volume of the plenum was 0.036 gallon $/ \mathrm{ft}^{2}$, therefore the recovery time at $0.5 \mathrm{gpm} / \mathrm{ft}^{2}$ was approximately $0.036 /$ $0.53 \times 60=4$ seconds. A flux of $0.53 \mathrm{gpm} / \mathrm{ft}^{2}$ was taken because that was close to the filtrate flux right after a backpulse, Fig. 10.) 


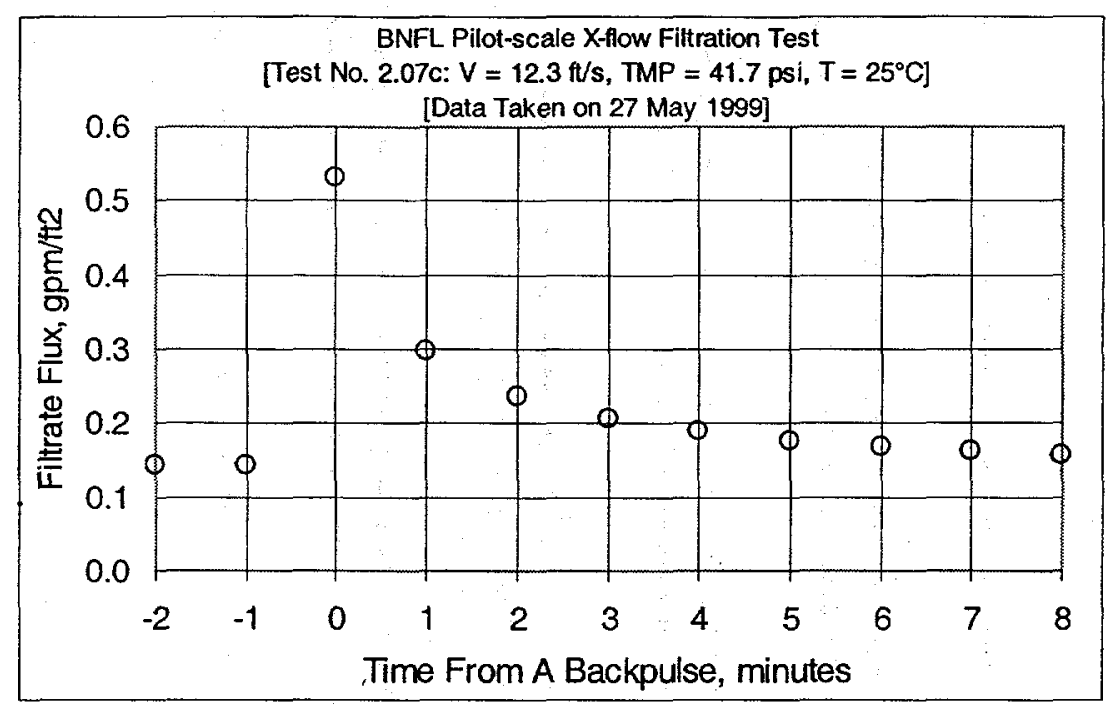

Figure 10. Filtrate flux immediately following a backpulse

10. Allow the test rig to run for approximately 2 hours.

11. Backpulse the filter once again.

12. Repeat from Step 6 for next set of flow conditions or shut down the test rig, if near the end of the work day.

13. End the test run.

Daily testing activities for wash test runs -

[Do Steps 3 to 9 from above, but just before Step 6 pour in a volume of distilled and filtered water equal to the volume of slurry in the test rig ( $\sim 50$ liters).]

10. Switch valve V13 to the open-loop position so that the filtrate is not returned to the slurry loop, but is collected outside the test rig.

11. Allow the test rig to run until a volume of filtrate is removed that is equal to the volume of water that was put in.(Slightly more mass is taken out than was put in because of the filtrate's higher density.)

12. Switch valve V13 to the close-loop position.

13. Backpulse the filter once again.

14. Repeat from Step 6 for each wash run until finished with all wash runs.

15. End the test run.

Daily testing activities for post-wash dewatering/plugging test run -

[Do Steps 3 to 9 from above.]

10. Switch valve V13 to the open-loop position so that the filtrate is not returned to the slurry loop, but is collected outside the test rig.

11. Continue run until either the filter or pumps do not allow further operation.

12. End the test run. 


\section{Shakedown}

Before beginning test runs with water to evaluate the filter's hydraulic characteristics, the test rig (TR) was cleaned to remove any foreign contamination that may have been left inside the system from past testing or that could have been introduced when modifications were made. In March of 1999, before the new seven-tube filter unit was installed, the entire TR was cleaned with $1 \mathrm{wt} \%$ solution of Alconox in distilled and filtered ( 0.2 micron) water (referred to as DIF water). Fifty liters of this phosphate based solution was circulated in the TR for several hours at $35^{\circ} \mathrm{C}$. This was followed with several DIF water rinses, until the water returned crystal clear. During the cleaning and rinsing the filter tubes were soaked in water for 4 days. With the TR clean and the filter installed, the slurry reservoir was filled with 75 liters of DIF water. Several runs were done with water to characterize the Mott filter.

A cross-flow filter (XF) is significantly different from a dead-end filter in that the main slurry flow is not forced through the filter medium. Instead, the slurry flows parallel to the filter substrate while allowing the filtrate to be removed perpendicularly, as a result of the transmembrane pressure (TMP). In this way the XF is basically self cleaning as the turbulent slurry flow tend to shear solids away from the filter wall as they try to adhere. However, because of this cross flowing stream, there is an added degree of freedom. For instance, an increase in slurry velocity may, but not necessarily, lead to an increase in filtrate flux. This is because the slurry system pressure can be made to decrease. That is, the slurry system pressure can be controlled independently from the slurry axial velocity and both of these quantities will affect the rate of filtrate flow. With this in mind, the following figures are shown to illustrate the character of the XF with DIF water, which contains no solids.

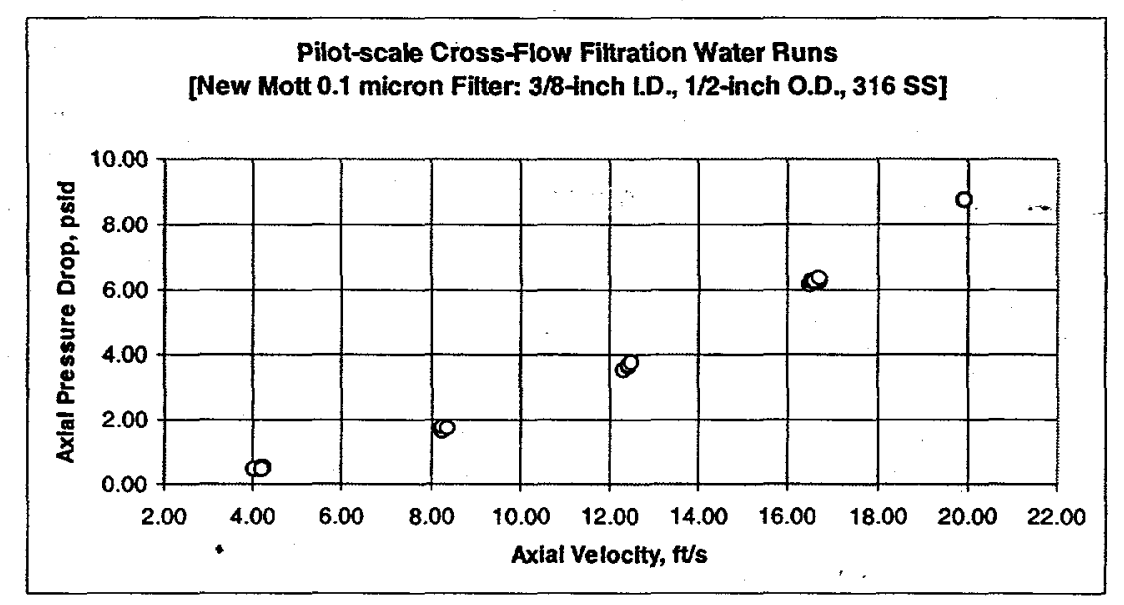

Figure 11. Axial pressure drop vs. axial velocity of water in the cross-flow filter

Figure 11 is the axial pressure drop versus the axial velocity. Those velocities came from the TR flow settings of 10,20,30,40, and $50 \mathrm{gpm}$. These obtained results were expected because a pre-test calculation indicated that the pressure drop at $12.6 \mathrm{ft} / \mathrm{s}$ should be close to $4 \mathrm{psid}$, and it is. The calculation was not straight forward because to determine an 
accurate pressure drop involves knowing the several contributions to that drop. Figures 1 and 5 show that the pressure taps were located in a diverging/converging plenum region on either side of the filter housing. Therefore the pressure drop is not only the drop along the porous filter tube, but it also includes the effects of the tube sheet inserts, expansion and contraction into the plenums, and the diverging and converging plenums themselves (where the pressure taps are located). A rough calculation determined that the actual axial pressure drop along just the porous section of tube is between $60 \%$ and $70 \%$ of the measured drop. Another aspect of Fig. 11 is the several data points shown for each combination of pressure drop and velocity. The system pressure at the filter was increased three fold from approximately 5 to $15 \mathrm{psig}$ which resulted in filtrate fluxes from approximately $0.1 \mathrm{gpm} / \mathrm{ft}^{2}$ to $0.5 \mathrm{gpm} / \mathrm{ft}^{2}$. The increased pressure had a insignificant effect on the axial pressure drop as can be seen from the grouping of point in Fig. 11.

The effect of system pressure on filtrate flux at a fixed axial velocity is apparent in Fig. 12. The lines on the graph are isobars, or better, lines of constant transmembrane pressure (TMP). These data were obtained by adjusting the valves on the test rig to maintain a constant axial velocity while changing the system pressure. The highest TMP measured was at 4.4 psid due to the limitation of measuring filtrate flux to a maximum of $0.53 \mathrm{gpm} / \mathrm{ft}^{2}$. This limitation existed because the expected filtrate flowrate of slurry was to be between 0.02 and $0.2 \mathrm{gpm} / \mathrm{ft}^{2}$. Therefore, a flowmeter was calibrated to accurately measure that target range. However, it did limit measurement with water. Near the end of the experiment another meter was installed to measure up to $2.2 \mathrm{gpm} / \mathrm{ft}^{2}$, so the final water run (2.22) has higher TMPs.

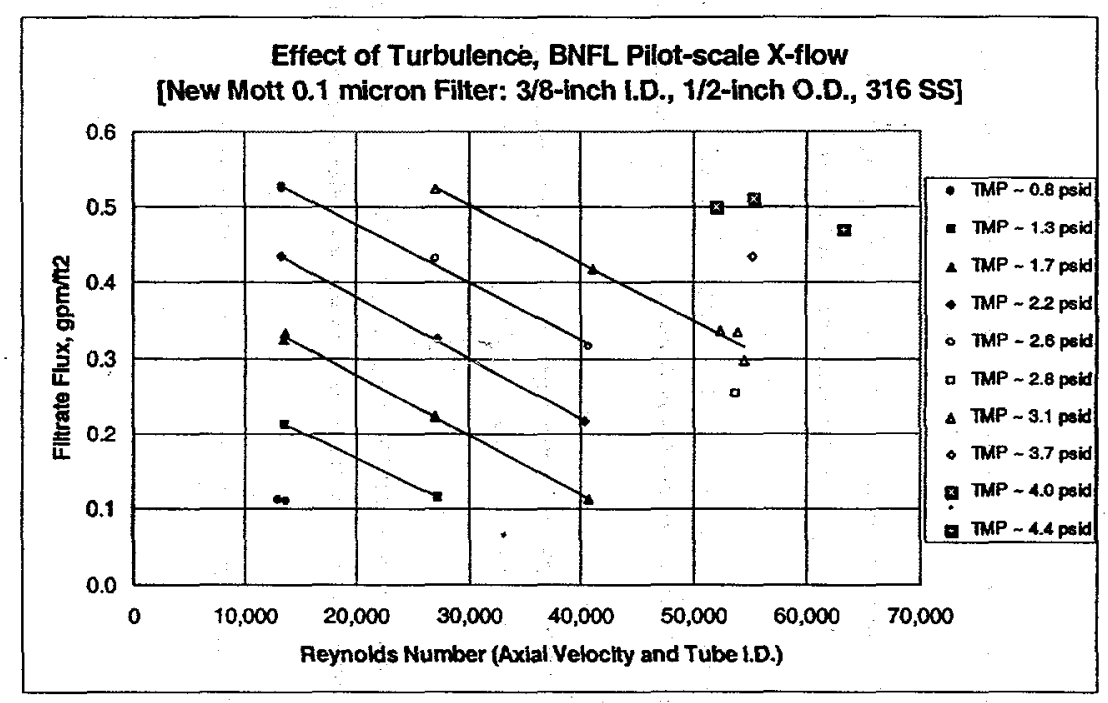

Figure 12. Filtrate flux vs. axial velocity of water in the cross-flow filter

What is interesting in Fig. 12 is that for a constant TMP, the filtrate flux decreases as the velocity increases. A cross-flow filter is really only useful when there is something to filter. Without solids only the fluid dynamics affect the flow. As can be seen in Fig. 13 the increase axial velocity leads to an increase in the Reynolds number. 


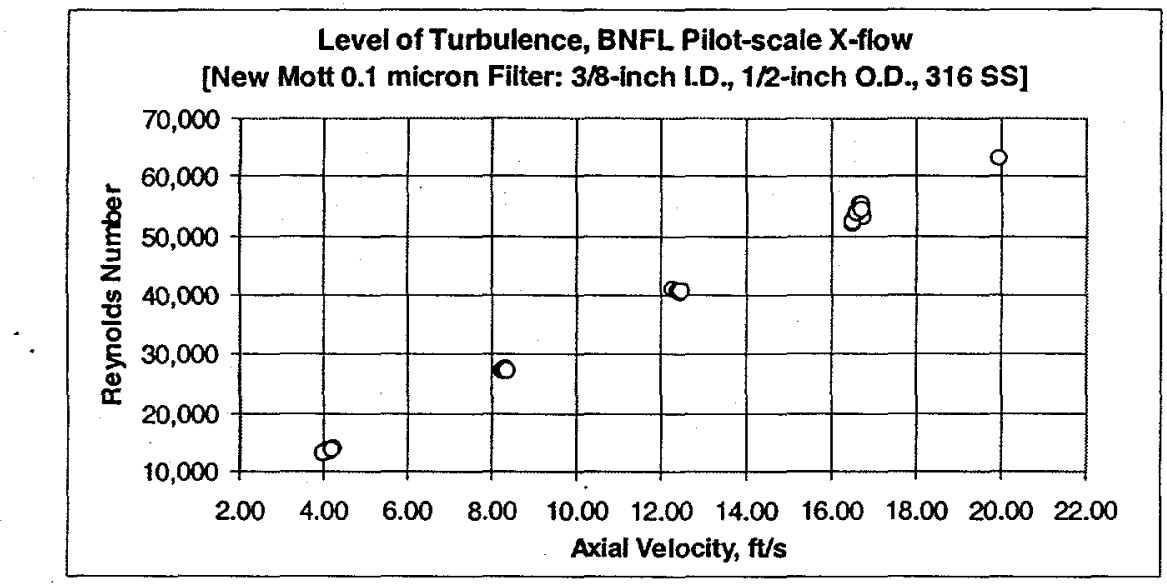

Figure 13. Reynolds vs. axial velocity of water in the cross-flow filter

This is not surprising since the Reynolds number is directly proportional to the velocity, along with the diameter of the flow stream, and inversely proportional to the kinematic viscosity. The purpose of Fig. 13 is to show the intensity of turbulence. As turbulence increases, the laminar sublayer decreases, an inertial sublayer is created and increases, and the scale of energy dissipating eddies become increasingly smaller (18). What this means is that increasing the shear environment at the tube wall forces the water to enter into the main stream more than forcing the water through the thin laminar sublayer which coats the porous-tube wall.

Finally, due to the added degree of freedom, the filtrate flux cannot be simply determined from just the axial flow velocity; the TMP must also be specified, leading to the family of curves in Fig. 12. However, an attempt was made to collapse those curves into a single curve to be more useful. Figure 14 show the results of that attempt.

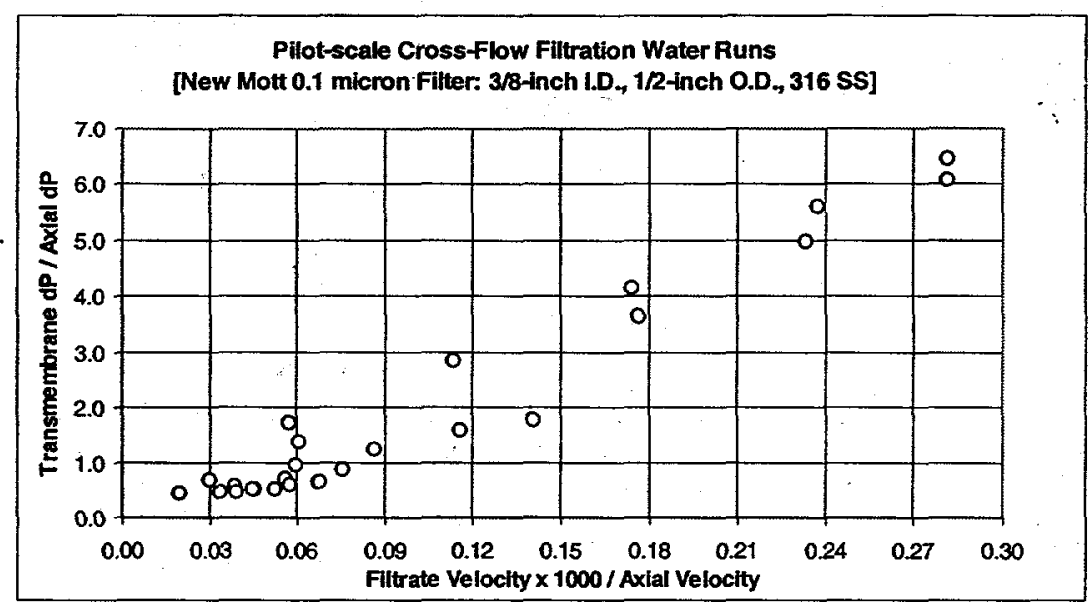

Figure 14. Normalized TMP vs. filtrate velocity in the cross-flow filter 


\section{RESULTS AND DISCUSSION}

\section{General}

The different phases of the test matrix that we will discuss are: initial water baseline, low solids concentration, high solids concentration, slurry wash, plugging, cleaning, and final water baseline. After a discussion on some of the analytical and washing results, a discussion of the hydraulic results will follow the chronological order with the exception of the water and cleaning runs. Those runs will be given together in order to see any lasting effect of the slurry on the filter medium and thereby have a clear perspective of these test runs. The test matrix (3) was:

\begin{tabular}{|c|c|c|c|c|}
\hline Run & $\begin{array}{l}\text { Test Duration } \\
\text { minutes }\end{array}$ & $\begin{array}{c}\text { Slurry Velocity } \\
\mathrm{ft} / \mathrm{s}\end{array}$ & $\begin{array}{l}\text { TMP } \\
\text { psid }\end{array}$ & Condition \\
\hline 2.00 & 120 & 12.2 & 40 & Water \\
\hline 2.01 & 120 & 6.6 & 30 & Low Solids Concentration \\
\hline 2.02 & 120 & 6.6 & 40 & Low Solids Concentration \\
\hline 2.03 & 120 & 3.3 & 30 & Low Solids Concentration \\
\hline 2.04 & 120 & 6.6 & 15 & Low Solids Concentration \\
\hline 2.05 & 120 & 6.6 & 30 & Low Solids Concentration \\
\hline 2.06 & 120 & 9.1 & 20 & Low Solids Concentration \\
\hline 2.07 & 120 & 12.2 & 40 & Low Solids Concentration \\
\hline 2.08 & 120 & 12.2 & 55 & Low Solids Concentration \\
\hline 2.09 & 120 & 12.2 & 70 & Low Solids Concentration \\
\hline 2.10 & 120 & 9.1 & Best & Low Solids Concentration \\
\hline 2.11 & 120 & 15.2 & Best & Low Solids Concentration \\
\hline 2.12 & 120 & 12.2 & 55 & Low Solids Concentration \\
\hline 2.13 & 120 & 6.6 & 30 & Low Solids Concentration \\
\hline 2.14 & 120 & Best & Best & High Solids Concentration \\
\hline 2.15 & N/A & 12.2 & 40 & Wash $^{*}$ \\
\hline 2.16 & N/A & 12.2 & 55 & Wash \\
\hline 2.17 & N/A & 12.2 & 70 & Wash* \\
\hline 2.18 & N/A & 9.1 & Best & Wash* \\
\hline 2.19 & N/A & 15.2 & Best & Wash* \\
\hline 2.20 & N/A & Best & Best & Plugging \\
\hline 2.21 & N/A & N/A & N/A & Cleaning $1 \mathrm{M} \mathrm{NaOH}$ \\
\hline 2.22 & $N / A$ & N/A & N/A & Water \\
\hline
\end{tabular}

Figure 15. Test matrix as stated in the test specification (3)

\section{Test Run Sequence}

As will be explained in the following sections, there were some deviations from the Test Matrix shown in Fig. 15. For example run, 2.10 was done three times and referred to as $2.10,2.10 \mathrm{~b}$, and 2.10c. It was repeated for the Best Permeability and the Best Filtrate Flux flow conditions, since they were different. After run 2.13, run 2.07 (chosen for the its flow settings since it had the best filtrate flux results) was repeated too, i.e., $2.07 \mathrm{~b}$ and 2.07c. At the suggestion of the task leader, and with the concurrence of the customer, $2.07 \mathrm{~b}$ was a $7+$ hour run without backpulsing to see if an asymptotic value for the filtrate flux could be reached. Run $2.07 \mathrm{c}$ was another all-day run but this time there were a series of different backpulsing frequencies, i.e., 30, 15, and 5 minutes. After run $2.07 \mathrm{c}$ the test rig had an unplanned pluggage while attempting to raise the solids concentration in the slurry for run 2.14 . This plugging caused some down time to clean the test rig and 
make more simulant. In attempting to unplug the test rig the simulant became slightly more dilute than required for the test. Therefore, run 2.14 was done as if it already went through one washing cycle. That is, run 2.17 was left out of the matrix when doing washing runs 2.15 to 2.19 because of the more dilute starting point. However, time allowed a repeat of runs 2.14 to 2.19 with a new batch of simulant, therefore those runs were referred to as $2.14 \mathrm{~b}$ to $2.19 \mathrm{~b}$. Runs $2.20 \mathrm{~b}, 2.21 \mathrm{~b}, 2.22 \mathrm{~b}$ are not repeat runs but have $a$ " $b$ " included because they were done after run $2.19 \mathrm{~b}$. Finally, runs $2.21 \mathrm{~b}$ and $2.22 \mathrm{~b}$ are broken down further as $2.21 \mathrm{~b} 1$ and $\mathrm{b} 2$ and $2.22 \mathrm{~b} 1$ and $\mathrm{b} 2$ to illustrate different aspects of the same run.

\section{Analytical Test Results}

[See Appendix $E$ for the entire set of data sheets.]

\section{Filter Effectiveness}

First and foremost, the task objective was to determine if the nominal rated 0.1-micron Mott filter could remove all the insoluble solids from the simulant. As already mentioned in the preceding experimental section of this report, the insoluble solids were made of 7 compounds: 6 metals ( $\mathrm{Al}, \mathrm{Ca}, \mathrm{Cr}, \mathrm{Fe}, \mathrm{Mn}$, and $\mathrm{Ni}$ ) with Chromium being the largest quantity by mass, and Sodium Oxalate, which was the largest single quantity by mass (Fig. 8). Based on a real-sample analysis (Fig. 9a), the particle sizes purchased for the solids ranged from 0.5 to 5 microns. Fig. $9 \mathrm{~b}$ indicates the sizes of solids used were close to the target values. From Tbl. 1 it is apparent that the filter removed all the solids. Note, the table shows that the analytical results only indicated the solids present in the filtrate were less than values shown (see Appendix E).

\begin{tabular}{|c|cc|}
\hline \multirow{2}{*}{ Run No. } & \multicolumn{2}{|c|}{ Insoluble Solids } \\
\cline { 2 - 3 } & in Slurry, wt\% & in Filtrate, wt\% \\
\hline Target (LS) & 0.5 & 0 \\
2.01 & 0.45 & $<0.003$ \\
2.13 & 0.29 & $<0.003$ \\
$2.14 \mathrm{~b}$ & 8.2 & $<0.01^{\star}$ \\
$2.16 \mathrm{~b}$ & 5.5 & $<0.01$ \\
$2.20 \mathrm{~b}$ start & 5 & $<0.01$ \\
$2.20 \mathrm{~b}$ end & $16.2^{* *}$ & $<0.004$ \\
Target (HS) & 20 & 0 \\
\hline *From run 2.15b because a measurement \\
for 2.14b was not made \\
**Estimated from remaining slurry volume \\
LS = Low insoluble solids concentration \\
HS = High insoluble solids concentration \\
\hline \multicolumn{3}{|l}{} \\
\hline
\end{tabular}

Table 1. Insoluble solids in the slurry and the filtrate throughout the test

The filter was very effective in removing all the insoluble solids. Furthermore, the basic sizes of the solid particles did not change during the course of the experiment. Particles smaller than 0.1 micron could have compromised the filter. Figure 16 shows that the particle diameter (by a volume distribution analysis) started at approximately 2.5 microns and remained that size. The standard deviations were on the same order of magnitude as the particle diameters. This was expected since the purchased solids were requested to be 
between 0.5 and 5 microns. However, the largest number of particles was closer to 1 micron. When analyzing the particles by a number distribution, Fig. 17, the mean particle size is very close to 1 micron with one standard deviation being 0.4 micron. As seen in Figs. 16 and 17, one measurement from each had a bimodal distribution. These bimodal distributions could have been caused by the clumping of particles while samples awaited analysis, or by agglomerated solids that were not fully broken down when the samples were mixed before measurements were taken. In general, the particle sizes did conform to the required sizes and the particle sizes remained basically intact throughout the experiment. See Appendix E for details on the particle size analyses.

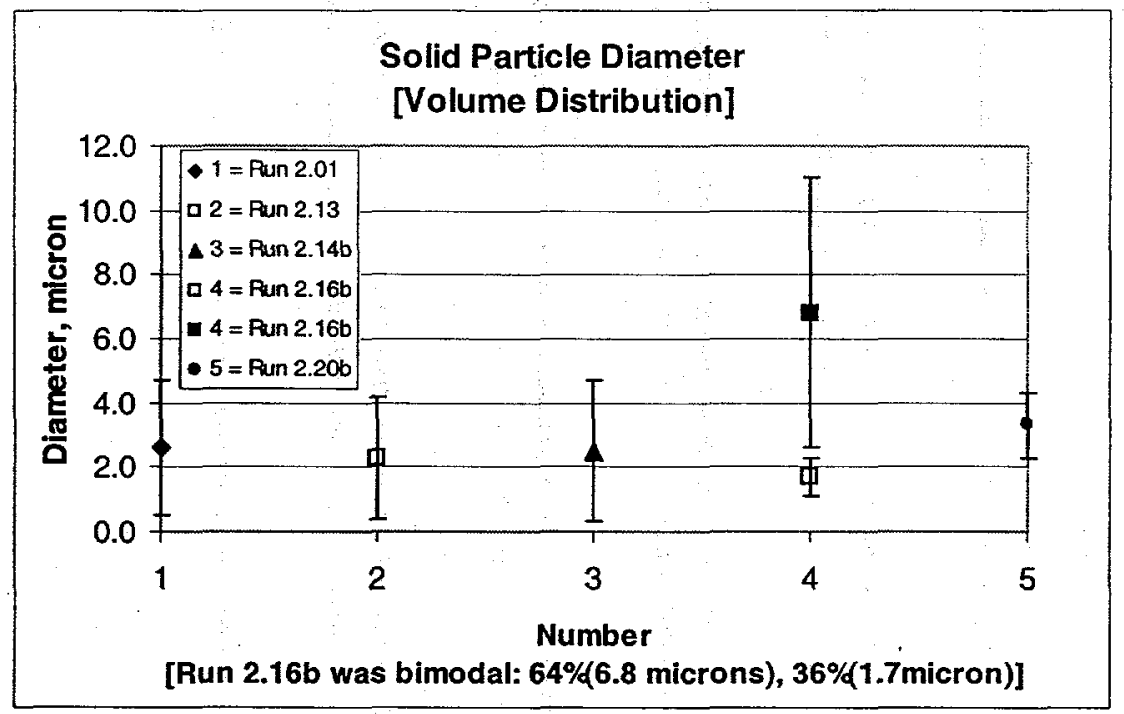

Figure 16. Particle size based on a volume distribution

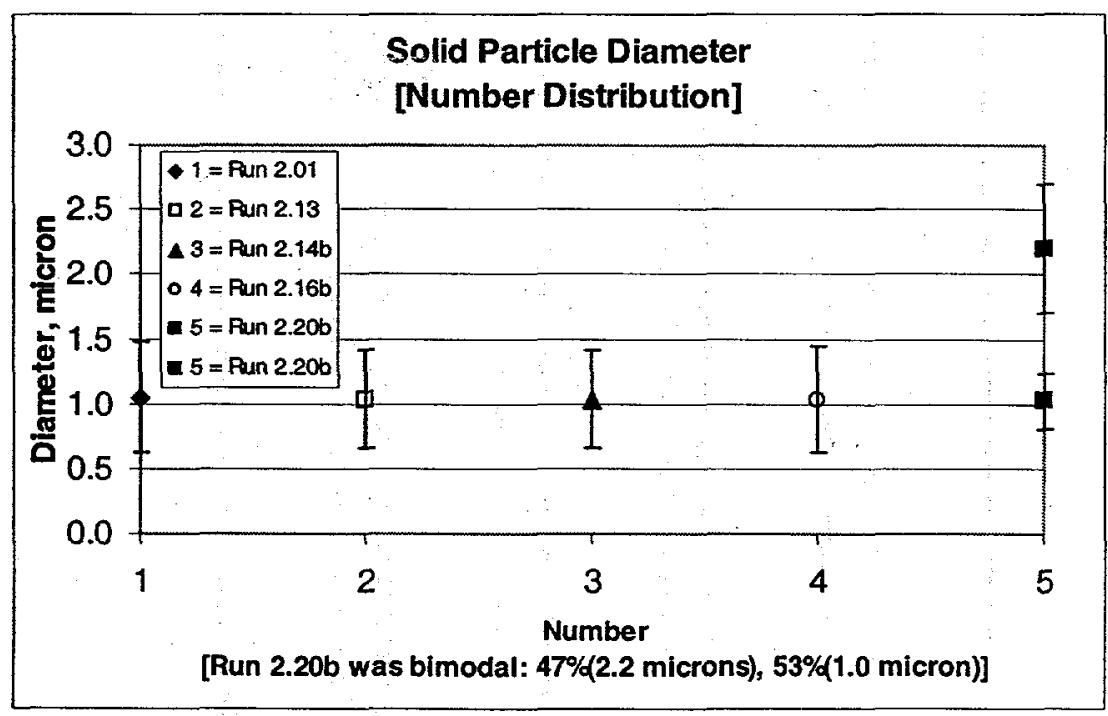

Figure 17. Particle size based on a number distribution 


\section{Washed Slurry}

As already mentioned, there were two sets of washing runs: 2.15 to 2.19 and $2.15 \mathrm{~b}$ to $2.19 \mathrm{~b}$. During the first set, run 2.17 was not done because during the concentrating run 2.14 the test rig plugged and in the process of unplugging the rig the slurry was diluted. The slurry for run 2.14 received enough water that it made the slurry equivalent to an initial wash run. Therefore, to keep the number of wash runs the same, run 2.17 was omitted. Further, because of the dilution it was thought best to make another batch of slurry to redo 2.14 , which became $2.14 \mathrm{~b}$, which thereby allowed the wash runs to be repeated. While there are some differences between the two set of test runs, the data are similar and only those for test runs $2.15 \mathrm{~b}$ to $2.19 \mathrm{~b}$ are discussed here (see Appendix $\mathrm{E}$ for all the data).

* Sodium *

One of the major reasons for washing is to reduce sodium content. Figure 18 shows the $\mathrm{Na}^{+}$reduction.

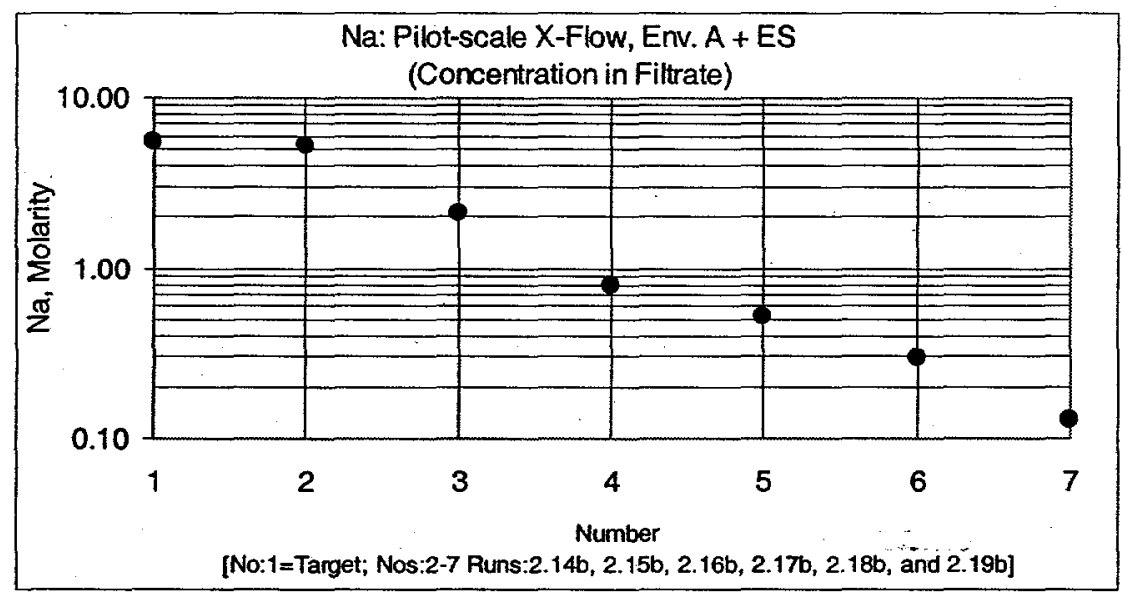

Figure 18. Reduction of sodium with successive washings

Point number 1 was the target sodium concentration of $5.5 \mathrm{M}$. Point number 2 shows the actual sodium concentration for run $2.14 \mathrm{~b}$ was $5.2 \mathrm{M}$. Numbers 3 to 7 show the sodium level after each batch of 50 liters of water was added to the slurry reservoir that held approximately 50 liters of slurry. The line of points in Fig. 18 from number 2 to 7 is fairly straight on the semi-log scale, which was not unexpected. Figs. 19 and 20 show how the filtrate density and viscosity changed as the sodium level decreased from approximately $5 \mathrm{M}$ to $0.1 \mathrm{M}$. 


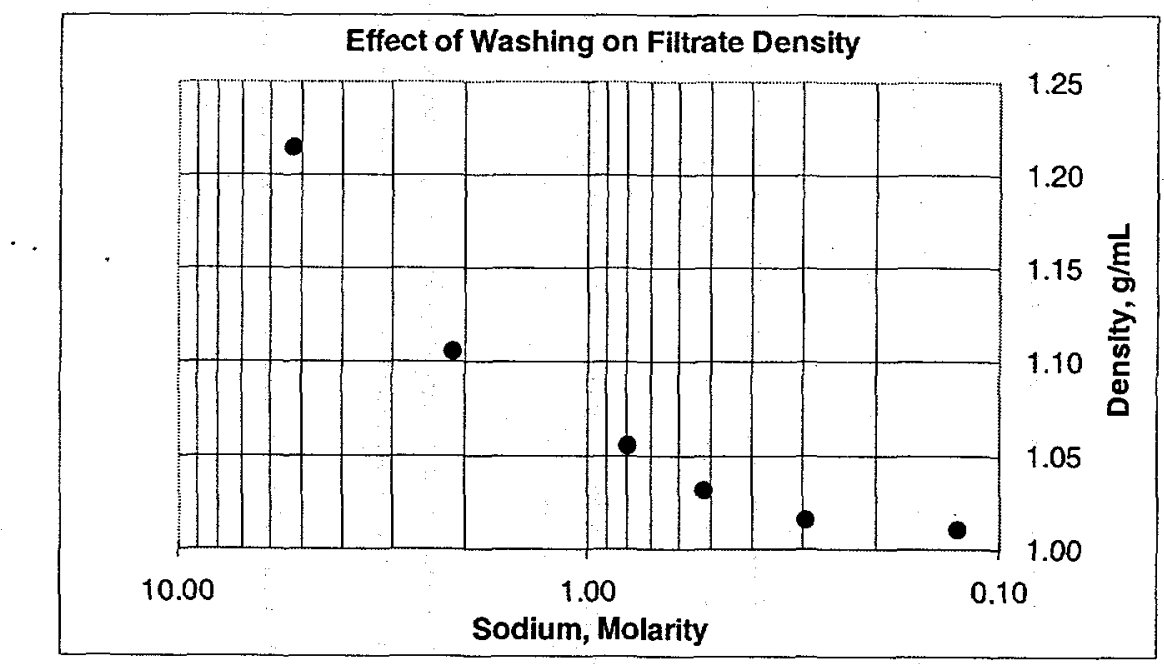

Figure 19. Filtrate density vs. sodium during washing

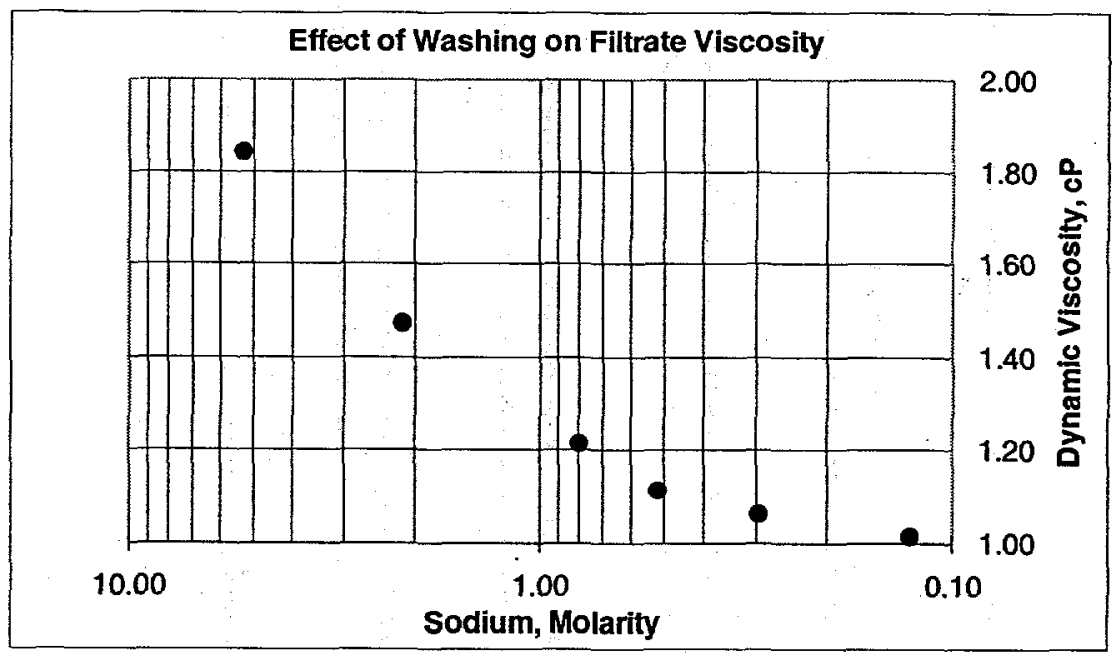

Figure 20. Filtrate viscosity vs. sodium during washing

\section{* Oxalate *}

A chemical that may have had an impact on the changes in solids loading was the chemical compound of oxalate. As seen in Fig. 8, approximately 50\% of the "insoluble" solids that were added to the slurry was comprised of sodium oxalate. Of all the solids this one was expected to give the largest problem because of it being more readily dissolved in the simulant than any of the others. However, the simulant was designed such that the oxalates added as insoluble solids should have stayed undissolved. The liquid portion of the simulant, the supernate, was to be saturated with sodium oxalate before adding the solids. 


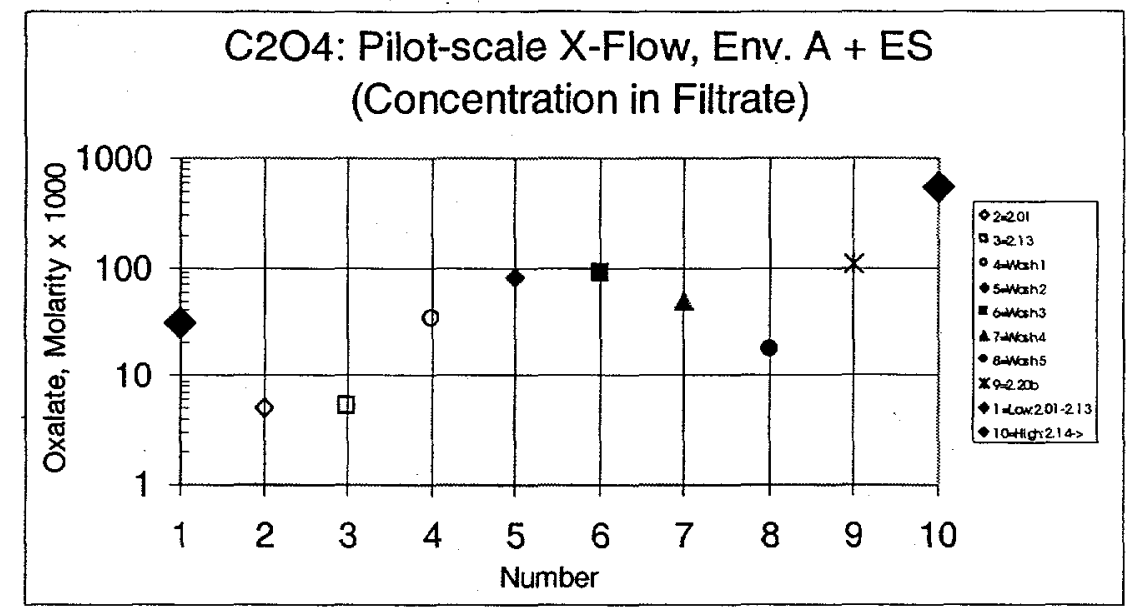

Figure 21. Oxalate changes in the filtrate during the test [Note: Except for nos. 1 and 10 all oxalate values are from the filtrate]

Figure 21 implies that most of the oxalates in solid form remained that way. The oxalate concentration in the filtrate, nos 2 and 3, for the low concentration runs of 2.01 and 2.13, was approximately $0.005 \mathrm{M}$. Number 1 is the value of the oxalate concentration from all its sources in the slurry, $0.03 \mathrm{M}$, and of this amount 0.004 was already included in the supernate. This indicates that after the solids were introduced, the liquid picked up about another $10 \%$ in oxalates, i.e., $0.001 \mathrm{M}+0.004 \mathrm{M}=0.005 \mathrm{M}$. It is assumed that the supernate was fully saturated with oxalate at $0.005 \mathrm{M}$. The value of number 10 , i.e., 0.55 $\mathrm{M}$, is the amount of oxalates in the slurry for all test runs starting with run 2.14. The oxalate values for numbers 4 through 9 are from the filtrate samples that came from the slurry with this higher oxalate concentration. However, the supernate of the slurry before washing should have still been saturated at the $0.005-\mathrm{M}$ level. Therefore, the oxalate concentration could only increase as the saturation level increased during the wash runs. Looking at the results from all the wash runs $2.15 \mathrm{~b}$ to $2.19 \mathrm{~b}$ (numbers 4 to 8 ) the oxalate in the supernate does increase as more and more water is added but it showed a maximum of $0.089 \mathrm{M}$ on the third wash. Afterwards, the concentration decreased on the fourth and fifth wash runs. Note that all 5 wash runs were done in succession, and all on the same day. The time frame was short between water additions and the oxalate values, i.e., 4 to 8 , may not be from a mixture at equilibrium. The oxalate value in the filtrate at the beginning of run $2.20 \mathrm{~b}$ is $0.11 \mathrm{M}$, shown as No. 9 in Fig. 21.' This filtrate sample was taken from the same dilute slurry that gave the result for run $2.19 \mathrm{~b}$, no. 8 . The only difference is that run $2.19 \mathrm{~b}$ was finished at $8 \mathrm{p} . \mathrm{m}$. On one night and the sample for the beginning of run $2.20 \mathrm{~b}$ was taken at 11 a.m. on the following day. That is, the slurry sat for 15 hours. This may indicate that the slurry was not at equilibrium on the preceding day, but then it was allowed to reach its full saturation level, which may be $0.11 \mathrm{M}$ of oxalate. In any case, this still left $0.55 \mathrm{M}-0.11 \mathrm{M}=0.44 \mathrm{M}$ of oxalate in the slurry which probably stayed in the solid forms of sodium oxalate and calcium oxalate. 
Therefore, there seems to be some loss of the sodium oxalate solids into the supernate but not all. Figure 8 shows that sodium oxalate comprised approximate $50 \%$ of the mass of the solids. The data indicate that only 10 to $30 \%$ of the oxalate solids was incorporated into the supernate.

For further information on the concentration of the many species in the simulant slurry, see Appendix E. All the analytical data taken and graphical results for many of the chemical concentrations can be found behind Table E1 in that appendix.

\section{Hydraulic Test Results}

\section{Water Test Runs 2.00 and $2.22 \mathrm{~b}$ and the Cleaning Run $2.2 \mathrm{lb}$}

[See Appendix A for the entire set of data sheets.]

Permission to start the test was received on 5/12/99 and testing began on 5/14/99 with the first required test: water. As explained in the shakedown section, the filtrate flowmeter could only measure a maximum of $0.53 \mathrm{gpm} / \mathrm{ft}^{2}$. As can be seen from Fig. 22, for run 2.00 , at $0.43 \mathrm{gpm} / \mathrm{ft}^{2}$, the TMP was only $3 \mathrm{psid}$ and therefore the $40 \mathrm{psid}$ requested by the test specification was not possible. The intention was to repeat the final water run, 2.22 , with the same TMP so a comparison could be made. Figure 22 shows the results.

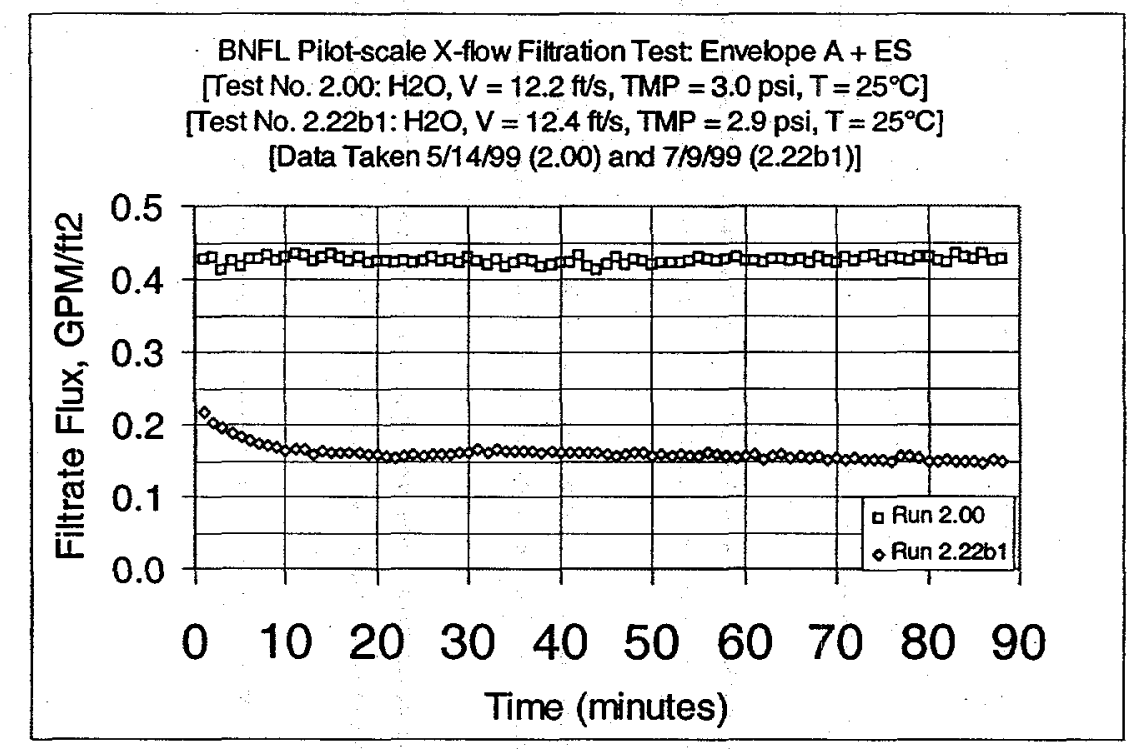

Figure 22. Water runs before and after the Env. A test

It is clear from the figure that the more than 60 hours of filter operation with slurry took its toll. The new-filter filtrate flux of approximately $0.43 \mathrm{gpm} / \mathrm{ft}^{2}$ was reduced to 0.16 $\mathrm{gpm} / \mathrm{ft}^{2}$. However, there are at least two reasons, which mitigate this significant difference: 1 , new filter and 2. low TMP. 
1. New filter - Since this test started with a brand new filter it is not surprising the filter would have a reduced filtrate flux after many hours of slurry filtration. The filter was cleaned for more than 36 hours, as per the test specification, with a $1 \mathrm{M} \mathrm{NaOH}$ solution. Figure 23 shows results of two portions of the cleaning run. Since the flow parameters were changed several times during the run only two were chosen for this figure. The different run numbers, $2.21 \mathrm{~b} 1$ and $2.21 \mathrm{~b} 2$ only indicate that different TMPs were used. The slope of those curves in Fig. 23 decrease very slowly with time indicating that while the filter may be clean some residue remains. There was enough time to clean the filter twice, so another 20 hours of cleaning was done. The data in Figure 23 were taken during the second cleaning cycle. It appears that further cleaning would not return the filter to its original state.

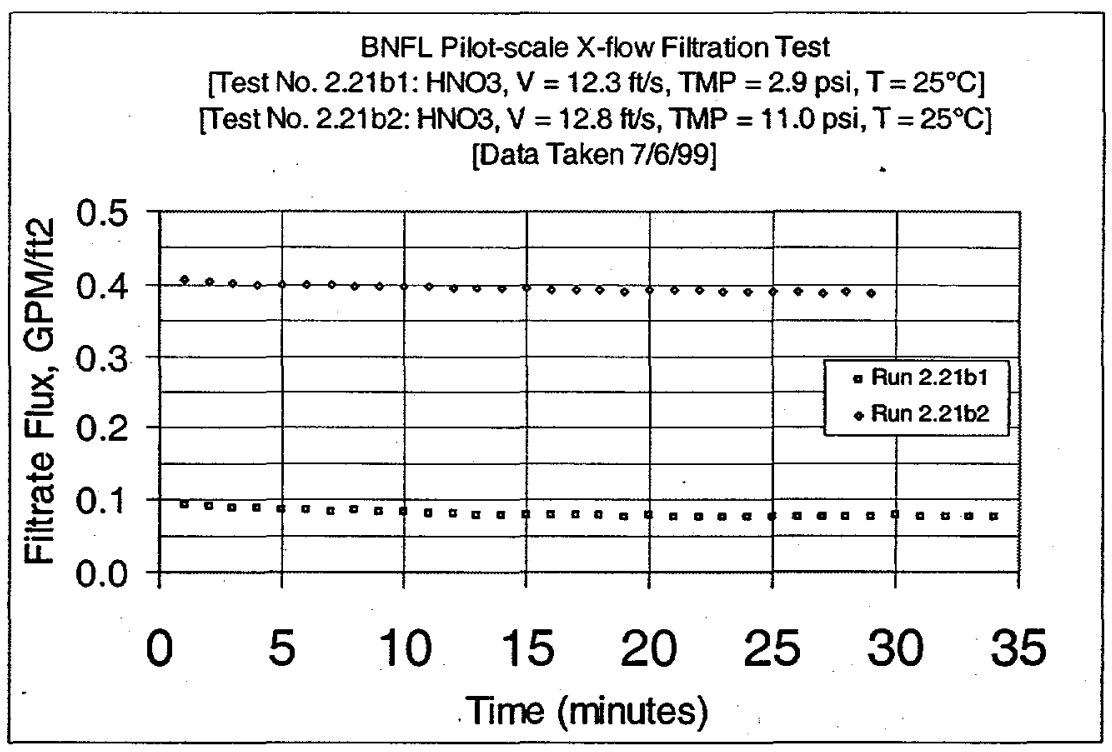

Figure 23. Cleaning run

2. Low TMP - A TMP of 3 psid was not easy to maintain for run $2.22 \mathrm{~b}$. Backpulsing was not effective because the filtrate flowrate would not return after a backpulse. To obtain data the TMP had to be increased until the filtrate flow was established, then the TMP could be reduced to 3 psid. (This was not the case for the new filter.) The difficulty to reestablish flow clearly indicated that the filter was not returned to the same level of cleanliness as when it was new. This dynamic stability could only be maintained as long as a backpulse was not done at this low TMP. Some of the smallest solid particles from the slurry must have lodged within the filtrate wall makings its removal more difficult. However, the intention is to operate the filter with a TMP of more than 10 times this low-pressure difference, therefore this effect at the higher operational TMP will be insignificant. 
On 7/13/99 another filtrate flowmeter, Q3, with a larger flow range, was installed on the test rig, in series with the original flowmeter, Q2, see Fig. 1. This allowed higher filtrate fluxes to be measured in run $2.22 \mathrm{~b}$. Figure 24 show those results.

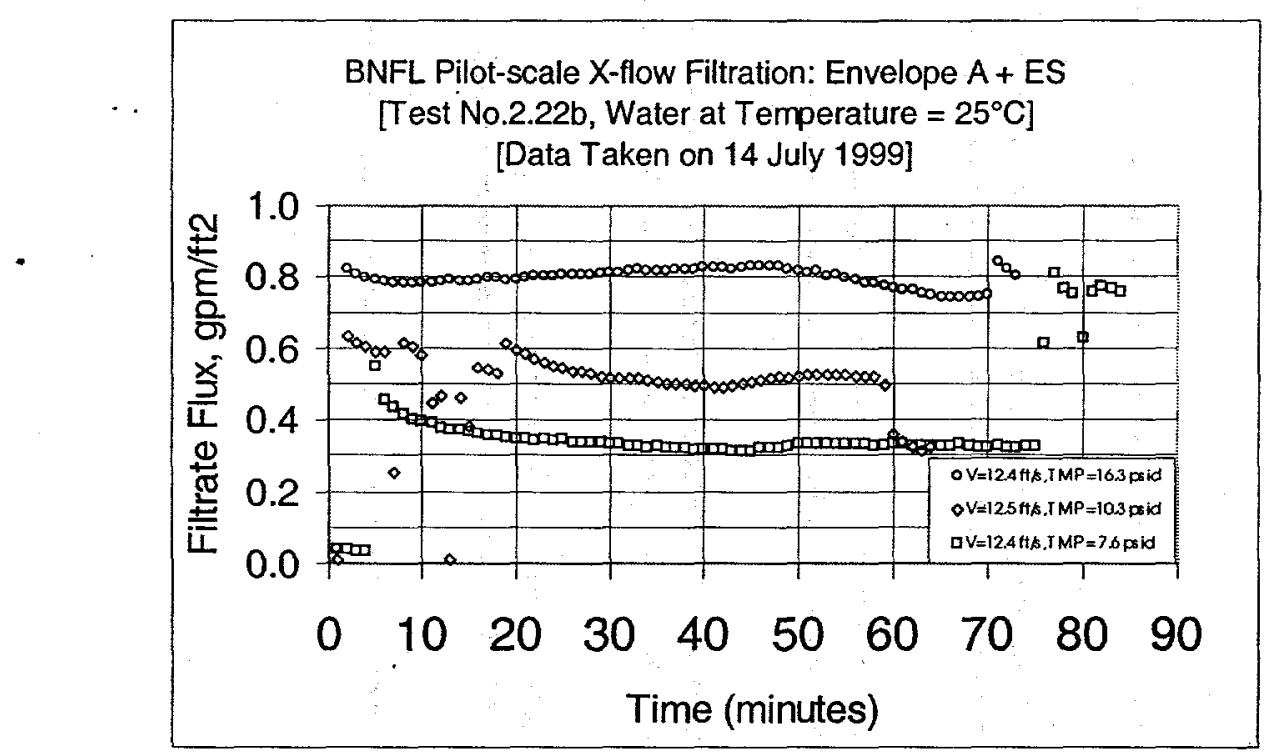

Figure 24. Water run at higher TMP using flowmeter Q3

Low Solids Concentration Test Runs 2.01 to 2.13

[See Appendix B for the entire set of data sheets.]

Included in this series of test runs are 13 planned runs and 4 unplanned runs $(2.07 \mathrm{~b}$, $2.07 \mathrm{c}, 2.10 \mathrm{~b}$, and 2.10c). By far, this series of runs comprised the largest amount of data taken.

* Overall comparison *

Figure 25 is an attempt to compare all the low solids concentration test runs together.

Unfortunately, a direct comparison among all the runs is not straight forward because run times differed for many reasons. Therefore several methods of comparison were chosen. Figure 25 show three different filtrate flux values: The mean value over the entire time of the test between backpulses, the value at $1 / 2$ hour after a backpulse, and an integrated value for the first $1 / 2$ hour of filtering. (Note that the numbers on the abscissa of the graph correspond to the numbers in the table below the graph.)

In general, it appears the integrated value is always larger than the mean or point value. This makes sense because the integrated value is only for the first $1 / 2$ hour, which includes the high filtrate flux just after a backpulse. (The period of $1 / 2$ hour was chosen because there are only approximately 22 minutes of data for run 2.03 and the largest interval between backpulses for run $2.07 \mathrm{c}$ is $1 / 2$ hour.) Now, the mean value also includes the data near the backpulse, but the mean is taken over the entire time of the test run which 
reduces the weighing of those points. (Run $2.07 \mathrm{~b}$ is the exception because it lasted 7.5 hours. For that run, the mean value was obtained for the first 2 hours after the backpulse so that it could be compared to the other runs.) Coincidentally, the point value of $1 / 2$ hour is generally equal to the mean value, based on approximately 2 hours of data. While this is an interesting fact, and maybe useful to know, it is only a coincidence. Some other exceptions are: For number 3 (run 2.03 ) because of having only 22 minutes of run time an extrapolation of the data to 30 minutes was done to obtain the $1 / 2$-hour value and the integrated value at $1 / 2$ hour of the filtrate fluxes. Number 17 (run $2.07 \mathrm{c}$ ) had backpulsing every 30 minutes (for 3 hours), 15 minutes (for 2 hours), and 5 minutes (for 1.5 hours), therefore there is no one-hour value. Therefore, the mean filtrate flux is based on the first 30 minutes, which give a high values and is closer to the integrated value than the point value at $1 / 2$ hour.

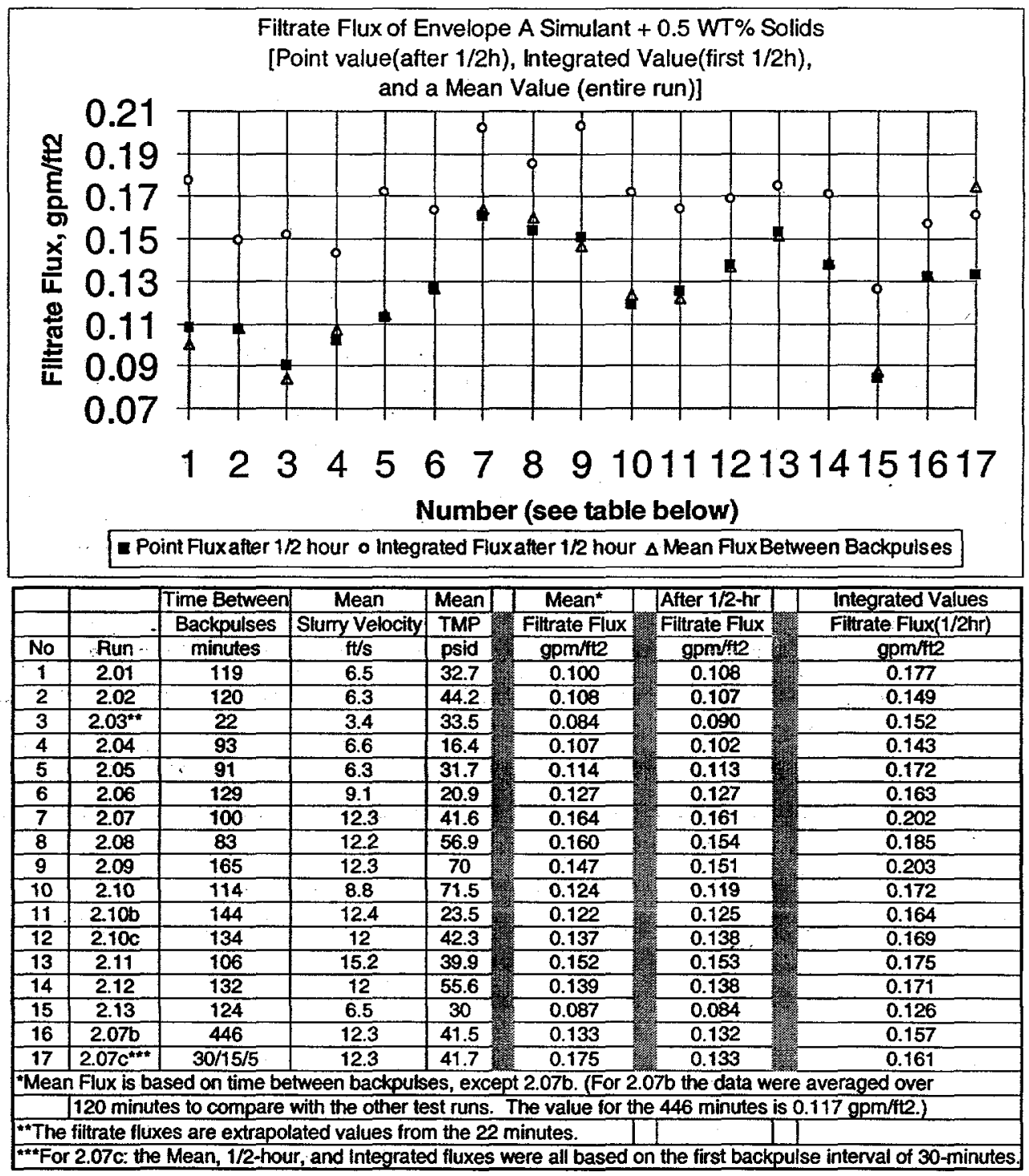

Figure 25. Composite of all 17 low solids concentration test runs 
From Fig. 25 it would appear that the flow conditions of either number 7 (run 2.07), 9 (run 2.09), or 13 (run 2.11) could produce the best filtrate flux. Of interest is that for runs 2.07 and 2.09 the axial slurry velocity is the same, $12 \mathrm{ft} / \mathrm{s}$, but the TMP differs by $30 \mathrm{psid}$. It would appear that the added TMP is not very effective in increasing filtrate flow. Run 2.11 has the same TMP as run 2.07 but the slurry velocity is higher by $3 \mathrm{ft} / \mathrm{s}$. When comparing 2.07 with 2.11 it would not appear that the added velocity helps. However, what needs to be considered is the fact that with time the filter flow is affected by how the filter becomes dirty and by the size of the solids particles. A look at Fig. 26 shows the reduction of filtrate flux for similar slurry velocity and TMP conditions.

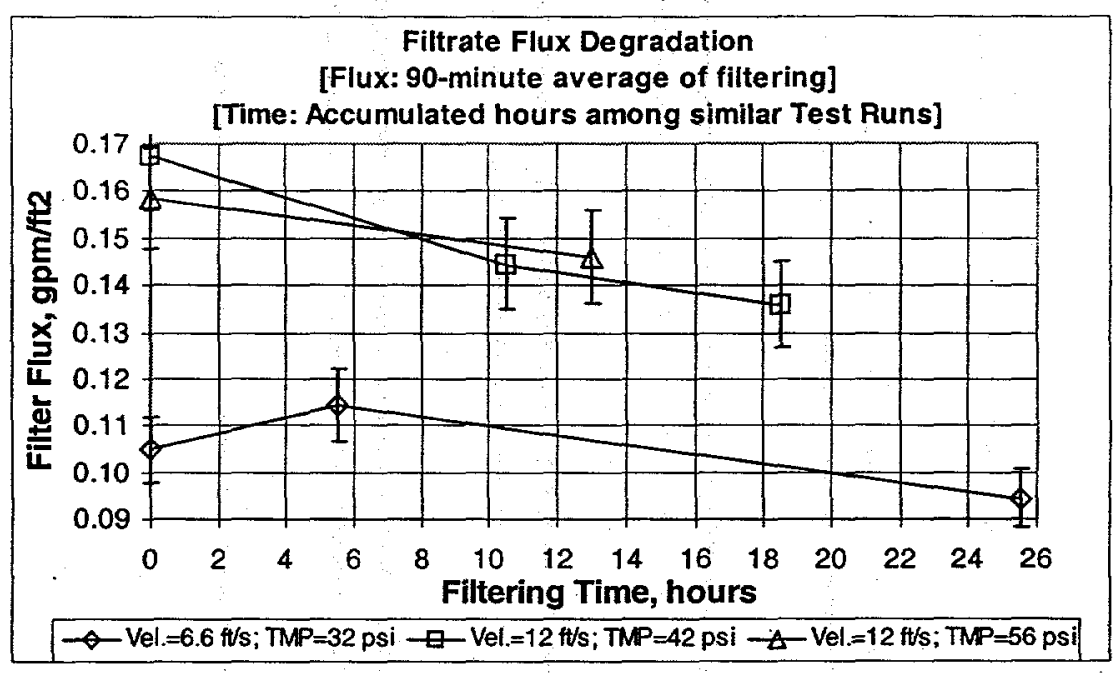

Figure 26. Effect of time on filtrate flow

[Filtrate Flux $=90$-minute average of filtering]

[Filtering Time $=$ accumulated filtering hours among Runs with the same flow conditions]

The error bars included in Fig. 26 are from the calculated measurement uncertainty of $6.72 \%$ for filtrate flux that can be found in Appendix F. Note that time shown is based on the number of accumulated filtering hours among tests with the same flow conditions, and not the number of hours of the entire test program. For example, the zero time for the three tests that had the flow conditions: slurry velocity $=6.6 \mathrm{ft} / \mathrm{s}$, TMP $=32 \mathrm{psid}$, is the time that the first of those three tests began, etc. As stated, this filtrate flux reduction is due to the slurry becoming more difficult to filter (smaller particles) or the filter becoming filled with solids that do not dislodge with a backpulse. While the former effect did exist, it was insignificant. From the analytical measurements in Appendix E the measurement of the particle sizes can be found before and after the low solids concentration runs. Those results are repeated here:

$\begin{array}{llll}\text { Test } & \text { Insoluble } & \text { Avg Particle } & \text { Avg. Particle } \\ \text { Run } & \text { Solids Loading } & \text { Diam. (by Volume) } & \text { Diam.(by Number) } \\ 2.01 & 0.5 \text { wt } \% & 2.59 \text { microns } & 1.031 \text { microns } \\ 2.13 & 0.3 w t \% & 2.32 \text { microns } & 1.027 \text { microns }\end{array}$


A portion of the "insoluble" particles seems to have been lost or dissolved into the slurry liquid since a measurement of the solids loading indicate a decrease of $40 \%$. Because of the small quantities of insoluble solids the measurement uncertainty may make this difference insignificant. However, there did seem to be a $10 \%$ decrease in particle size (by Volume). If particle reduction occurred, some of that reduced mass could have been lodged within the walls of the porous filters. Still, this possible depth fouling was small compared to the surface fouling since a backpulse would increase the flux by about four fold (for example, see the right hand side of Fig. 29 after the final backpulse was made).

Even with filtrate flux degradation occurring, comparisons can be made among the many test runs to determine an appropriate set of flow conditions to operate the cross-flow filter. During the first 16 runs only the TMP and the Axial slurry velocity were changed. (For number 17, run $2.07 \mathrm{c}$, the backpulse frequency was varied.) Therefore, a closer look at that those changes should elicit the information necessary.

* Filtrate Flux as a function of TMP *

Figures 27a, b, c, and d show a composite of four graphs; each for a constant axial slurry velocity. Figure $27 \mathrm{a}$ is for slurry velocity of $6.5 \mathrm{ft} / \mathrm{s}$ and a TMP from 16 to $44 \mathrm{psid}$.

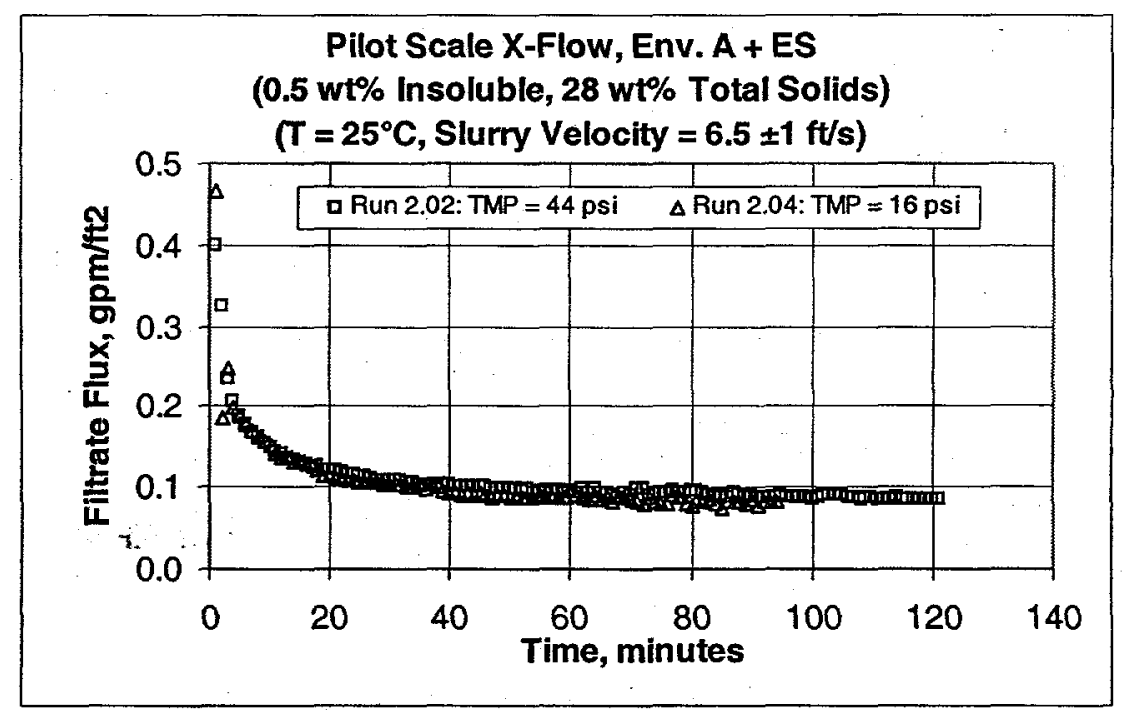

Figure 27a. Effect of TMP at a slurry velocity of $6.5 \mathrm{ft} / \mathrm{s}$

For all intents and purposes both data curves in Fig. 27a are the same. This indicates that the filtrate flux is at best a weak function of TMP. In fact, that pattern repeats itself in Fig. 27b. In Fig. $27 \mathrm{~b}$ the two curves are practically on top of each other; it appears that the large TMP increase from $20 \mathrm{psid}$ to $70 \mathrm{psid}$ is just wasted energy. 


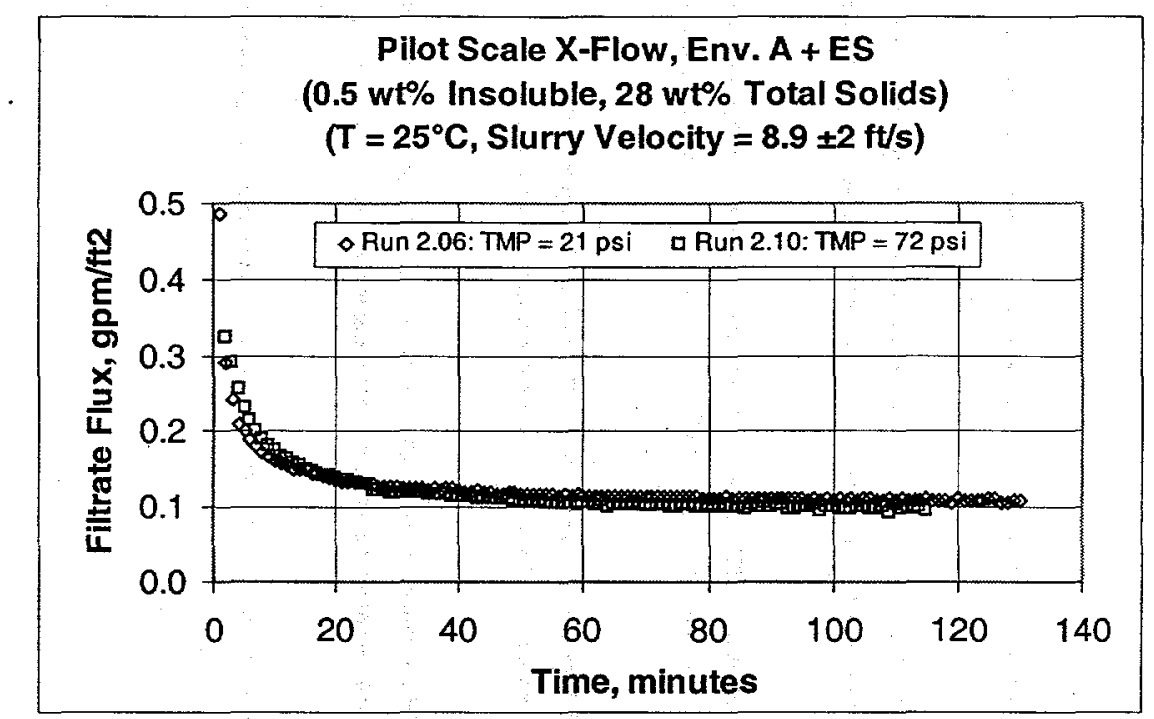

Figure 27b. Effect of TMP at a slurry velocity of $9 \mathrm{ft} / \mathrm{s}$

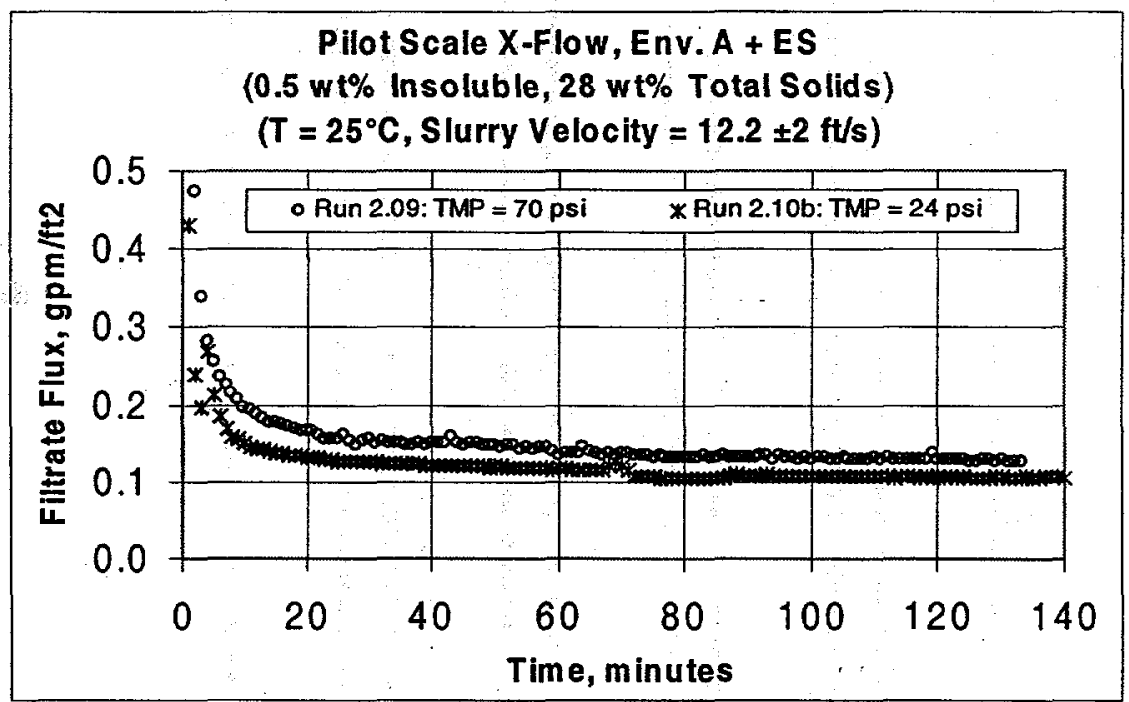

Figure 27c. Effect of TMP at a slurry velocity of $12 \mathrm{ft} / \mathrm{s}$ 


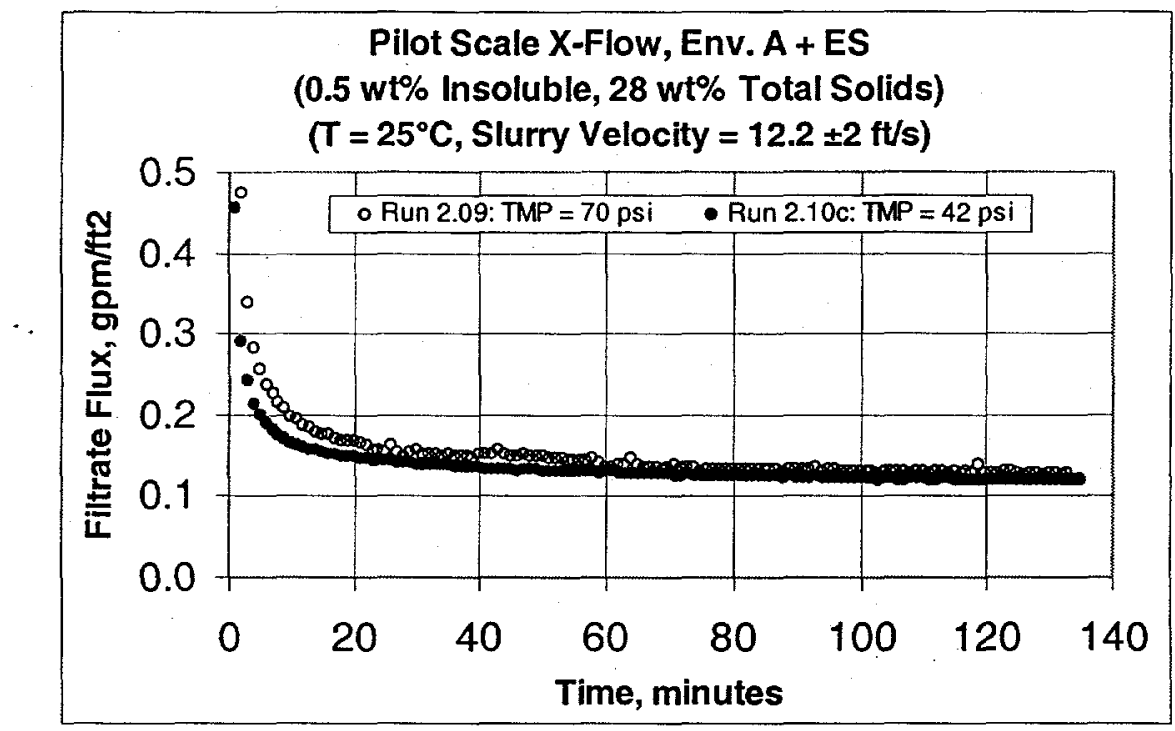

Figure $27 \mathrm{~d}$. Effect of TMP at a slurry velocity of $12 \mathrm{ft} / \mathrm{s}$

From Fig. 27c, the higher TMP does seem to play a role when the slurry velocity increases. At a slurry velocity of $12 \mathrm{ft} / \mathrm{s}$ there is an approximate $20 \%$ increase in filtrate flux when the TMP is increased from $24 \mathrm{psid}$ to $70 \mathrm{psid}$. Since the measurement uncertainty of the filtrate flux is $\pm 7 \%$ this increase is significant. However, a TMP increase to $70 \mathrm{psid}$ may not be necessary. Figure $27 \mathrm{~d}$ shows that by increasing the pressure from 24 psid to 42 psid, the filtrate flux is within $7 \%$ of the 70 -psid curve, which is a statistically insignificant difference.

* Filtrate Flux as a function of Axial Slurry Velocity *

Figures 28a, b, and $\mathrm{c}$ show a composite of three graphs; each for a constant TMP. Figure $28 \mathrm{a}$ is for a constant TMP of $20 \mathrm{psid}$. At that pressure only two runs were done at slurry velocities of 9 and $12 \mathrm{ft} / \mathrm{s}$. The two curves are almost exactly the same, which could mean that velocity has no effect on filtrate flux but since the TMP is very low and the velocities are close, more data are needed. Figure $28 \mathrm{~b}$ doubles the TMP to 42 psid. Here there is a significant difference between the curve for a slurry velocity of $6 \mathrm{ft} / \mathrm{s}$ and 15 $\mathrm{ft} / \mathrm{s}$.

Specifically, the filtrate flux is approximately $60 \%$ higher at $15 \mathrm{ft} / \mathrm{s}$ than at $6 \mathrm{ft} / \mathrm{s}$. Moreover, it must be noted that there was approximately 20 hours of filtering between these two runs, 2.02 and 2.11, see Fig. 15. During that time period Fig. 26 indicates that under similar conditions the filtrate flux decreased by about $20 \%$. Therefore, the top curve (run 2.11) in Fig. $28 \mathrm{~b}$ could have been $20 \%$ higher if data were taken at the same time as the bottom curve (run 2.02). This means the filtrate flux could have conceivably been $80 \%$ higher at $15 \mathrm{ft} / \mathrm{s}$ than at $6 \mathrm{ft} / \mathrm{s}$ ! Even between the top two curves (runs 2.10c and 2.11 ) there is a $12 \%$ increase in the filtrate flux. These two runs were done consecutively on the same day so there should have been no effect of time. However, this $12 \%$ difference is just barely significant. 


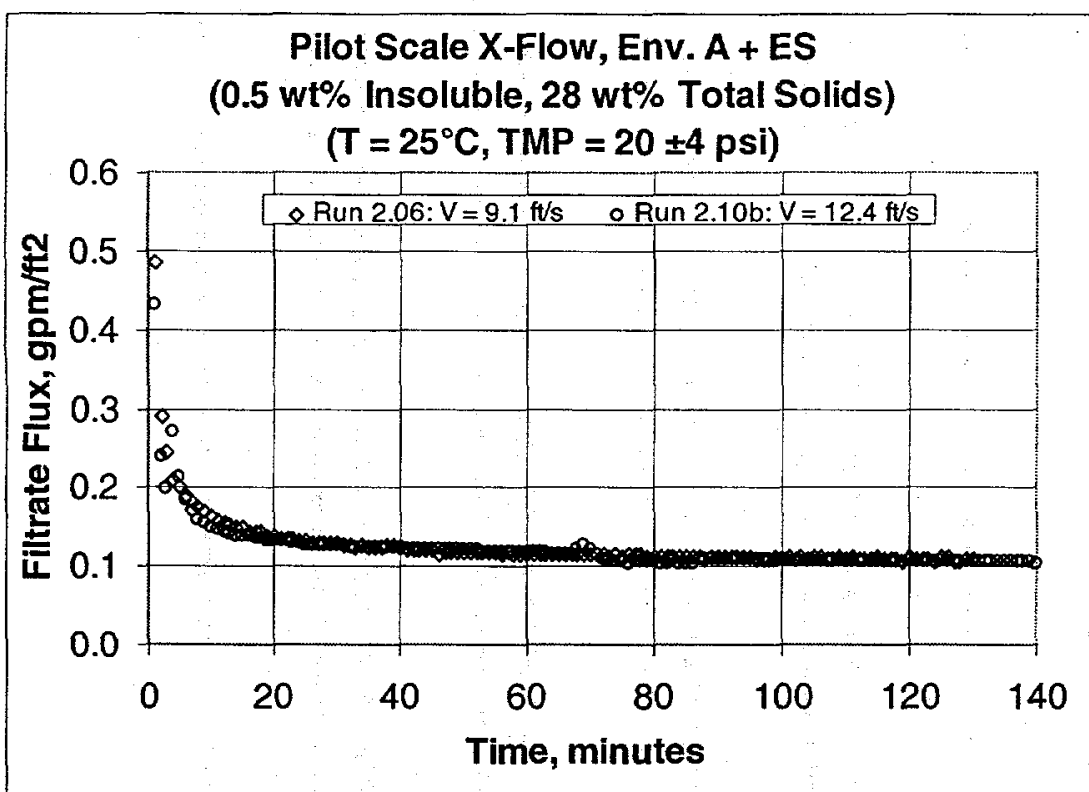

Figure 28a. Effect of axial slurry velocity at a TMP of 20 psid

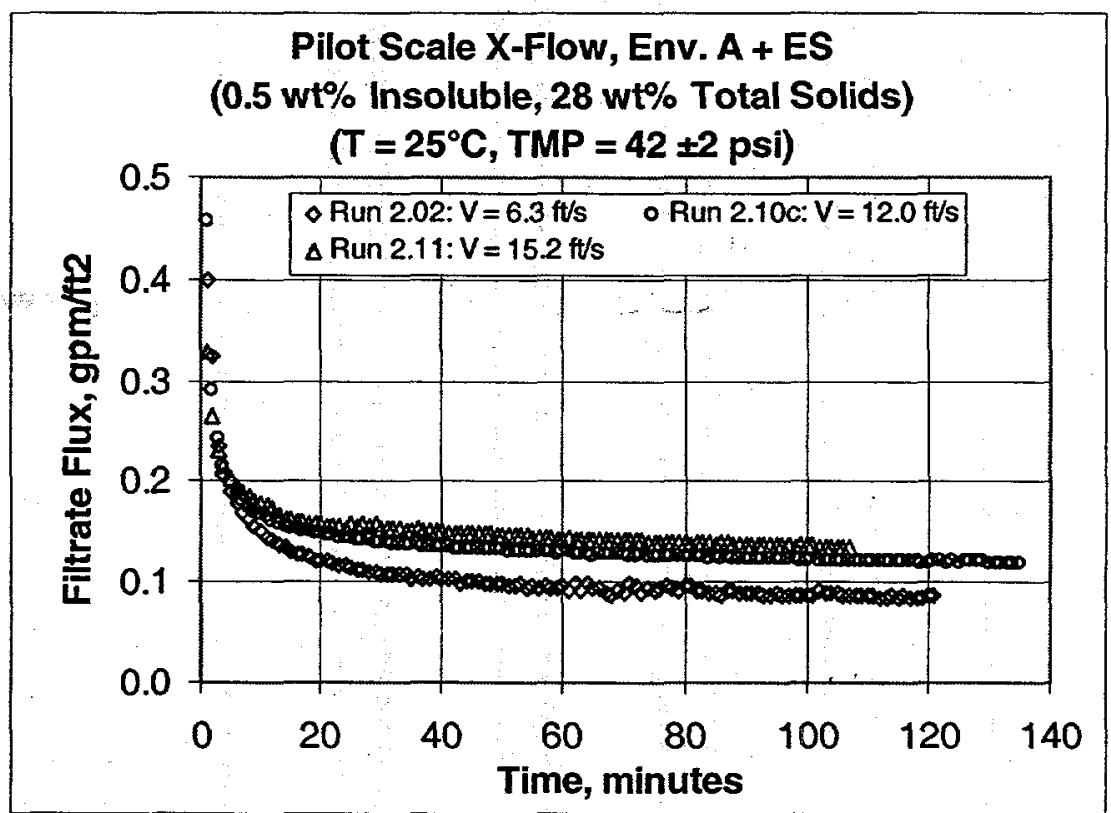

Figure 28b. Effect of axial slurry velocity at a TMP of 42 psid 
Fig. 28c clearly shows a significant improvement in the filtrate flux (30\%) when the slurry velocity of $9 \mathrm{ft} / \mathrm{s}$ is increased to $12 \mathrm{ft} / \mathrm{s}$ at a constant TMP of $71 \mathrm{psid}$. Once again, these two runs ( 2.09 and 2.10 ) were done consecutively so the slurry filter and slurry characteristics should have been the same. Except for the lowest TMP, 20 psid, the relationship between filtrate flux and axial slurry velocity appears to be linear. That is, for a $10 \%$ increase in velocity there is approximately a corresponding $10 \%$ increase in filtrate flux.

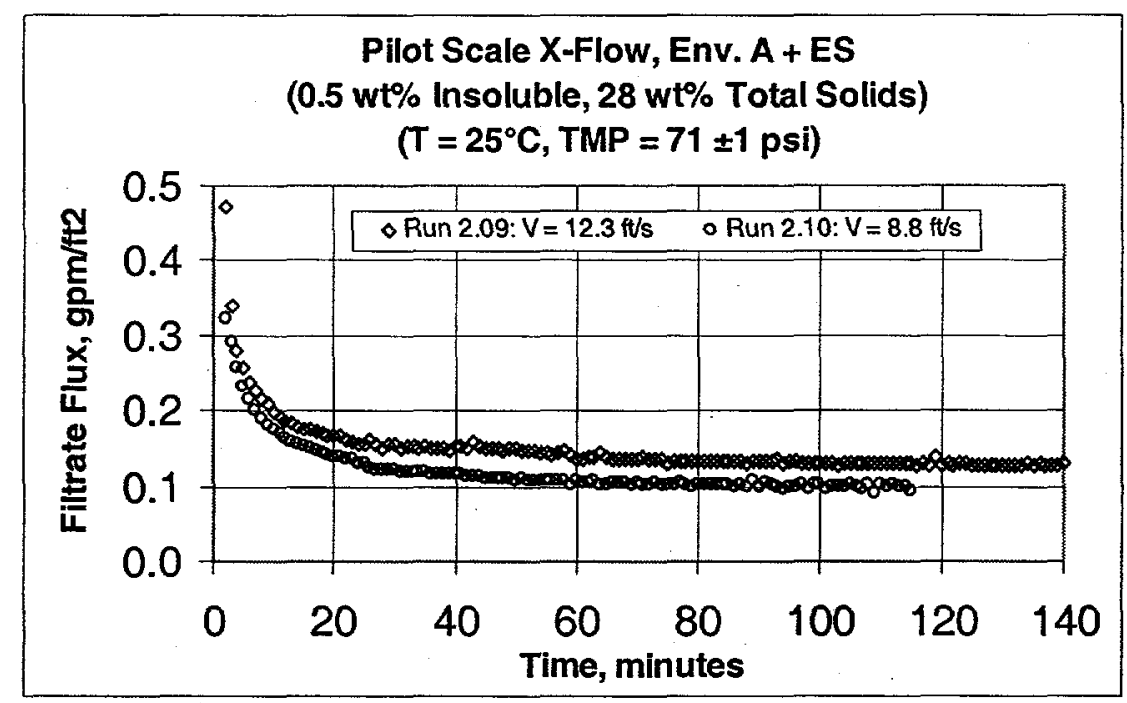

Figure 28c. Effect of axial slurry velocity at a TMP of $71 \mathrm{psid}$

Finally, backpulsing clearly improved throughput of filtrate but that improvement must be balanced against the downtime caused by the increased frequency of cleaning. That is, excessive backpulsing can be detrimental to long-term performance, depending on the type filter used. For this task, the filter manufacturer recommends that the backpulse frequency be no greater than once an hour; the longer the time between backpulses the better. Even though the filter elements used had a thick wall $(0.0625$ inch as opposed to a thin membrane filter), it is made to function as a surface, and not a depth, filter. The solids to be removed from the slurry are to remain on the surface of the filter and not lodged within the filter wall. As the filter cake builds, it itself becomes a filter removing smaller particles than the fixed filter on which it lies. When a backpulse occurs, most, or all of the filter cake is knocked off the fixed filter surface, which allows a higher filtrate flux, but also exposes the filter substrate to smaller solid particles. Over time these smaller particles will cause depth fouling and a reduced performance that cannot be improved though backpulsing. Fortunately, the long-term performance, without backpulsing, still gave an adequate filtrate flux. Figure 29 show the results of a test done over more than seven hours between backpulses. At the end of the test, the filtrate flux. was still above $0.10 \mathrm{gpm} / \mathrm{ft}^{2}$ and by the asymptotic behavior, the flux appears fairly constant after 7 hours and possibly could have been maintained for many more hours without a backpulse. (Note, the sudden drop at the end of the run was caused by taking a 
filtrate sample which involves opening the filtrate flow system, thus causing a reduction in system pressure.) The mean filtrate flux over the 446 minutes of the test was 0.118 $\mathrm{gpm} / \mathrm{ft}^{2}$ (see Fig. B16 and the accompanying data in Appendix B).

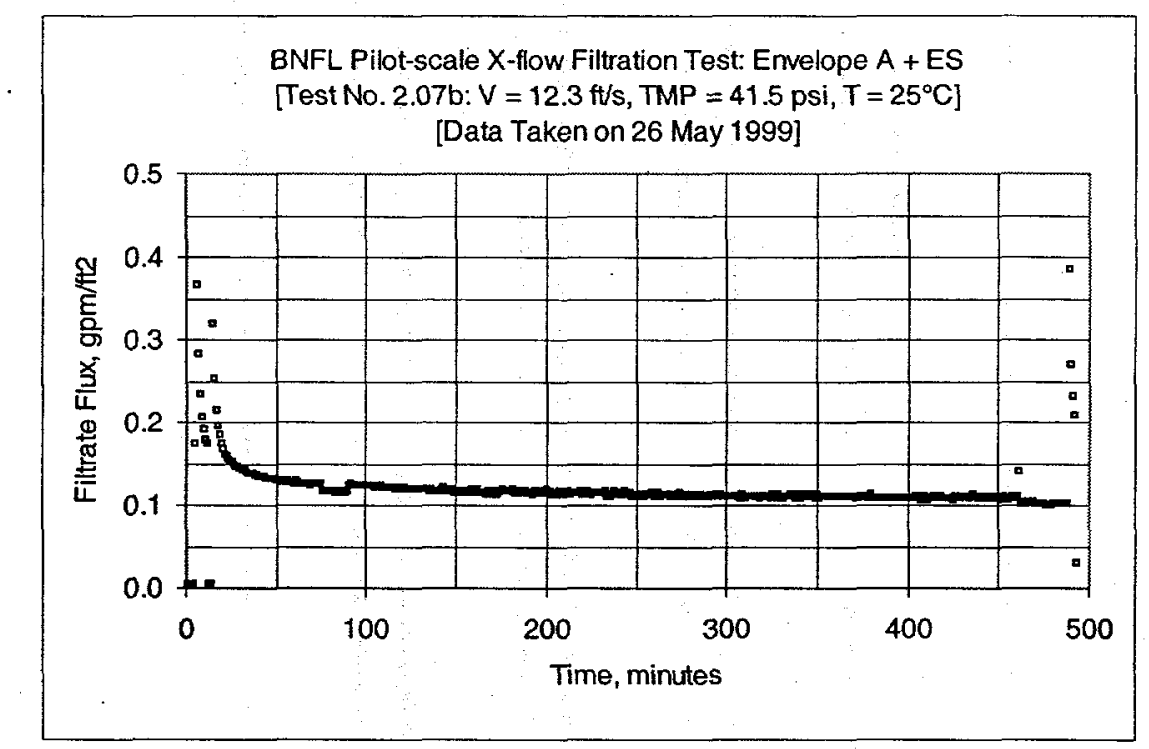

Figure 29. Long term filter operation between backpulses

Even though there are reasons to minimize backpulsing, there was interest in knowing how increasing the backpulse frequency increases the filtrate flux. Figure 30 compares the results from 3 runs that had similar flow conditions (see Fig. 25 for the conditions and actual times): $2.07 \mathrm{~b}$ (with $\sim 7.5$ hours between backpulses), $2.10 \mathrm{c}$ (with $\sim 2$ hours between backpulses), and 2.07c (with 30, 15, and 5 minutes between backpulses; see Figs B17a and B17b in Appendix B); the increase is significant. That is, by increasing the backpulse frequency by a factor of $90,[(7.5 \mathrm{hrs} /(5 \mathrm{~min} / 60)=90]$, the filtrate flux increased, but only 2 fold, [from 0.12 to $0.25 \mathrm{gpm} / \mathrm{ft}^{2}$ ]. Many studies $(19,20,21,22)$ clearly show the advantage of increasing the backpulse frequency, even to frequencies of 10 to $20 \mathrm{~Hz}$. However, filters that work well at those frequencies are very thin membranes where depth fouling is generally not a factor, i.e., a particle that manages to enter a filter pore just goes right through because of the thin membrane. For the robust sintered-metal filter, used in this task, depth fouling cannot be ruled out. Therefore, it must be reiterated that an increase in filtrate flux may come at the expense of an increased rate of depth fouling. Figure 26 implies that for runs with approximately a 2hour backpulse frequency, the filtrate flux is reduced by 10 to $15 \%$ over a 24 -hour period of continuous filtering. Time did not allow evaluation of the long-term consequences on filtrate flux for other backpulse frequencies, but it seems logical that the steady-state flux would decrease faster as the frequency increased. Since high frequency backpulsing means the fixed filter surface remains freer of a filter cake, the smallest solids particles in the slurry would have more time to challenge the filter wall. 


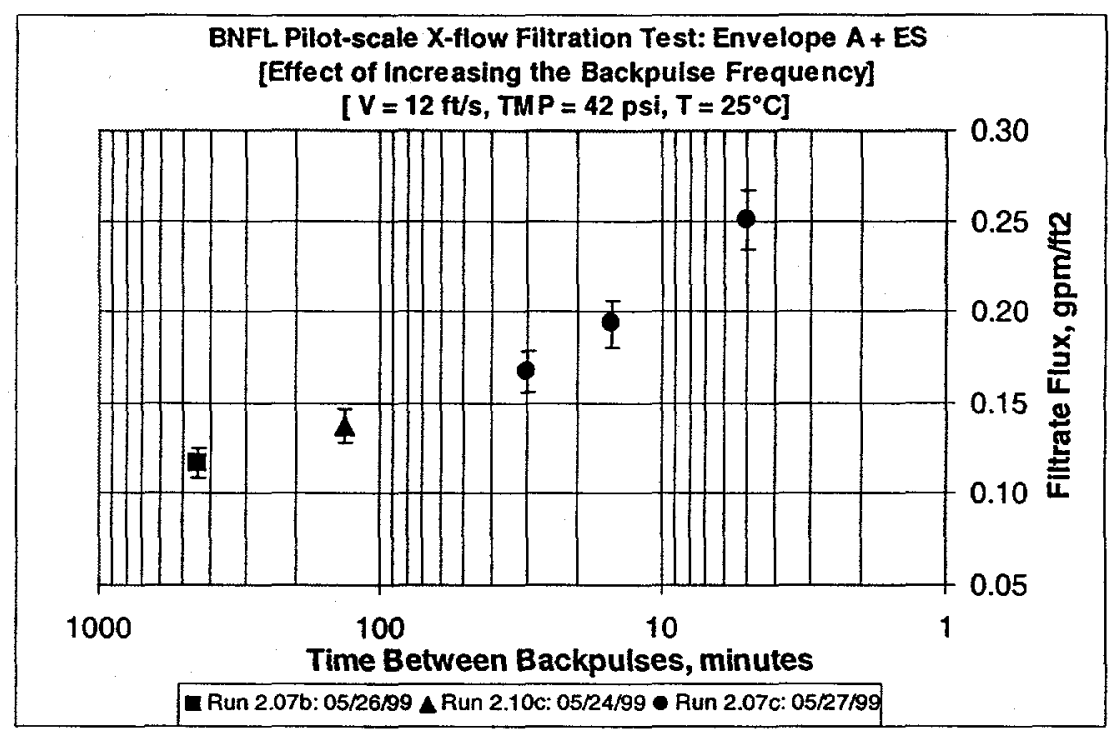

Figure 30. Filter operation with an increasing backpulse frequency

High Solids Concentration Test Runs 2.14, 2.14a (Pre-wash)

[See Appendix C for the entire set of data sheets.]

Two test runs were done before washing occurred. Originally, there was to be only one run, 2.14, before washing, but in concentrating the slurry the test rig became plugged. In an attempt to free the plug from the test rig the slurry became diluted with water.

Subsequently, the washing runs, 2.15 to 2.19 were done, with 2.14 assumed to be the first wash run because of the added water. However, time allowed the mixing of another batch of similant, thus a new set of runs was done starting with $2.14 \mathrm{~b}$. While there were two pre-wash runs, the solids loading was never brought above the required $20 \mathrm{wt} \%$ because of plugging concerns. Furthermore, instead of straight dewatering, the slurry was concentrated by adding solids directly to the slurry after a fixed amount of filtrate was removed. This method was used to allow for a much smaller starting volume of slurry. Theoretically, this method was possible because the two quantities, i.e., supernate and insoluble solids, were thought not to interact with each other except for physical space. Unfortunately, after removing 37 liters of filtrate from the 75 liters of slurry, problems occurred on adding the solids to the supernate. When the insoluble solids loading was between $10 \mathrm{wt} \%$ and $15 \mathrm{wt} \%$ the test rig became plugged. In an attempt to prevent a long shut down and free up the test rig immediately, the 37 liters of filtrate was returned to the slurry. The added filtrate did not relieve the plug so three separate additions of DIF water were added, for a total of 38 liters. Despite the water addition, the test rig remained plugged and had to be shut down. The majority of the dilute slurry was drained from the test rig, which was then dismantled to remove the pluggage. [Note: When the test rig was disassembled the plug was found in the test-rig piping and not the filter. The pluggage occurred because of the way the solids were incorporated into the slurry. In pouring the solids directly into the slurry reservoir of the test rig some of the solids did not have time to become well mixed in the slurry; isolated clumps of solids were found in the pipes. Those clumps contained dry solids that did not did not mix with 
the liquid and when a clump met a bend in a pipe it stuck, which prevented further flow. The second batch of simulant was made in a separate tank to make sure the slurry was well mixed before introducing it into the test rig.]

After the test rig was cleaned, the experiment continued. Run 2.14 was done with the remaining slurry, which had a calculated insoluble solids content of $9 \mathrm{wt} \%$. A subsequent measurement showed the solids loading to be closer to $7 \mathrm{wt} \%$. This difference may have come from some of the solid sodium oxalate dissolving in the more dilute slurry.

Based on the low-solids concentration runs, the best combination of axial slurry velocity and TMP was chosen to be $12 \mathrm{ft} / \mathrm{s}$ and $40 \mathrm{psid}$, respectively. Figure 31 shows that a relatively high filtrate flux was obtained despite the $7 \mathrm{wt} \%$ insoluble solids loading. However, since the slurry was diluted with water and the sodium level is estimated to have been close to $3 \mathrm{M}$, instead of the original $5 \mathrm{M}$. [Note, that there are two curves in Fig. 31 because the run was restarted to adjust the TMP, which drifted high.] As already stated above, since time allowed, the slurry was adjusted to raise the sodium level back to over $5 \mathrm{M}$ to redo the run, which was called run $2.14 \mathrm{~b}$.

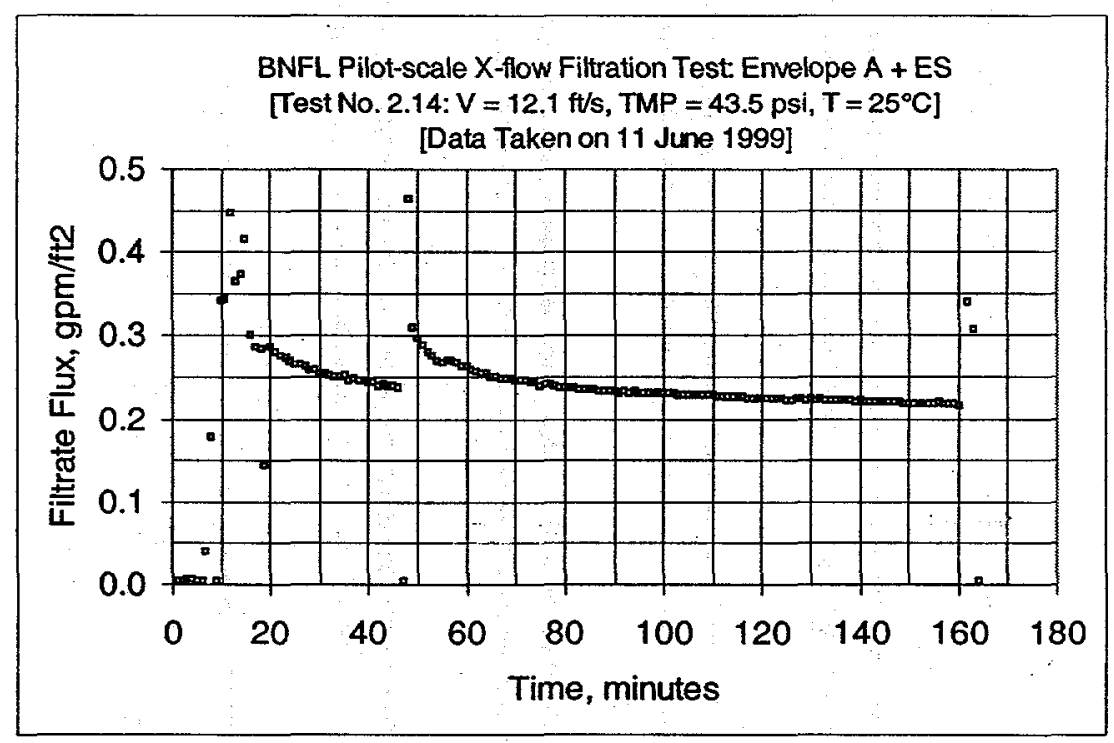

Figure 31. Run 2.14: $7 \mathrm{wt} \%$ insoluble solids; $26 \mathrm{wt} \%$ total solids

Figure 32 shows the results of the new run with the sodium level back over $5 \mathrm{M}$. The insoluble solids loading was calculated at $11 \mathrm{wt} \%$ but a subsequent sample analysis indicated a value closer to $8 \mathrm{wt} \%$. The filtrate flux over the entire run stayed above 0.1 $\mathrm{gpm} / \mathrm{ft}^{2}$ and in fact was very similar to the last low-concentration continuous run, $2.07 \mathrm{~b}$ which had very similar flow conditions (see Fig. B16 in Appendix B). This indicates the added insoluble solids had an insignificant effect on filter operation. From this experience higher pre-wash slurry concentrations are possible and maybe even reaching 
and surpassing the target $20 \mathrm{wt} \%$. However, because of the aforementioned circumstances there are no quantitative data to make a more definitive statement.

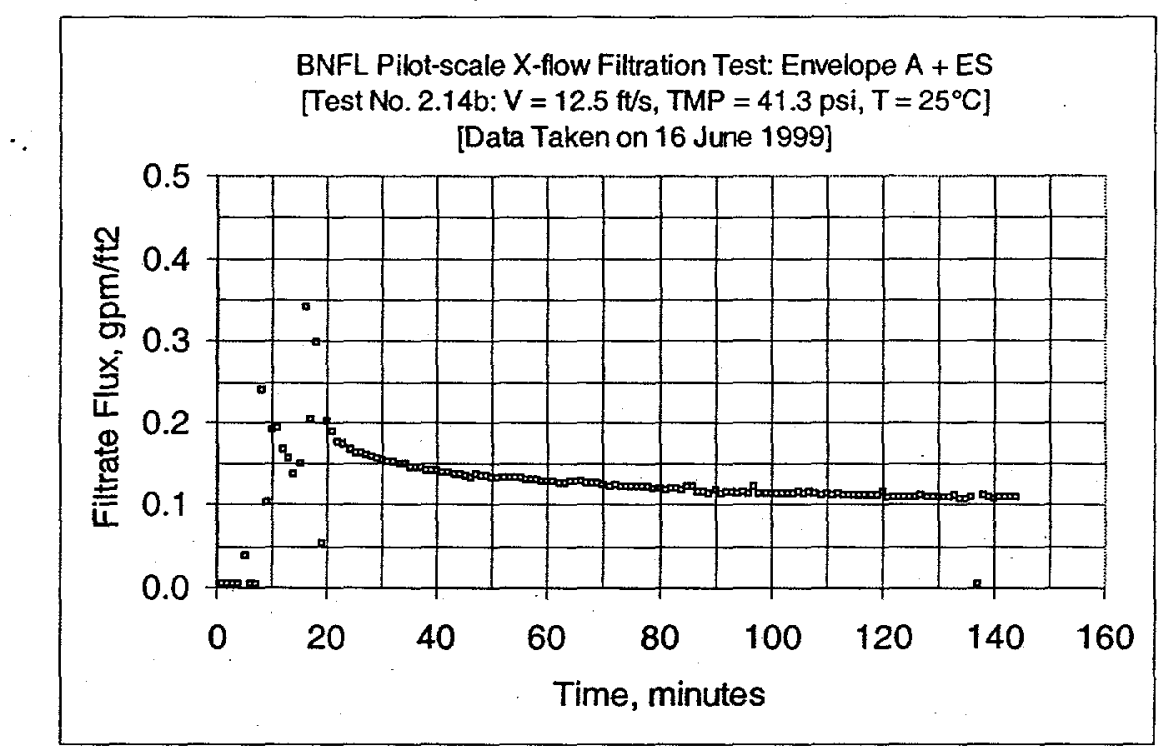

Figure 32. Run 2.14b: 8 wt\% insoluble solids; $36 \mathrm{wt} \%$ total solids

Wash Test Runs 2.15-2.19 and 2.15b-2.19b

[See Appendix D for the entire set of data sheets.]

There were nine different wash test runs. Test runs 2.15-2.19 were repeated when a new batch of slurry was made to repeat run 2.14. The new tests are referred to as $2.14 \mathrm{~b}-2.19 \mathrm{~b}$, with the first wash run beginning with $2.15 \mathrm{~b}$. From all these runs the hydraulic aspects are best illustrated by run 2.15, Fig. 33 .

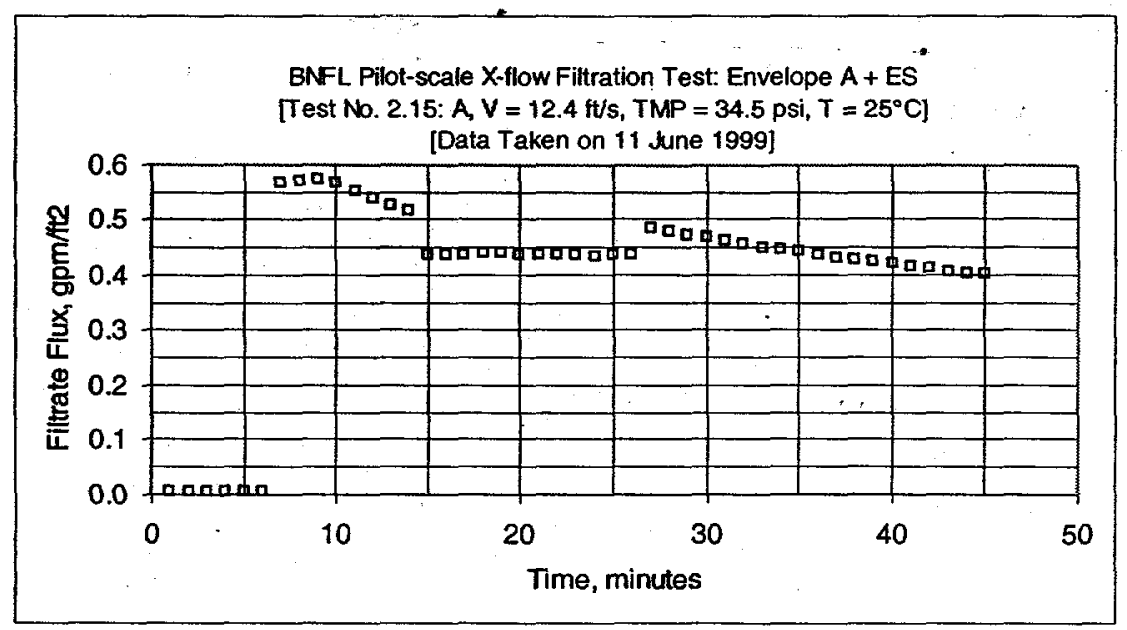

Figure 33. Typical wash test run 
Figure 33 shows two different characteristics: 1 . A descending curve, typical of a crossflow filter curve for slurry after a backpulse, and 2. a relatively flat curve that lasted approximately twelve minutes. This flat curve occurred when the filtrate system was opened to remove 45 liters of filtrate. (These numbers match the data in Fig. 33, because $45 \mathrm{~L} / 3.785 \mathrm{~L} / \mathrm{gal} / 12 \mathrm{~min} . / 2.29 \mathrm{ft}^{2}=0.43 \mathrm{gpm} / \mathrm{ft}^{2}$, which is close to graphical result shown.) That is, to dewater the slurry, so that the next charge of washing water could be introduced into the test rig, the filtrate system was opened using valve V13 in Fig. 1; the filtrate was collected and sampled. While the filtrate was collected, the open valve allowed the pressure in the filtrate loop to drop since it was not forced back to the slurry loop. This reduced pressure caused the flow parameters, i.e., slurry velocity and TMP, to change. Therefore, the initial flow conditions were set so that when the filtrate valve was opened the flow conditions came close to the test specification requirements. It was not always easy to set the correct flow and therefore many of the data sheets for the washing runs show quite a bit of adjustment before the filtrate was actually drawn from the test rig.

During the washing runs there was a concern about the filtrate flux increasing above the measurable limit of $0.53 \mathrm{gpm} / \mathrm{ft}^{2}$. Because of the water additions, the filtrate flux was expected to increase as the slurry became successively more dilute. As mentioned, run 2.15 was considered the second wash run since the slurry for run 2.14 was already diluted with water because of the test rig pluggage. In Fig. 33, the first couple of points after the backpulse are above the calibrated range of the filtrate flowmeter and are therefore meaningless. As a backup measurement, a bucket and stopwatch technique was used to verify the filtrate flux when filtrate was drawn. Fortunately, the portion of the curve when the filtrate was being drawn was always below the threshold of the filtrate flowmeter for all test runs.

\section{Dewatering/Plugging Test Run $2.20 \mathrm{~b}$}

[See Appendix $\mathrm{C}$ for the entire set of data sheets.]

Figure 34 shows the result of this relatively short test of 50 minutes from the backpulse. The goal was to dewater/concentrate the post-washed slurry to the point that filtration was no longer possible, due to either the filter plugging or for some other operational reason. Starting with approximately 80 liters of slurry in the test rig, the slurry was dewatered by removing filtrate in batches of approximately 7.3 liters. After each batch removal, the density of the slurry was measured and samples were taken three times to have information on the slurry as it approached possible plugging. A total of 6 full batches of filtrate were removed before stopping during a $7^{\text {th }}$ batch, which reduce the slurry volume to less than 35 liters. (The actual final volume was closer to 30 liters.) The filtering never stopped and while the filtrate flux decreased throughout the test, at the end it still was filtering at $0.25 \mathrm{gpm} / \mathrm{ft}^{2}$ when the insoluble solids loading was estimated at approximately $16 \mathrm{wt} \%$ [see Table 1 (page 26), run $2.20 \mathrm{~b}$ end]. 


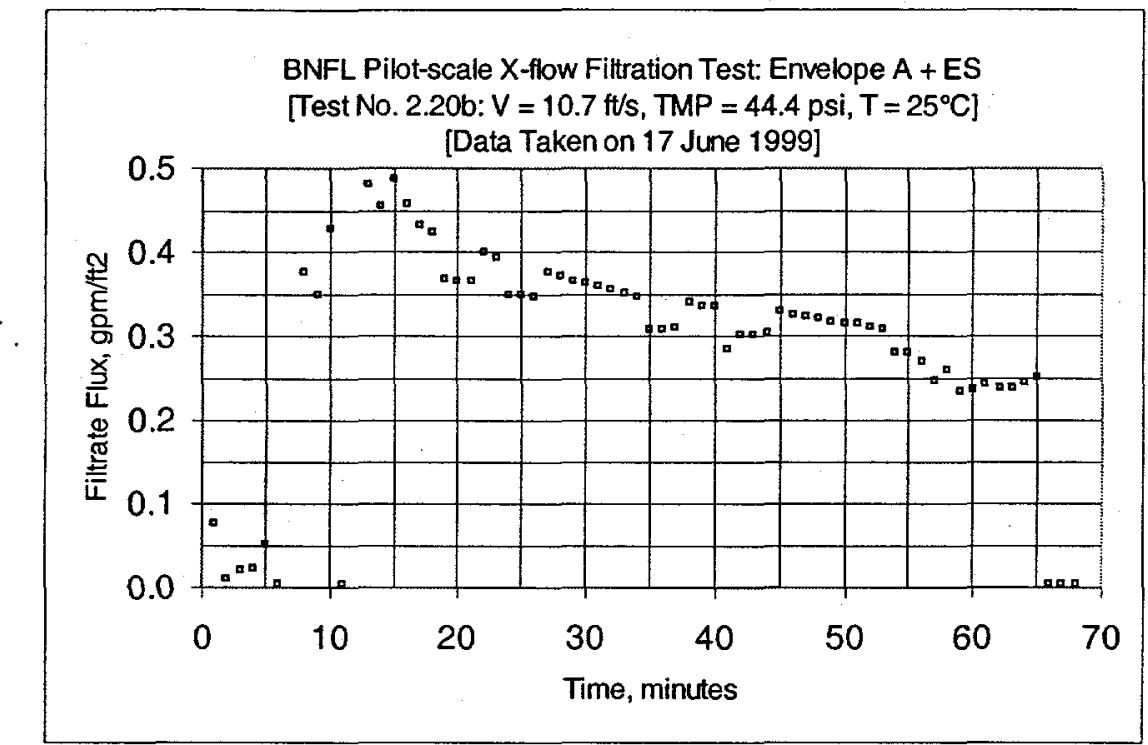

Figure 34. Dewatering/Plugging test run

Figure 35 shows how the density of the post-washed slurry increased after each of the 6 batches of filtrate was removed. Included in Fig. 35 are three measurements of solids loading that were made. The middle set of numbers (at 65 liters of slurry remaining) has no reading for insoluble solids because the analytical measurement was in error and had to be discarded. Finally, in attempting the $7^{\text {th }}$ batch the test rig was stopped when flow could not be maintained. The test rig needed 26 liters to keep it liquid solid and the extra 4 liters of the remaining 30 liters of thickened slurry were not sufficient to maintain the pump suction pipe full. The slurry was spread around the tank such that a good sample could not be taken, therefore a final density was not obtained

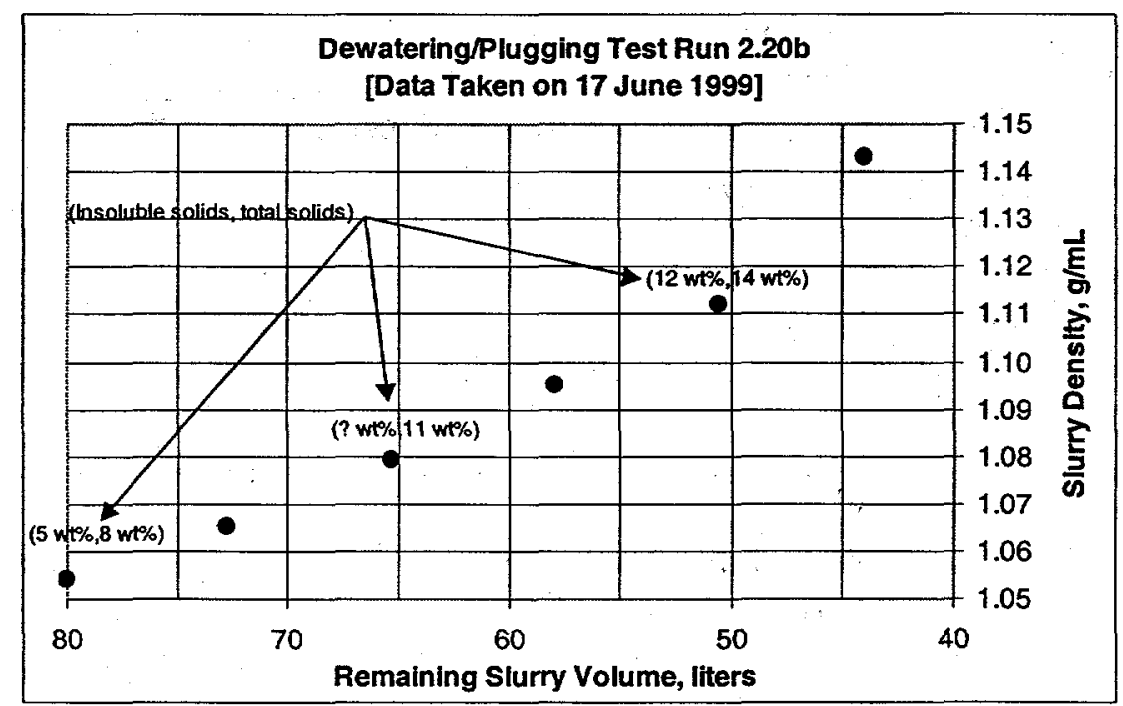

Figure 35. Dewatering/Plugging test run with post-washed slurry 


\section{CONCLUSIONS}

The following conclusions are for the nominal rated 0.1 micron Mott cross-flow filter which was used under the conditions stated herein at a slurry temperature of $25^{\circ} \mathrm{C}$.

\section{Filter Effectiveness}

1. There was no measurable quantity of insoluble solids in the filtrate under any circumstance from the filtered slurry that had a solids loading from $0.5 \mathrm{wt} \%$ to greater than $16 \mathrm{wt} \%$ and for particle sizes measured as small as 0.76 micron.

\section{$\underline{\text { Slurry Wash }}$}

2. Using 4 equal quantities of distilled and filtered water (each quantity equaling the volume of the slurry to be washed), the sodium molarity of the filtrate decreased from $5.2 \mathrm{M}$ to $0.29 \mathrm{M}$, while the dynamic viscosity decreased from $1.8 \mathrm{cP}$ to $1.1 \mathrm{cP}$ and the density decreased from $1.214 \mathrm{~g} / \mathrm{mL}$ to $1.015 \mathrm{~g} / \mathrm{mL}$. For a fifth wash those numbers decreased to $0.13 \mathrm{M}, 1.01 \mathrm{cP}$, and 1.0095 , respectively.

\section{Hydraulic Characteristics}

3. Water flux through a used cleaned filter may be as low as a third that of a new filter.

4. Surface fouling of the filter is the dominant mechanism of fouling.

5. Higher slurry velocities and higher transmembrane pressures lead to higher filtrate fluxes. However, the increase in filtrate flux is strongly affected by the slurry velocity but only weakly by TMP.

6. Slurry velocities for steady-state operation should be $12 \mathrm{ft} / \mathrm{s}$ or higher.

7. A TMP of 40 psid or 55 psid, with the velocity in conclusion 6 , will give close to the best filter flux performance. Increasing the TMP to 70 psid will increase the filtrate flux slightly but that small increase may not justify the larger energy expenditure for the higher pressure. Also, the lower TMP will increase the life of the cross-flow filter due to a lower cleaning frequency.

8. For a low concentrations of insoluble solids $(0.5 \mathrm{wt} \%)$, based on conclusion 7 , run 2.07, shown in Fig. 25, gave the best overall filtrate flux of $0.20 \mathrm{gpm} / \mathrm{ft}^{2}$ at the conditions of a slurry velocity of $12.3 \mathrm{ft} / \mathrm{s}$ and a TMP of 42 psid. This flux is based on an integrated value of the measured flux for the first one half hour of operation. Even for the run that lasted more than 7 hours without backpulsing (Fig. 29), the mean filtrate flux was still $0.12 \mathrm{gpm} / \mathrm{ft}^{2}$, and it appeared that this flux could be easily sustained for many more hours.

9. For high concentrations of insoluble solids ( $8 \mathrm{wt} \%)$ the filtrate flux remains above $0.10 \mathrm{gpm} / \mathrm{ft}^{2}$ for at least 2 hours after a backpulse.

10. The cross-flow filter still functions satisfactorily for an insoluble solids loading of 16 wt\%; the post-washed slurry had filtrate fluxes better than $0.2 \mathrm{gpm} / \mathrm{ft}^{2}$.

11. An average filtrate flux of $0.12 \mathrm{gpm} / \mathrm{ft}^{2}$ can be maintained for at least 7 hours without backpulsing. It can be increased to $0.16 \mathrm{gpm} / \mathrm{ft}^{2}$ with a backpulse interval of 30 minutes. 
12. In all the test runs the filtrate flux was never lower than the River Protection Project waste treatment plant design basis of $0.037 \mathrm{gpm} / \mathrm{ft}^{2}$, and typically it was above three times that value.

13. A backpulse filtrate volume of $0.036 \mathrm{gal} / \mathrm{ft}^{2}$ with a filter overpressure of $30 \mathrm{psi}$ was found to be sufficient to knock the filter cake off the filter element. A backpulse frequency of 30 minutes leads to a filtrate flux loss of $0.0012 \mathrm{gpm} / \mathrm{ft}^{2}$ rate, which is only a few percent of the lowest steady-state filtrate flux measured of $0.05 \mathrm{gpm} / \mathrm{ft}^{2}$.

\section{RECOMMENDATIONS}

The following recommendations are for the nominal rated 0.1 micron Mott cross-flow filter when used for an Envelope A slurry at a temperature of $25^{\circ} \mathrm{C}$.

1. Use a slurry axial velocity of at least $12 \mathrm{ft} / \mathrm{s}$. Lower velocities significantly reduce filtrate flux.

2. Use a transmembrane pressure of 40 to 55 psid. Lower pressures significantly reduce filtrate flux and higher pressures do not increase the filtrate flux significantly.

3. Backpulse the filter twice to three times in a 24-hour period of continuous use to maintain an average filtrate flux of $0.1 \mathrm{gpm} / \mathrm{ft}^{2}$ and to minimize filter cleaning.

4. Backpulse the filter every 30 minutes during continuous use to increase the average filtrate flux to $0.16 \mathrm{gpm} / \mathrm{ft}^{2}$.

5. Use a backpulse of $0.036 \mathrm{gal} / \mathrm{ft}^{2}$ to minimize the loss of filtrate flux. 


\section{APPROVALS}

H.N. Hevenem

H. N. Guerrero, Technical Reviewer, WSRC/SRTC

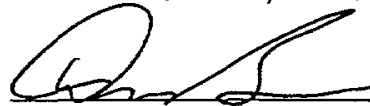

D. B. Burns, Experimental Thermal Fluids Group Manager, WSRC/SRTC

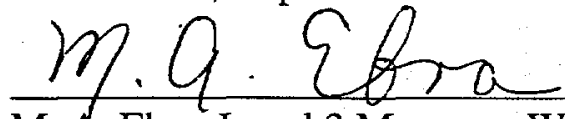

M. A. Ebra, Level 3 Manager, WSRC/SRTC

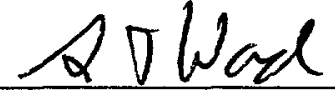

S. T. Wach, Waste Processing Technology Manager, WSRC/SRTC

Not Reguried as per BVF-003-98-0239, April 24, 2000

P. S. T Wwnson, Ultrafiltration Development Manager, BNFL
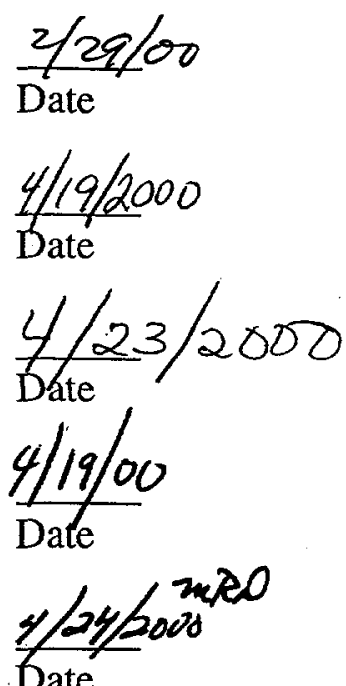

\section{REFERENCES}

1. Nash, C. A., Technical Task Request, Document No. BNF-003-98-0014, Rev. 0, Oct. 15, 1998.

2. Johnson, M. E., "TWRS-P Contract No. DE-AC06-96RL13308 - W375 Equipment for the Pilot Scale Cross-Flow Filter Unit." Letter to S. T. Wach No. 000427, Oct. 29, 1998.

3. Townson, P. S., Ultrafiltration and Solids Dissolution Test Specification, Revision 1, Document No. 000750, Nov. 23, 1998.

4. Duignan, "BNFL Pilot-scale Cross-flow Filter Test," Task Notebook, Document No. WSRC-NB-00254. [Pages 5 (Sept. 30, 1998) to 41 (Apr. 28, 1999) are for the test rig construction and shakedown activities, Pages 42 (May 12, 1999) to 73 (Jun. $25,1999)$, are for the test run.].

5. Duignan, M. R., "BNFL Pilot Scale Cross Flow Filtration Test," Task Technical and Quality Assurance Plan, Document No. BNF-003-98-0015, Rev. 0, Nov. 18, 1998.

6. Duignan, M. R., "TWRS Privatization Part B, SRTC WFO-98-003, Submittal of Pilot X-flow Test Rig Conceptual Design,” Document No: BNF-003-98-00445, January 12, 1999. (Accompanied with the WSRC drawing: "BNFL Pilot Scale Crossflow Filter Test: Test Rig Assembly," Document No. EES-22699-M6-001, Rev. 0., by T. J. Steeper.)

7. Herting, D. L., "Results of Dilution Studies with Waste from Tank 241-AN-105," PNNL Doc. No. HNF-SD-WM-DTR-046, Rev. 0, Oct. 10, 1997.

8. Herting, D. L., "Results of Dilution Studies with Waste from Tank 241-AN-105," PNNL Doc. No. HNF-SD-WM-DTR-046, Rev. 0A; Oct. 14, 1999.

9. Fowley, M. D., Screening Process Hazards Review Report, Feb. 22, 1999 
10. Duignan, M. R. Environmental Evaluation Checklist, EEC Document No. TC-99002, Approved on Feb. 24, 1999.

11. Duignan, M. R., SRS Final Acceptance Inspection of New or Altered Facilities or Equipment (SM-51), Approved on Mar. 24, 1999.

12. Steimke, J. L., C. M. Hart, and S. E. Sponseller, "Results from Tests of Du Pont Crossflow Filter (U)," Document No. WSRC-TR-94-0322, October 1994.

13. Nash, C. A. and J. Siler, "Filtration of Nonradioactive Handford Waste Simulants (U)," Document No. SRTC-BNFL-016, Rev. 0, Sept. 30, 1997.

14. Nash, C. A., "Hanford Envelope A Characterizaton of Solids and Liquid (U)," Document No. SRTC-BNFL-007, Rev. 0, April 21, 1997.

15. Wach, S. T., "RPP Privatization Part B, SRTC WFO-98-Transmittal of Preliminary Filtration Data," letter to P. S. Townson No. BNF-003-98-0187, Nov. 91999. [Attachment contains 207 pages of preliminary data for the Envelope A Test.]

16. Duignan, M. R., "BNFL Pilot-scale Cross-flow Filtration Test," EDS Field Procedure, Document No. FP-801, Rev. 0., Apr. 22, 1999.

17. Duignan, M. R., Operational Instructions Nos. 1-18, starting from No. 1: "Cleaning of X-flow Test Rig," Mar. 1, 1999 to "Cleanup Activities Between Simulant A and C Test Runs, Jun. 21, 1999

18. Tennekes, H. and J. L. Lumley, A First Course in Turbulence, MIT Press, Cambridge, Mass., 1983. (ISBN 0-262-20019-8)

19. Levesley, J. A. and M. Hoare, "The effect of high frequency backflushing on the microfiltration of yeast homogenate suspensions for recovery of soluble proteins," J. Membrane Science, Vol. 158, pp. 22-39, 1999.

20. Mores, W. D., C. N. Bowman, and R. H. Davis, "Theoretical and experimental flux maximization by optimization of backpulsing," J. Membrane Science, Vol. 165, pp. 225-236, 2000.

21. Gan, Q, "Evaluation of solids reduction and backflush technique in crossflow microfiltration of a primary sewage effluent,": Resources, Conservation, and Recycling, Vol. 27, pp. 9-14, 1999.

22. Ramirez, J. A. and R. H. Davis, "Application of cross-flow microfiltration with rapid backpulsing to wastewater treatment;" J. Hazardous Materials B, Vol. 63, pp. 179-197, 1998.

23. Mandel, J., The Statistical Analysis of Experimental Data, National Bureau of Standards, Dover Publications, New York, 1964. (ISBN 0-486-64666-1) 


\section{APPENDIX A}

\section{EXPERIMENTAL DATA: WATER AND CLEANING}

\section{Appendix Contents}

1. Nomeclature sheet for data tables

2. Experimental data:

Fig. Run

Solution

Done on

A1 2.00,

Water

$5 / 14 / 99$

A3 2.22b1

Water

$7 / 9 / 99$

A3 $2.22 b 2$

Water

7/14/99 (added filtrate flowmeter, Q3)

A4 2.21b,

$1 \mathrm{M} \mathrm{NaOH}$ Cleaning 7/6/99

General Note: For measurement uncertainties see Appendix F

\section{Special Notes:}

a. The data for every test run are highlighted with two graphs: Filtrate Flux vs. Time and Permeability vs. Time. Those graphs include all the data taken during the run period.

b. The beginning and end of the data for most graphs show large deviations from the overall series of points. Those deviations were caused by backpulsing the filter that temporarily stopped the flow of filtrate.

c. All columns of data, in all the tables, are ended with several statistical values of that column, i.e., Average, Maximum, Median, Minimum, Standard Deviation, and Number of Points used (in calculating the 5 statistical quantities.

d. To calculate those quantities mentioned in item c, only those data points that start from the end of a backpulse to just before the ending backpulse were included. This is the reason why the quantity of Number of Points Used was given.

e. The data for the graphs, and all the data taken for the individual test run that the graphs represent, immediately follow the specific figure. 
Nomenclature For Data Sheets

(See Figure 1: Main Test Rig - Pilot Scale Cross Flow for the instrument Location)

\begin{tabular}{|c|c|}
\hline Column & Heading ${ }^{\circ}$ \\
\hline$A=$ & DATE \\
\hline$B=$ & TIME \\
\hline$C=$ & SOLENOID \\
\hline$D=$ & FLTRT (deg \\
\hline$E=$ & CL LOOP ( \\
\hline$F=$ & SL LOOP (C \\
\hline $\mathbf{G}=$ & UP AMB (de \\
\hline$H=$ & BOT AMB ( \\
\hline$I=$ & $T 6(\operatorname{deg} C)$ \\
\hline$J=$ & BOT DP (ps \\
\hline$K=$ & FLTR (psig) \\
\hline$L=$ & FLTRDP $(\mathrm{p}$ \\
\hline$M=$ & TOP DP (ps \\
\hline$N=$ & FLTRATE ( \\
\hline $0=$ & PISTON (ps \\
\hline$P=$ & SLFLOW \\
\hline$Q=$ & FLTR FLOV \\
\hline$R=$ & v9 \\
\hline
\end{tabular}

$\begin{array}{ll}= & \text { Full Heading } \\ = & \text { DATE } \\ = & \text { TIME } \\ = & \text { SOLENOID } \\ = & \text { FLTRT (deg C) T2 } \\ = & \text { CL LOOP (deg C) T3 } \\ = & \text { SL LOOP (deg C) T1 } \\ = & \text { UP AMB (deg C) T4 } \\ = & \text { BOT AMB (deg C) T5 } \\ = & \text { T6 (deg C) SPARE } \\ = & \text { BOT DP (psid) dP2 } \\ = & \text { FLTR (psig) P1 } \\ = & \text { FLTR DP (psid) dP1 } \\ = & \text { TOP DP (psig) dP3 } \\ = & \text { FLTRATE (psig) P2 } \\ = & \text { PISTON (psig) P3 } \\ = & \text { SL FLOW (gpm) Q1 } \\ = & \text { FLTR FLOW (gpm) Q2 }\end{array}$

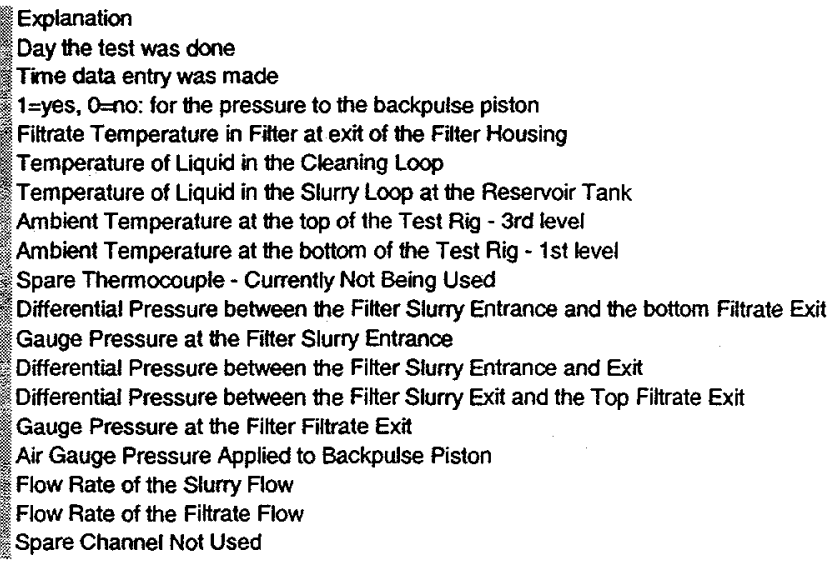

The following columns are caiculated results based on the appropriate columns

\begin{tabular}{|c|c|c|c|c|}
\hline $\mathbf{S}=$ & Number & $=$ & Number & Data number which is equivalent to 1 minute since this was the acquisition frequency \\
\hline$T=$ & Vel, $\mathrm{ft} / \mathrm{s}$ & $=$ & Vel, ft/s & Axial slumy velocity $=[$ Column P $] / 7.48 \mathrm{gal} / \mathrm{ft} 2 / 60 \mathrm{sec} / \mathrm{min} /$ flow area $\left(=0.005369 \mathrm{ft} 2^{*}\right)$ \\
\hline$U=$ & TMP,PSI & $=$ & TMP, PSI & Transmembrane Pressure $=([$ Column $\mathrm{J}]+[$ Column M] $) / 2$ \\
\hline$V=$ & TMP. bar & $=$ & TMP, bar & 叠[Column U] / 14.504 bar/psi \\
\hline$W=$ & GPW/FT2 & $=$ & GPMFT2 & {$\left[\right.$ Column Q] / inside diameter filter surface area $\left(=2.29 \mathrm{ft}^{* *}\right)$} \\
\hline$x=$ & GPMFT2 & $=$ & GPMFT2 at $25^{\circ} \mathrm{C}$ & Test Spec. correction factor: [Column W] $\times \exp (2500 \times((1 /(273+[$ Column $T]))-(1 / 298)))$ \\
\hline$Y=$ & PERMARBIUTY. & $=$ & 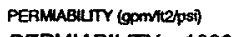 & {$[$ Column $X] /[$ Column U] } \\
\hline $\mathbf{Z}=$ & $\times 1000$ & $=$ & PERMIABILITY $\times 1000$ & [Column Z] X 1000 \\
\hline$A A=$ & PERMAABIUTY & $=$ & PEAMHABAUTY (m/daybar) & [Column $Y] \times$ conversion factor ( $=851.0145 \mathrm{~m} /$ day/bar $/ \mathrm{gpm} / \mathrm{ft} / \mathrm{bar}$ ) \\
\hline
\end{tabular}

"Axial slurry flow area is based on 7 porous tubes with an inside diameter of $3 / 8$ inch: $7 \times$ pi $/ 4 *(0.375 \text { inch } / 12 \text { inches/ft })^{\wedge} 2=0.005369 \mathrm{tt} 2$ "Inside diameter filter surface area for 7 tubes with an inside diameter of $3 / 8$ inch, 40 -inches long: $7 \times$ pi $\times(0.375$ inch $) \times 40$ inches $/ 144$ in^2/fM $2=2.29 \mathrm{ft} 2$

\section{Exceptions:}

1. For Run 2.21b (Cleaning); This run was carried out over a three different periods on three days therefore there are two NUMBER COLUMNS: S \& T. Cotumn $S$ is continuous and Column $T$ is continuous but starts over for each period. All the columns to the right of Column $S$ are shifted by one. 2. For Run 2.22b (Water); After July 10, 1999 a second filtrate flow meter was added to measure flow rates from 1.2 to $5 \mathrm{gpm}$. The final water test run (Run 2.22 b) has an extra fittrate flow rate column. Column $R$, the spare column, was made the new flow rate:

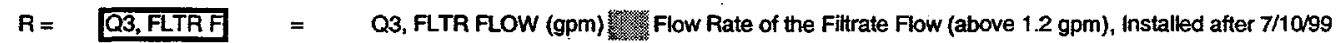

also Run 2.22b has two NUMBER columns (like Run 2.21b) so Exception 1 also applies. 

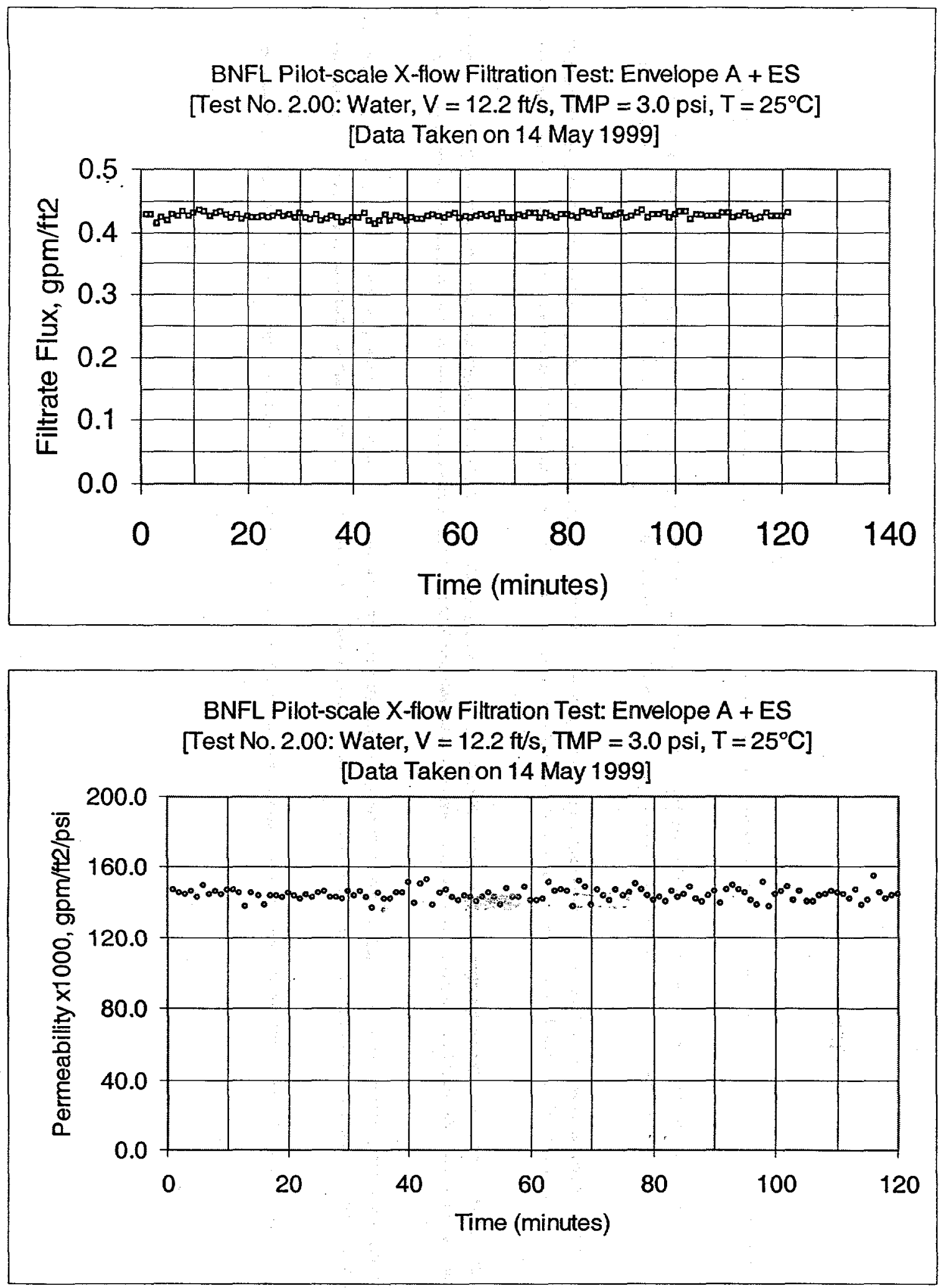

Figure A1: Test Run 2.00, Deionized and Filtered ( 0.2 micron) Water 


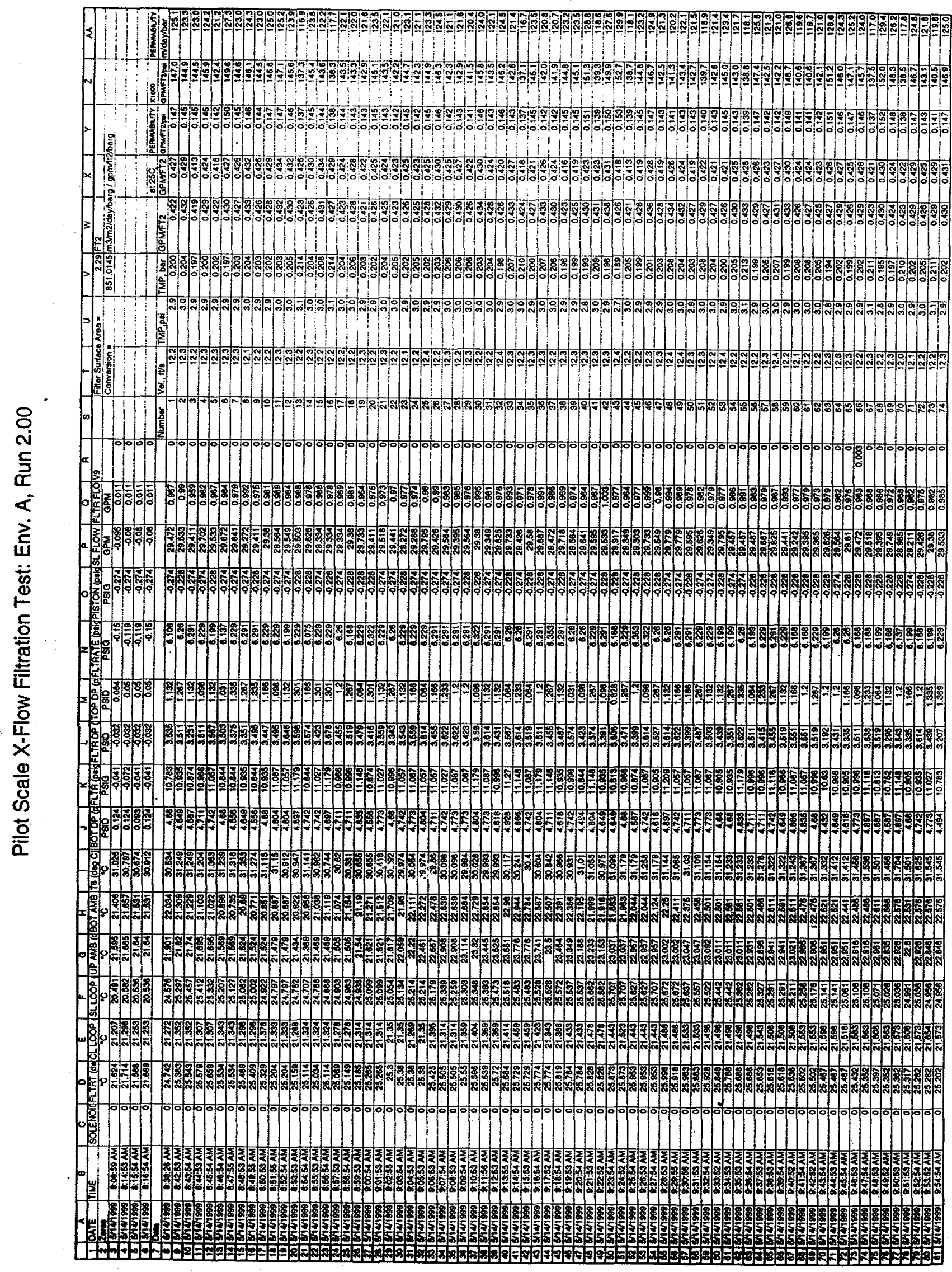




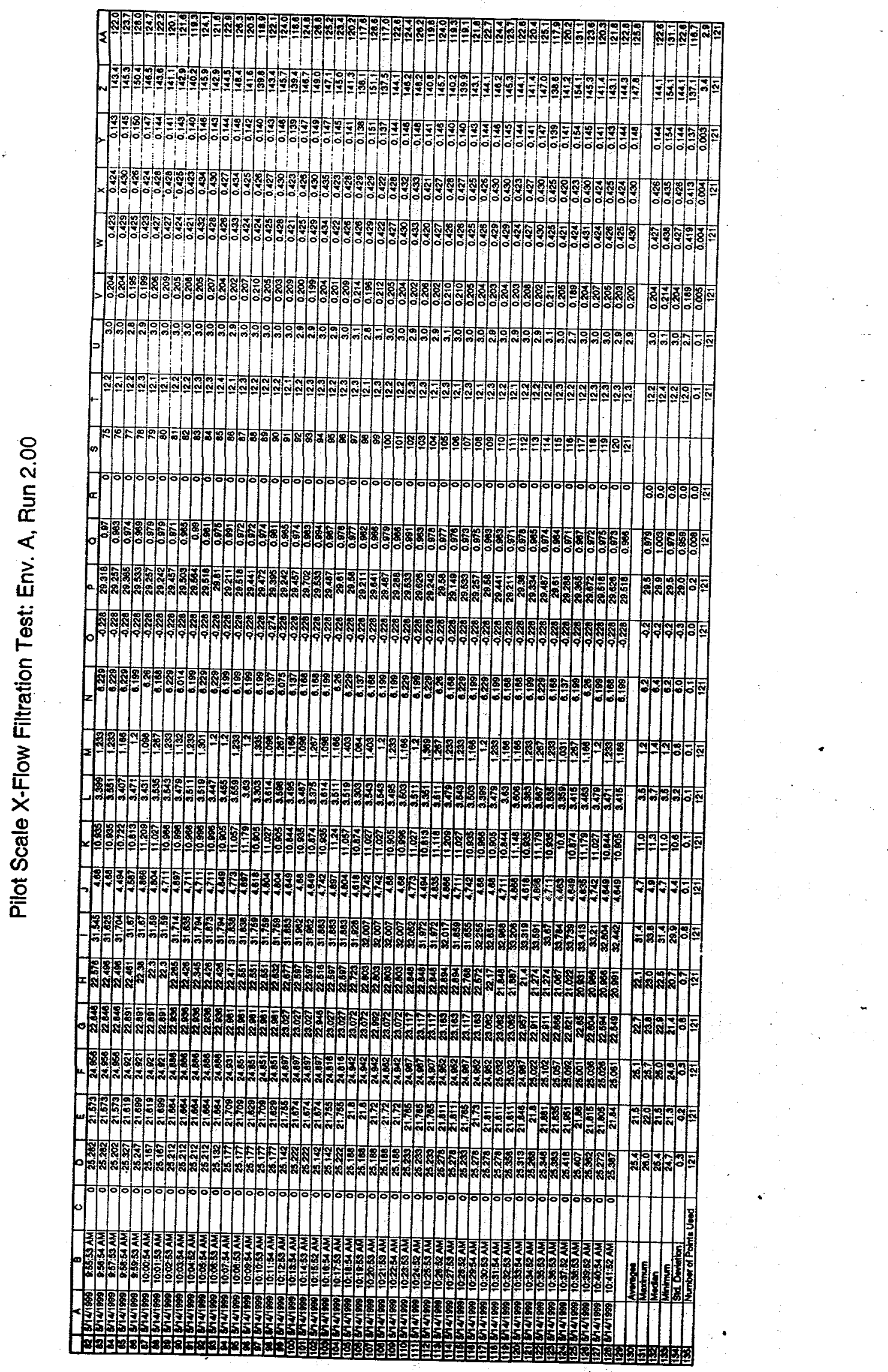



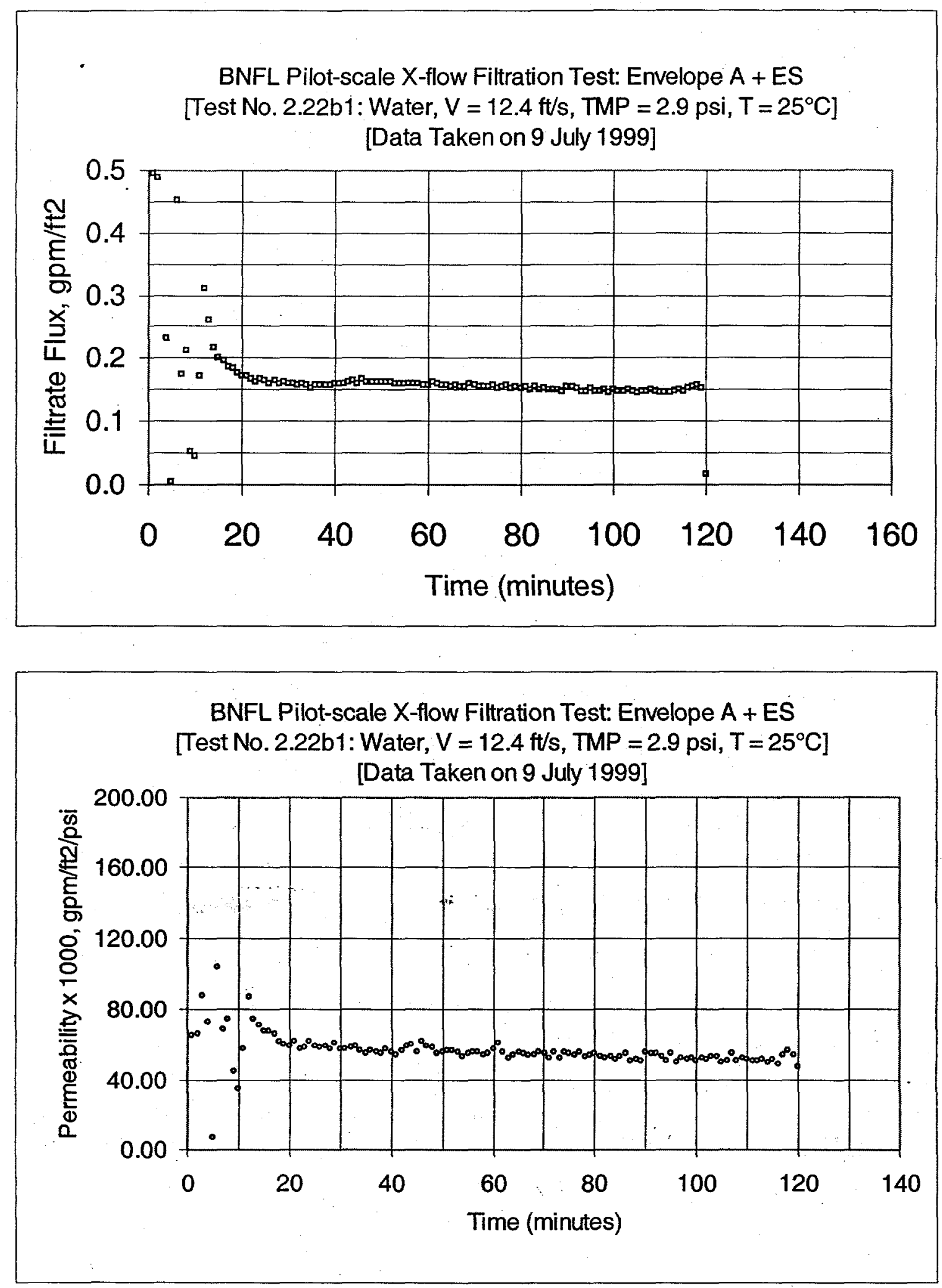

Figure A2: Test Run 2.22b1, Deionized and Filtered ( 0.2 micron) Water 


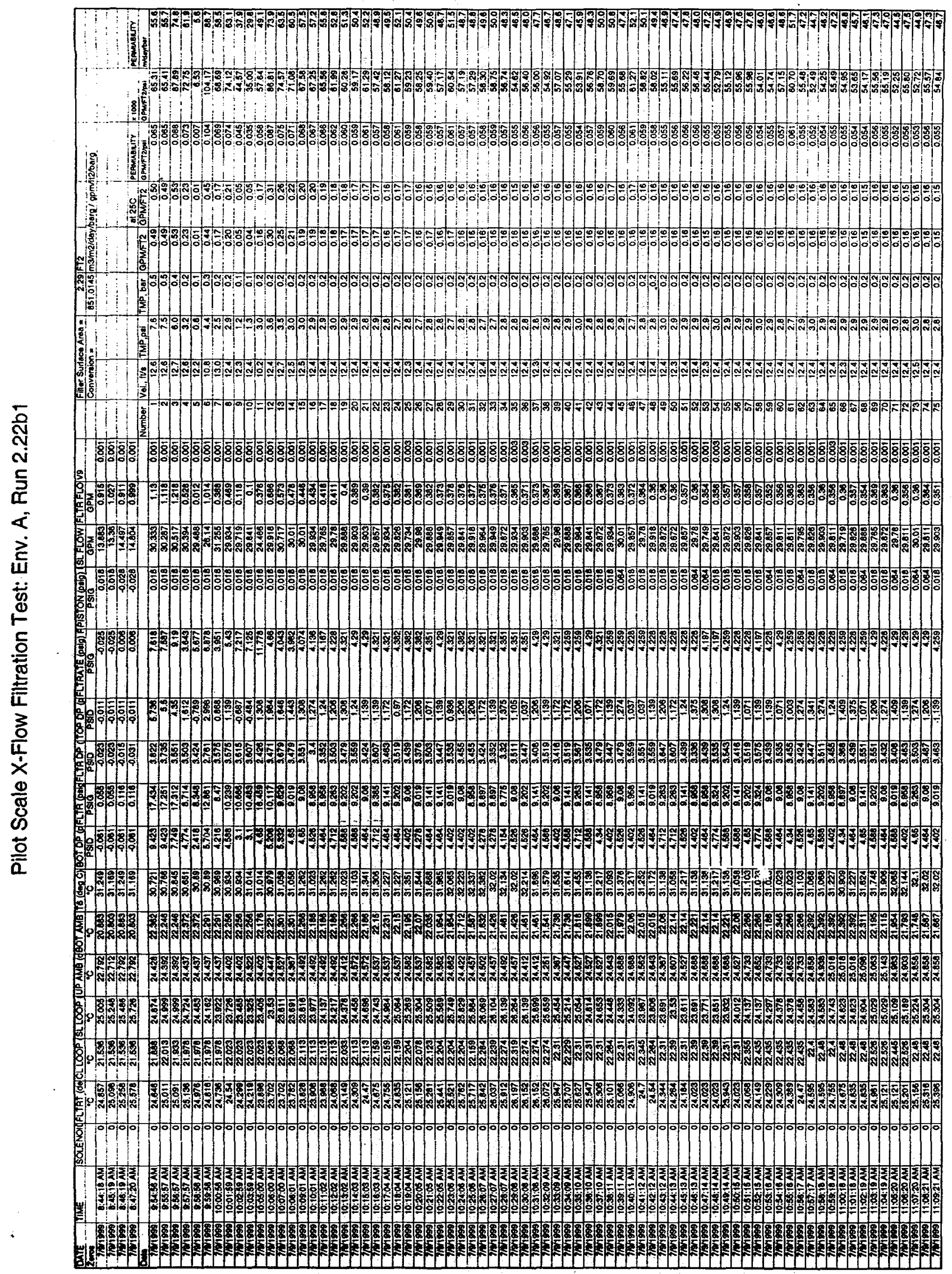




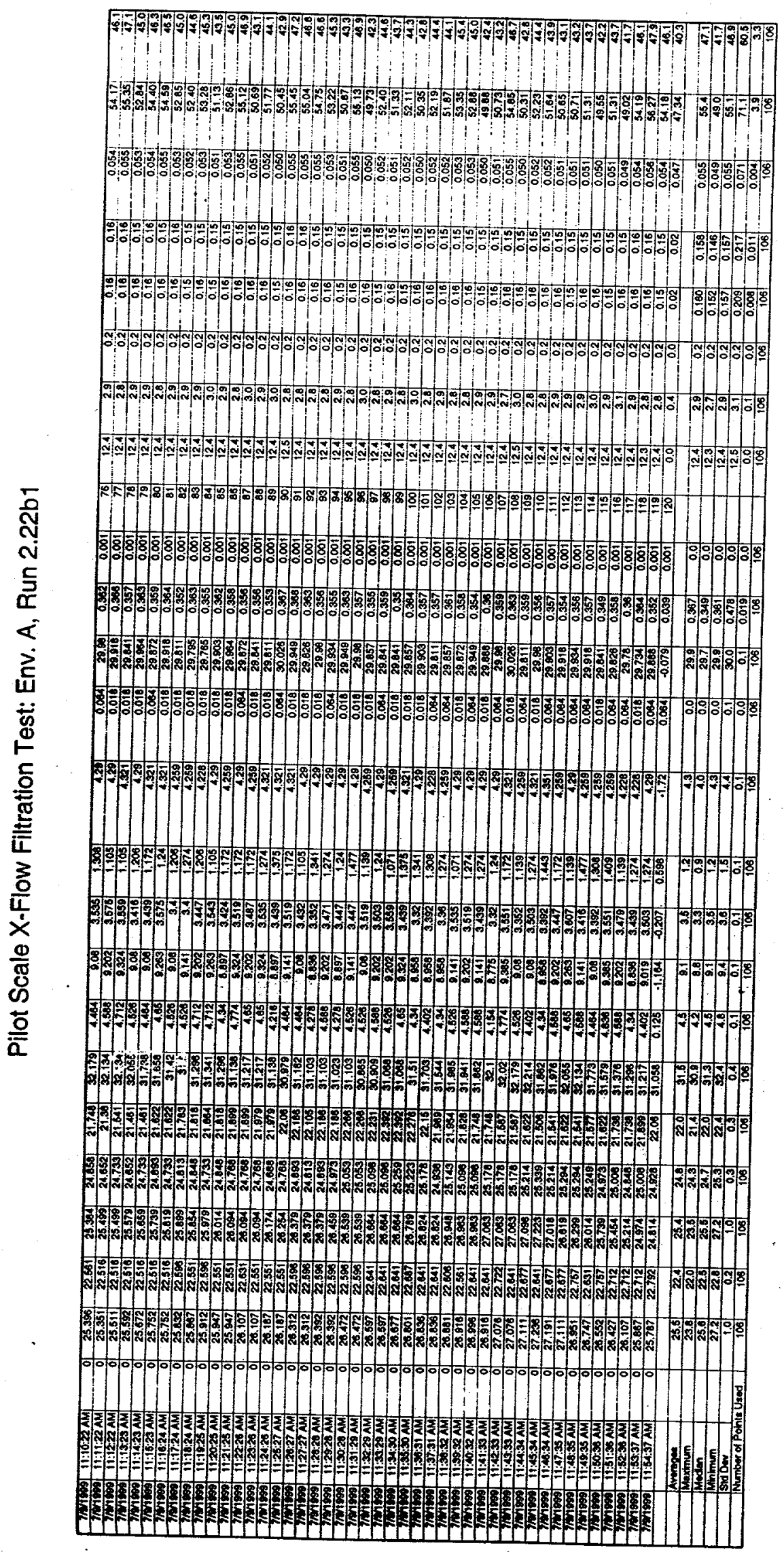



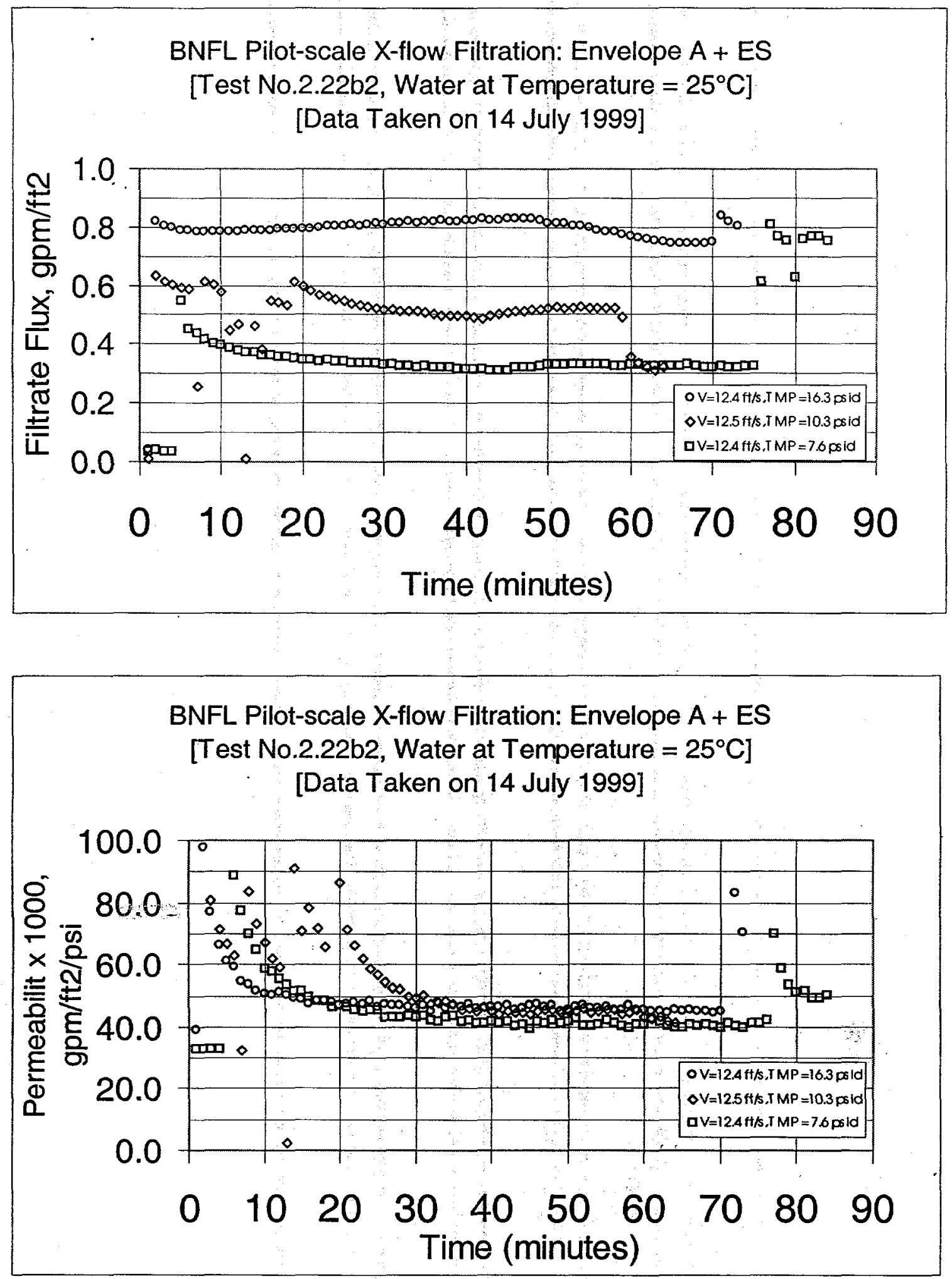

Figure A3: Test Run 2.22b, Deionized and Filtered ( 0.2 micron) Water 


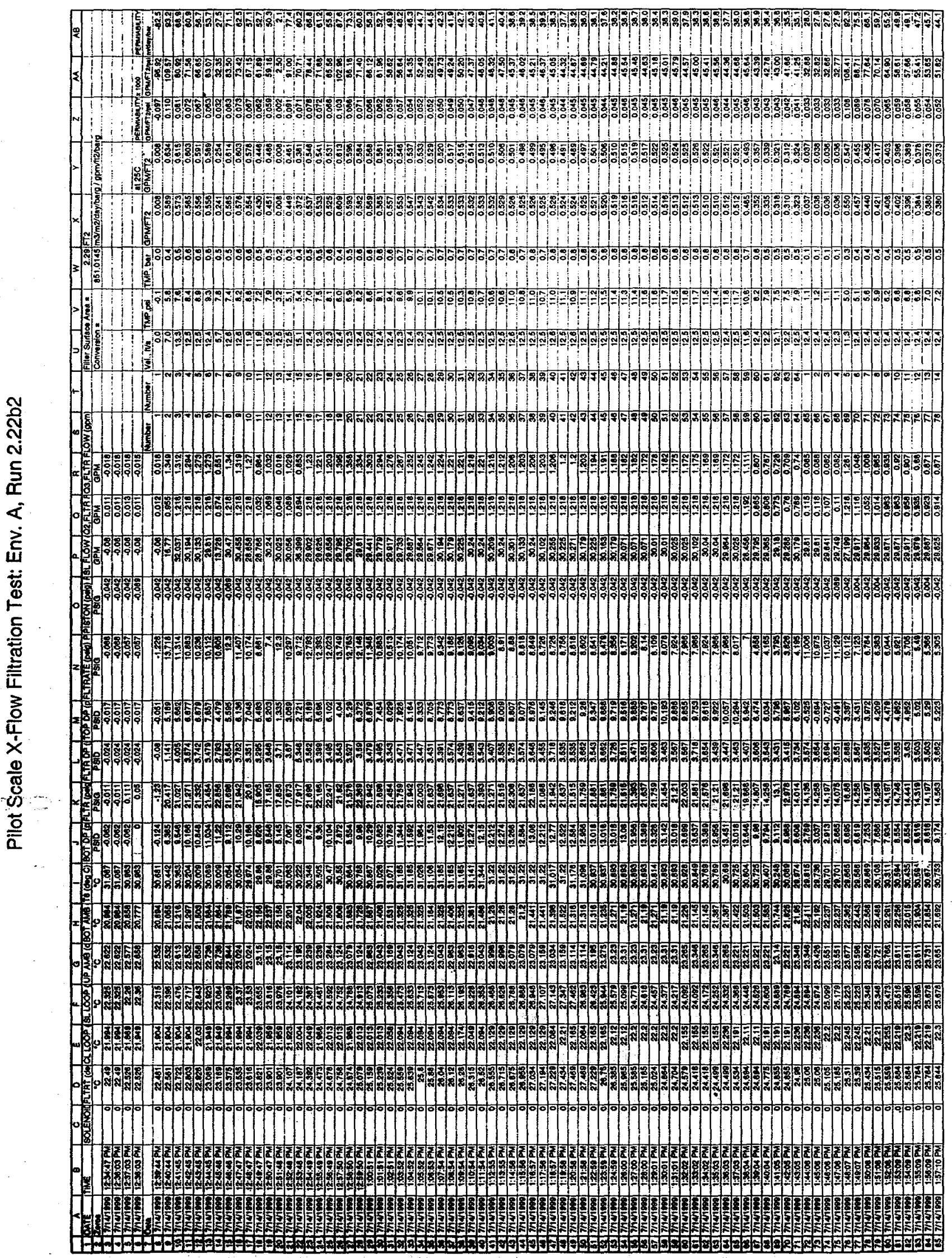




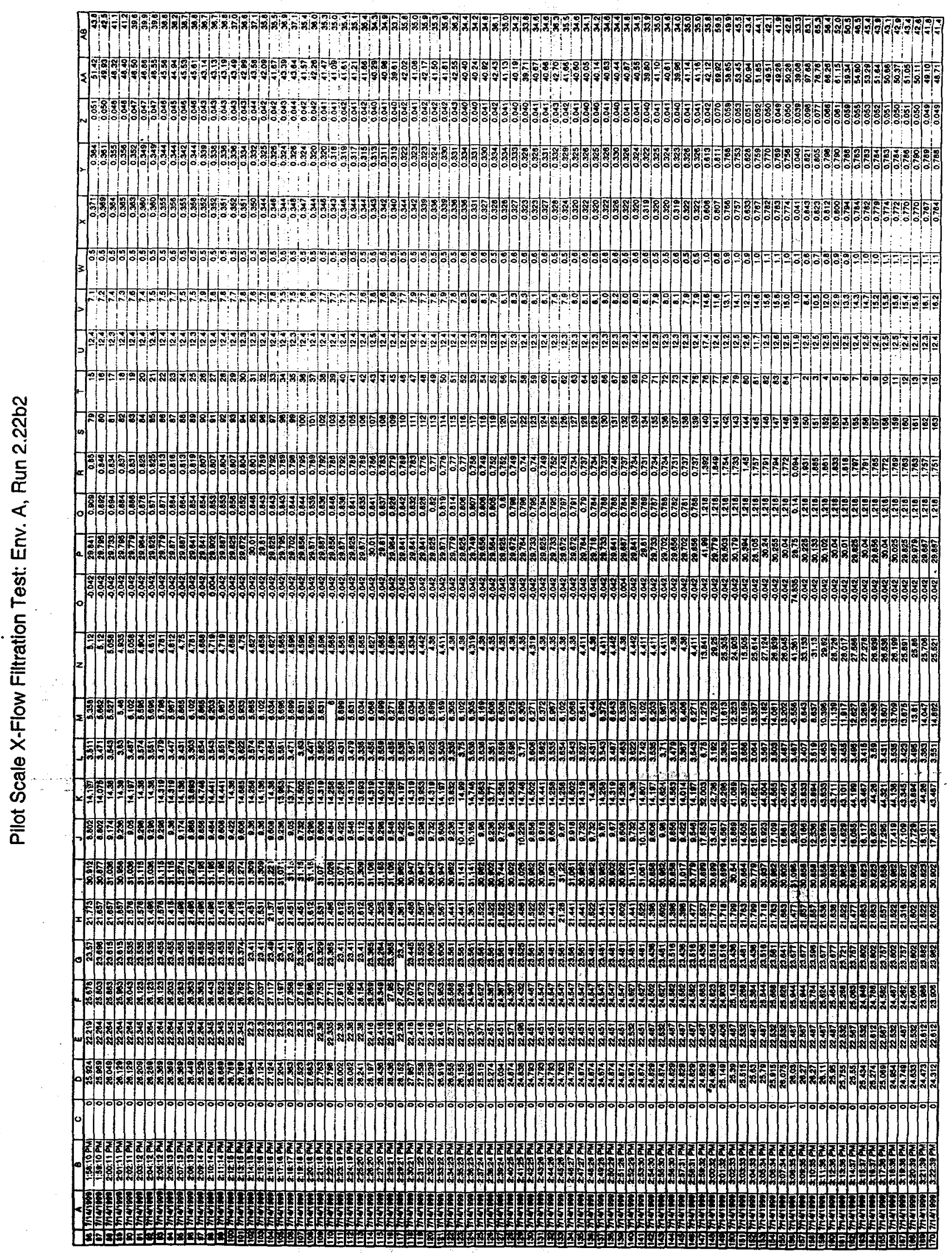




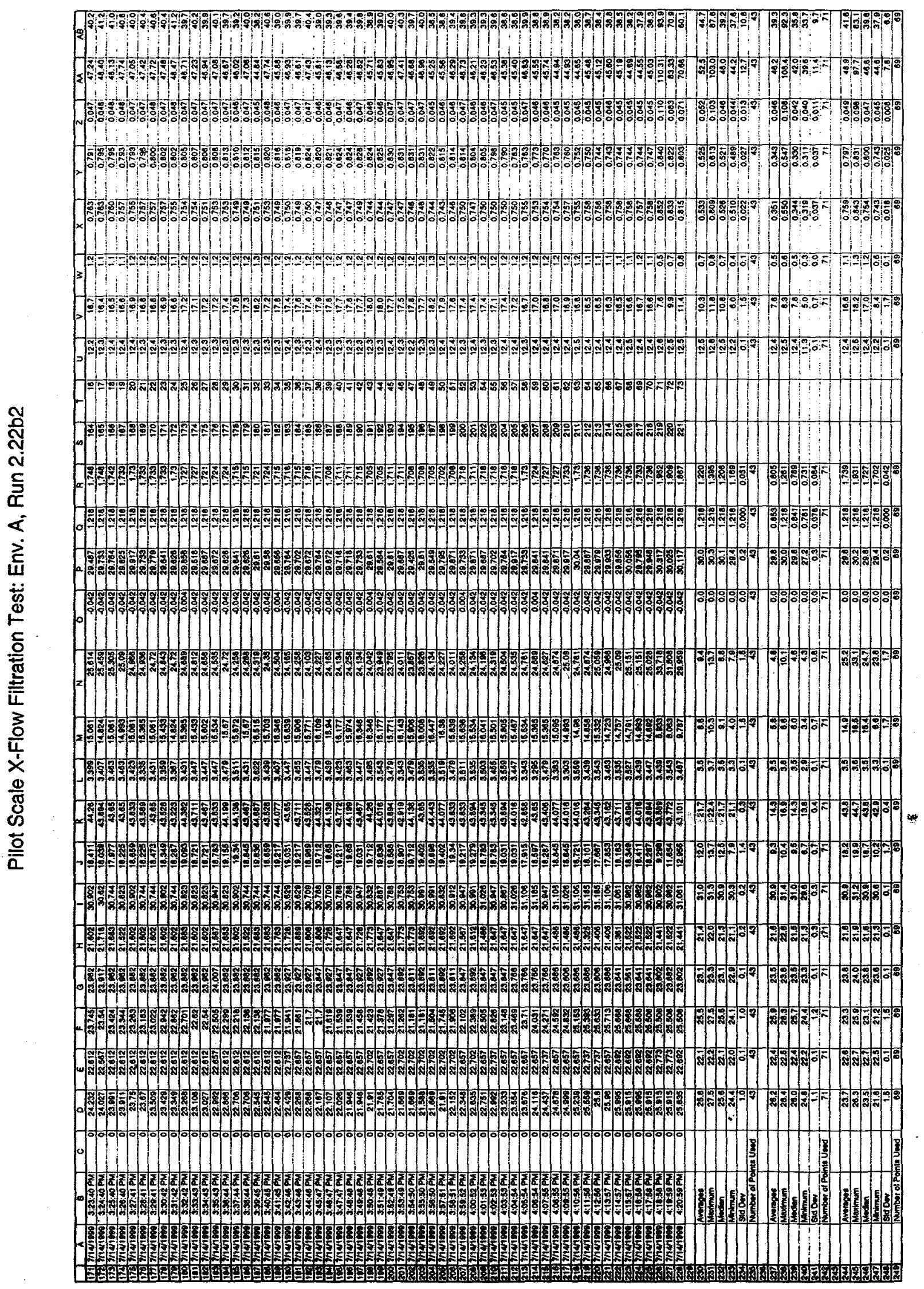



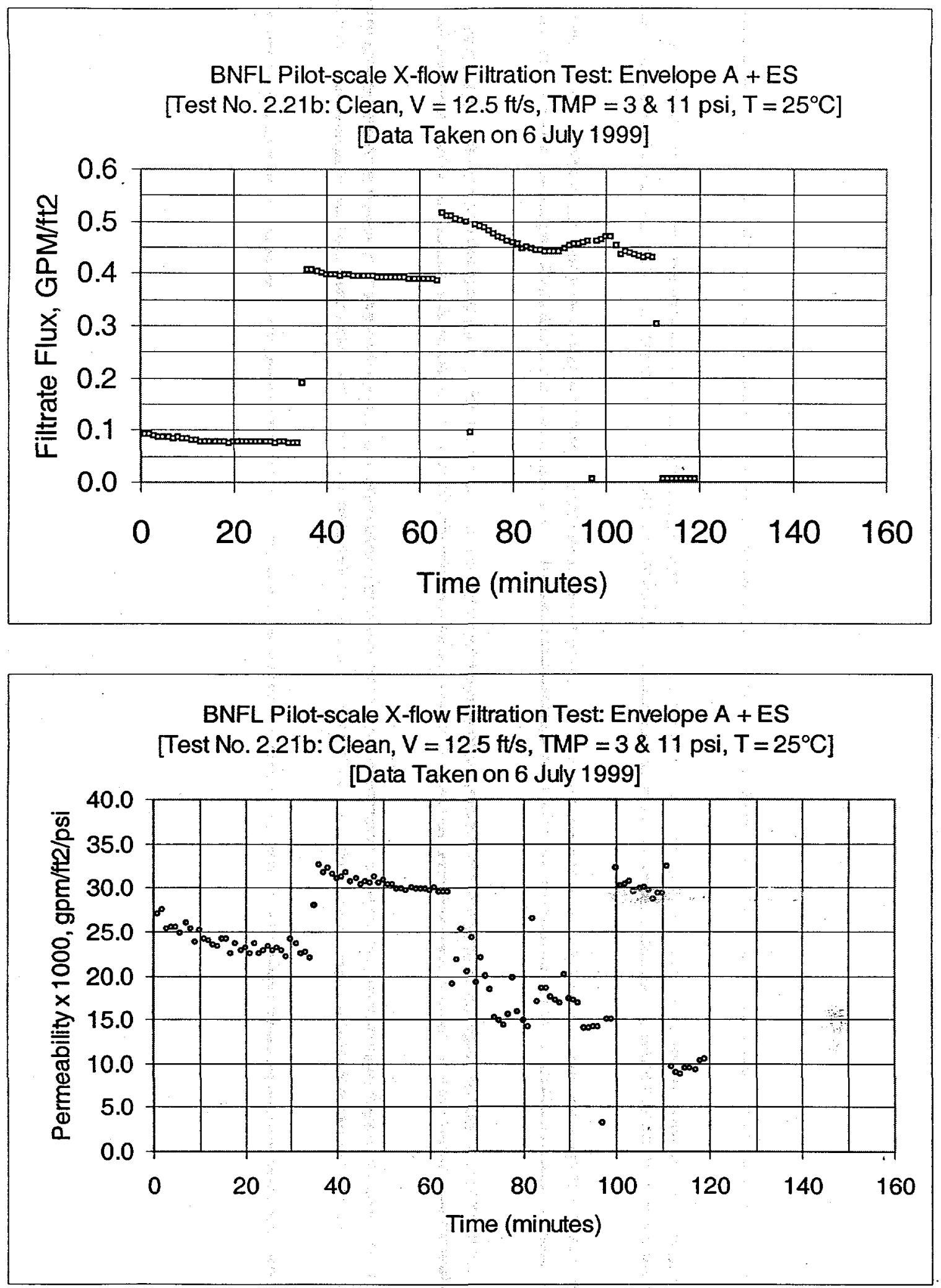

Figure A4: Test Run 2.21b, $1 \mathrm{M} \mathrm{NaOH}$ Cleaning 


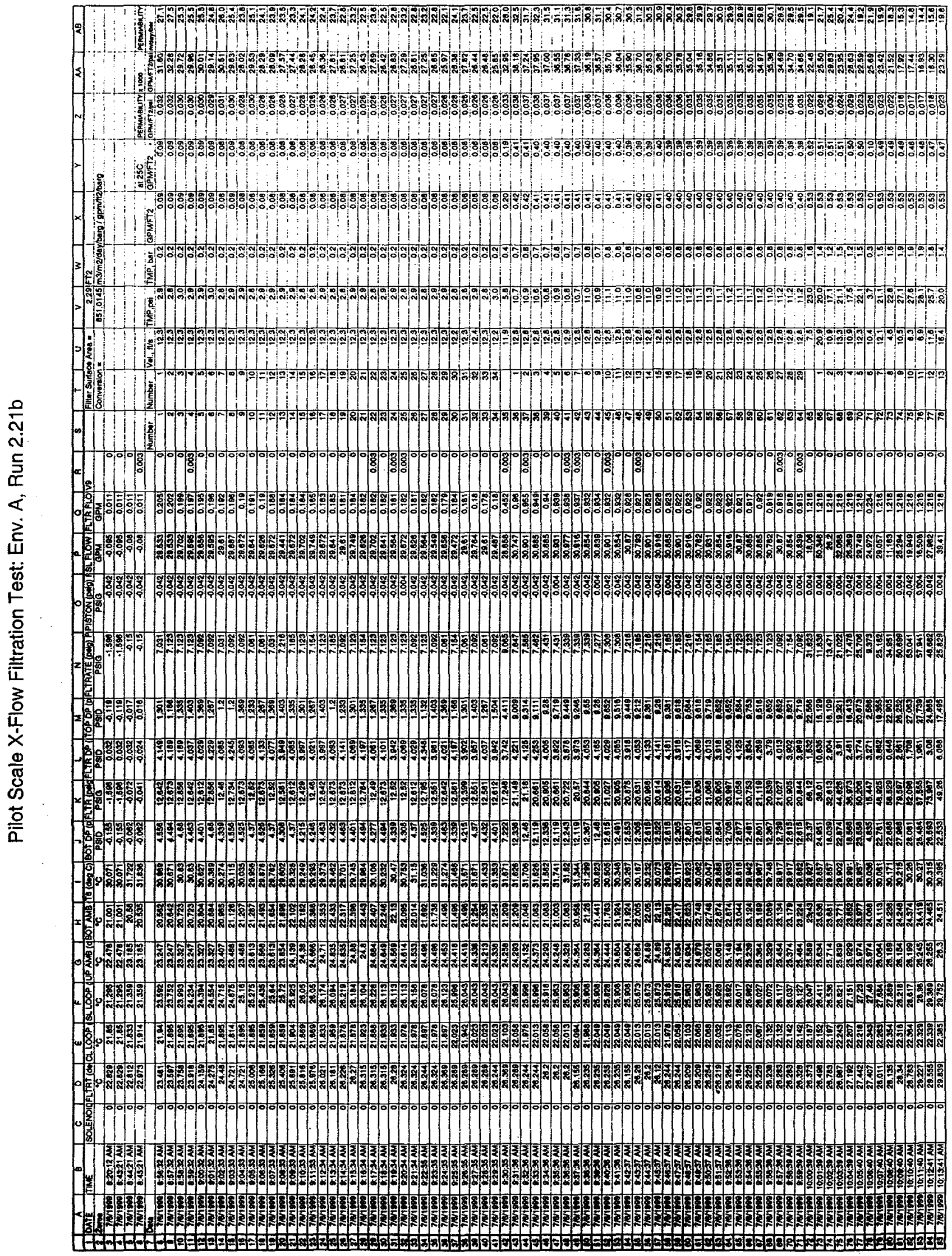




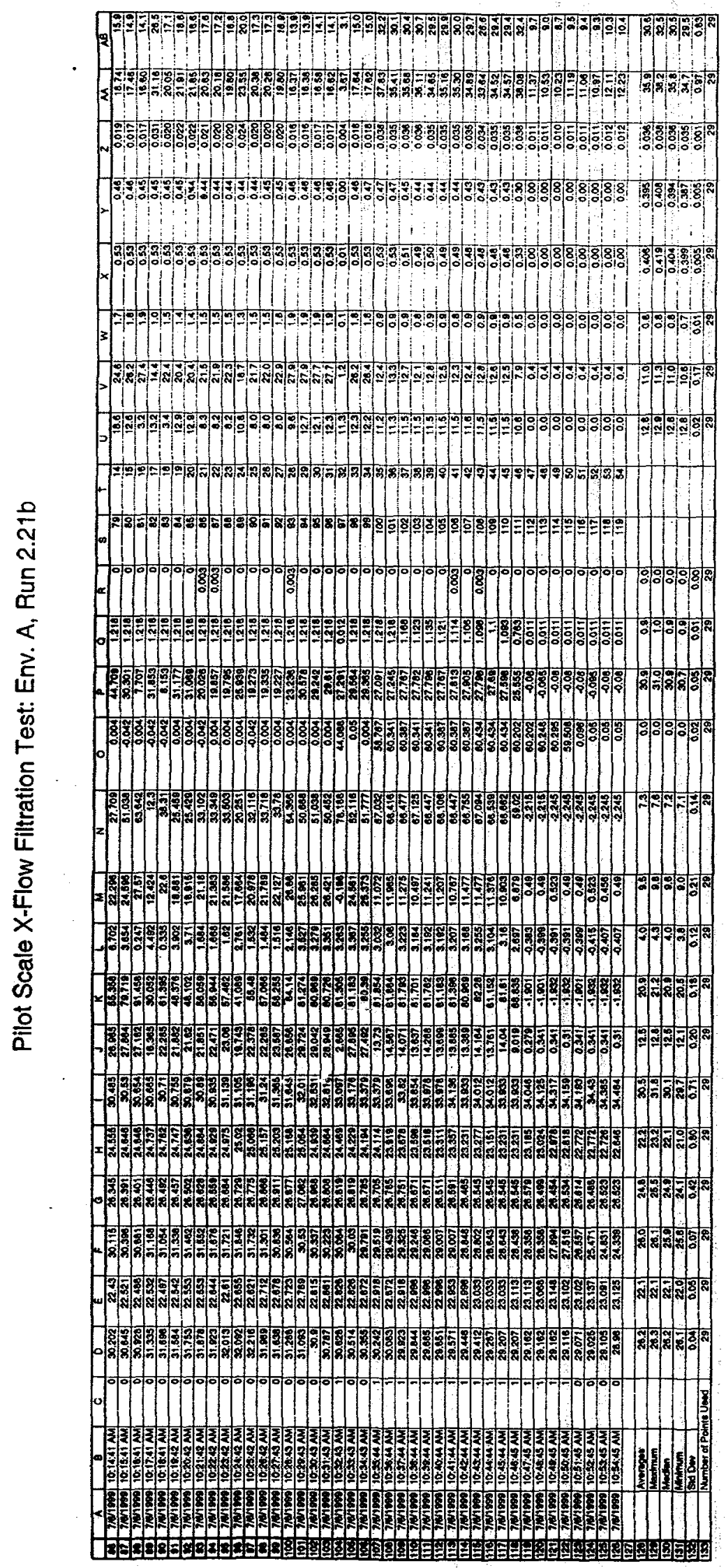




\section{APPENDIX B}

\section{EXPERIMENTAL DATA: LOW SOLIDS CONCENTRATION}

\begin{tabular}{|c|c|c|c|}
\hline $\begin{array}{l}\text { App } \\
\text { 1. N } \\
\text { 2. Ex }\end{array}$ & $\begin{array}{l}\operatorname{dix} \mathrm{Co} \\
\text { heclatu } \\
\text { erimen }\end{array}$ & for data tables & \\
\hline Fig. & Run & Solution & Done on \\
\hline $\mathrm{B} 1$ & 2.01 & $0.5 \mathrm{wt} \%$ Solids & $5 / 17 / 99$ \\
\hline B2 & 2.02 & $0.5 \mathrm{wt} \%$ Solids & $5 / 18 / 99$ \\
\hline B3 & 2.03 & 0.5 wt\% Solids & $5 / 18 / 99$ \\
\hline B4 & 2.04 & $0.5 \mathrm{wt} \%$ Solids & $5 / 18 / 99$ \\
\hline B5 & 2.05 & $0.5 \mathrm{wt} \%$ Solids & $5 / 19 / 99$ \\
\hline B6 & 2.06 & $0.5 \mathrm{wt} \%$ Solids & $5 / 19 / 99$ \\
\hline B7 & 2.07 & $0.5 \mathrm{wt} \%$ Solids & $5 / 19 / 99$ \\
\hline B8 & 2.08 & $0.5 \mathrm{wt} \%$ Solids & $5 / 19 / 99$ \\
\hline B9 & 2.09 & $0.5 \mathrm{wt} \%$ Solids & $5 / 20 / 99$ \\
\hline B10 & 2.10 & 0.5. wt\% Solids & $5 / 20 / 99$ \\
\hline B11 & $2.10 \mathrm{~b}$ & $0.5 \mathrm{wt} \%$ Solids & $5 / 24 / 99$ \\
\hline B12 & $2.10 \mathrm{c}$ & $0.5 \mathrm{wt} \%$ Solids & $5 / 24 / 99$ \\
\hline B13 & 2.11 & $0.5 \mathrm{wt} \%$ Solids & $5 / 24 / 99$ \\
\hline B14 & 2.12 & $0.5 \mathrm{wt} \%$ Solids & $5 / 25 / 99$ \\
\hline B15 & 2.13 & $0.5 \mathrm{wt} \%$ Solids & $5 / 25 / 99$ \\
\hline B16 & $2.07 \mathrm{~b}$ & $0.5 \mathrm{wt} \%$ Solids & $5 / 26 / 99$ \\
\hline B17 & $2.07 \mathrm{c}$ & $0.5 \mathrm{wt} \%$ Solids & $5 / 27 / 99$ \\
\hline
\end{tabular}

General Note: For measurement uncertainties see Appendix F

Special Notes:

a. The data for every test run are highlighted with two graphs: Filtrate Flux vs. Time and Permeability vs. Time. Those graphs include all the data taken during the run period.

b. The beginning and end of the data for most graphs show large deviations from the overall series of points. Those deviations were caused by backpulsing the filter that temporarily stopped the flow of filtrate.

c. All columns of data, in all the tables, are ended with several statistical values of that column, i.e., Average, Maximum, Median, Minimum, Standard Deviation, and Number of Points used (in calculating the 5 statistical quantities). Most of the data with time were maintain constant, and therefore the statistics are meaningful for normally distributed data, however Filtrate Flux and Permeability decrease with time and therefore are not normally distributed.

d. To calculate those quantities mentioned in item c, only those data points that start from the end of a backpulse to just before the ending backpulse were included. This is the reason why the quantity of Number of Points Used was given.

e. The data for the graphs, and all the data taken for the individual test run that the graphs represent, immediately follow the specific figure. 
f. Run 2.03 only has about 35 minutes of data. The run was made for the full two hours required, but the data acquisition system was accidentally stopped in the middle, and was not noticed until the run was complete.

g. Run 2.10 was redone twice, Runs $2.10 \mathrm{~b}$ and $2.10 \mathrm{c}$, because the meaning of "best" run by filtrate flux and permeability were also evaluated.

h. Run 2.07 was redone, Runs $2.07 \mathrm{~b}$ and $2.07 \mathrm{c}$, after Run 2.13 to investigate the filter operation over a longer period than just two hours. Run $2.07 \mathrm{~b}$ was one continuous run without interruption from a backpulse and Run $2.07 \mathrm{c}$ was done with varying backpulse frequencies.

Nomenclature For Data Sheets

(See Figure 1: Main Test Rig - Pilot Scale Cross Flow for the Instrument Location)

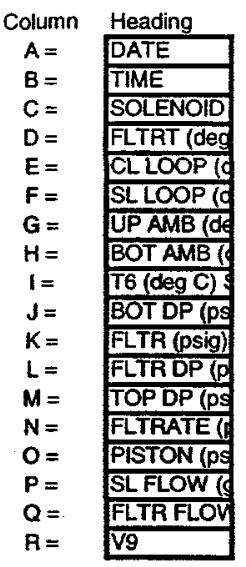

$$
\begin{array}{ll}
= & \text { Full Heading } \\
= & \text { DATE } \\
= & \text { TIME } \\
= & \text { SOLENOID } \\
= & \text { FLTRT (deg C) T2 } \\
= & \text { CLLOOP (deg C) T3 } \\
= & \text { SL LOOP (deg C) T1 } \\
= & \text { UP AMB (deg C) T4 } \\
= & \text { BOT AMB (deg C) T5 } \\
= & \text { BOT DP (psid) dP2 } \\
= & \text { FLTR (psig) P1 } \\
= & \text { FLTR DP (psid) dP1 } \\
= & \text { TOP DP (psig) dP3 } \\
= & \text { FLTRATE (psig) P2 } \\
= & \text { PISTON (psig) P3 } \\
= & \text { SL FLOW (gpm) Q1 } \\
= & \text { FLTR FLOW (gpm) Q2 } \\
= &
\end{array}
$$

The following columns are calculated results based on the appropriate columns

\begin{tabular}{|c|c|c|c|c|}
\hline $\mathbf{S}=$ & Number & $=$ & Number & Data number whicti is equivalent to 1 minute since this was the acquisition frequency \\
\hline $\mathrm{T}=$ & Vel, fus & $=$ & Vèl, ft/s & Axial slurry velocity $=[$ Column $P] / 7.48 \mathrm{gal} / \mathrm{tt} / 60 \mathrm{sec} / \mathrm{min} /$ flow area $\left(=0.005369 \mathrm{ft} 2^{*}\right)$ \\
\hline $\mathbf{U}=$ & TMP,PSI & $=$ & TMP, PSI & Transmembrane Pressure $=([$ Column $\mathrm{J}]+[$ Column M] $] / 2$ \\
\hline$V=$ & TMP, bar & $=$ & TMP, bar & [Column U]/14.504 bar/psi \\
\hline $\mathbf{W}=$ & GPWFT2 & $=$ & GPMFT2 & [Column Q] / inside diameter fitter surface area $\left(=2.29 \mathrm{ft} 2^{*}\right)$ \\
\hline$x=$ & GPMFT2 & $=$ & GPMFT2 at $25^{\circ} \mathrm{C}$ & Test Spec. correction factor. [Column W] $\times \exp (2500 \times((1 /(273+[$ Column T] $))-(1 / 298)))$ \\
\hline$Y=$ & PeramagtuTy & $=$ & PERMAABUTY (gPm/R2ps) & [Column X]/[Column U] \\
\hline $\mathbf{Z}=$ & $\times 1000$ & $=$ & PERMIABILITY $\times 1000$ & [Column Z] $\times 1000$ \\
\hline$A A=$ & PERMABUTtY & $=$ & 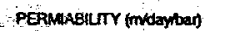 & [Column $Y$ ] $x$ corversion facter ( $=351.0145 \mathrm{~m} /$ day/bar $/ \mathrm{gpm} / \mathrm{ft} 2 / \mathrm{bar})$ \\
\hline
\end{tabular}

"Axial slurry flow area is based on 7 porous tubes with an inside diameter of $3 / 8$ inch: $7 \times$ pi $/ 4 *(0.375$ inch $/ 12$ inches/ft) $2=0.005369 \mathrm{ft} 2$ *Inside diameler fitter surface area for 7 tubes with an inside diameter of $3 / 8$ inch, 40 -inches long: $7 \times$ pi $x(0.375$ inch) $\times 40$ inches $/ 144$ ins/ft' $2=2.29$ fte

\section{Exceptions:}

1. For Run 2.21b (Cleaning); This run was carried out over a three different periods on three days therefore there are two NUMBER COLUMNS: S \& T. Column $S$ is continuous and Column $T$ is continuous but starts over for each period. All the columns to the right of Column $S$ are shiftediby one. 2. For Run 2.22b (Water); After July 10, 1999 a second filtrate flow meter was added to measure flow rates from 1.2 to $5 \mathrm{gpm}$. The final water test run (Run 2.22b) has an extra filtrate flow rate column. Column $R$, the spare column, was made the new flow rate:

$$
R=\text { Q3, FLTRF }=\text { Q3, FLTR FLOW }(\mathrm{gpm}) \text { flow Rate of the Fitrate Flow (above 1.2 gpm), installed after 7/1099 }
$$

also Run 2.22b has two NUMBER columns (like Run 2.21b) so Exception 1 also applies: 

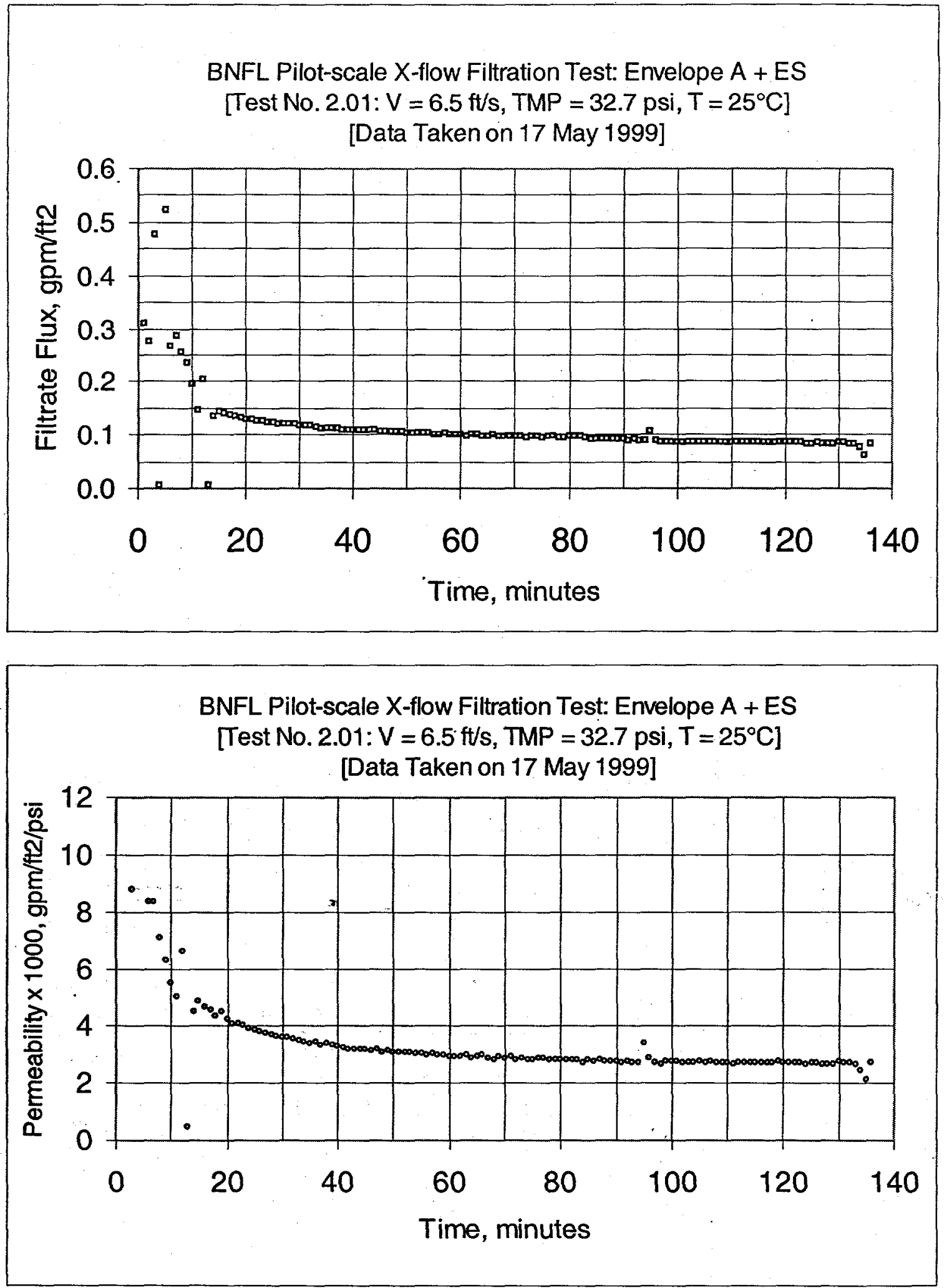

Figure B1: Test Run 2.01, 0.5 wt\% Insoluble Solids Concentration 


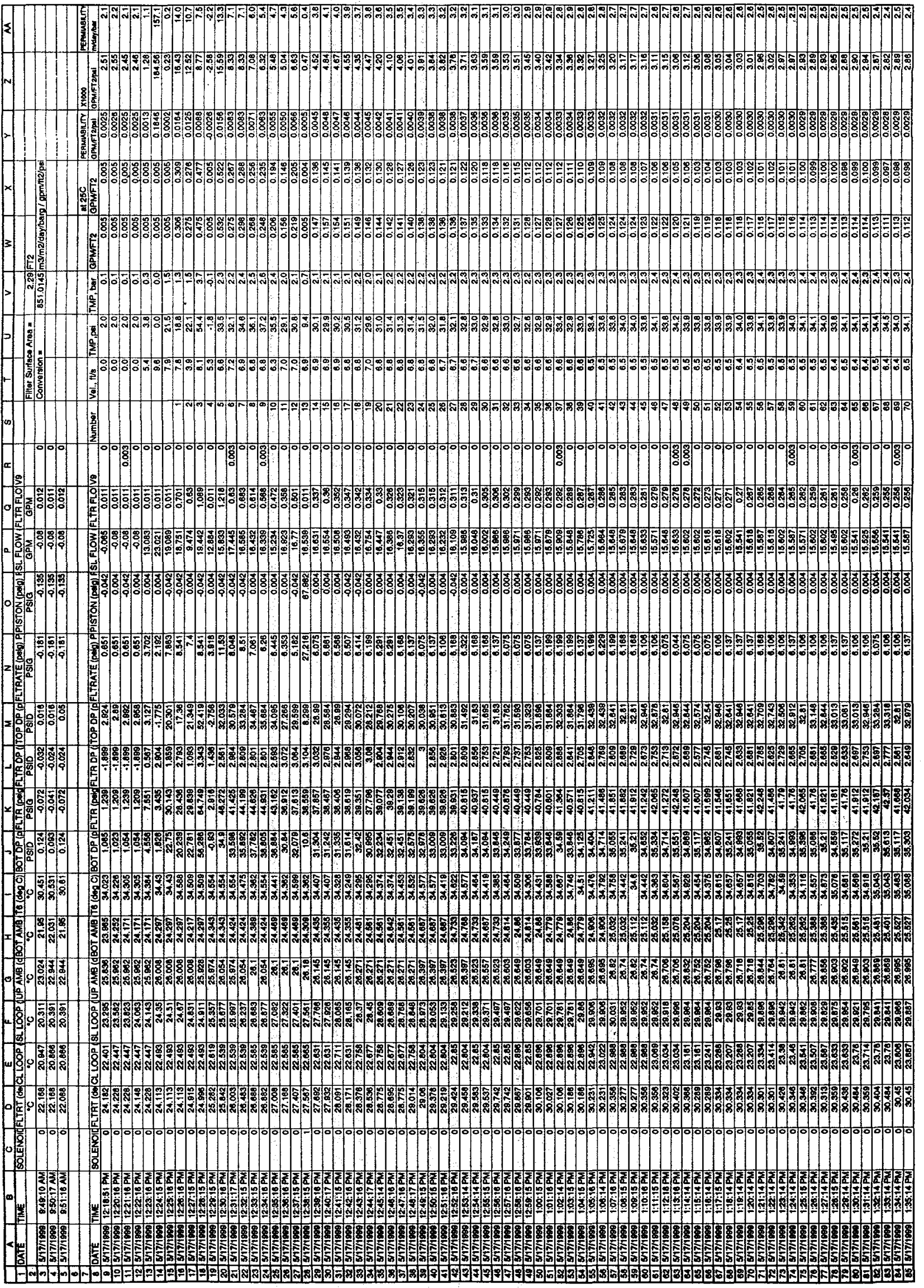




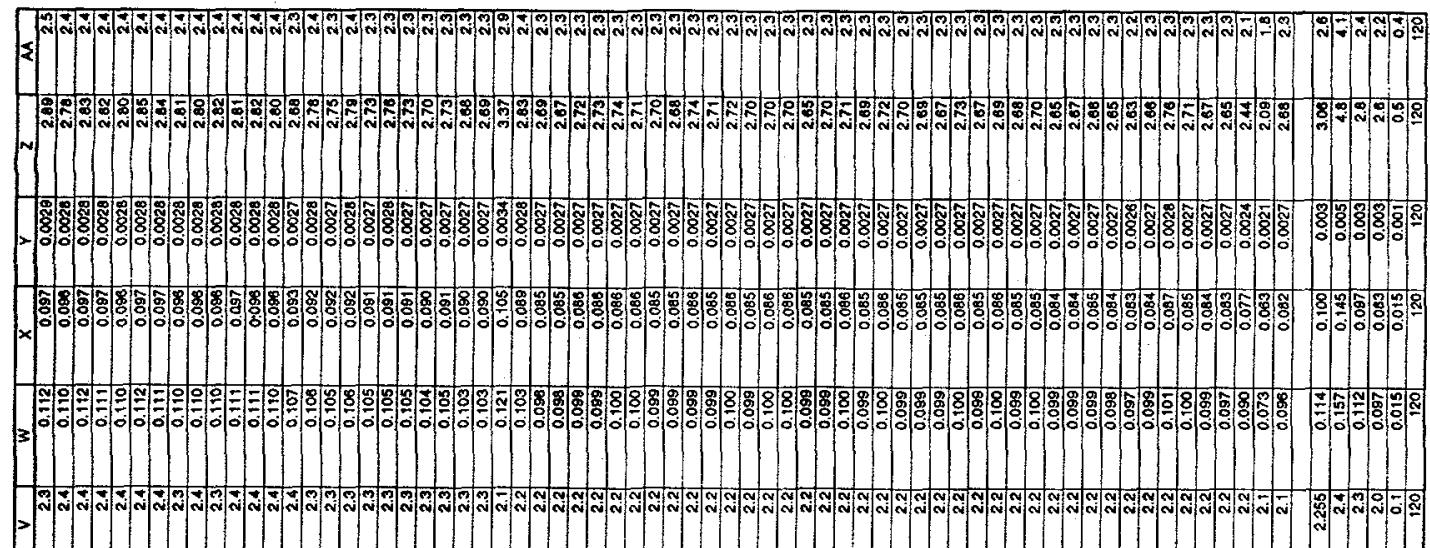

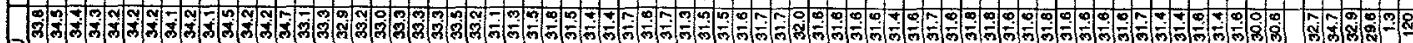

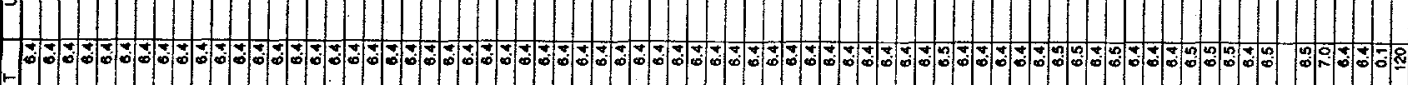

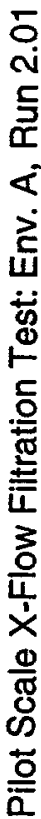

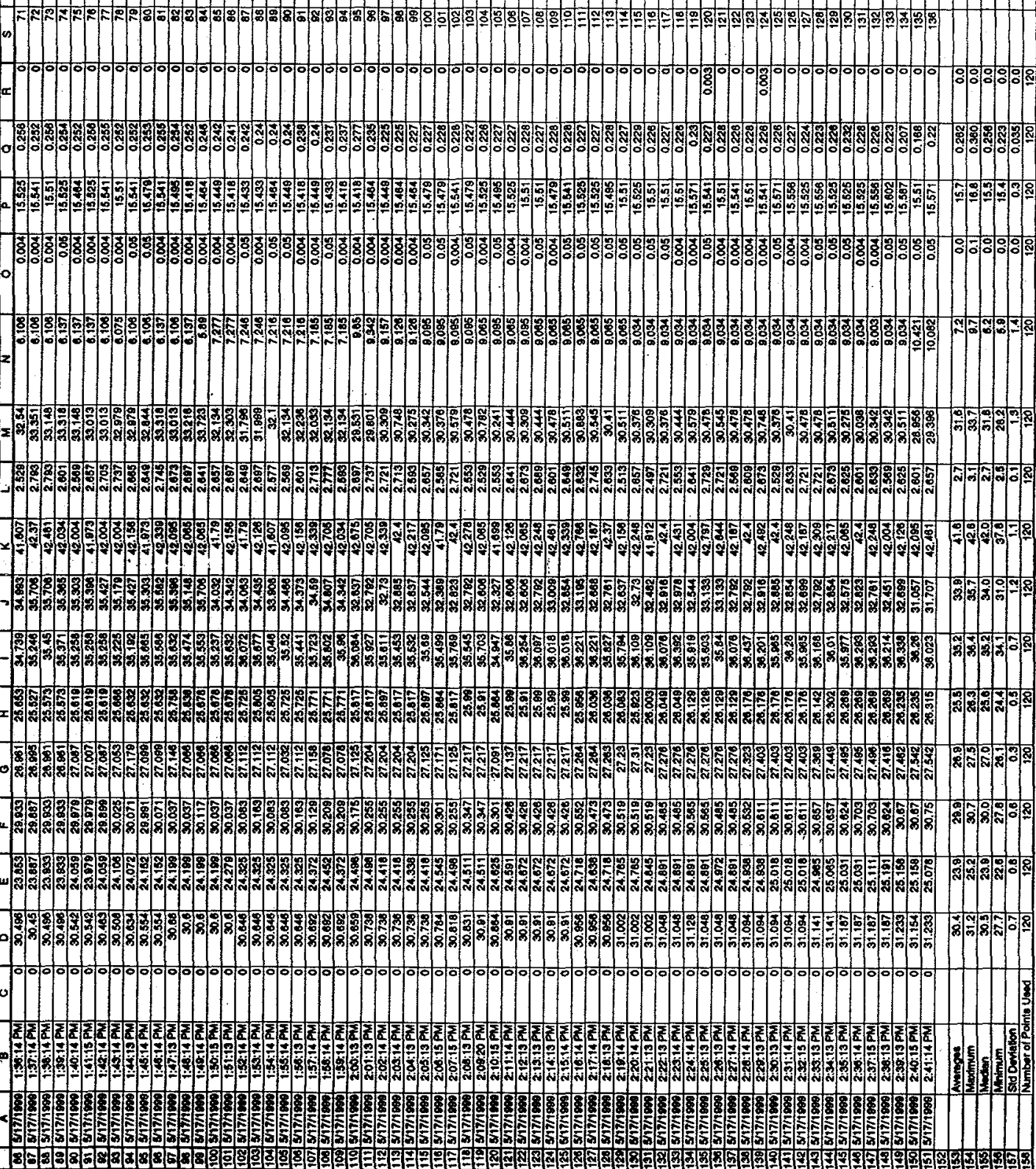



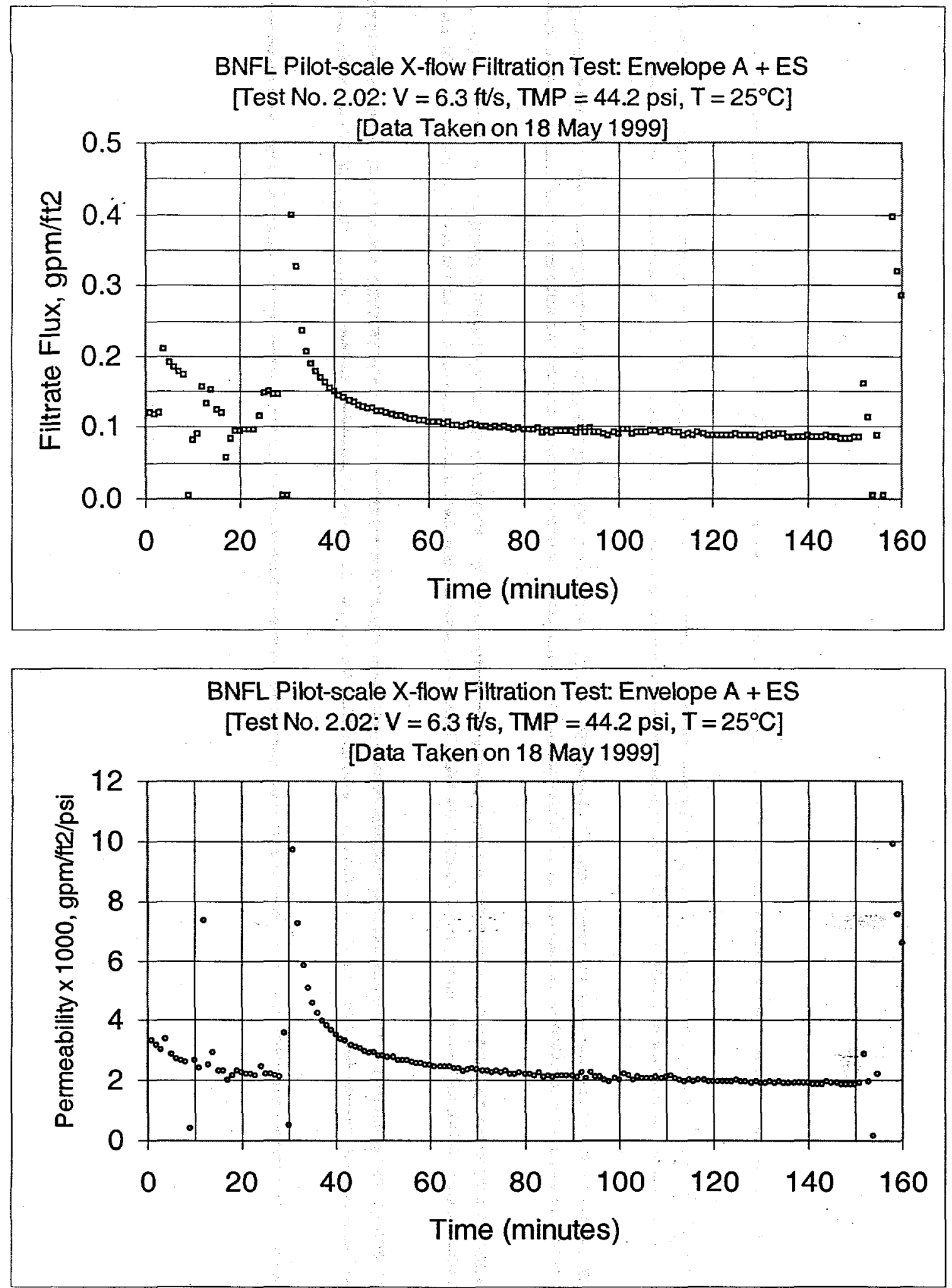

Figure B2: Test Run 2.02, 0.5 wt\% Insoluble Solids Concentration 


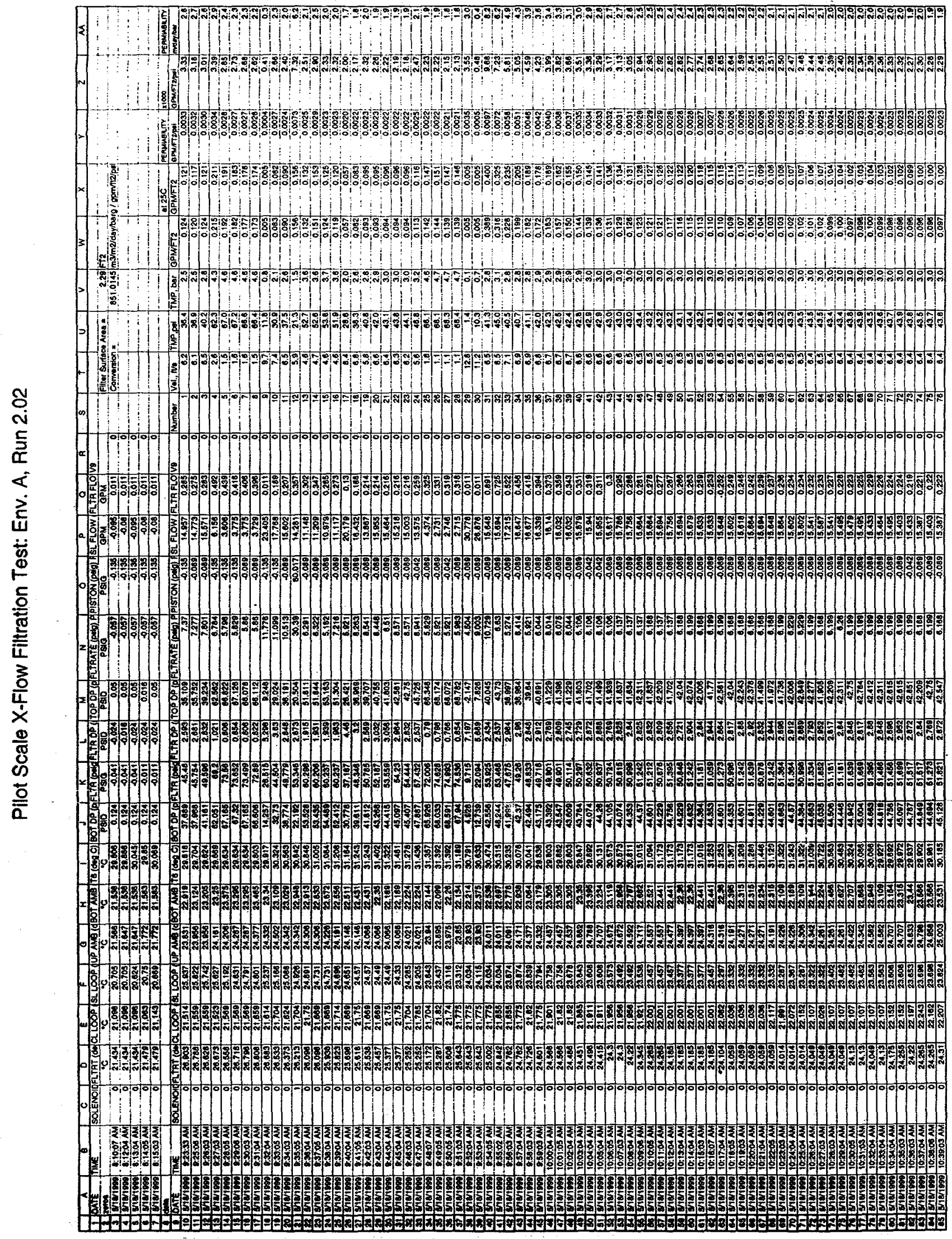




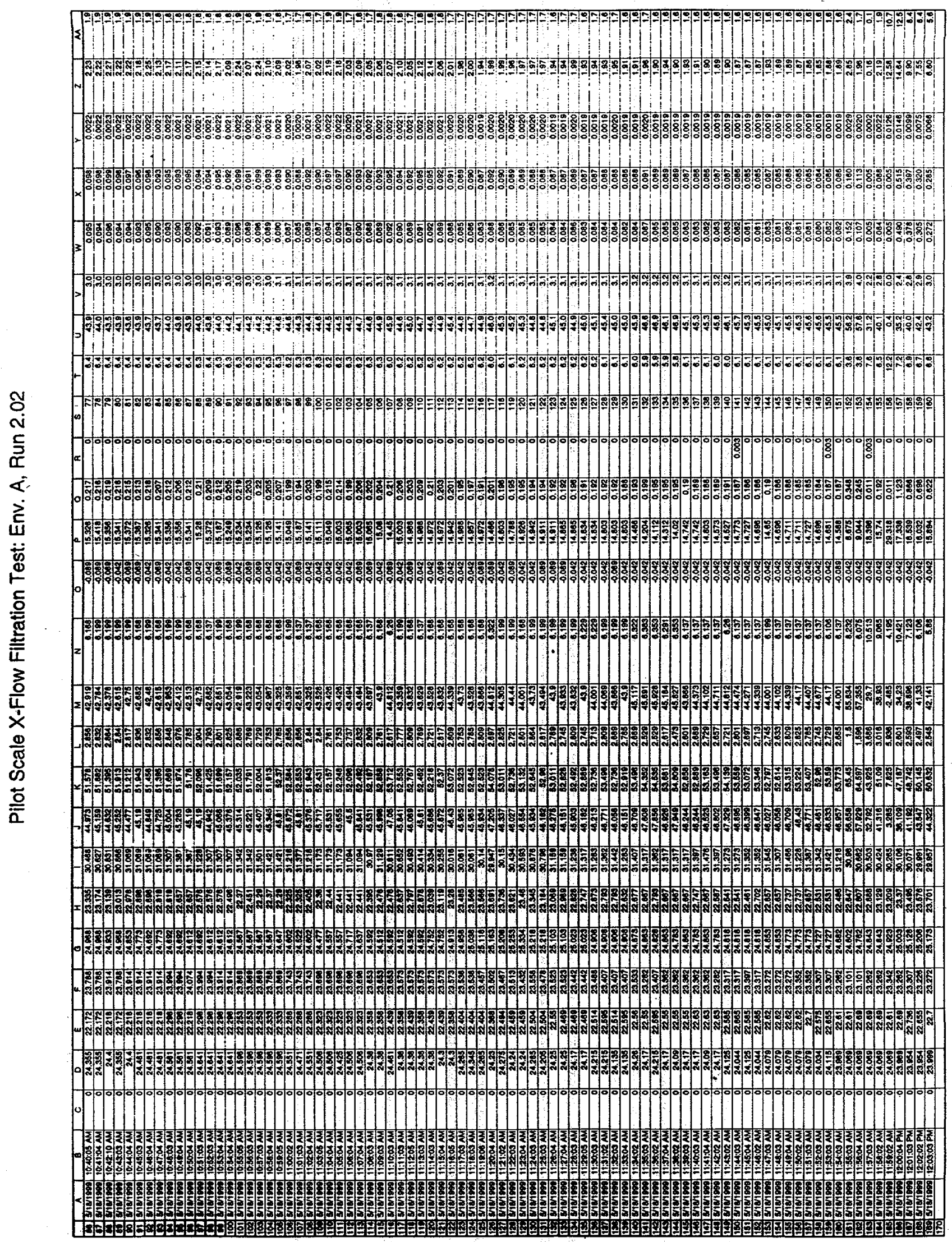


Pilot scale X-flow: EnvA+ES

Page 74 of 226

BNF-003-98-0221

Revision 0

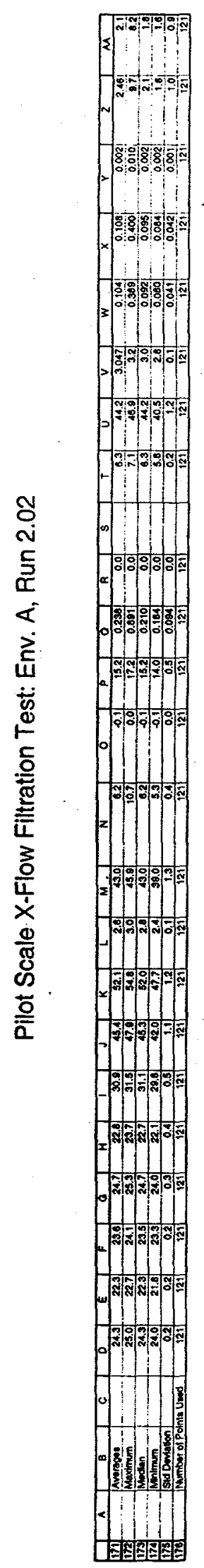




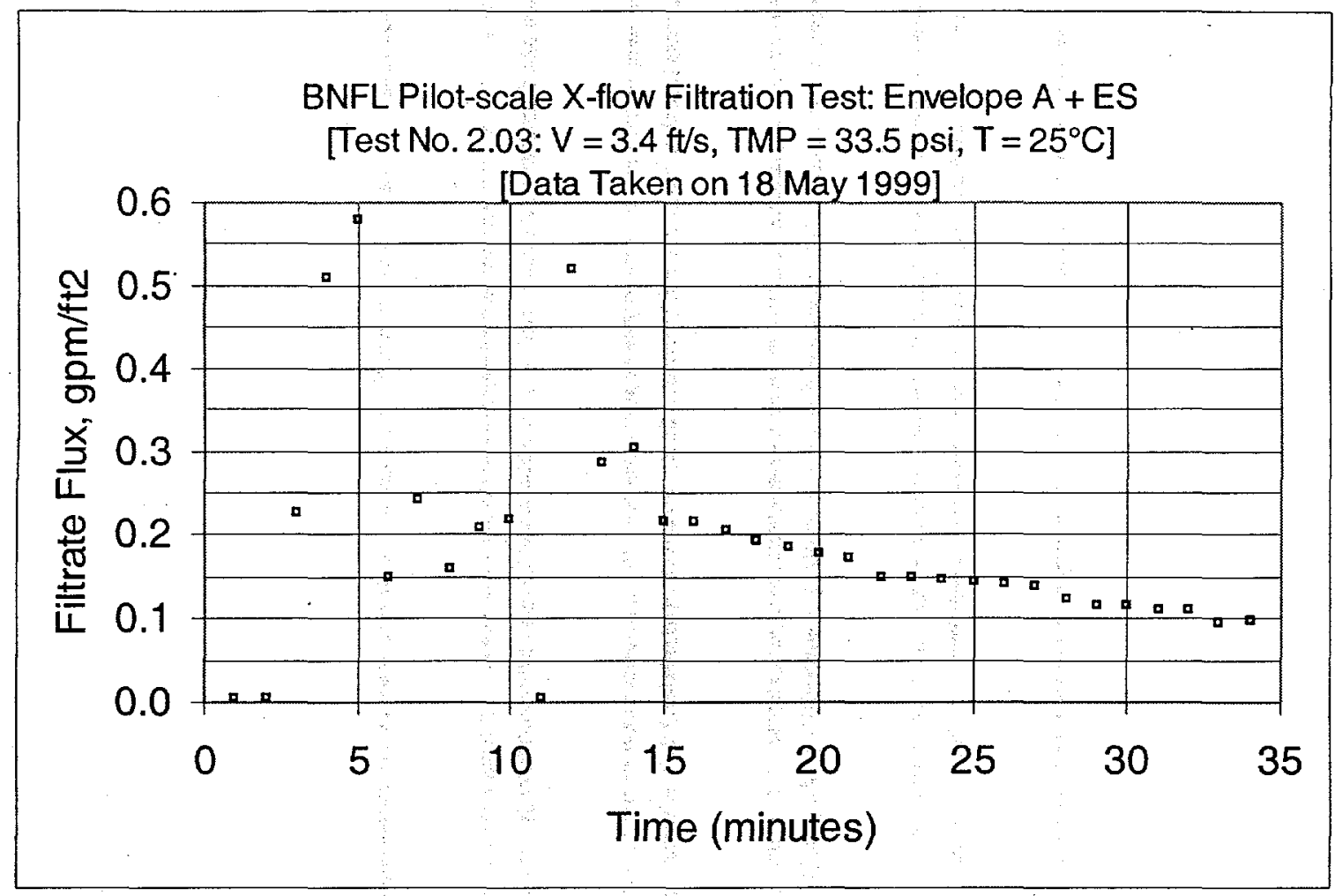

BNFL Pilot-scale X-flow Filtration Test: Envelope A + ES

[Test No. 2.03: $\mathrm{V}=3.4 \mathrm{ft} / \mathrm{s}, \mathrm{TMP}=33.5 \mathrm{psi}, \mathrm{T}=25^{\circ} \mathrm{C}$ ]

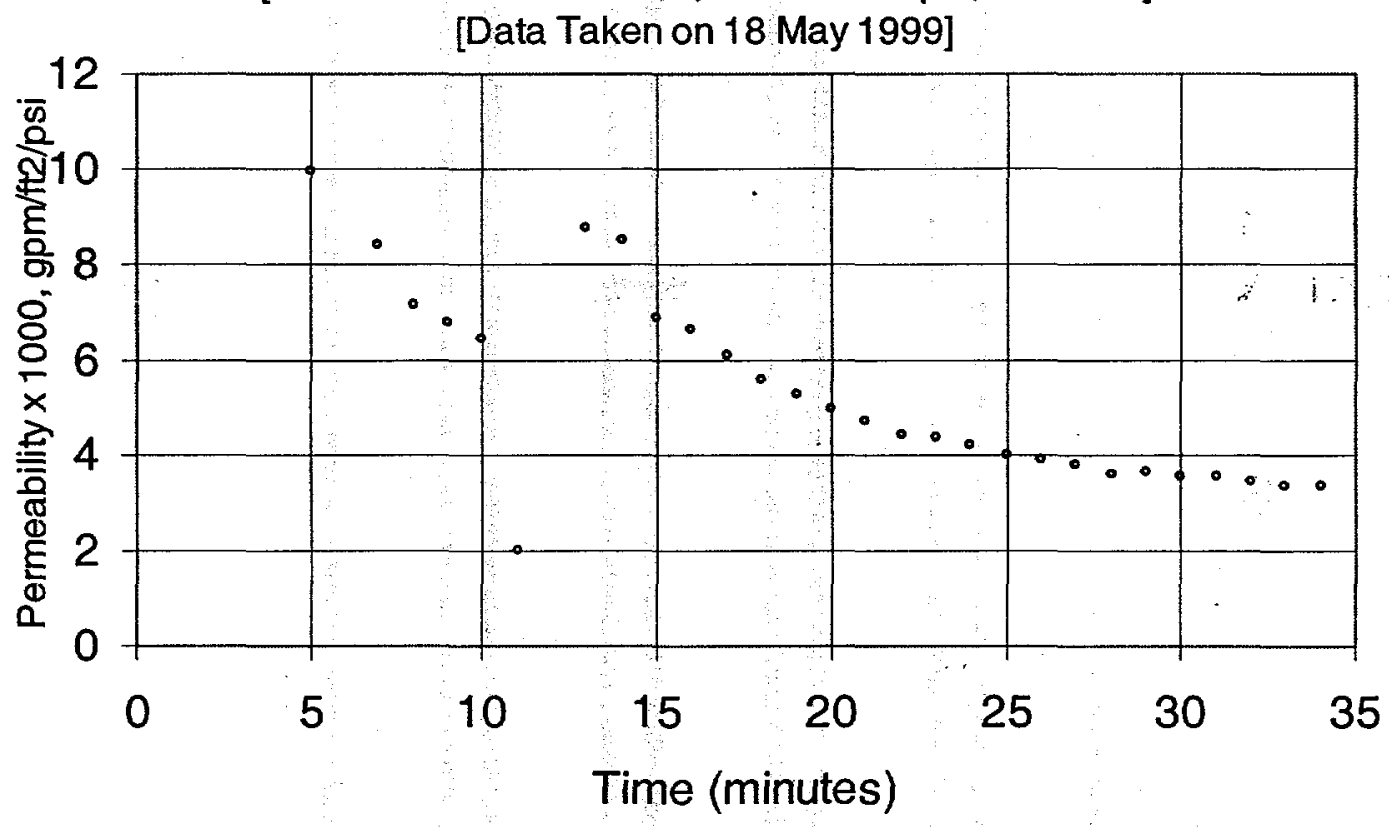

Figure B3: Test Run 2.03, 0.5 wt\% Insoluble Solids Concentration 


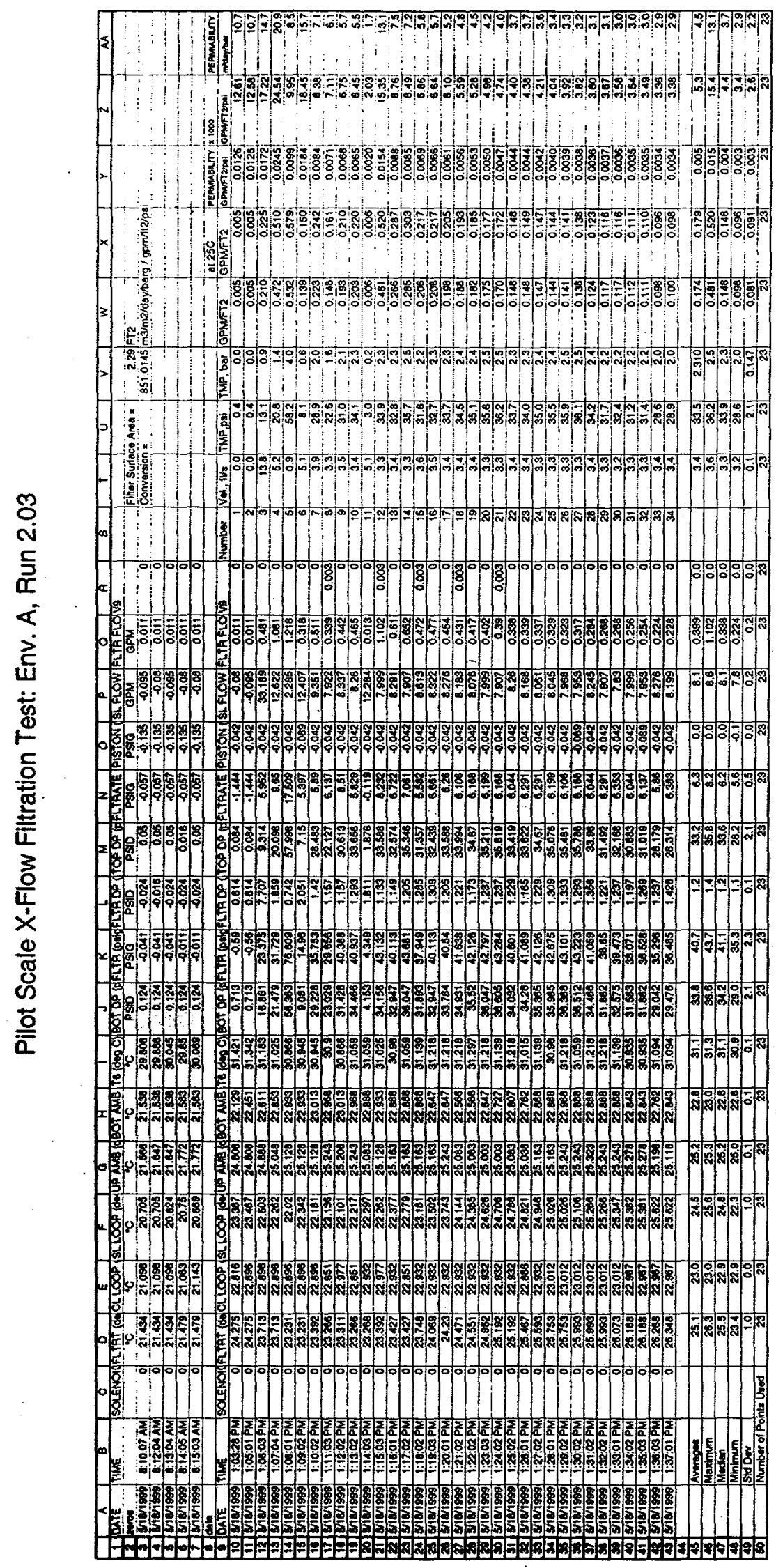



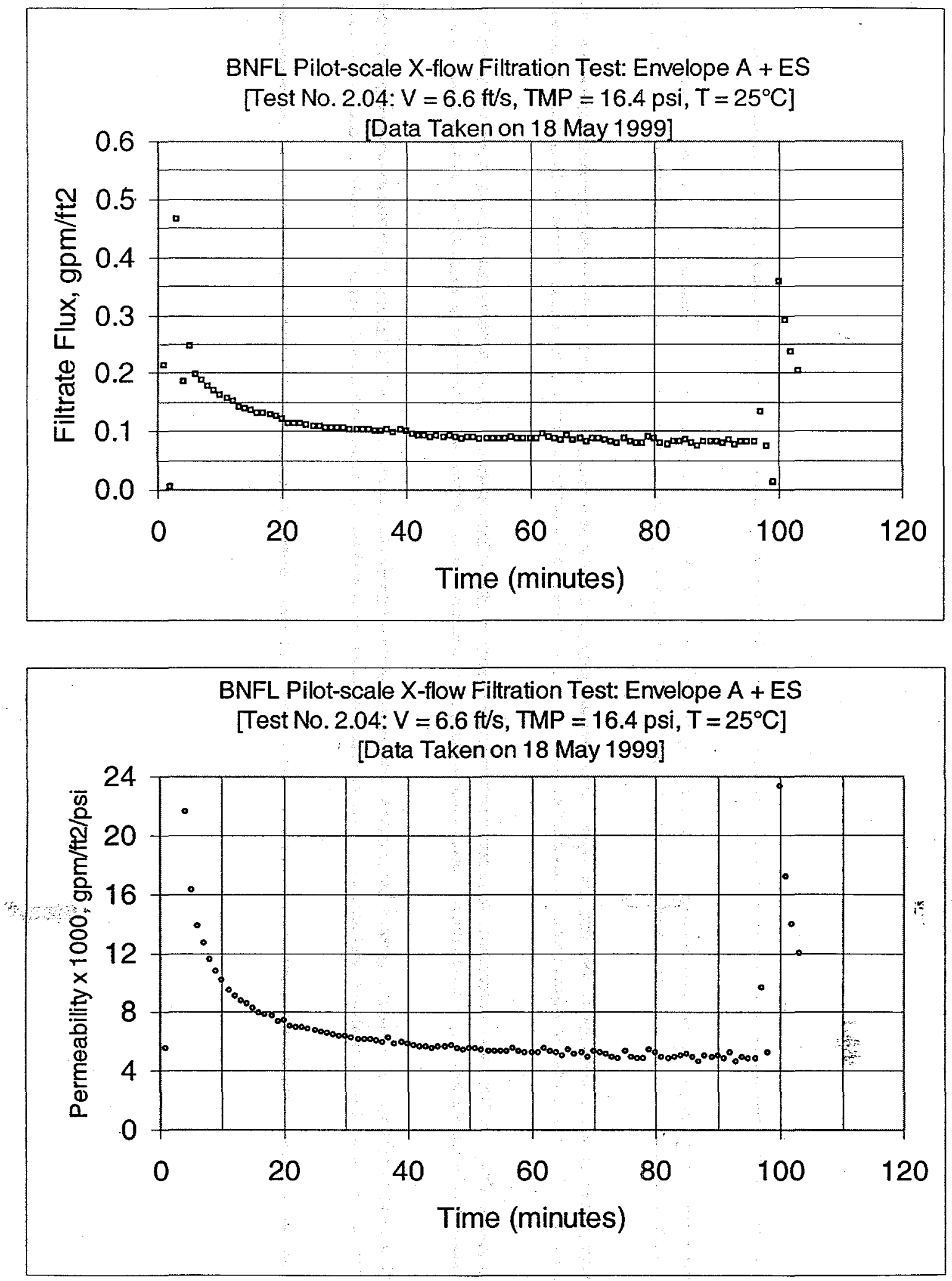

Figure B4: Test Run 2.04, 0.5 wt\% Insoluble Solids Concentration 


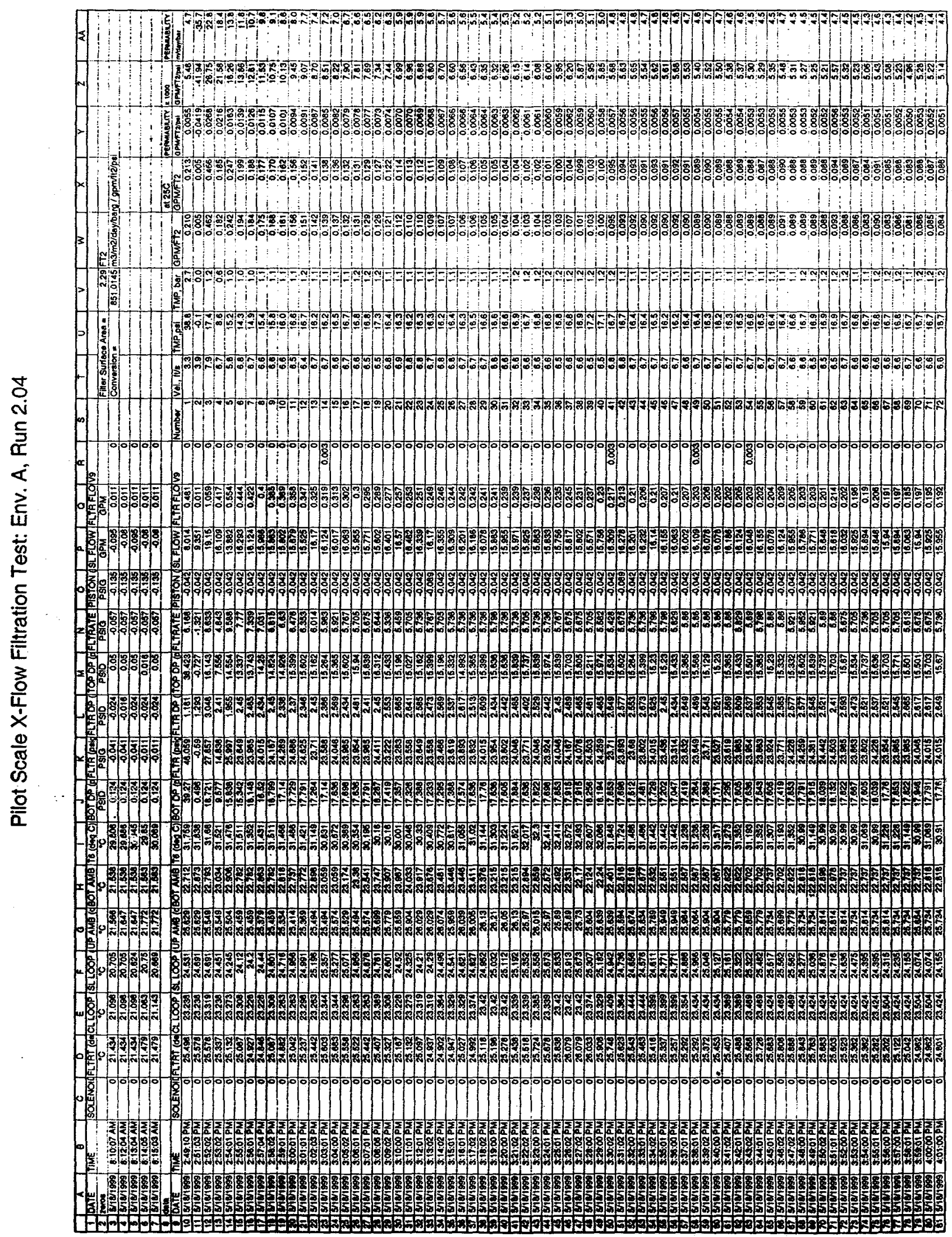




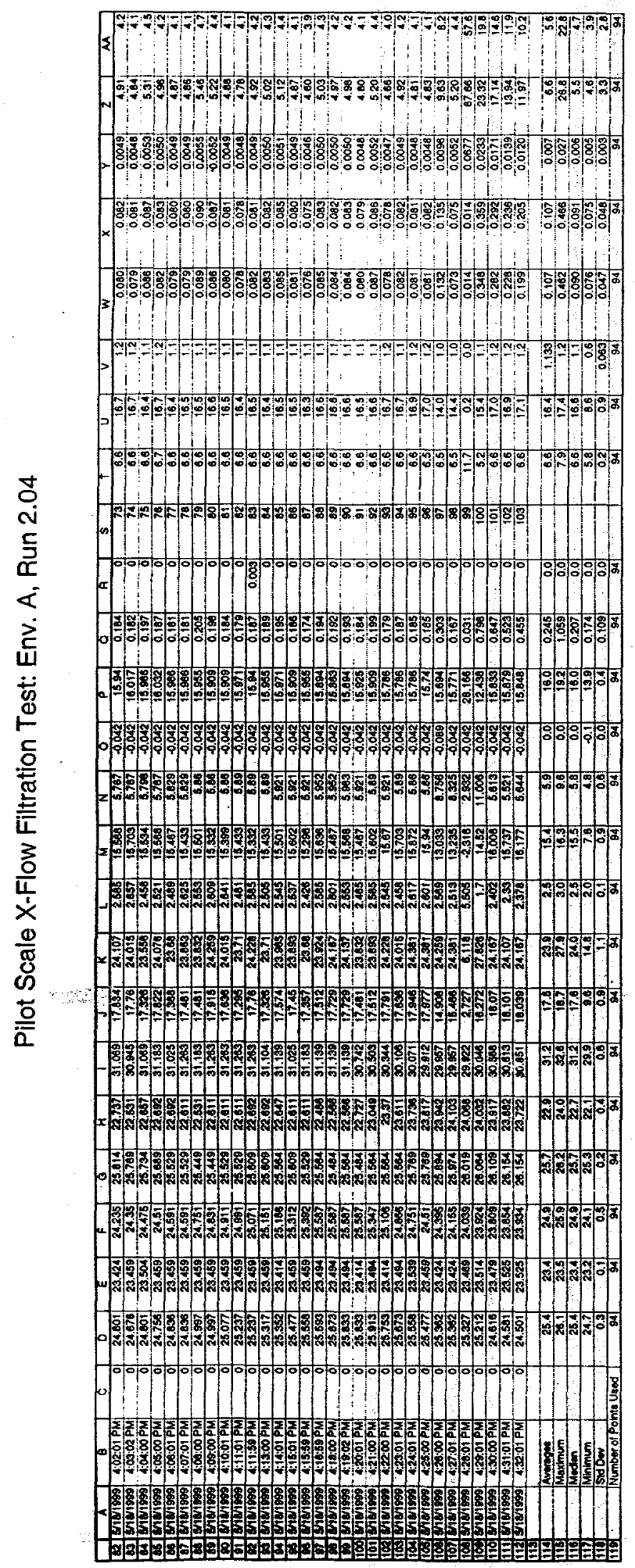



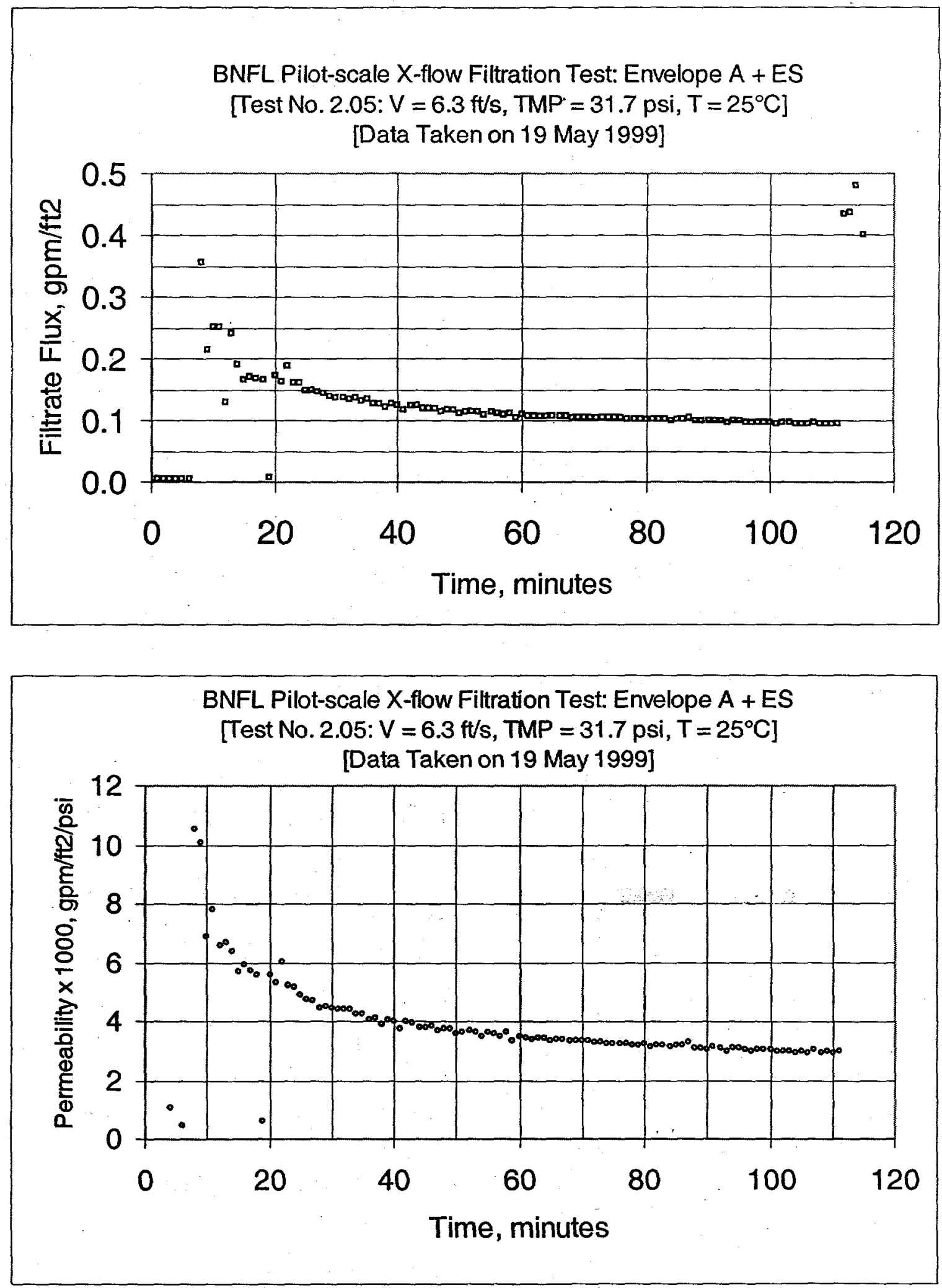

Figure B5: Test Run 2.05, 0.5 wt\% Insoluble Solids Concentration 


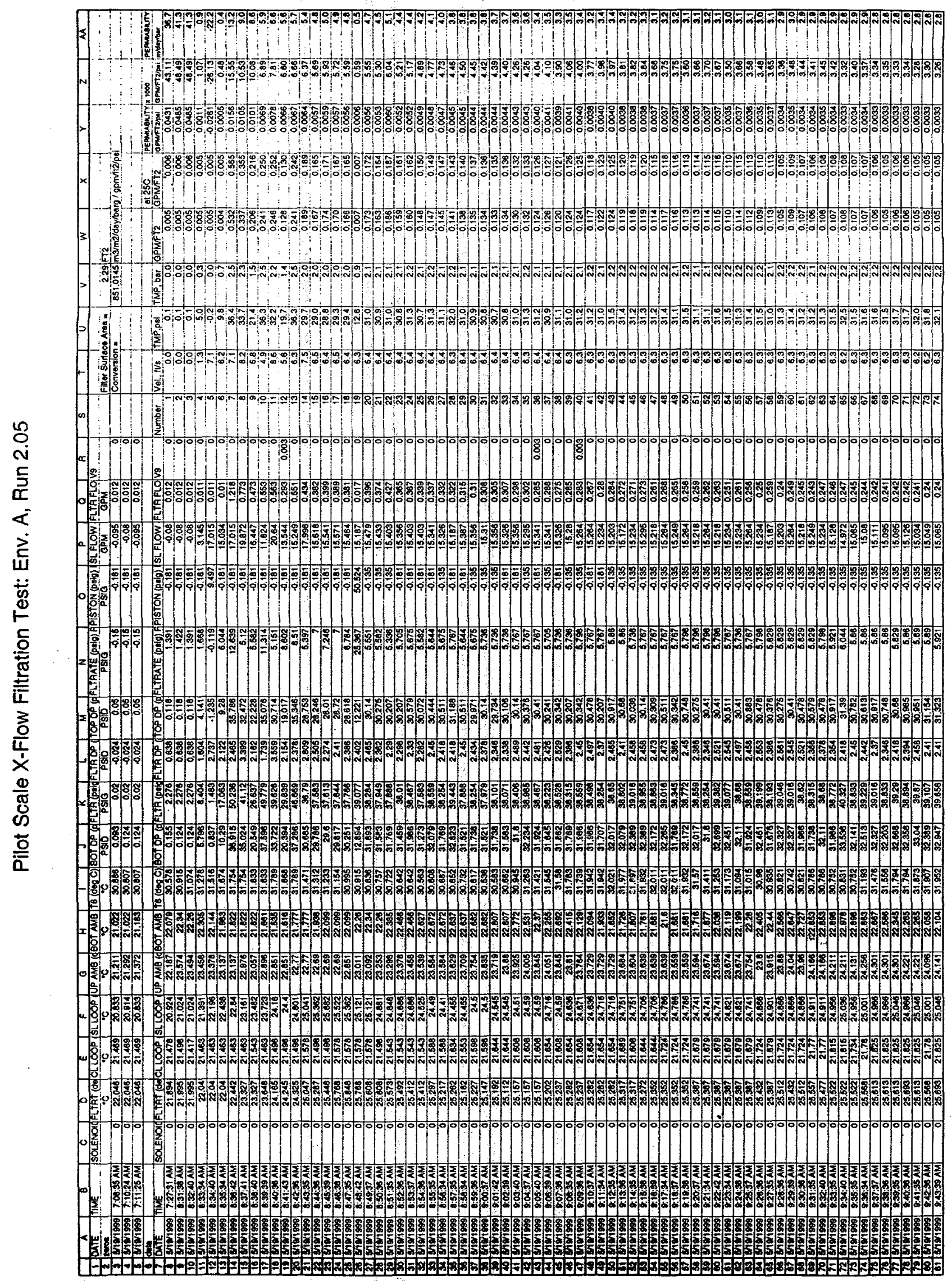




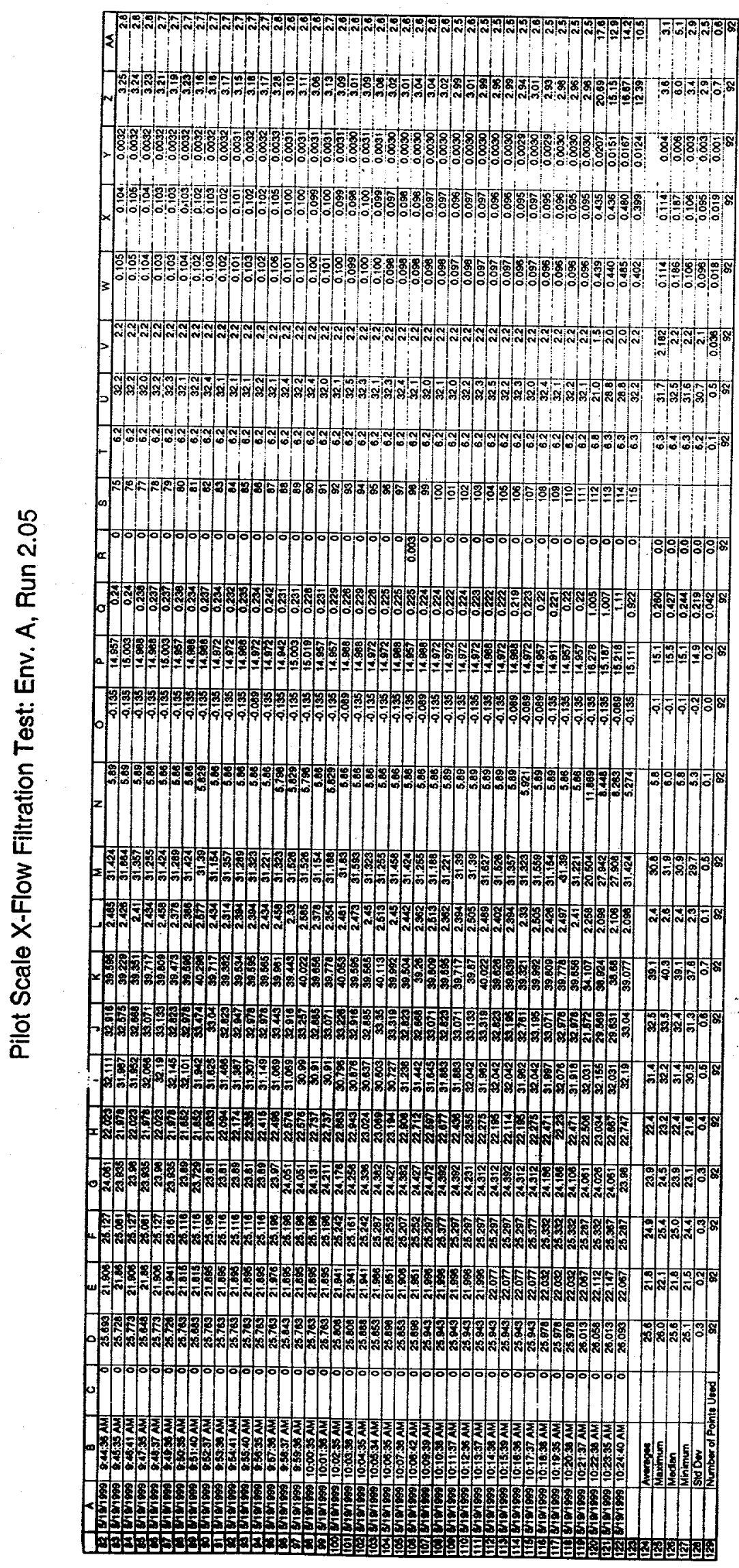



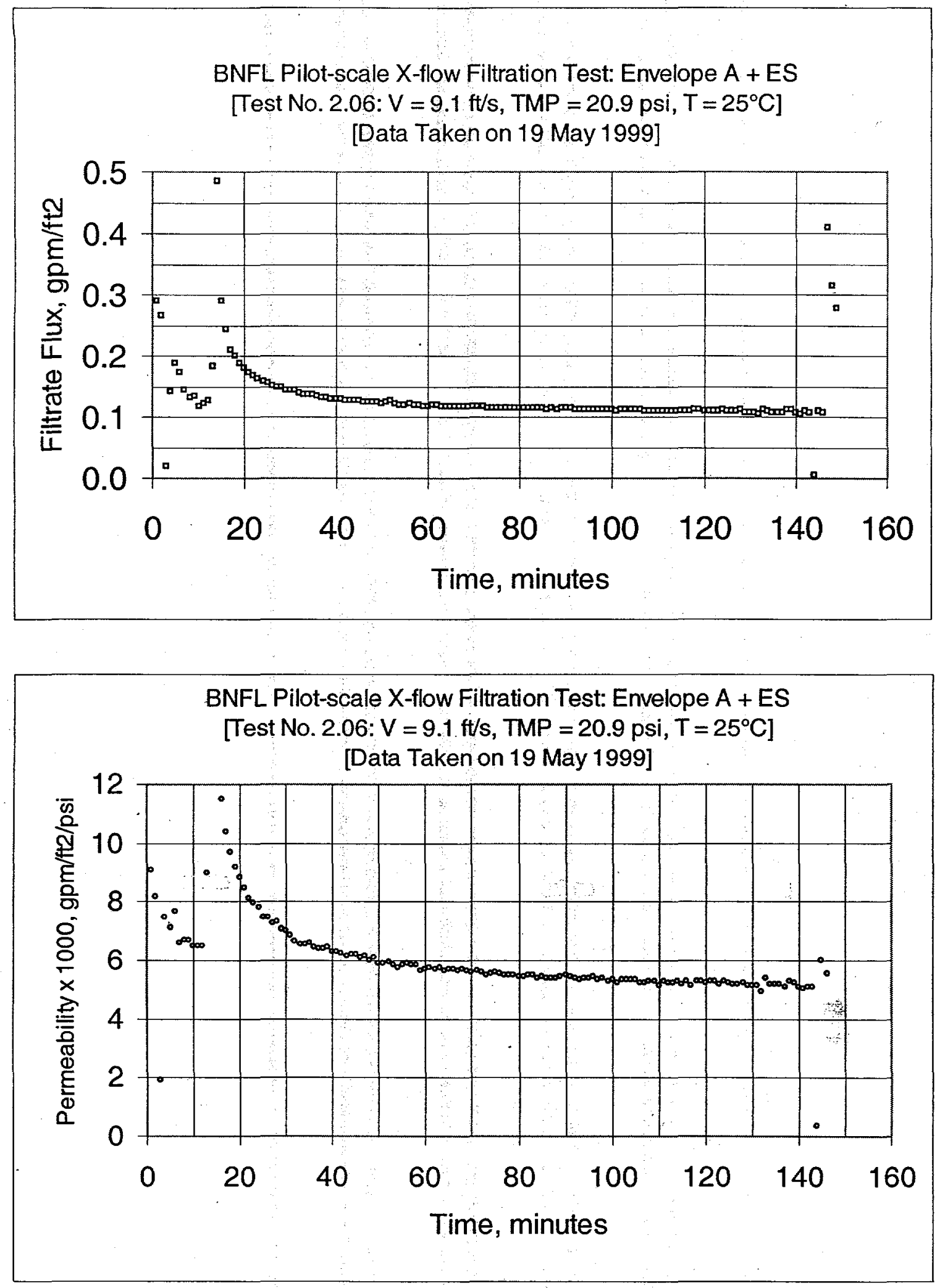

Figure B6: Test Run 2.06, 0.5 wt\% Insoluble Solids Concentration 


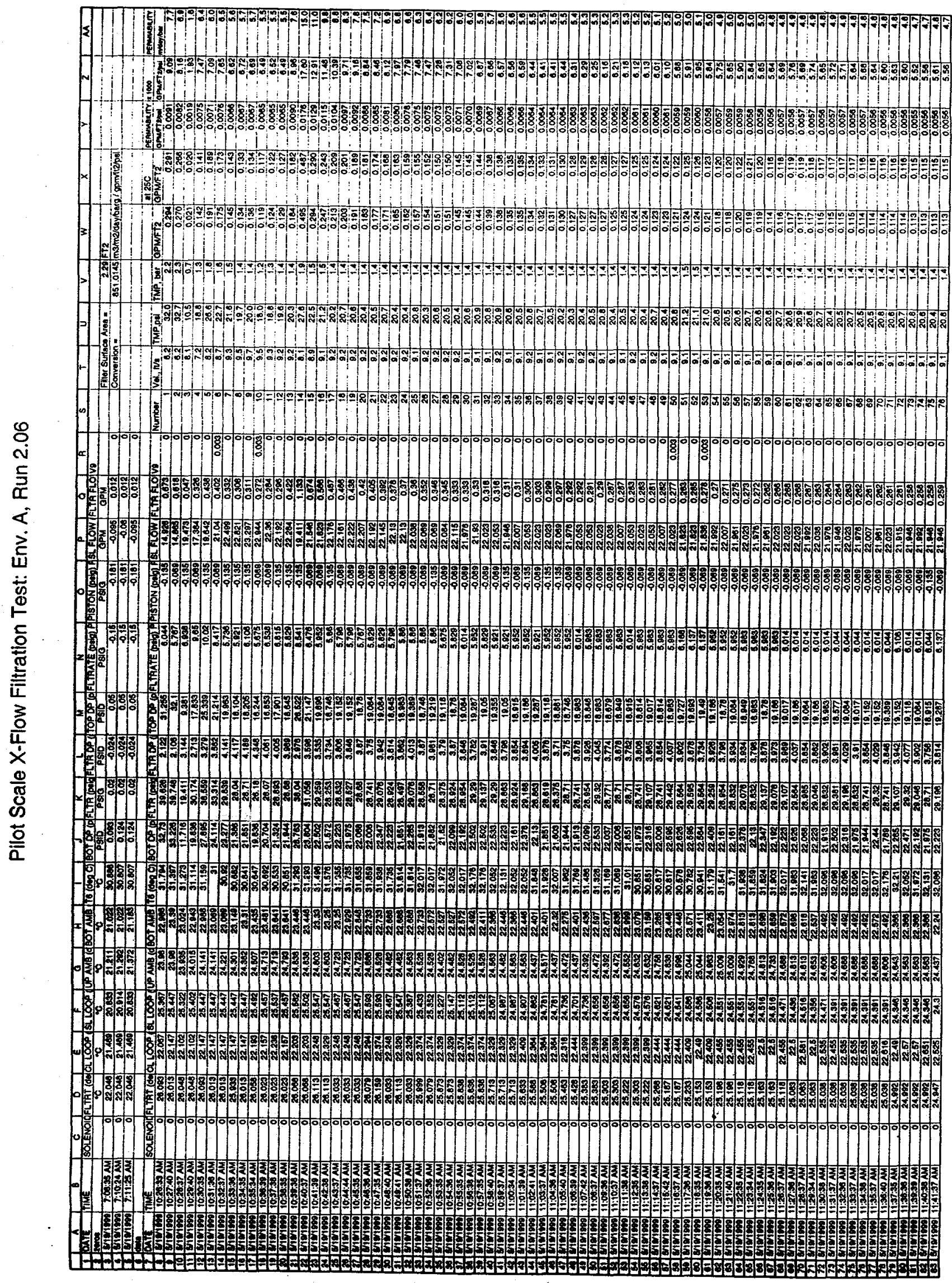




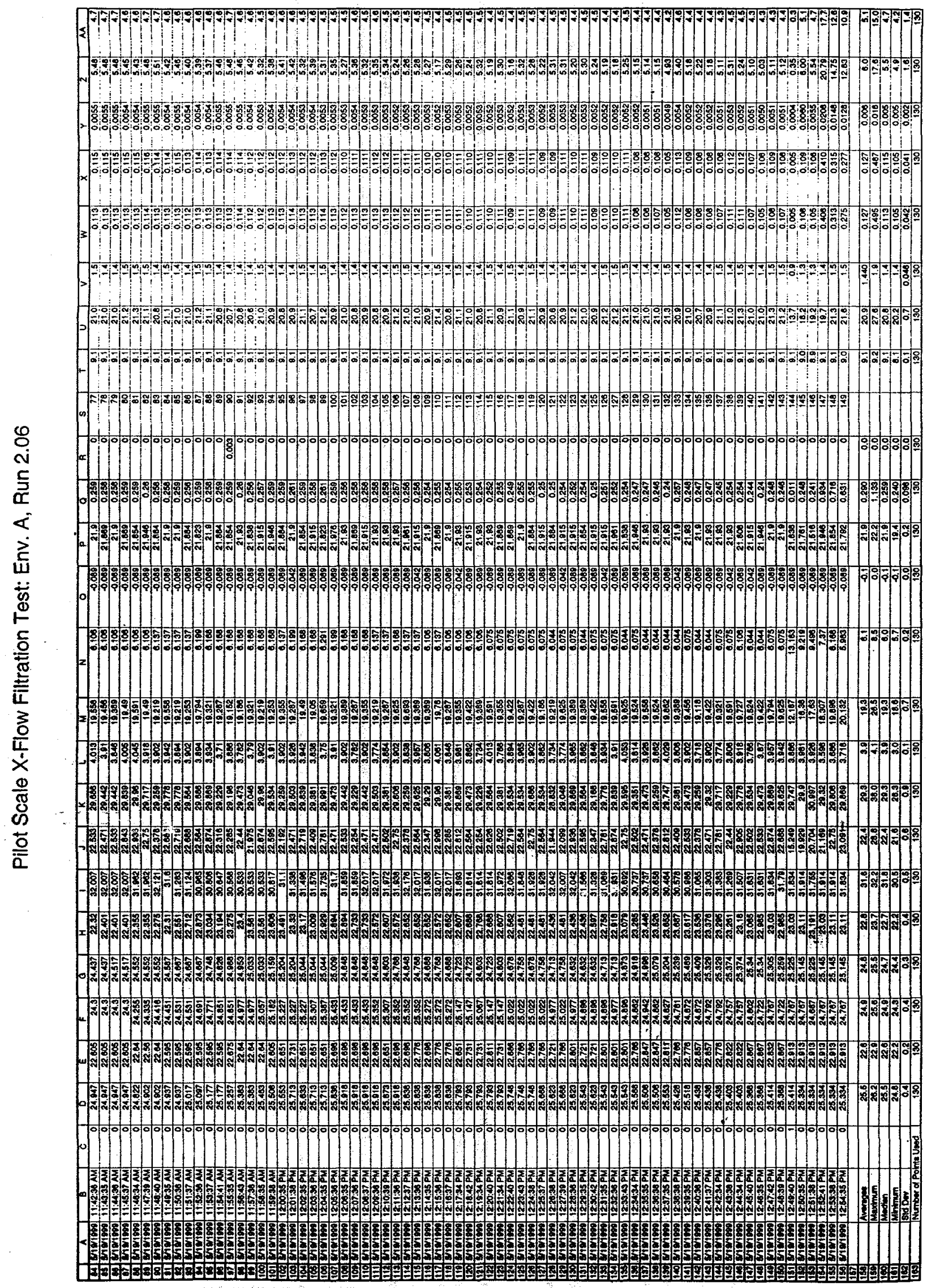



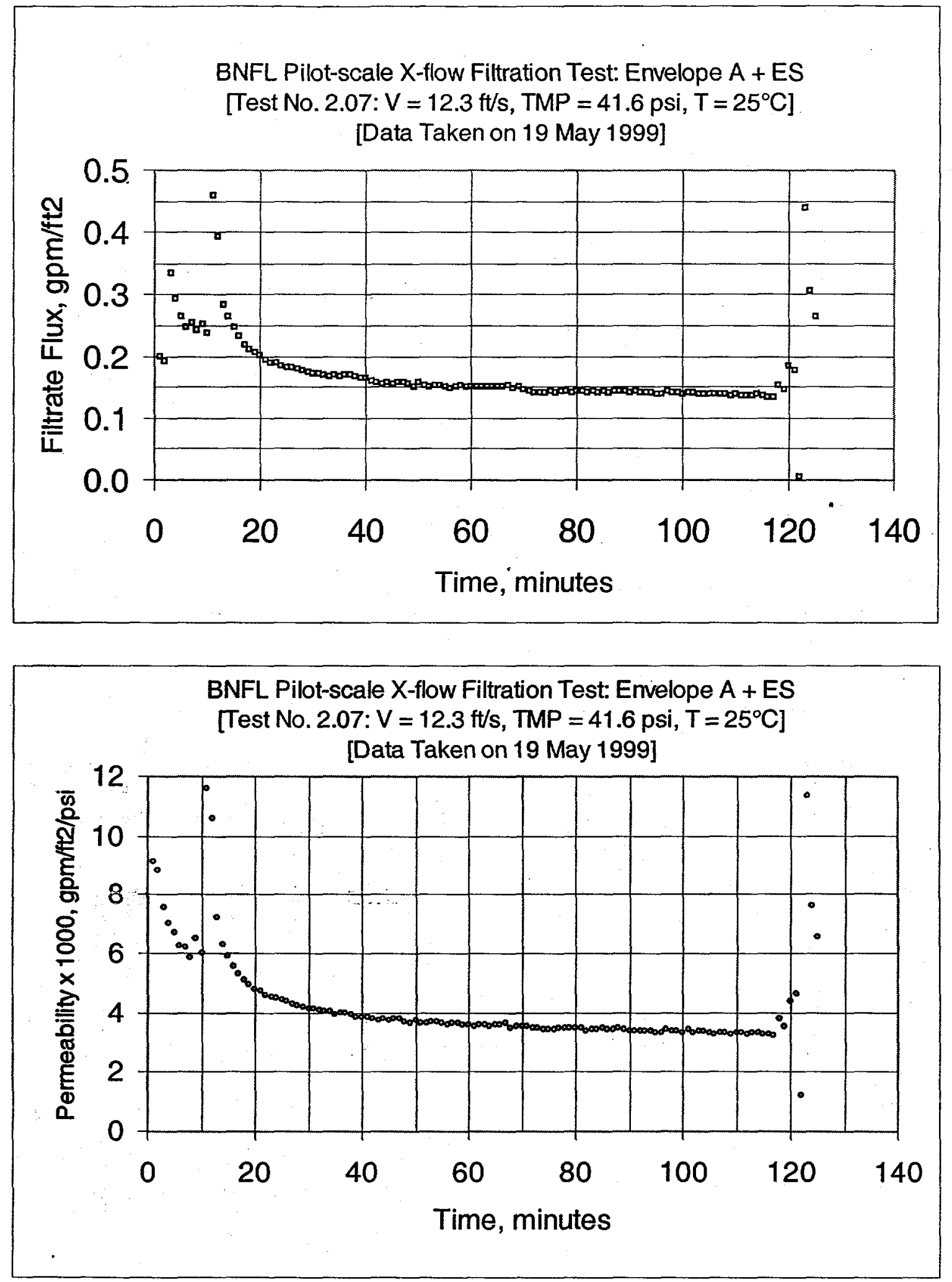

Figure B7: Test Run 2.07, 0.5 wt\% Insoluble Solids Concentration 


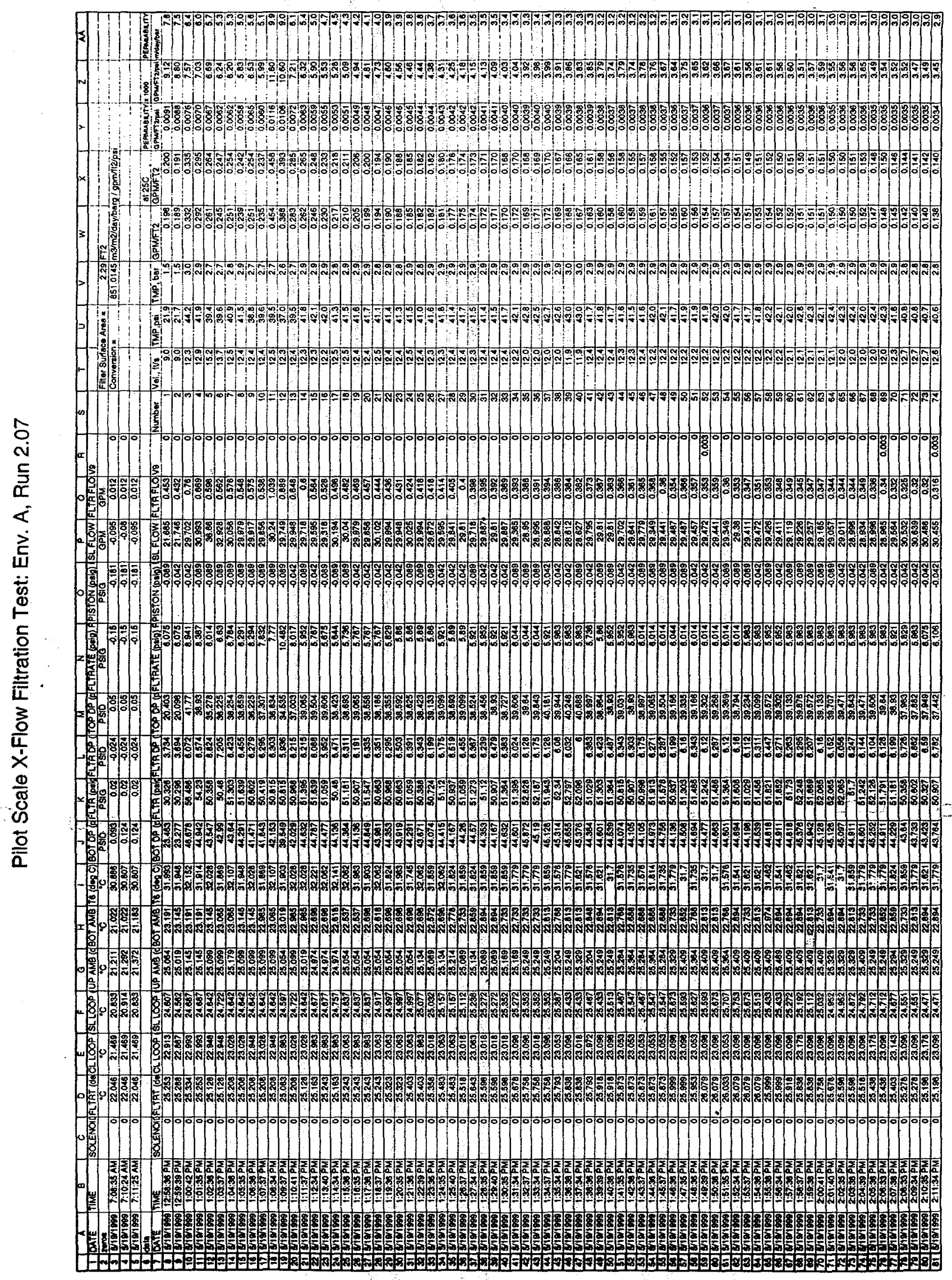




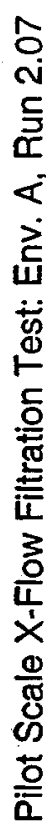

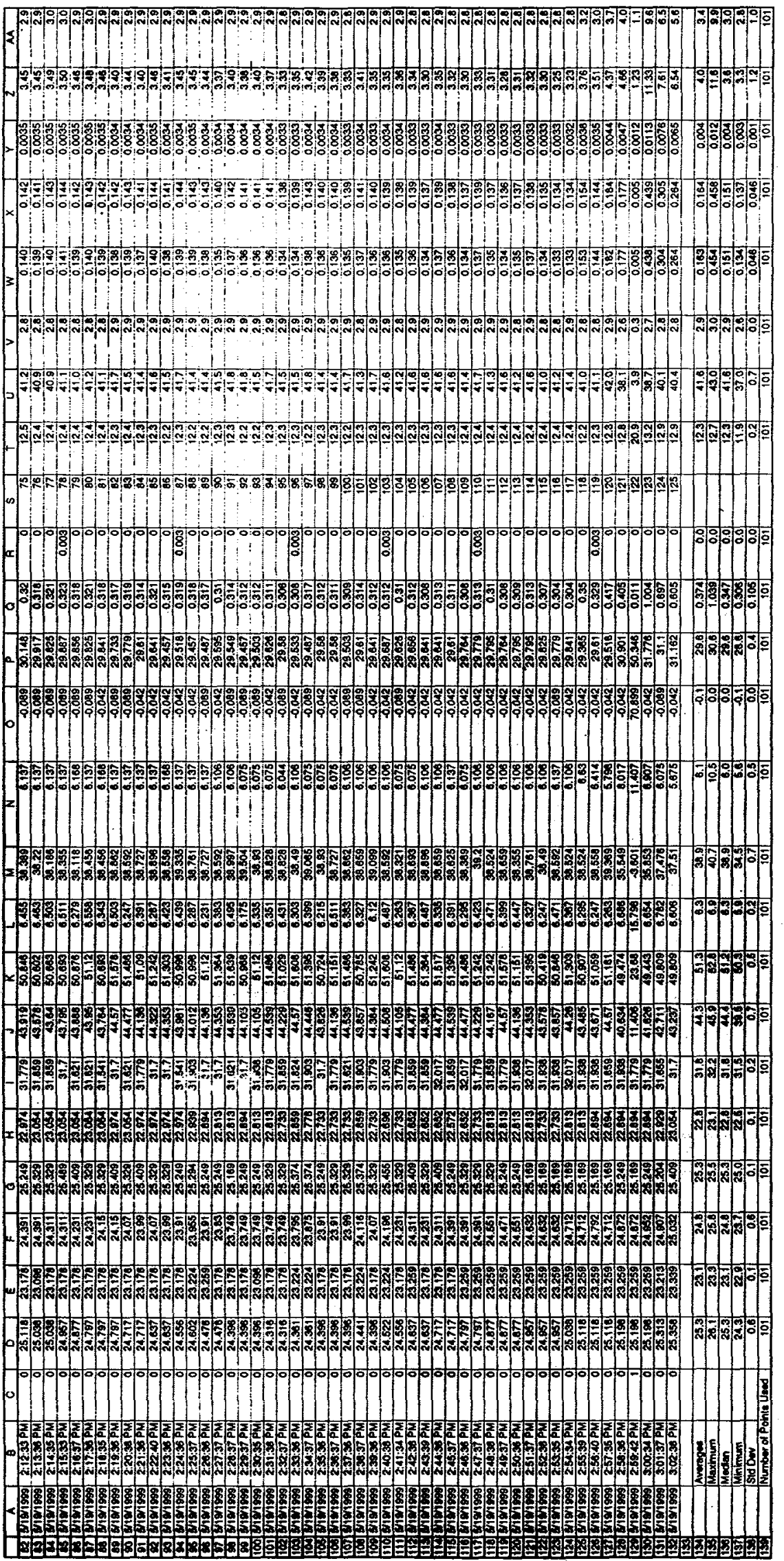



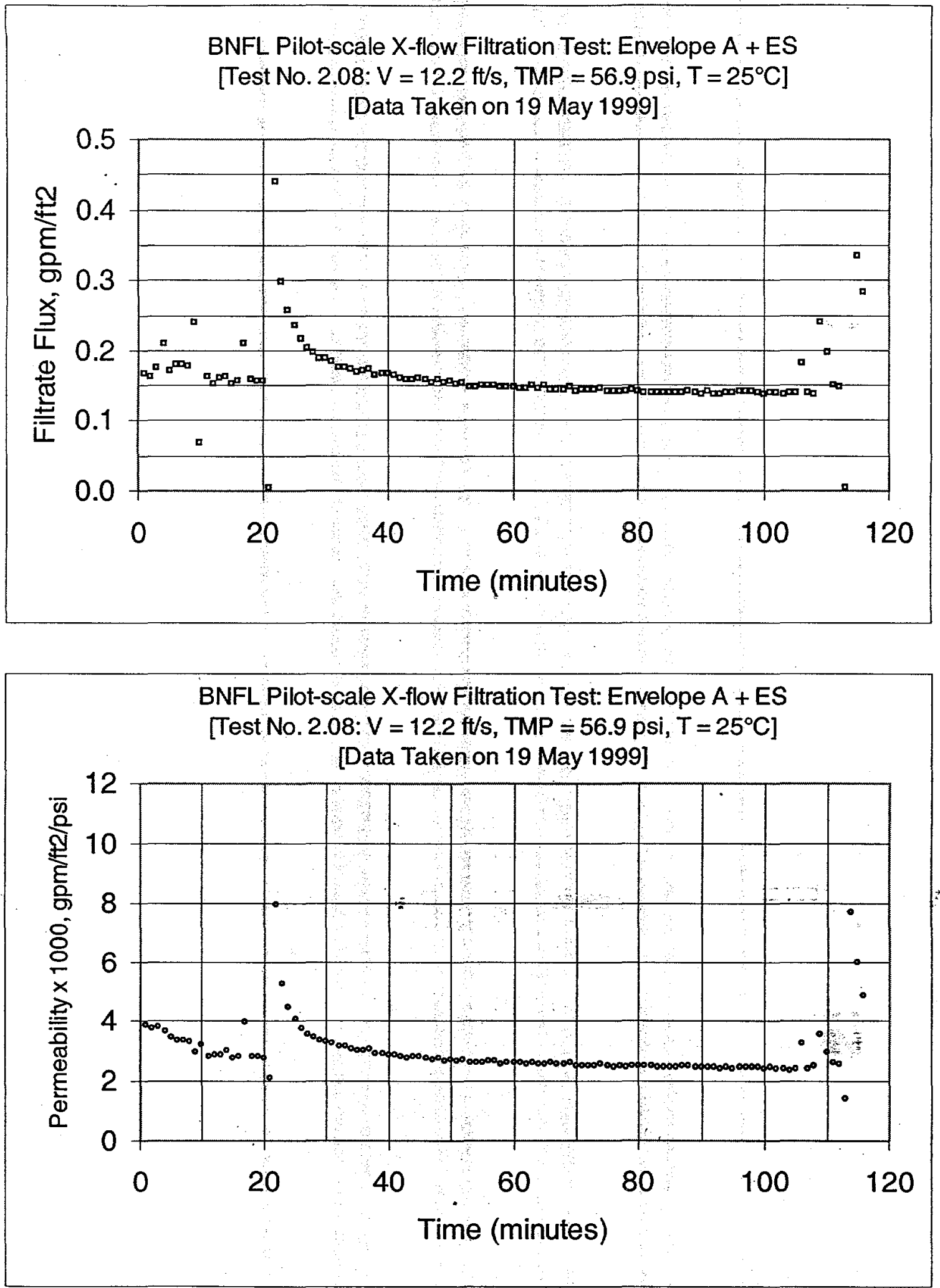

Figure B8: Test Run 2.08, 0.5 wt\% Insoluble Solids Concentration 


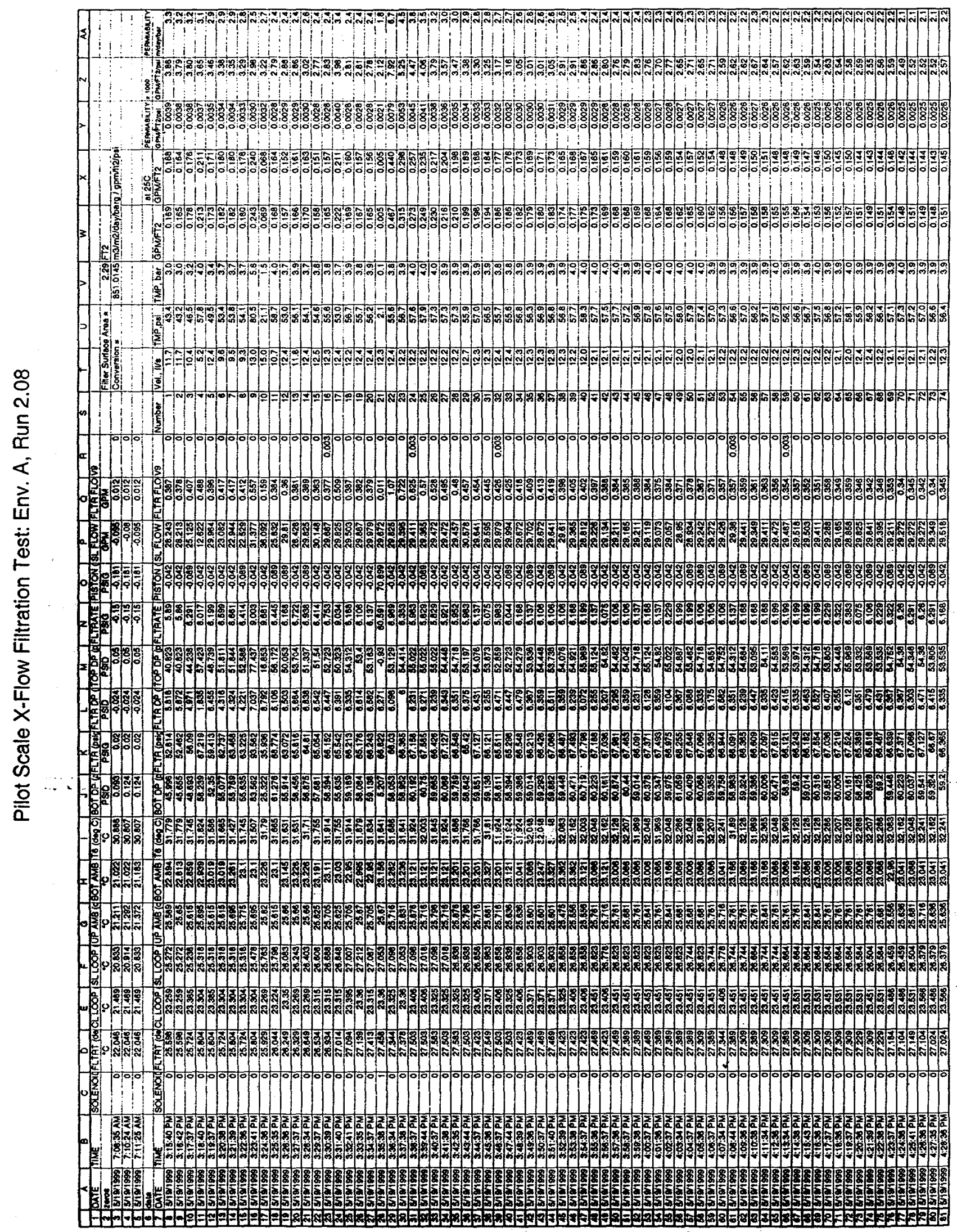




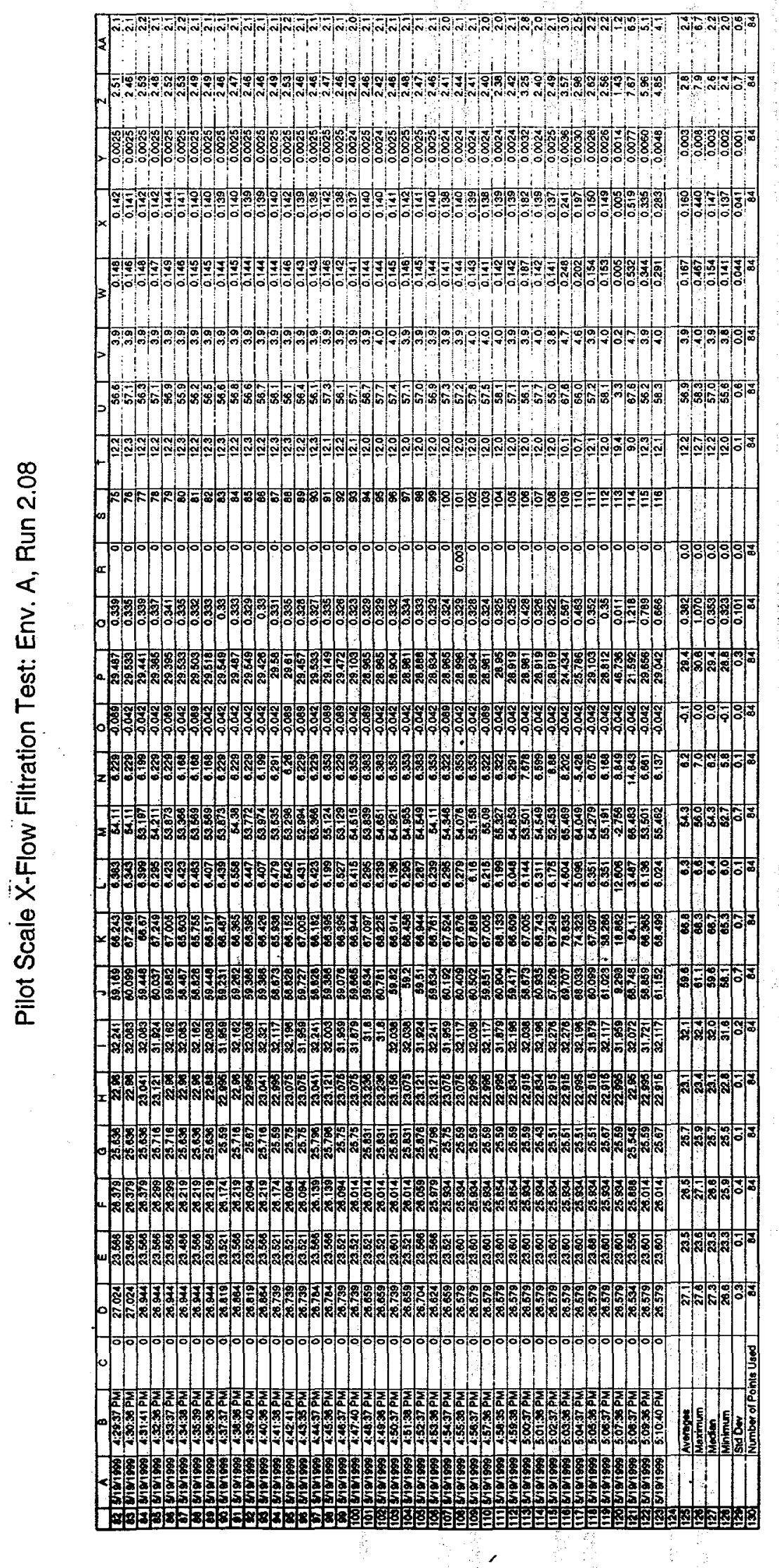



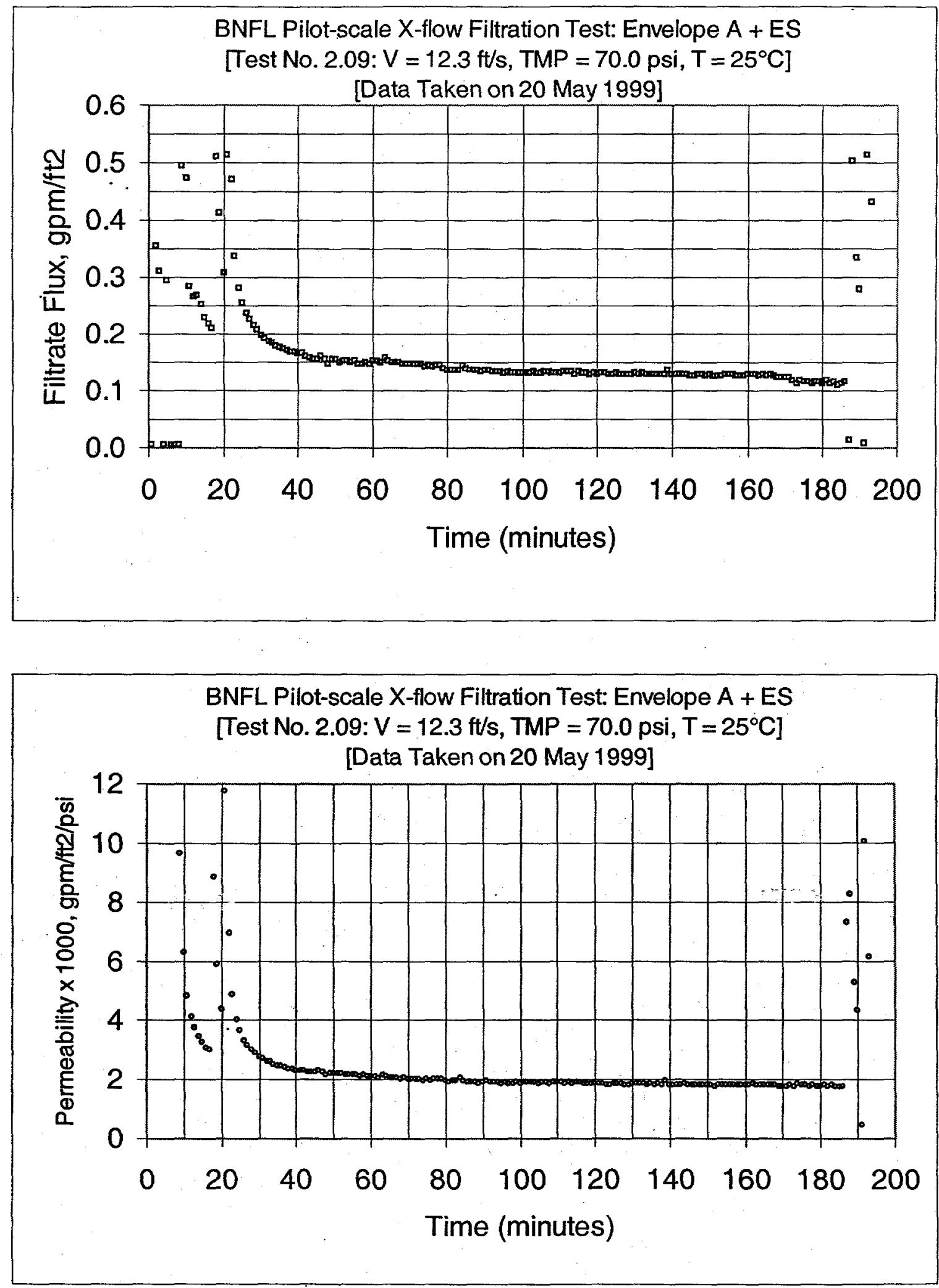

Figure B9:: Test Run 2.09, 0.5 wt\% Insoluble Solids Concentration 
Pilot scale X-flow: EnvA+ES

Page 93 of 226

BNF-003-98-0221

Revision 0

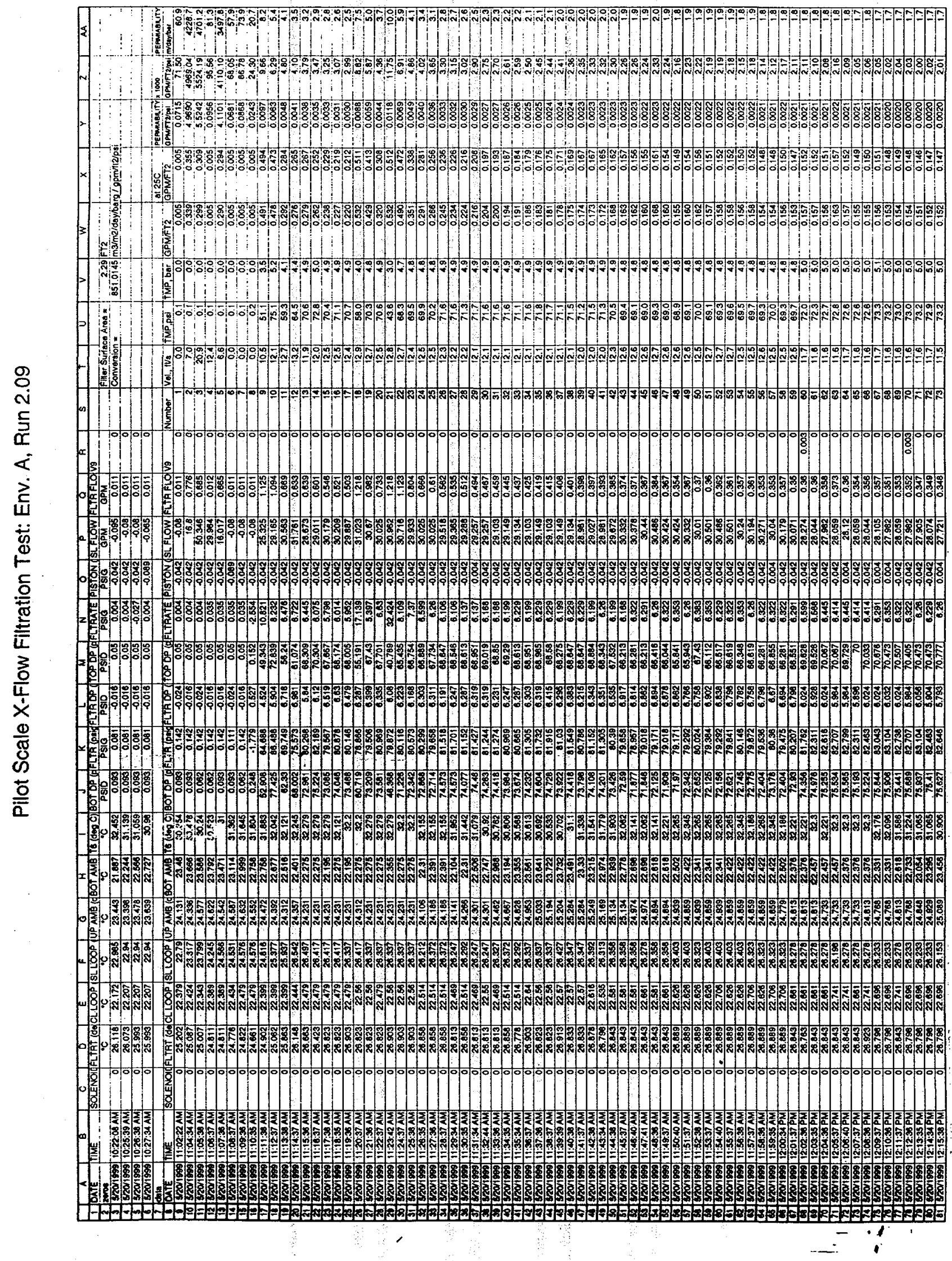




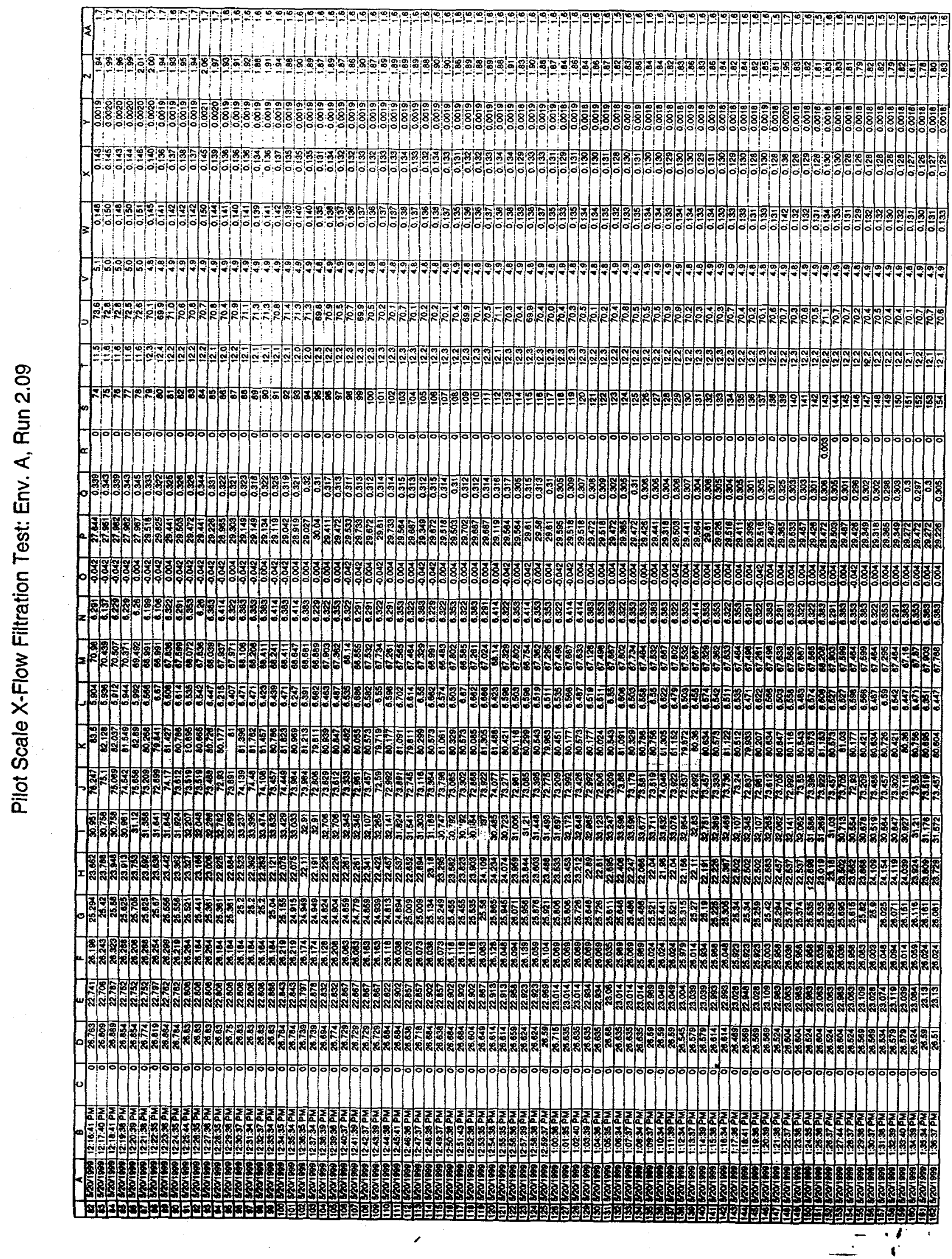




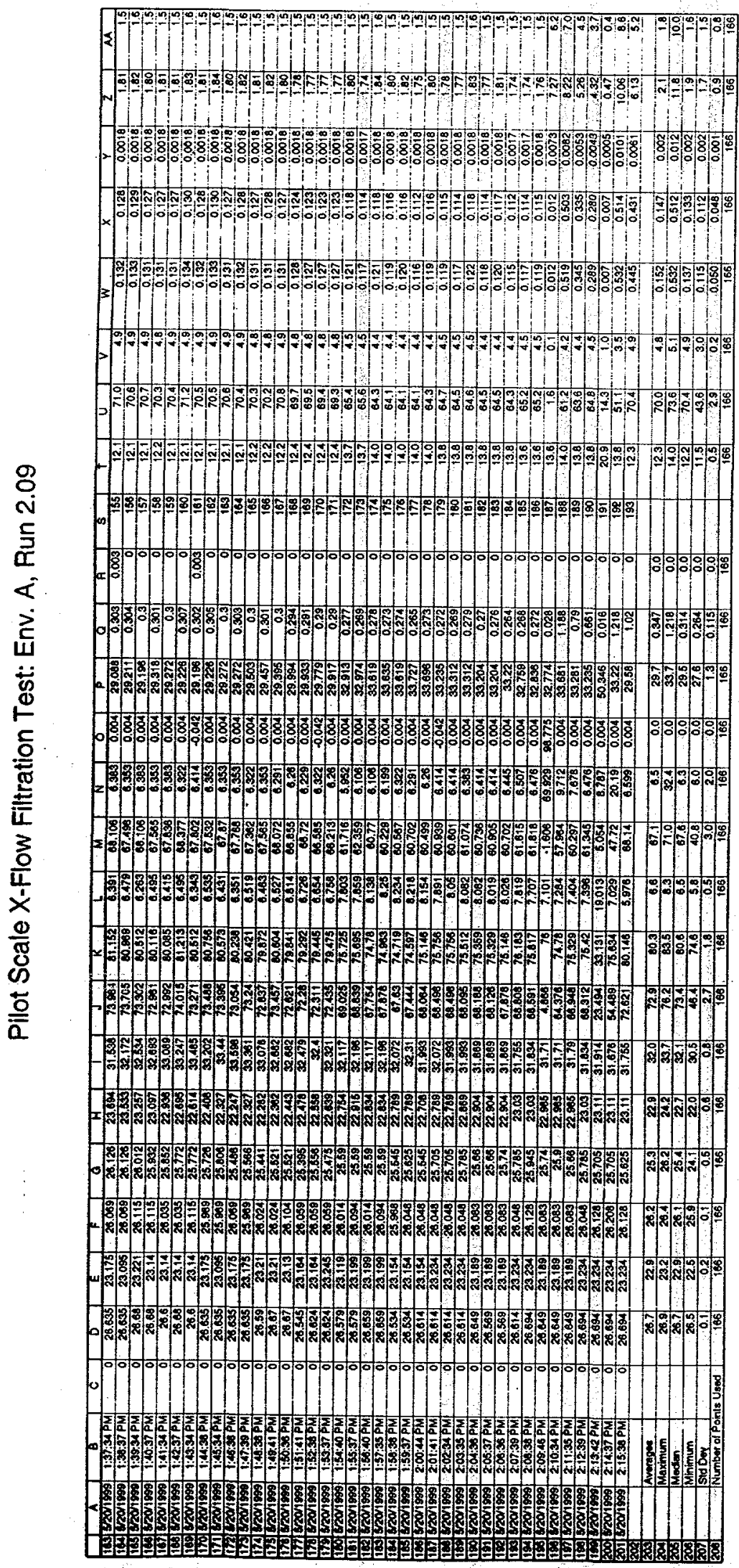



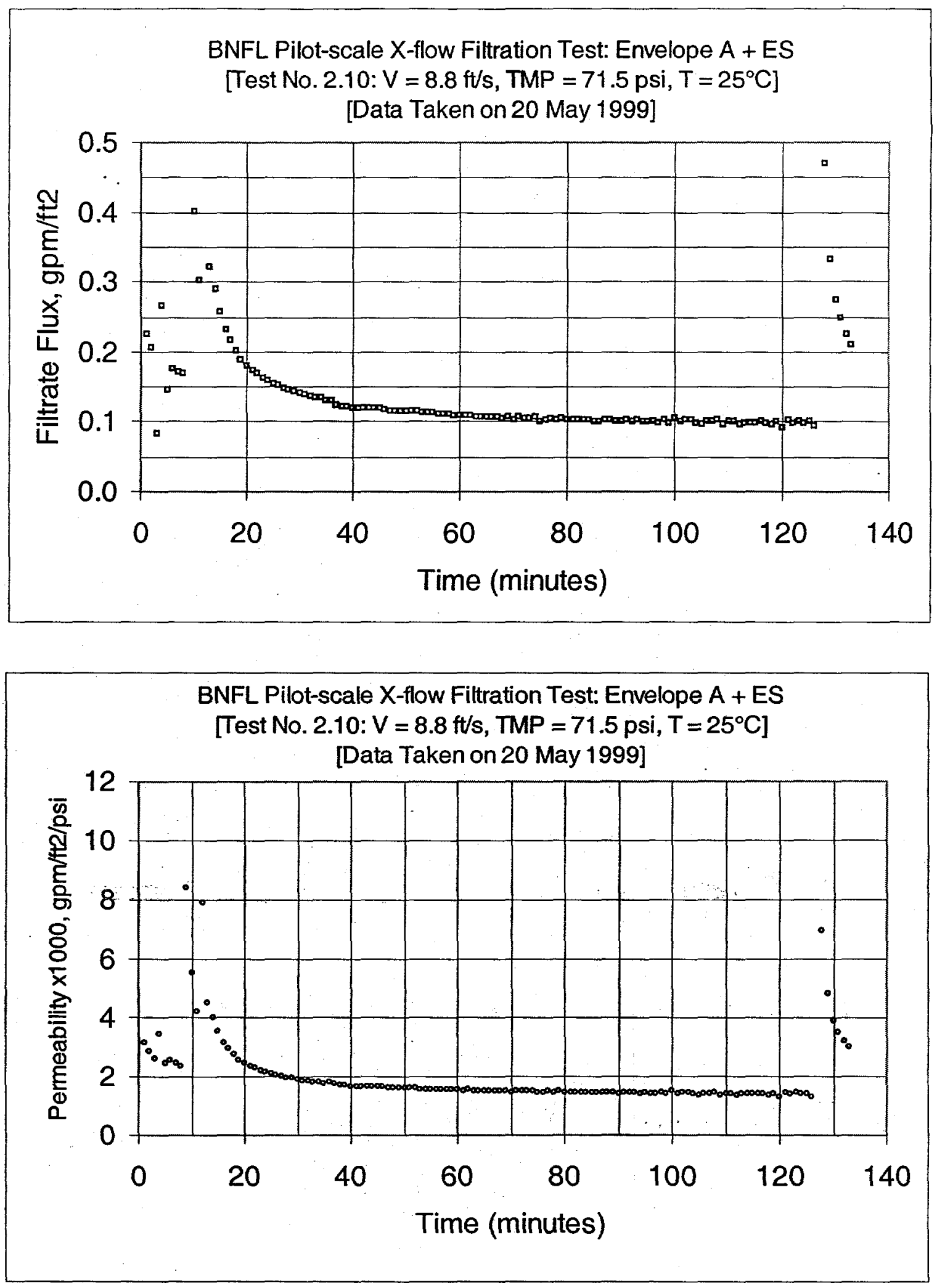

Figure B10: Test Run 2.10, $0.5 \mathrm{wt} \%$ Insoluble Solids Concentration 


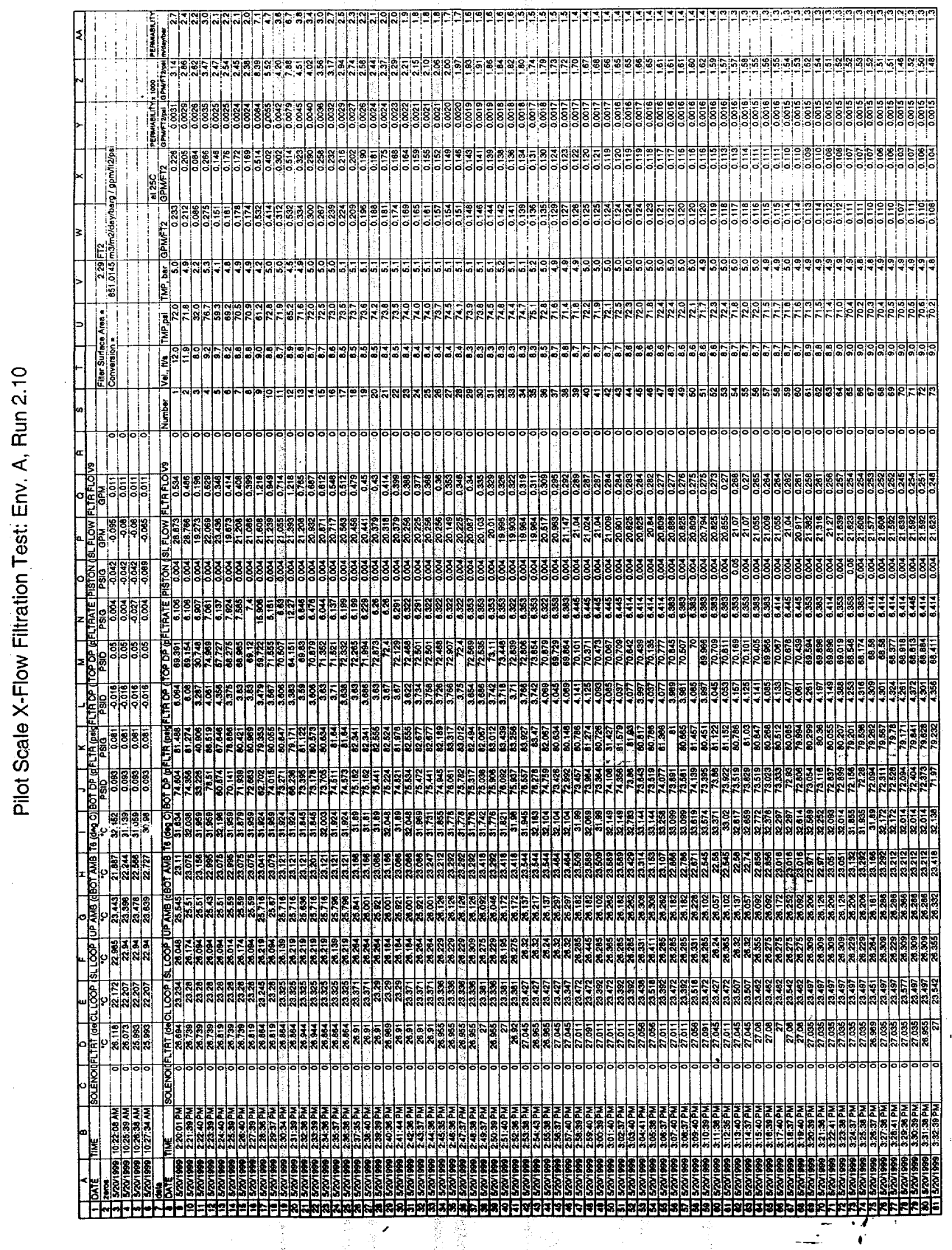


Pilot scale X-flow: EnvA+ES Page 98 of 220

BNF-003-98-0221

Revision 0

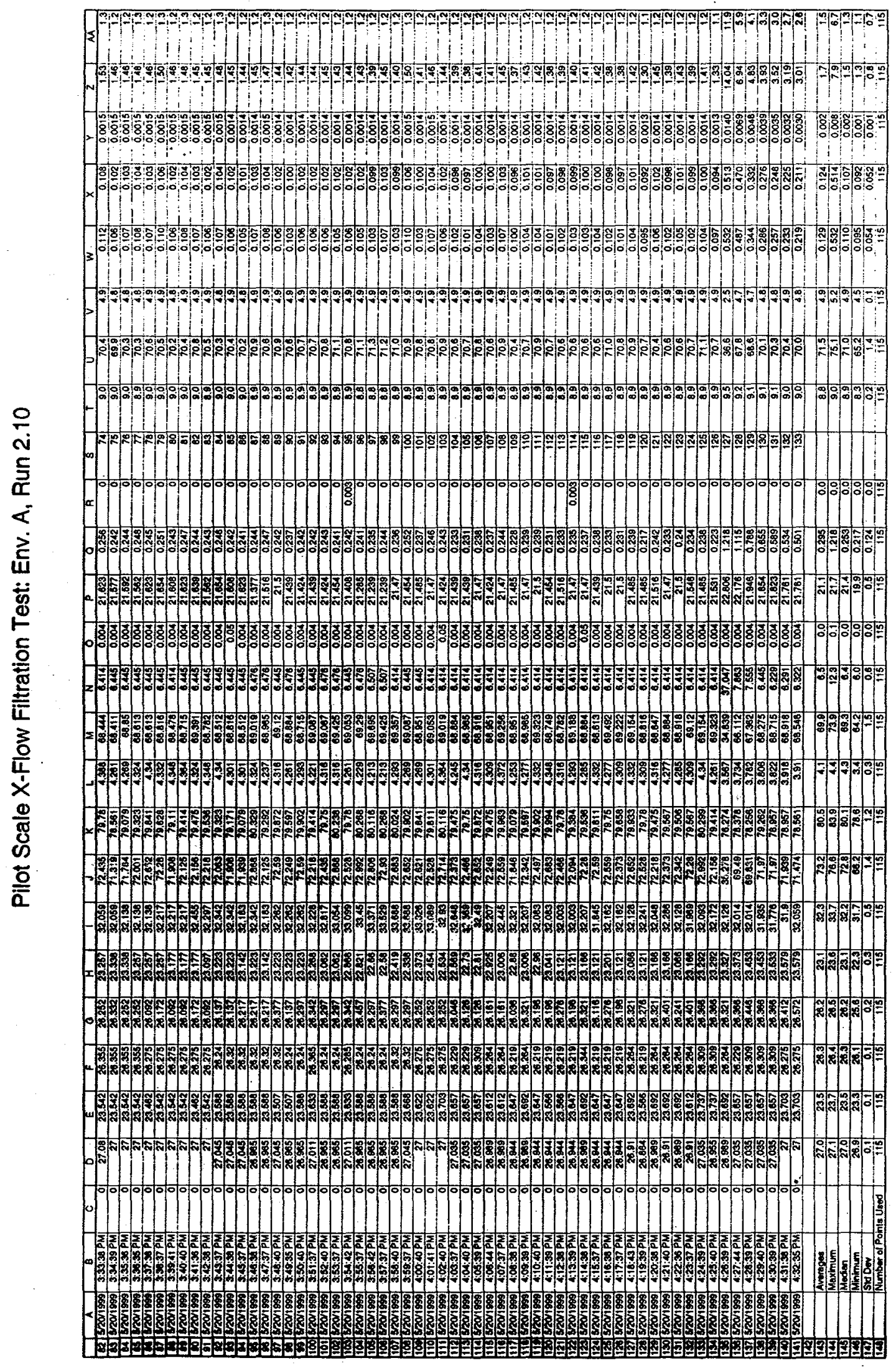



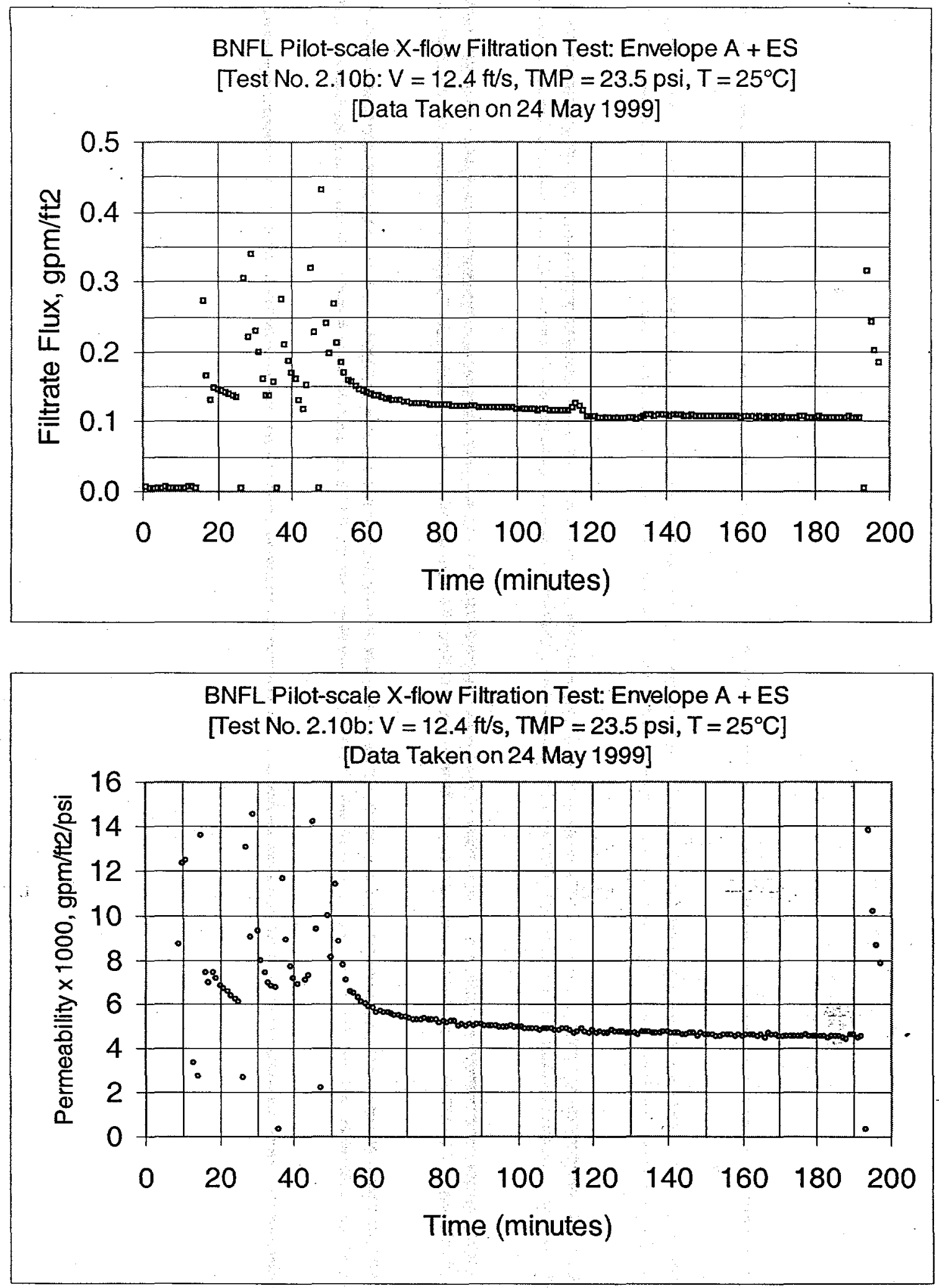

Figure B11: Test Run 2.10b, 0.5 wt\% Insoluble Solids Concentration 
Pilot scale X-flow: EnvA+ES Page 100 of 226

BNF-003-98-0221

Revision 0

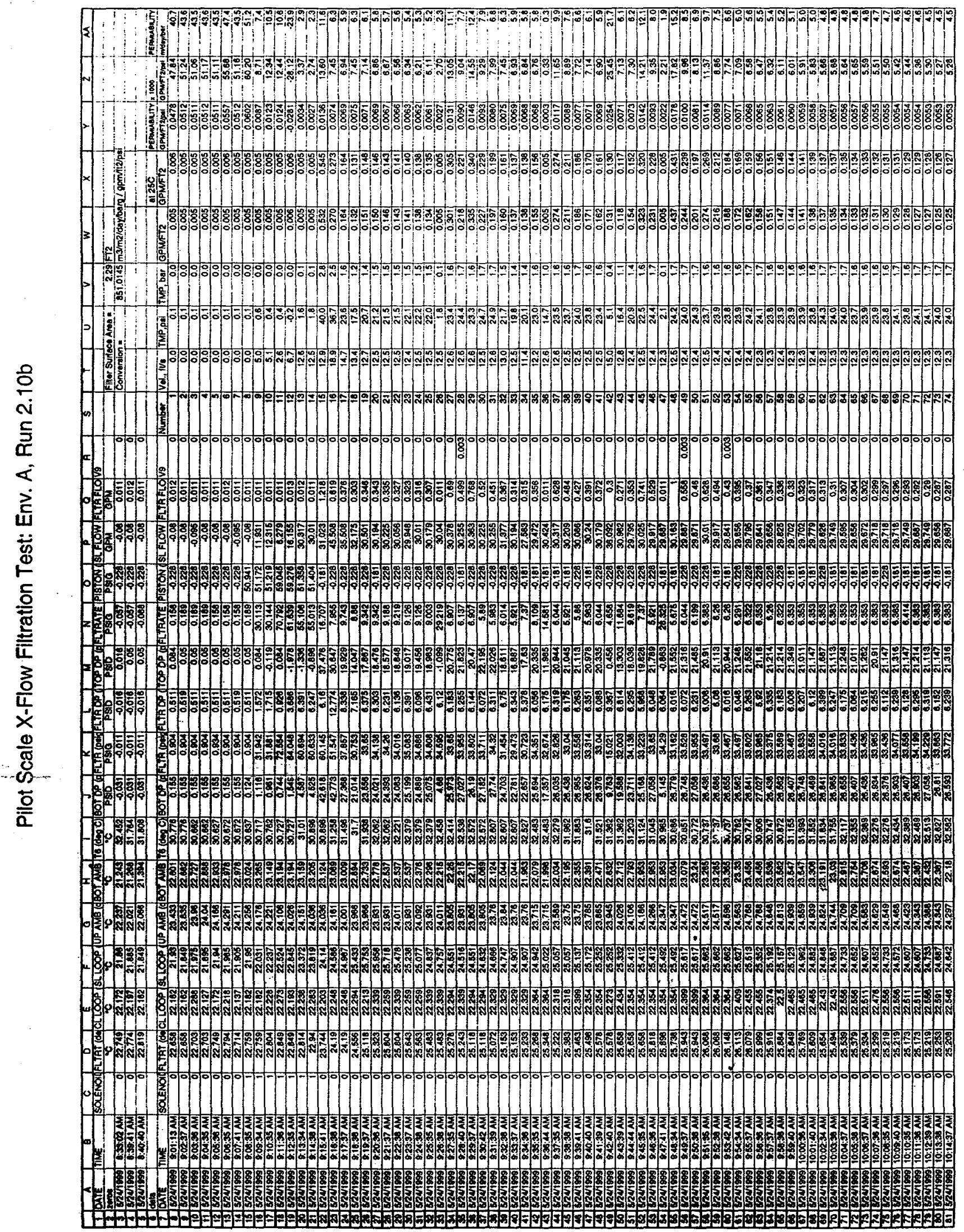

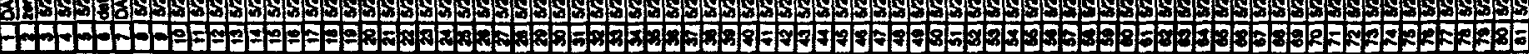




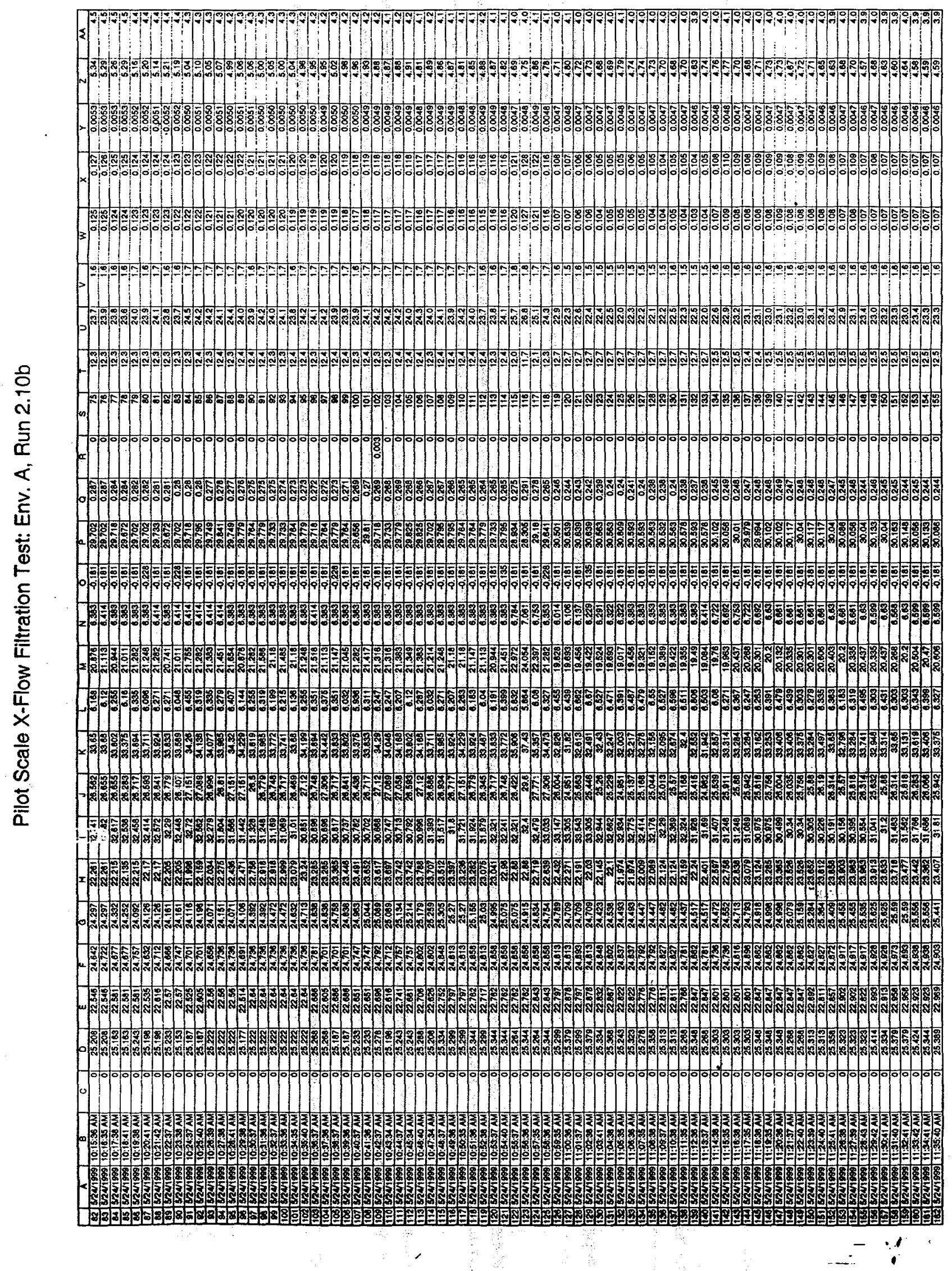




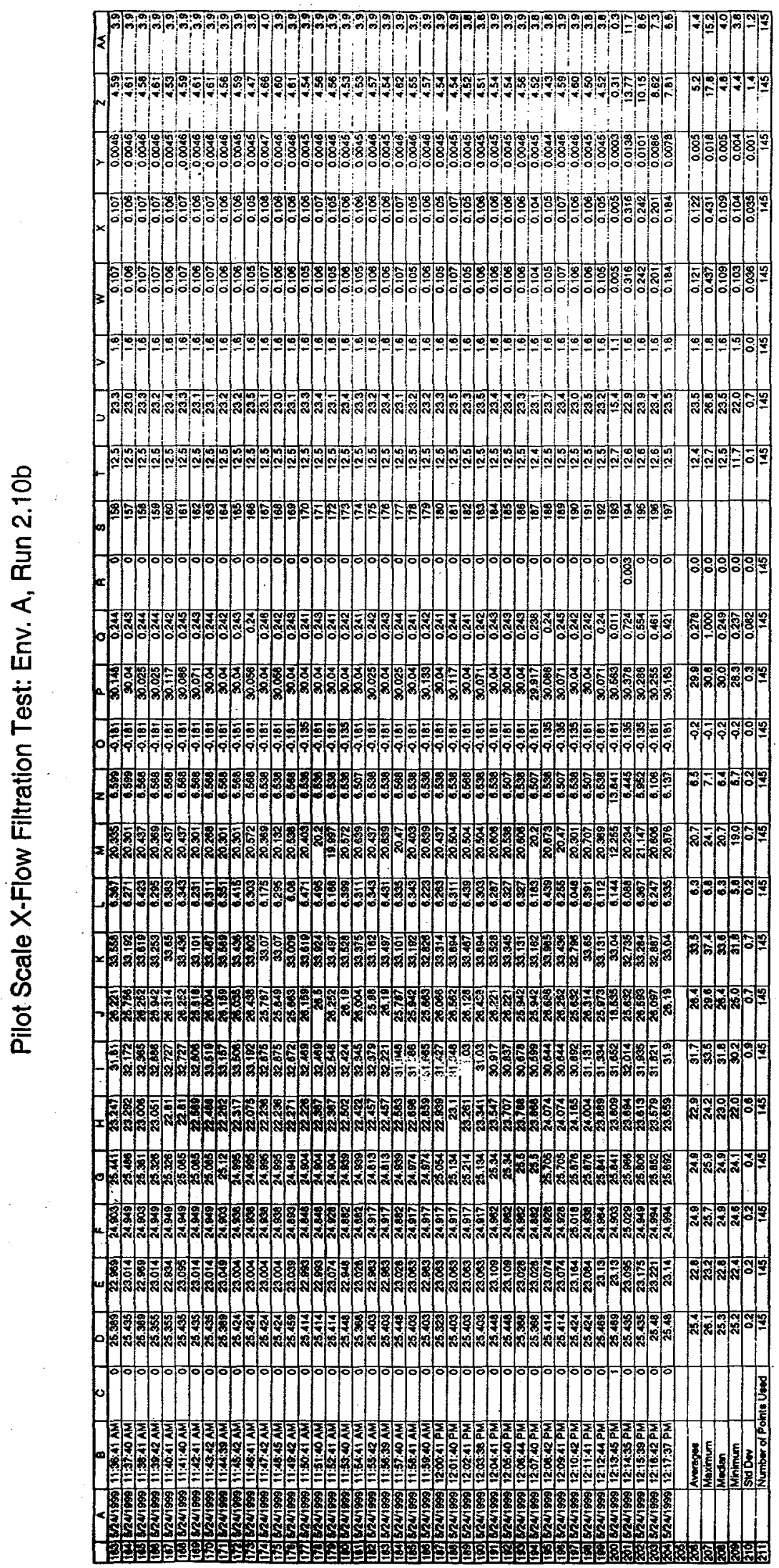



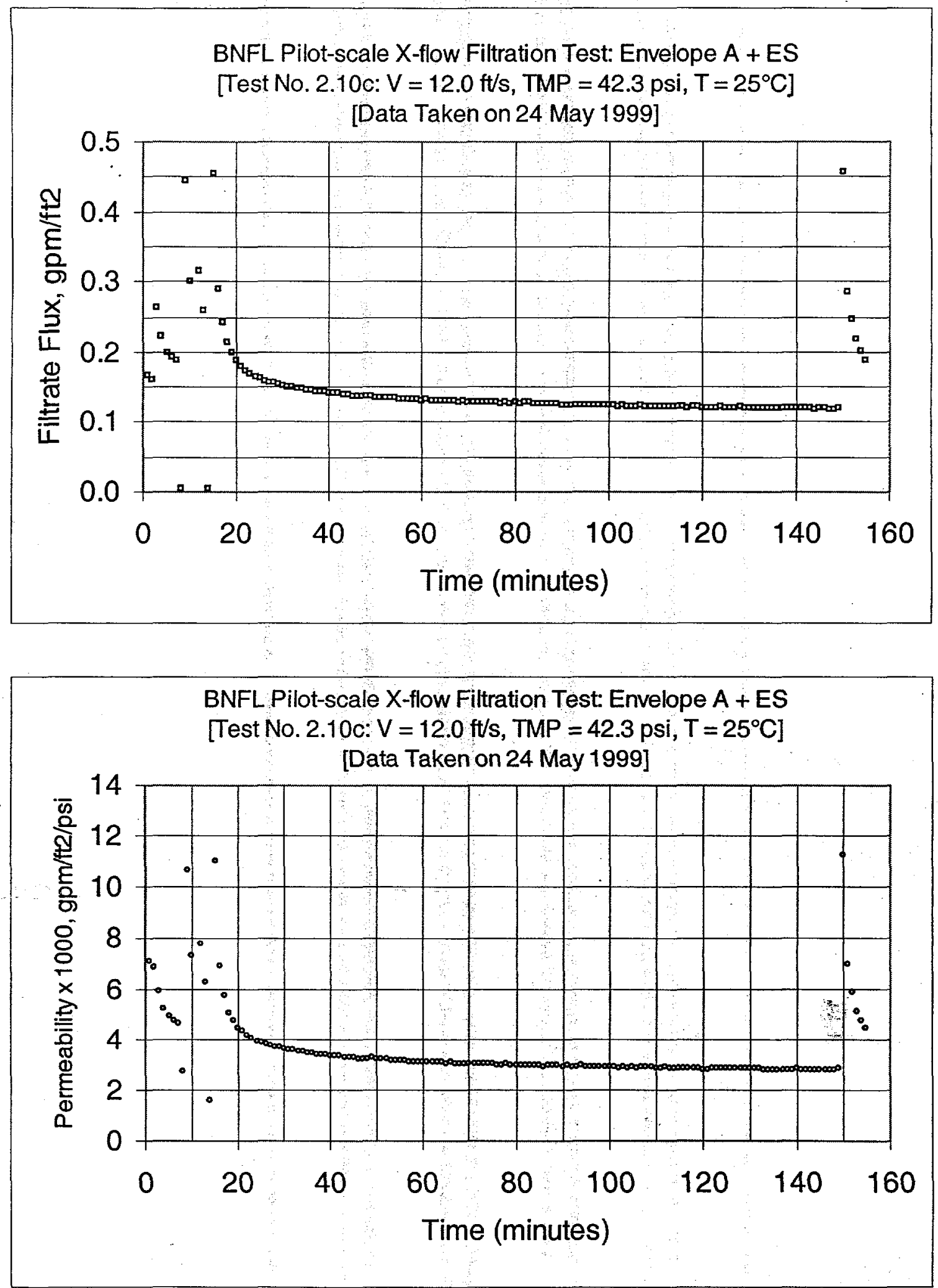

Figure B12: Test Run 2.10c, 0.5 wt\% Insoluble Solids Concentration 


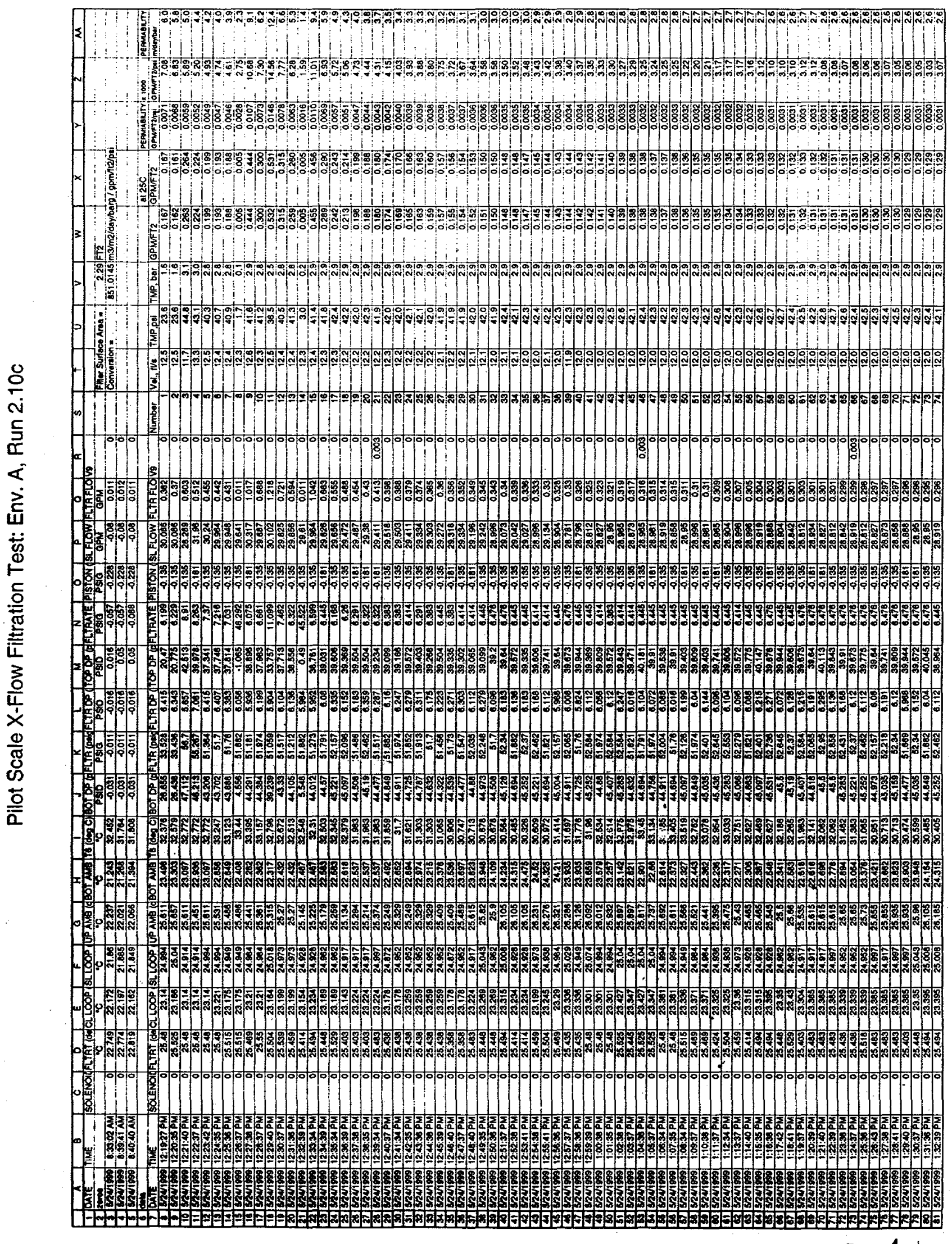




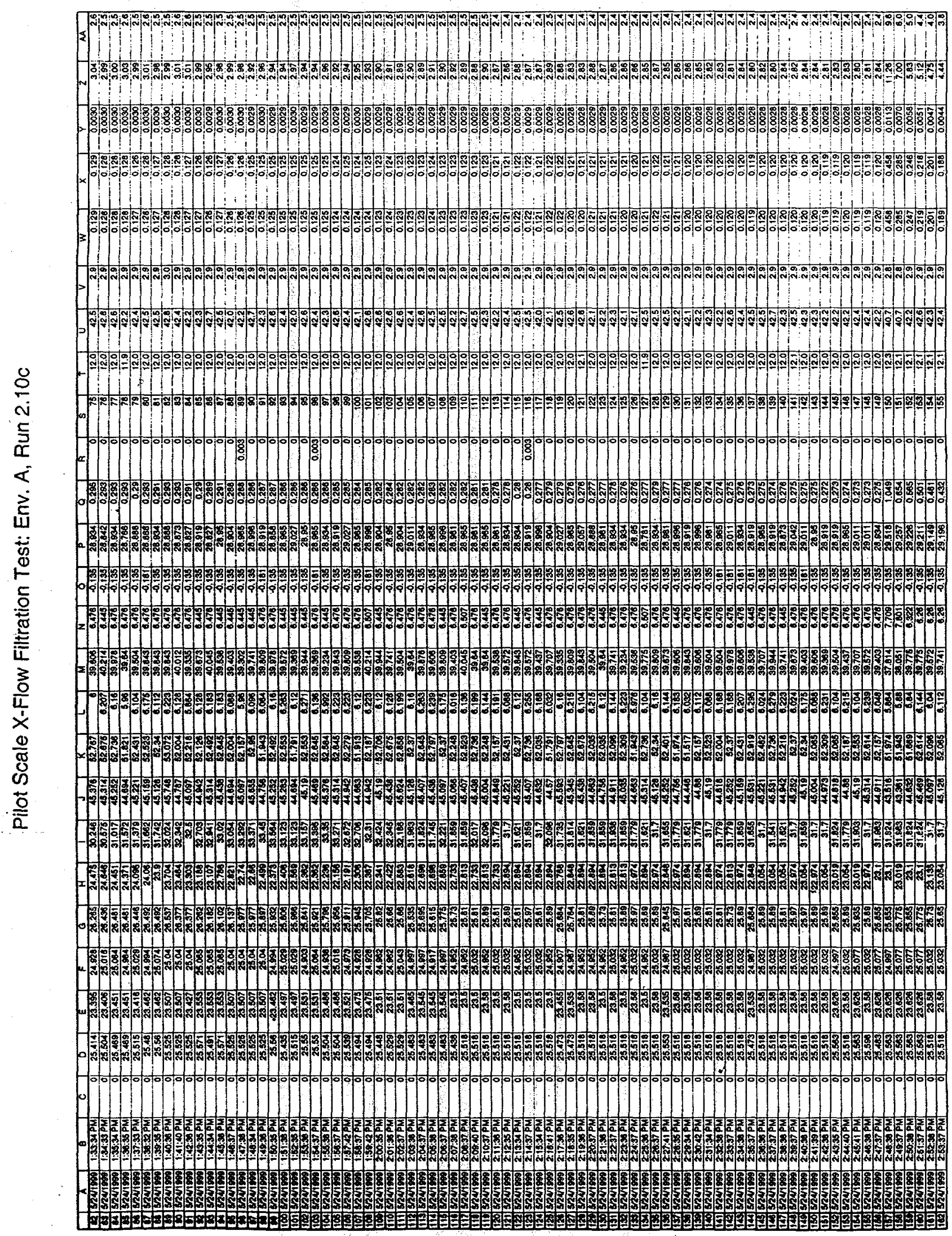


Pilot scale X-flow: EnvA+ES

Page 106 of 226

BNF-003-98-0221

Revision 0

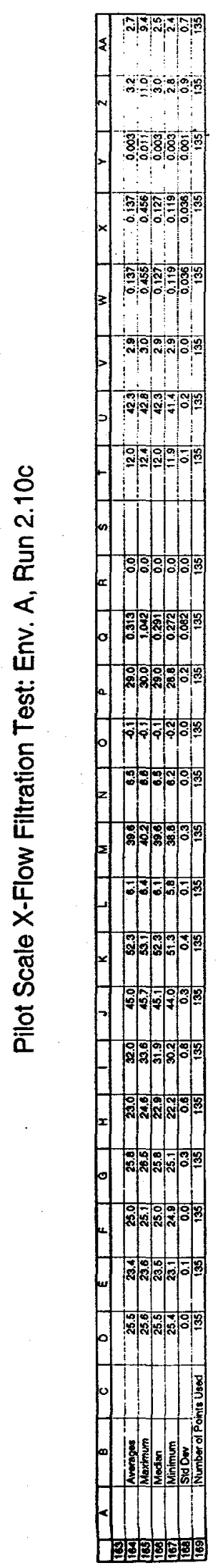



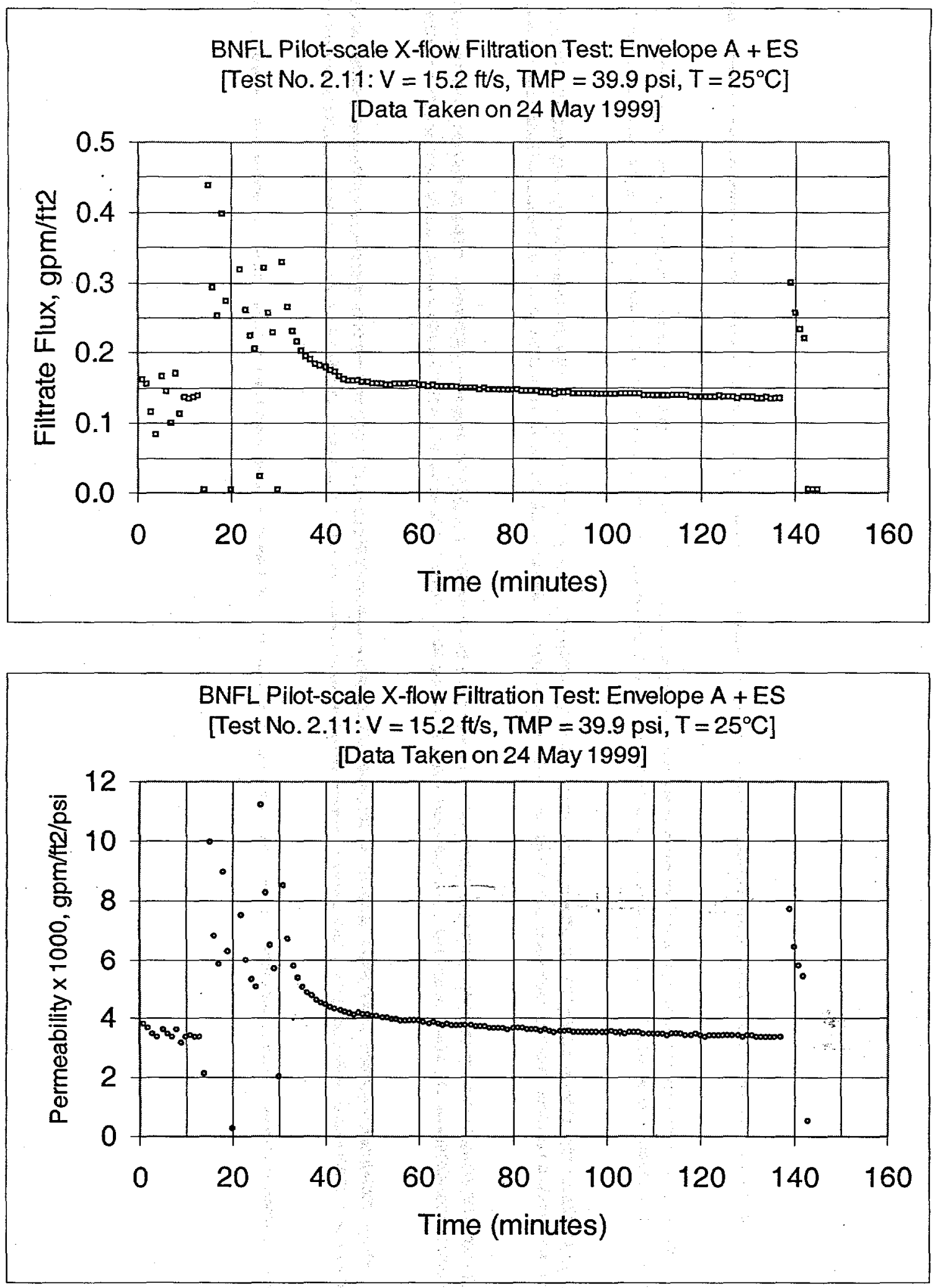

Figure B13: Test Run 2.11, 0.5 wt\% Insoluble Solids Concentration 


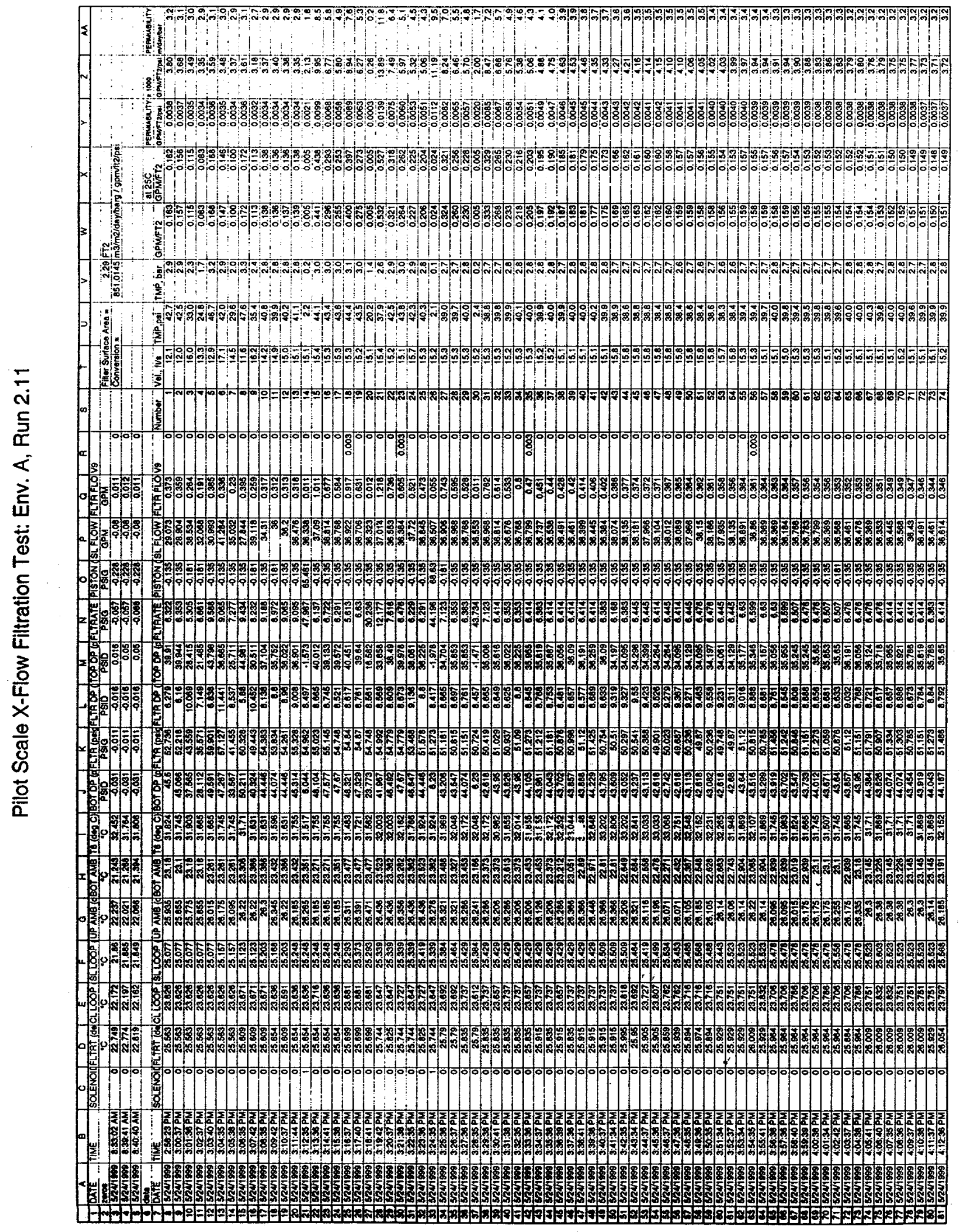




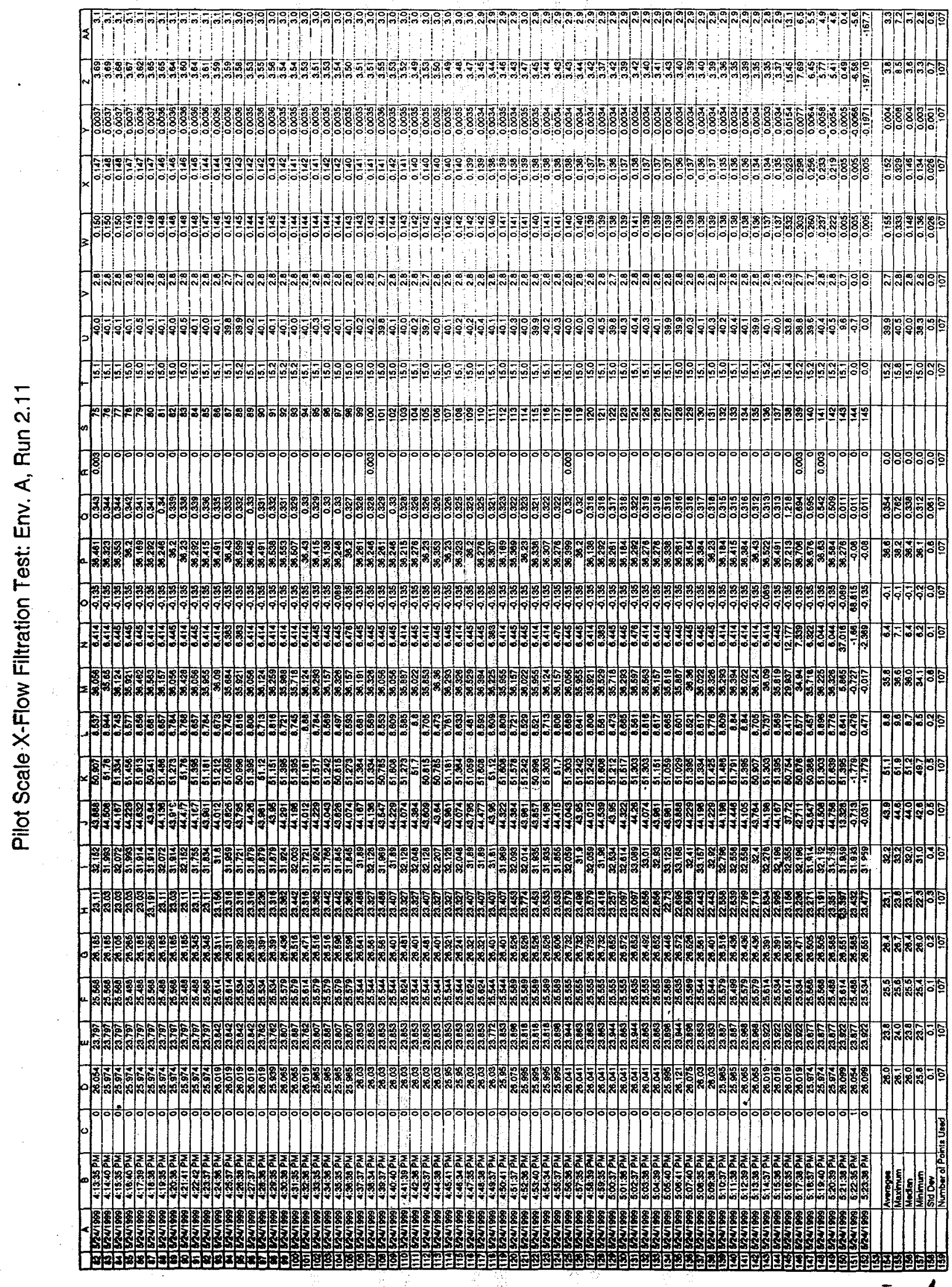



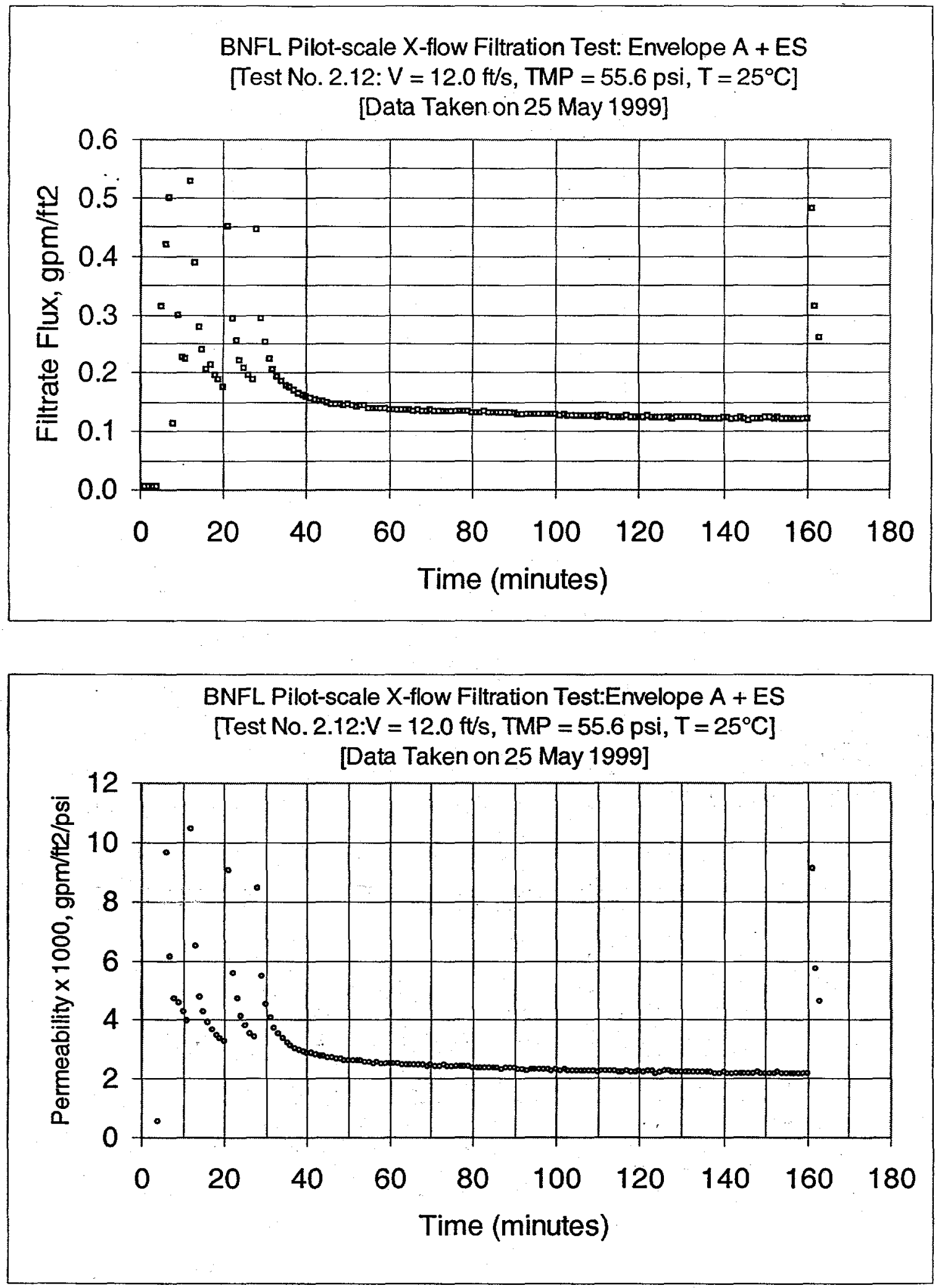

Figure B14: Test Run 2.12, 0.5 wt\% Insoluble Solids Concentration 
Pilot scale X-flow: EnvA+ES Page 111 of 226

BNF-003-98-0221

Revision 0

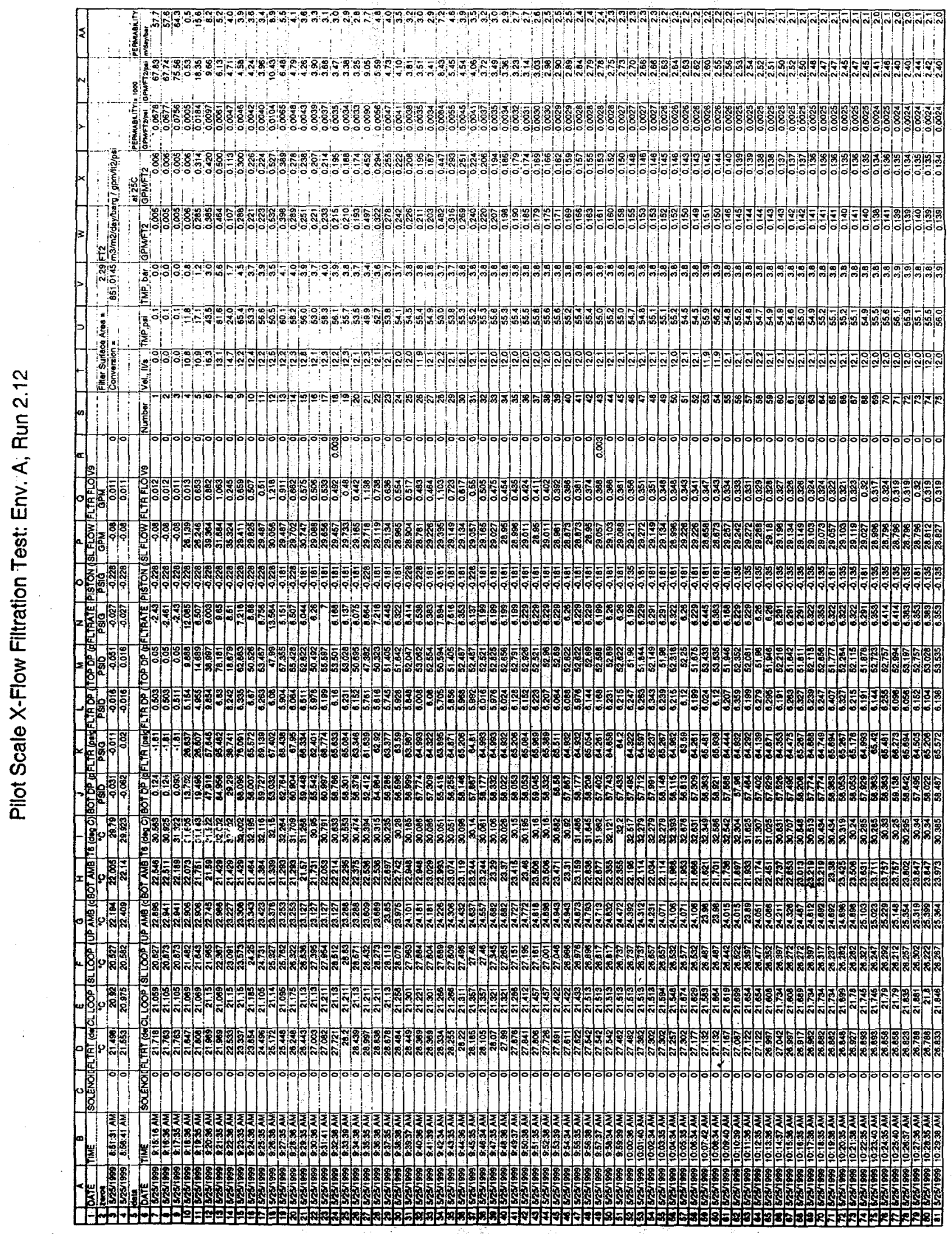




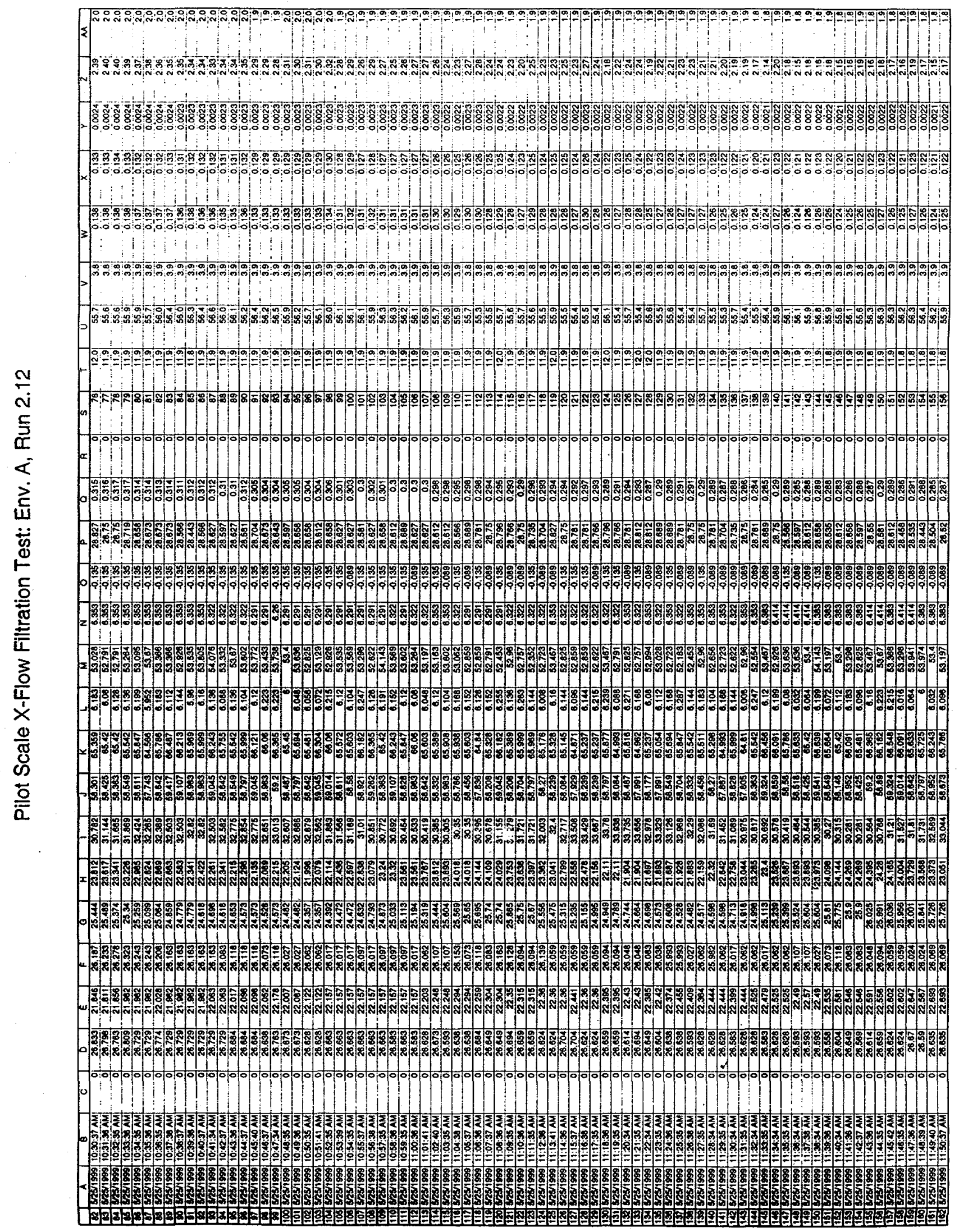




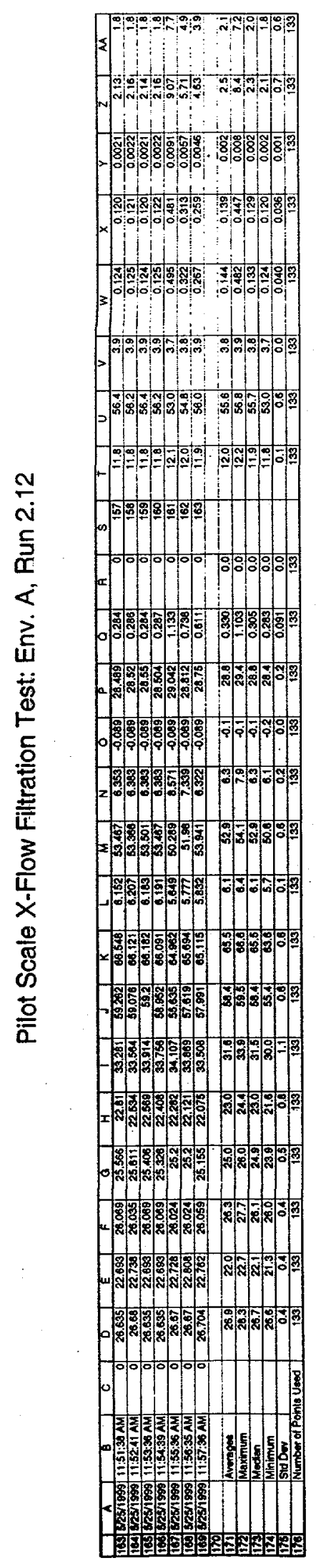



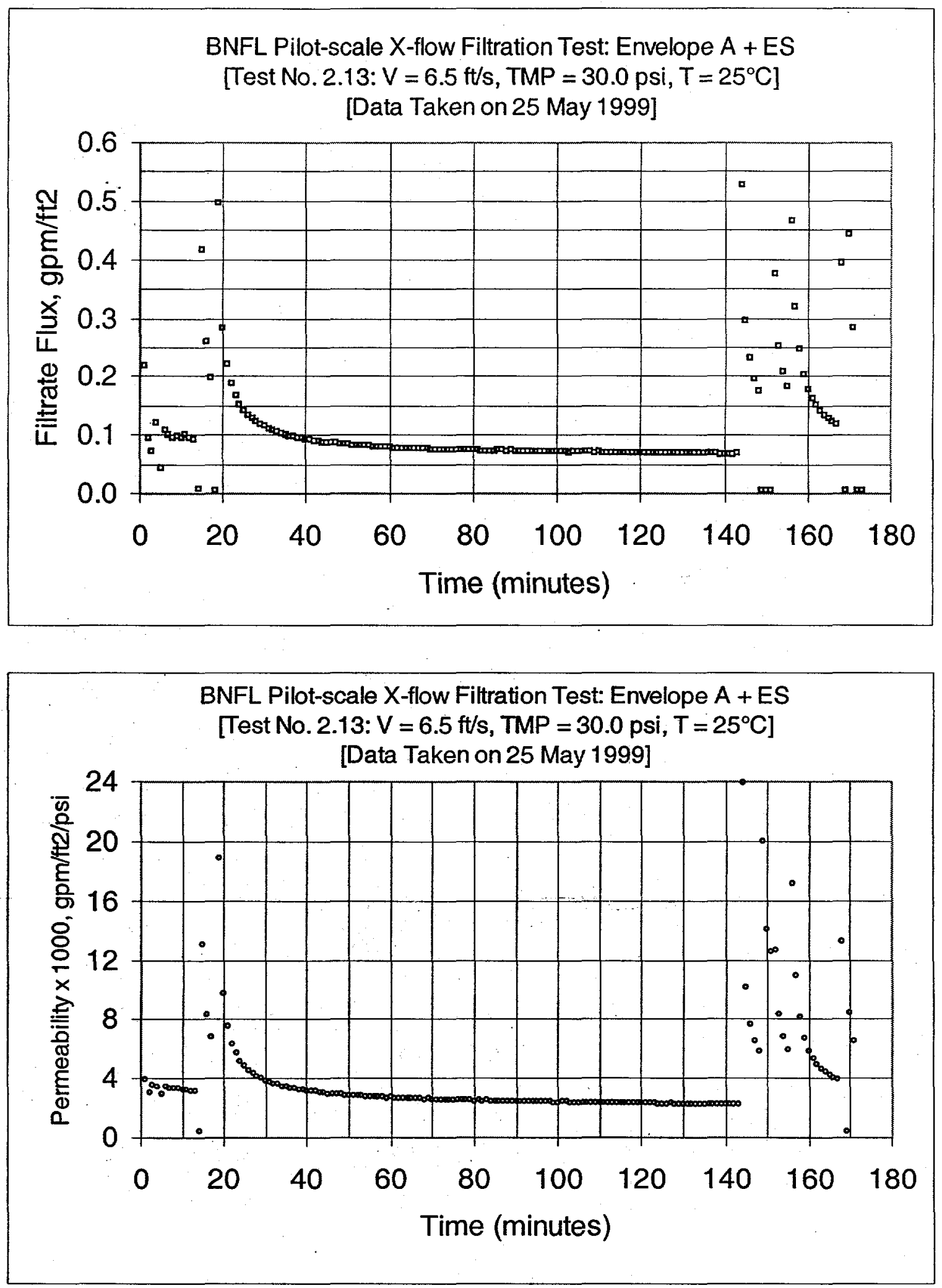

Figure B15: Test Run 2.13, 0.5 wt\% Insoluble Solids Concentration 


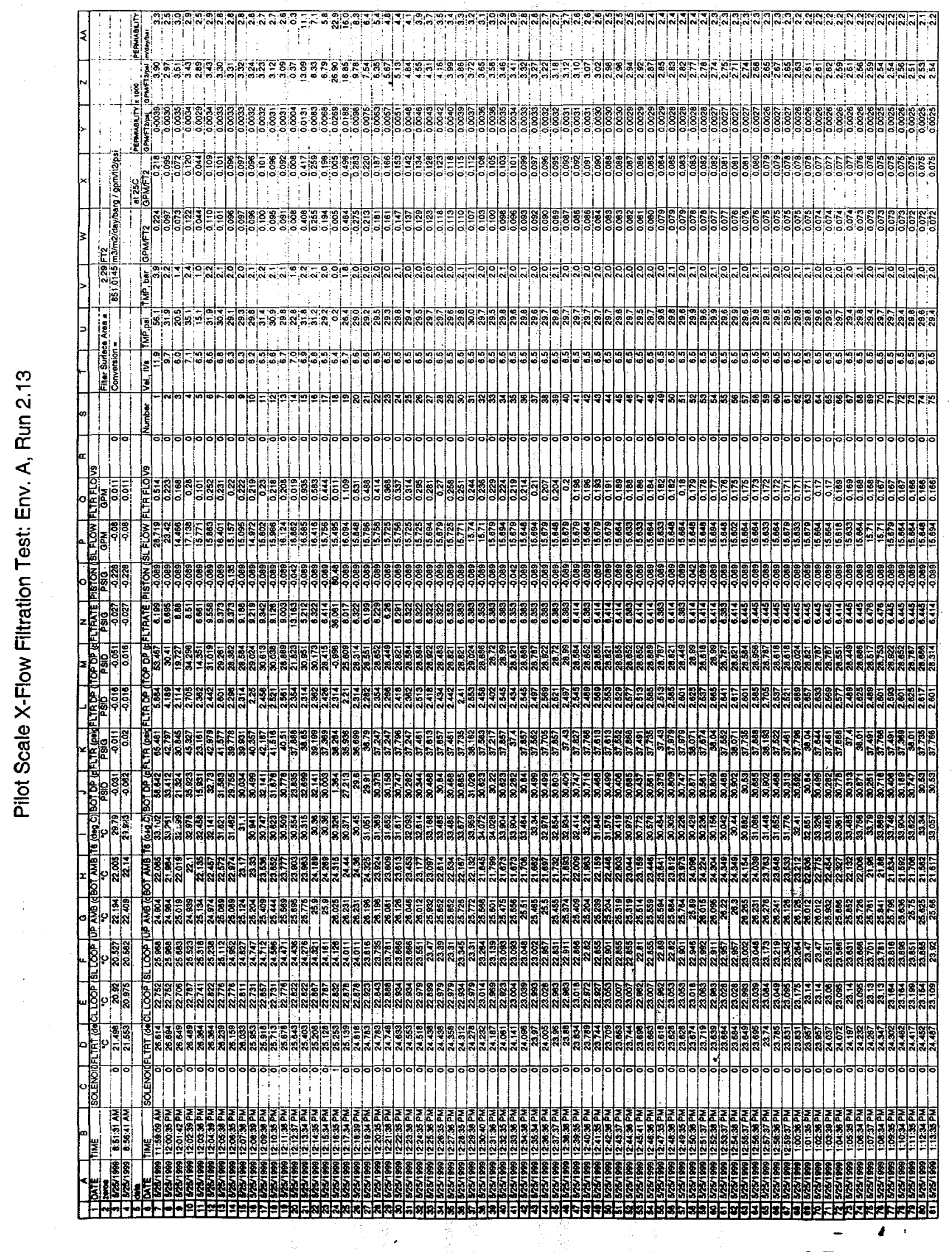




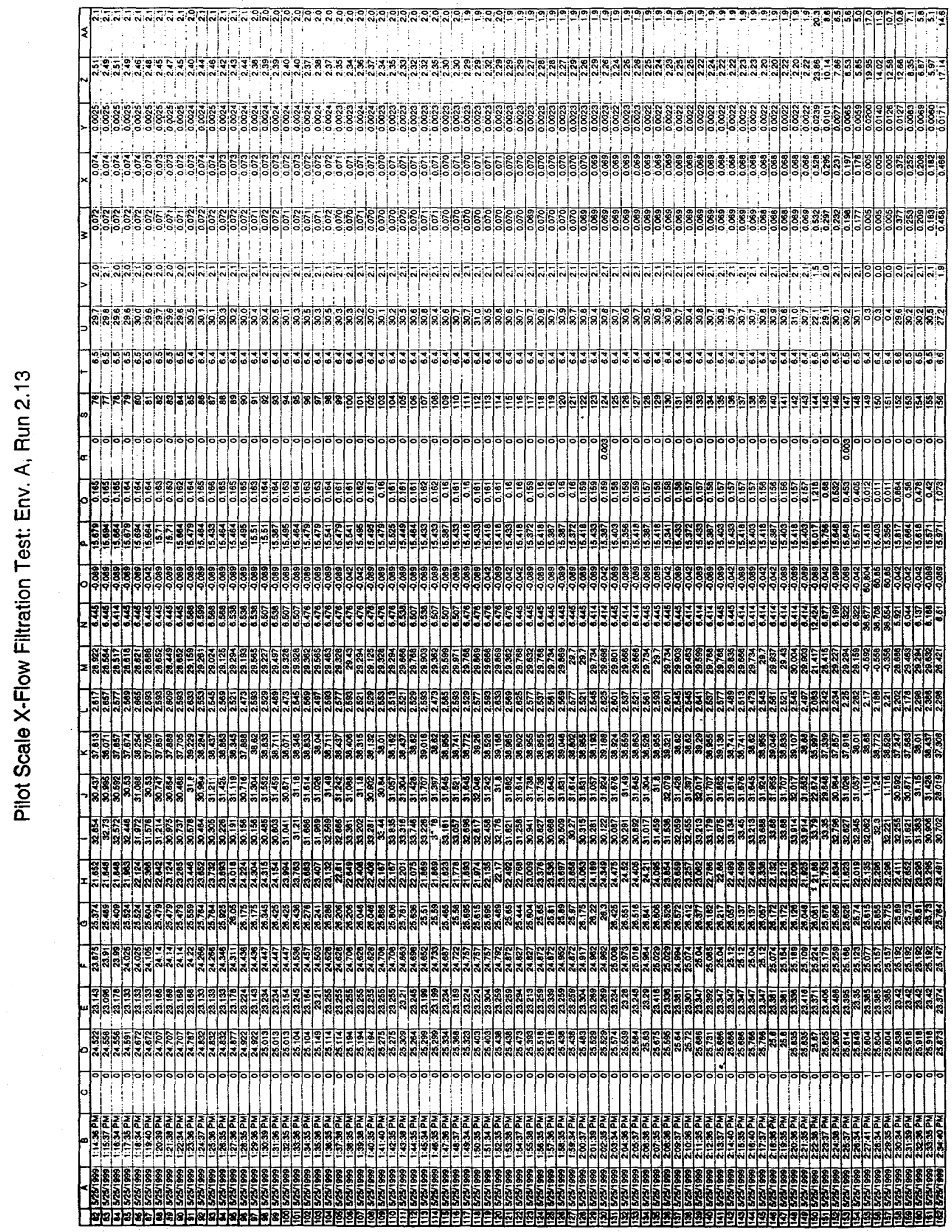




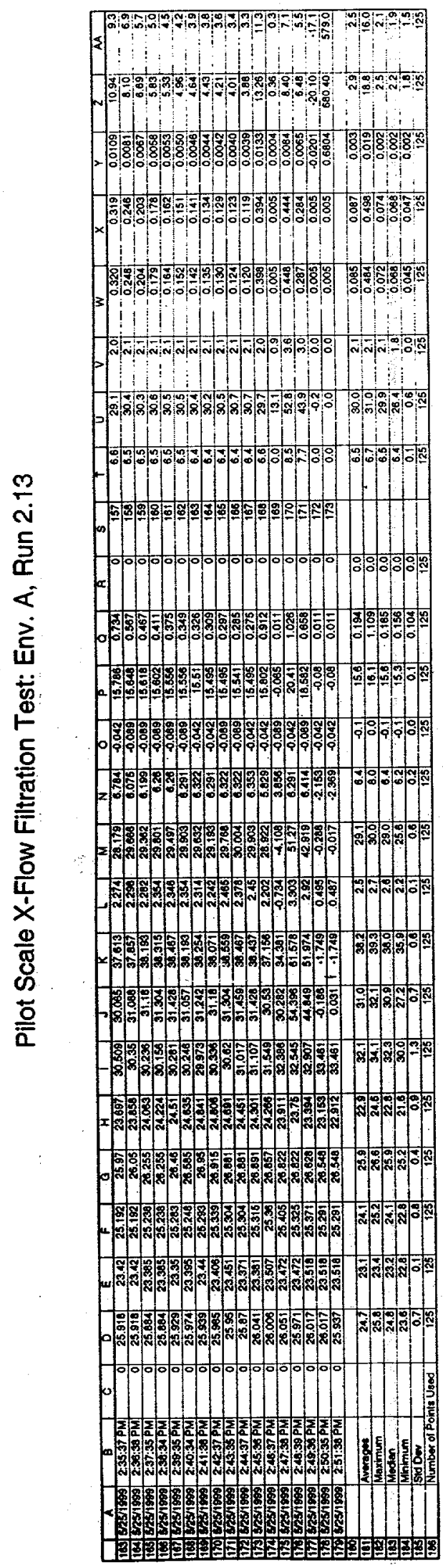



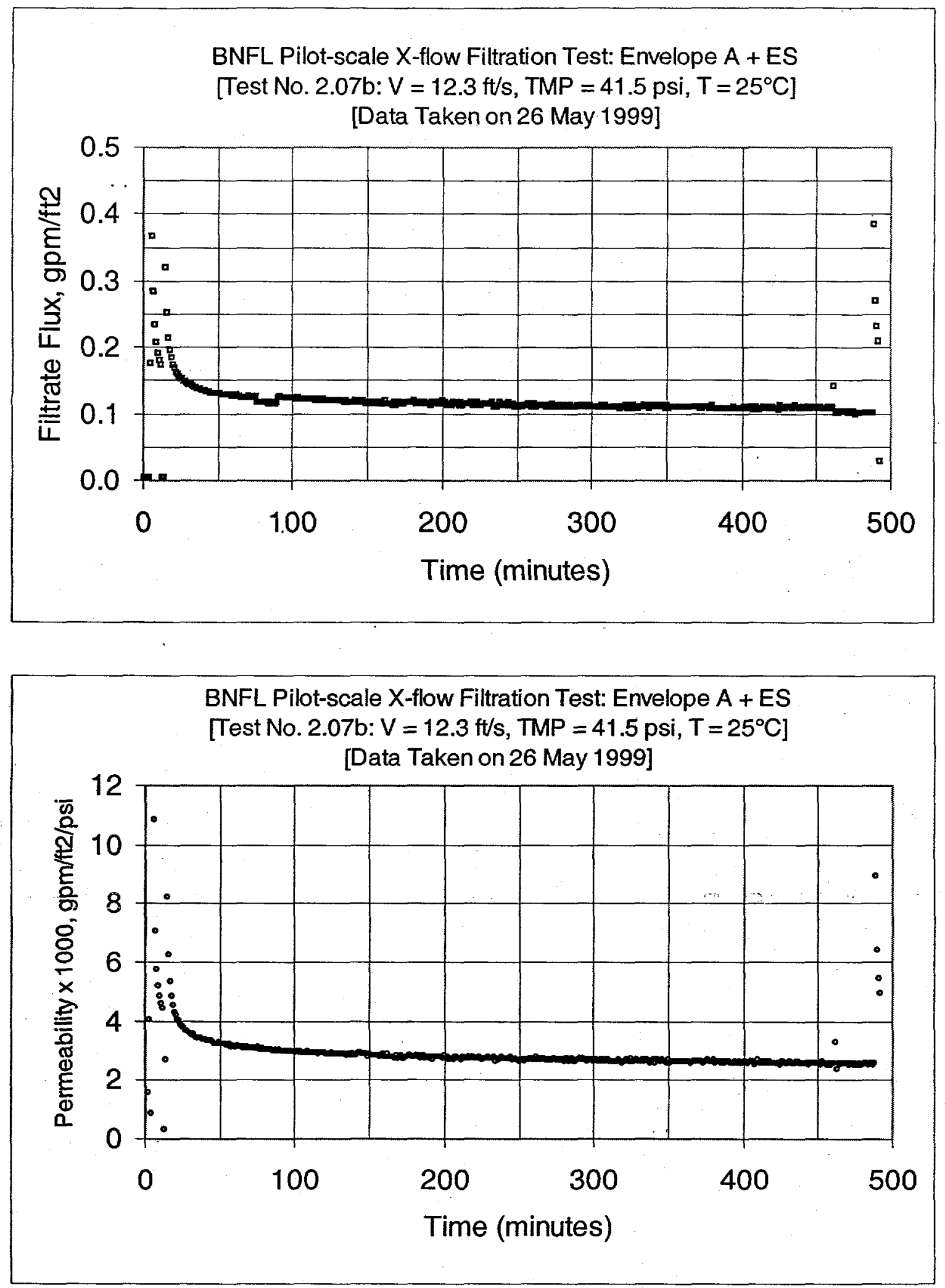

Figure B16: Test Run 2.07b, 0.5 wt\% Insoluble Solids Concentration 
Pilot scale X-flow: EnvA+ES $\quad$ Page 119 of 226

BNF-003-98-0221

Revision 0

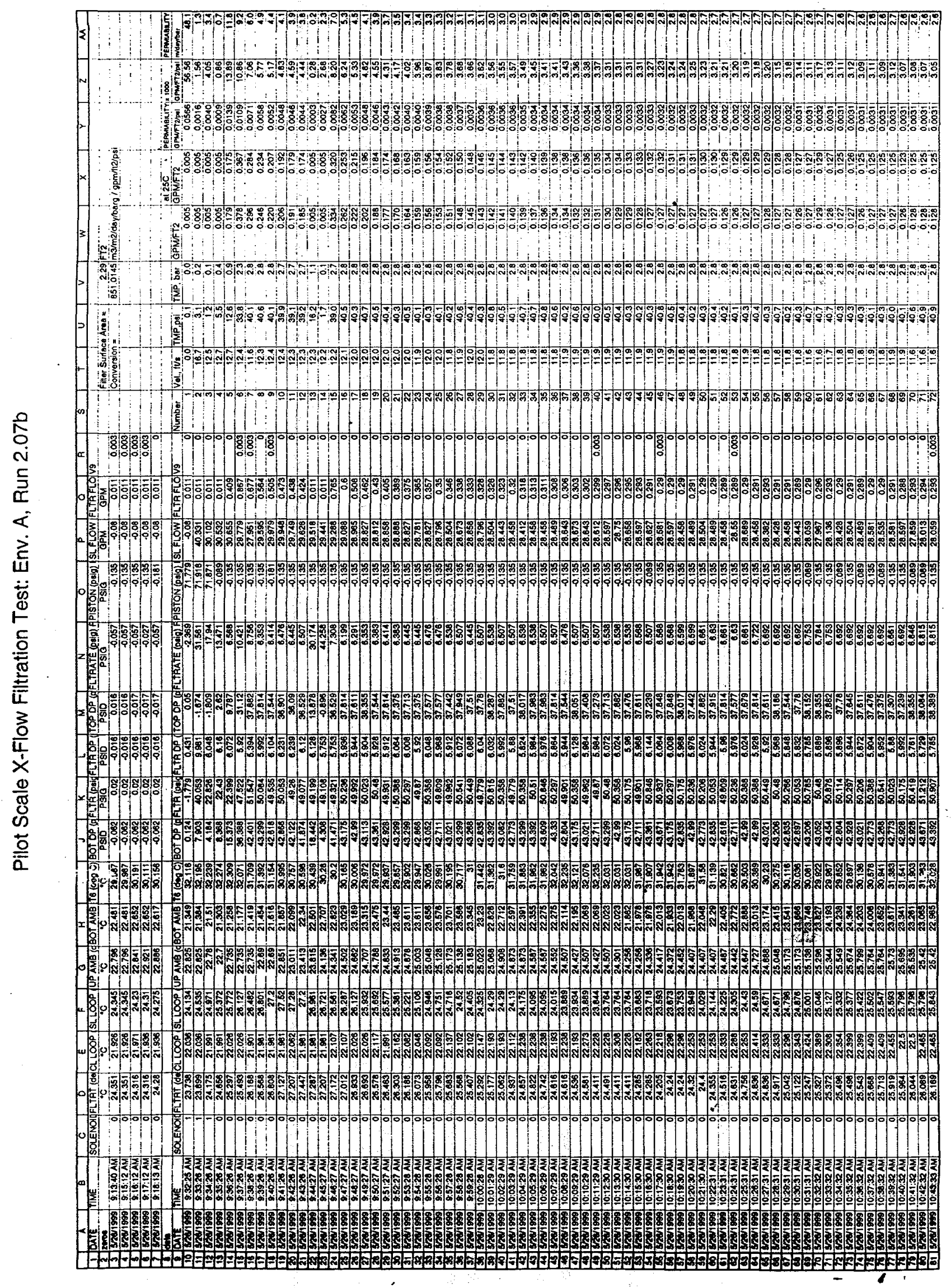




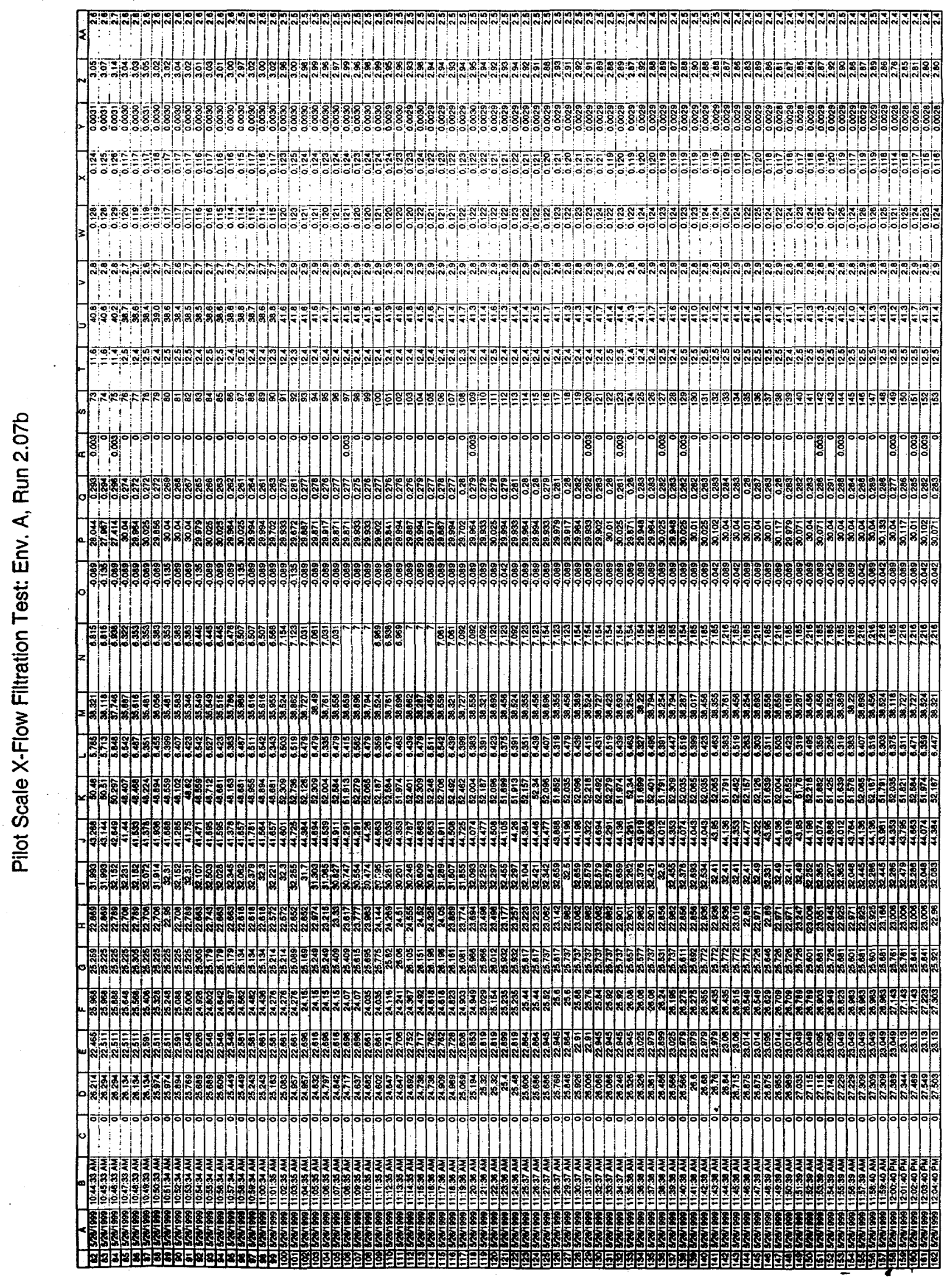




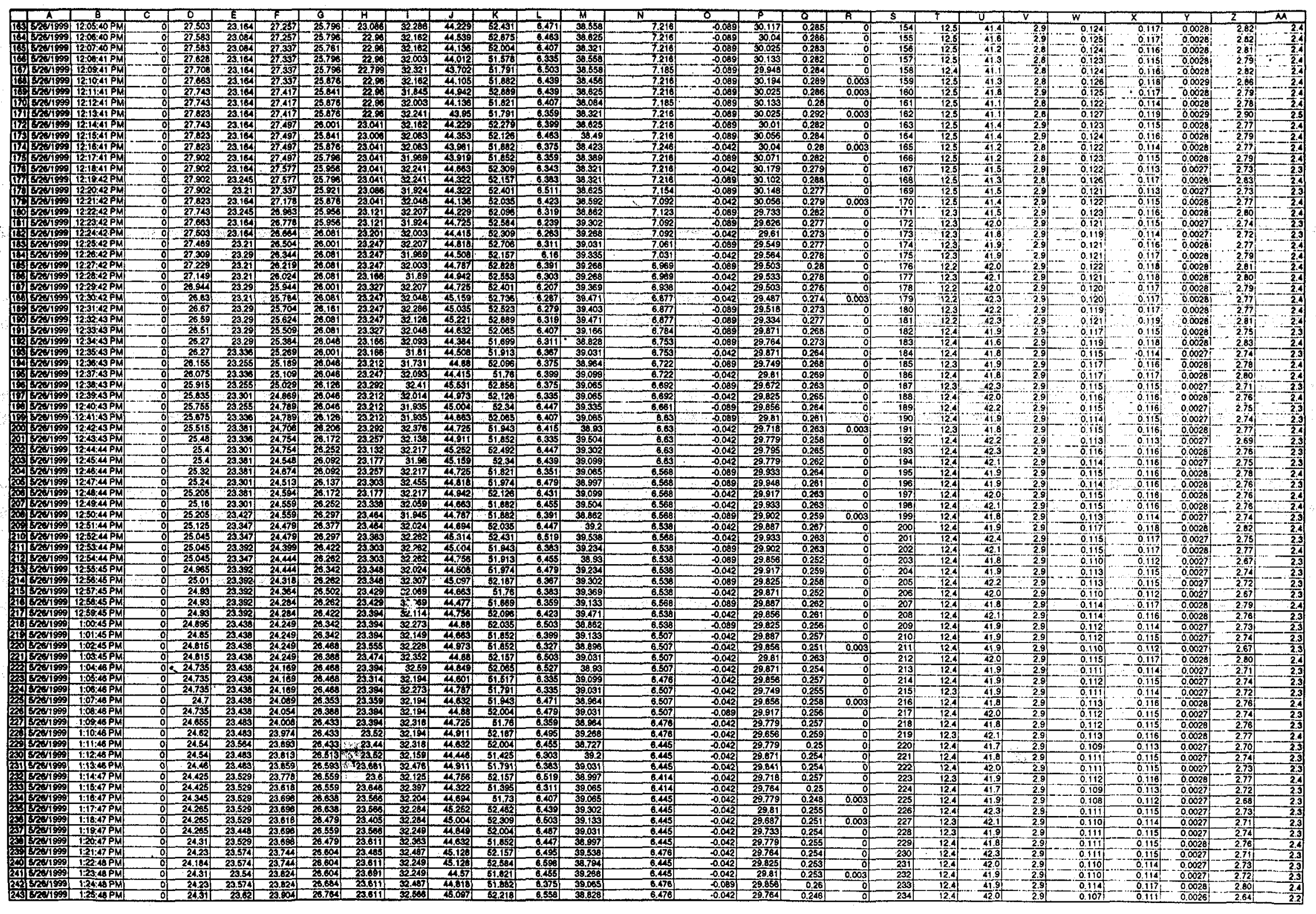




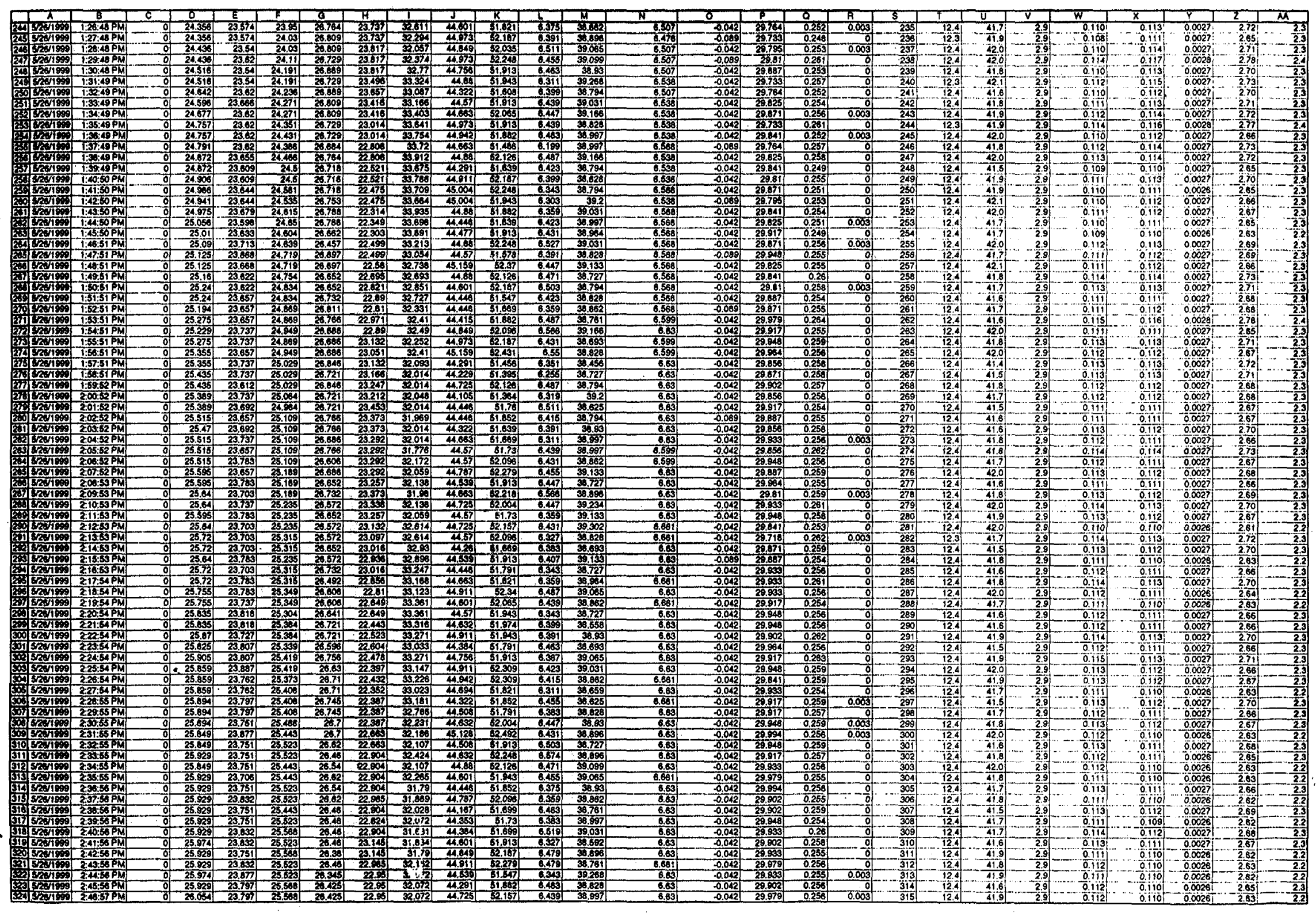




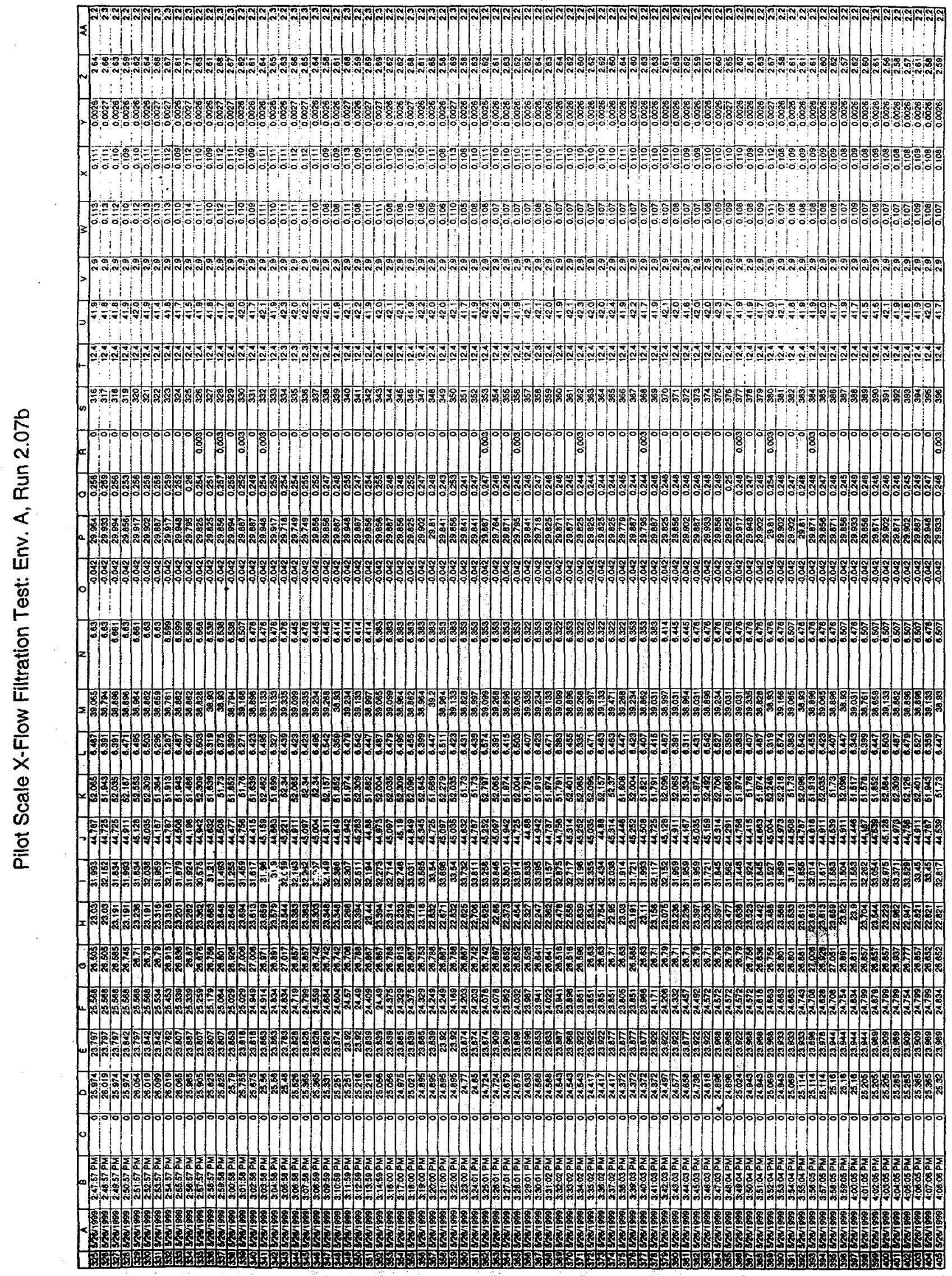




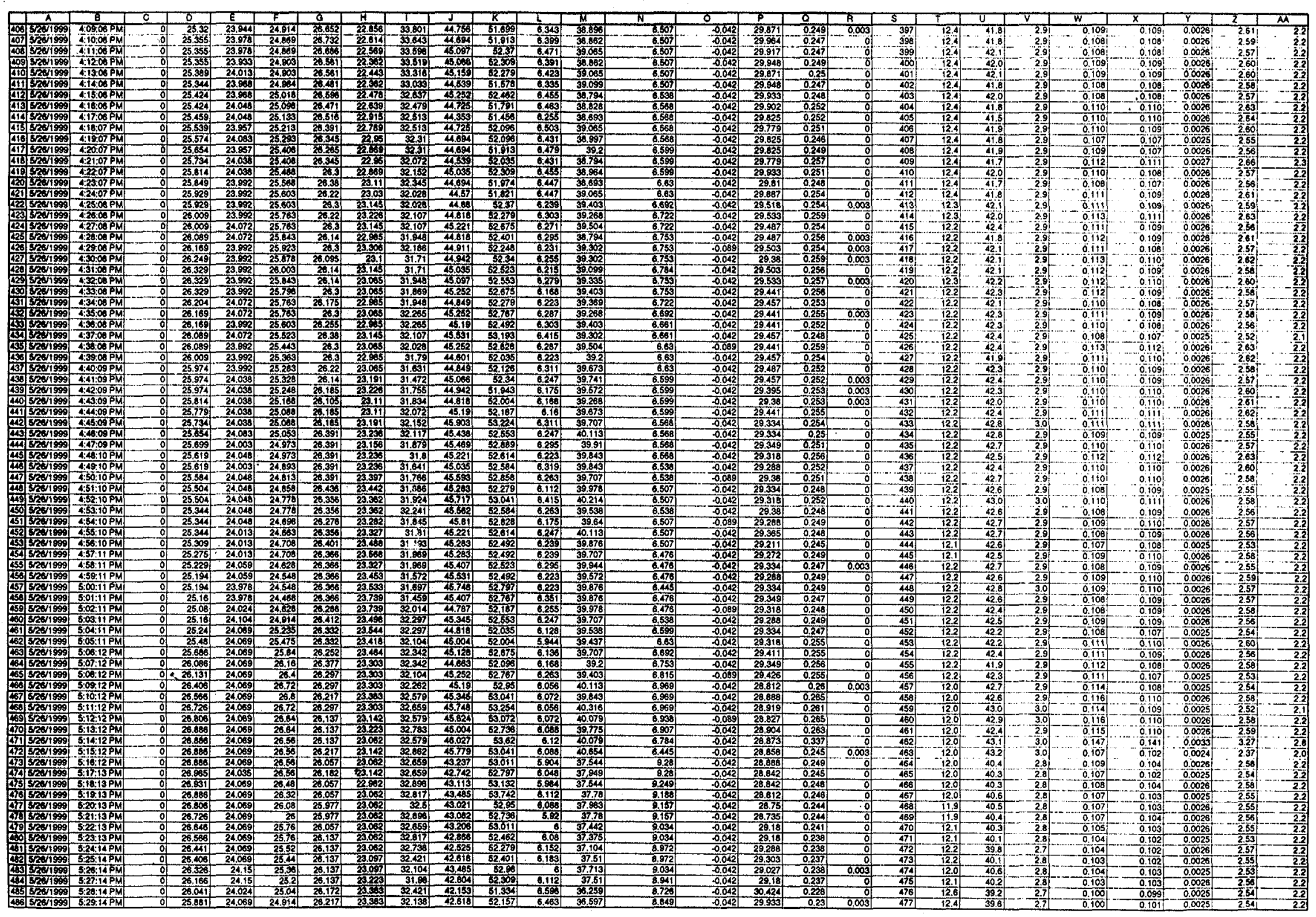


Pilot Scale X-Flow Filtration Test: Env. A, Run 2.07b

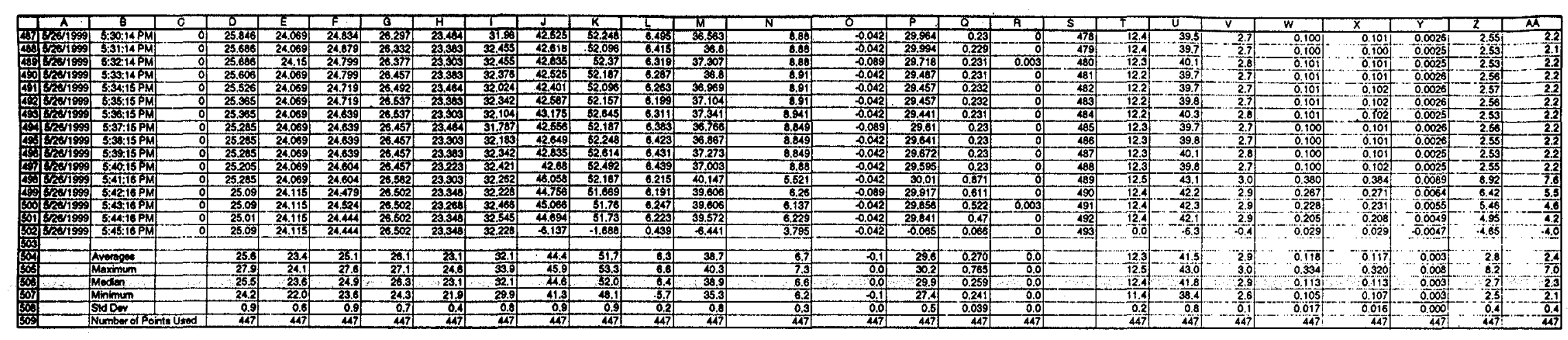



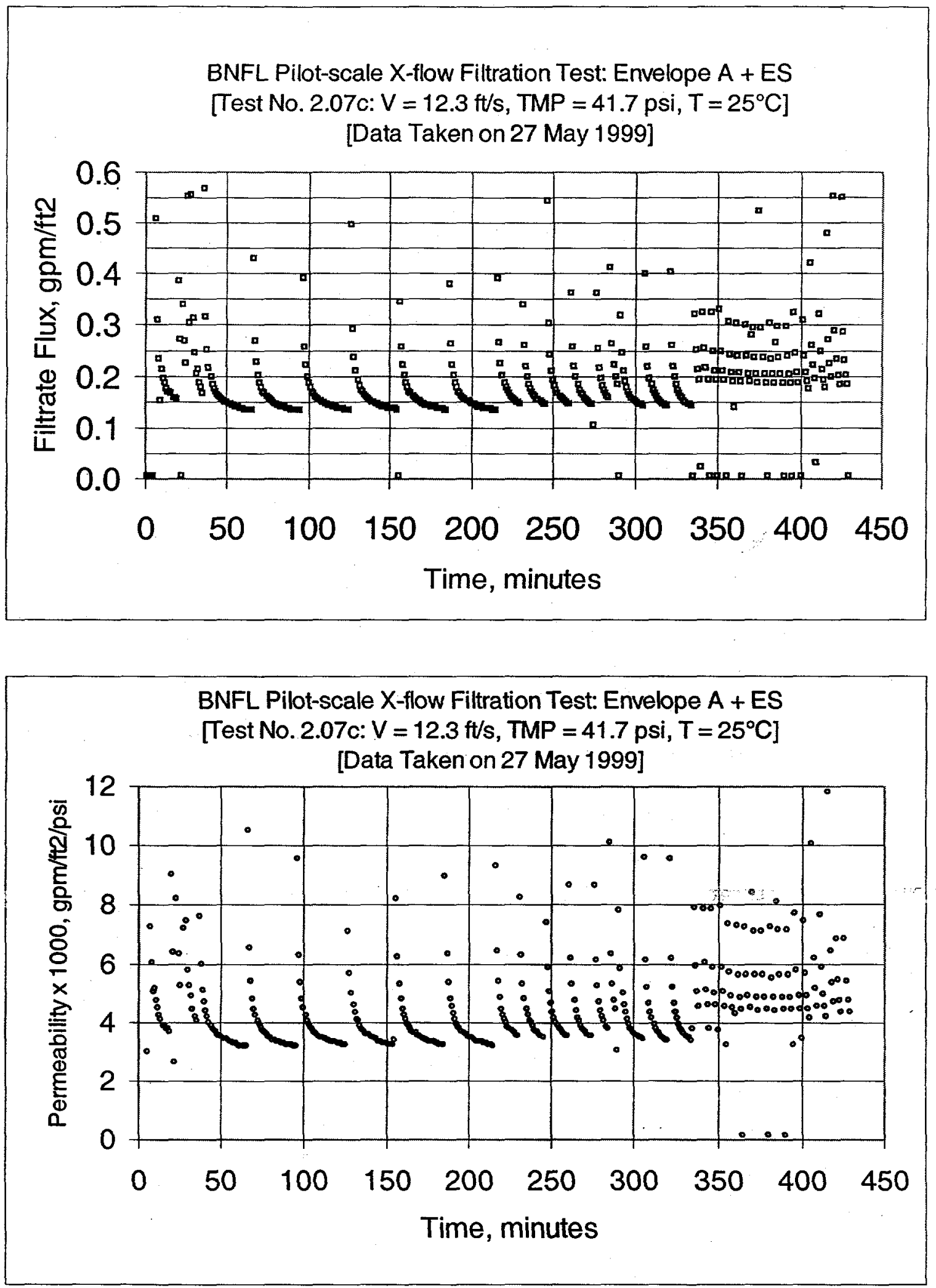

Figure B17a: Test Run 2.07c, 0.5 wt\% Insoluble Solids Concentration (Entire Run) 

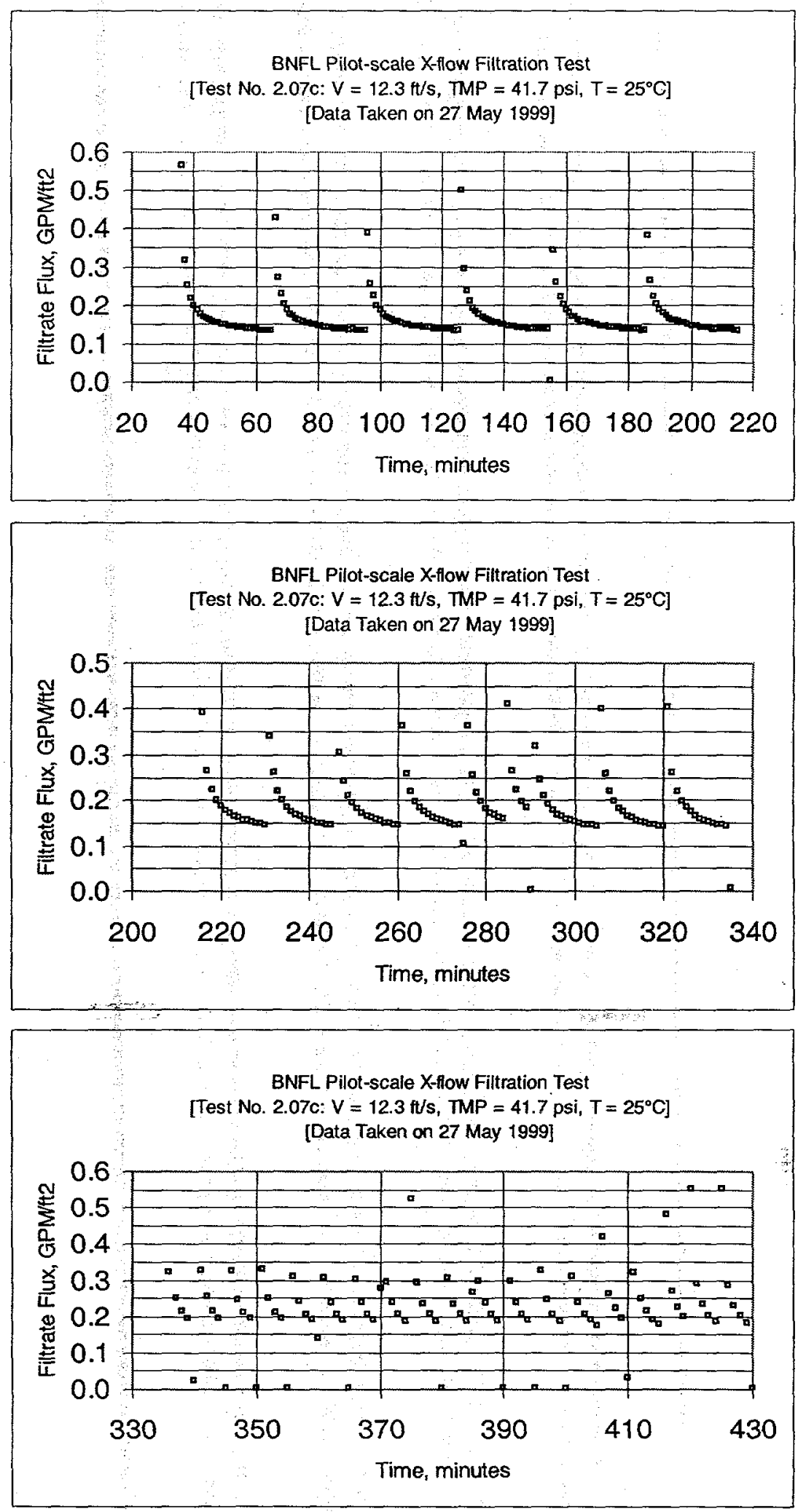

Figure B17b: Test Run 2.07c, 0.5 wt\% Insoluble Solids Concentration (30, 15, \& 5 min. Backpulsing) 


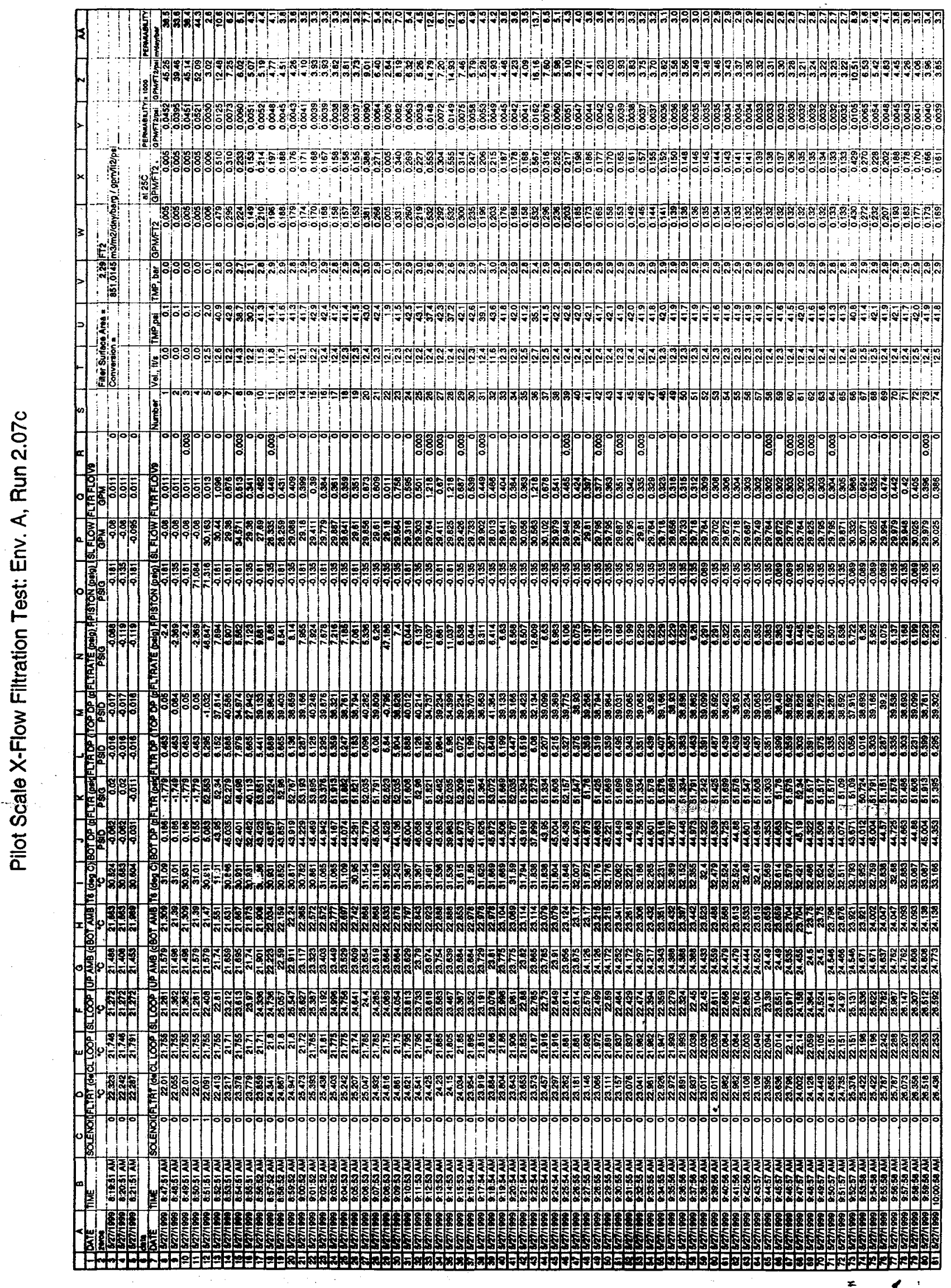




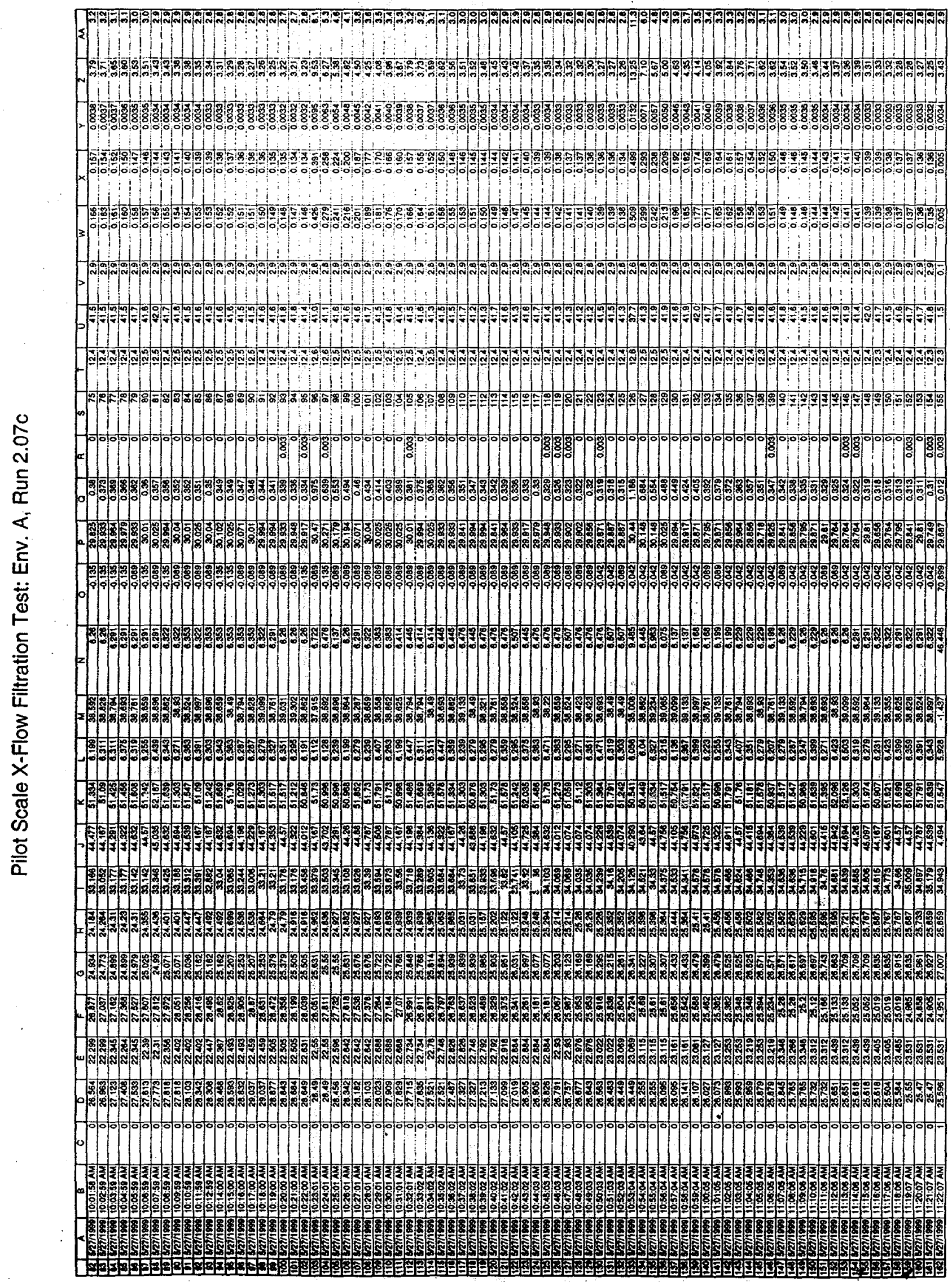


Pilot scale X-flow: EnvA+ES Page 130 of 226

BNF-003-98-0221.

Revision 0

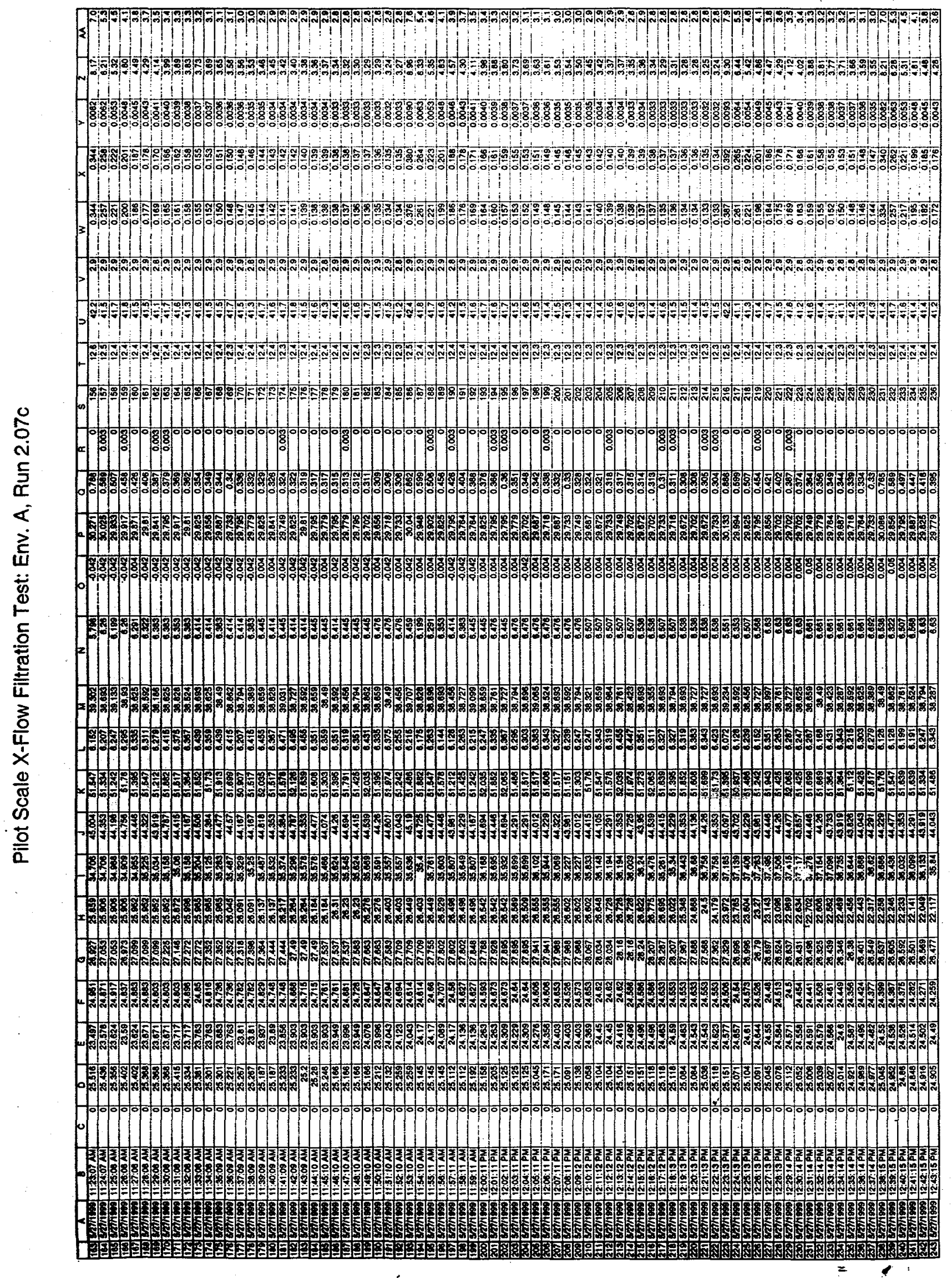




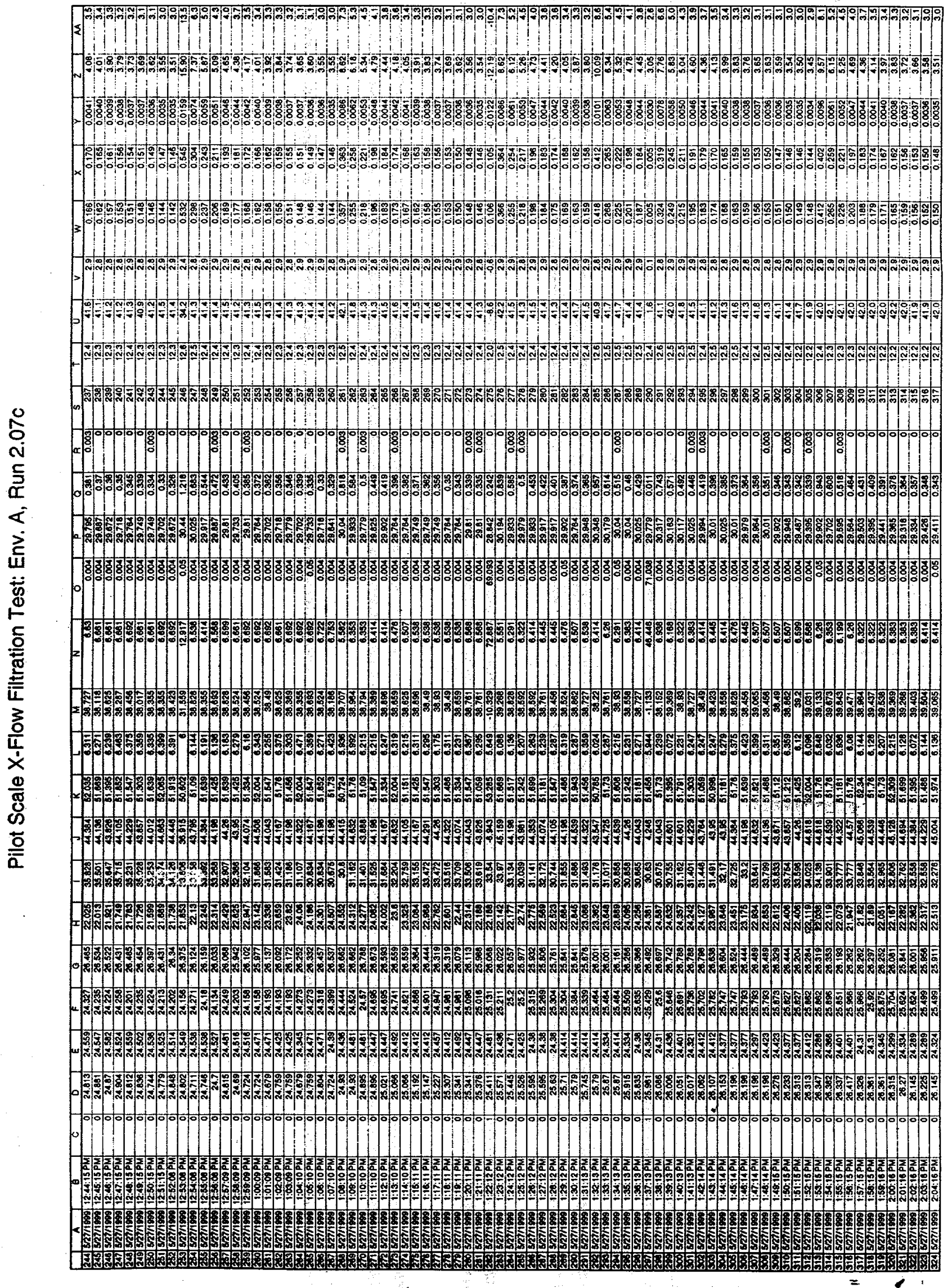




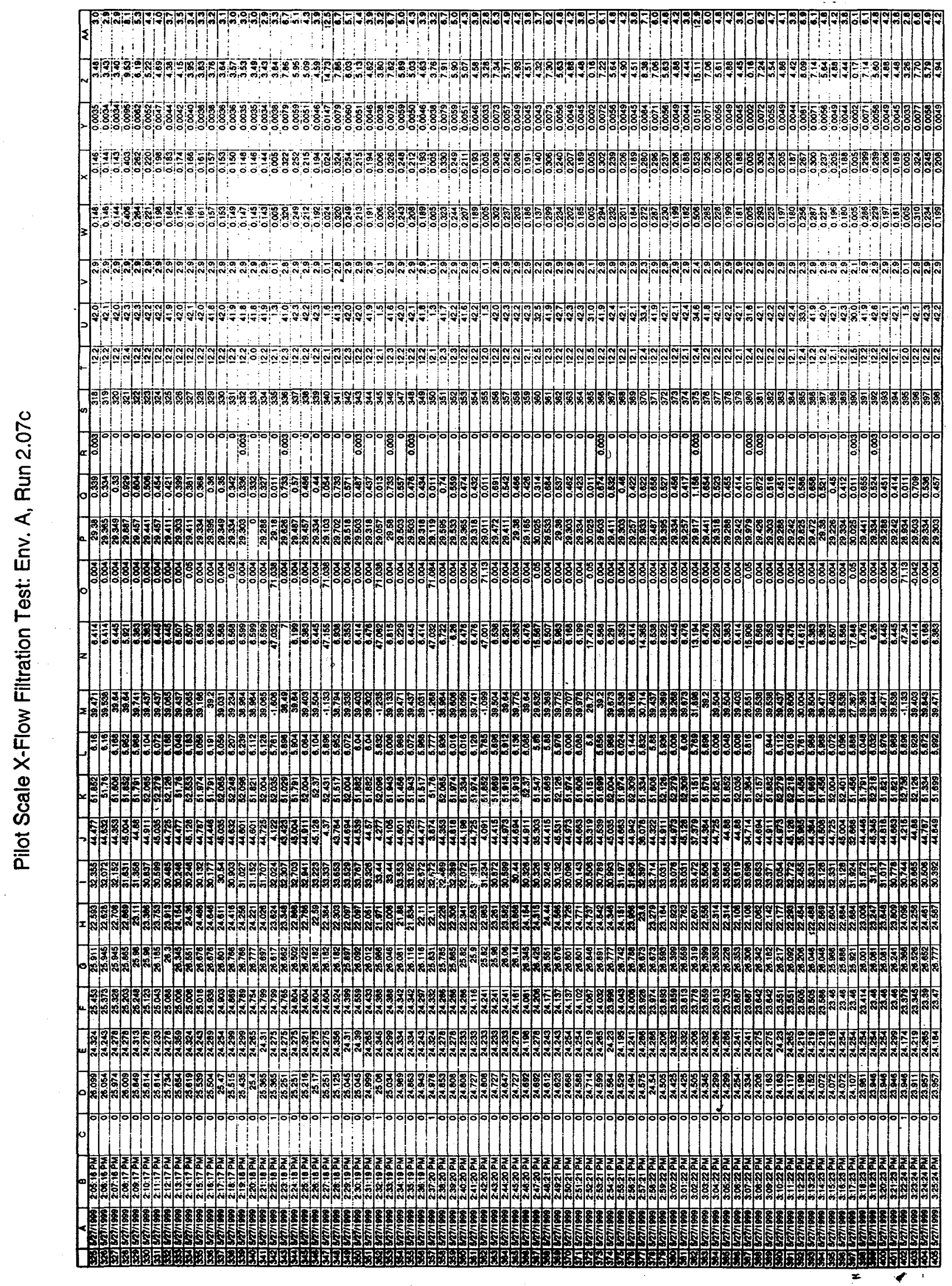




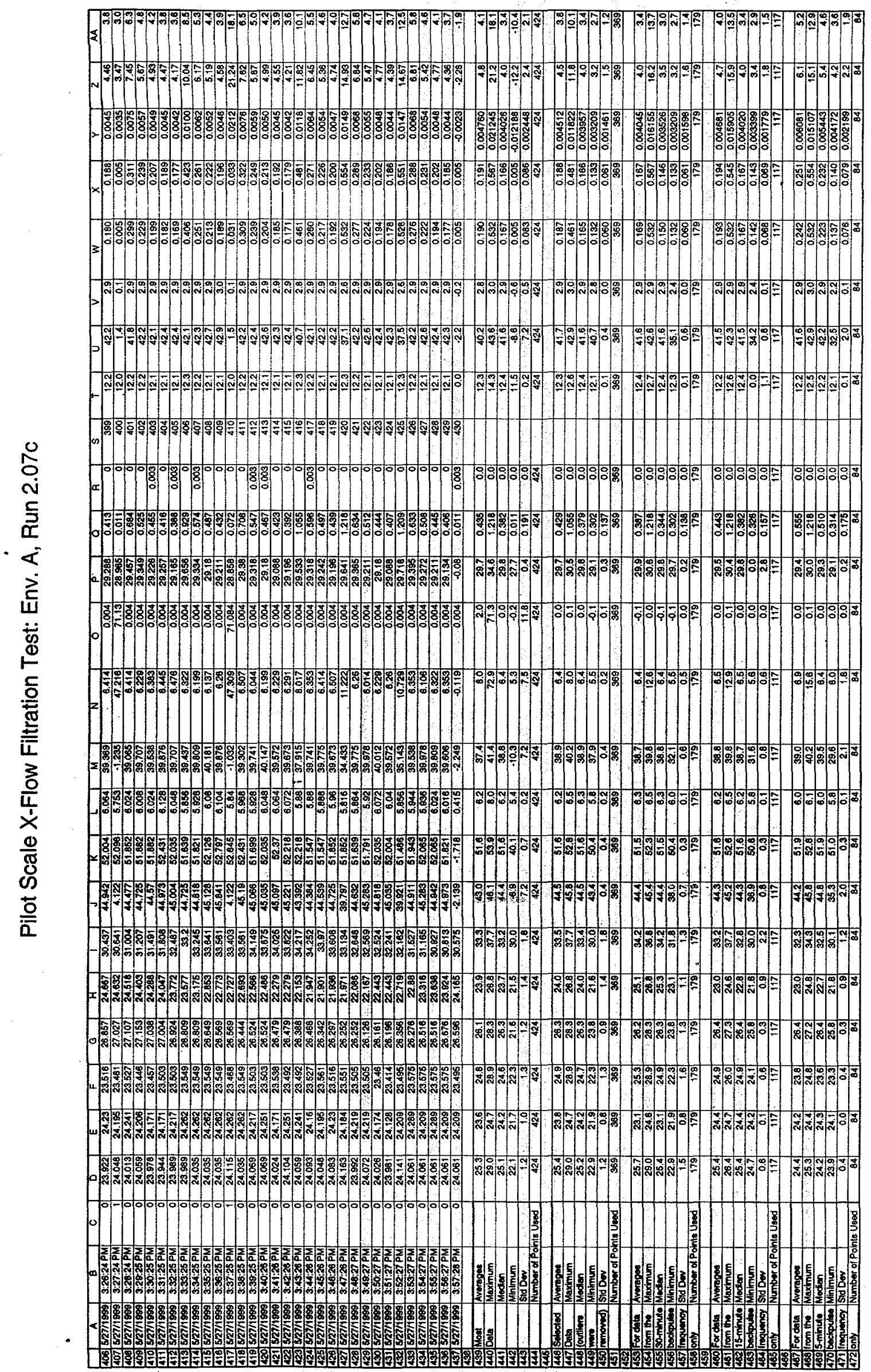




\section{APPENDIX C}

\section{EXPERIMENTAL DATA: HIGH SOLIDS CONCENTRATION}

\section{Appendix Contents}

1. Nomeclature sheet for data tables

2. Experimental data:

$\begin{array}{llll}\text { Fig. } & \text { Run } & \text { Solution } & \text { Done on } \\ \text { C1 } & 2.14 & 7 \text { wt\% Solids } & 6 / 11 / 99 \\ \text { C2 } & 2.14 b & 8 \text { wt\% Solids } & 6 / 16 / 99 \\ \text { C3 } & 2.20 \mathrm{~b} & 5 \text { to } 16 \text { wt\% Solids } & 6 / 17 / 99\end{array}$

General Note: For measurement uncertainties see Appendix F

Special Notes:

a. The data for every test run are highlighted with two graphs: Filtrate Flux vs. Time and Permeability vs. Time. Those graphs include all the data taken during the run period.

b. The beginning and end of the data for most graphs show large deviations from the overall series of points. Those deviations were caused by backpulsing the filter that temporarily stopped the flow of filtrate.

c. All columns of data, in all the tables, are ended with several statistical values of that column, i.e., Average, Maximum, Median, Minimum, Standard Deviation, and Number of Points used (in calculating the 5 statistical quantities). Most of the data with time were maintain constant, and therefore the statistics are meaningful for normally distributed data, however Filtrate Flux and Permeability decrease with time and therefore are not normally distributed.

d. To calculate those quantities mentioned in item c, only those data points that start from the end of a backpulse to just before the ending backpulse were included. This is the reason why the quantity of Number of Points Used was given.

e. The data for the graphs, and all the data taken for the individual test run that the graphs represent, immediately follow the specific figure.

f. Run 2.14 was done after the test rig was cleaned due plugging when the solids concentration was increased from $0.5 \mathrm{wt} \%$ to between 10 and $15 . \mathrm{wt} \%$. In an attempt to unplug the test rig in a hurry the slurry was diluted with water. Therefore, the slurry for this run had a sodium concentration closer to $3 \mathrm{M}$ instead of the target of $5.5 \mathrm{M}$. After the wash run another batch of slurry was made and a new run was done and called $2.14 \mathrm{~b}$.

g. Run $2.20 \mathrm{~b}$ was not a steady-state run like 2.14 and $2.14 \mathrm{~b}$, where the filtrate returns to the slurry to maintain its concentration. Run $2.20 \mathrm{~b}$ was done to successively make the slurry more concentrated until the filter plugged. That is why the Filtrate Flux graph of Fig. C3 appears to have steps. Starting with approximately 80 liters of postwashed slurry, approximately 7.3 liters of filtrate was removed 6 times and the remaining 36 liters just barely covered the bottom of the slurry reservoir. The run had to stop because the cooling coils were totally exposed and couldn't cool the slurry which became very hot and the pumps began to draw in air because the thick slurry 
couldn't supply the suction line with slurry fast enough. Fortunately, the filter did not plug at all.

Nomenclature For Data Sheets

(See Figure 1: Main Test Aig - Pilot Scale Cross Flow for the Instrument Location)

\begin{tabular}{|c|c|}
\hline Column & Heading \\
\hline$A=$ & DATE \\
\hline$B=$ & TIME \\
\hline$c=$ & SOLENOID \\
\hline$D=$ & FLTRT (deg \\
\hline$E=$ & CLLOOP $(\mathrm{C}$ \\
\hline $\mathbf{F}=$ & SL LOOP $(\mathrm{d}$ \\
\hline $\mathrm{G}=$ & UP AMB (df \\
\hline$H=$ & BOT AMB (S \\
\hline $1=$ & $T 6(\operatorname{deg} C)$ \\
\hline$J=$ & BOT DP (pS \\
\hline$K=$ & FLTR (psig) \\
\hline$L=$ & FLTR DP (p \\
\hline$M=$ & TOP DP (ps \\
\hline$N=$ & FLTAATE \\
\hline $0=$ & PISTON (pS \\
\hline$P=$ & SL FLOW (g \\
\hline$Q=$ & FLTR FLOY \\
\hline $\mathrm{A}=$ & V9 \\
\hline
\end{tabular}

$\begin{array}{ll}= & \text { Full Heading } \\ = & \text { DATE } \\ = & \text { TIME } \\ = & \text { SOLENOID } \\ = & \text { FLTRT (deg C) T2 } \\ = & \text { CLLOOP (deg C) T3 } \\ = & \text { SL LOOP (deg C) T1 } \\ = & \text { BOT AMB (deg C) T4 } \\ = & \text { T6 (deg C) SPARE } \\ = & \text { BOT DP (psid) dP2 } \\ = & \text { FLTR (psig) P1 } \\ = & \text { FLTR DP (psid) dP1 } \\ = & \text { TOP DP (psig) dP3 } \\ = & \quad \text { FLTRATE (psig) P2 } \\ = & \text { PISTON (psig) P3 } \\ = & \text { SL FLOW (gpm) Q1 } \\ = & \text { FLTR FLOW (gpm) Q2 } \\ = & \quad\end{array}$

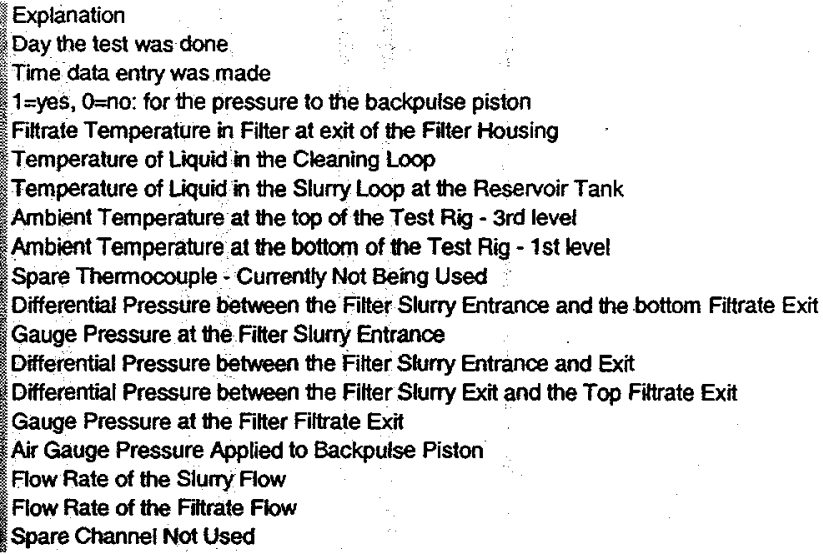

The following columns are calculated results based on the appropriate columns

\begin{tabular}{|c|c|}
\hline$S=$ & Number \\
\hline$T=$ & Vel, $\mathrm{f} / \mathrm{s}$ \\
\hline$U=$ & TMP, PSI \\
\hline$V=$ & TMP, bas \\
\hline $\mathbf{w}=$ & GPMFT2 \\
\hline$x=$ & GPWFT2 \\
\hline$Y=$ & PERMAaAtLTV \\
\hline$z=$ & $\times 1000$ \\
\hline$A A=$ & PERMABHTY \\
\hline
\end{tabular}

$=$
$=$
$=$
$=$
$=$
$=$
$=$
$=$
$=$

Number

Vel, tis

TMP, PSI

TMP, bar

GPNFT2

GPMFT2 at $25^{\circ} \mathrm{C}$

PERMABUITY gomeapsi

PERMIABILITY $\times 1000$

PERMMABUTTY (mitaytoan)

Data number which is equivalent to 1 minute since this was the acquisition frequency Axial silurry velocity $=[$ Column $P] / 7.48 \mathrm{gal} / \mathrm{t} 2 \mathrm{f} / 60 \mathrm{sec} / \mathrm{min} /$ flow area $\left(=0.005369 \mathrm{ft}{ }^{*}\right)$ Transmembrane Pressure $=([$ Column $\mathrm{J}]+[$ Column M] $) / 2$ [Column U] / 14.504 bar/psi

[Cohumn Q] / inside diameter filter surface area (=2.29 f(2*)

Test Spec. correction factor: [Column W] $\times \exp (2500 \times((1 /(273+[$ Column T] $))-(1 / 298)))$

[Column X] / [Column U]

$[$ Column Z] $\times 1000$

[Column $\bigvee$ ] conversion factor ( $=851.0145 \mathrm{~m} /$ dayfbar $/ \mathrm{gpm} / \mathrm{ft} 2 \mathrm{bar}$ )

-Axial slurry flow area is based on 7 porous tubes with an inside diameter of $3 / 8$ inch: $7 \times$ pi $/ 44^{*}(0.375$ inch $/ 12$ inches/ft) $2=0.005369 \mathrm{tt}$ *Inside diameter fitter surface area for 7 thbes with an inside diameter of $3 / 8$ inch, 40 -inches long: $7 \times$ pi $x(0.375$ inch) $\times 40$ inches $/ 144$ ins/fth $=2.29$ ft2

Exceptions:

1. For Run 2.21b (Cleaning); This run was carried out over a three different periods on three days therefore there are two NUMBER COLUMNS: S \& T. Column $S$ is continuous and Column $T$ is continuous but starts over for each period. All the columns to the right of Colurnn $S$ are shifted by one.

2. For Run 2.22b (Water); After July 10,1999 a second fitrate flow meter was added to measure flow rates from 1.2 to $5 \mathrm{gpm}$. The final water test run (Run 2.220 ) has an extra filtrate flow rate column. Column $R_{2}$ the spare column, was made the new flow rate:

$R=Q 3, F L T R F=\quad$ Q3, FLTR FLOW (gpm)

also Run 2.22b has two NUMBER columns (like Run 2.21b) so Exception 1 also applies. 

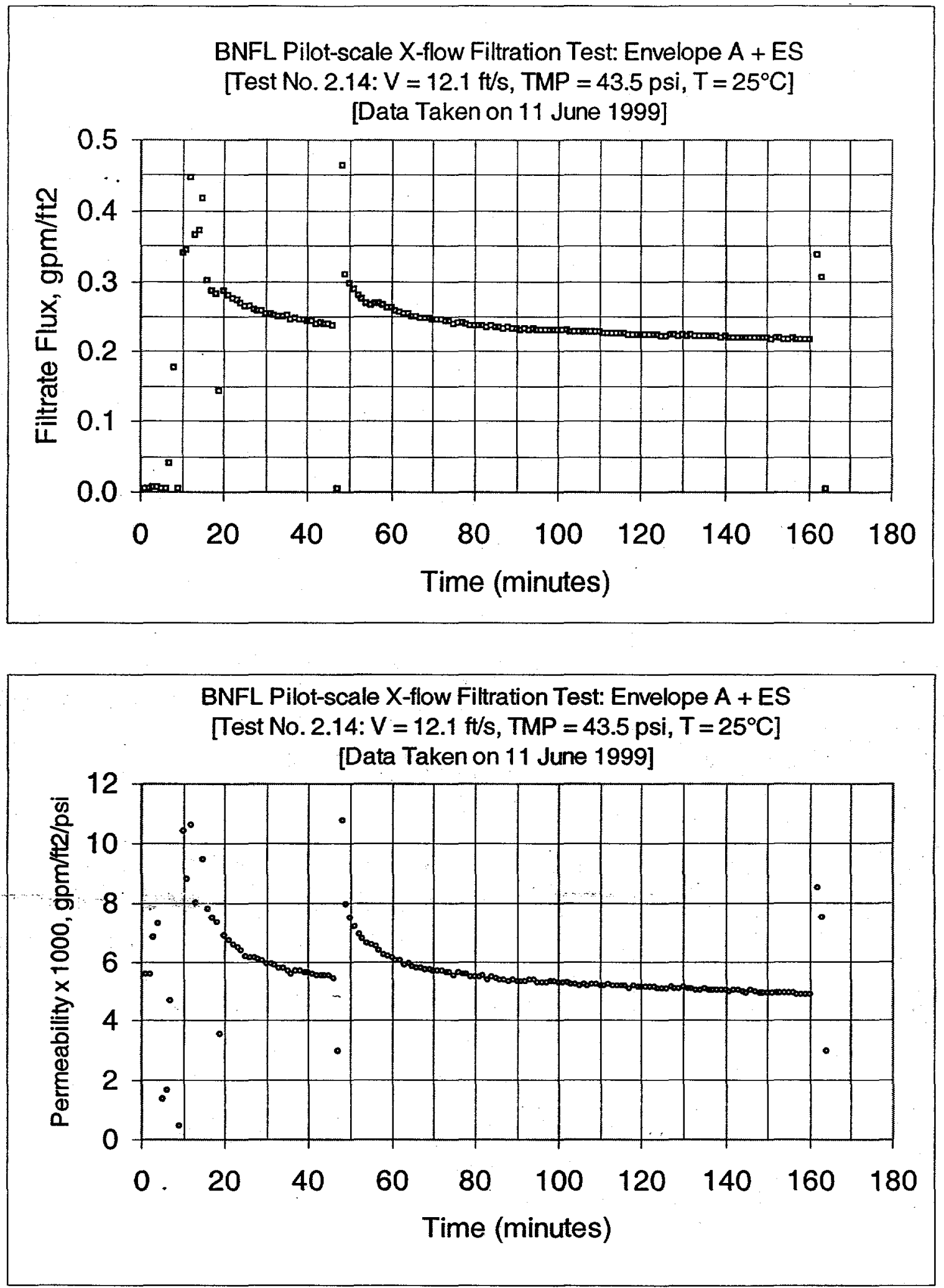

Figure C1: Test Run $2.14,7$ wt\% Insoluble Solids Concentration 


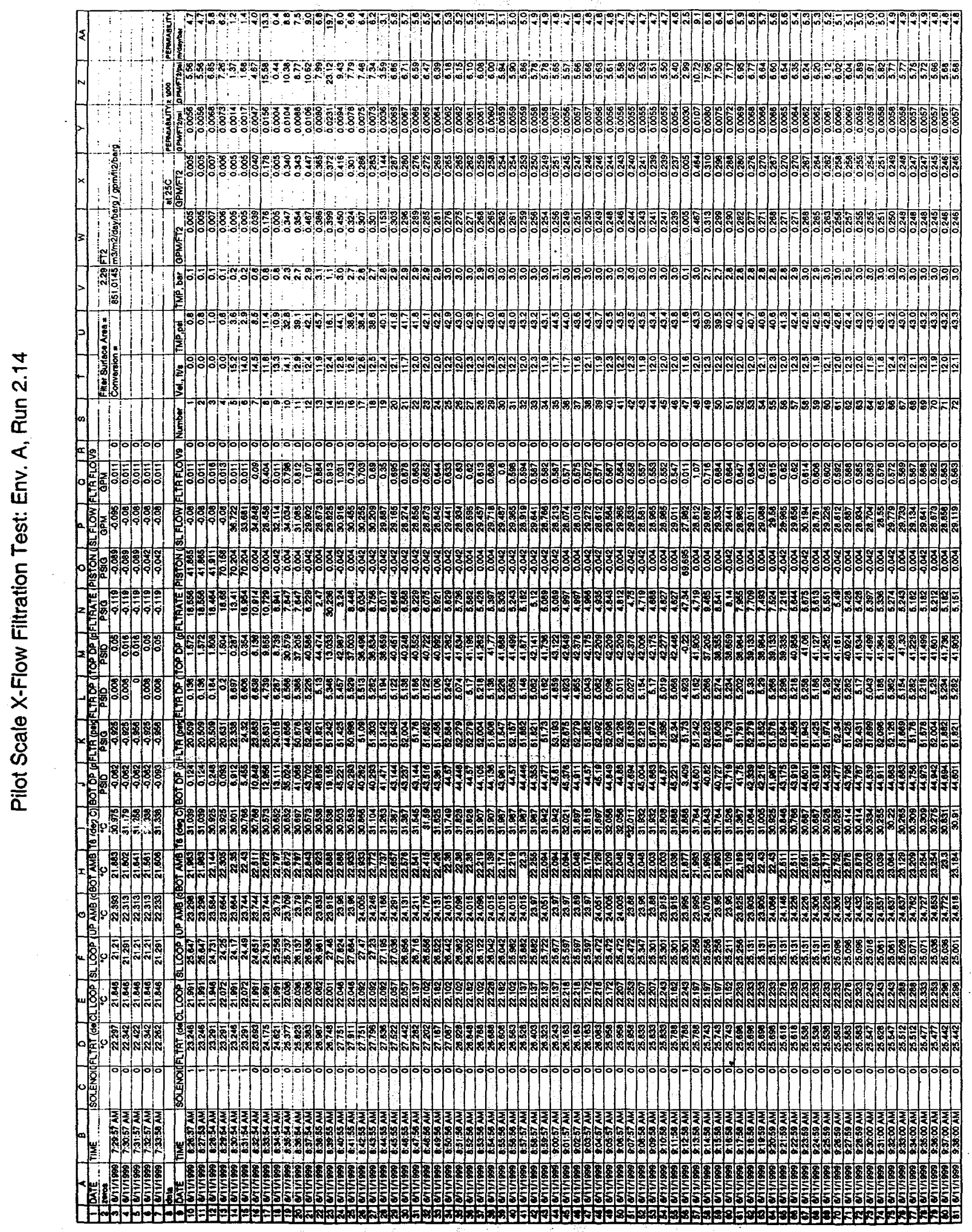




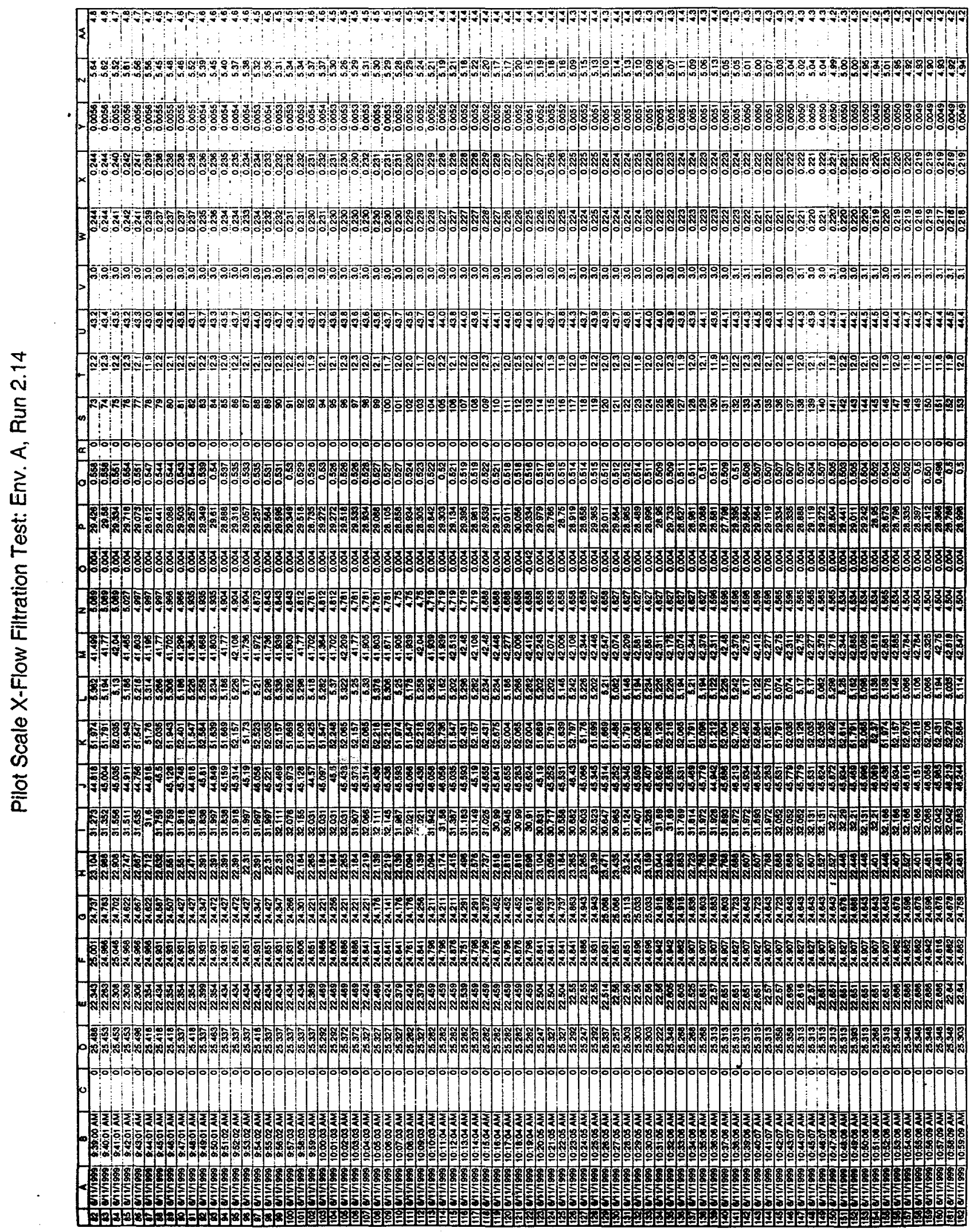




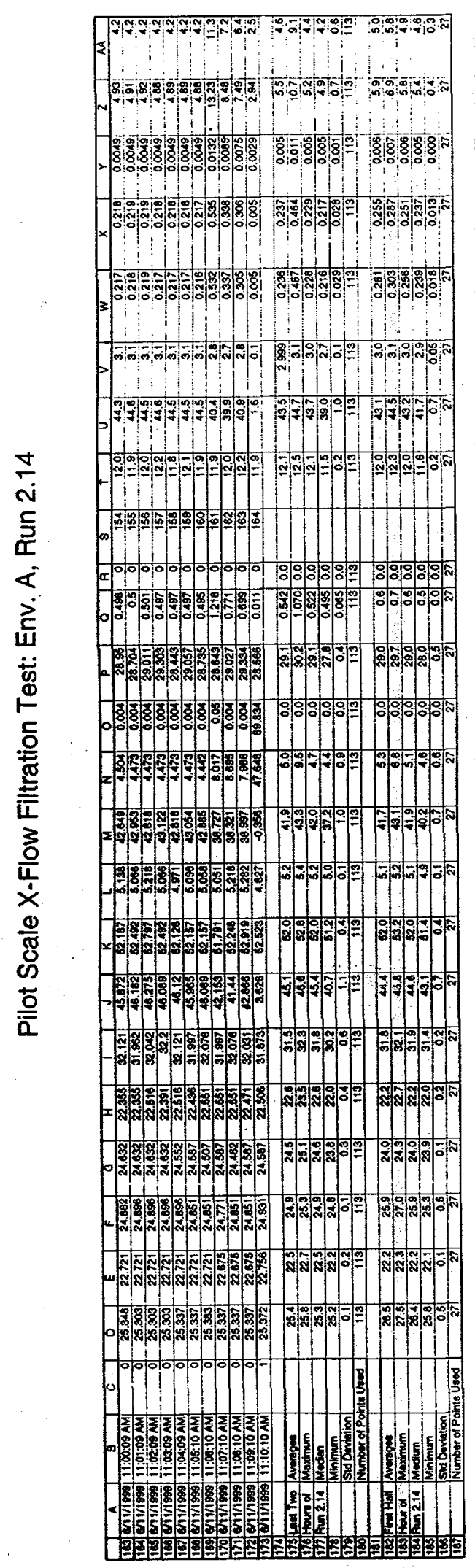



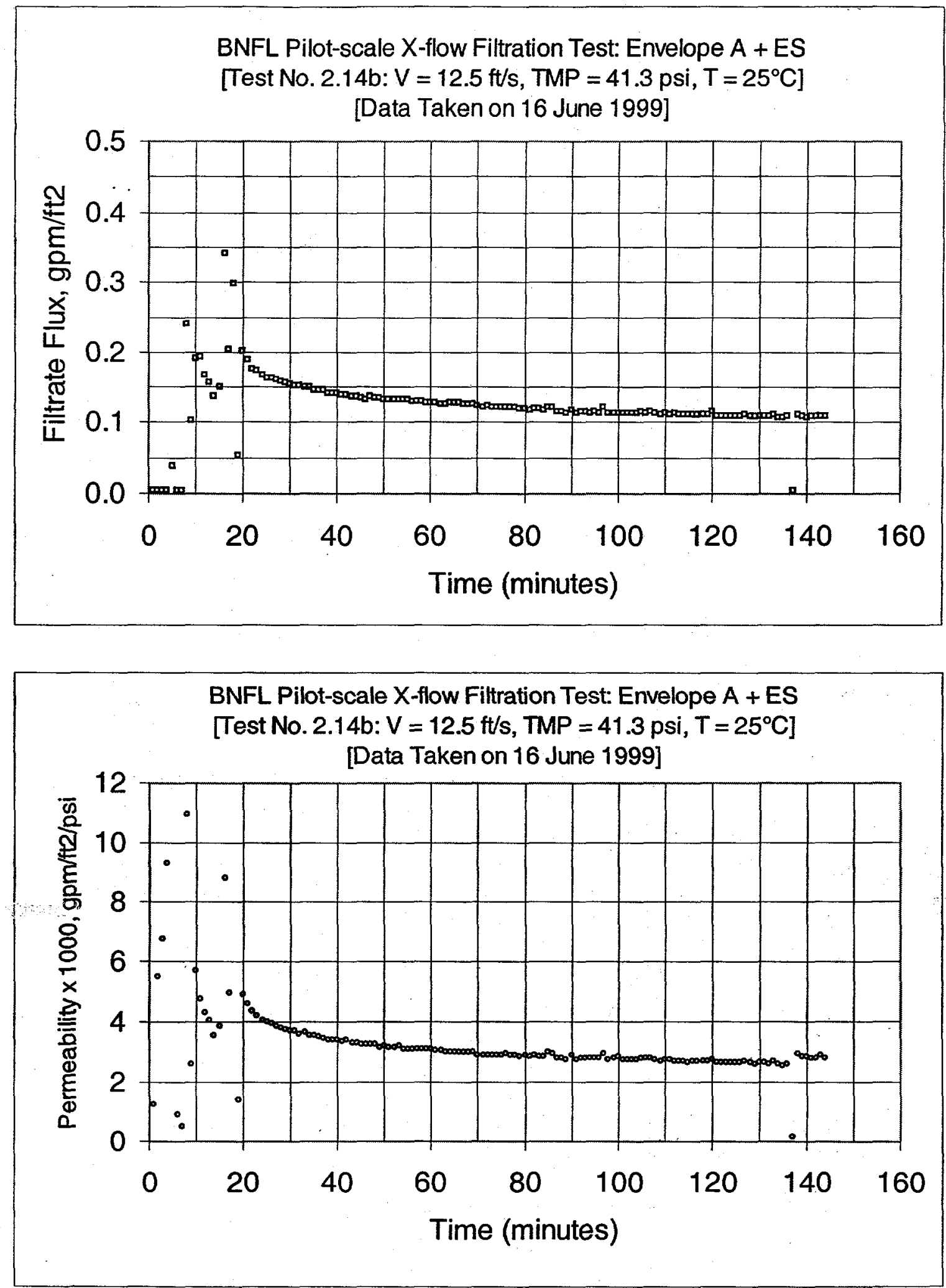

Figure C2: Test Run 2.14b, 8 wt\% Insoluble Solids Concentration 


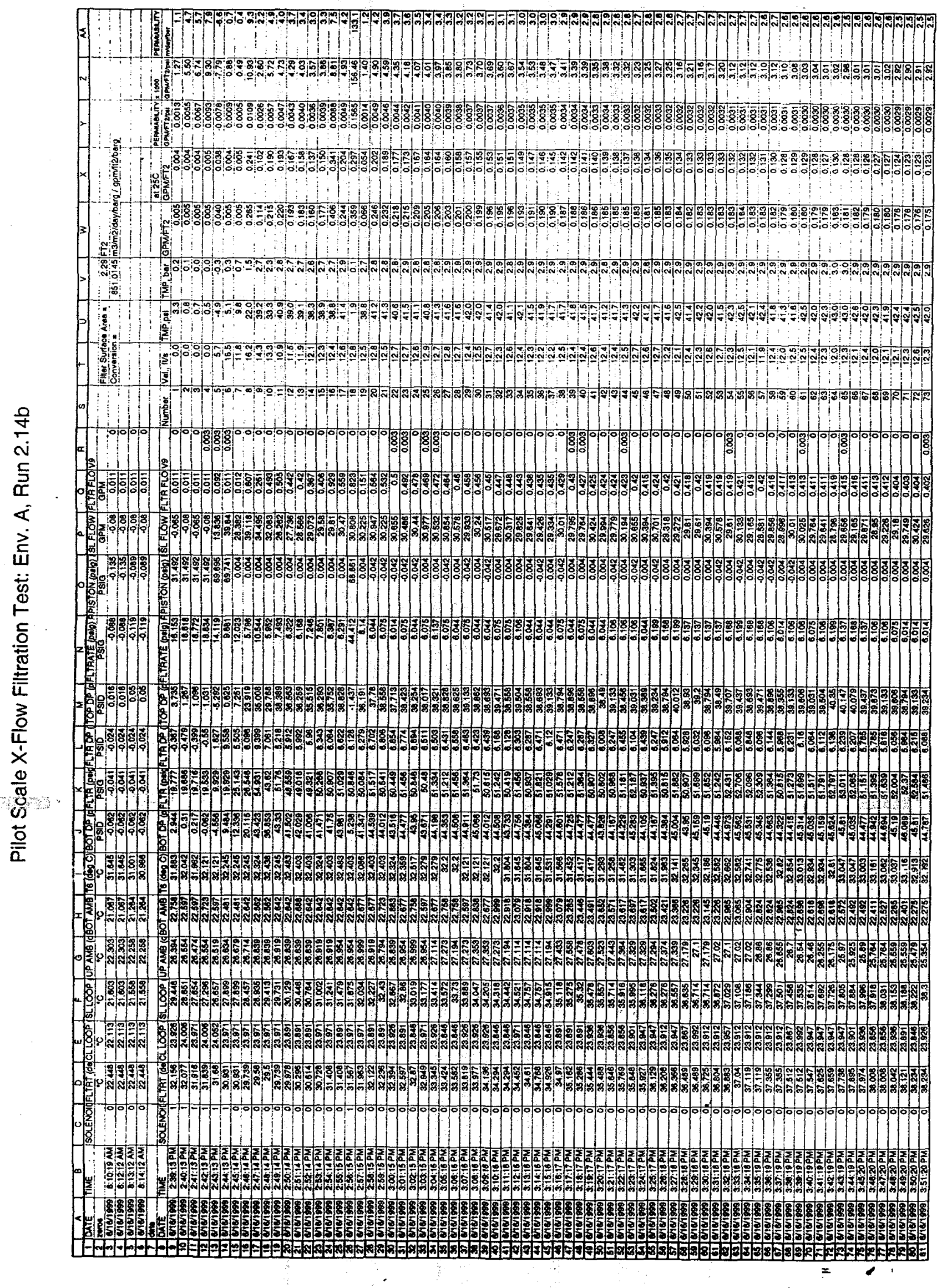


Pilot scale X-flow: EnvA+ES Page 142 of 226

BNF-003-98-0221

Revision 0

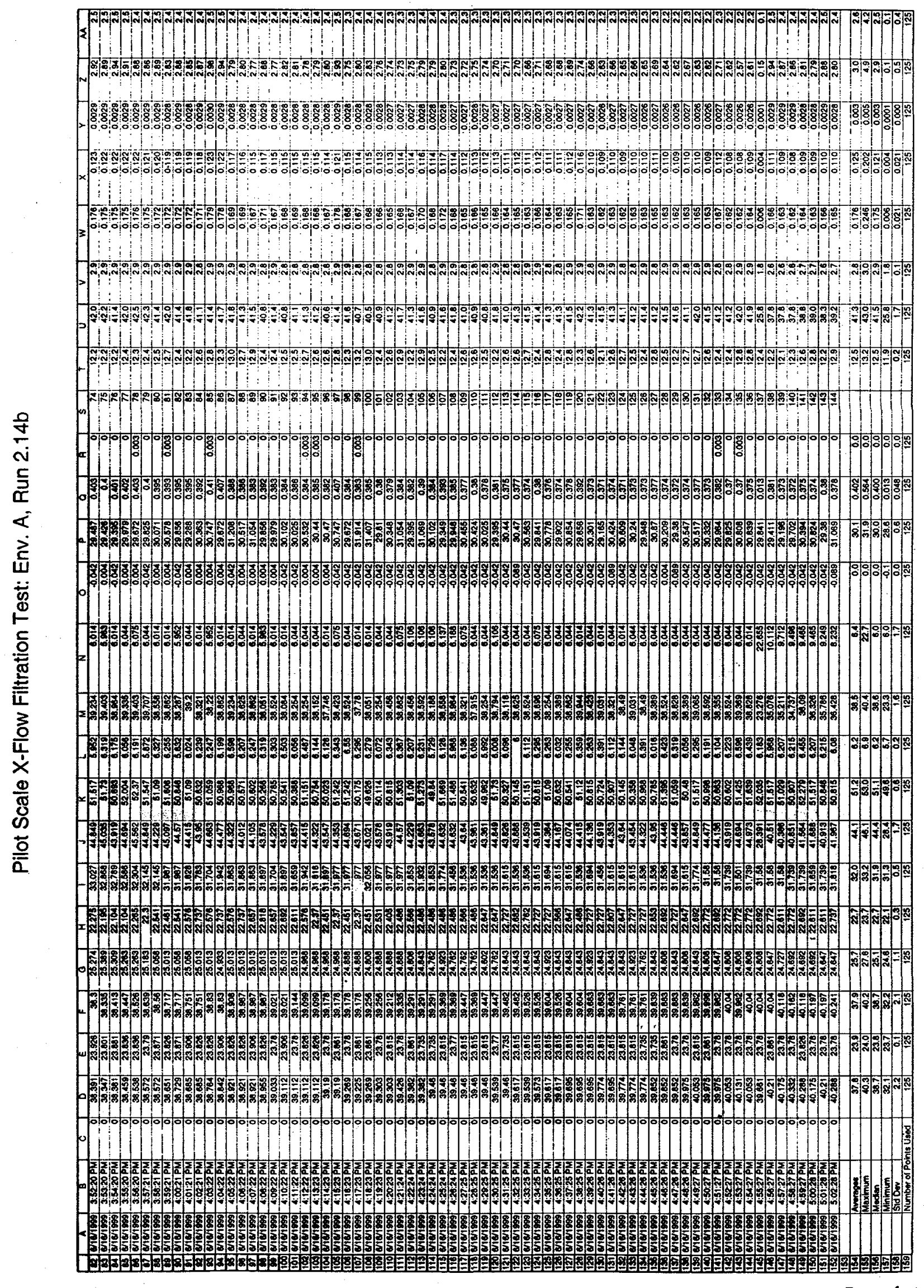



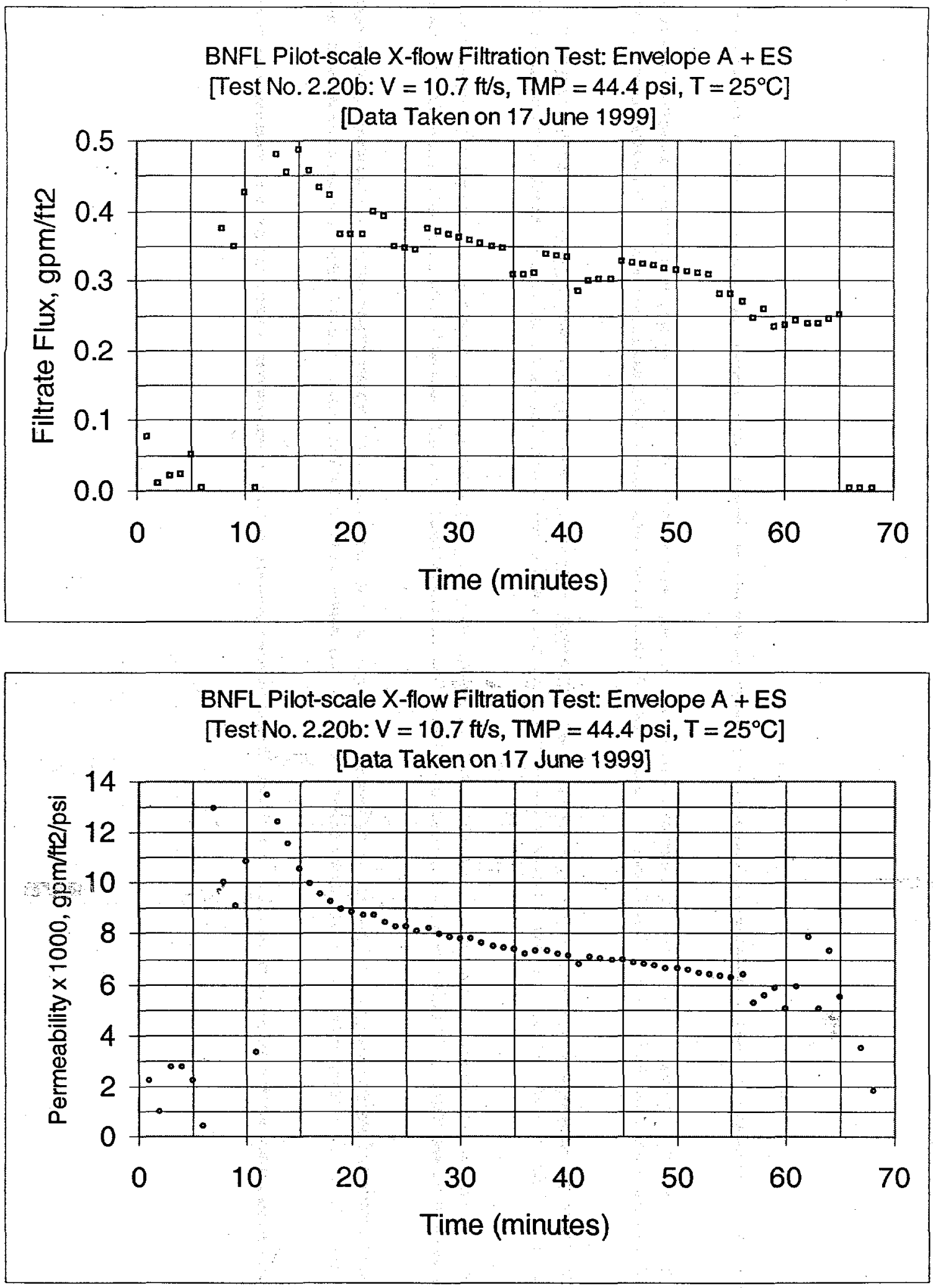

Figure C3: Test Run 2.20b, 5 wt\% to $16 \mathrm{wt} \%$ Insoluble Solids Concentration 
Pilot scale X-flow: EnvA+ES Page 144 of 226

BNF-003-98-0221

Revision 0

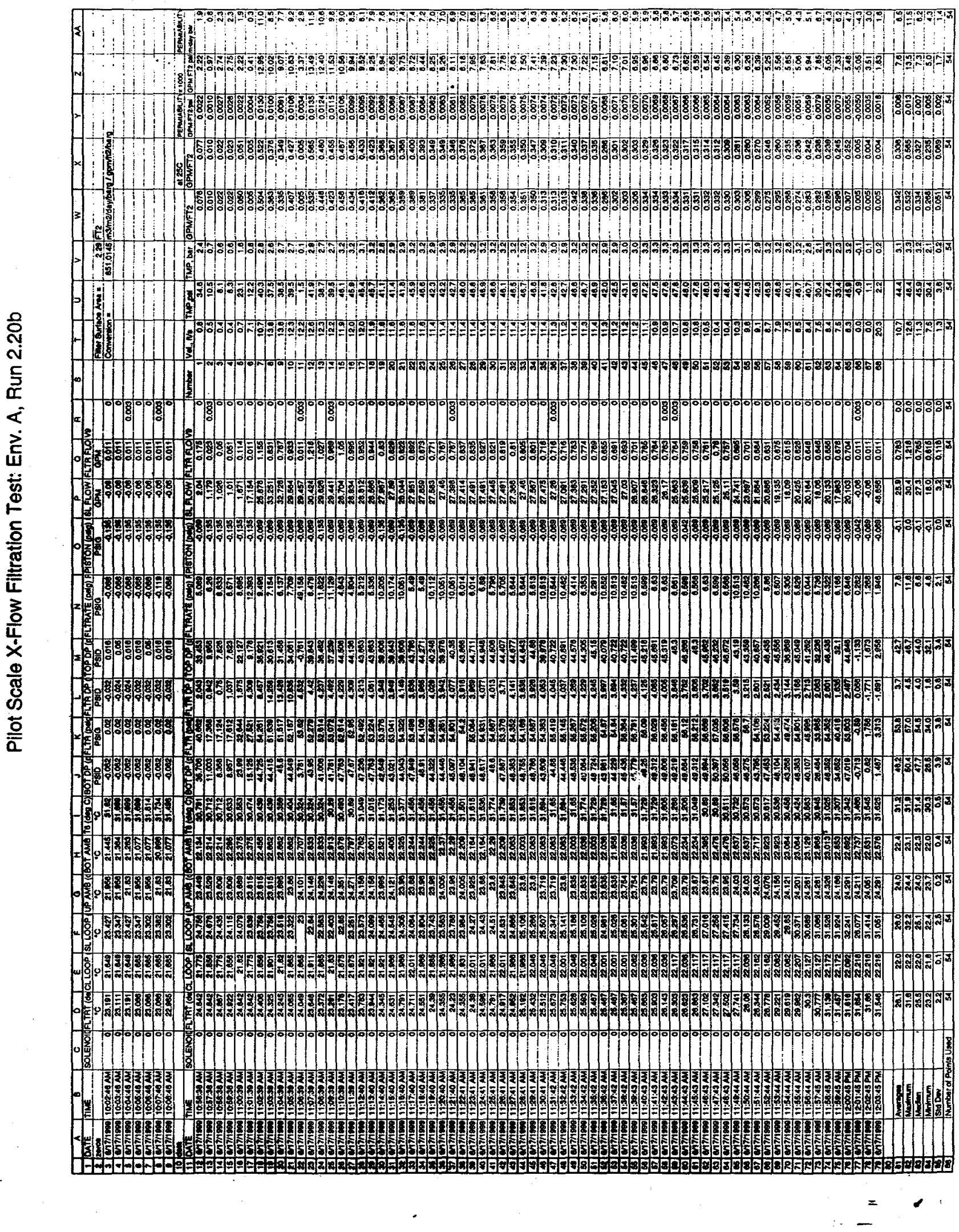




\section{APPENDIX D}

\section{EXPERIMENTAL DATA: SLURRY WASH}

Appendix Contents

1. Nomeclature sheet for data tables

2. Experimental data:

$\begin{array}{llll}\text { Fig. } & \text { Run } & \text { Solution } & \text { Done on } \\ \text { D1 } & 2.15 & \text { First Wash 1 } & 6 / 11 / 99 \\ \text { D2 } & 2.16 & \text { First Wash 2 } & 6 / 14 / 99 \\ \text { D3 } & 2.18 & \text { First Wash 3 } & 6 / 14 / 99 \\ \text { D4 } & 2.19 & \text { First Wash 4 } & 6 / 14 / 99 \\ \text { D5 } & 2.15 b & \text { Second Wash 1 } & 6 / 16 / 99 \\ \text { D6 } & 2.16 \mathrm{~b} & \text { Second Wash 2 } & 6 / 16 / 99 \\ \text { D7 } & 2.17 \mathrm{~b} & \text { Second Wash 3 } & 6 / 16 / 99 \\ \text { D8 } & 2.18 \mathrm{~b} & \text { Second Wash 4 } & 6 / 16 / 99 \\ \text { D9 } & 2.19 \mathrm{~b} & \text { Second Wash 5 } & 6 / 26 / 99\end{array}$

General Note: For measurement uncertainties see Appendix F

Special Notes:

a. Run 2.17 was not done because run 2.14 began with a dilute slurry that was taken as a first wash run.

b. The data for every test run are highlighted with the top two graphs in each figure: Filtrate Flux vs. Time and Permeability vs. Time. Those graphs include all the data taken during the run period.

c. The bottom graph of each figure is a subset of the Filtrate Flux vs. Time data during the period that the filtrate was being removed to prepare for another charge of water.

d. The beginning and end of the data for most graphs show large deviations from the overall series of points. Those deviations were caused by backpulsing the filter that temporarily stopped the flow of filtrate.

e. All columns of data, in all the tables, are ended with several statistical values of that column, i.e., Average, Maximum, Median, Minimum, Standard Deviation, and Number of Points used (in calculating the 5 statistical quantities). Most of the data with time were maintain constant, and therefore the statistics are meaningful for normally distributed data, however Filtrate Flux and Permeability decrease with time and therefore are not normally distributed.

f. To calculate those quantities mentioned in item e, only those data points that start from the end of a backpulse to just before the ending backpulse were included. This is the reason why the quantity of Number of Points Used was given.

g. The data for the graphs, and all the data taken for the individual test run that the graphs represent, immediately follow the specific figure.

h. As second set of statistical values is given for the time period just during when filtrate was removed from the test rig. This is shown as the bottom graph of all the figures as explained in item 
i. Note, the flowmeter for the filtrate flux, $\mathrm{Q} 2$, could only measure up to $0.533 \mathrm{gpm} / \mathrm{ft} 2$. Any data above that value is meaningless.

Nomenclature For Data Sheets

(See Figure 1: Main Test Rig - Pilot Scale Cross Flow for the Instrument Location)

\begin{tabular}{|c|c|}
\hline Column & Heading \\
\hline$A=$ & DATE \\
\hline$B=$ & TIME \\
\hline$c=$ & SOLENOID \\
\hline$D=$ & FLTRT deg \\
\hline$E=$ & CLLOOP(C \\
\hline$F=$ & SLLOOP \\
\hline$G=$ & UP AMB (d \\
\hline$H=$ & BOT AMB ( \\
\hline$I=$ & $T 6(\operatorname{deg} C)$ \\
\hline $\mathbf{J}=$ & BOTDP (ps \\
\hline$K=$ & FlTR(psig) \\
\hline$L=$ & FLTR DP ( $\mathrm{p}$ \\
\hline$M=$ & TOP OP (pS \\
\hline$N=$ & FLTRATE \\
\hline $0=$ & PISTON (pS \\
\hline$P=$ & SLFLOW \\
\hline$Q=$ & FLTR FLOV \\
\hline$R=$ & V9 \\
\hline
\end{tabular}

$\begin{array}{ll}= & \text { Full Heading } \\ = & \text { DATE } \\ = & \text { TIME } \\ = & \text { SOLENOID } \\ = & \text { FLTAT (deg C) T2 } \\ = & \text { CL LOOP (deg C) T3 } \\ = & \text { SL LOOP (deg C) T1 } \\ = & \text { UP AMB (deg C) T4 } \\ = & \text { BOT AMB (deg C) T5 } \\ = & \text { T6 (deg C) SPARE } \\ = & \text { BOT DP (psid) dP2 } \\ = & \text { FLTR (psig) P1 } \\ = & \text { FLTR DP (psid) dP1 } \\ = & \text { TOP DP (psig) dP3 } \\ = & \text { FLTRATE (psig) P2 } \\ = & \text { PISTON (psig) P3 } \\ = & \text { SL FLOW (gpm) Q1 } \\ = & \text { FLTR FLOW (gpm) Q2 } \\ = & \end{array}$

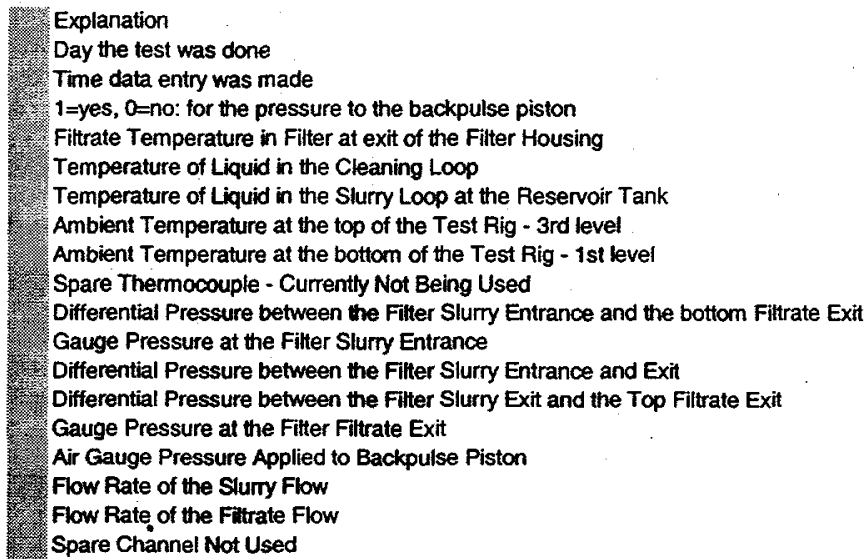

The following columns are calculated results based on the appropriate columns

\begin{tabular}{|c|c|c|c|c|}
\hline $\mathbf{S}=$ & Number & $=$ & Number & Data number which is equivalent to 1 minute since this was the acquisition frequency \\
\hline$T=$ & Vel, ft's & $=$ & Vel, ft/s & Axial slurry velocity $=[$ Column $P] / 7.48 \mathrm{gaV} / \mathrm{ft} 2 / 60 \mathrm{sec} / \mathrm{min} /$ flow area $\left(=0.005369 \mathrm{ft} 2^{*}\right)$ \\
\hline $\mathbf{u}=$ & TMP, PSI & $=$ & TMP, PSI & Transmembrane Pressure $=([$ Column $J]+[$ Column M] $) / 2$ \\
\hline$V=$ & TMP, bar & $=$ & TMP, bar & [Column U]/ 14.504 barfosi \\
\hline $\mathbf{w}=$ & GPMFT2 & $=$ & GPMFT2 & [Column 0 ] / inside diameter filter surface area $\left(=2.29\left(2^{* *}\right)\right.$ \\
\hline$x=$ & GPMFT2 & $=$ & GPNFT2 at $25^{\circ} \mathrm{C}$ & Test Spec. correction factor: [Column W] $\times \exp (2500 \times((1 /(273+[$ Column T] $))-(1 / 298)))$ \\
\hline $\mathbf{Y}=$ & PERMUAEITYY & $=$ & PEAMABALTY (gPTME2ps) & {$[$ Column X] / [Column U] } \\
\hline$z=$ & $x+000$ & $=$ & PERIMIABILITY $\times 1000$ & [Column Z] x 1000 \\
\hline$A A=$ & PERMAaBuTY & $=$ & PERAMAgAUTY (m/daybar) & iColumn $Y \times$ conversion factor ( $=851.0145 \mathrm{~m} /$ day $/ \mathrm{bar} / \mathrm{gpm} / \mathrm{t} 2 / \mathrm{bar}$ ) \\
\hline
\end{tabular}

- Axial slumy flow area is based on 7 porous tubes with an inside diameter of $3 / 8$ inch: $7 \times$ pi $/ 4 * 0.375$ inch $/ 12$ inches/ft) $/ 2=0.005369 \mathrm{ft}$ - Inside diameter filter surface area for 7 tubes with an inside diameter of $3 / 8$ inch, 40 -incties long: $7 \times$ pi $\times(0.375$ inch) $\times 40$ inches $/ 144$ in^2/ft $2=2.29$ ft2

Exceptions:

1. For Run 2.21b (Cleaning); This run was carried out over a three different periods on three days therefore there are two NUMBER COLUMNS: $S$ \& $T$.

Column $S$ is continuous and Column $T$ is continuous but starts over for each period. All the columns to the right of Column $S$ are shifted by one.

2. For Run 2.226 (Water); After July 10, 1999 a second filtrate flow meter was added to measure flow rates from 1.2 to $5 \mathrm{gpm}$. The final water test run (Rin 2.22b) has an extra filtrate flow rale column. Column $R$, the spare column, was made the new flow rate: 

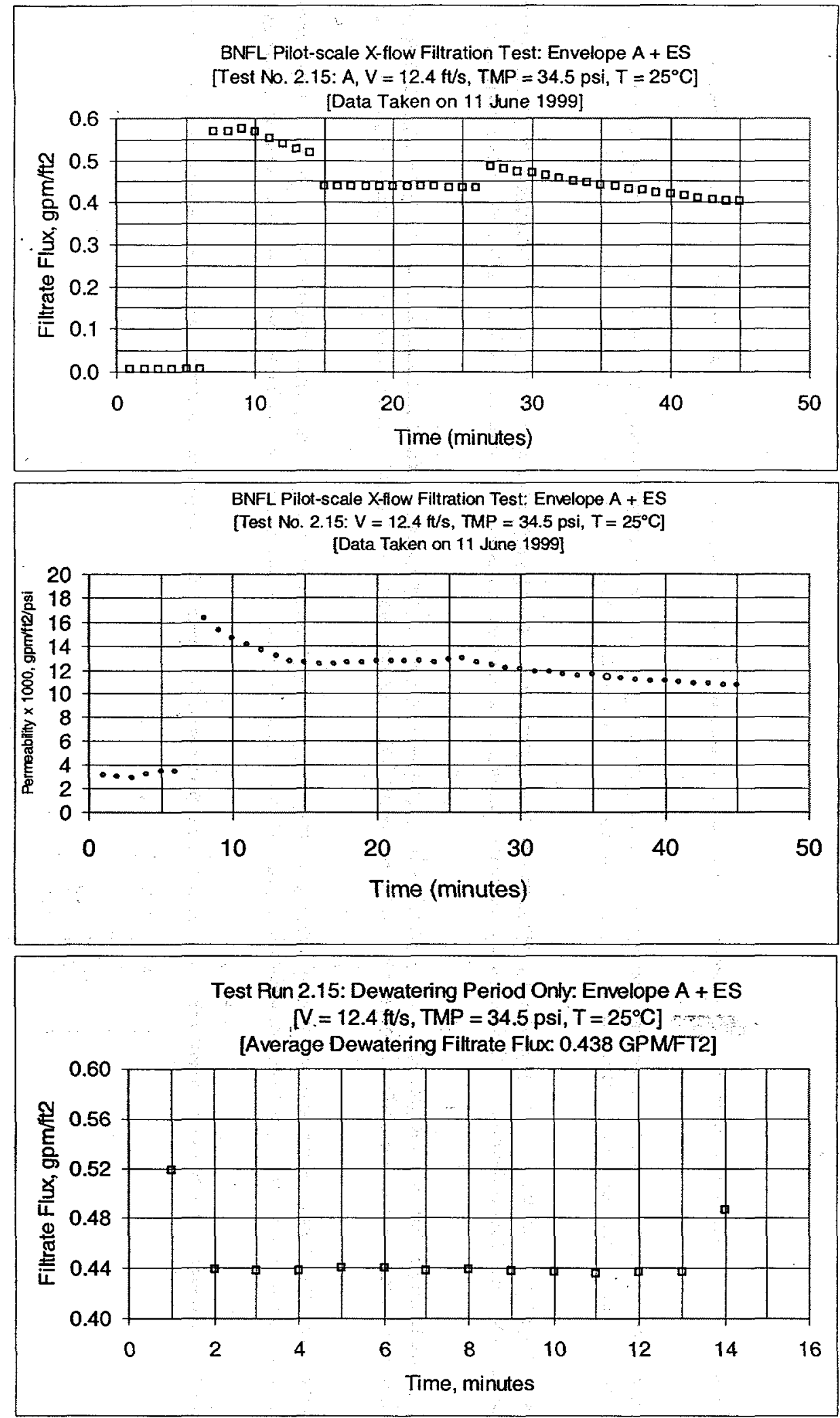

Figure D1: Test Run 2.15, First Wash 1 


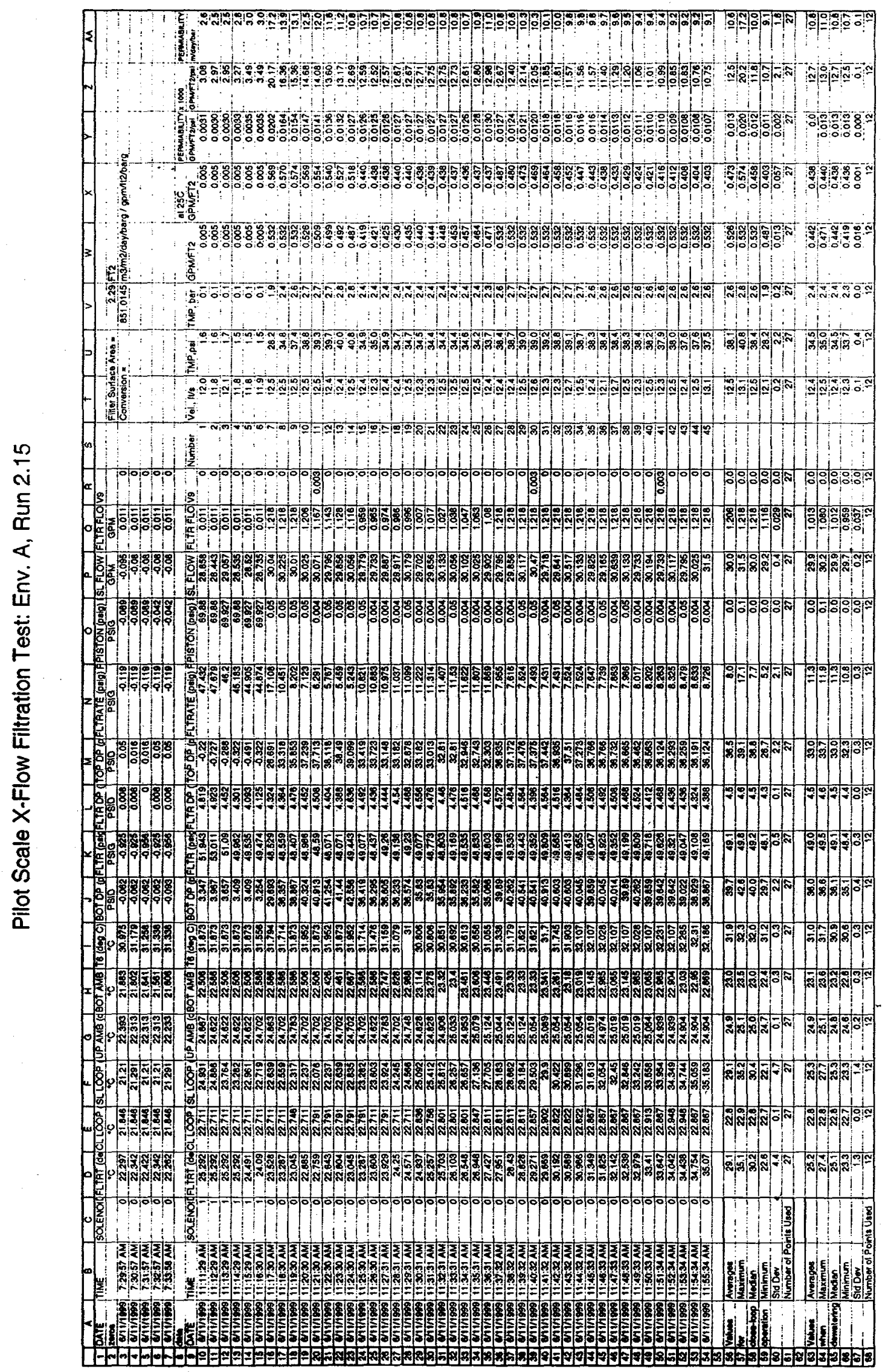



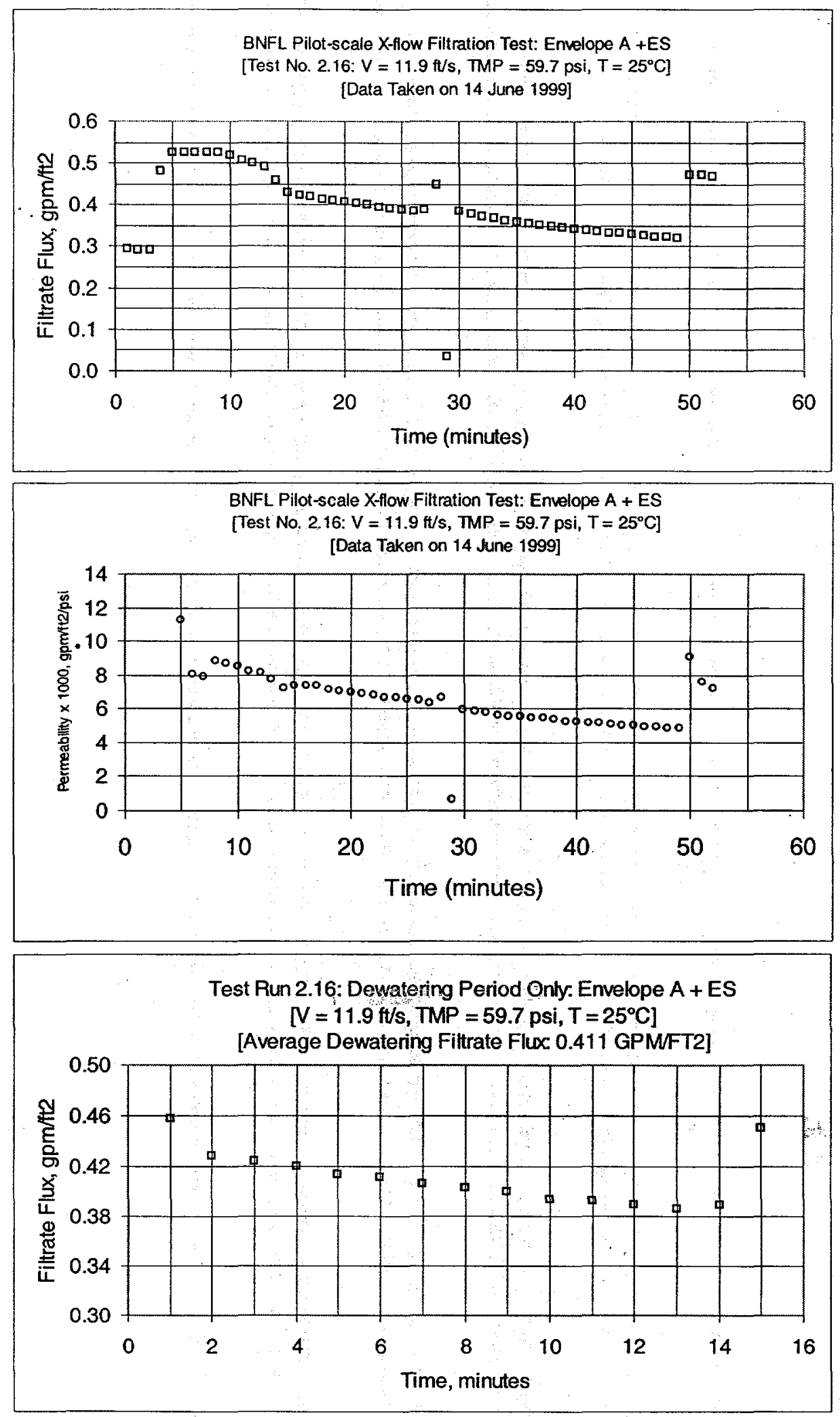

Figure D2: Test Run 2.16, First Wash 2 


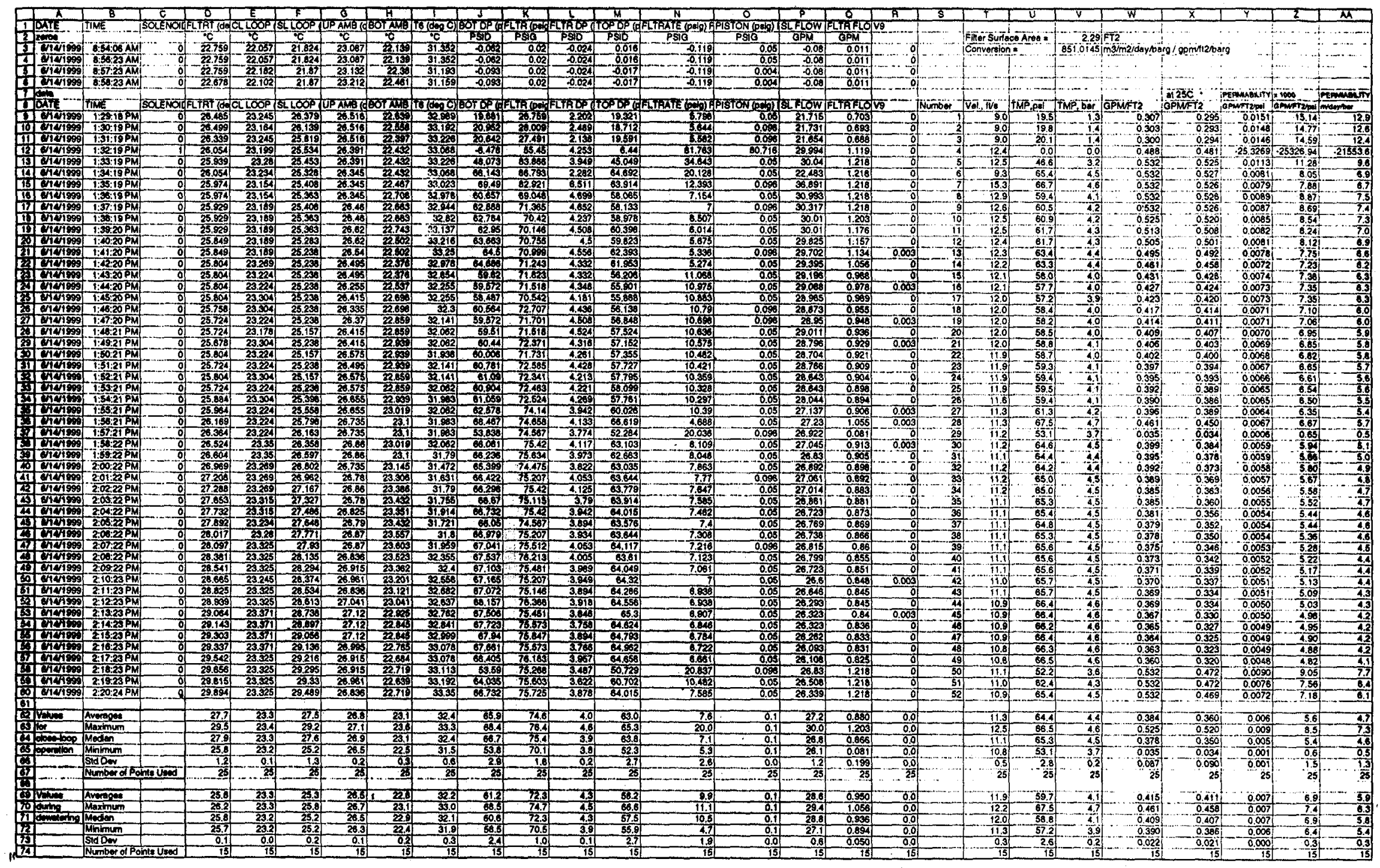



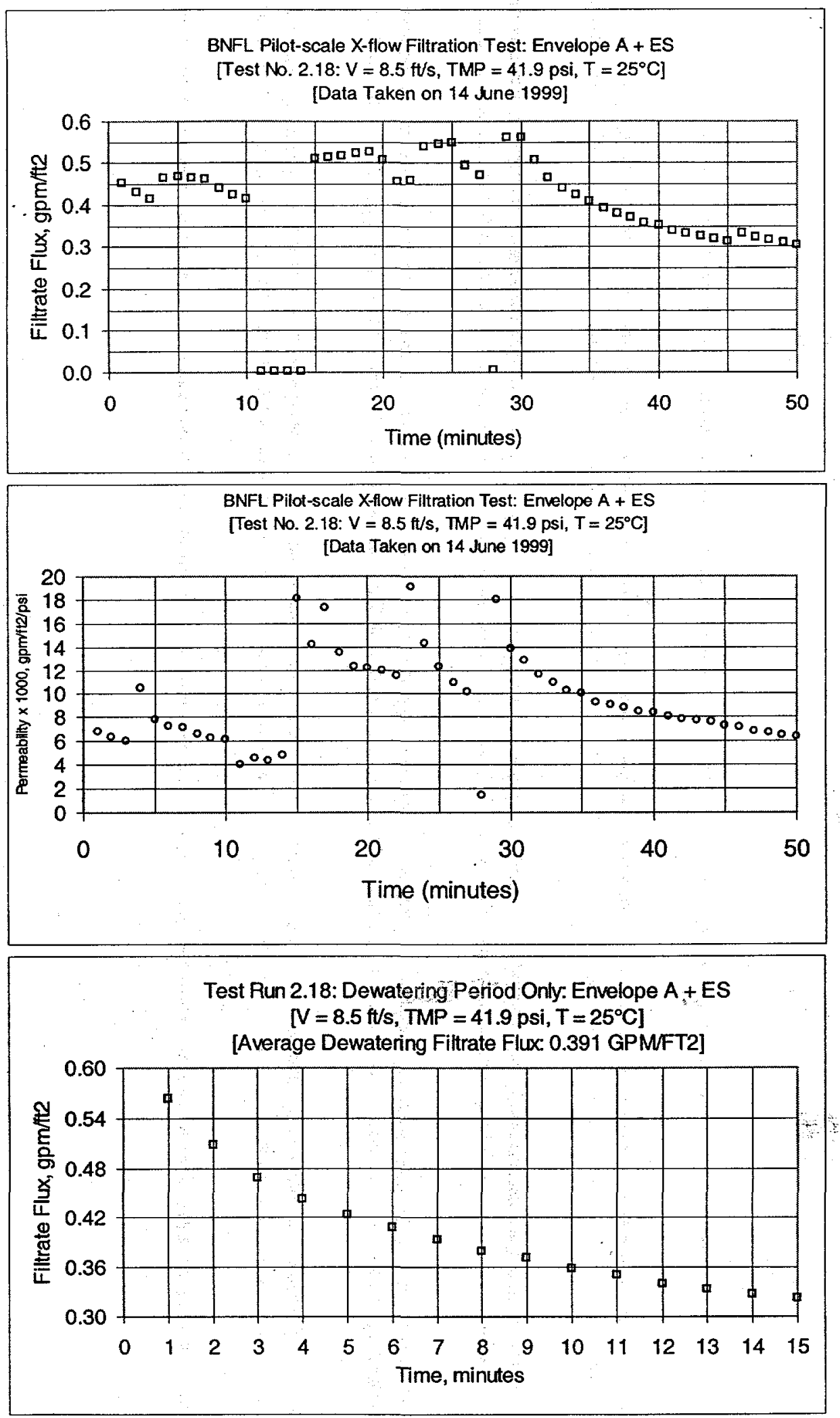

Figure D3: Test Run 2.18, First Wash 3 
Pilot scale X-flow: EnvA+ES Page 152 of 226

BNF-003-98-0221

Revision 0

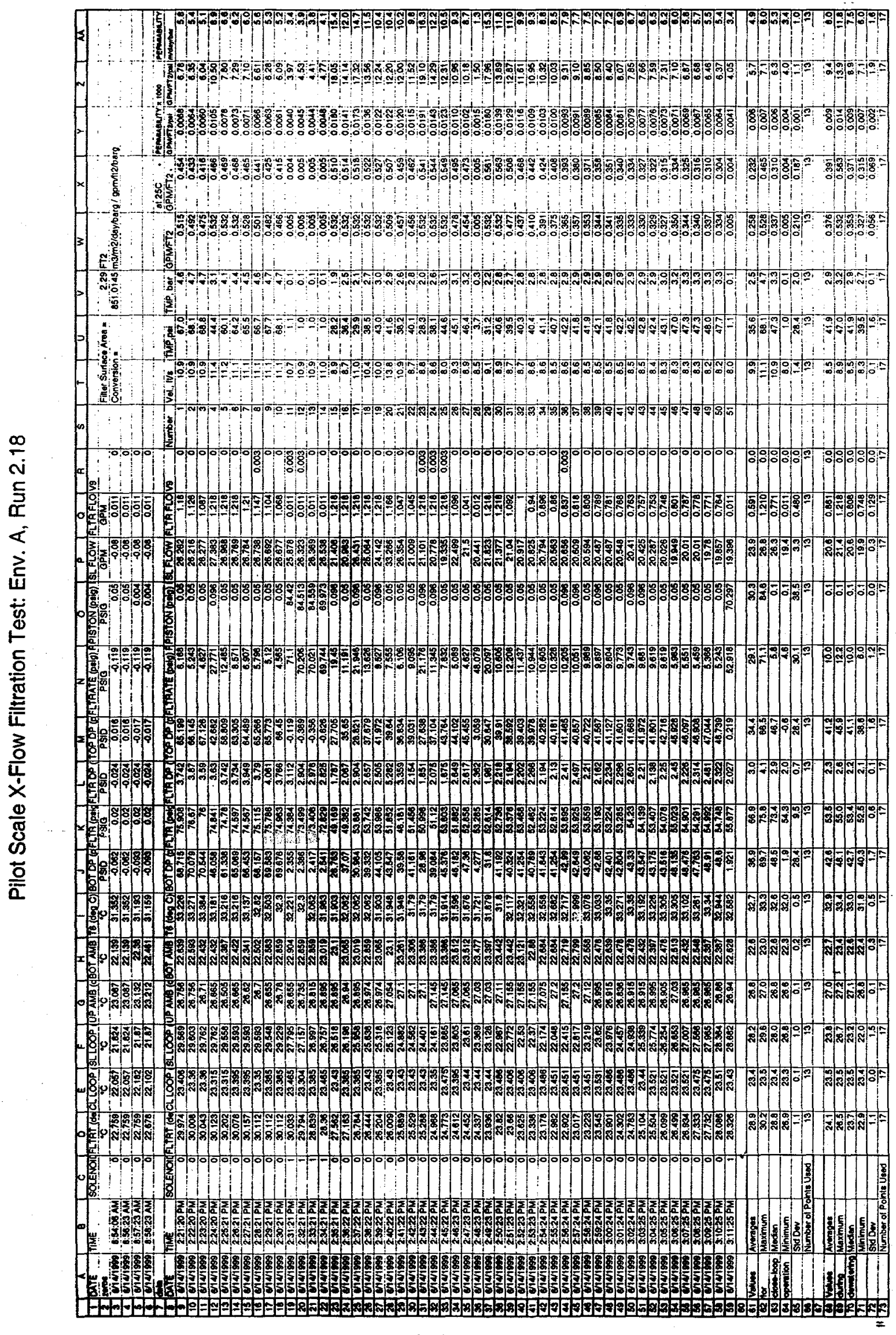



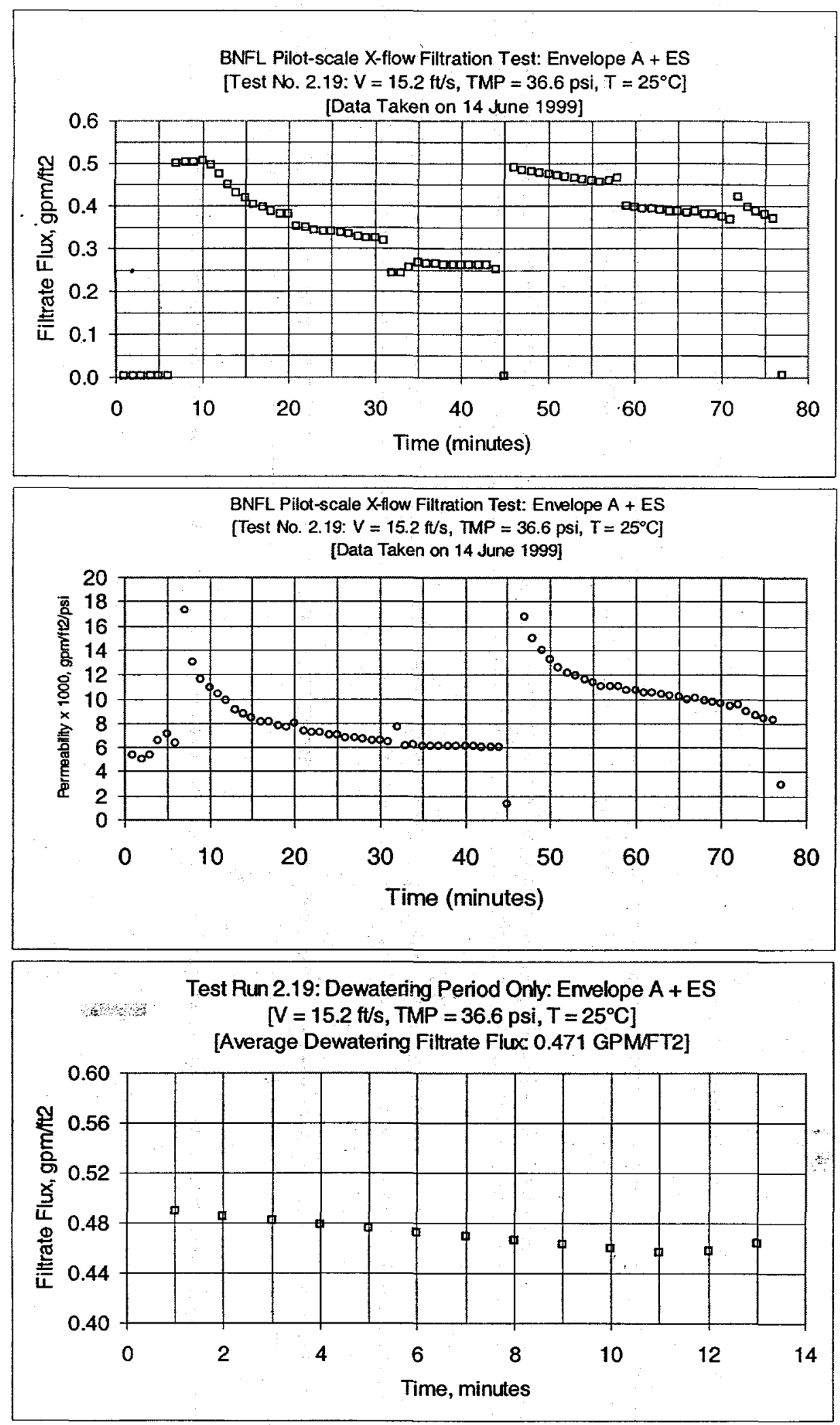

Figure D4: Test Run 2.19, First Wash 4 
Pilot scale X-flow: EnvA+ES Page 154 of 226

BNF-003-98-0221

Revision 0

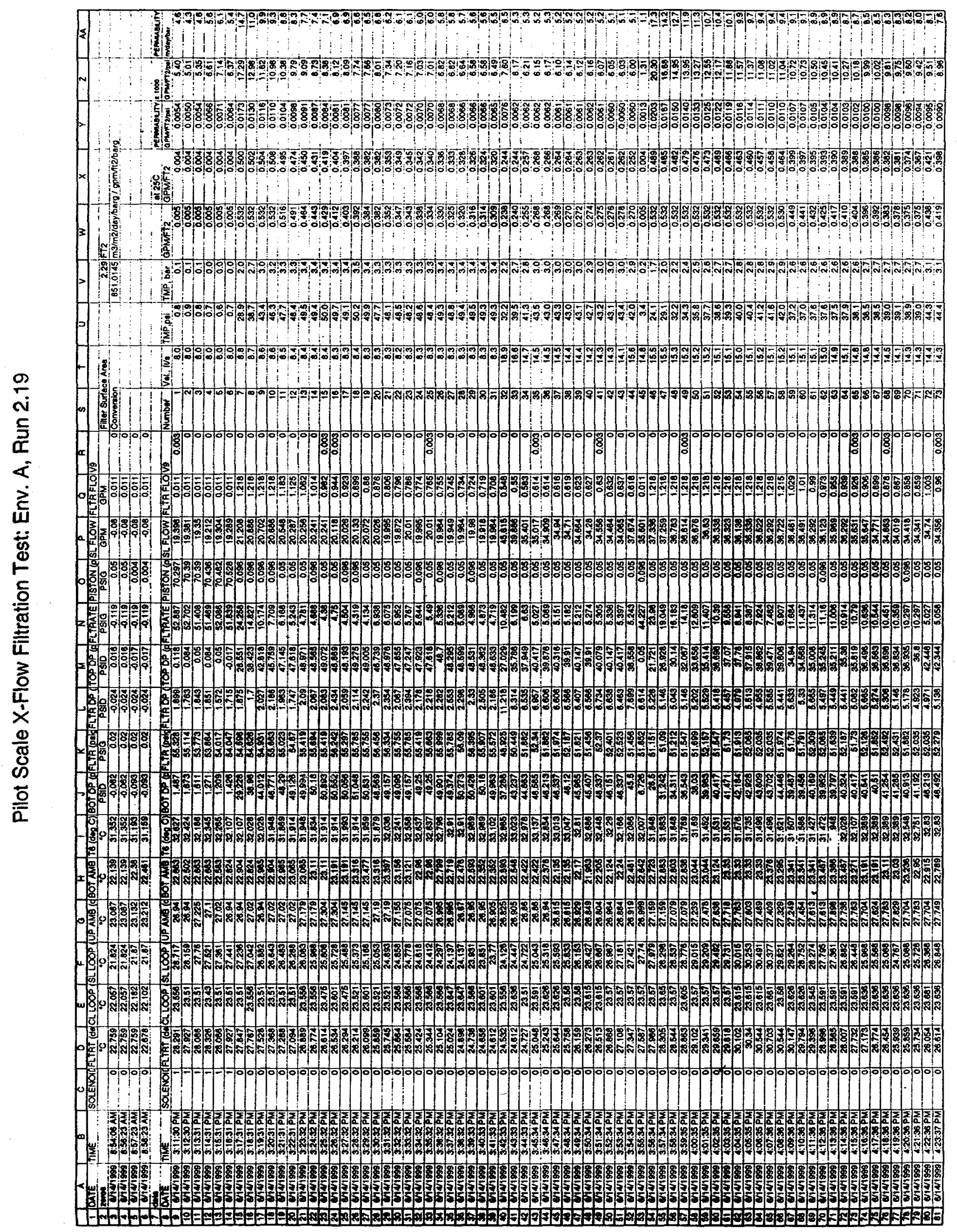




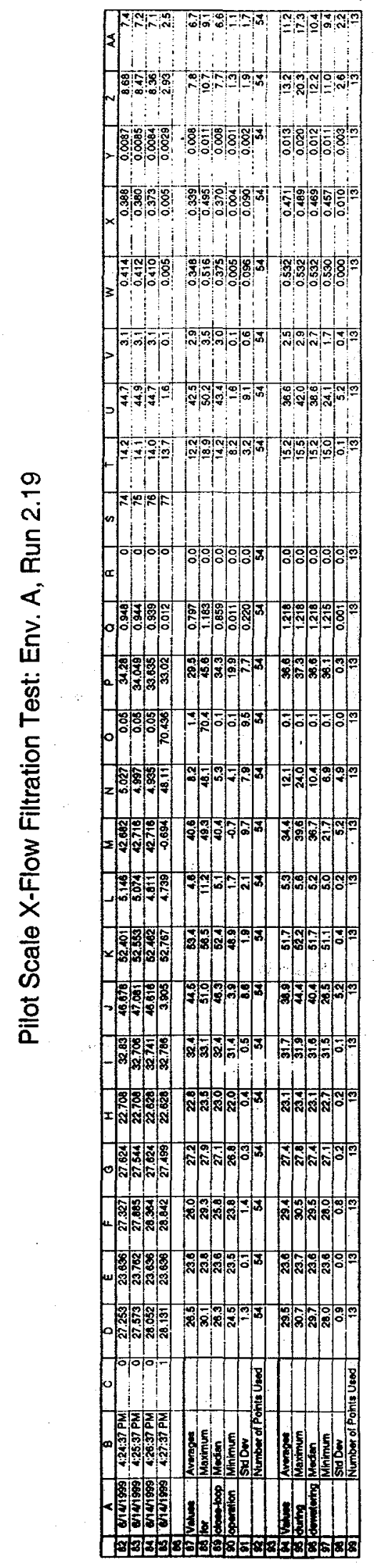



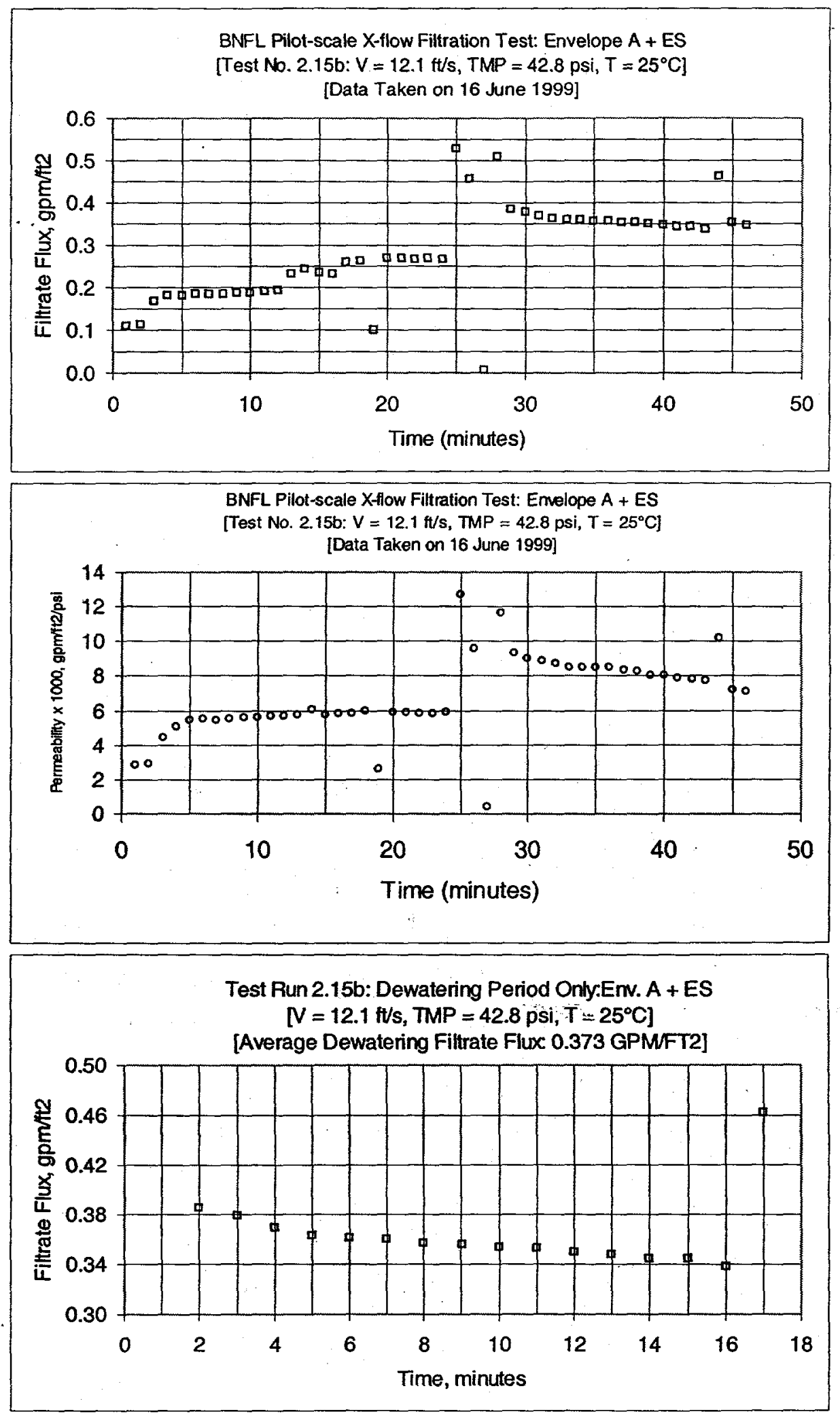

Figure D5: Test Run 2.15b, Second Wash 1 
Pilot scale X-flow: EnvA+ES Page 157 of 226

BNF-003-98-0221

Revision 0

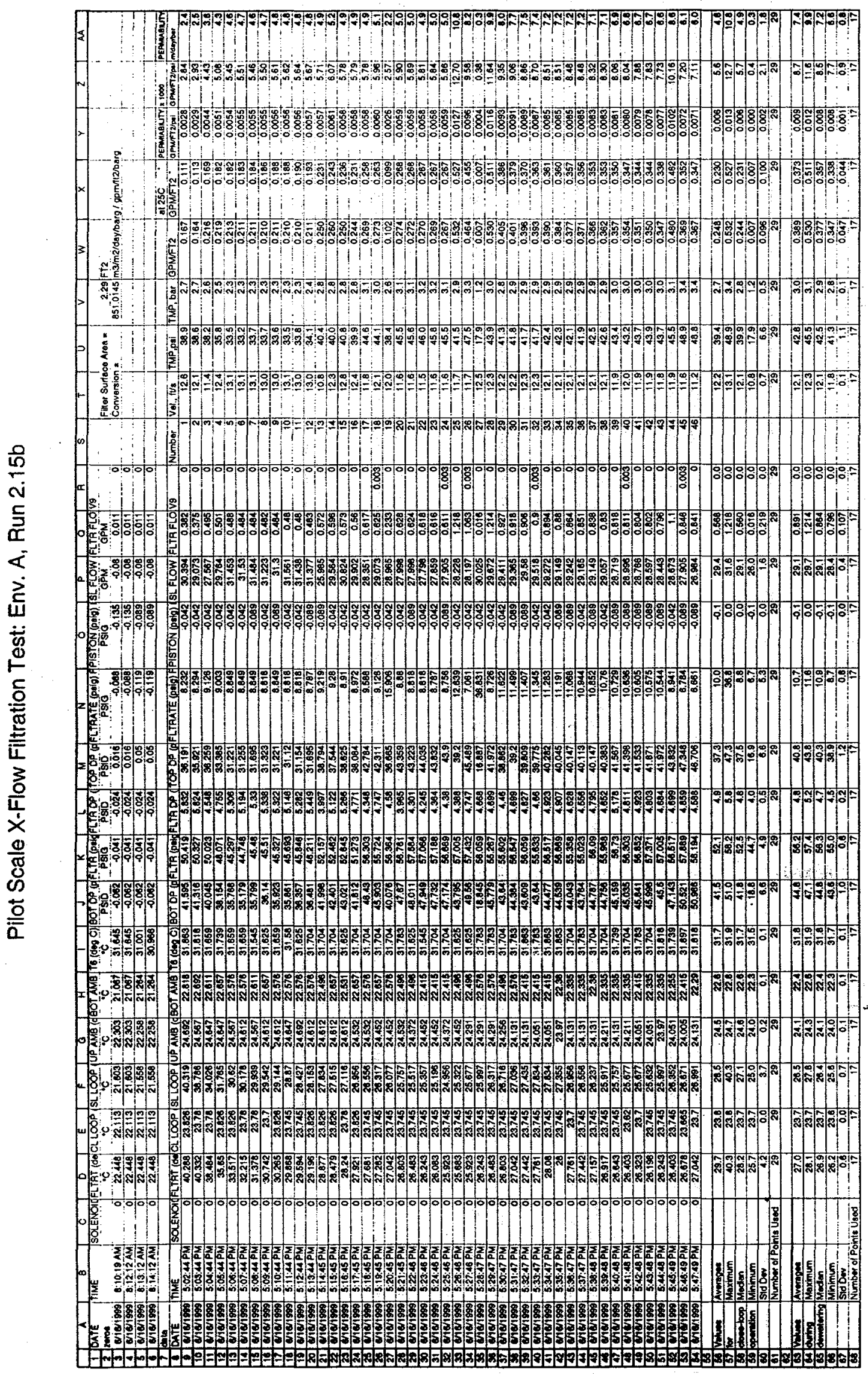



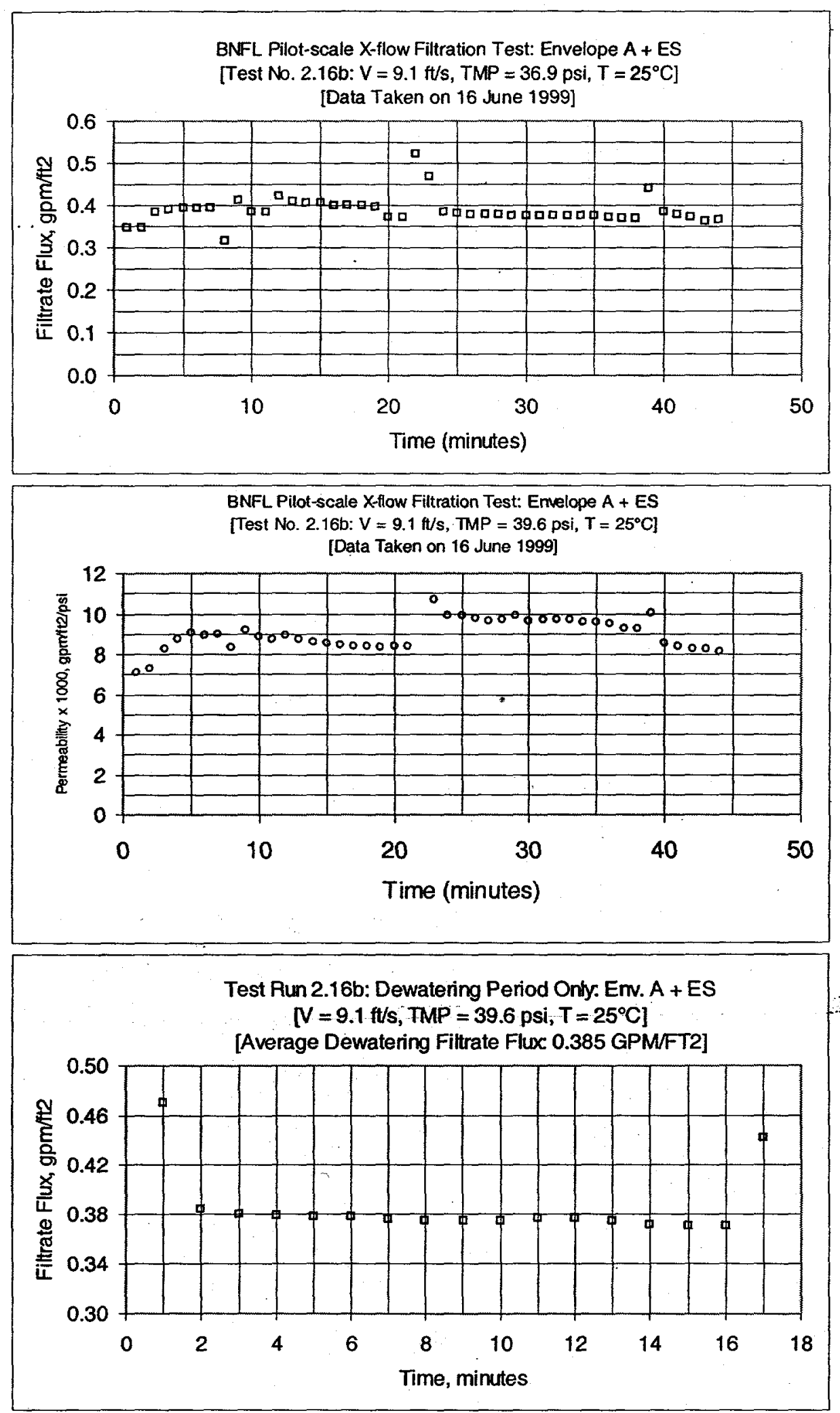

Figure D6: Test Run 2.16b, Second Wash 2 
Pilot scale X-flow: EnvA+ES Page 159 of 226

BNF-003-98-0221

Revision 0

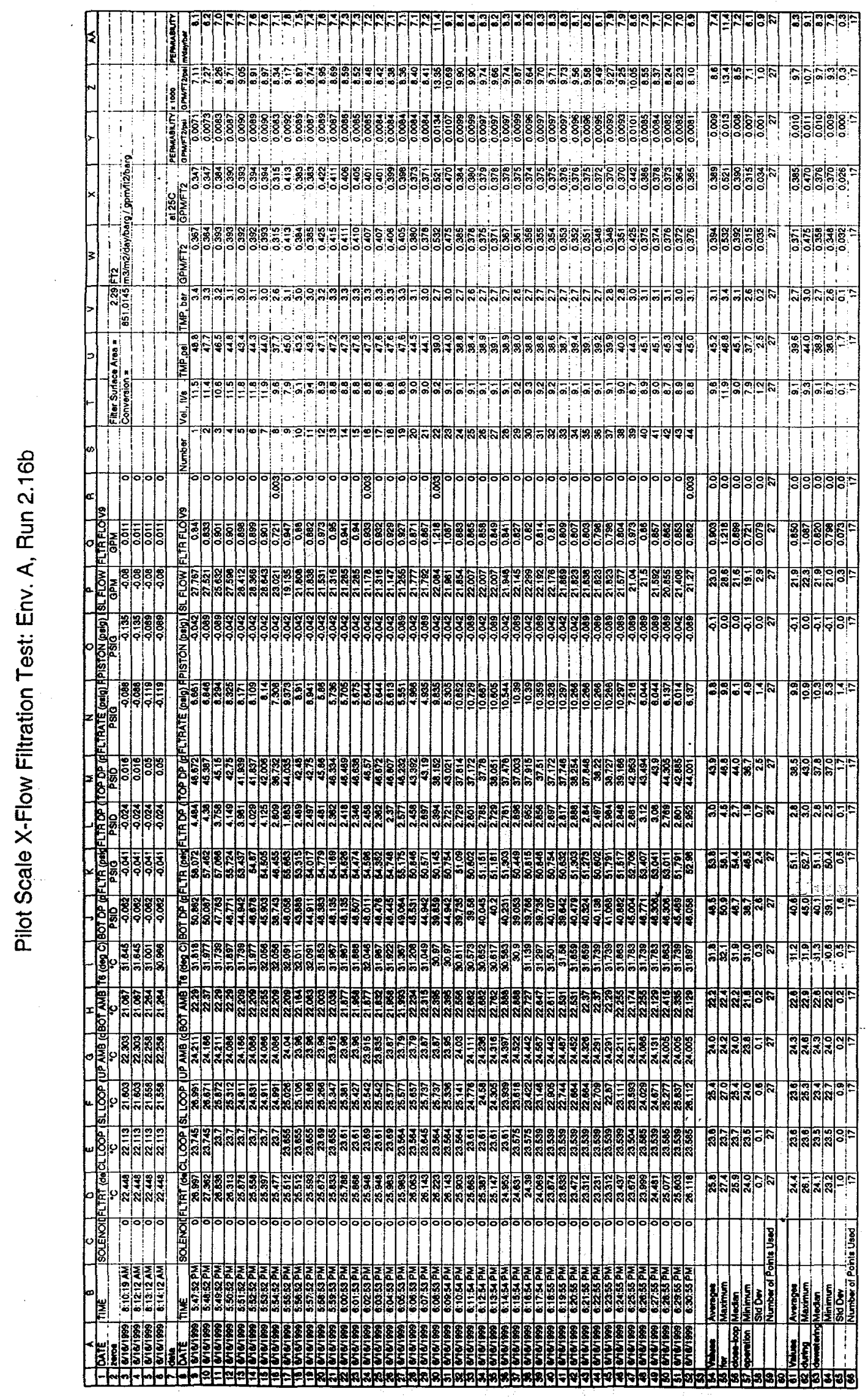



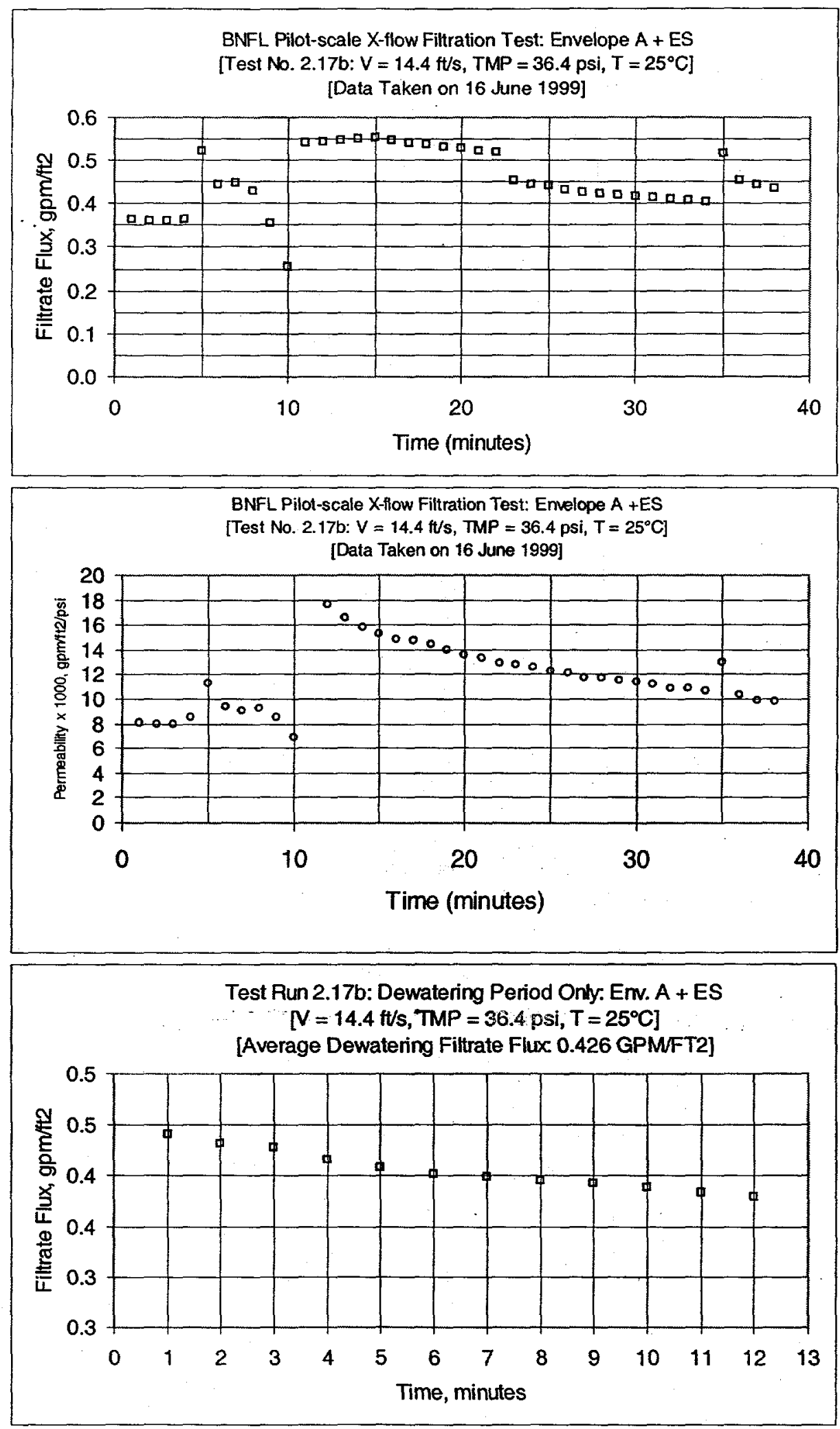

Figure D7: Test Run 2.17b, Second Wash 3 


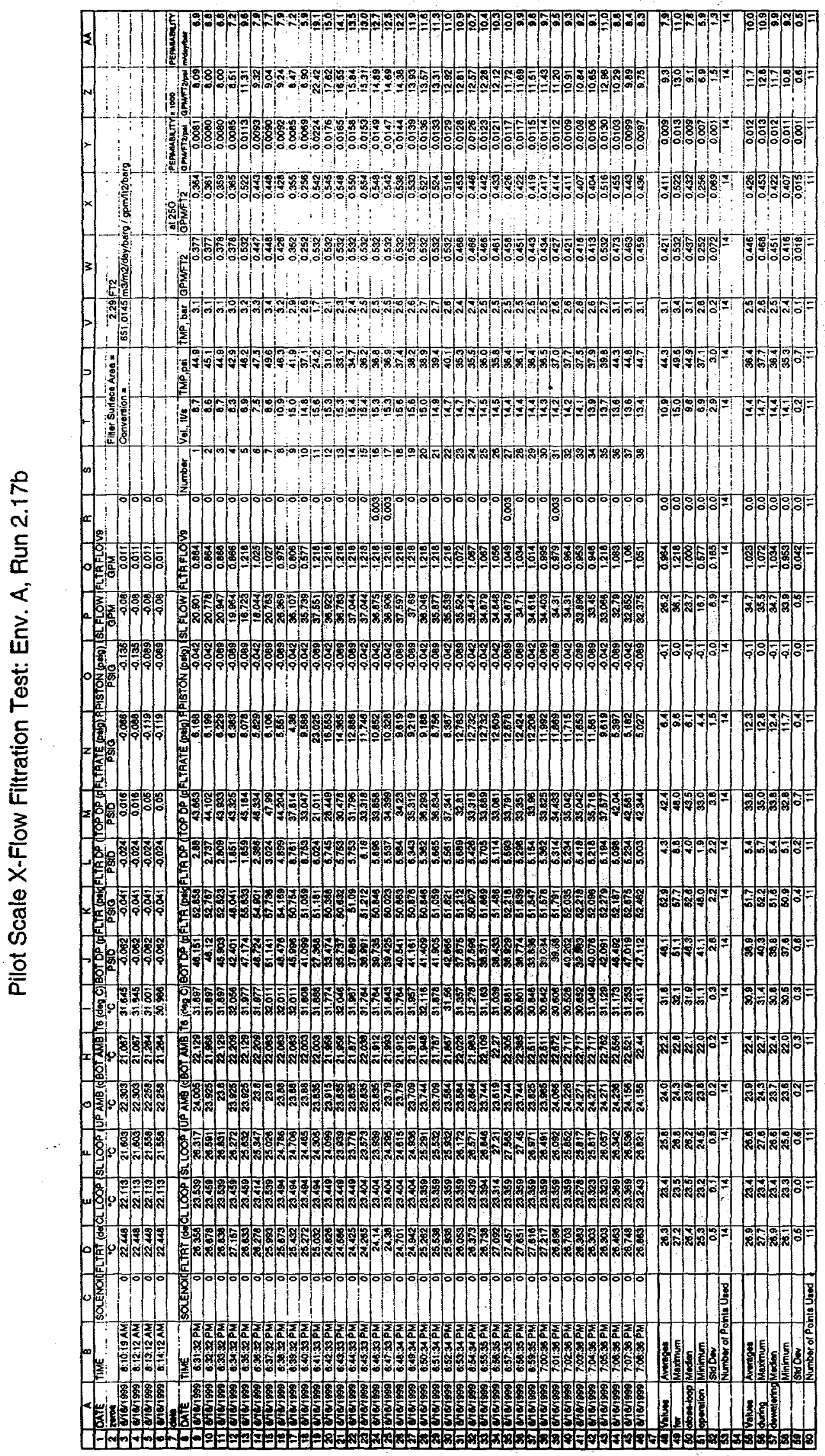



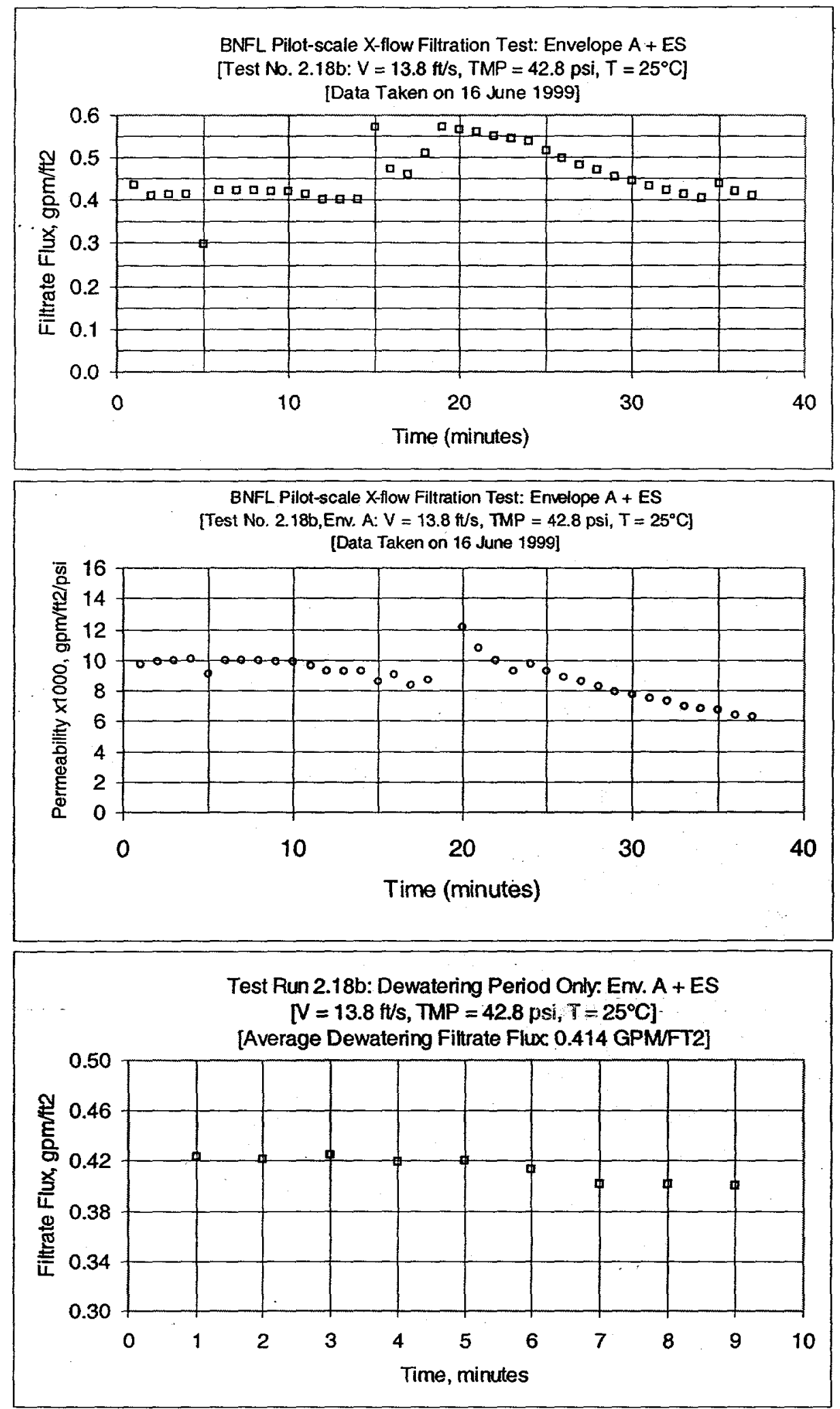

Figure D8: Test Run 2.18b, Second Wash 4 


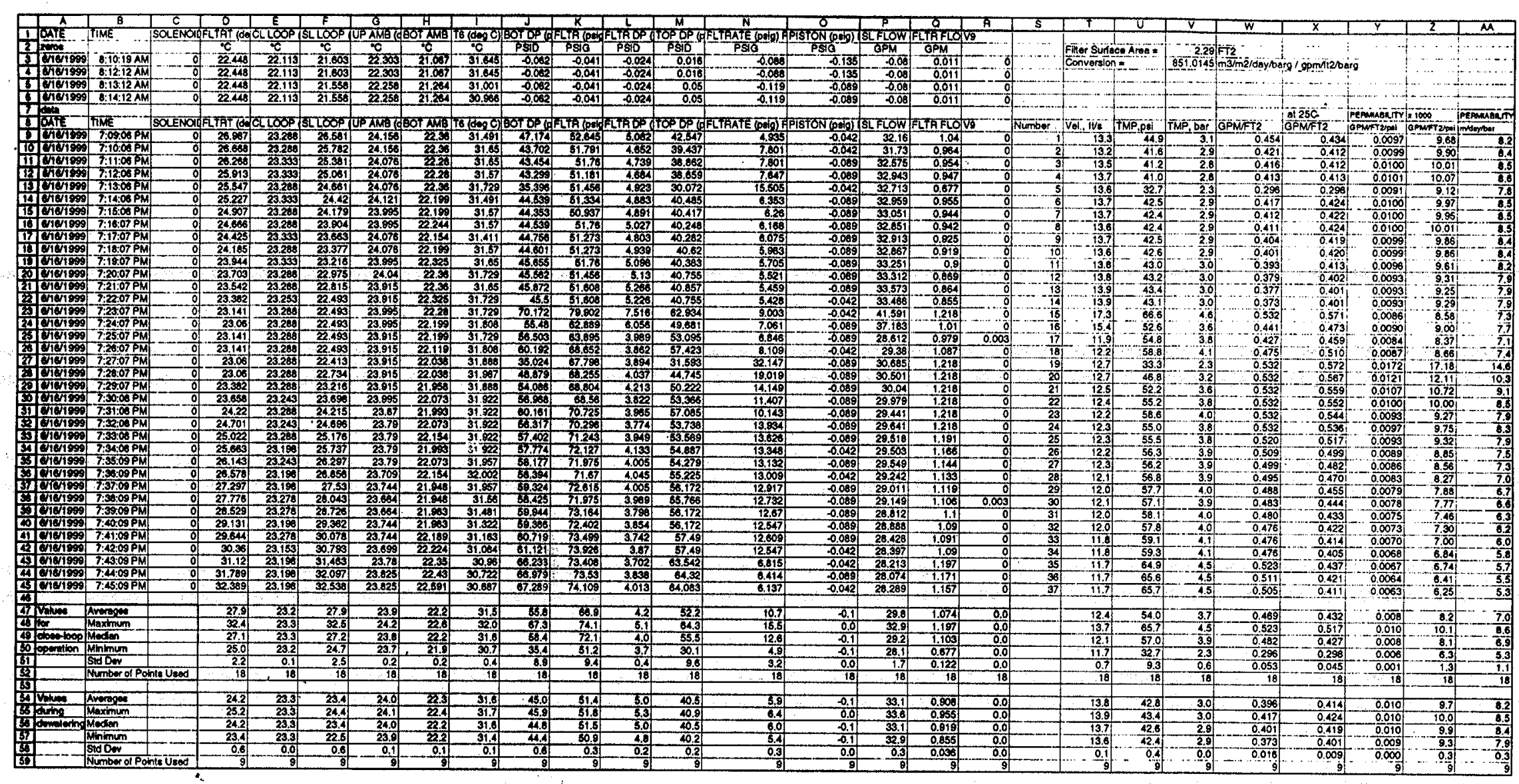



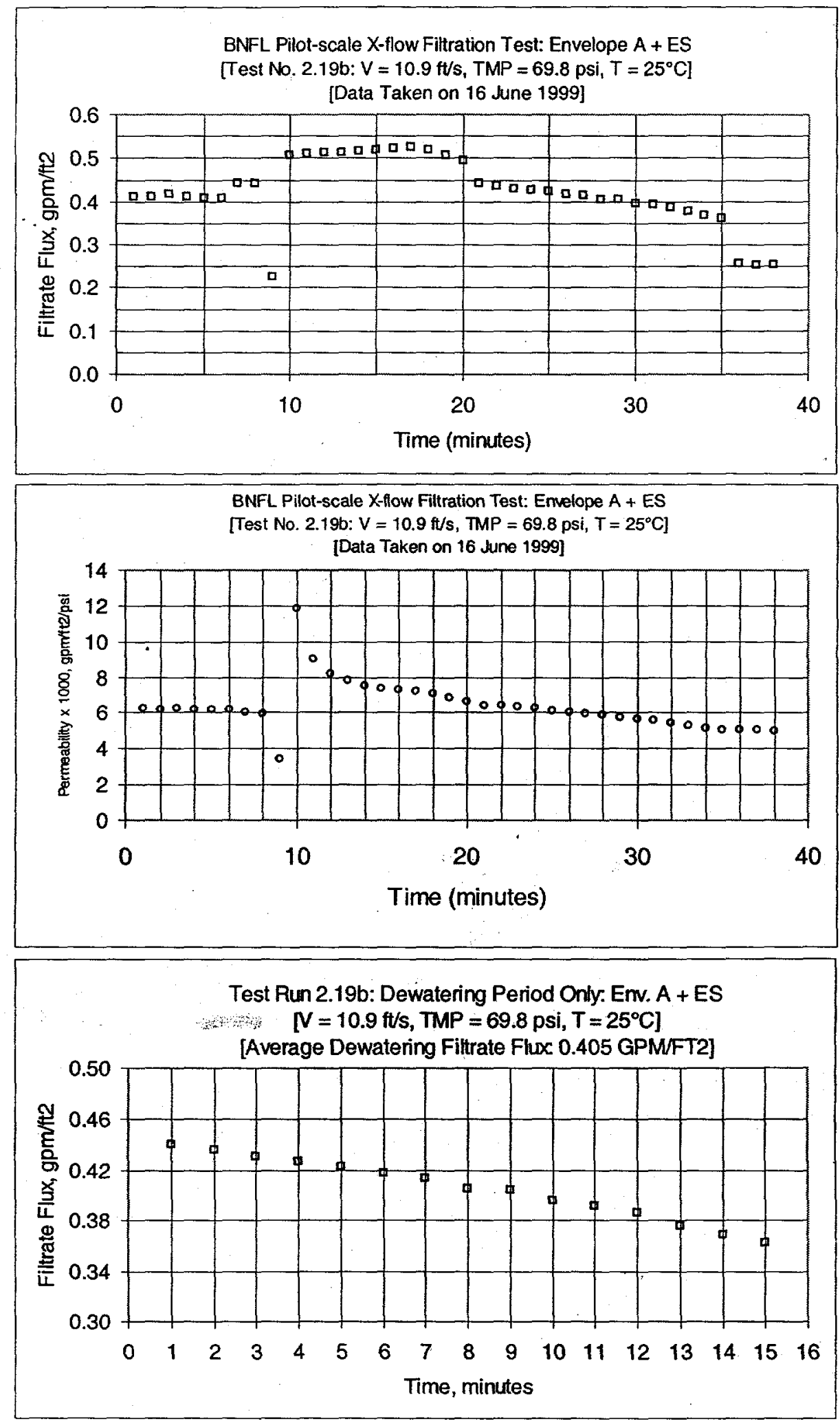

Figure D9: Test Run 2.19b, Wash 5 
Pilot scale X-flow: EnvA+ES Page 165 of 226

BNF-003-98-0221

Revision 0

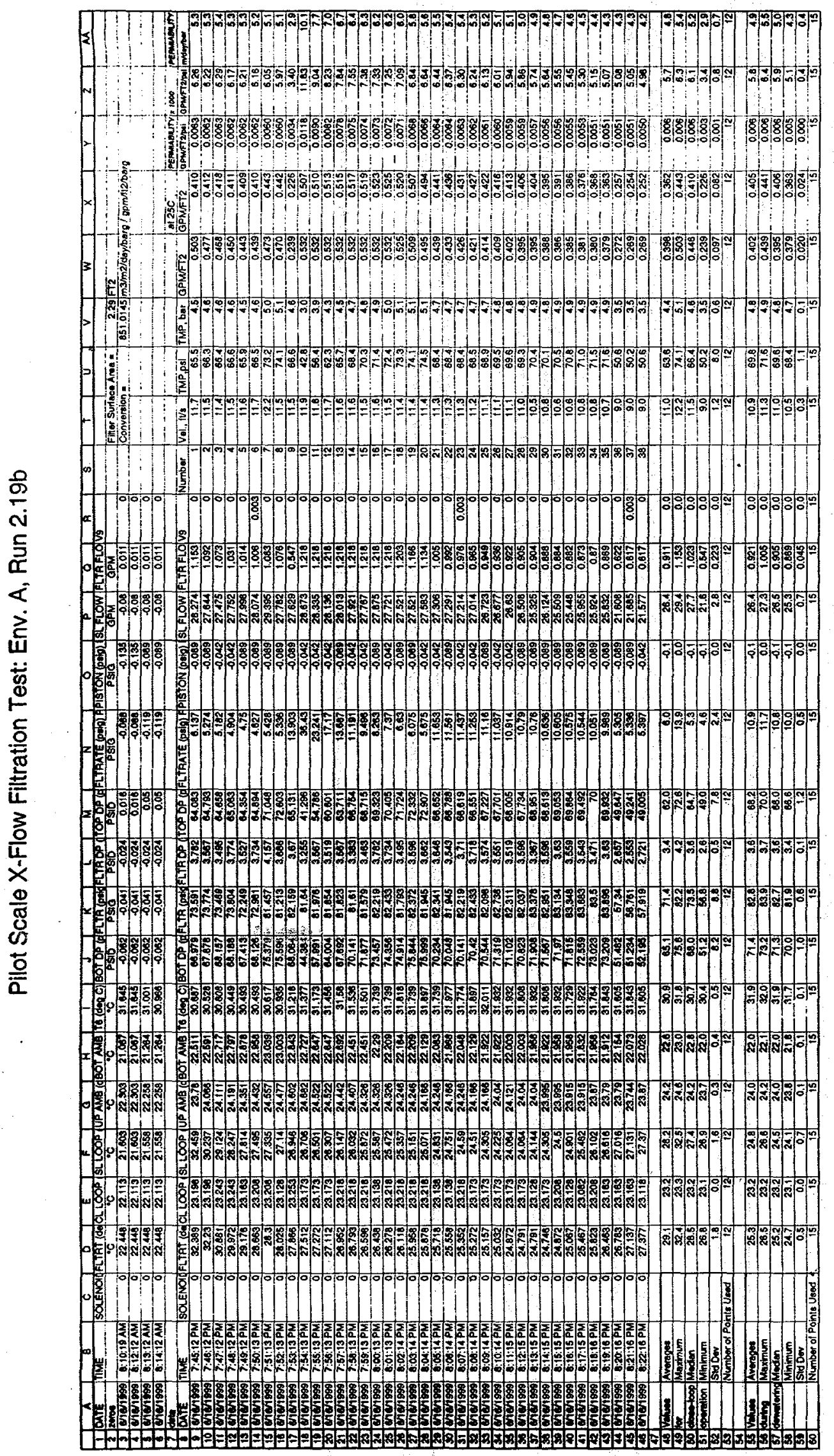




\section{APPENDIX E}

\section{ANALYTICAL DATA}

\section{Appendix Contents}

1. Eleven pages of Table E1 contain all of the analytical data.

2. Slurry Rheology: Fig. E1, Run 2.13; Fig. E2, Run 2.14b, Fig. E3, Run 2.20b

2. Graphs of selected chemical element concentrations throughout the test by molarity

Figures E4-E17 are Al, Ca, Cl, Cr, F, Fe, K, Mn, Mo, Na, Ni, P, Pb, and $\mathrm{Si}$

3. Graphs of selected chemical compounds concentration throughout the test by molarity. Figures E18-E20 are: Oxalate, Phosphate, and Sulfate

4. Graphs and tabular data on the particle distibutions throughout the test

Figure E21 is: particle distibution from a real waste sample

Figures E22A, E22B, to E29A, and E29B are for test runs: Pre-test, 2.01, 2.13, $2.14,2.16,2.14 b, 2.16 b, 2$.

\section{Special Notes:}

a. There are no measurement uncertainties listed because the measurement uncertainties for analytical data are beyond the scope and control of this task. There is reason to believe that all analytical data can be at least $15 \%$ accurate but no quantitative data are given to this effect. Density and filtrate viscosity are the only slurry property data that were obtained at the test rig location and the uncertainty of those data can be stated as:

Density: $\leq 0.5 \%$ of reading by calibration Viscosity: $0.34 \mathrm{wt} \%$ of reading by manufacturer's statement.

b. Only three figure, E1, E2, E3 are given for the slurry rheology because the rheology was similar for all samples. The slurry basically act as a Newtonian fluid but at the highest solids loading there is a small amount of yield stress which drops off very rapidly after the slurry is put into motion.

c. Each particle analysis was done by a Volume and a Number distribution, thus there are two figures for each, e.g., 19A and 19B.) 


\begin{tabular}{|c|c|c|c|c|c|c|}
\hline & A & $\mathrm{B}$ & $\mathrm{C}$ & $\mathrm{D}$ & $E$ & $F$ \\
\hline 1 & \multicolumn{2}{|c|}{ TEST RUN } & Most Recent Entry Date & & $\therefore \quad 2.00$ & 2.00 \\
\hline 2 & \multicolumn{2}{|c|}{ BNFL Sample ID ….............. } & February/22/2000 & Pre-Test Sample & BNF-SXF2055-A+ES_01a & BNF-SXF2055-A+ES_016 \\
\hline 3 & \multicolumn{3}{|c|}{ ADS Sample ID } & 3-126787 & \begin{tabular}{|l|} 
\\
\end{tabular} & $3-127888$ \\
\hline 4 & \multicolumn{3}{|c|}{ Type Sample -.......... } & slurry & slurry loop & slurry loop \\
\hline 5 & Sample Size - -............... & $\mathrm{mL}$ & & 125 & 15 & 15 \\
\hline 6 & Measurement(s) Made $\rightarrow \cdots$ & \multicolumn{2}{|c|}{ (SEE NOMECLATURE TO EXPLANN LETTERS) } & 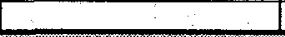 & SSICP.ESANTL-TOCASEAC-AMONS & SSNCP-ESIMATC-TOCNSEAC-ANONS \\
\hline 7 & Item Measured & Units & Analyst Name & 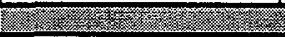 & \multicolumn{2}{|c|}{ Ty } \\
\hline 8 & Density & $g / \mathrm{mL}$ & Thermal Fluids Lab & 1.20 & water before test 2.00 & water after test 2.00 \\
\hline 9 & Al & $\mathrm{ug} / \mathrm{mL}$ & Frank Pennebaker & 15650 & $<0.6$ & $<0.6$ \\
\hline 10 & $\mathrm{~B}$ & $\mathrm{ug} / \mathrm{mL}$ & Frank Pennebaker & 15.7 & $<0.3$ & $<0.3$ \\
\hline 11 & $\mathrm{Ba}$ & $\mathrm{ug} / \mathrm{mL}$ & Frank Pennebaker & $<0.5$ & $<0.1$ & $<0.1$ \\
\hline 12 & $\mathrm{Ca}$ & $\mathrm{ug} / \mathrm{mL}$ & Frank Pennobaker & 39.1 & $<0.4$ & $<0.4$ \\
\hline 13 & $\mathrm{Cd}$ & $\mathrm{ug} / \mathrm{mL}$ & Frank Pennebaker & $<0.5$ & $<0.1$ & $<0.1$ \\
\hline 14 & $\mathrm{Cl}$ & $\mathrm{ug} / \mathrm{mL}$ & Robert Ray/Joyce Cartledge & 3766 & N/A & N/A \\
\hline 15 & Cl Sample & $\mathrm{ug} / \mathrm{mL}$ & Robert Ray/Sarah Brown & N/A & 342.47 & N/A \\
\hline 16 & $\mathrm{Co}$ & $\mathrm{ug} / \mathrm{mL}$ & Frank Pennebaker & $<0.5$ & $<0.1$ & $<0.1$ \\
\hline 17 & $\mathrm{Cr}$ & $\mathrm{ug} / \mathrm{mL}$ & Frank Pennebaker & 329 & $<0.1$ & $<0.1$ \\
\hline 18 & $\mathrm{Cu}$ & $\mathrm{ug} / \mathrm{mL}$ & Frank Pennebaker & $<0.5$ & $<0.1$ & $<0.1$ \\
\hline 19 & F (Fluoride) -(only rough rdg) & $\mathrm{ug} / \mathrm{mL}$ & Robert Ray/Soyce Cartledge & $<20$ & N/A & N/A \\
\hline 20 & F Sample & $\mathrm{ug} / \mathrm{mL}$ & Robert Ray/Sarah Brown & $N / A$ & $<1$ & N/A \\
\hline 21 & $\mathrm{Fe}$ & $\mathrm{ug} / \mathrm{mL}$ & Frank Pennebaker & 25.1 & $<0.2$ & $<0.2$ \\
\hline 22 & HCOO (Formate) & $\mathrm{ug} / \mathrm{mL}$ & Robert Ray/Joyce Cartledge & 1447 & N/A & N/A \\
\hline 23 & $\mathrm{~K}$ & $\mathrm{ug} / \mathrm{mL}$ & Sarah Brown & $\mathrm{N} / \mathrm{A}$ & 0.918 & N/A \\
\hline 24 & La & $4 \mathrm{~g} / \mathrm{mL}$ & Frank Pennebaker & N/A & $<0.28$ & $<0.28$ \\
\hline 25 & Li & ug/mL & Frank Pennebaker & $<6.6$ & $<1.2$ & $<1.2$ \\
\hline 26 & $\mathrm{Mg}$ & $\mathrm{ug} / \mathrm{mL}$ & Frank Pennebaker & 6.2 & $<0.1$ & $<0.1$ \\
\hline 27 & $\mathrm{Mn}$ & $u g / m L$ & Frank Pennebaker & 7.8 & $<0.1$ & $<0.1$ \\
\hline 28 & Mo & $u g / \mathrm{mL}$ & Frank Pennebaker & 30.4 & $<0.1$ & $<0.1$ \\
\hline 29 & $\mathrm{Na}$ & $\mathrm{ug} / \mathrm{mL}$ & Frank Pennebaker & 98700 & 14 & 12 \\
\hline 30 & $\mathrm{Ni}$ & $\mathrm{ug} / \mathrm{mL}$ & Frank Pennebaker & $<0.6$ & $<0.15$ & $<0.15$ \\
\hline 31 & NOR (Nitrite) & $\mathrm{ug} / \mathrm{mL}$ & Robent Ray/Joyce Cartledge & 44946 & N/A & N/A \\
\hline 32 & NO3 (Nitrate) & $\mathrm{ug} / \mathrm{mL}$ & Robert Ray/Joyce Cartledge & 57471 & N/A & N/A \\
\hline 33 & C2O4 (Oxalate) & $\mathrm{ug} / \mathrm{mL}$ & Robert Ray/Joyce Cartledge & 743 & N/A & N/A \\
\hline 34 & $P$ & $49 / \mathrm{mL}$ & $\therefore$ Frank Pennebaker & 69.3 & $<$ & $<2$ \\
\hline 35 & PO4 (Phosphate) & $\omega g / m L$ & Robert Ray/Joyce Cartledge & 405 & N/A & N/A \\
\hline 36 & $\mathrm{~Pb}$ & $4 \mathrm{~g} / \mathrm{mL}$ & Frank Pennebaker & $<5$ & $<1$ & $<1$ \\
\hline 37 & $\mathrm{Si}$ & $\mathbf{w} / \mathrm{mL}$ & Frank Pennebaker & 126 & $<1$ & $<1$ \\
\hline 38 & Sn & ug/mL & Frank Pennobaker & $<4$ & $<0.8$ & $<0.8$ \\
\hline 39 & SO4 (Suffate) & $\mathrm{ug} / \mathrm{mL}$ & Robert Ray/Joyce Cartledge & 343 & NA & N/A \\
\hline 40 & $\mathrm{Sr}$ & $\mathrm{ug} / \mathrm{mL}$ & Frank Pennebaker & $<1$ & $<0.1$ & $<0.1$ \\
\hline 41 & $T i$ & $\mathrm{ug} / \mathrm{mL}$ & Frank Pennobaker & $<0.5$ & $<0.1$ & $<0.1$ \\
\hline 42 & 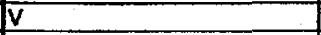 & $\mathrm{ug} / \mathrm{mL}$ & - Frank Pennebaker & $<1.5$ & $<0.1$ & $<0.1$ \\
\hline 43 & $\overline{Z n}$ & $\mathrm{ug} / \mathrm{mL}$ & Frank Pennebaker & 11.1 & $<0.1$ & $<0.1$ \\
\hline 44 & $\mathrm{Zr}$ & $\mathrm{ug} / \mathrm{mL}$ & Frank Pennebaker & $<1.5$ & $<0.3$ & $<0.3$ \\
\hline 45 & Total Organic Cartoon & $\mu g / \mathrm{mL}$ & Robert Ray & 1509 & 35.24 & N/A \\
\hline 46 & Total Inorganic Carbon & $\mathrm{ug} / \mathrm{mL}$ & Robert Ray & 1924 & 0.41 & N/A \\
\hline 47 & Suspended Solids & $w+\%$ & Beverly Burch & N/A & $<0.003$ & N/A \\
\hline 48 & Total Solids & $w+\%$ & Beverly Burch & N/A & N/A & N/A \\
\hline 49 & Mean Particle Size by Volume & micron & Don Blankenship & $2.4 / 309$ & N/A & N/A \\
\hline 50 & Mean Particle Size by Number & micron & Don Blankenship & $\mathrm{N} / \mathrm{A}$ & N/A & N/A \\
\hline 51 & Kinematic Viscosity & cSt & CONETTNX-CAPILLARY/TFL & N/A & N/A & N/A \\
\hline 52 & Dynamic Viscosity & $\mathrm{CP}$ & Calculated & N/A & N/A & N/A \\
\hline 53 & Comment & & & bimodel particle distribution & water before test & water after test \\
\hline
\end{tabular}

Table E1: Analytical - All data, Page1 


\begin{tabular}{|c|c|c|c|c|c|c|}
\hline & \begin{tabular}{|c|} 
\\
\end{tabular} & $\mathrm{H}$ & 1 & J & $K$ & $\mathbf{L}$ \\
\hline 1 & 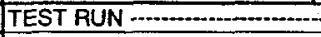 & $\ldots$ & 2.01 & 2.01 & 2.01 & 2.01 \\
\hline 2 & BNFL Sample ID & $\ldots \ldots$ & Unplanned Sample & BNF-SXF2055-A+ES_02 & BNF-SXF2055-A+ES_03 & No Sample Kept \\
\hline 3 & ADS Sample ID & $\rightarrow \cdots$ & TNX Sample/No Number & $3-127890$ & $3-127891$ & No Sample Number \\
\hline 4 & Type Sample ...................... & $\ldots+\cdots+1$ & slurry & slurry & slurry & filtrate \\
\hline 5 & Sample Size $-\cdots \cdot \cdots+\cdots$ & $\mathrm{mL}$ & 150 & 50 & 15 & $100 \mathrm{~mL}$ /returned to mixture \\
\hline 6 & Measurement(s) Made ........ & $\ldots$ & TSISSNISCOSITY/DENSITY & MICROTRAC & TSISS & DENSITY ONLY \\
\hline 7 & Item Measured & Units & 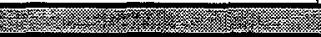 & 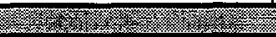 & 76 & স4; \\
\hline 8 & Density & $\mathrm{g} / \mathrm{mL}$ & 1.240 & 1.232 & 1.232 & 1.231 \\
\hline 9 & $A \mid$ & $u g / m L$ & N/A & N/A & NA & $N / A$ \\
\hline 10 & B & ug/mL & N/A & N/A & N/A & N/A \\
\hline 11 & $\mathrm{Ba}$ & $\mathrm{ug} / \mathrm{mL}$ & N/A & N/A & N/A & N/A \\
\hline 12 & $\mathrm{Ca}$ & $\mathrm{ug} / \mathrm{mL}$ & N/A & N/A & N/A & N/A \\
\hline 13 & Cd & $u g / \mathrm{mL}$ & N/A & N/A & N/A & NA \\
\hline 14 & $\mathrm{al}$ & $u g / m L$ & N/A & N/A & N/A & N/A \\
\hline 15 & CI Sample & $\mathrm{ug} / \mathrm{mL}$ & N/A & N/A & N/A & N/A \\
\hline 16 & Co & $\mathrm{u} g / \mathrm{mL}$ & N/A & N/A & N/A & N/A \\
\hline 17 & $\mathrm{Cr}$ & $u g / \mathrm{mL}$ & N/A & N/A & N/A & N/A \\
\hline 18 & $\mathrm{Cu}$ & $4 \mathrm{~g} / \mathrm{mL}$ & N/A & N/A & N/A & N/A \\
\hline 19 & F (Fluoride) -(only rough rdg) & $\mathrm{ug} / \mathrm{mL}$ & N/A & N/A & $N / A$ & N/A \\
\hline 20 & F Sample & $\mathrm{ug} / \mathrm{mL}$ & NA & N/A & N/A & N/A \\
\hline 21 & $\mathrm{Fe}$ & $\mathrm{ug} / \mathrm{mL}$ & N/A & N/A & N/A & N/A \\
\hline 22 & HCOO (Formate) & $\mathrm{ug} / \mathrm{mL}$ & N/A & N/A & N/A & N/A \\
\hline 23 & $\mathrm{~K}$ & $\mathrm{ug} / \mathrm{mL}$ & N/A & N/A & N/A & N/A \\
\hline 24 & La & ug $/ \mathrm{mL}$ & NA & N/A & N/A & N/A \\
\hline 25 & $\mathrm{Li}$ & $\mathrm{ug} / \mathrm{mL}$ & N/A & N/A & NIA & N/A \\
\hline 26 & $\mathrm{Mg}$ & $\mathrm{ug} / \mathrm{mL}$ & N/A & N/A & N/A & N/A \\
\hline 27 & $\mathrm{Mn}$ & $\mathrm{ug} / \mathrm{mL}$ & NA & N/A & N/A & N/A \\
\hline 28 & Mo & $\mathrm{ug} / \mathrm{mL}$ & N/A & N/A & N/A & N/A \\
\hline 29 & $\mathrm{Na}$ & $\mathrm{ug} / \mathrm{mL}$ & N/A & N/A & N/A & N/A \\
\hline 30 & $\mathrm{Ni}$ & $\mathrm{ug} / \mathrm{mL}$ & N/A & $N / A$ & N/A & N/A \\
\hline 31 & NO2 (Nitrite) & ug/mL & N/A & N/A & N/A & N/A \\
\hline 32 & NO3 (Nitrate) & $u g / \mathrm{mL}$ & N/A & N/A & N/A & N/A \\
\hline 3 & C204 (Oxalate) & $u g / \mathrm{mL}$ & N/A & N/A & N/A & N/A \\
\hline 34 & $\mathbf{P}$ & $u g / m L$ & N/A & N/A & N/A & NA \\
\hline 35 & PO4 (Phosphate) & $u g / \mathrm{mL}$ & N/A & N/A & N/A & N/A \\
\hline 36 & $\mathrm{~Pb}$ & $\mathrm{ug} / \mathrm{mL}$ & N/A & N/A & N/A & N/A \\
\hline 37 & $\mathrm{Si}$ & $\mathrm{ug} / \mathrm{mL}$ & N/A & N/A & N/A & N/A \\
\hline 38 & Sn & $\mathrm{ug} / \mathrm{mL}$ & N/A & N/A & N/A & N/A \\
\hline 39 & SO4 (Sulfate) & $\mathrm{ug} / \mathrm{mL}$ & N/A & N/A & N/A & N/A \\
\hline 40 & $\mathrm{Sr}$ & $u g / \mathrm{mL}$ & N/A & N/A & N/A & N/A \\
\hline 41 & $\frac{T}{T i}$ & $\mathrm{ug} / \mathrm{mL}$ & $\mathrm{N} / \mathrm{A}$ & N/A & $N / A$ & N/A \\
\hline 42 & $\mathbf{v}$ & $u g / m L$ & N/A & N/A & N/A & N/A \\
\hline 43 & $2 n$ & ug/mL & N/A & N/A & N/A & N/A \\
\hline 44 & $\mathbf{Z} r$ & $\mathrm{ug} / \mathrm{mL}$ & N/A & N/A & N/A & N/A \\
\hline 45 & Total Organic Carbon & $\mathrm{ug} / \mathrm{mL}$ & N/A & N/A & N/A & N/A \\
\hline 46 & Total Inorganic Carbon & $\mathrm{ug} / \mathrm{mL}$ & N/A & N/A & N/A & N/A \\
\hline 47 & Suspended Solids & $w+\%$ & 0.52 & NA & 0.4509 & NA \\
\hline 48 & Total Solids & $w+\%$ & 30.57 & NA & 28.26 & N/A \\
\hline 49 & Mean Particle Size by Volume & micron & N/A & 2.59 & NA & N/A \\
\hline 50 & Mean Particle Size by Numbe & micron & N/A & 1.05 & N/A & N/A \\
\hline 51 & Kinematic Viscosity & $\mathrm{cSt}$ & 2.4 & N/A & N/A & N/A \\
\hline 52 & Dynamic Viscosity & CP. & 3.0 & N/A & N/A & N/A \\
\hline 53 & Comment & & HAAKE/SPINNING CONE & & & \\
\hline
\end{tabular}

Table E1: Analytical - All data, Page2 


\begin{tabular}{|c|c|c|c|c|c|c|}
\hline & $M$ & $N$ & 0 & $\mathbf{P}$ & $Q$ & R \\
\hline 1 & TEST RUN & $\ldots \ldots$ & 2.01 & 2.13 & 2.13 & 2.13 \\
\hline 2 & BNFL Sample ID …................. & $\cdots$ & BNF-SXF2055-A+ES_04 & BNF-SXF2055-A+ES_02b & BNF-SXF2055-A+ES_03b & Unplanned Sample \\
\hline 3 & ADS Sample ID & $\ldots$ & $3-127889$ & $3-128290$ & $3-128291$ & TNX Sample/No Number \\
\hline 4 & Type Sample - - & $-\cdots$ & fiftrate & slurry - & slurry & slurry \\
\hline 5 & Sample Size - & $\mathrm{mL}$ & 15 & 50 & 15 & 150 \\
\hline 6 & Measurement(s) Made ...... & $\longrightarrow$ & SSHCP-ESIANTC-TOCNSEMC-ANHONS & MICROTRAC & TS/SS & TSISSNISCOSITY/DENSITY \\
\hline 7 & \begin{tabular}{|l|} 
Hem Measured \\
\end{tabular} & Units & 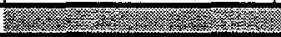 & 1. & 1) & r \\
\hline 8 & Density & $\mathrm{g} / \mathrm{mL}$ & N/A & 1.232 & 1.240 & 1.256 \\
\hline 9 & A & $\mathrm{ug} / \mathrm{mL}$ & 17900 & N/A & N/A & NA \\
\hline 10 & 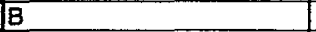 & $\mathrm{ug} / \mathrm{mL}$ & 25 & N/A & N/A & N/A \\
\hline 11 & $\mathrm{Ba}$ & $\mathrm{ug} / \mathrm{mL}$ & $<0.1$ & N/A & N/A & N/A \\
\hline 12 & $\mathrm{Ca}$ & $\mathrm{ug} / \mathrm{mL}$ & 0.5 & N/A & N/A & N/A \\
\hline 13 & $\mathrm{Cd}$ & $\mathrm{ug} / \mathrm{mL}$ & $<0.1$ & N/A & N/A & N/A \\
\hline 14 & a & $\mathrm{ug} / \mathrm{mL}$ & 3644 & $\mathrm{~N} / \mathrm{A}$ & N/A & N/A \\
\hline 15 & CI Sample & $\mathrm{ug} / \mathrm{mL}$ & 5186.57 & N/A & $\mathrm{N} / \mathrm{A}$ & N/A \\
\hline 16 & Co & $\mathrm{ug} / \mathrm{mL}$ & $<0.1$ & N/A & $N / A$ & N/A \\
\hline 17 & $\mathrm{Cr}$ & $\mathrm{ug} / \mathrm{mL}$ & $<0.1$ & N/A & N/A & NAA \\
\hline 18 & $\mathrm{Cu}$ & ug $/ \mathrm{mL}$ & $<0.1$ & N/A & N/A & N/A \\
\hline 19 & F (Fluoride) -(only rough rdg) & ug $/ \mathrm{mL}$ & 206 & N/A & N/A & N/A \\
\hline 20 & F Sample & $\mathrm{ug} / \mathrm{mL}$ & 219 & N/A & N/A & N/A \\
\hline 21 & $\mathrm{Fe}$ & ug $/ \mathrm{mL}$ & 2.7 & N/A & N/A & N/A \\
\hline 22 & HCOO (Formate) & $4 \mathrm{~g} / \mathrm{mL}$ & 1529 & NA & N/A & N/A \\
\hline 23 & $\mathrm{~K}$ & ug/mL & 3480.6255 & $\mathrm{~N} / \mathrm{A}$ & N/A & N/A \\
\hline 24 & La & $4 \mathrm{~g} / \mathrm{mL}$ & $<0.28$ & N/A & N/A & N/A \\
\hline 25 & LL & $\mathrm{ug} / \mathrm{mL}$ & $<1.2$ & N/A & NA & N/A \\
\hline 26 & $\mathrm{Mg}$ & $\mathrm{ug} / \mathrm{mL}$ & $<0.1$ & N/A & N/A & N/A \\
\hline 27 & $\operatorname{Mn}$ & $\mathrm{ug} / \mathrm{mL}$ & 50.1 & N/A & NA & N/A \\
\hline 28 & Mo & $\mathrm{ug} / \mathrm{mL}$ & 35 & N/A & N/A & N/A \\
\hline 29 & $\mathrm{Na}$ & $\mathrm{ug} / \mathrm{mL}$ & 112000 & $N / A$ & N/A & N/A \\
\hline 30 & $\mathrm{Ni}$ & $\mathrm{ug} / \mathrm{mL}$ & $<0.15$ & N/A & N/A & NA \\
\hline 31 & NO2 (Nitrite) & $u g / m L$ & 47422 & N/A & N/A & N/A \\
\hline 32 & NO3 (Nitrate) & $\mathrm{ug} / \mathrm{mL}$ & 67777 & N/A & N/A & N/A \\
\hline 33 & C204 (Oxalate) & ug $/ \mathrm{mL}$ & 452 & N/A & N/A & N/A \\
\hline 34 & $P$ & $\mathrm{ug} / \mathrm{mL}$ & 85 & N/A & N/A & N/A \\
\hline 35 & PO4 (Phosphate) & $\mathrm{ug} / \mathrm{mL}$ & 155 & N/A & N/A & N/A \\
\hline 36 & $\mathrm{~Pb}$ & ug/mL & $<1$ & N/A & N/A & N/A \\
\hline 37 & $\mathrm{Si}$ & $\mathrm{ug} / \mathrm{mL}$ & 93 & N/A & N/A & N/A \\
\hline 38 & $\mathrm{Sn}$ & $\mathrm{ug} / \mathrm{mL}$ & $<0.8$ & N/A & N/A & N/A \\
\hline 39 & SO4 (Sulfate) & $\mathrm{ug} / \mathrm{mL}$ & 304 & NA & N/A & N/A \\
\hline 40 & $\mathrm{Sr}$ & $\mathrm{ug} / \mathrm{mL}$ & $<0.1$ & N/A & N/A & N/A \\
\hline 41 & Ti & $\mathrm{ug} / \mathrm{mL}$ & $<0.1$ & N/A & N/A & N/A $x=-1$ \\
\hline 42 & V & $\mathrm{ug} / \mathrm{mL}$ & $<0.1$ & N/A & N/A & $\mathrm{NAA}^{-2}$ \\
\hline 43 & $\bar{Z} \mathbf{n}$ & $\mathrm{ug} / \mathrm{mL}$ & 5.8 & N/A & N/A & N/A \\
\hline 44 & $\mathbf{Z r}$ & $\mathrm{ug} / \mathrm{mL}$ & $<0.3$ & N/A & N/A & N/A \\
\hline 45 & Total Organic Carbon & $\mathrm{ug} / \mathrm{mL}$ & 1553 & N/A & N/A & N/A \\
\hline 46. & Total Inorganic Carbon & $\mathrm{ug} / \mathrm{mL}$ & 493.5 & N/A & N/A & N/A \\
\hline 47 & Suspended Solids & $w t \%$ & $<0.003$ & N/A & 0.2875 & 0.83 \\
\hline 48 & Total Solids & $w t \%$ & N/A & N/A & 28.50 & 30.95 \\
\hline 49 & Mean Particle Size by Volum & micron & N/A & 2.32 & N/A & N/A \\
\hline 50 & Mean Particle Size by Numb & micron & N/A & 1.03 & N/A & N/A \\
\hline 51 & Kinematic Viscosity & cSt & N/A & N/A & N/A & 2.4 \\
\hline 52 & Dynamic Viscosity & $\mathrm{cP}$ & N/A & N/A & N/A & 3.0 \\
\hline 53 & Comment & & $\therefore$ & & & HAAKE/SPINNING CONE \\
\hline
\end{tabular}

Table E1: Analytical - All data, Page 3 


\begin{tabular}{|c|c|c|c|c|c|c|}
\hline & $s$ & $T$ & $U$ & $\bar{v}$ & $W$ & $\bar{x}$ \\
\hline 1 & 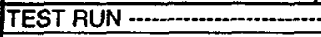 & $\ldots$ & 2.13 & 2.14 & 2.14 & 2.14 \\
\hline 2 & BNFL Sample 10 & $\ldots$ & BNF-SXF2055-A+ES_04b & No Sample Kept & BNF-SXF2055-A+ES_05 & BNF-SXF2055-A+ES 06 \\
\hline 3 & ADS Sample ID & $m>>$ & 3-128292 & No Sample Number & $3-129261$ & TNX Sample/No Number \\
\hline 4 & Type Sample & $\ldots \rightarrow$ & filtrate & filtrate & slurry & slurry \\
\hline 5 & Sample Size …_...... & $\mathrm{mL}$ & 15 & toomL/returned to mixture & 50 & 150 \\
\hline 6 & Measurement(s) Made & 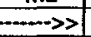 & SSHCP-ESIAATIC-TOCNSENCANONS & DENSITY ONLY & MICROTRAC/C-ANIONS & TS/SSNISCOSITY/OENSITY \\
\hline 7 & Item Measured & Units & 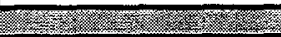 & 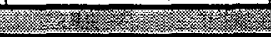 & (35) & 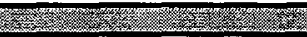 \\
\hline 8 & Density & $g / m L$ & N/A & 1.144 & 1.202 & 1.186 \\
\hline 9 & $\mathbf{A}$ & $\mathrm{ug} / \mathrm{mL}$ & 17700 & N/A & N/A & N/A \\
\hline 10 & $\mathrm{~B}$ & ug/mL & 28 & N/A & N/A & N/A \\
\hline 11 & $\mathrm{Ba}$ & $\mathrm{ug} / \mathrm{mL}$ & $<0.2$ & N/A & N/A & N/A \\
\hline 12 & $\mathrm{Ca}$ & $\mathrm{ug} / \mathrm{mL}$ & 2 & N/A & N/A & N/A \\
\hline 13 & Cd & $\mathrm{ug} / \mathrm{mL}$ & $<0.5$ & N/A & N/A & N/A \\
\hline 14 & $\mathrm{Cl}$ & $\mathrm{ug} / \mathrm{mL}$ & 4539 & $N / A$ & 2509 & N/A \\
\hline 15 & CI Sample & $\mathrm{ug} / \mathrm{mL}$ & 5401.07 & N/A & $\mathrm{N} / \mathrm{A}$ & N/A \\
\hline 16 & Co & $\mathrm{ug} / \mathrm{mL}$ & $<0.5$ & N/A & NA & N/A \\
\hline 17 & $\mathrm{Cr}$ & $u g / \mathrm{mL}$ & 1.1 & N/A & N/A & N/A \\
\hline 18 & $\mathrm{Cu}$ & $\mathrm{ug} / \mathrm{mL}$ & $<0.5$ & N/A & N/A & N/A \\
\hline 19 & F (Fluoride) -(only rough rdg) & $4 \mathrm{~g} / \mathrm{mL}$ & $<20$ & N/A & 72 & N/A \\
\hline 20 & F Sample & $\mathrm{Hg} / \mathrm{mL}$ & 814.8 & N/A & N/A & N/A \\
\hline 21 & $\mathrm{Fe}$ & $\mathrm{ug} / \mathrm{mL}$ & 3.2 & N/A & N/A & N/A \\
\hline 22 & HCOO (Formate) & $u g / m L$ & 1724 & N/A & 991 & N/A \\
\hline 23 & $\mathrm{~K}$ & $40 / \mathrm{mL}$ & 3908.9460 & N/A & N/A & N/A \\
\hline 24 & La & $\mathrm{ug} / \mathrm{mL}$ & $<1.4$ & N/A & NA & NA \\
\hline 25 & $\mathrm{Li}$ & $u / \mathrm{mL}$ & $<6.6$ & N/A & N/A & N/A \\
\hline 26 & $\mathrm{Mg}$ & $40 / \mathrm{mL}^{2}$ & $<0.5$ & N/A & N/A & N/A \\
\hline 27 & $\mathrm{Mn}$ & $40 / m L$ & $<0.5$ & N/A & N/A & N/A \\
\hline 28 & Mo & $\mathrm{tg} / \mathrm{mL}$ & 324 & N/A & $\mathrm{N} / \mathrm{A}$ & N/A \\
\hline 29 & $\mathrm{Na}$ & $\mathrm{ug} / \mathrm{mL}$ & 101850 & $N / A$ & N/A & NA \\
\hline 30 & $\mathrm{Ni}$ & ug/mL & $<0.6$ & N/A & $\mathrm{N} / \mathrm{A}$ & N/A \\
\hline 31 & NO2 (Nitrite) & $\mathrm{ug} / \mathrm{mL}$ & 52524 & N/A & 30508 & N/A \\
\hline 32 & NO3 (Nitrate) & ug $/ \mathrm{mL}$ & 72581 & N/A & 38503 & N/A \\
\hline 33 & C204 (Oxalate) & $\mathrm{ug} / \mathrm{mL}$ & 469 & N/A & 10676 & NA \\
\hline 34 & $P$ & $\mathrm{ug} / \mathrm{mL}$ & 780 & N/A & N/A & N/A \\
\hline 35 & PO4 (Phosphate) & ug/mL & 161 & N/A & 234 & N/A \\
\hline 36 & $\mathrm{~Pb}$ & $\mathrm{ug} / \mathrm{mL}$ & $<5$ & N/A & N/A & N/A \\
\hline 37 & Si & $\mathrm{ug} / \mathrm{mL}$ & 99 & N/A & N/A & N/A \\
\hline 38 & sn & ugimL & 1.2 & N/A & N/A & NA \\
\hline 39 & SO4 (Sulfate) & $\mathrm{ug} / \mathrm{mL}$ & 317 & $N / A$ & 207 & $\mathbf{N} / \mathbf{A}$ \\
\hline 40 & Sr & $4 \mathrm{~g} / \mathrm{mL}$ & $<0.5$ & N/A & N/A & N/A \\
\hline 41 & $\mathrm{Ti}$ & $\mathrm{ug} / \mathrm{mL}$ & $<0.5$ & N/A & N/A & N/A \\
\hline 42 & V & $40 / \mathrm{mL}$ & $<1.2$ & N/A & N/A & N/A \\
\hline 43 & $\mathrm{Zn}$ & $\mathrm{ug} / \mathrm{mL}$ & 4.3 & N/A & N/A & N/A \\
\hline 44 & $\mathrm{Zr}$ & $\mu g / \mathrm{mL}$ & $<1.5$ & N/A & N/A & NA \\
\hline 45 & Total Organic Carbon & ug/mL & 2284 & N/A & NA & N/A \\
\hline 46 & Total Inorganic Carbon & $\mathrm{ug} / \mathrm{mL}$ & 0.89 & N/A & NA & N/A \\
\hline 47 & Suspended Solids & $w+\%$ & $<0.003$ & N/A & N/A & 6.87 \\
\hline 48 & $\begin{array}{l}\text { Total Solids } \\
\end{array}$ & $w t \%$ & $N / A$ & N/A & N/A & 25.81 \\
\hline 49 & Mean Particle Size by Volume & micron & N/A & N/A & $1.63 / 4.89 / 223$ & N/A \\
\hline 50 & Mean Particle Size by Numbel & micron & N/A & N/A & 1.03 & N/A \\
\hline 51 & Kinematic Viscosity & ost & N/A & N/A & N/A & 2.1 \\
\hline 52 & Dymamic Viscosity & $\mathbf{c P}$ & N/A & N/A & N/A & 2.5 \\
\hline 53 & Comment & & & & Trimodal partical distribution & HAAKEISPINNING CONE \\
\hline
\end{tabular}

Table E1: Analytical - All data, Page 4 


\begin{tabular}{|c|c|c|c|c|c|c|}
\hline & $Y$ & $\mathrm{Z}$ & $\mathbf{A A}$ & $\mathrm{AB}$ & $\mathrm{AC}$ & $\mathrm{AD}$ \\
\hline 1 & TEST RUN …................... & ( & $2.14 \mathrm{~b}$ & $2.14 \mathrm{~b}$ & $2.14 \mathrm{~b}$ & $2.14 b$ \\
\hline 2 & BNFL Sample ID, & $\cdots$ & BNF-SXF2055-A+ES_05b & BNF-SXF2055-A+ES_05c & BNF-SXF2055-A+ES_05c & BNF-SXF2055-A+ES_06b \\
\hline 3 & ADS Sample ID & -....- & $3-129114$ & $3-130102$ & $3-130102$ & TNX Sample/No Number \\
\hline 4 & Type Sample & (n.....-1 & slurry & slurry (diluted\&filtered) & slurry (solids were dissolved) & slumy \\
\hline 5 & Sample Size - & $\mathrm{mL}$ & 50 & 15 & 16 & 150 \\
\hline 6 & Measurement(s) Made - & $\rightarrow \rightarrow$ & MICROTRAC & TS/SSICP-ESAC-ANIONS & ICP-ES & TS/SSNISCOSITYÍDENSITY \\
\hline 7 & \begin{tabular}{|l|l|} 
tem Measured \\
\end{tabular} & Units & 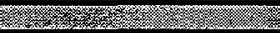 & 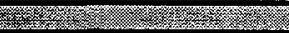 & 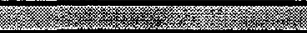 & 27. \\
\hline $\mathbf{B}$ & Density & $g / m L$ & 1.281 & 1.281 & 1.281 & 1.275 \\
\hline 9 & A & $\mathrm{ug} / \mathrm{mL}$ & N/A & 16350 & 16805 & N/A \\
\hline 10 & $\mathrm{~B}$ & $\mathrm{ug} / \mathrm{mL}$ & N/A & $<1.3$ & NA & N/A \\
\hline 11 & $\mathrm{Ba}$ & $\mathrm{ug} / \mathrm{mL}$ & N/A & $<0.2$ & 6 & N/A \\
\hline 12 & $\mathrm{Ca}$ & $\mathrm{ug} / \mathrm{mL}$ & N/A & 1420 & 1513 & N/A \\
\hline 13 & Cd & $u g / m L$ & N/A & $<0.2$ & $<5.1$ & $N / A$ \\
\hline 14 & $\mathrm{Cl}$ & $\mathrm{ug} / \mathrm{mL}$ & N/A & 3886 & 3887 & N/A \\
\hline 15 & CI Sample & $\mathrm{ug} / \mathrm{mL}$ & N/A & N/A & & N/A \\
\hline 16 & Co & $u g / \mathrm{mL}$ & N/A & $<0.5$ & $<13$ & N/A \\
\hline 17 & $\mathrm{Cr}$ & ug $/ \mathrm{mL}$ & N/A & 3100 & 4411 & N/A \\
\hline 18 & $\mathrm{Cu}$ & $\mathrm{ug} / \mathrm{mL}$ & N/A & 2.3 & $<13$ & N/A \\
\hline 19 & F (Fluoride) -(only rough rdg) & $\mathrm{ug} / \mathrm{mL}$ & N/A & 187 & N/A & N/A \\
\hline 20 & F Sample & $4 \mathrm{~g} / \mathrm{mL}$ & NA & NA & NA & N/A \\
\hline 21 & $F_{e}$ & $u g / m L$ & N/A & 406 & 1606 & $N / A$ \\
\hline 22 & HCOO (Formate) & $\log / \mathrm{mL}$ & N/A & 1481 & N/A & N/A \\
\hline 23 & $\mathrm{~K}$ & ug/mL & $N / A$ & N/A & N/A & N/A \\
\hline 24 & La & $u g / \mathrm{mL}$ & N/A & $<1.4$ & $<15.1$ & $N / A$ \\
\hline 25 & Li & $\mathrm{ug} / \mathrm{mL}$ & N/A & $<7$ & $<25.1$ & N/A \\
\hline 26 & $\mathrm{Mg}$ & $\mathrm{ug} / \mathrm{mL}$ & N/A & 16 & $<22.52$ & NA \\
\hline 27 & $M n$ & $\log / \mathrm{mL}$ & N/A & 265 & 298 & N/A \\
\hline 28 & Mo & $4 \mathrm{~g} / \mathrm{mL}$ & NA & 37 & 43 & NA \\
\hline 29 & $\mathrm{Na}$ & $4 \mathrm{~g} / \mathrm{mL}$ & N/A & 120000 & 119178 & N/A \\
\hline 30 & $\mathrm{Ni}$ & $\mathrm{ug} / \mathrm{mL}$ & N/A & 73 & 455 & NA \\
\hline 31 & NO2 (Nitrite) & $\mathrm{ug} / \mathrm{mL}$ & N/A & 45950 & NA & $\mathrm{NA}$ \\
\hline 32 & NO3 (Nitrate) & $\mathrm{ug} / \mathrm{mL}$ & N/A & 61214 & NA & N/A \\
\hline 33 & $\mathrm{C}_{204}$ (Oxalate) & $\mathrm{ug} / \mathrm{mL}$ & N/A & 10698 & N/A & $\mathbf{N} / \mathbf{A}$ \\
\hline 34 & $\mathbf{P}$ & $\mathrm{ug} / \mathrm{mL}$ & N/A & 151 & $<170.2$ & N/A \\
\hline 35 & PO4 (Phosphate) & $\mathrm{ug} / \mathrm{mL}$ & N/A & 299 & N/A & N/A \\
\hline 36 & $\mathrm{~Pb}$ & $\mathrm{ug} / \mathrm{mL}$ & $\mathrm{N} / \mathrm{A}$ & $<5$ & $<151$ & N/A \\
\hline 37 & $\mathrm{Si}$ & $\mathrm{ug} / \mathrm{mL}$ & N/A & 665 & 43065 & N/A \\
\hline 38 & Sn & $\operatorname{ug} / \mathrm{mL}$ & N/A & $<4$ & $<65.1$ & N/A \\
\hline 39 & SO4 (Sulfate) & $u g / m L$ & N/A & 266 & NA & $\mathbf{N} / \mathbf{A}$ \\
\hline 40 & $\mathrm{Sr}$ & ug/mL & N/A & 3.1 & $<2.51$ & N/A \\
\hline 41 & $\mathbf{T i}$ & $u g / m L$ & N/A & 1 & $<35.1$ & N/A \\
\hline 42 & $\mathbf{v}$ & $4 \mathrm{~g} / \mathrm{mL}$ & $N / A$ & $<1.2$ & $<32.53$ & N/A \\
\hline 43 & Zn & ug/mL & NA & 1.5 & $<92.57$ & $\mathbb{N / A}$ \\
\hline 44 & $\mathbf{Z r}$ & ug $/ \mathrm{mL}$ & N/A & $<0.15$ & N/A & N/A \\
\hline 45 & Total Organic Carbon & ug $/ \mathrm{mL}$ & N/A & N/A & NA & N/A \\
\hline 46 & Total inorganic Carbon & $4 \mathrm{~g} / \mathrm{mL}$ & N/A & N/A & N/A & N/A \\
\hline 47 & Suspended Solids & $m \%$ & N/A & 8.17 & NA & 8.23 \\
\hline 48 & Total Solids & $w+\%$ & N/A & 36.2 & N/A & 34.48 \\
\hline 49 & Mean Particle Size by Volume & micron & 2.49 & N/A & NA & NA \\
\hline 50 & Mean Particle Size by Numbe & micron & 1.028 & N/A & NA & $-N / A$ \\
\hline 51 & Kinematic Viscosity & CSt & $\mathrm{N} / \mathrm{A}$ & NA & NA & .2 .4 \\
\hline 52 & Dynamic Viscosity & $\mathrm{CP}$ & NA & NA & NA & 3.1 \\
\hline 53 & Comment & & & Acid Diluent affected solids & Solids Info for Comparison & HAAKE/SPINNING CONE \\
\hline
\end{tabular}

Table E1: Analytical - All data, Page 5 


\begin{tabular}{|c|c|c|c|c|c|c|}
\hline & $\mathrm{AE}$ & AF & $A G$ & $\mathrm{AH}$ & Al & A.J \\
\hline 1 & TEST RUN & $\Longrightarrow$ & $2.14 \mathrm{~b}$ & 2.15 & $2.15 \mathrm{~b}$ & 2.16 \\
\hline 2 & BNFL Sample ID - & $\cdots \rightarrow$ & No Sample Kept & BNF-SXF2055-A+ES_07 & BNF-SXF2055-A+ES O7b & BNF-SXF2055-A+ES_08 \\
\hline 3 & ADS Sample ID - & $(\ldots+\cdots>>$ & No Sample Number & 3-129284 & $3-129117$ & $3-129262$ \\
\hline 4 & Type Sample - & 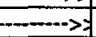 & filtrate & filtrate & filtrate & slurry \\
\hline 5 & Sample Size -.........-->> & $\mathrm{mL}$ & $100 \mathrm{~m}$ Vreturned to mixture & 15 & 15 & 50 \\
\hline 6 & Measurement(s) Made & $\Longrightarrow$ & VISCOSITY IDENSITY & SSICP-ESAAMTK-TOCASEACANIONS & SSICP-ESYANTIC-TOCASERGAANONS & MICAOTRAC \\
\hline 7 & Item Measured & Units & 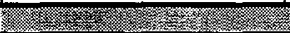 & 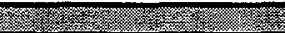 & (2) & 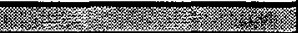 \\
\hline 8 & Density & $\mathrm{g} / \mathrm{mL}$ & 1.214 & 1.080 & 1.105 & 1.082 \\
\hline 9 & Al & $\mathrm{ug} / \mathrm{mL}$ & N/A & 5160 & 7115 & N/A \\
\hline 10 & $\mathrm{~B}$ & $\mathrm{ug} / \mathrm{mL}$ & N/A & 7.6 & 10 & N/A \\
\hline 11 & $\overline{B a}$ & $\mathrm{ug} / \mathrm{mL}$ & N/A & $<0.5$ & $<0.05$ & N/A \\
\hline 12 & $\overline{\mathrm{Ca}}$ & $u g / m L$ & N/A & 2 & 0.9 & N/A \\
\hline 13 & cd & $4 \mathrm{~g} / \mathrm{mL}$ & N/A & $<0.2$ & $<0.05$ & NA \\
\hline 14 & $\mathrm{Cl}$ & $4 \mathrm{~g} / \mathrm{mL}$ & N/A & 1255 & 1773 & N/A \\
\hline 15 & CI Sample & $\mathrm{ug} / \mathrm{mL}$ & NA & 1336.7 & 1841 & N/A \\
\hline 16 & Co & $\mathrm{ug} / \mathrm{mL}$ & $\mathrm{N} / \mathrm{A}$ & $<0.5$ & $<0.05$ & N/A \\
\hline 17 & $\mathrm{Cr}$ & $\mathrm{ug} / \mathrm{mL}$ & N/A & 2 & 2.2 & NA \\
\hline 18 & $\mathrm{Cu}$ & $\mathrm{ug} / \mathrm{mL}$ & NA & $<0.4$ & $<0.05$ & N/A \\
\hline 19 & F (Fluoride) -(only rough rdg) & $\mathrm{ug} / \mathrm{mL}$ & N/A & 46 & 63 & N/A \\
\hline 20 & F Sample & $\mathrm{ug} / \mathrm{mL}$ & $N / A$ & 53.95 & $<10$ & $\mathrm{~N} / \mathrm{A}$ \\
\hline 21 & $\mathrm{Fe}$ & $\mathrm{ug} / \mathrm{mL}$ & N/A & $<0.6$ & 0.88 & N/A \\
\hline 22 & HCOO (Formate) & $\mathrm{ug} / \mathrm{mL}$ & N/A & 532 & 721 & N/A \\
\hline 23 & $\mathrm{~K}$ & $\mathrm{ug} / \mathrm{mL}$ & N/A & 1076.8566 & 1594.698 & N/A \\
\hline 24 & La & $\mathrm{ug} / \mathrm{mL}$ & N/A & $<1.4$ & $<0.14$ & N/A \\
\hline 25 & Li & $\mathrm{ug} / \mathrm{mL}$ & N/A & $<7$ & $<0.7$ & N/A \\
\hline 26 & $\mathrm{Mg}$ & $\mathrm{ug} / \mathrm{mL}$ & $\mathrm{N} / \mathrm{A}$ & $<0.5$ & $<0.03$ & NA \\
\hline 27 & $\mathrm{Mn}$ & $\mathrm{ug} / \mathrm{mL}$ & N/A & $<0.4$ & $<0.02$ & NA \\
\hline 28 & Mo & $\mathrm{ug} / \mathrm{mL}$ & N/A & 12.7 & 15 & N/A \\
\hline 29 & $\mathrm{Na}$ & $\mathrm{ug} / \mathrm{mL}$ & N/A & 38550 & 49000 & N/A \\
\hline 30 & $\mathrm{Ni}$ & $\mathrm{ug} / \mathrm{mL}$ & N/A & $<0.6$ & 0.1 & N/A \\
\hline 31 & NO2 (Nitrite) & $\mathrm{ug} / \mathrm{mL}$ & N/A & 16553 & 21918 & N/A \\
\hline 32 & NO3 (Nitrate) & $u g / m L$ & NA & 25451 & 35660 & N/A \\
\hline 33 & $\mathrm{C2O} 4$ (Oxalate) & $u g / m L$ & N/A & 4383 & 2969 & N/A \\
\hline 34 & $\mathbf{P}$ & $\mathrm{ug} / \mathrm{mL}$ & NA & 23 & 63 & NA \\
\hline 35 & PO4 (Phosphate) & $u g / m L$ & N/A & 67 & 272 & N/A \\
\hline 36 & $\mathrm{~Pb}$ & $4 \mathrm{~g} / \mathrm{mL}$ & N/A & $<0.5$ & $<0.5$ & NA \\
\hline 37 & $\overline{S i}$ & $u g / m L$ & N/A & 32 & 62 & NA \\
\hline 38 & $\mathrm{Sn}$ & $\mathrm{ug} / \mathrm{mL}$ & N/A & $<0.5$ & $<0.4$ & N/A \\
\hline 39 & SO4 (Sulfate) & $4 \mathrm{~g} / \mathrm{mL}$ & N/A & 96 & 154 & NA \\
\hline 40 & Sr & $\mathrm{ug} / \mathrm{mL}$ & N/A & $<0.5$ & $<0.05$ & N/A \\
\hline 41 & $\pi i$ & $\mathrm{ug} / \mathrm{mL}$ & NA & $<0.5$ & $<0.05$ & NA \\
\hline 42 & $\mathrm{~V}$ & ug/mL & N/A & $<1.2$ & $<0.12$ & N/A \\
\hline 43 & $\mathrm{Zn}$ & $\mathrm{ug} / \mathrm{mL}$ & N/A & 1.0 & 2 & N/A \\
\hline 44 & $\mathrm{Zr}$ & $\mathrm{ug} / \mathrm{mL}$ & N/A & $<1.5$ & $<0.15$ & NA \\
\hline 45 & Total Organic Carbon & ug/mL & N/A & 1998 & 543 & N/A \\
\hline 46 & Total Inorganic Carbon & $u g / m L$ & N/A & 1774 & 524 & NA \\
\hline 47 & Suspended Solids & $w \%$ & N/A & $<0.02$ & $<0.01$ & NA \\
\hline 48 & Total Solids & $w+\%$ & NA & NAA & NA & NA \\
\hline 49 & Mean Particle Size by Volume & micron & N/A & N/A & N/A & $1.61 / 4.91 / 213$ \\
\hline 50 & Mean Particle Size by Number & micron & N/A & N/A & N/A & 1.03 \\
\hline 51 & Kinematic Viscosity & cSt & 1.51 & N/A & 1.33 & N/A \\
\hline 52 & Dymamic Viscosity & $\mathrm{cP}$ & \begin{tabular}{|c|}
1.84 \\
\end{tabular} & N/A & 1.47 & N/A \\
\hline 53 & Comment & & viscosity done by capillary & & viscosity done by capillany & Trimodal particle distribution \\
\hline
\end{tabular}

Table E1: Analytical - All data, Page 6 


\begin{tabular}{|c|c|c|c|c|c|c|}
\hline & AK & $\mathrm{AL}$ & $\mathrm{AM}$ & AN & $\mathrm{AO}$ & AP \\
\hline 1 & TEST RUN & $\cdots$ & 2.16 & 2.16 & 2.16 & $2.16 b$ \\
\hline 2 & BNFL Sample ID & $\cdots \cdots$ & $\therefore$ Unplanned Sample & BNF-SXF2055-A+ES_09 & BNF-SXF2055-A+ES_10 & BNF-SXF2055-A+ES_08b \\
\hline 3 & ADS Sample ID - & $\rightarrow \rightarrow$ & TNX Sample/No Number & $3-129288$ & 3-129285 & $3-129115$ \\
\hline 4 & Type Sample - & $\cdots$ & shurry & slurry & fittrate & slurry \\
\hline 5 & Sample Size & $\mathrm{mL}$ & 150 & 15 & 15 & 50 \\
\hline 6 & Measurement(s) Made -........ & $\rightarrow \rightarrow$ & VISCOSITY ONLY & TS/SS & SSICP-ESIMUTLC-TOCASENC-ANIONS & MICROTRAC \\
\hline 7 & Item Measured & Units & 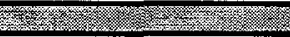 & 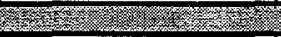 & 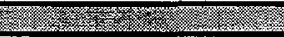 & 2 \\
\hline 8 & Density & $g / m L$ & 1.082 & 1.082 & 1.045 & N/A \\
\hline 9 & Al & $\mathrm{ug} / \mathrm{mL}$ & $N / A$ & N/A & 2685 & N/A \\
\hline 10 & $\mathrm{~B}$ & ug/mL & N/A & N/A & 3.7 & N/A \\
\hline 11 & $\mathrm{Ba}$ & $\mathrm{ug} / \mathrm{mL}$ & $N / A$ & N/A & $<0.5$ & $\mathrm{~N} / \mathrm{A}$ \\
\hline 12 & $\mathrm{Ca}$ & $u g / \mathrm{mL}$ & $N / A$ & N/A & $<2$ & N/A \\
\hline 13 & $\mathrm{Cd}$ & $\mathrm{ug} / \mathrm{mL}$ & N/A & N/A & $<0.2$ & $N / A$ \\
\hline 14 & $\mathrm{Cl}$ & $\mathrm{ug} / \mathrm{mL}$ & N/A. & $N / A$ & 528 & N/A \\
\hline 15 & C Sample & $\mathrm{ug} / \mathrm{mL}$ & N/A & N/A & 645.4 & N/A \\
\hline 16 & Co & $\mathrm{ug} / \mathrm{mL}$ & N/A & N/A & $<0.5$ & N/A \\
\hline 17 & $\mathrm{Cr}$ & $\mathrm{ug} / \mathrm{mL}$ & N/A & N/A & 0.8 & $N / A$ \\
\hline 18 & $\mathrm{Cu}$ & $\mathrm{ug} / \mathrm{mL}$ & $N / A$ & N/A & $<0.4$ & N/A \\
\hline 19 & F (Fluoride) -(only rough $\mathrm{rdg}$ ) & $\mathrm{ug} / \mathrm{mL}$ & N/A & N/A & 26 & N/A \\
\hline 20 & F Sample & $\mathrm{ug} / \mathrm{mL}$ & N/A & $\mathrm{N} / \mathrm{A}$ & 11.5 & N/A \\
\hline 21 & $\mathrm{Fe}$ & $\mathrm{ug} / \mathrm{mL}$ & N/A & N/A & $<0.6$ & $N / A$ \\
\hline 22 & HCOO (Formate) & $\mathrm{ug} / \mathrm{mL}$ & $\mathrm{N} / \mathrm{A}$ & N/A & 233 & N/A \\
\hline 23 & $\mathrm{~K}$ & $\mathrm{ug} / \mathrm{mL}$ & N/A & N/A & 490.297 & N/A \\
\hline 24 & La & $\mathrm{ug} / \mathrm{mL}$ & N/A & N/A & $\therefore<1.4$ & N/A \\
\hline 25 & Li & $\mathrm{ug} / \mathrm{mL}$ & N/A & N/A & $<7$ & N/A \\
\hline 26 & $\mathrm{Mg}$ & $\mathrm{ug} / \mathrm{mL}$ & N/A & N/A & $<0.5$ & N/A \\
\hline 27 & Mn & $\mathrm{ug} / \mathrm{mL}$ & $\mathbf{N} / \mathbf{A}$ & N/A & $<0.4$ & N/A \\
\hline 28 & Mo & ug $/ \mathrm{mL}$ & N/A & N/A & 6.9 & N/A \\
\hline 29 & $\mathrm{Na}$ & $\mathrm{ug} / \mathrm{mL}$ & N/A & NA & 23400 & N/A \\
\hline 30. & $\mathrm{Ni}$. & $\mathrm{ug} / \mathrm{mL}$ & N/A & N/A & $<.6$ & N/A \\
\hline 31 & NO2 (Nitrite) & $\mathrm{ug} / \mathrm{mL}$ & N/A & $N / A$ & 7286 & N/A \\
\hline 32 & NO3 (Nitrate) & ug/mL & $\mathrm{N} / \mathrm{A}$ & N/A & 10353 & N/A \\
\hline 33 & $\mathrm{C}_{204}$ (Oxalate) & ug/mL & N/A & N/A & 9419 & N/A \\
\hline 34 & $\mathbf{P}$ & $\mathrm{ug} / \mathrm{mL}$ & N/A & N/A & 11 & N/A \\
\hline 35 & PO4 (Phosphate) & $u g / m L$ & $N / A$ & N/A & 30 & N/A \\
\hline 36 & $\mathrm{~Pb}$ & $u g / m L$ & N/A & N/A & $<5$ & N/A \\
\hline 37 & $\mathrm{Si}$ & ug/mL & N/A & N/A & 13 & N/A \\
\hline 38 & Sn. & $\mathrm{ug} / \mathrm{mL}$ & N/A & N/A & $<4$ & N/A \\
\hline 39 & SO4 (Sulfate) & ug/mL & $\mathrm{N} / \mathrm{A}$ & N/A & 44 & N/A \\
\hline 40 & $\mathrm{Sr}$ & ug/mL & N/A & N/A & $<0.5$ & N/A \\
\hline 41 & $\mathrm{Ti}$ & ug/mL & $N / A$ & N/A & $<0.5$ & N/A \\
\hline 42 & $\mathbf{V}$ & $u g / \mathrm{mL}$ & $N / A$ & $\mathrm{~N} / \mathrm{A}$ & $<1.2$ & N/A \\
\hline 43 & $\mathrm{Zn}$ & $\mathrm{ug} / \mathrm{mL}$ & N/A & N/A & 5.1 & N/A \\
\hline 44 & $\mathrm{Zr}$ & ug/mL & N/A & N/A : & $<1.5$ & N/A \\
\hline 45 & Total Organic Carbon & $\mathrm{ug} / \mathrm{mL}$ & N/A & $\mathrm{N} / \mathrm{A}$ & $\mathbf{3 3 7 0}$ & N/A \\
\hline 46. & Total Inorganic Carbon & $4 \mathrm{~g} / \mathrm{mL}$ & N/A & $\mathrm{N} / \mathrm{A}$ & 1124 & N/A \\
\hline 47 & Suspended Solids & $w \%$ & N/A & 4.85 & $<0.02$ & N/A \\
\hline 48 & Total Solids & $w+\%$ & N/A. & 10.518 & $\mathbf{N} / \mathbf{A}$ & N/A \\
\hline 49 & Mean Particle Size by Volume & micron & N/A & N/A & N/A & $1.7 / 6$ \\
\hline 50 & Mean Particle Size by Number & micron & N/A & N/A & N/A & 1.046 \\
\hline 51 & Kinematic Viscosity & cSt & $<1.8$ & N/A & N/A & N/A \\
\hline 52 & Dynamic Viscosity & $\mathrm{CP}$ & $<2$ & $\mathrm{~N} / \mathrm{A}$ & $\mathbf{N} / \mathbf{A}$ & N/A \\
\hline 53 & Comment & & HAAKE/SPINNING CONE & & & bimodal particle distibution \\
\hline
\end{tabular}

Table E1: Analytical - All data, Page 7 


\begin{tabular}{|c|c|c|c|c|c|c|}
\hline & $\mathrm{AQ}$ & AR & AS & AT & $\mathrm{AU}$ & AV \\
\hline 1 & TEST RUN & $\ldots \ldots$ & $2.16 \mathrm{~b}$ & $2.16 b$ & $2.17 \mathrm{~b}$ & 2.18 \\
\hline 2 & BNFL Sample ID & $\cdots \cdots$ & BNF-SXF2055-A+ES_09b & BNF-SXF2055-A+ES_10b & BNF-SXF2055-A+ES $11 \mathrm{~b}$ & BNF-SXF2055-A+ES 12 \\
\hline 3 & ADS Sample ID & $\cdots \rightarrow$ & $3-129123$ & $3-129118$ & $3-129119$ & $3-129286$ \\
\hline 4 & Type Sample - & $\cdots$ & slurry & filtrate & fittrate & filtrate \\
\hline 5 & Sample Size ...............->> & $\mathrm{mL}$ & 15 & 15 & 15 & 15 \\
\hline 6 & Measurement(s) Made & $\rightarrow \cdots>$ & TS/SS & SSICPESSAATKC-TOCASERCANHONS & SSICP-ES/AATIC-TOCNSEACNWONS & SSICPESMUTKC-TOCNSERC-ANHOWS \\
\hline 7 & Item Measured & Units & 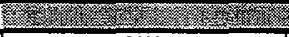 & 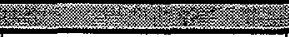 & 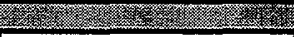 & 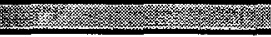 \\
\hline 8 & Density & $g / m L$ & NA & 1.055 & 1.031 & 1.025 \\
\hline 9 & Al & $\mathrm{ug} / \mathrm{mL}$ & N/A & 3180 & 1535 & 1320 \\
\hline 10 & $B$ & $\mathrm{wg} / \mathrm{mL}$ & N/A & 4.9 & 2.5 & $<1.5$ \\
\hline 11 & $\mathrm{Ba}$ & $\mathrm{ug} / \mathrm{mL}$ & N/A & $<0.05$ & $\leq 0.05$ & $<0.5$ \\
\hline 12 & $\mathrm{Ca}$ & $u g / \mathrm{mL}$ & N/A & 1.2 & 3.1 & $<2$ \\
\hline 13 & $\mathrm{Cd}$ & $\mathrm{ug} / \mathrm{mL}$ & N/A & $<0.05$ & $<0.05$ & $<0.05$ \\
\hline 14 & $\mathrm{Cl}$ & $\mathrm{ug} / \mathrm{mL}$ & N/A & 735 & 295 & 233 \\
\hline 15 & CI Sample & $\mathrm{ug} / \mathrm{mL}$ & N/A & 1973 & 360 & 319.3 \\
\hline 16 & $\mathrm{Co}$ & $\mathrm{ug} / \mathrm{mL}$ & N/A & $<0.05$ & $<0.05$ & $<0.2$ \\
\hline 17 & $\mathrm{Cr}$ & $\mathrm{ug} / \mathrm{mL}$ & N/A & 1.1 & 0.7 & $<0.5$ \\
\hline 18 & Cu & $\underline{u g} / \mathrm{mL}$ & N/A & $<0.05$ & $<0.05$ & $<0.4$ \\
\hline 19 & F (Fluoride) -(only rough rdg) & $\mathrm{ug} / \mathrm{mL}$ & N/A & 36 & 18 & 13 \\
\hline 20 & F Sample & $\mathrm{ug} / \mathrm{mL}$ & NA & $<10$ & $<10$ & 7.35 \\
\hline 21 & $\mathrm{Fe}$ & $\mathrm{ug} / \mathrm{mL}$ & N/A & 0.31 & 0.23 & $<0.6$ \\
\hline 22 & HCOO (Formate) & $\mathrm{ug} / \mathrm{mL}$ & N/A & 320 & 140 & 96 \\
\hline 23 & $\mathrm{~K}$ & $\mathrm{ug} / \mathrm{mL}$ & N/A & 689.5910 & 303.408 & 250.207 \\
\hline 24 & La & $40 / \mathrm{mL}$ & NA & $<0.14$ & $<0.14$ & $<1.4$ \\
\hline 25 & Li & $\mathrm{ug} / \mathrm{mL}$ & NA & $<0.7$ & $<0.7$ & $<7$ \\
\hline 26 & $\mathrm{Mg}$ & $\mathrm{ug} / \mathrm{mL}$ & N/A & $<0.03$ & $\leq 0.03$ & $<0.5$ \\
\hline 27 & Mn & $\mathrm{ug} / \mathrm{mL}$ & N/A & $<0.02$ & $<0.02$ & $<0.4$ \\
\hline 28 & Mo & $\mathrm{ug} / \mathrm{mL}$ & NA & 7.2 & 3.3 & 3.9 \\
\hline 29 & $\mathrm{Na}$ & $\mathrm{ug} / \mathrm{mL}$ & $N / A$ & 18300 & 11850 & 12450 \\
\hline 30 & $\mathbf{N i}$ & $u g / \mathrm{mL}^{\prime}$ & N/A & $<0.06$ & $<0.06$ & $<0.6$ \\
\hline 31. & NO2 (Nitrite) & $\mathrm{ug} / \mathrm{mL}$ & N/A & 9718 & 4279 & 3527 \\
\hline 32 & NO3 (Nitrate) & ug/mL & N/A & 14285 & 5487 & 4686 \\
\hline 33. & C2O4 (Oxalate) & $\mathrm{ug} / \mathrm{mL}$ & N/A & 7057 & 7755 & 6325 \\
\hline 34 & $\mathbf{P}$ & $\mathrm{ug} / \mathrm{mL}$ & N/A & 29 & 13 & $<9$ \\
\hline 35 & PO4 (Phosphate) & ug $/ \mathrm{mL}$ & NA & 67 & 36 & 11 \\
\hline 36. & $\mathrm{~Pb}$ & $\mathrm{ug} / \mathrm{mL}$ & $N / A$ & $<0.5$ & $<0.5$ & $<5$ \\
\hline 37 & Si & $\underline{u g} / \mathrm{mL}$ & NA & 30 & 17 & $<6$ \\
\hline 38 & $\mathrm{Sn}$ & $\mathrm{ug} / \mathrm{mL}$ & N/A & $<0.4$ & $<0.4$ & $<4$ \\
\hline 39 & SO4 (Sulfate) & $\mathrm{ug} / \mathrm{mL}$ & N/A & 57 & 25 & 23 \\
\hline 40 & $\mathrm{Sr}$ & $\mathrm{ug} / \mathrm{mL}$ & N/A & $<0.05$ & $\leq 0.05$ & $<0.5$ \\
\hline 41. & $\mathrm{Ti}$ & $\mathrm{ug} / \mathrm{mL}$ & N/A & $<0.05$ & -1 & $<0.5$ \\
\hline 42 & $\mathrm{~V}$ & $\mathrm{ug} / \mathrm{mL}$ & NA & $<0.12$ & $<0.12$ & $<1.2$ \\
\hline 43 & $\mathrm{Zn}$ & $u g / \mathrm{mL}$ & N/A & 1 & 0.2 & 5.2 \\
\hline 44 & $\mathrm{Zr}$ & $4 \mathrm{~g} / \mathrm{mL}$ & N/A & $<0.15$ & $<0.15$ & $<1.5$ \\
\hline 45 & Total Organic Carbon & $\mathrm{ug} / \mathrm{mL}$ & N/A & 966 & 1039 & 2492 \\
\hline 46. & Total Inorganic Carbon & $\mathrm{ug} / \mathrm{mL}$ & NA & 298 & 199 & 498 \\
\hline 47 & Suspended Solids & wt\% & 5.49 & $<.01$ & $<.01$ & $<0.02$ \\
\hline 48 & Total Solids & $w+\%$ & 12.88 & N/A & N/A & NA \\
\hline 49 & Mean Particle Size by Volume & micron & N/A & N/A & N/A & NA \\
\hline 50 & Mean Particle Size by Numbe & micron & N/A & N/A & NA & N/A \\
\hline 51 & Kinematic Viscosity & cSt & NA & 1.15 & 1.08 & N/A \\
\hline 52 & Dynamic Viscosity & $\mathrm{CP}$ & N/A & 1.21 & 1.11 & N/A \\
\hline 53 & Comment & & & viscosity done by capillary & viscosity done by capillary & \\
\hline
\end{tabular}

Table E1: Analytical - All data, Page 8 


\begin{tabular}{|c|c|c|c|c|c|c|}
\hline & AW & $A X$ & AY & $A Z$ & BA & $B B$ \\
\hline 1 & TEST RUN & $\ldots$ & $2.18 \mathrm{~b}$ & 2.19 & $2.19 b$ & 2.206 \\
\hline 2 & BNFL Sample 10 - & $\cdots$ & BNF-SXF2055-A+ES_12b & BNF-SXF2055-A+ES_13 & BNF-SXF2055-A+ES_13b & BNF-SXF2055-A+ES_14b \\
\hline 3 & ADS Sample 10 & 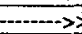 & $3-129120$ & $3-129287$ & $3-129121$ & $3-129116$ \\
\hline 4 & Type Sample -.................... & 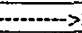 & filtrate & filtrate & filtrate & slurry ( 80 -liter starting volume) \\
\hline 5 & Sample Size -........->> & $\mathrm{mL}$ & 15 & 15 & 15 & 50 \\
\hline 6 & Measurement(s) Made $\ldots$ & $\ldots$ & SSICP-ESAANTLC-TOCASENC-ANHONS & SSACP-ESAANTK-TOCASEIC-ANONS & SSICP-ES/AATKC-TOCASENC-ANWONS & MICROTRAC \\
\hline 7 & litem Measured & Units & 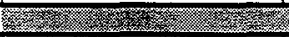 & (2) & 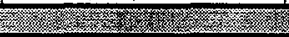 & X \\
\hline 8 & Density & $g / m L$ & 1.015 & 1.010 & 1.0095 & from 1.054 to 1.143 \\
\hline 9 & Al & $\mathrm{ug} / \mathrm{mL}$ & 845 & 680 & 367 & $\mathrm{~N} / \mathrm{A}$ \\
\hline 10 & $B$ & $\mathrm{ug} / \mathrm{mL}$ & 1.5 & $<1.5$ & 0.9 & N/A \\
\hline 11 & $\mathrm{Ba}$ & $\mathrm{ug} / \mathrm{mL}$ & $<0.05$ & $<0.5$ & $<0.05$ & N/A \\
\hline 12 & $\mathrm{Ca}$ & ug/mL & $<0.2$ & $<2$ & $<0.2$ & N/A \\
\hline 13 & $\mathrm{~cd}$ & ug/mL & $<0.05$ & $<0.2$ & $<0.05$ & N/A \\
\hline 14 & $\mathrm{Cl}$ & $\mathrm{ug} / \mathrm{mL}$ & 149 & 127 & 61 & $N / A$ \\
\hline 15 & CI Sample & ug/mL & 542 & 159.3 & 445 & N/A \\
\hline 16 & co & $\mathrm{ug} / \mathrm{mL}$ & $\leq 0.05$ & $<0.5$ & $<0.05$ & N/A \\
\hline 17 & $\mathrm{Cr}$ & $\mathrm{ug} / \mathrm{mL}$ & $<0.1$ & $<0.5$ & $<0.1$ & N/A \\
\hline 18 & $\mathrm{Cu}$ & $\mathrm{ug} / \mathrm{mL}$ & $<0.05$ & $<0.4$ & $<0.05$ & N/A \\
\hline 19 & F (Fluoride) -(only rough rdg) & ug/mL & 11 & 8 & 6 & N/A \\
\hline 20 & F Sample & $\mathrm{ug} / \mathrm{mL}$ & $\leq 10$ & 3.05 & $<10$ & N/A \\
\hline 21 & $\mathrm{Fe}$ & $\mathrm{ug} / \mathrm{mL}$ & 0.16 & $<0.6$ & 0.07 & N/A \\
\hline 22 & HCOO (Formate) & $\mathrm{ug} / \mathrm{mL}$ & 76 & 59 & 37 & N/A \\
\hline 23 & $\mathrm{~K}$ & $\mathrm{ug} / \mathrm{mL}$ & 159.9815 & 131.8985 & 62.0455 & N/A \\
\hline 24 & La & $\mathrm{ug} / \mathrm{mL}$ & $<0.14$ & $<1.4$ & $<0.14$ & N/A \\
\hline 25 & Li & $\mathrm{ug} / \mathrm{mL}$ & $<0.7$ & $<7$ & $<0.7$ & N/A \\
\hline 26 & $\mathrm{Mg}$ & $\mathrm{ug} / \mathrm{mL}$ & $<0.03$ & $<0.5$ & $<0.03$ & N/A \\
\hline 27 & $\mathrm{Mn}$ & $\mathrm{ug} / \mathrm{mL}$ & $<0.02$ & $<0.4$ & $<0.02$ & N/A \\
\hline 28 & $\mathrm{Mo}$ & $\mathrm{ug} / \mathrm{mL}$ & 1.8 & 2.7 & 0.8 & N/A \\
\hline 29 & $\mathrm{Na}$ & ug $/ m L$ & 6735 & 6665 & 2905 & N/A \\
\hline 30 & Ni & ug/mL & $<0.06$ & $<0.6$ & $<0.06$ & $N / A$ \\
\hline 31 & NO2 (Nitrite) & ug $/ \mathrm{mL}$ & 2254 & 1850 & 868 & $N / A$ \\
\hline 32 & NO3 (Nitrate) & $\mathrm{ug} / \mathrm{mL}$ & 3652 & 2897 & 1281 & N/A \\
\hline 33 & C204 (Oxalate) & $\mathrm{ug} / \mathrm{mL}$ & 4294 & 3888 & 1564 & N/A \\
\hline 34 & $\mathbf{P}$ & $\mathrm{ug} / \mathrm{mL}$ & 7 & $<9$ & 3 & NA \\
\hline 35 & PO4 (Phosphate) & $\mathrm{ug} / \mathrm{mL}$ & 19 & $<10$ & 4 & N/A \\
\hline 36 & Pb & $\mathrm{ug} / \mathrm{mL}$ & $<0.5$ & $<5$ & $<0.5$ & N/A \\
\hline 37 & $\mathrm{Si}$ & $\mathrm{ug} / \mathrm{mL}$ & 12 & $<6$ & 8.6 & N/A \\
\hline 38 & Sn & $\mathrm{ug} / \mathrm{mL}$ & $<0.4$ & $<4$ & $<0.4$ & $\mathbf{N} / \mathbf{A}$ \\
\hline 39 & SO4 (Sulfate) & $u g / m L$ & 13 & 12 & 6 & N/A \\
\hline 40 & $\mathrm{Sr}$ & $\mathrm{ug} / \mathrm{mL}$ & $<0.05$ & $<0.5$ & $<0.05$ & N/A \\
\hline 41 & $\pi$ & ug/mL & $<0.05$ & $<0.5$ & $<0.05$ & N/A \\
\hline 42 & v & $\mathrm{ug} / \mathrm{mL}$ & $<0.12$ & $<1.2$ & $<0.12$ & N/A \\
\hline 43 & Zn & $\mathrm{ug} / \mathrm{mL}$ & 0.06 & $<0.4$ & $\leq 0.03$ & N/A \\
\hline 44 & $\mathrm{Zr}$ & $\mathrm{ug} / \mathrm{mL}$ & $<0.15$ & $<1.5$ & $<0.15$ & $\mathrm{~N} / \mathrm{A}$ \\
\hline 45 & Total Organic Carbon & $\mathrm{ug} / \mathrm{mL}$ & 581 & 1589 & 262 & N/A \\
\hline 46 & Total Inorganic Carbon & $\mathrm{ug} / \mathrm{mL}$ & 143 & 336 & 88 & N/A \\
\hline 47 & Suspended Solids & $w+\%$ & $<.01$ & $<0.02$ & $<.01$ & N/A \\
\hline 48 & Total Solids & $w+\%$ & N/A & NA & N/A & N/A \\
\hline 49 & Mean Particle Size by Volume & micron & N/A & N/A & N/A & 3.33 \\
\hline 50 & Mean Particle Size by Numbe & micron & N/A & N/A & N/A & $1.016 / 2.164$ \\
\hline 51 & Kinematic Viscosity & cSt & 1.04 & NA & 1.00 & N/A \\
\hline 52 & Dynamic Viscosity & $\mathrm{cP}$ & 1.06 & N/A & 1.01 & N/A \\
\hline 53 & Comment & & viscosity done by capillary & & viscosity done by capillary & Post-wash De-watering \\
\hline
\end{tabular}

Table E1: Analytical - All data, Page 9 


\begin{tabular}{|c|c|c|c|c|c|c|}
\hline & $B C$ & BD & BE & $\mathrm{BF}$ & $\mathrm{BG}$ & $\mathrm{BH}$ \\
\hline 1 & TEST RUN & $\rightarrow$ & $2.20 \mathrm{~b}$ & $2.20 \mathrm{~b}$ & $2.20 \mathrm{~b}$ & $2.20 \mathrm{~b}$ \\
\hline 2 & BNFL Sample 10 - & $\rightarrow$ & BNF-SXF2055-A+ES 15b & BNF-SXF2055-A+ES_16b & Viscosity 2 & Viscosity 3 \\
\hline 3 & ADS Sample ID - & $m$ & $3-129124$ & TNX Sample/No Number & TNX Sample/No Number & TNX Sample/No Number \\
\hline 4 & Type Sample & $\rightarrow \rightarrow$ & Slurry ( 80 -liter starting volume & flurny ( 80 -liter starting volume & slurry ( 57.9 liters remain) & slurry ( 43.1 liters remain) \\
\hline 5 & Sample Size - - & $\mathrm{mL}$ & 15 & 150 & 150 & 150 \\
\hline 6 & Measurement(s) Made _ & $\rightarrow$ & TS/SS & TS/SSNVISCOSITY/DENSITY & TS/SSNISCOSITY/DENSITY & TSISSNISCOSITY/DENSITY \\
\hline 7 & fitem Measured & Units & 供 & 1 & (6) & 1 \\
\hline 8 & Density & $g / m L$ & 1.054 & 1.053 & 1.077 & 1.106 \\
\hline 9 & Al & $40 / \mathrm{mL}$ & NAA & N/A & N/A & N/A \\
\hline 10 & $\mathrm{~B}$ & $u g / \mathrm{mL}$ & N/A & N/A & N/A & N/A \\
\hline 11 & $\mathrm{Ba}$ & $\mathrm{ug} / \mathrm{mL}$ & N/A & N/A & N/A & NA \\
\hline 12 & $\mathrm{Ca}$ & $u g / m L$ & N/A & NA & N/A & N/A \\
\hline 13 & Cd & $\mathrm{ug} / \mathrm{mL}$ & NA & $N / A$ & N/A & N/A \\
\hline 14 & a & $u g / m L$ & N/A & N/A & N/A & N/A \\
\hline 15 & C Sample & $4 g / \mathrm{mL}$ & N/A & N/A & NAA & N/A \\
\hline 16 & Co & $40 / \mathrm{mL}$ & N/A & N/A & N/A & N/A \\
\hline 17 & $\mathrm{Gr}$ & $u g / m L$ & N/A & NA & N/A & N/A \\
\hline 18 & $\mathbf{C u}$ & $u g / \mathrm{mL}$ & NA & N/A & N/A & NA \\
\hline 19 & F (Fluoride) -(only rough rdg) & eg/mL & N/A & N/A & N/A & N/A \\
\hline 20 & F Sample & ug/mL & N/A & N/A & N/A & NAA \\
\hline 21 & $\mathrm{Fe}$ & $\mathbf{u g} / \mathrm{mL}$ & N/A & N/A & N/A & NA \\
\hline 22 & HCOO (Formate) & $4 \mathrm{~g} / \mathrm{mL}$ & N/A & NA & $N / A$ & NA \\
\hline 23 & $\mathbf{K}$ & $u g / m L$ & NA & N/A & N/A & NA \\
\hline 24 & La & ug $/ \mathrm{mL}$ & N/A & N/A & N/A & NA \\
\hline 25 & $L i$ & $\mathrm{ug} / \mathrm{mL}$ & NA & N/A & NA & NA \\
\hline 26 & $\mathrm{Mg}$ & $\mathrm{ug} / \mathrm{mL}$ & N/A & N/A & N/A & N/A \\
\hline 27 & $\mathrm{Mn}$ & $40 / \mathrm{mL}$ & $\mathrm{N} / \mathrm{A}$ & N/A & N/A & NA \\
\hline 28 & Mo & $u g / m L$ & N/A & N/A & $\mathrm{N} / \mathrm{A}$ & NA \\
\hline 29 & $\mathrm{Na}$ & ug/mL & N/A & N/A & N/A & N/A \\
\hline 30 & $\mathrm{Ni}$ & $\mathrm{ug} / \mathrm{mL}$ & N/A & N/A & N/A & NA \\
\hline 31 & NO2 (Nitrite) & $u g / m L$ & N/A & NA & N/A & NA \\
\hline 32 & NO3 (Nitrate) & $\mathrm{ug} / \mathrm{mL}$ & N/A & N/A & N/A & N/A \\
\hline 33 & C2O4 (Oxalate) & $\mathrm{ug} / \mathrm{mL}$ & N/A & N/A & N/A & N/A \\
\hline 34 & $P$ & $4 \mathrm{~g} / \mathrm{mL}$ & N/A & $N / A$ & N/A & N/A \\
\hline 35 & PO4 (Phosphate) & $\mathrm{Lg} / \mathrm{mL}$ & N/A & NA & NAA & NA \\
\hline 36 & $\overline{P \mathscr{b}}$ & $\mathrm{ug} / \mathrm{mL}$ & N/A & N/A & N/A & N/A \\
\hline 37 & Si & $\log / \mathrm{mL}$ & N/A & N/A & N/A & N/A \\
\hline 38 & Sn & $\log / \mathrm{mL}$ & N/A & NA & N/A & NA \\
\hline 39 & SO4 (Sulfate) & $\mathrm{ug} / \mathrm{mL}$ & N/A & N/A & N/A & N/A \\
\hline 40 & $\mathrm{Sr}$ & $u g / m L$ & NA & NA & N/A & N/A \\
\hline 41 & $\mathrm{Ti}$ & ug/mL & N/A & NA & NA & N/A \\
\hline 42 & $\mathrm{~V}$ & $u g / m L$ & NA & NA & NA & NA \\
\hline 43 & $\mathrm{Zn}$ & uog/mL & NA & NA & N/A & N/A \\
\hline 44 & $\mathrm{Zr}$ & ugiml & NA & N/A & N/A & NA \\
\hline 45 & Total Organic Carbon & $40 / m L$ & NA & N/A & N/A & N/A \\
\hline 46 & Total Inorganic Carbon & $\log / \mathrm{mL}$ & NA & N/A & N/A & NA \\
\hline 47 & Suspended Solids & $w t \%$ & 5.04 & 4.97 & N/A & 11.69 \\
\hline 48 & \begin{tabular}{|l|} 
Total Solids \\
\end{tabular} & wt $\%$ & 6.98 & 7.85 & 10.79 & 14.36 \\
\hline 49 & Mean Particle Size by Volume & micron & NA & N/A & N/A & NA \\
\hline 50 & Mean Particte Size by Numbe & micron & NA & NA & N/A & N/A \\
\hline 51 & Kinematic Viscosity & cost & NA & 1.6 & 1.5 & 1.4 \\
\hline 52 & Dynamic Viscosity & $C P$ & N/A & 1.6 & 1.6 & 1.6 \\
\hline 53 & Comment & & Post-wash De-watering & HAAKE/SPINNING CONE & HAAKE/SPINNING CONE & HAAKE/SPINNING CONE \\
\hline
\end{tabular}

Table E1: Analytical - All data, Page 10 


\begin{tabular}{|c|c|c|c|c|}
\hline & BI & BJ & BK & $\mathrm{BL}$ \\
\hline 1 & TEST RUN & $\ldots$ & $2.20 \mathrm{~b}$ & Final Concentrate \\
\hline 2 & BNFL Sample ID -.................. & 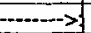 & BNF-SXF2055-A+ES_17b & BNF SXF2055-A+ES_18b \\
\hline 3 & ADS Sample ID & $m-\infty$ & $3-129122$ & $3-130103$ \\
\hline 4 & Type Sample -........................ & $m-\cdots$ & filtrate & filtrate ( -30 liters left) \\
\hline 5 & Sample Size $\ldots \ldots \ldots$ & $\mathrm{mL}$ & 15 & 15 \\
\hline 6 & Measurement(s) Made & $\cdots>>$ & SSICP-ESIAATICTOCCASEMC-ANHONS & TS/SS/ICP-ES \\
\hline 7 & Item Measured & Units & 1. & 78 \\
\hline 8 & Density & $\mathrm{g} / \mathrm{mL}$ & 1.019 & 1.019 \\
\hline 9 & Al & $\mathrm{ug} / \mathrm{mL}$ & 705 & 16.6 \\
\hline 10 & $\mathrm{~B}$ & $\mathrm{ug} / \mathrm{mL}$ & 1.4 & $<0.13$ \\
\hline 11 & $\mathrm{Ba}$ & $\mathrm{ug} / \mathrm{mL}$ & $<0.05$ & $<0.02$ \\
\hline 12 & $\mathrm{Ca}$ & $u g / m L$ & $<0.2$ & 3.3 \\
\hline 13 & Cd & $\mathrm{ug} / \mathrm{mL}$ & $<0.05$ & 0.1 \\
\hline 14 & $\mathrm{Cl}$ & $\mathrm{ug} / \mathrm{mL}$ & 116 & N/A \\
\hline 15 & CI Sample & $\mathrm{ug} / \mathrm{mL}$ & 145 & N/A \\
\hline 16 & Co & $\mathrm{ug} / \mathrm{mL}$ & $<0.05$ & $<0.02$ \\
\hline 17 & $\mathrm{Cr}$ & $\mathrm{ug} / \mathrm{mL}$ & 1 & 1.5 \\
\hline 18 & $\mathrm{Cu}$ & ug/mL & $<0.05$ & 0.07 \\
\hline 19 & $F$ (Fluoride) -(only rough rdg) & ug/mL & 9 & N/A \\
\hline 20 & F Sample & $\mathrm{ug} / \mathrm{mL}$ & $<10$ & N/A \\
\hline 21 & $\mathrm{Fe}$ & $\mathrm{ug} / \mathrm{mL}$ & 0.07 & 21.4 \\
\hline 22 & HCOO (Formate) & $\mathrm{ug} / \mathrm{mL}$ & 60 & $N / A$ \\
\hline 23 & $\mathrm{~K}$ & $\mathrm{ug} / \mathrm{mL}$ & 131.1485 & N/A \\
\hline 24 & La & $4 \mathrm{~g} / \mathrm{mL}$ & $<0.14$ & $<0.14$ \\
\hline 25 & Li & $\mathrm{ug} / \mathrm{mL}$ & $<0.7$ & $<0.7$ \\
\hline 26 & $\mathrm{Mg}$ & $4 \mathrm{~g} / \mathrm{mL}$ & $<0.03$ & 1.1 \\
\hline 27 & $\mathrm{Mn}$ & $\mathrm{ug} / \mathrm{mL}$ & $<0.02$ & 0.16 \\
\hline 28 & $\mathrm{Mo}$ & $\mathrm{ug} / \mathrm{mL}$ & 1.5 & 0.15 \\
\hline 29 & $\mathrm{Na}$ & $\mathrm{ug} / \mathrm{mL}$ & 8475 & 38.7 \\
\hline 30 & $\widehat{\mathrm{Ni}}$ & $\mathrm{ug} / \mathrm{mL}$ & $<0.06$ & 1.2 \\
\hline 31 & NO2 (Nitrite) & $u g / \mathrm{mL}$ & 1817 & N/A \\
\hline 32 & NO3 (Nitrate) & $\mathrm{ug} / \mathrm{mL}$ & 2885 & N/A \\
\hline 33 & $\mathrm{C} 204$ (Oxalate) & $\mathrm{ug} / \mathrm{mL}$ & 9453 & N/A \\
\hline 34 & $\mathbf{P}$ & $\mathrm{ug} / \mathrm{mL}$ & 6 & $<0.9$ \\
\hline 35 & PO4 (Phosphate) & $\mathrm{ug} / \mathrm{mL}$ & 12 & N/A \\
\hline 36 & $\mathrm{~Pb}$ & $u g / m L$ & $<0.5$ & 1.5 \\
\hline 37 & $\mathbf{S i}$ & $\mathrm{ug} / \mathrm{mL}$ & 13 & 1.4 \\
\hline 38 & Sn & $u g / m L$ & $<0.4$ & $<0.4$ \\
\hline 39 & SO4 (Sulfate) & $\mathrm{ug} / \mathrm{mL}$ & 11 & N/A \\
\hline 40 & $\mathrm{Sr}$ & $u g / m L$ & $<0.05$ & $<0.05$ \\
\hline 41 & $\mathrm{Ti}$ & $4 \mathrm{~g} / \mathrm{mL}$ & $<0.05$ & 0.56 \\
\hline 42 & V & $\mathrm{ug} / \mathrm{mL}$ & $<0.12$ & $<0.12$ \\
\hline 43 & $\mathrm{Zn}$ & $\mathrm{ug} / \mathrm{mL}$ & $<0.03$ & 0.33 \\
\hline 44 & $\overline{\mathrm{Zr}}$ & $\mathrm{ug} / \mathrm{mL}$ & $<0.15$ & 0.15 \\
\hline 45 & Total Organic Carbon & $\mathrm{ug} / \mathrm{mL}$ & 1184 & N/A \\
\hline 46 & Total Inorganic Carbon & $\mathrm{ug} / \mathrm{mL}$ & 163 & $N / A$ \\
\hline 47 & Suspended Solids & $w t \%$ & $<.01$ & $<0.004$ \\
\hline 48 & Total Solids & $w t \%$ & N/A & N/A \\
\hline 49 & Mean Particle Size by Volume & micron & N/A & $\mathbf{N} / \mathbf{A}$ \\
\hline 50 & Mean Particle Size by Number & micron & $\mathrm{N} / \mathrm{A}$ & N/A \\
\hline 51 & \begin{tabular}{|l|} 
Kinematic Viscosity \\
\end{tabular} & cSt & N/A & N/A \\
\hline 52 & Dynamic Viscosity & $\mathrm{CP}$ & N/A & N/A \\
\hline 53 & Comment & & & fird out remaining solids \\
\hline
\end{tabular}

Table E1: Analytical - All data, Page 11 


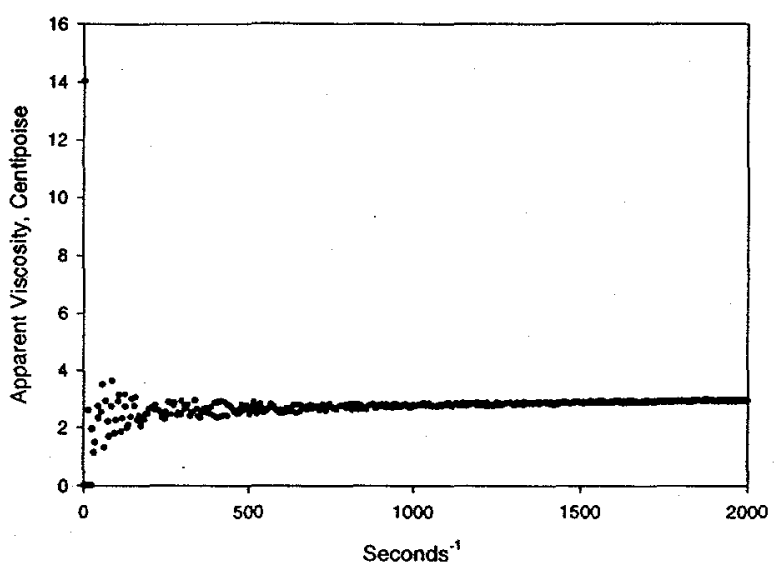

Figure E1. Slurry at $0.5 \mathrm{wt} \%$ insoluble solids and $29 \mathrm{wt} \%$ total solids: Run 2.13

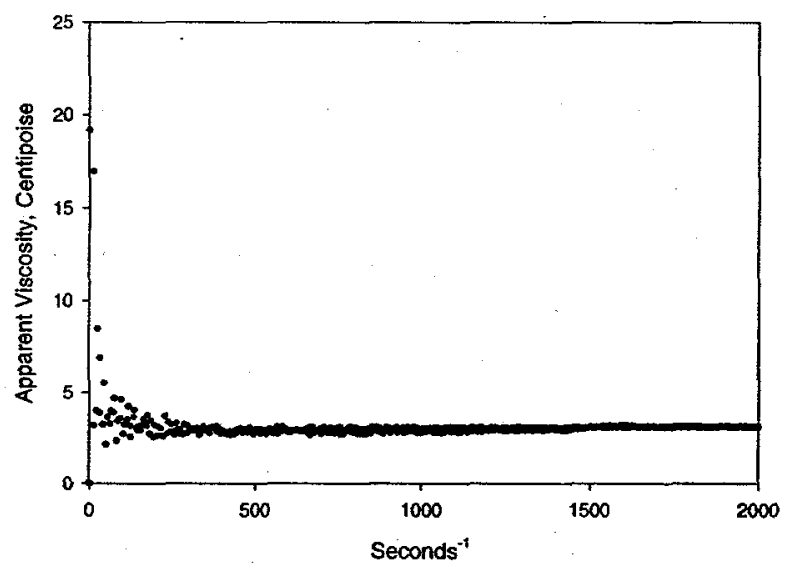

Figure E2. Slurry at $8 \mathrm{wt} \%$ insoluble solids and $36 \mathrm{wt} \%$ total solids: Run $2.14 \mathrm{~b}$

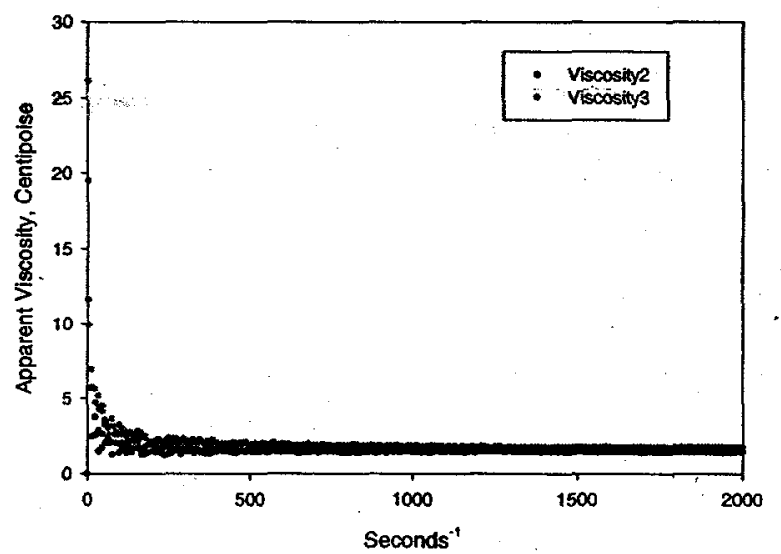

Figure E3. Slurry at $12 \mathrm{wt} \%$ insoluble solids and $14 \mathrm{wt} \%$ total solids: Run $2.20 \mathrm{~b}$ 

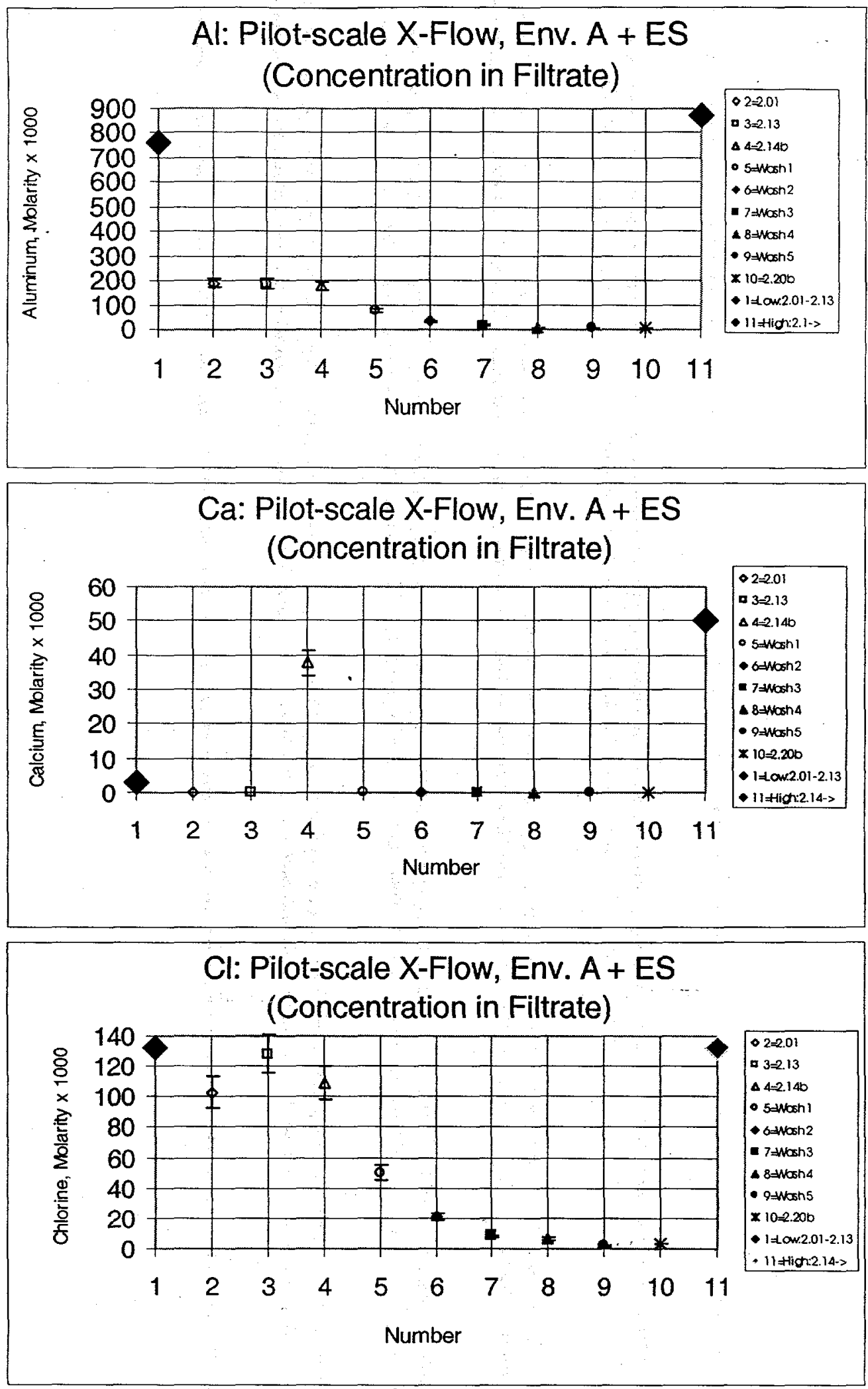

Figure E4, E5, and E6. Aluminum, Calcium, and Chlorine, respectively 
Pilot scale X-flow: EnvA+ES Page 180 of 226
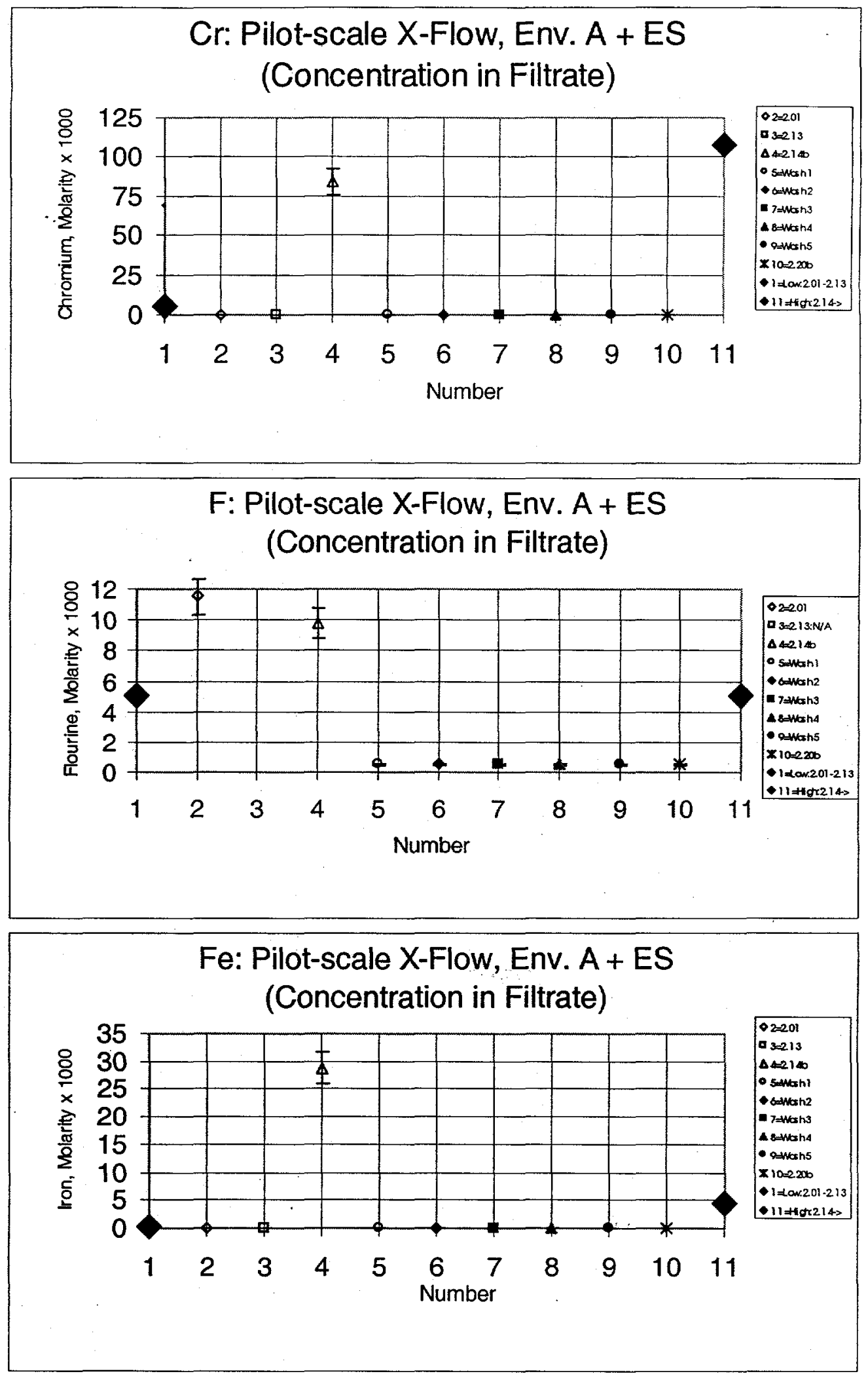

Figure E7, E8, and E9. Chromium, Florine, and Iron, respectively 

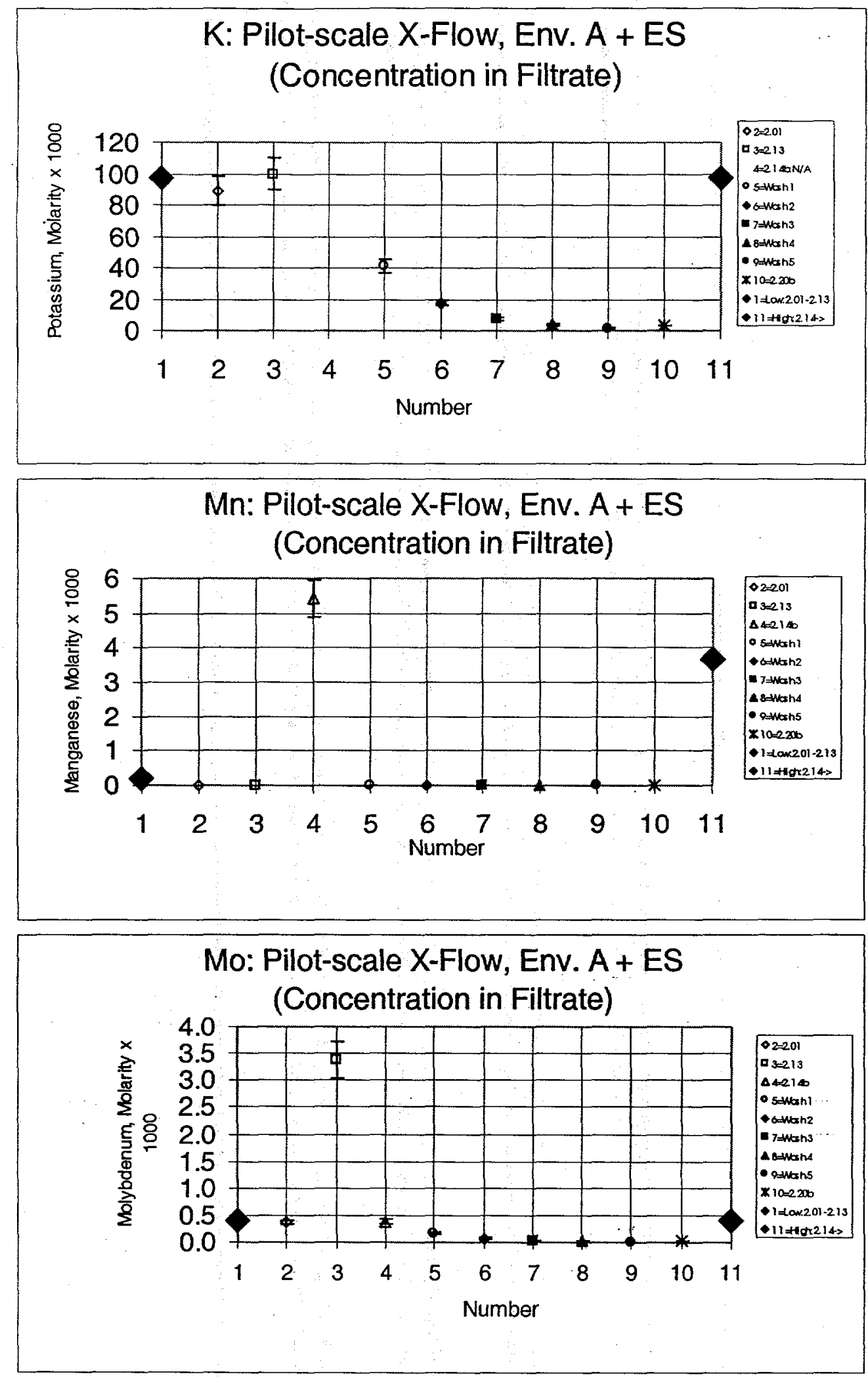

Figure E10, E11, and E12.Potassium, Manganese, and Molybdenum, respectively 

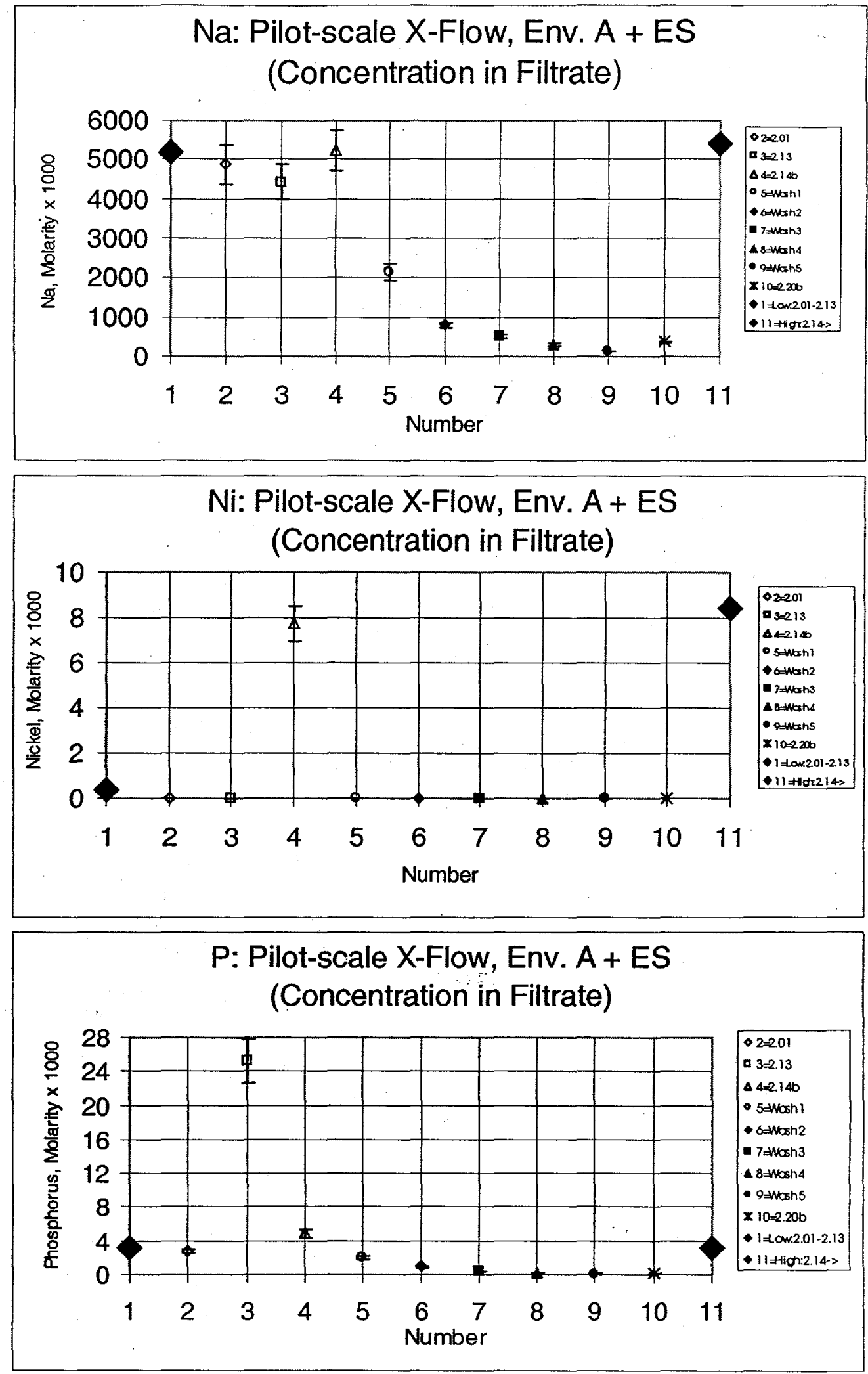

Figure E13, E14, and E15. Sodium, Nickel, and Phosphorous, respectively 

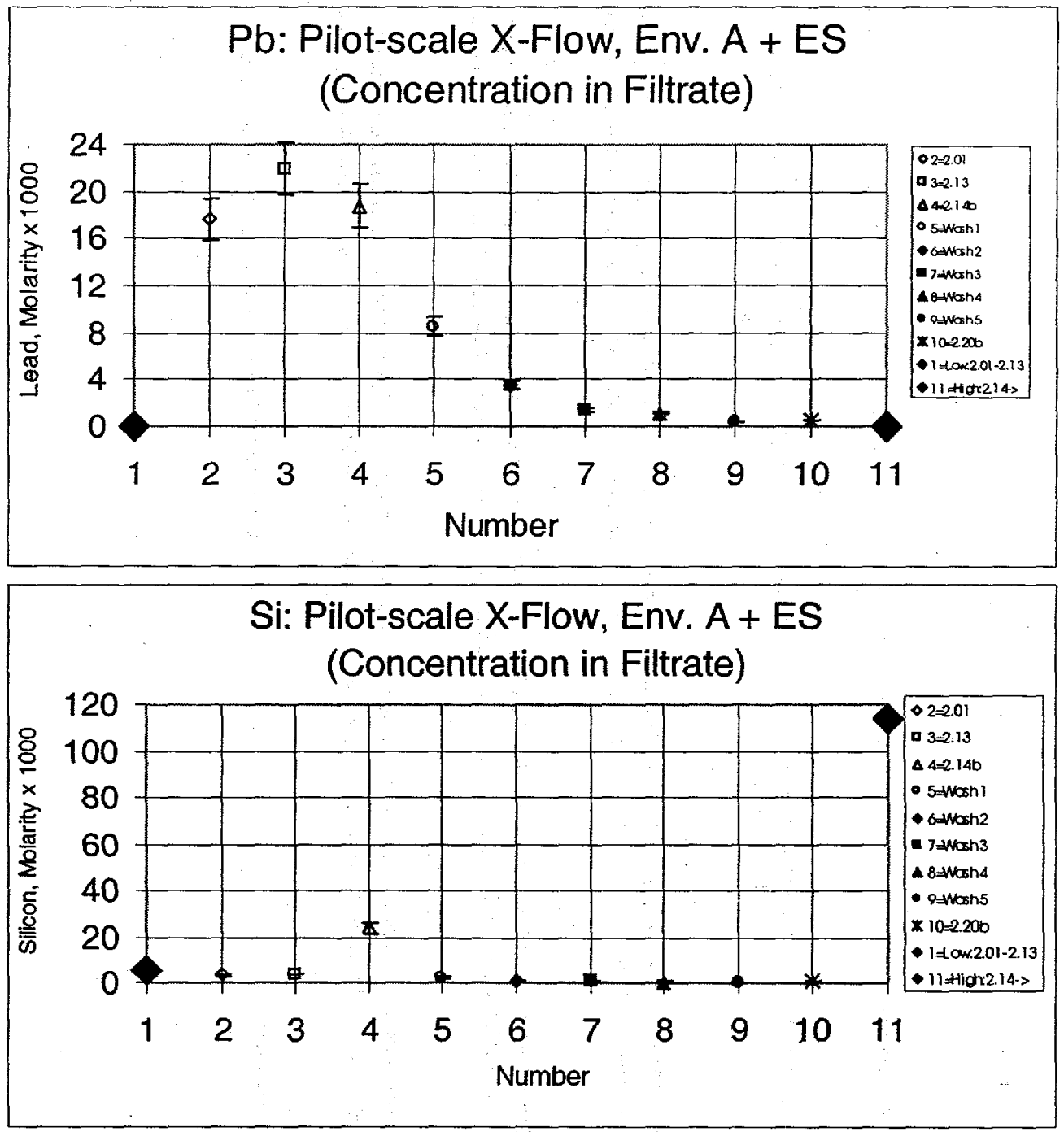

Figure E16 and E17. Lead and Silicon, respectively 

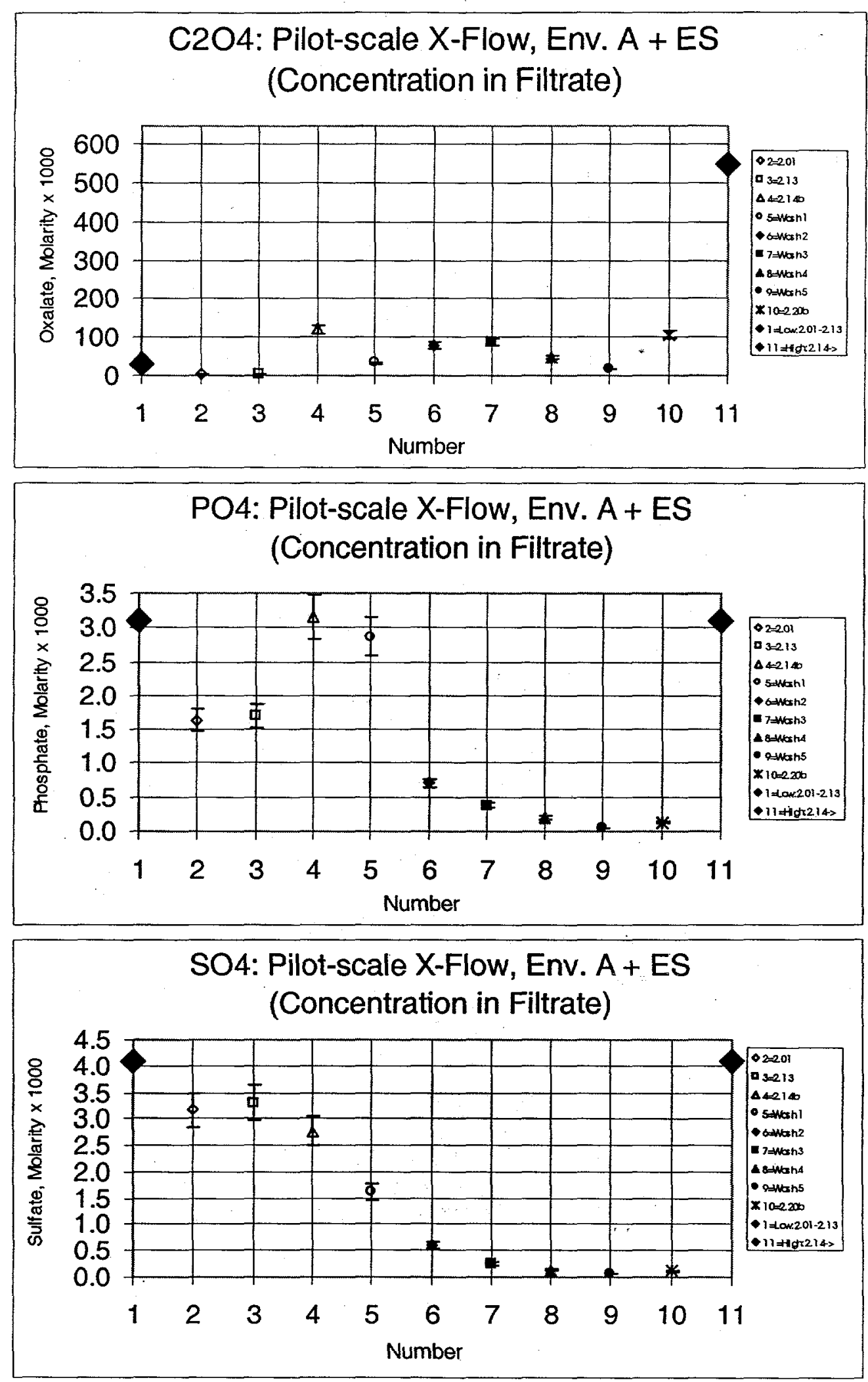

Figure E18, E19, and E20. Oxalate, Phosphate, and Sulfate, respectively 
- Particle Size Info

Source: "Results of Dilution Studies with Waste from Tank 241-AN-105" by D. L. Herting, HNF-SD-DTR-046, Rev. 0, 10/10/1997.

Undiluted whole tank composite sample of $241-\mathrm{AN}-105$ had as follows:
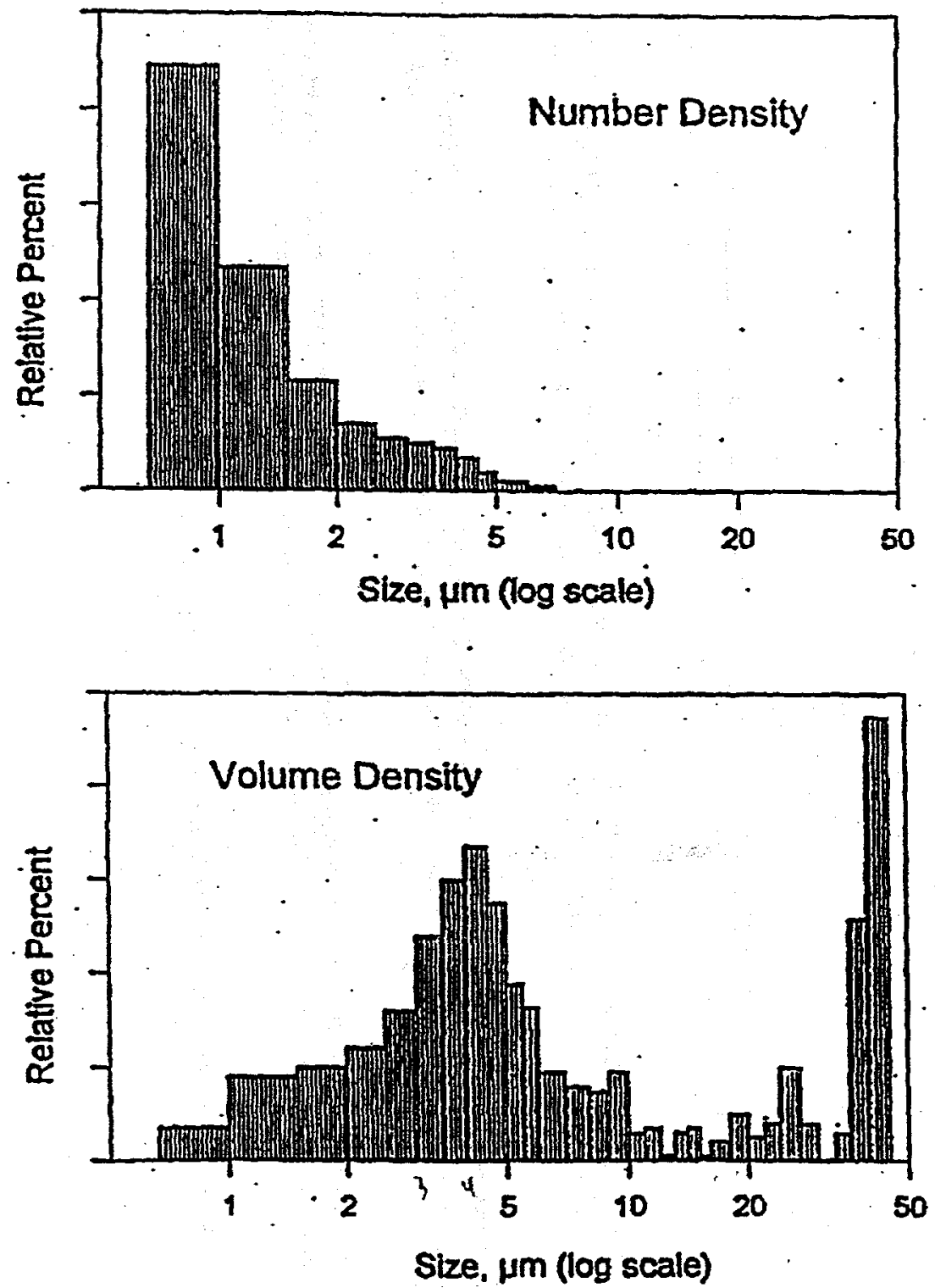

Figure E21. Insoluble Solids Distribution from Actual Tank AN-105 Waste Sample 


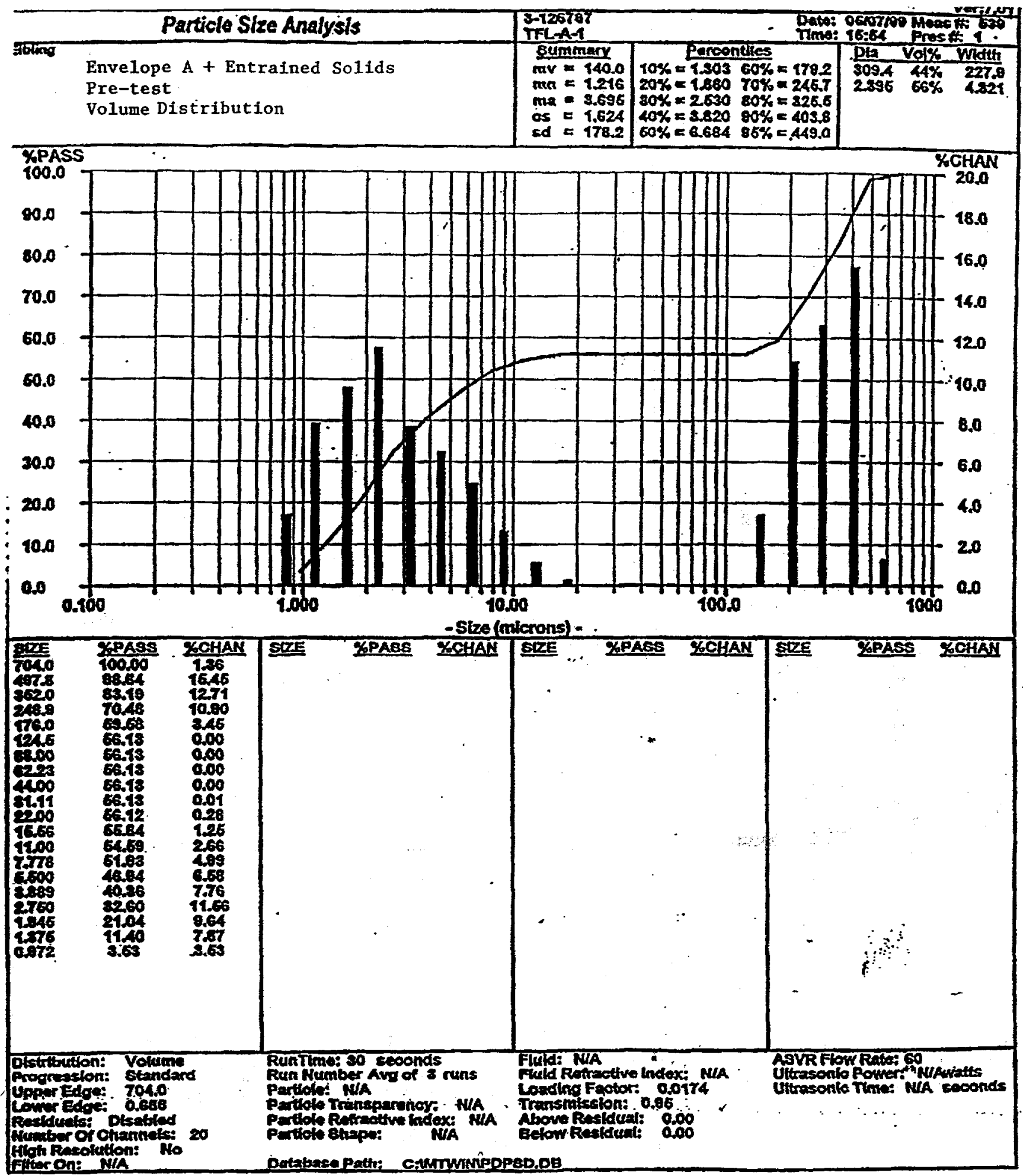

Figure E22A.Envelope A+ES Insoluble Solids Volume Distribution: Pre-test Sample (125 mL sample of simulant was made prior to large batch) 


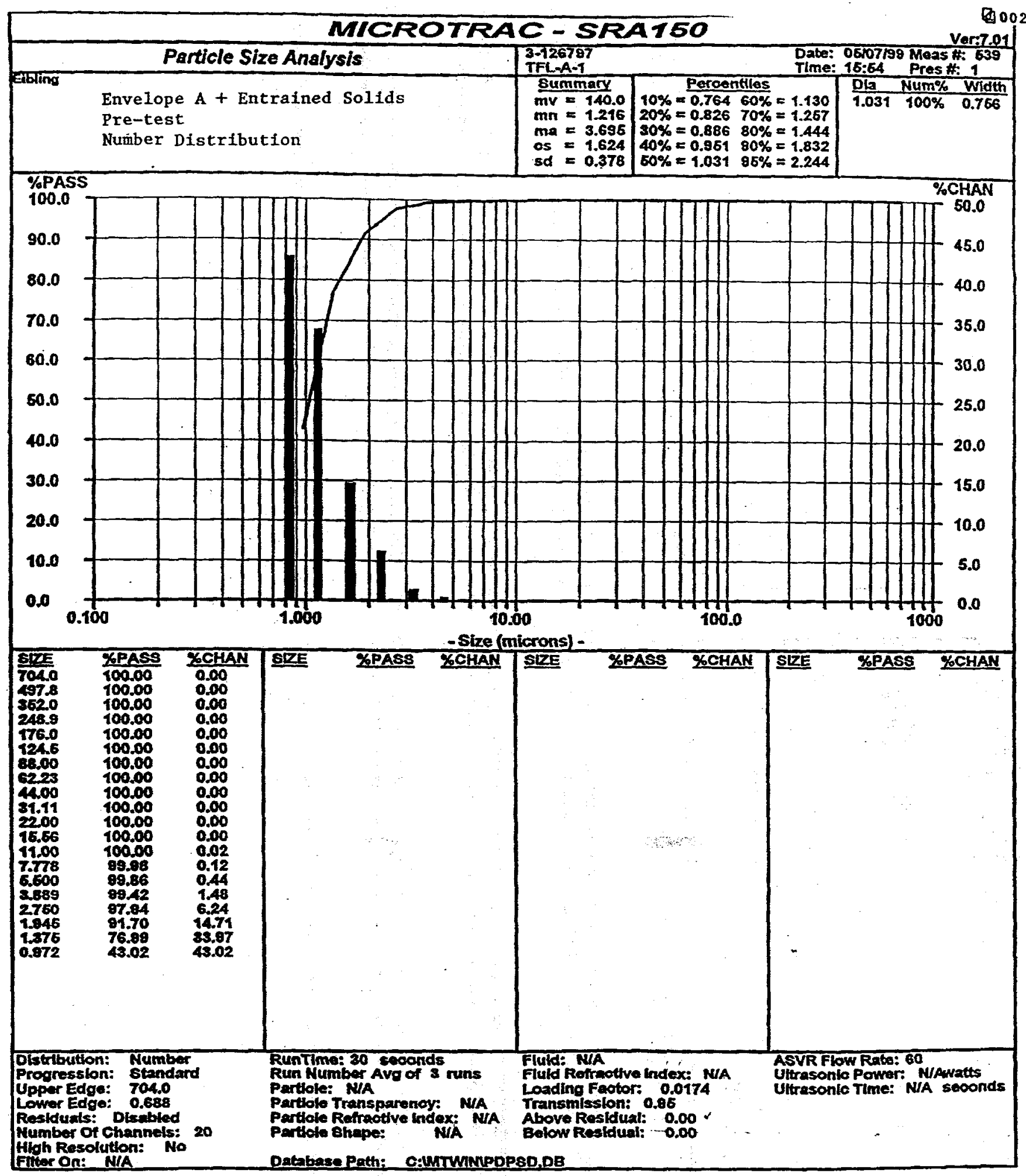

Figure E22B.Envelope A+ES Insoluble Solids Number Distribution: Pre-test Sample (125 $\mathrm{mL}$ sample of simulant was made prior to large batch) 


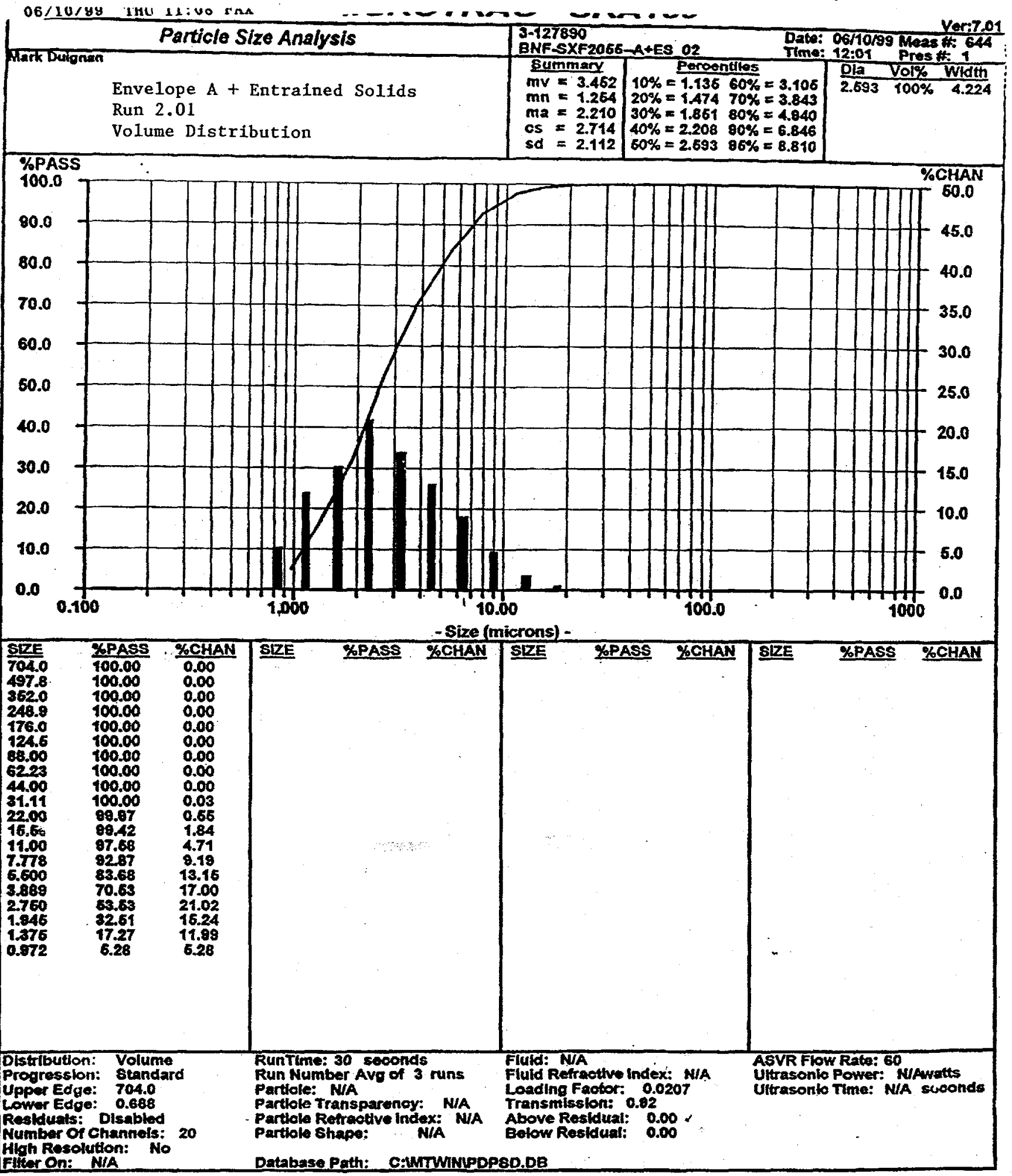

Figure E23A.Envelope A+ES Insoluble Solids Volume Distribution: Run 2.01 (Low-solids-concentation slurry experienced about 1 hour of circulation) 


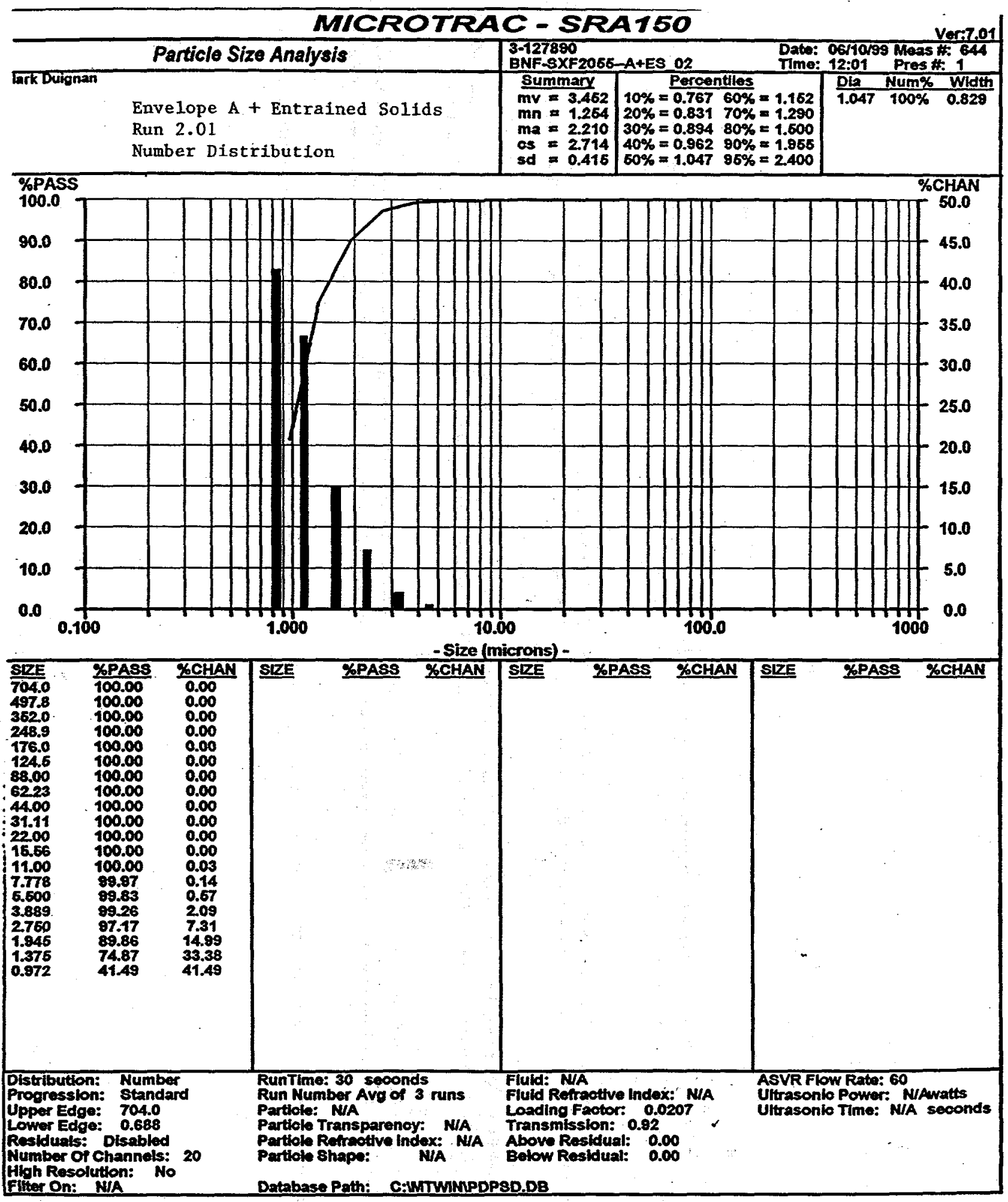

Figure E23B.Envelope A+ES Insoluble Solids Number Distribution: Run 2.01 (Low-solids-concentation slurry experienced about 1 hour of circulation) 


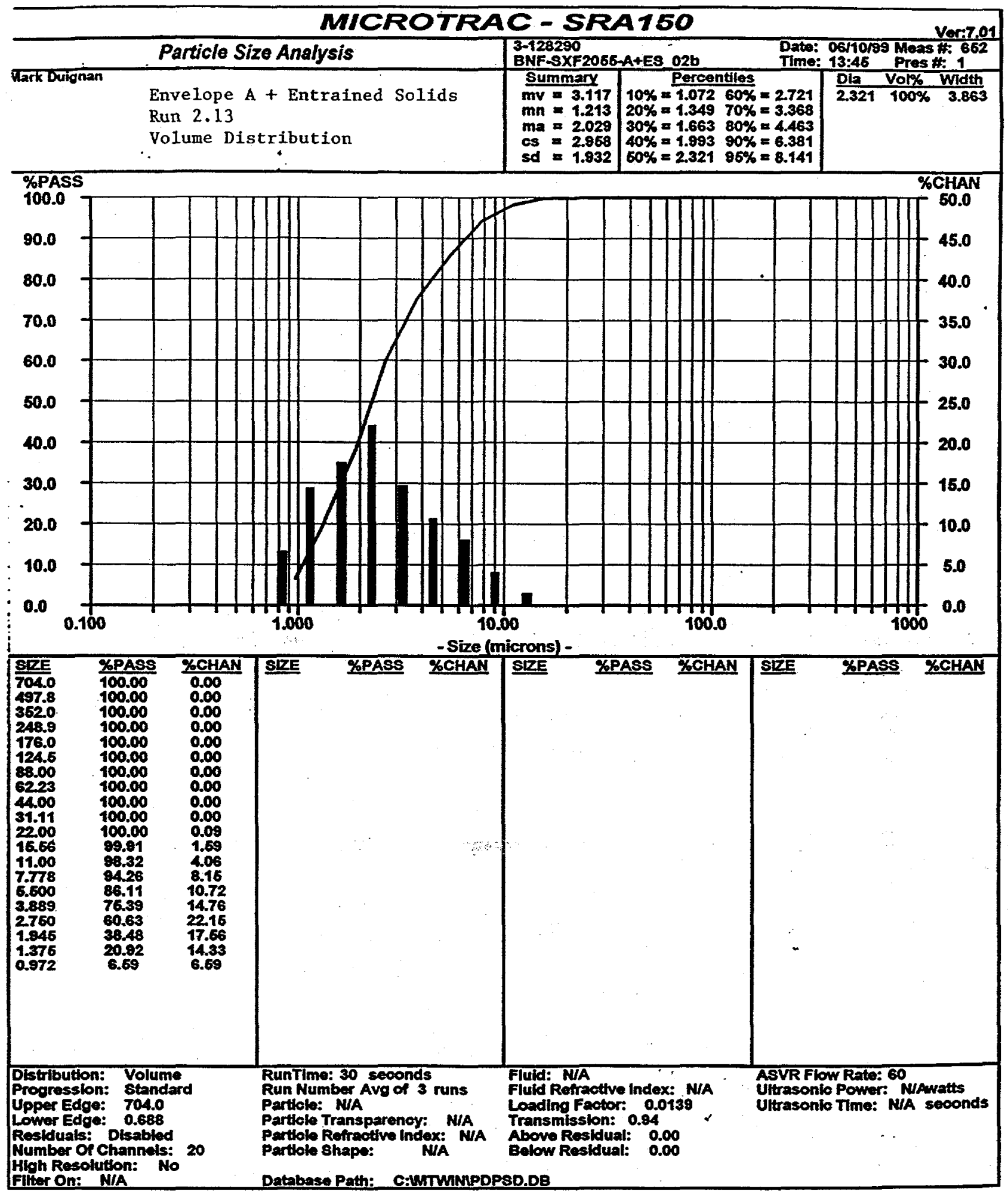

Figure E24A.Envelope A+ES Insoluble Solids Volume Distribution: Run 2.13

(Low-solids-concentation slurry experienced about 24 hours of circulation) 


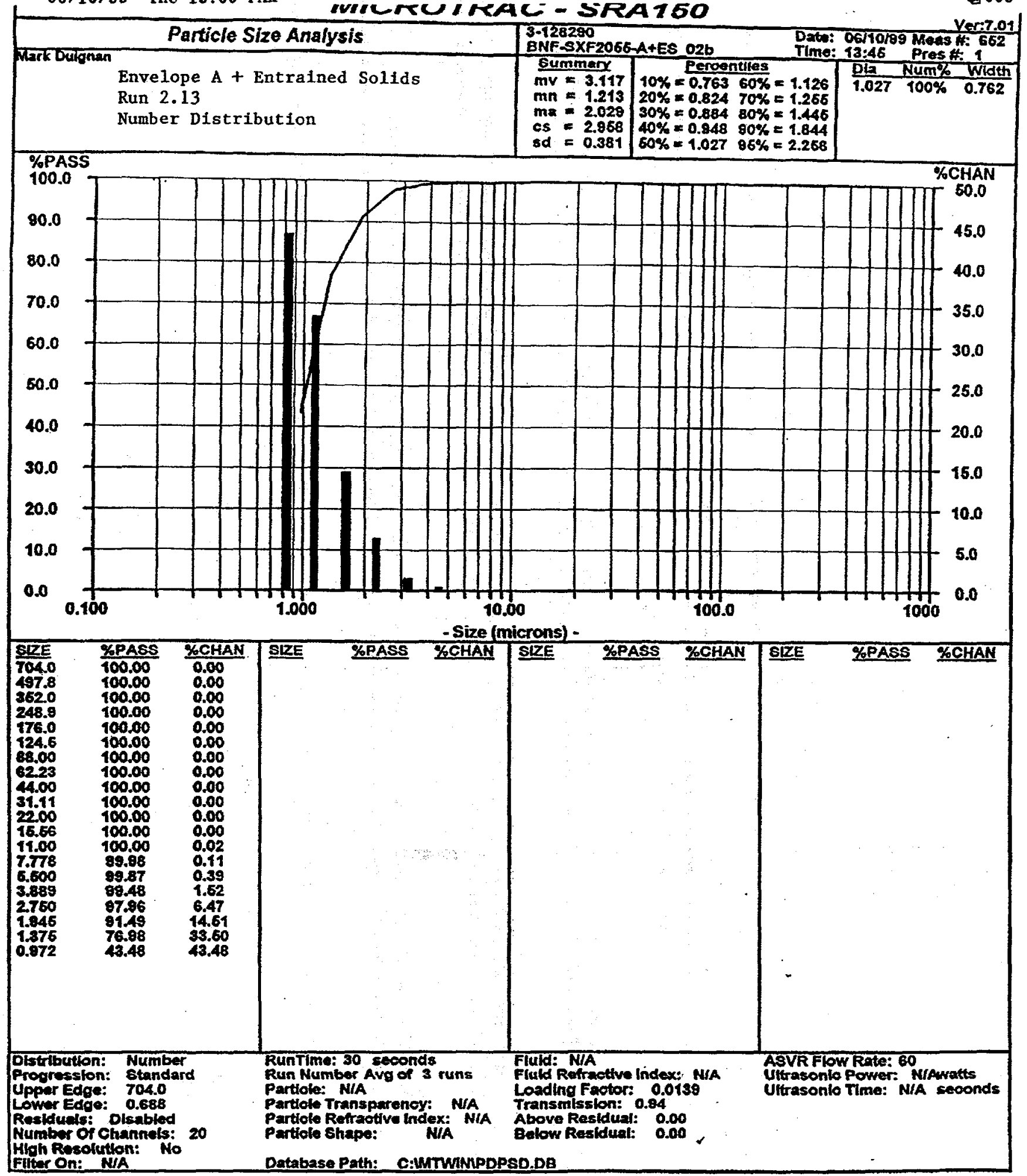

Figure E24B.Envelope A+ES Insoluble Solids Number Distribution: Run 2.13 (Low-solids-concentation slurry experienced about 24 hours of circulation) 


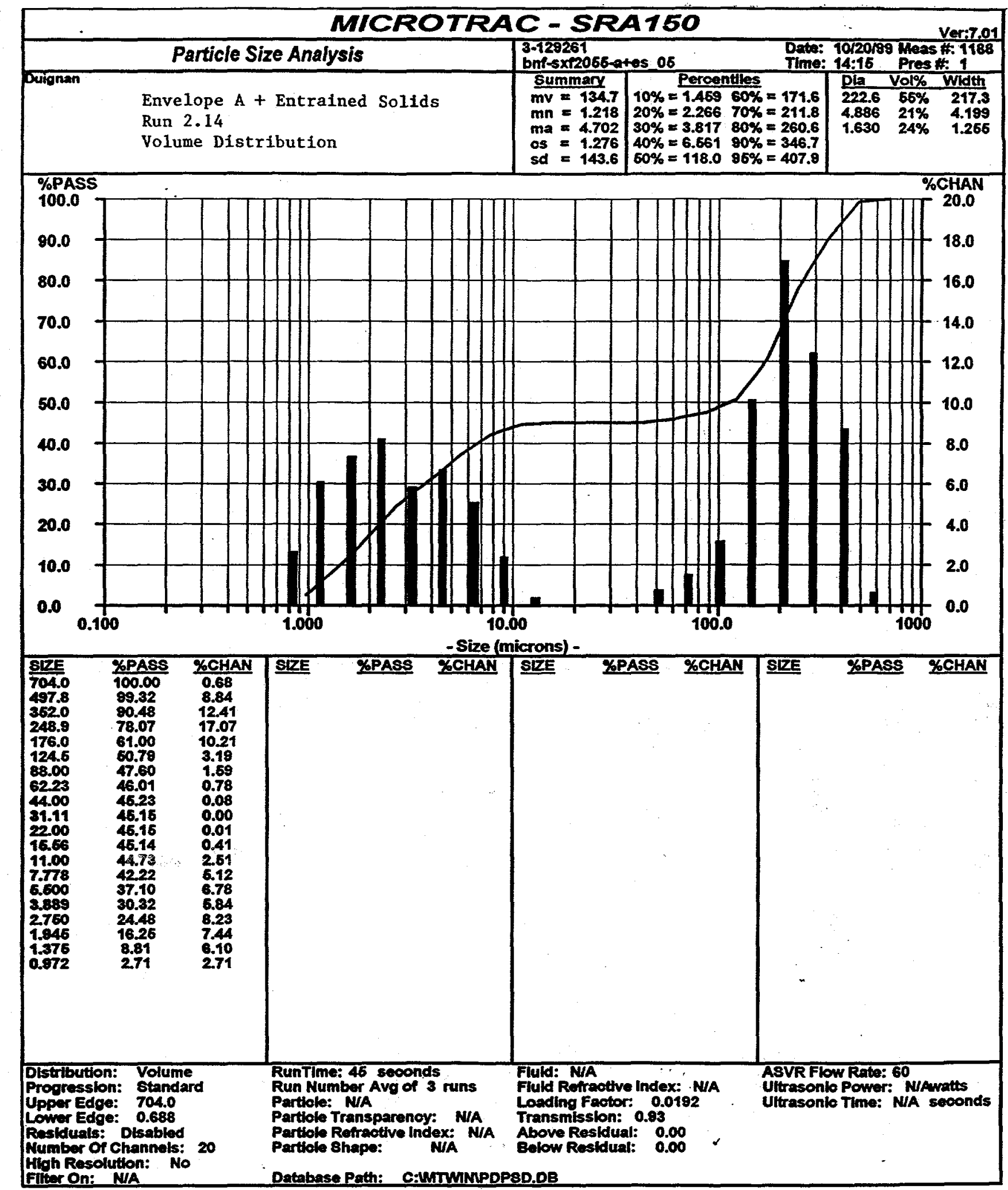

Figure E25A.Envelope A+ES Insoluble Solids Volume Distribution: Run 2.14 (Slurry after new solids were added: Concentration approximately $9 \mathrm{wt} \%$ ) 


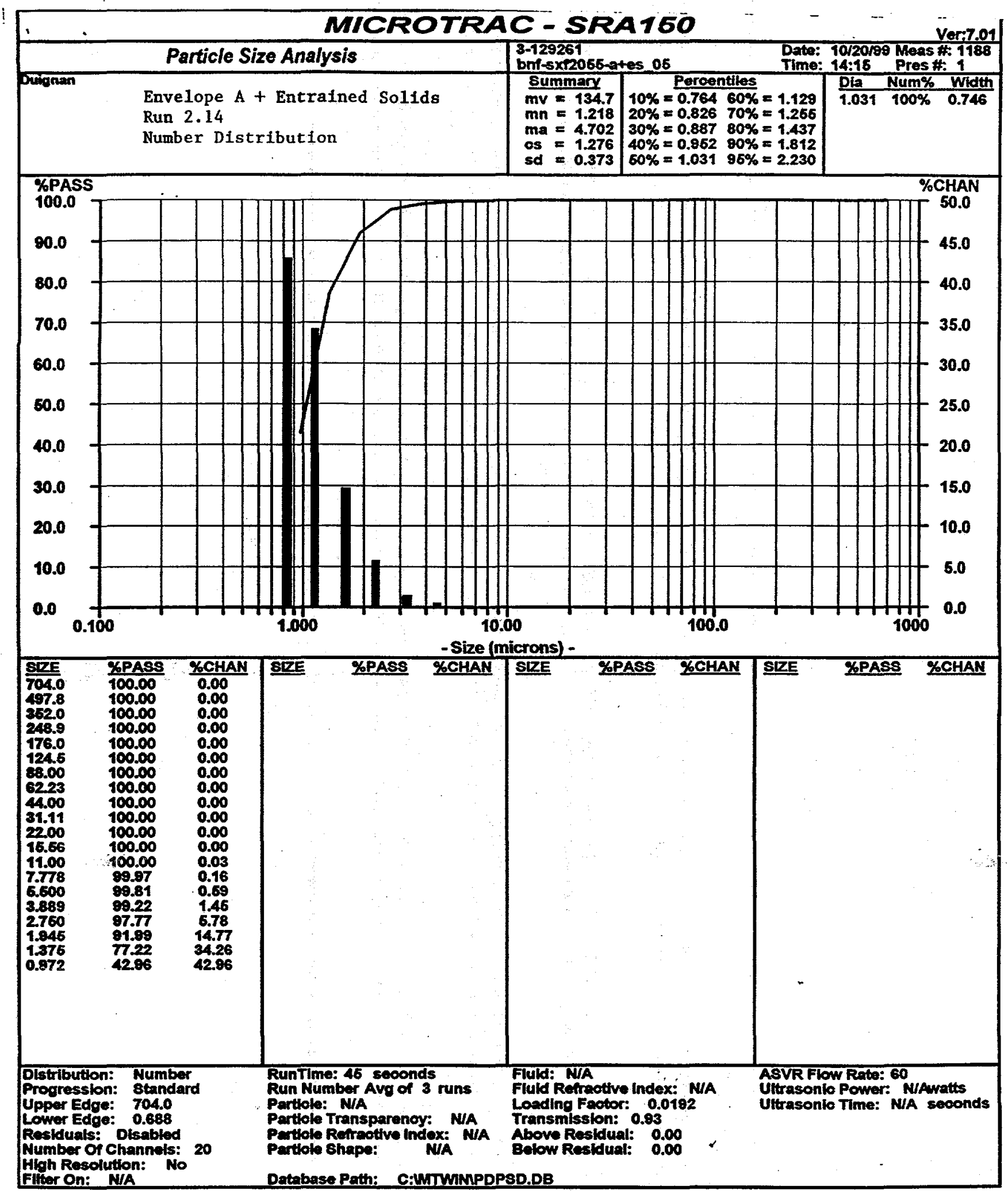

Figure E25B.Envelope A+ES Insoluble Solids Number Distribution: Run 2.14 (Slurry after new solids were added: Concentration approximately $9 \mathrm{wt} \%$ ) 


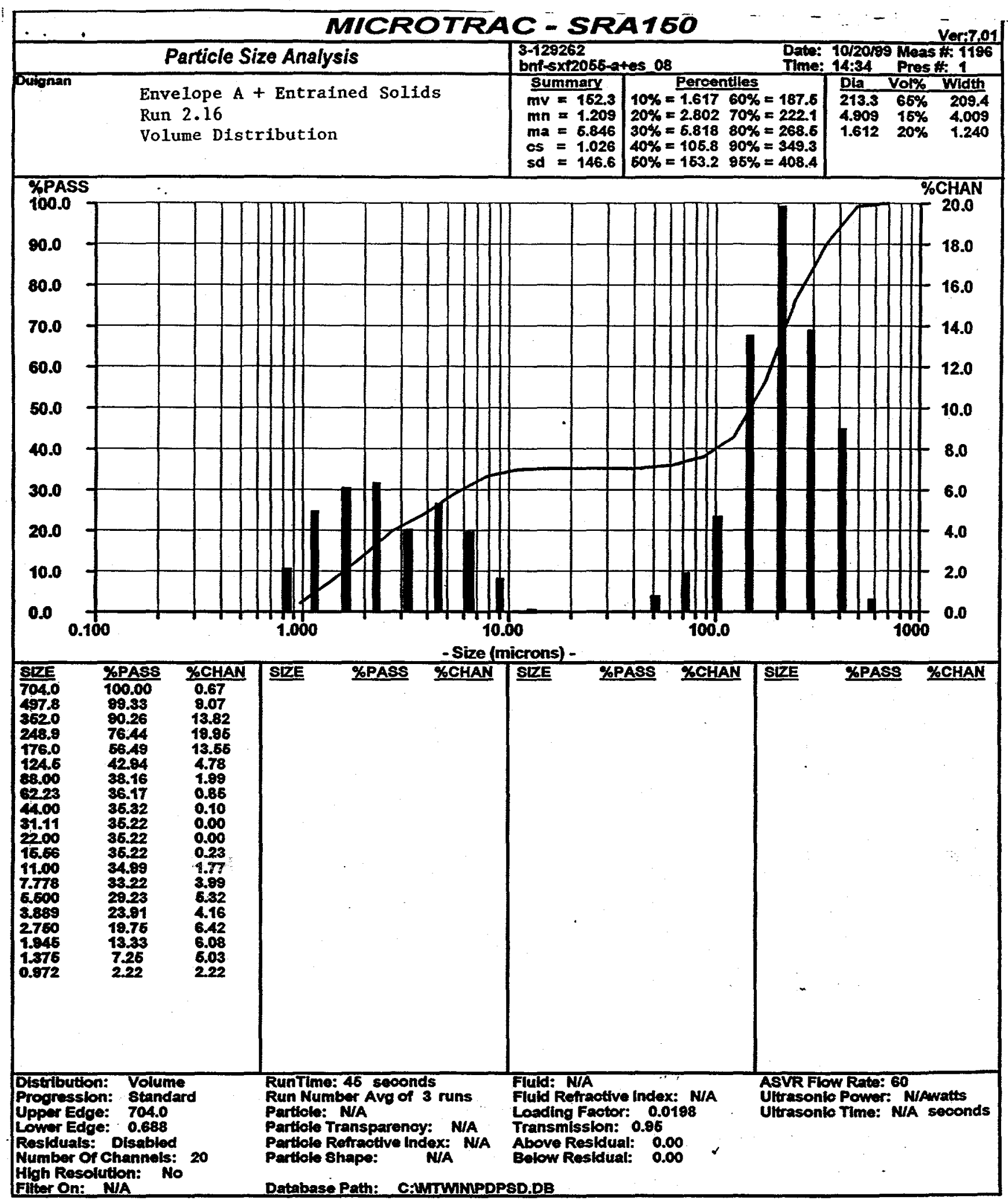

Figure E26A.Envelope A+ES Insoluble Solids Volume Distribution: Run 2.16 (Slurry after $2^{\text {nd }}$ Wash) 


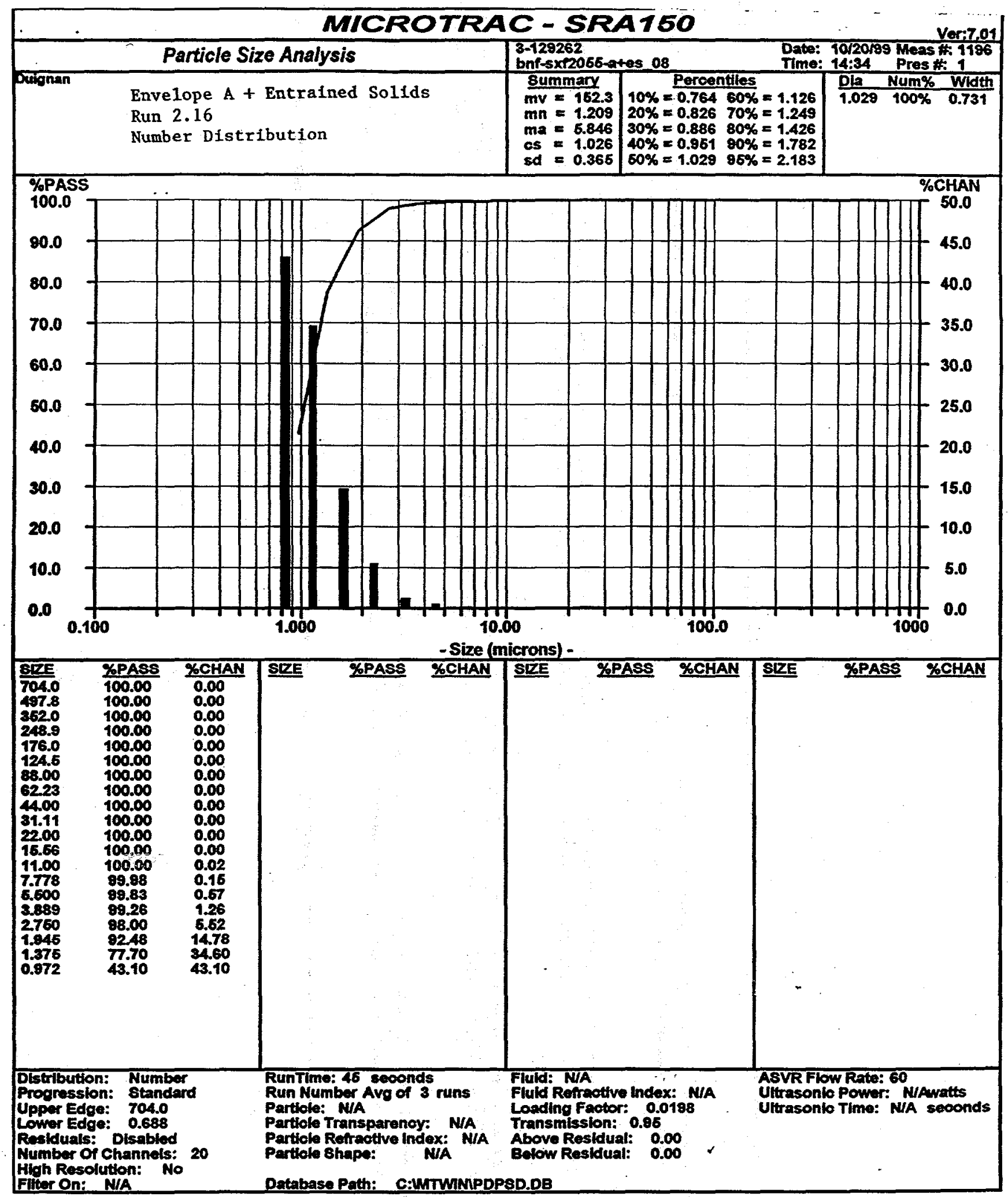

Figure E26B.Envelope A+ES Insoluble Solids Number Distribution: Run 2.16 (Slurry after $2^{\text {nd }}$ Wash) 


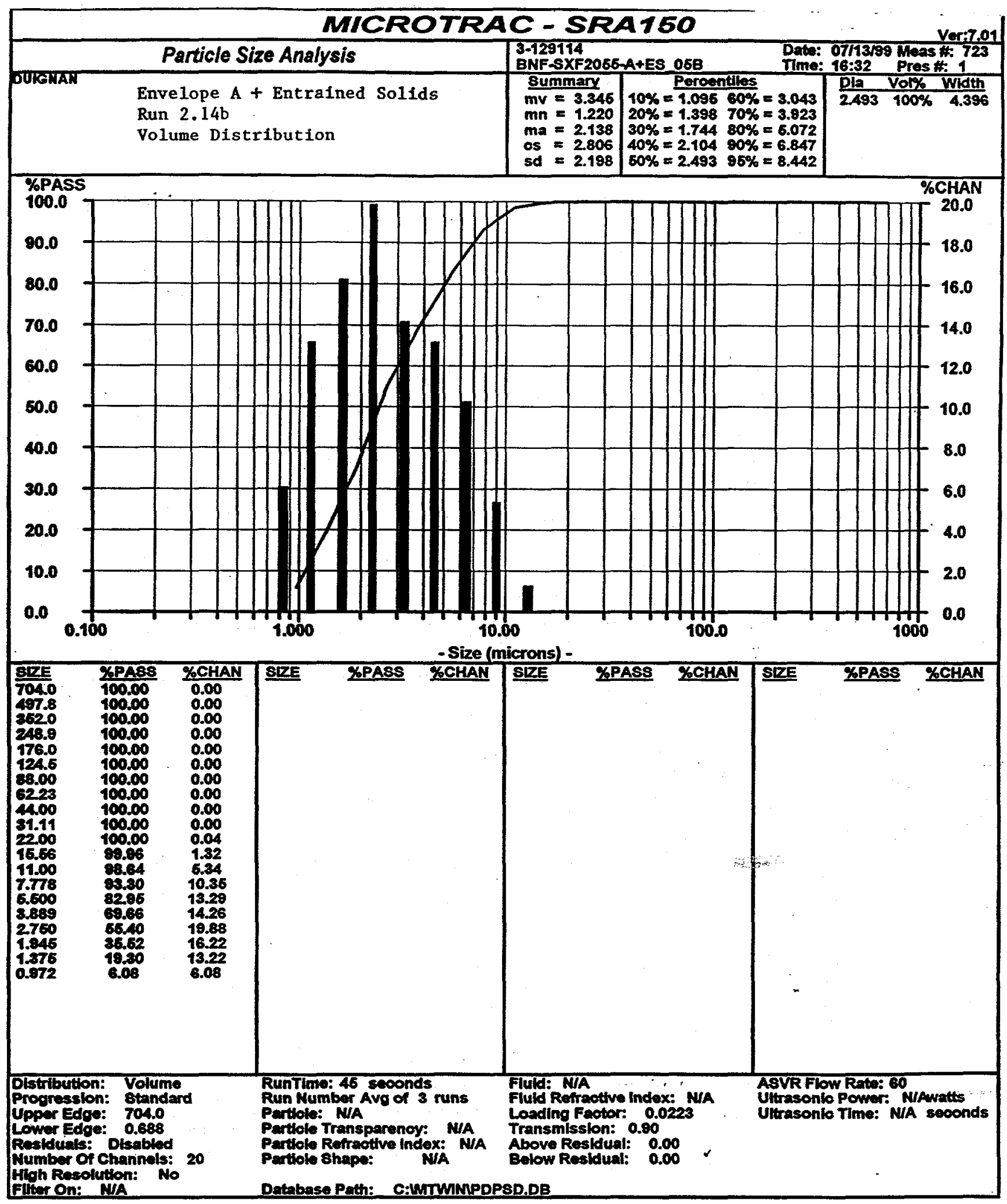

Figure E27A.Envelope A+ES Insoluble Solids Volume Distribution: Run 2.14b (Run 2.14 was redone after the slurry $\mathrm{Na}^{+}$concentration was raised above $5 \mathrm{M}$ ) 
Pilot scale X-flow: EnvA+ES Page 197 of 226

BNF-003-98-0221

Revision 0

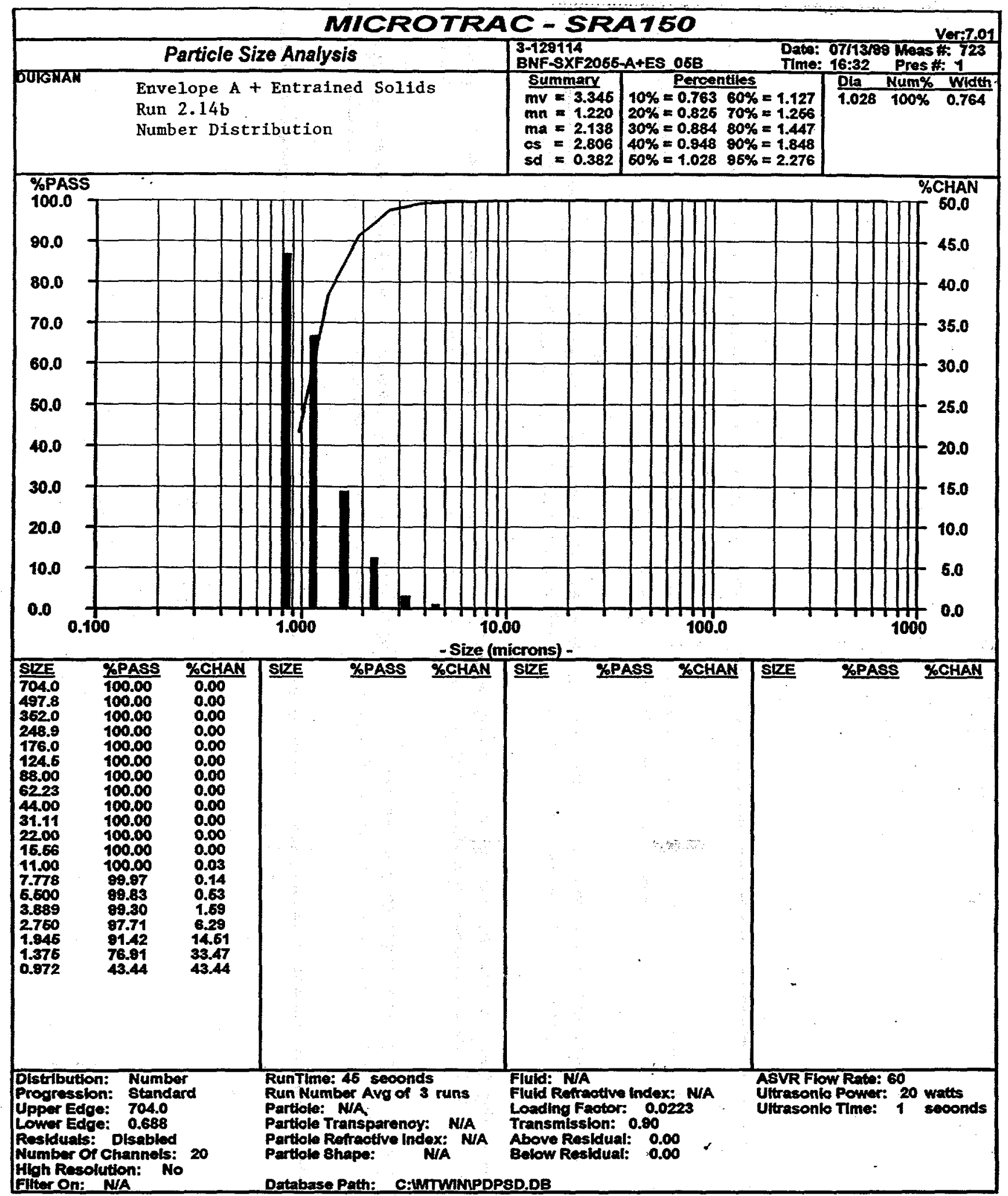

Figure E27B.Envelope A+ES Insoluble Solids Number Distribution: Run 2.14b (Run 2.14 was redone after the slurry $\mathrm{Na}^{+}$concentration was raised above $5 \mathrm{M}$ ) 


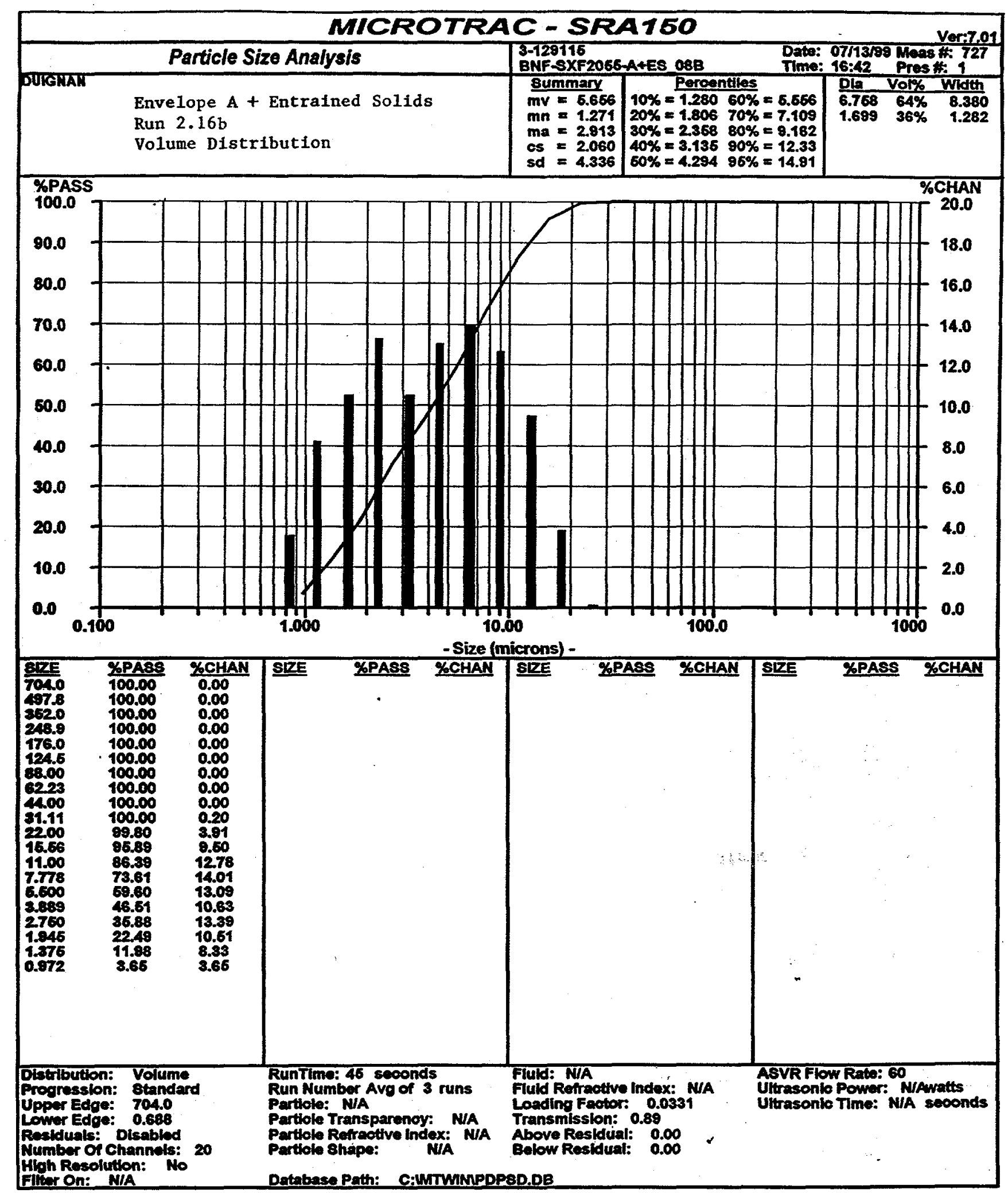

Figure E28A.Envelope A+ES Insoluble Solids Volume Distribution: Run 2.16b (Slurry after $2^{\text {nd }}$ Wash; $2^{\text {nd }}$ attempt) 


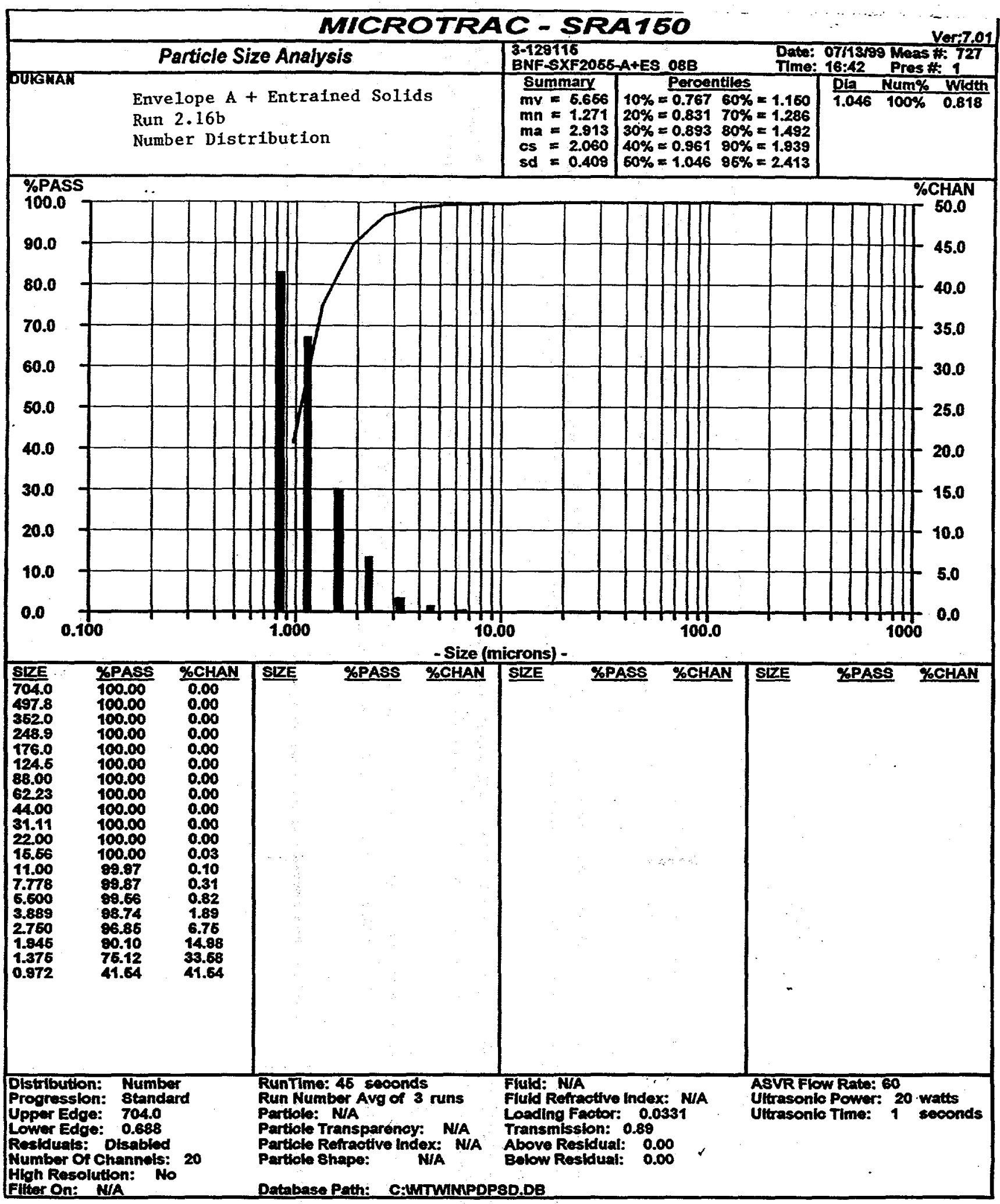

Figure E28B.Envelope A+ES Insoluble Solids Number Distribution: Run 2.16b (Slurry after $2^{\text {nd }}$ Wash; $2^{\text {nd }}$ attempt) 


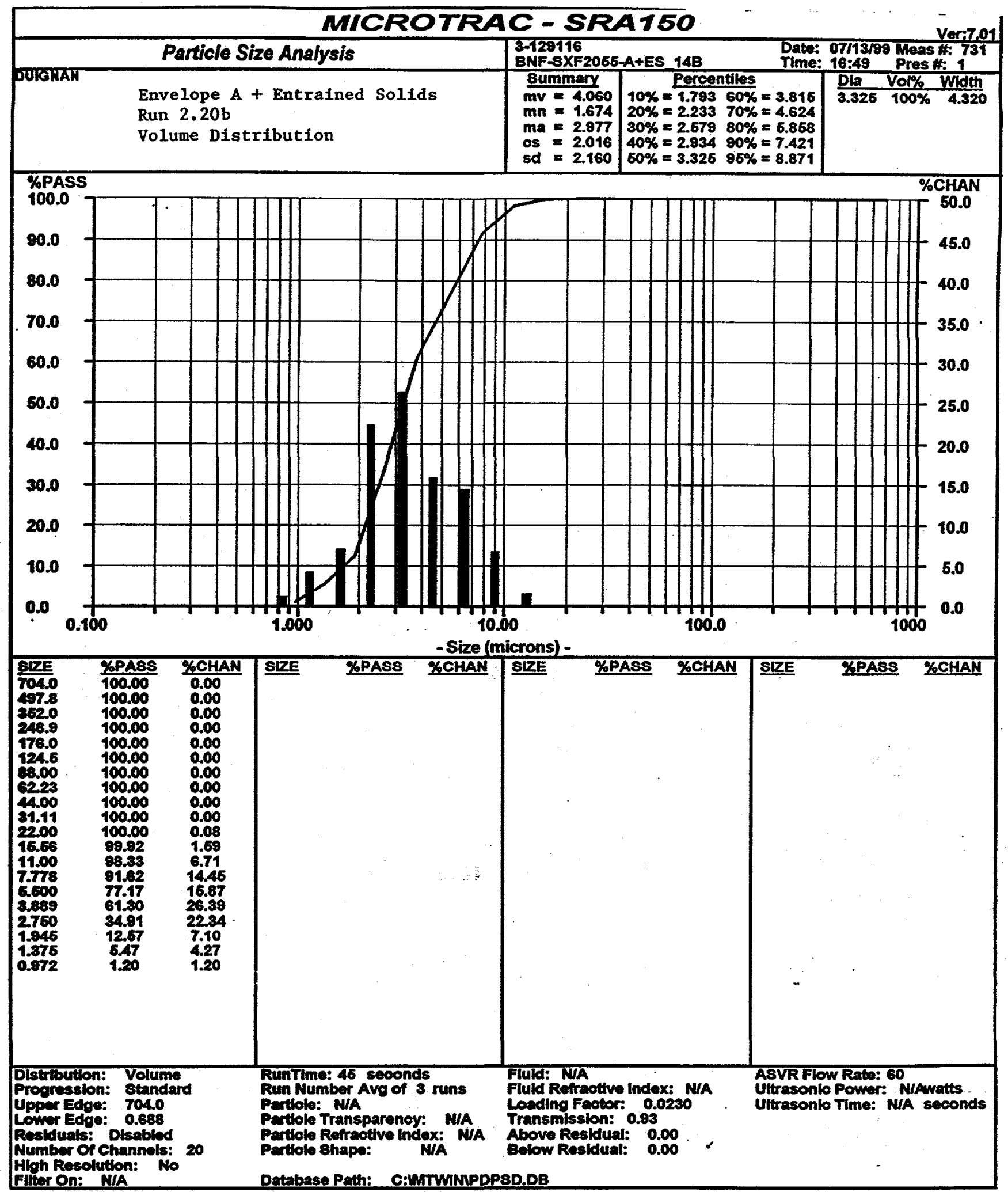

Figure E29A.Envelope A+ES Insoluble Solids Volume Distribution: Run 2.20b

(Dewatering after wash test runs: sample was taken before dewatering) 


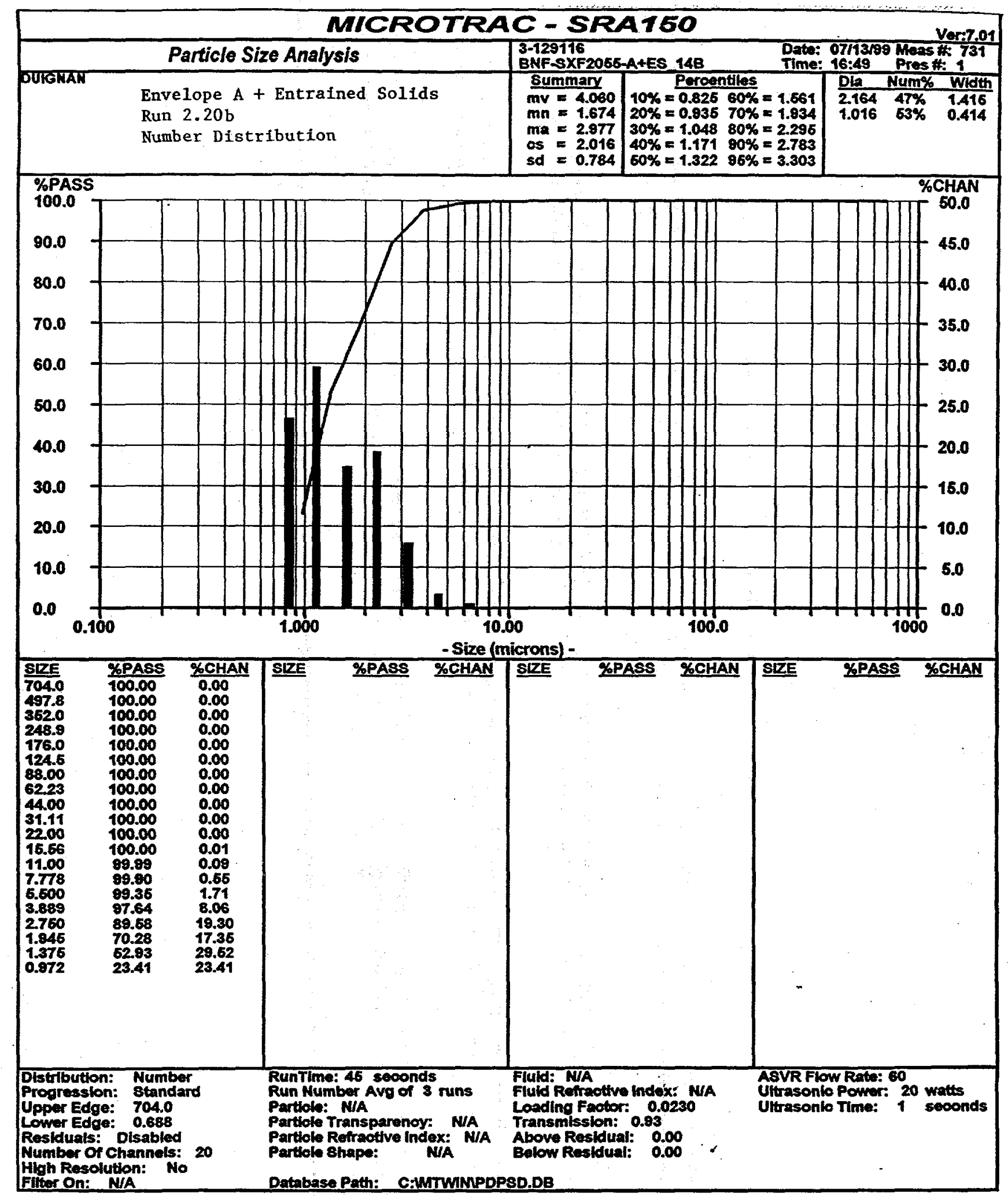

Figure E29B.Envelope A+ES Insoluble Solids Number Distribution: Run 2.20b (Dewatering after wash test runs: sample was taken before dewatering) 


\section{APPENDIX F}

\section{INSTRUMENTATION AND MEASUREMENT UNCERTAINTY}

\section{Appendix Contents}

1. Experimental measurement uncertainty

2. Figure F1. Instrumentation used with their transfer functions

3. Figure F2. Pressure transducer locations

3. Figures F3 to F16. Calibration sheet for the 14 instruments

Special Note:

As mentioned in Appendix E, there are no measurement uncertainties listed for the analytical data they are beyond the scope and control of this task. There is reason to believe that all analytical data can be at least $15 \%$ accurate but no quantitative data are given to this effect. 


\section{EXPERIMENTAL MEASUREMENT UNCERTAINTY}

As always, any measurement made has an attributed error which must be known before a level of confidence can be attained for the results obtained. This error may come from one or all of the following: the measurement instrument, the way an instrument is set up to make a measurement in relation to the experimental phenomenon to be measured, and the person using the instrument. It is not the purpose of this section to exhaust all possible ávenues of measurement uncertainty, but rather to illustrate the level of measurement uncertainty in the results presented in Appendices A, B, C, D. (Outside of density and capillary viscometer measurements taken, the measurement uncertainty of the analytical data in Appendix $E$ is beyond the scope of this task.) In general, the measurement uncertainties present here are for a reading or calculation at any instant. That is, the fluctuations that occur during experimentation are not addressed here. The magnitude of measurement fluctuations with time that occur during an experimental run can be seen at the bottom of each data table from the preceding appendices. Each column of data includes the average value of those data and their standard deviation.

In all the data sheets included in Appendices A, B, C, D there are raw data columns (all columns to the left of the Number column, which is usually column $S$ ) and there are calculated data columns to the right of the Number column. The uncertainty of a raw data measurement is the calibrated uncertainty of the individual instrument.

Example to find the measurement uncertainty of a raw data point:

1. Find the data column $\mathrm{D}$ in any Appendix A through $\mathrm{D}$.

2. Check the column heading against the Nomenclature, included in the beginning of each Appendix, to find that the data in column $\mathrm{D}$ were obtained by Thermocouple T2.

3. Look up Thermocouple T2 on Fig. F1 in this Appendix to see that the average* calibrated uncertainty is $1.2^{\circ} \mathrm{C}$ (95\% confidence level $\left.{ }^{* *}\right)$. If a closer look on how that specific systematic error was obtained is desired, then check the appropriate calibration sheet. Thermocouple T2 is shown as Fig. F4. (The calibration sheets are in order of the fourteen instruments that are listed in Fig. F1, with the first instrument T1 shown in Fig. F3 and the fast instrument Q3 shown in Fig. F16.)

[*A pre- and post-test calibration was done on each instrument. For this example, the measurement uncertainties for $\mathrm{T} 2$ were $1.3^{\circ} \mathrm{C}$ and $1.1^{\circ} \mathrm{C}$ respectively, see Fig. F1. The true instrument uncertainty was somewhere between the pre- and post-test results. For this task each uncertainty was given equal weight, therefore an "average" of the two numbers was used, i.e., $1.2^{\circ} \mathrm{C}$.

**The confidence level comes from the Student's $t$ distribution function used in determining an instrument uncertainty.]

4. The magnitude of the random error can be obtained from the standard deviation shown at the bottom of each column of raw data. The standard deviation from the average value, obtained from a specific instrument for a specific test run, will be a good indication of random error for all but the filtrate flowrates, Q2 and Q3. Temperatures, pressures, and slurry flowrates were maintained constant, therefore the fluctuations around the mean should be normally distributed. The filtrate flowrates decreased with time, due to the nature of the experiment. Therefore, the random error for Q2 and Q3 should only be obtained when the filtrate flowrates reach some 
asymptote. (In some rare cases, like on Run $2.20 \mathrm{~b}$ when the goal was to dewater the slurry until pluggage occurred the temperature could not be held constant, but increased with time. In these cases the standard deviation will not properly represent random fluctuations. To facilitate the evaluation of such occurrences each column of data also has the maximum, minimum, and median values along with the average and standard deviation. Note that the number of points used to determine these values is also given. Extreme points, like when backpulsing occurs were excluded. With the number of data points known the standard error of the mean may be obtained (i.e. standard error $=$ standard deviation / square root (number of points)) [Ref. 16].

Measurement uncertainties for the calculated results can be obtained by the general method of the Law of Propagation of Errors (section 4.7 of Ref. 23). The derivation will not be given here and the following is just one example for one type of relation, albeit a common relation.

For example, a calculated entity has an uncertainty of $\delta a$. The entity a is a function of three measured quantities: $b, c$, and $d$ by the following relationship: $a=b \times c / d$ and these quantities have measurement uncertainties of $\delta b, \delta c$, and $\delta d$, respectively. The uncertainty can be shown as:

$$
(\delta \mathrm{a})^{2}=[(\partial \mathrm{a} / \partial \mathrm{b}) \delta \mathrm{b}]^{2}+[(\partial \mathrm{a} / \partial \mathrm{c}) \delta \mathrm{c}]^{2}+[(\partial \mathrm{a} / \partial \mathrm{d}) \delta \mathrm{d}]^{2},
$$

if the error terms are independent and symmetrical. The term $\delta a$ is squared to capture both the negative and positive error terms.

Then for the relation $a=b c / d$ the relative uncertainty can be shown to be:

$$
\delta a / a=\left[(\delta b / b)^{2}+(\delta c / c)^{2}+(\delta d / d)^{2}\right]^{1 / 2}
$$

Using the above the relation (1) an uncertainty for velocity, transmembrane pressure, filtrate flux, and permeability are determined. The method of determining the measurement uncertainty of any of the calculated results will the same as the following analyses. However, only one example of each calculated result is shown below. To show an example, any specific calculated quantity is sufficient. An arbitrary choice of a representative group of results is: Run 2.01 at the $120^{\text {th }}$ minute [The data for Run 2.01 can be found in Appendix $B$ in the first table and the $120^{\text {th }}$ minute is row 135.]

The measurement uncertainty for the following values will be shown:

$$
\begin{array}{llll}
\mathrm{V}, \mathrm{ft} / \mathrm{s} & \mathrm{TMP}, \mathrm{psi} & \mathrm{Fc}\left(\text { at } 25^{\circ} \mathrm{C}\right), \mathrm{gpm} / \mathrm{ft} 2, & \mathrm{P}, \mathrm{gpm} / \mathrm{ft} 2 / \mathrm{psi} \\
6.4 & 31.8 & 0.085^{*} & 0.00267
\end{array}
$$

*actual temperature was $30.6^{\circ} \mathrm{C}$ but was adjusted to $25^{\circ} \mathrm{C}$ as per the customer specification, Ref. 3 , therefore Fc means the corrected filtrate flux. 
The results of the measurement uncertainties found below at the $95 \%$ confidence level are:

$\begin{array}{llll}\text { Slurry Velocity } & = & \text { V } & \mathbf{+ 8 . 1 6 \%} \\ \text { Transmembrane Pressure } & = & \text { TMP } & \mathbf{1 . 0 7} \% \\ \text { Temperature Corrected Filtrate Flux } & = & \text { Fc } & \mathbf{6 . 7 2} \% \\ \text { Permeability } & = & \mathbf{P} & \mathbf{6 6 . 8 0} \%\end{array}$

\section{F.1 Velocity $\left[\mathrm{V}=\mathrm{Q} 1 / \mathrm{A}_{\text {cross-section }}\right]$}

This uncertainty is combination of the instrument, Q1, uncertainty and from the lack of knowledge of the exact inside diameters of the filter tubes. The instrument uncertainty is obtained for that instrument's calibrated uncertainty. An accurate measurement of the average inside diameter of the filtrate tubes was impossible since it may vary down the length for each filter tube and may vary from tube to tube. Even measuring the diameter at the filter tube ends is difficult because of the weldments to the tube sheets. What will be used is the manufacturer's tolerances. For a Mott 3/8-inch tube the diameter tolerances are stated by the vendor to be +0.025 inch and -0.005 inch. The diameter of the filter tubes can presumably vary anywhere between those tolerances therefore for this task the diameter uncertainty will be taken as the average tolerance, i.e., \pm 0.015 inch.

The measurement uncertainty estimate:

Calibrated uncertainty (Figs. F1 and F14): $\delta \mathrm{Q} 1= \pm 0.25 \mathrm{gpm}$

Slurry flow rate: $\mathrm{Q} 1=15.54 \mathrm{gpm}$ [Run 2.01, Row 135, Column P: Appendix B]

Filter tube inside diameter: $\delta \mathrm{d}= \pm 0.015$ inch

Filter tube inside diameter: $d=0.375$ inch

$\mathrm{V}=\mathrm{Q} / \mathrm{A}=\mathrm{Q} 1 /\left(\pi \mathrm{d}^{2} / 2\right)$

In the form of Eq. $(1): \delta \mathrm{V} / \mathrm{V}=\left[(\delta \mathrm{Q} 1 / \mathrm{Q} 1)^{2}+4(\delta \mathrm{d} / \mathrm{d})^{2}\right]^{1 / 2}$

[Note the multiplier 4. This results from the derivation $\partial \mathrm{V} / \partial \mathrm{d}$ because of the exponent]

Therefore, $\left[(0.25 / 15.54)^{2}+4(0.015 / 0.375)^{2}\right]^{1 / 2} \times 100 \%= \pm 8.16 \%$

The uncertainty of the example $V$ is: $6.4 \pm 0.6 \mathrm{ft} / \mathrm{s}$

[since $6.4 \times 0.0816 \sim 0.52$ ]

\section{F.2 Transmembrane Pressure $[\mathrm{TMP}=(\mathrm{dP2}+\mathrm{dP3}) / 2]$}

This uncertainty is will come from two instruments, $\mathrm{dP} 2$ and $\mathrm{dP} 3$. Also, there is another uncertainty do to location of the pressure taps. As seen in Figs. 1 and F2, dP2 is located at the bottom to the filter housing (upstream to the filter) and dP3 is located at the top of the filter housing (downstream to the filter). Due to the same fluid being in the pressure lines 
(water) a liquid-filled system will give the corrected pressure drops, however, the slurry pressures lost upstream to the filter and gained downstream of the filter are not symmetrical and therefore do not cancel out. With this said, this addition to the uncertainty is small compared to the assumption that true TMP is represented by the average of two pressures at the ends of a filter. Because the filter is oriented perpendicular to gravity and the flow causes a pressure and concentration gradient along the entire tube wall it is not clear what TMP would be representative of the entire filter unit. On the other hand, the way measurements were taken probably will be similar to the field use of this filter and therefore a good measurement for design purposes. The uncertainty is actually the uncertainty of two measurement devices, and nothing more. Finally, the Law of Propogation of Errors by Eq. (1) does not lend itself to additive contributions to uncertainties. Fortunately, the two quantities are similar in magnitude and calibrated uncertainty. Equation (1) will be used as long as it give an uncertainty larger than the largest calibrated uncertainty for the two pressure transducers.

The measurement uncertainty estimate:

Calibrated uncertainty (Figs. F1 and F12): $\delta \mathrm{dP} 2= \pm 0.23 \mathrm{psi}$

Pressure drop: $\mathrm{dP} 2=33.13$ psid [Run 2.01, Row 135, Column J: Appendix B]

Calibrated uncertainty (Figs. F1 and F13): $\delta \mathrm{dP} 3= \pm 0.25 \mathrm{psi}$

Pressure drop: $\mathrm{dP3}=30.49$ psid [Run 2.01, Row 135, Column M: Appendix B]

$\mathrm{TMP}=(\mathrm{dP} 2+\mathrm{dP} 3) / 2$

In the form of Eq. $(1): \delta T M P / T M P=\left[(\delta d P 2 / d P 2)^{2}+(\delta d P 3 / d P 3)^{2}\right]^{1 / 2}$

Therefore, $\left[(0.23 / 33.13)^{2}+(0.25 / 30.49)^{2}\right]^{1 / 2} \times 100 \%= \pm 1.07 \%$

The uncertainty of the example TMP is: $31.8 \pm 0.4$ psid

[since $31.8 \times 0.0107 \sim 0.34$ ]

\section{F.3 Filtrate Flux $\left[\mathbf{F}=\mathbf{Q} 2 / \mathbf{A}_{\text {inner-surface }}\right]$}

This uncertainty is combination of the instrument, Q2, uncertainty and from the lack of knowledge of the exact inside diameters and length of the filter tubes. The instrument uncertainty is obtained for that instruments calibrated uncertainty. The uncertainty of the inside diameter of the filter tubes has already been addressed in section F.1 and it was estimated at 0.015 inch. The uncertainty of the length of the filter tubes was estimate from in-house measurements. The requested tube length from the manufacturer was 40 inches. Because of weldments at the ends and the center (the 40-inch length was made of two 20-inch tube sections) the active length seemed closer to $397 / 8$ inches. However, since it was difficult to get an exact measurement, not being able to measure inside, the 40 -inch length was used to determine the inner surface area and the $1 / 8$-inch difference will be used for the length uncertainty. 
The measurement uncertainty estimate:

Calibrated uncertainty (Figs. F1 and F15): $\delta Q 2= \pm 0.009 \mathrm{gpm}$

Filtrate flow rate: $\mathrm{Q} 2=0.227 \mathrm{gpm}$ [Run 2.01, Row 135, Column Q: Appendix B]

Tube inside diameter uncertainty: $\delta \mathrm{d}= \pm 0.015$ inch (from manufacturer)

Tube inside diameter: $\mathrm{d}=0.375$ inch

Tube length uncertainty: $\delta \mathrm{L}= \pm 0.125$ inch

Tube length: $L=40$ inches

$\mathrm{F}=\mathrm{Q} / \mathrm{A}=\mathrm{Q} 2 / \pi \mathrm{d} \mathrm{L}$

In the form of Eq. (1): $\delta \mathrm{F} / \mathrm{F}=\left[(\delta \mathrm{Q} 2 / \mathrm{dQ} 2)^{2}+(\delta \mathrm{d} / \mathrm{d})^{2}+(\delta \mathrm{L} / \mathrm{L})^{2}\right]^{1 / 2}$

Therefore, $\left[(0.009 / 0.227)^{2}+(0.015 / 0.375)^{2}+(0.125 / 40)^{2}\right]^{1 / 2} \times 100 \%= \pm 5.64 \%$

The uncertainty of the example $F$ is: $0.085 \pm 0.005 \mathrm{gpm} / \mathrm{ft} 2$

[since $0.085 \times 0.0564 \sim 0.0048$ ]

\section{F.3.1 Effect of Temperature on the Measurement Uncertainty on F}

As per the customer specification the filtrate flux was to adjusted such that it would give a result at $25^{\circ} \mathrm{C}$. The equation as was stated is:

$$
\begin{aligned}
& \mathrm{F}=\mathrm{Q} 2(\text { Temperature }) / \text { Area }=\mathrm{Q} 2 \times \text { Correction Factor } / \text { Area } \\
& \mathrm{CF}=e^{[2500((1 / 273+\text { Slurry Temperature }))-(1 / 298))]}
\end{aligned}
$$

Only the correction factor's effect on measurement uncertainty is dealt with here. The equation is accepted as error free, i.e., method, constants, etc. Only the uncertainty of the temperature measurement which leads to the correction will be addressed.

Generally, the adjustment to $\mathbf{F}$ is small because, whenever possible, the slurry's operational temperature was maintained at $25^{\circ} \mathrm{C}$ which would result in a zero adjustment. However, the example chosen to show measurement uncertainty had a temperature difference of $5.6^{\circ} \mathrm{C}$. That is, for Run 2.01 at the $120^{\text {th }}$ minute the slurry temperature was $30.6^{\circ} \mathrm{C}$ [Initial test runs were only cooled with water cooling coils which were not sufficient. The temperature was better maintained after the coolant was changed to ethylene glycol.]. Unfortunately, the fact that a temperature correction is applied means the temperature uncertainty will effect the calculated result at any temperature. That is, even if the slurry temperature were $25^{\circ} \mathrm{C}$, which would make the correction $=1.0$, the uncertainty of that temperature and thereby the correction, leads to an inherent uncertainty of value that is being corrected, i.e, F. For this task the slurry temperature was measured with thermocouple $\mathrm{T} 1$, which had a calibrated measurement uncertainty of $\pm 1.3^{\circ} \mathrm{C}$ [see Fig. F1]. If at $25^{\circ} \mathrm{C}$ the temperature has an uncertainty of $\pm 1.3^{\circ} \mathrm{C}$, then the 
correction can be either 0.9642 to 1.0374 , or approximately $\pm 3.66 \%$ [i.e., ((1$.9642)+(1.0374-1)) / 2 / 1.00=0.0366]$. To show the measurement uncertainty mathematically from the correction equation is beyond the scope of this task, however it can be shown graphically. For a range of slurry temperatures from $15^{\circ} \mathrm{C}$ to $40^{\circ} \mathrm{C}$, then the correction can be shown to change from 1.34 to 0.67 , respectively. However, with a measurement uncertainty of $\pm 1.3^{\circ} \mathrm{C}$ this factor can be in error from approximately $3.9 \%$ to $3.3 \%$, respectively, see the Figure below:

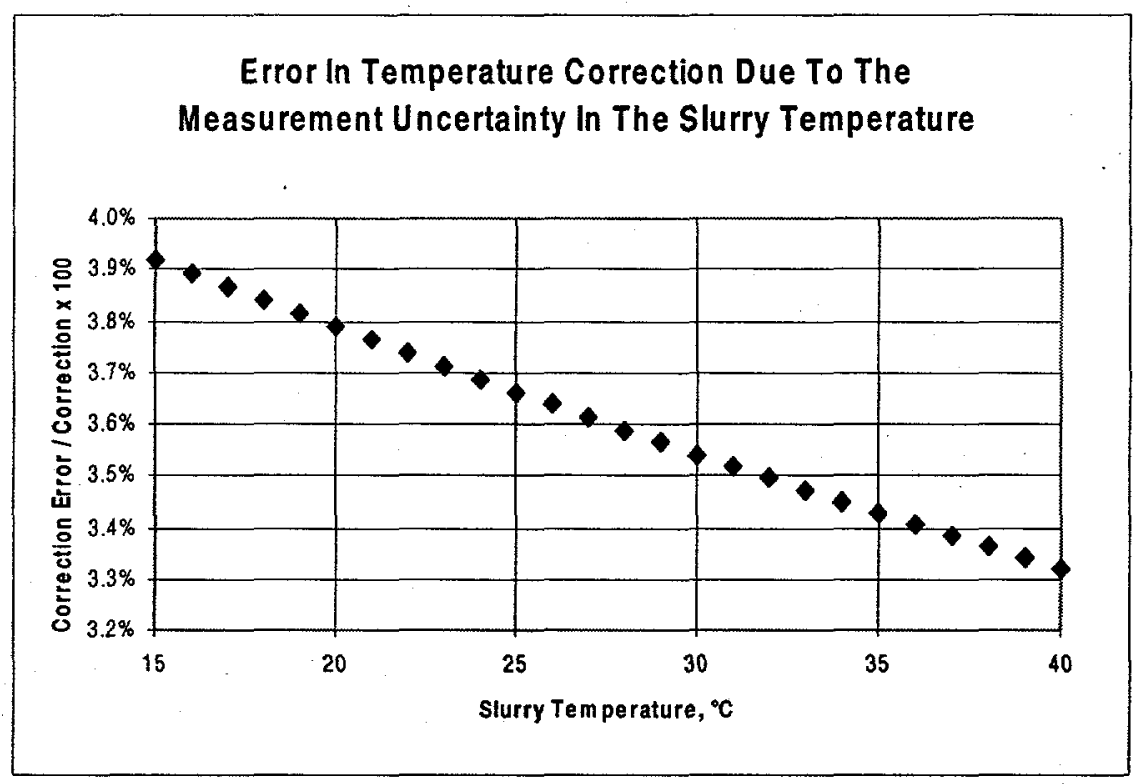

Therefore, for the sake of this example the relative uncertainty of the correction factor do to the temperature will be assumed to be $3.7 \%$ since most of the data were obtained at $25^{\circ} \mathrm{C}$. Using this constant value is not a bad assumption because between $20^{\circ} \mathrm{C}$ and $30^{\circ} \mathrm{C}$ this uncertainty only fluctuates by approximately $0.1 \%$.

This increased uncertainty to the filtrate flux is then a combination of two uncertainties already calculated above for $\mathrm{F}$ and the correction factor. The analyses still follows Eq. (1) therefore:

The measurement uncertainty estimate:

Filtrate flux relative uncertainty: $\delta \mathrm{F} / \mathrm{F}= \pm 5.64 \%$ [section F.3]

Correction factor relative uncertainty: $\delta \mathrm{CF} / \mathrm{CF}= \pm 3.66 \%$ [section F.2]

Fcorrected $=\mathrm{F} \times \mathrm{CF}$

In the form of Eq. $\left.(1): \delta \mathrm{Fc} / \mathrm{Fc}=\left[(\delta \mathrm{F} / \mathrm{F})^{2}+(\delta \mathrm{CF} / \mathrm{CF})\right]^{2}\right]^{1 / 2}$

Therefore, $\left[(5.64)^{2}+(3.66)^{2}\right]^{1 / 2}= \pm 6.72 \%$ 
The uncertainty of the example Fc is: $0.085 \pm 0.006 \mathrm{gpm} / \mathrm{ft} 2$

[since $0.085 \times 0.0672 \sim 0.0057$ ]

\section{F.4 Permeability [ $P$ = F / TMP ]}

This uncertainty is combination of two uncertainties already calculated above, in section F.2 and F.3. The analyses still follows Eq. (1) therefore:

The measurement uncertainty estimate:

Filtrate flux relative uncertainty: $\delta \mathrm{Fc} / \mathrm{Fc}= \pm 6.72 \%$ [section F.3]

TMP relative uncertainty: $\delta$ TMP/TMP $= \pm 1.07 \%$ [section F.2]

$\mathrm{P}=\mathrm{Fc} / \mathrm{TMP}$

In the form of Eq. $\left.(1): \delta \mathrm{P} / \mathrm{P}=\left[(\delta \mathrm{Fc} / \mathrm{Fc})^{2}+(\delta \mathrm{TMP} / \mathrm{TMP})\right]^{2}\right]^{1 / 2}$

Therefore, $\left[(6.72)^{2}+(1.07)^{2}\right]^{1 / 2}= \pm 6.80 \%$

The uncertainty of the example $F$ is: $0.00267 \pm 0.00018 \mathbf{~ g p m} / \mathrm{ft} 2 / \mathrm{psi}$

[since $0.00267 \times 0.0680 \sim 0.000182$ ]

\section{F.5 Second-Order Effects to Measurement Uncertainty}

There were other effects on the measurement uncertainty which are not included because they are thought to be of second order. For example, since the test rig was very tall, approximately 30 feet, it was subjected an ambient temperature gradient. Ambient temperatures at the bottom of the rig were usually less than at the top. For the example used in this section, [Run 2.01, Row 135, Columns G and H: Appendix B], the temperatures were $26.1^{\circ} \mathrm{C}$ and $27.3^{\circ} \mathrm{C}$, respectively. This gradient varied hourly and daily for several reasons and it larger or smaller. Most importantly, the $1.2^{\circ} \mathrm{C}$ temperature variation shown in this example is on the same order of magnitude as the calibrated uncertainties for the thermocouples. Further, the slurry in the loop generally flowed fast, so the residence time in any one section of the rig was small. For Run 2.01 the flow rate was, $\mathrm{Q} 1=15.5 \mathrm{gpm}$. The loop volume was approximately 5 gallons so a fluid particle traversed the loop every 5/15.5 × $60 \sim 19$ seconds. [Note that the slurry flow rate for Run 2.01 was one of the slowest.] In this example, the slurry temperature was measured to be $30.6^{\circ} \mathrm{C}$, from one thermocouple located in the suction line of the pumps. While it is certain that the ambient temperatures had an effect on the slurry temperature it was small and at steady state the effect is incorporated in the slurry temperature. The same is true for the ambient temperature gradient but to a lesser extent and therefore not considered. 


\begin{tabular}{|c|c|c|c|c|c|c|c|c|c|}
\hline ISTRUMENTS USED & ON THE BNFL & & & & & & & & \\
\hline Test Rig No. & instrument & M\&TE \# & Make & Model & Calibrated Range & Uncertainty & Uncert ainty & Uncertainty & Cume Fit \\
\hline & & & & & & (pre-test) & (post-test) & Average - & \\
\hline & Thermocouple & Th-02925 & OMEGA & TMG-CXSS-18LL6-SB-OST M & 0 to $100 \mathrm{C}$ & $1.2 \mathrm{C}$ & $1.4 \mathrm{C}$ & $1.3 \mathrm{C}$ & $=0.00483+17040918 \times \mathrm{mV}=0.224284 \times \mathrm{mV}=0.0005038 \times \mathrm{m}$ \\
\hline $\mathrm{T}$ & Thermocouple & TR-02926 & OMEGA & $1,136-C \times S S-184-6-S B-05 T-M$ & 0 to $100 \mathrm{C}$ & 130 & 1.10 & $1.2 \mathrm{C}$ & $=0.00463+17.040918 \times \mathrm{mV}-0.224284 \times \mathrm{mV} 2+0.005038 \times \mathrm{m}$ \\
\hline T3 & Thermocouple & $\pi R-02928$ & OMEGA & TSO6-CXSS-18U-6-SQ OSTH & $010100 \mathrm{C}$ & 1.5 & 1.20 & 1.3 & $=0.00483+17040918 \times \mathrm{mV}-0224284 \times \mathrm{mVM}+0.005038 \times \mathrm{m}$ \\
\hline$T_{4}$ & Thermocouple & $\pi R-02930$ & OMEGA & 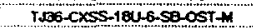 & 0101000 & 1.2 & $1.4 \mathrm{C}$ & 13 & $=0.00483+17040918 \times m v-0224284 \times m v 22+0.005038 \times m$ \\
\hline 15 & Thermocouple & TR-D & OMEGA & $T 336$ CXSS-18U-6 -58 OST & D to $100 \mathrm{C}$ & 1.0 & $1.4 \mathrm{C}$ & 1.2 & $=0.00483+17.040918 \times \mathrm{mV}^{2}-0.224284 \times \mathrm{mVM} 2+0.005038 \times$ \\
\hline & Pres. Transolucer & TR-02917 & Rosemount & 1151OPE2ATOOOEOR4 & 010100 PSIG & 0.13 PSIG & 0.21 PSIG & 0.17 PSIG & P(PSiG $)=6.211 \times m A-24895$ \\
\hline $\mathrm{p}_{2}$ & Pres. Transducer & TR-03ing & Rosemount & 1151096022 & -10 to 90 PSIG & 0.09 PSIG & $0.17 \mathrm{PSIG}$ & 0.13 PSIG & $P(P S I G)=6.293 \times \mathrm{mA}-75.524$ \\
\hline $\begin{array}{l}P_{3} \\
d P_{1}\end{array}$ & $\begin{array}{l}\text { Pres. Transducer } \\
\text { Pres. Transducer }\end{array}$ & $\begin{array}{l}\text { TR-02145 } \\
\text { TR-03495 }\end{array}$ & $\begin{array}{l}\text { Rosemount } \\
\text { Rosemount }\end{array}$ & $\begin{array}{c}11440-0200122 \\
1151 D P S E 22\end{array}$ & $\begin{array}{l}0 \text { to } 150 \mathrm{PSIG} \\
0 \text { to } 26 \mathrm{PSID}\end{array}$ & $\begin{array}{l}0.38 \text { PSIG } \\
0.02 \text { PSID }\end{array}$ & $\begin{array}{l}0.41 \text { PSIG } \\
0.088 \text { PSID }\end{array}$ & $\begin{array}{l}0.40 \text { PSIG } \\
0.056 \text { PSIO }\end{array}$ & $\begin{array}{l}P(P S I G)=9.422 \times \mathrm{mA}-37.712 \\
P(P S I D)=1.6249 \times \mathrm{mA}-6.4930\end{array}$ \\
\hline $\mathrm{dP2}$ & Pres. Transducer & TR.00532 & Rosemount & 1151APGE & 0 10 250 PSiG & $0.42 \mathrm{PSID}$ & NA & PPSID & $P(P S D)=15.648 \times \mathrm{mA}-62.400$ \\
\hline$d P 2(2$ fer $3 / 25 / 99)$ & Pres. Transducer & TR-005 & Rosemount & & 010100 PSIG & 0.13 PSID & 0.33 PSID & $0.23 \mathrm{PSID}$ & $P(P S I D)=6.314 \times \mathrm{mA} \cdot 25.227$ \\
\hline $\mathrm{dP3}$ & Pres. Transducer & TR.03115 & Rosemount & t15top7Ez2M3Et & -10 to 100 PSIG & 0.19PSID & $0.30 \mathrm{PSIO}$ & PSIO & $P(P S I D)=6898 \times \mathrm{mA}-37$ \\
\hline 01 & Mag. Flowmeter & IR-20350 & Fischer-Porter & $10014750 \% 1$ & O TO $50 \mathrm{GPM}$ & GPM & & & \\
\hline 02 & Mag. Flowmeter & TR.20053 & Fischer-Ponter & 9001475 SNOT PF 2 SFWM 2 CAC2 & 0 to $1.2 \mathrm{GPM}$ & $0.005 \mathrm{GPM}$ & $0.019 \mathrm{GPM}$ & $0.012 \mathrm{GPM}$ & $Q(G P M)=0.075 \times \mathrm{mA} \cdot 0.299$ \\
\hline & Mag. Flowmeter & TR-03562 & Fischer-Porter & $1001475 c$ Nel 1 Bal & 0 to 5 GPM & $0.02 \mathrm{GPH}$ & $0.01 \mathrm{GPM}$ & $0.015 \mathrm{GPM}$ & $Q(\mathrm{GPM})=0.311 \times \mathrm{mA}-1.237$ \\
\hline & & & & & & & & & ransfer Functions Used with the $D$ \\
\hline DAS Channel. & Instrument & & & DAS Calibration & Notes & post-test it & ncertainty inc & ludes, and & $\begin{array}{l}\text { Comersion from mA to Yohs } \\
P(P S I G)=124844 \times V-24895\end{array}$ \\
\hline & $P_{2}$ & & & Chan $07=0.4908 \mathrm{~mA}+0.003$ & & uncertainty & analyses. & & $P(P S I G)=12.616 \times V-35.561$ \\
\hline 8 & P3 & & & ChanOB $=0.498 \mathrm{~mA}+0.002$ & & The true in & istrument me & ent & $P(P S \mid G)=18.960 \times V-37.750$ \\
\hline 9 & $\mathrm{OPI}$ & & & Chan $09=0.4988 \mathrm{~mA}+0.003$ & & uncertainty & & & $P(P S 1 O)=3.267 \times \vee-6.503$ \\
\hline 10 & $d P 2$ & & & Chan10 $=0.4975 \mathrm{~mA}+0.00$ & & duning this 8 & xpeni & between & $P(P S(D)=31.453 \times V-62.463$ \\
\hline 10 & dP2(valio atter $3 / 25$; & recalibrated & on $3 / 24 / 999$ & Chan $10=0.4975 \mathrm{~mA}+0.002$ & & the pre and & post- & & $P(P S(D)=12.691 \times \vee-25.231$ \\
\hline 11 & $\frac{\mathrm{dP3}}{4}$ & & & & & uncertainty. & The & & $P(P S T D)=13.843 \times V-37.923$ \\
\hline 12 & 01 & & & Chan $12=0.4988 \mathrm{~mA}+0.007$ & & Uncertainty & was $t$ & ti & $Q(G P M)=6.289 \times V-12.553$ \\
\hline 13 & 02 & & & & & value betwe & en the & d post & $Q(G P M)=0.1508 \times \vee-0.2906$ \\
\hline 14 & 03 & Added on & $7 / 14 / 1999$ & Chan14 $=0.4988 \mathrm{~mA}+0.003$ & & results & & & $a(G P M)=0.6235 \times v-1.2553$ \\
\hline
\end{tabular}

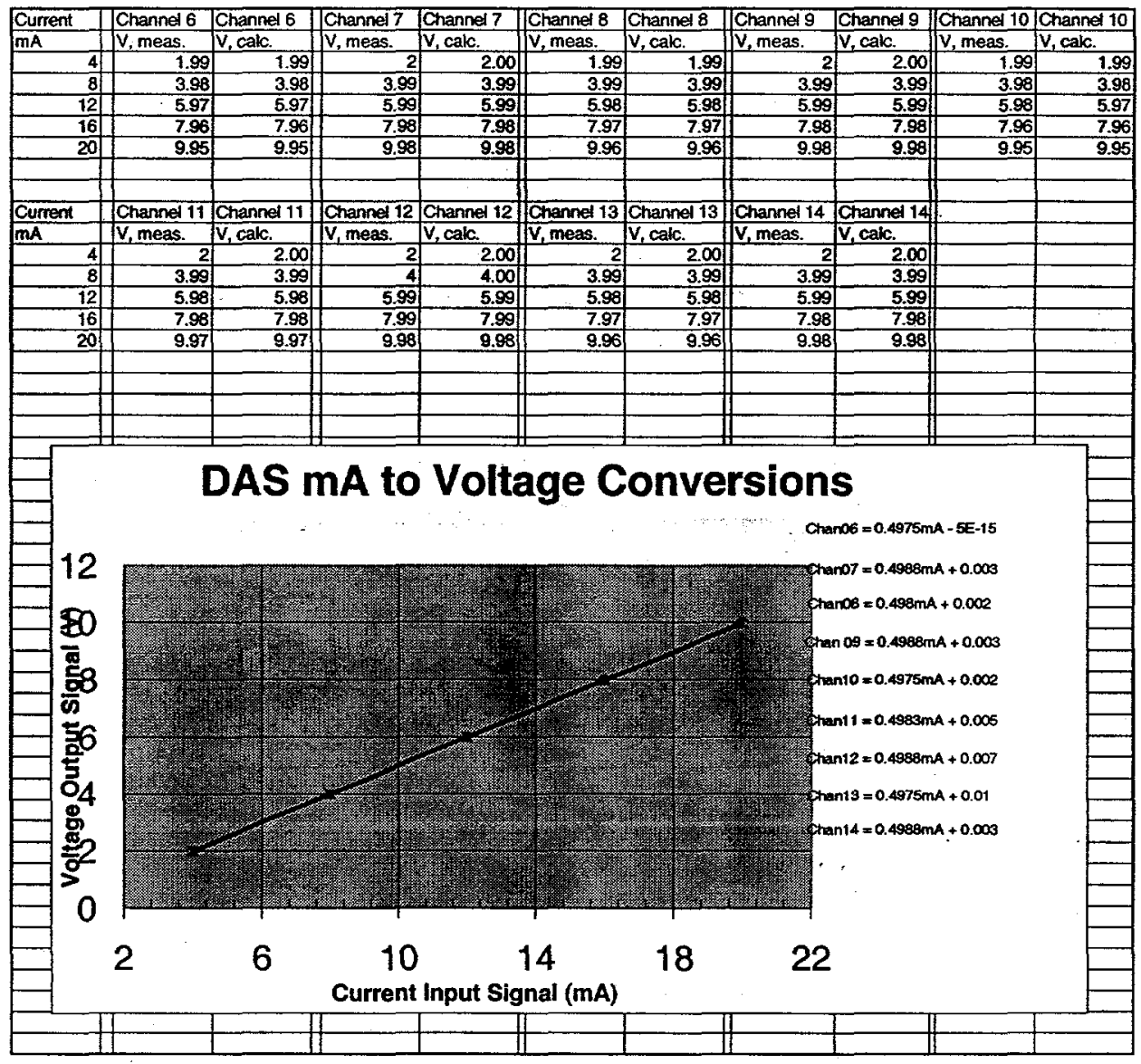

Figure F1. Instrumentation Used with their Transfer Functions 


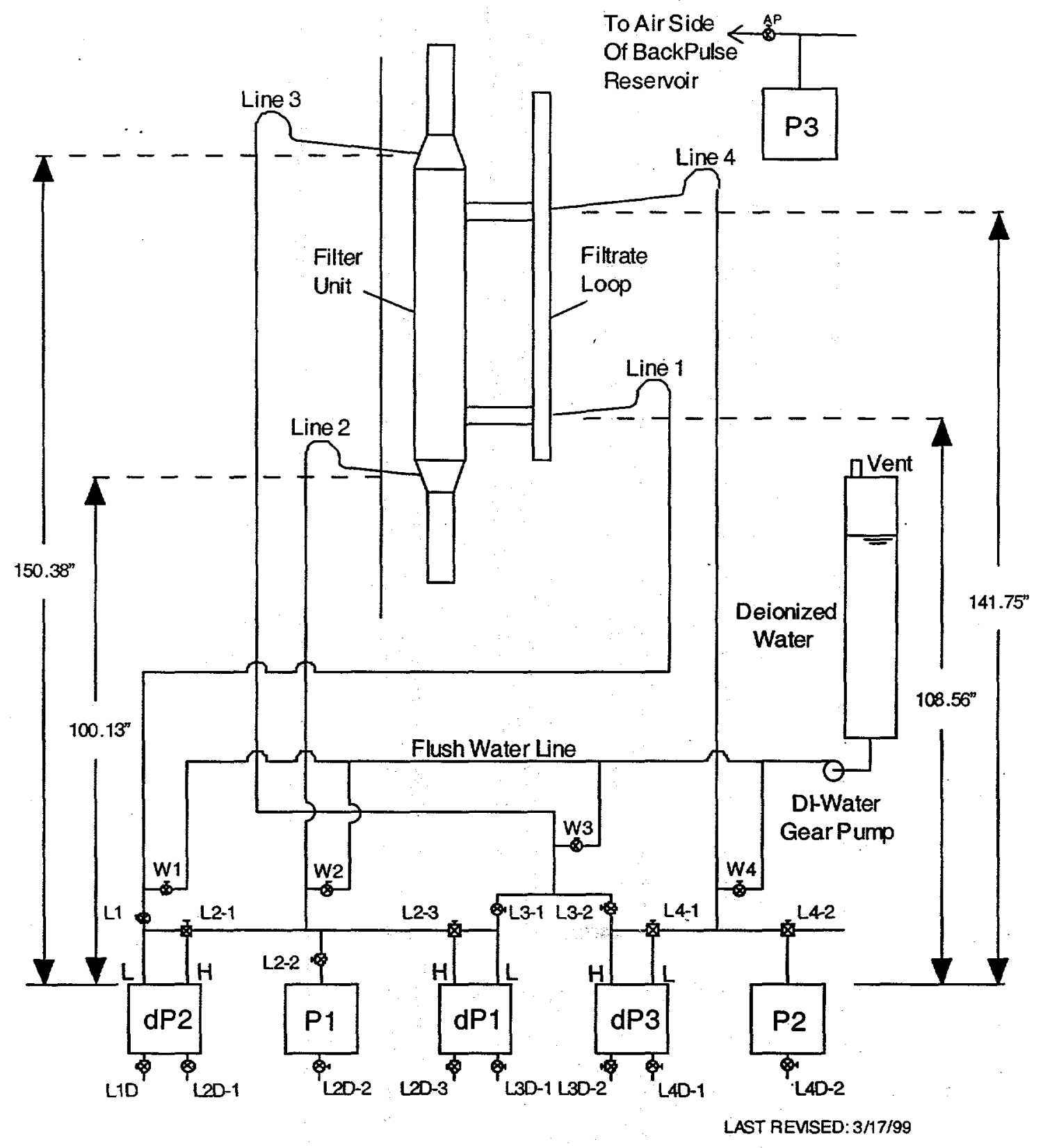

Figure F2. Pressure Transducer Locations 
UNCERTAINTY ANALYSIS REF. WSRC-TR-91-106

TR-2925

page

calibration date

\section{Calibration Data}

$\begin{array}{lcccc}\begin{array}{l}\text { Temperature } \\ \text { Medium }\end{array} & \begin{array}{c}\text { Standard } \\ \text { Temperature }\end{array} & \begin{array}{c}\text { Voltage } \\ \text { Output } \\ (\mathrm{mV})\end{array} & \begin{array}{c}\text { Calculated } \\ \text { Temperature } \\ (\text { eq. } 1)\end{array} & \begin{array}{c}\text { Error } \\ (\mathrm{C})\end{array} \\ \text { Boiling Water } & 100.70 & 6.338 & 100.28 & -0.4 \\ \text { Boiling Water } & 100.70 & 6.357 & 100.56 & -0.1 \\ \text { Boiling Water } & 100.70 & 6.345 & 100.39 & -0.3 \\ \text { Boiling Water } & 100.70 & 6.340 & 100.31 & -0.4 \\ \text { Ice Point } & 0.00 & -0.023 & -0.39 & -0.4 \\ \text { Ice Point } & 0.00 & -0.017 & -0.28 & -0.3 \\ \text { Ice Point } & 0.00 & -0.009 & -0.15 & -0.1 \\ \text { Ice Point } & 0.00 & -0.018 & -0.30 & -0.3 \\ \text { Room Temp } & 23.80 & 1.404 & 23.50 & -0.3 \\ \text { Room Temp } & 23.80 & 1.428 & 23.90 & 0.1 \\ \text { Room Temp } & 23.90 & 1.495 & 25.00 & 1.1 \\ \text { Room Temp } & 23.90 & 1.466 & 24.52 & 0.6\end{array}$

$T(C)=0.00483+17.040918^{*} \mathrm{mV}-0.224284^{*} \mathrm{mV} \wedge 2+0.005038^{*} \mathrm{mV} \wedge 3$ (eq. 1 ) (Limited Curve Fit, 0-100 C. From N.I.S.T. Reference Tables)

Uncertainty of the Standards: $\quad$ Temperature Curve Fit: $+/-\quad 0.010$ Thermometer: $+/-\quad 0.40 \quad \mathrm{C}$ Ice Bath: $+/-\quad 0.10 \quad C$

Multimeter: $+/-(0.0045 \% R D G+0.0005 \mathrm{mV})$ $=+\% \quad 0.012 \quad \mathrm{C} @ \quad 6.36 \mathrm{mV}$

Accepted Tolerance: $+/-\quad 1.7 \quad$ C

Statistical Info.

$\begin{array}{cccccccc} & & & & \text { Xbar } & \text { Sxx } & \text { SEE } & \text { MSE } \\ \mathbf{a} & \mathrm{b} & \mathrm{n} & \mathrm{T} & (\mathrm{C}) & \left(\mathrm{C}^{\wedge} 2\right) & \left(\mathrm{C}^{\wedge} 2\right) & \left(\mathrm{C}^{\wedge}\right) \\ -0.05 & 1.00 & 11.00 & 2.262 & 43.12 & 21815.1 & 1.809 & 0.2010\end{array}$

Calculated Uncertainties:

$\begin{array}{llll}\text { standard } & \text { curve-fit } & \text { fixed } & \text { total } \\ \text { uncertainty } & \text { uncertainty } & \text { uncertainty } & \text { uncertainty } \\ \text { (C) } & \text { (C) } & (\mathrm{C}) & \text { (C) } \\ 0.41 & 1.13 & 0.24 & 1.2\end{array}$

PASS CALIBRATION?

YES

Figure F3. Pre-test Calibration Data of Thermocouple T1 
UNCERTAINTY ANALYSIS

REF. WSRC-TR-91-106
TR-2926

\section{Calibration Data}

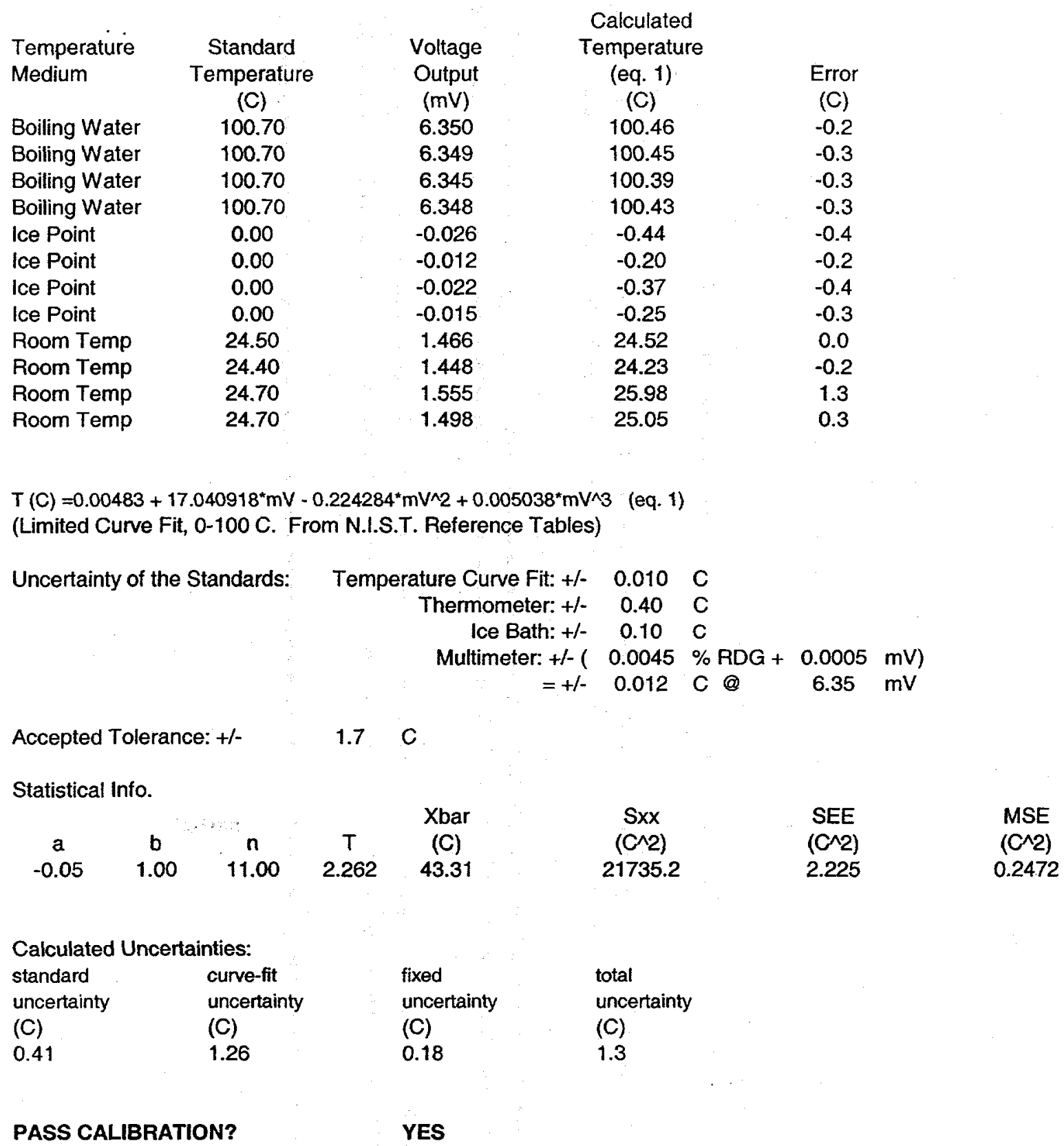

\author{
page ___ of \\ calibration date
}


UNCERTAINTY ANALYSIS

REF. WSRC-TR-91-106
TR-2929

page
calibration date

Calibration Data

\begin{tabular}{|c|c|c|c|c|}
\hline \multirow{3}{*}{$\begin{array}{l}\text { Temperature } \\
\text { Medium }\end{array}$} & & \multicolumn{3}{|c|}{ Calculated } \\
\hline & Standard & Voltage & Temperature & \\
\hline & $\begin{array}{c}\text { Temperature } \\
\text { (C) }\end{array}$ & $\begin{array}{l}\text { Output } \\
\text { (mV) }\end{array}$ & $\begin{array}{l}\text { (eq. 1) } \\
\text { (C) }\end{array}$ & $\begin{array}{l}\text { Error } \\
\text { (C) }\end{array}$ \\
\hline Boiling Water & 100.70 & 6.350 & 100.46 & -0.2 \\
\hline Boiling Water & 100.70 & 6.352 & 100.49 & -0.2 \\
\hline Boiling Water & 100.70 & 6.349 & 100.45 & -0.3 \\
\hline Boiling Water & 100.70 & 6.350 & 100.46 & -0.2 \\
\hline Ice Point & 0.00 & -0.026 & -0.44 & -0.4 \\
\hline Ice Point & 0.00 & -0.023 & -0.39 & -0.4 \\
\hline Ice Point & 0.00 & -0.019 & -0.32 & -0.3 \\
\hline Ice Point & 0.00 & -0.021 & -0.35 & -0.4 \\
\hline Room Temp & 21.10 & 1.211 & 20.32 & -0.8 \\
\hline Room Temp & 21.30 & 1.178 & 19.78 & -1.5 \\
\hline Room Temp & 21.30 & 1.182 & 19.84 & -1.5 \\
\hline Room Temp & 21.30 & 1.188 & 19.94 & -1.4 \\
\hline
\end{tabular}

$T(C)=0.00483+17.040918^{*} \mathrm{mV}-0.224284^{*} \mathrm{mV} \wedge 2+0.005038^{*} \mathrm{mV} / 3$ (eq. 1) (Limited Curve Fit, 0-100 C. From N.I.S.T. Reference Tables)

Uncertainty of the Standards: Temperature Curve Fit: $+/-0.010 \mathrm{C}$ Thermometer: $+1-\quad 0.40 \quad \mathrm{C}$ Ice Bath: + - $0.10 \quad \mathrm{C}$

Multimeter: $+/-(0.0045 \%$ RDG $+0.0005 \mathrm{mV})$ $=+1-0.012 \mathrm{C} @ 6.35 \mathrm{mV}$

Accepted Tolerance: +/- $\quad 1.7 \quad$ C

Statistical info.

\begin{tabular}{|c|c|c|c|c|c|c|c|}
\hline a & b & $\because y$ & $T$ & $\begin{array}{l}\text { Xbar } \\
\text { (C) }\end{array}$ & $\begin{array}{c}S x x \\
\left(C^{\wedge} 2\right)\end{array}$ & $\begin{array}{l}\text { SEE } \\
\left(\mathrm{C}^{\wedge} 2\right)\end{array}$ & $\begin{array}{l}\text { MSE } \\
\left(C^{\wedge} 2\right)\end{array}$ \\
\hline-0.73 & 1.00 & 11.00 & 2.262 & 42.41 & 22130.7 & 2.000 & 0.2222 \\
\hline
\end{tabular}

Calculated Uncertainties:

$\begin{array}{llll}\text { standard } & \text { curve-fit } & \text { fixed } & \text { total } \\ \text { uncertainty } & \text { uncertainty } & \text { uncertainty } & \text { uncertainty } \\ \text { (C) } & \text { (C) } & \text { (C) } & \text { (C) } \\ 0.41 & 1.18 & 0.73 & 1.5 \\ & & & \\ \text { PASS CALIBRATION? } & \text { YES } & \end{array}$

Figure F5. Pre-test Calibration Data of Thermocouple T3 
UNCERTAINTY ANALYSIS REF. WSRC-TR-91-106
TR-2930

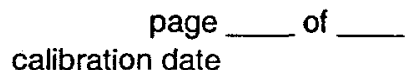

\section{Calibration Data}

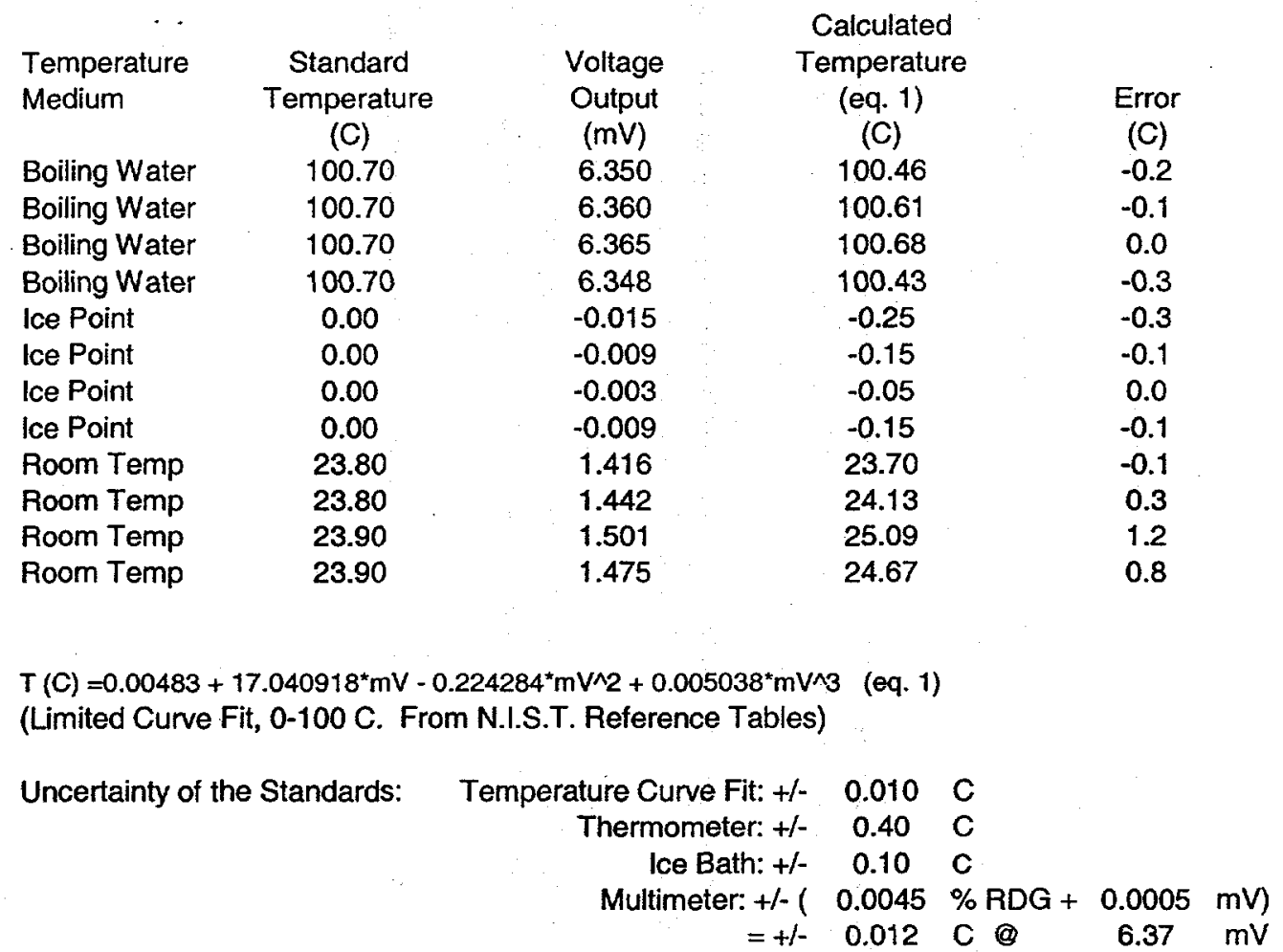

Accepted Tolerance: + - $\quad 1.7 \quad \mathrm{C}$

Statistical Info.

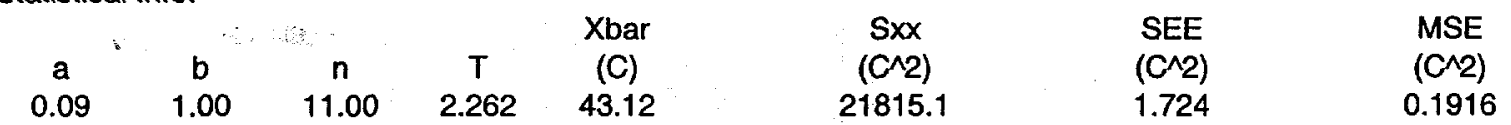

\section{Calculated Uncertainties:}

$\begin{array}{llll}\text { standard } & \text { curve-fit } & \text { fixed } & \text { total } \\ \text { uncertainty } & \text { uncertainty } & \text { uncertainty } & \text { uncertainty } \\ \text { (C) } & \text { (C) } & (\mathrm{C}) & (\mathrm{C}) \\ 0.41 & 1.11 & 0.09 & 1.2\end{array}$

PASS CALIBRATION?

YES

Figure F6. Pre-test Calibration Data of Thermocouple T4 
UNCERTAINTY ANALYSIS

REF. WSRC-TR-91-106

TR-2927

\section{Calibration Data}

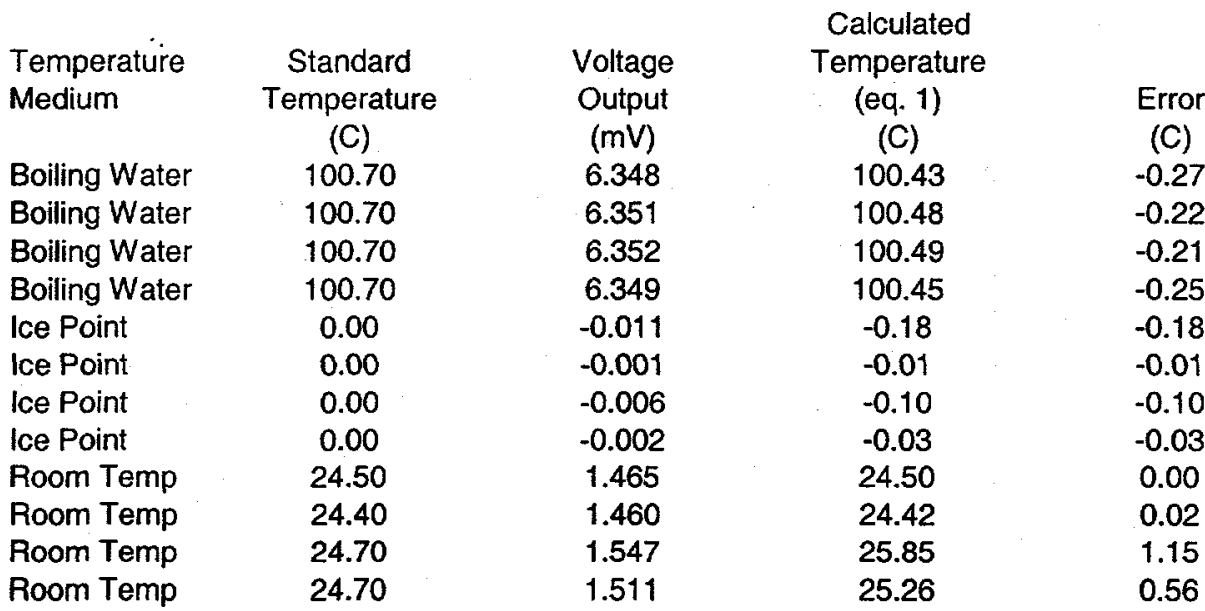

page calibration date of $\longrightarrow$

$T(C)=0.00483+17.040918^{\star} \mathrm{mV}-0.224284^{\star} \mathrm{mV} / 2+0.005038^{*} \mathrm{mV}^{\wedge} 3$ (eq. 1)

(Limited Curve Fit, 0-100 C. From N.I.S.T. Reference Tables)

Uncertainty of the Standards: Temperature Curve Fit: $+/-\quad 0.010$ C

Thermometer: + - $0.40 \quad \mathrm{C}$

Ice Bath: + - $\quad 0.10 \quad \mathrm{C}$

Multimeter: $+/-(0.0045 \% R D G+0.0005 \mathrm{mV})$

$$
=+\quad 0.012 \mathrm{C} @ 6.35 \mathrm{mV}
$$

Accepted Tolerance: + - $\quad 1.70 \quad$ C

Statistical Info.

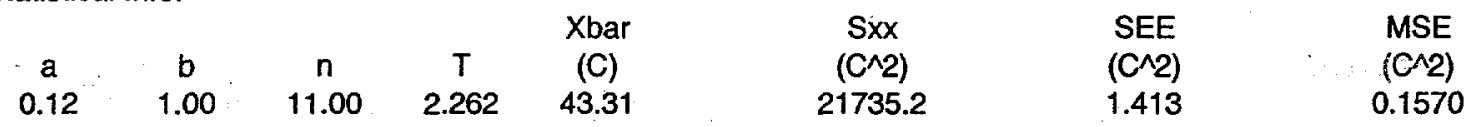

Calculated Uncertainties:

standard curve-fit

uncertainty uncertainty

(C) (C)

0.41

1.00

\section{fixed \\ uncertainty \\ (C)}

0.18

YES total

uncertainty

(C)

1.10 
UNCERTAINTY ANALYSIS

REF. WSRC-TR-91-106, REV. 0

\begin{tabular}{|c|c|c|c|}
\hline Nominal & & Applied & Gage \\
\hline $\begin{array}{c}\text { Pressure } \\
\text { (psig) }\end{array}$ & $\begin{array}{c}\text { Correction } \\
\text { (psig) }\end{array}$ & $\begin{array}{c}\text { Pressure } \\
\text { (psig) }\end{array}$ & $\begin{array}{l}\text { Reading } \\
\text { (mADC) }\end{array}$ \\
\hline 0.00 & 0 & 0.00 & 4.01 \\
\hline 21.00 & -0.71 & 20.29 & 7.28 \\
\hline 41.00 & -0.71 & 40.29 & 10.49 \\
\hline 61.00 & -0.71 & 60.29 & 13.71 \\
\hline 81.00 & -0.71 & 80.29 & 16.93 \\
\hline 100.00 & -0.71 & 99.29 & 20.00 \\
\hline 0.00 & 0 & 0.00 & 4.01 \\
\hline 21.00 & -0.71 & 20.29 & 7.28 \\
\hline 41.00 & -0.71 & 40.29 & 10.49 \\
\hline 61.00 & -0.71 & 60.29 & 13.71 \\
\hline 81.00 & -0.71 & 80.29 & 16.93 \\
\hline 100.00 & -0.71 & 99.29 & 20.00 \\
\hline 0.00 & 0 & 0.00 & 4.01 \\
\hline 21.00 & -0.71 & 20.29 & 7.28 \\
\hline 41.00 & -0.71 & 40.29 & 10.49 \\
\hline 61.00 & -0.71 & 60.29 & 13.71 \\
\hline 81.00 & -0.71 & 80.29 & 16.94 \\
\hline 100.00 & -0.71 & 99.29 & 20.00 \\
\hline 0.00 & 0 & 0.00 & 4.01 \\
\hline 21.00 & -0.71 & 20.29 & 7.28 \\
\hline 41.00 & -0.71 & 40.29 & 10.49 \\
\hline 61.00 & -0.71 & 60.29 & 13.71 \\
\hline 81.00 & -0.71 & 80.29 & 16.94 \\
\hline 100.00 & -0.71 & 99.29 & 20.00 \\
\hline
\end{tabular}

TR-2917

Standard Uncertainties: Multimeter: $+1-1$ Dead Weight Tester: $+1-$

Statistical Info:

$\begin{array}{cccccccc}a & b & n & T & p s i g & p^{2} i^{2} & \text { mADC }^{2} & \text { mADC } \\ 4.0083 & 0.1610 & 24.00 & 2.07 & 50.08 & 27719.23 & 0.0005 & 0.0000 .\end{array}$

\section{Calculated Uncertainties:}

$\begin{array}{cc}\text { standard } & \text { curve-fit } \\ \text { psig } & \text { psig } \\ 0.11 & 0.07\end{array}$

Accepted Tolerance: +/- curve-fit fixed

Total Uncertainty

psig

0.13 cal. date:

$\begin{array}{ccc}\begin{array}{c}\text { Curve } \\ \text { Fit } \\ \text { (mADC) }\end{array} & \begin{array}{c}\text { Error } \\ \text { (mADC) }\end{array} & \begin{array}{c}\text { Error } \\ \text { (psig) }\end{array} \\ 4.01 & -0.002 & -0.01 \\ 7.28 & -0.005 & -0.03 \\ 10.50 & 0.005 & 0.03 \\ 13.72 & 0.006 & 0.03 \\ 16.94 & 0.006 & 0.04 \\ 19.99 & -0.005 & -0.03 \\ 4.01 & -0.002 & -0.01 \\ 7.28 & -0.005 & -0.03 \\ 10.50 & 0.005 & 0.03 \\ 13.72 & 0.006 & 0.03 \\ 16.94 & 0.006 & 0.04 \\ 19.99 & -0.005 & -0.03 \\ 4.01 & -0.002 & -0.01 \\ 7.28 & -0.005 & -0.03 \\ 10.50 & 0.005 & 0.03 \\ 13.72 & 0.006 & 0.03 \\ 16.94 & -0.004 & -0.03 \\ 19.99 & -0.005 & -0.03 \\ 4.01 & -0.002 & -0.01 \\ 7.28 & -0.005 & -0.03 \\ 10.50 & 0.005 & 0.03 \\ 13.72 & 0.006 & 0.03 \\ 16.94 & -0.004 & -0.03 \\ 19.99 & -0.005 & -0.03\end{array}$

Xbar
psig
50.08

fixed
psig
0.00

Xbar
psig
50.08


fixed
psig
0.00

page of _

Error

$-0.01$

0.03

0.03

$-0.03$

$-0.03$

0.03

0.04

$-0.03$

$-0.03$

0.03

$-0.03$

$-0.03$

$-0.03$

0.03

$-0.03$

mADC)

$0.1 \quad$ psig

psig

PASS CALIBRATION? YES TRANSFER EQUATION PSIG = 
UNCERTAINTY ANALYSIS

REF. WSRC-TR-91-106, REV. 0
TR-3109

Calibration Data

$\begin{array}{cccc}\begin{array}{c}\text { Nominal } \\ \text { Pressure } \\ \text { (psid) }\end{array} & \begin{array}{c}\text { Correction } \\ \text { (psid) }\end{array} & \begin{array}{c}\text { Applied } \\ \text { Pressure } \\ \text { (psid) }\end{array} & \begin{array}{c}\text { Gage } \\ \text { Reading } \\ \text { (mADC) }\end{array} \\ -11.00 & 0.71 & -10.29 & 4.01 \\ 0.00 & 0 & 0.00 & 5.65 \\ 11.00 & -0.71 & 10.29 & 7.28 \\ 31.00 & -0.71 & 30.29 & 10.46 \\ 51.00 & -0.71 & 50.29 & 13.63 \\ 71.00 & -0.71 & 70.29 & 16.81 \\ 91.00 & -0.71 & 90.29 & 20.00 \\ -11.00 & 0.71 & -10.29 & 4.01 \\ 0.00 & 0 & 0.00 & 5.65 \\ 11.00 & -0.71 & 10.29 & 7.28 \\ 31.00 & -0.71 & 30.29 & 10.46 \\ 51.00 & -0.71 & 50.29 & 13.63 \\ 71.00 & -0.71 & 70.29 & 16.81 \\ 91.00 & -0.71 & 90.29 & 20.00 \\ -11.00 & 0.71 & -10.29 & 4.01 \\ 0.00 & 0 & 0.00 & 5.65 \\ 11.00 & -0.71 & 10.29 & 7.28 \\ 31.00 & -0.71 & 30.29 & 10.46 \\ 51.00 & -0.71 & 50.29 & 13.63 \\ 71.00 & -0.71 & 70.29 & 16.81 \\ 91.00 & -0.71 & 90.29 & 20.00 \\ -11.00 & 0.71 & -10.29 & 4.01 \\ 0.00 & 0 & 0.00 & 5.65 \\ 11.00 & -0.71 & 10.29 & 7.28 \\ 31.00 & -0.71 & 30.29 & 10.46 \\ 51.00 & -0.71 & 50.29 & 13.63 \\ 71.00 & -0.71 & 70.29 & 16.81 \\ 91.00 & -0.71 & 90.29 & 20.01\end{array}$

cal. date:

\author{
page__of
}

$\begin{array}{ccc}\begin{array}{c}\text { Curve } \\ \text { Fit } \\ \text { (mADC) }\end{array} & \begin{array}{c}\text { Error } \\ \text { (mADC) }\end{array} & \begin{array}{c}\text { Error } \\ \text { (psid) }\end{array} \\ 4.01 & 0.000 & 0.00 \\ 5.65 & -0.005 & -0.03 \\ 7.28 & 0.001 & 0.00 \\ 10.46 & -0.001 & -0.01 \\ 13.64 & 0.007 & 0.05 \\ 16.82 & 0.006 & 0.04 \\ 19.99 & -0.006 & -0.04 \\ 4.01 & 0.000 & 0.00 \\ 5.65 & -0.005 & -0.03 \\ 7.28 & 0.001 & 0.00 \\ 10.46 & -0.001 & -0.01 \\ 13.64 & 0.007 & 0.05 \\ 16.82 & 0.006 & 0.04 \\ 19.99 & -0.006 & -0.04 \\ 4.01 & 0.000 & 0.00 \\ 5.65 & -0.005 & -0.03 \\ 7.28 & 0.001 & 0.00 \\ 10.46 & -0.001 & -0.01 \\ 13.64 & 0.007 & 0.05 \\ 16.82 & 0.006 & 0.04 \\ 19.99 & -0.006 & -0.04 \\ 4.01 & 0.000 & 0.00 \\ 5.65 & -0.005 & -0.03 \\ 7.28 & 0.001 & 0.00 \\ 10.46 & -0.001 & -0.01 \\ 13.64 & 0.007 & 0.05 \\ 16.82 & 0.006 & 0.04 \\ 19.99 & -0.016 & -0.10\end{array}$

Standard Uncertainties:

Statistical Info:$$
\text { a }
$$

5.6454

Multimeter: $+/-$ ( Dead Weight Tester: +1

0.04

0.01

Xbar

psid

34.45

2.12

28.00

Calculated Uncertainties: standard

psid

psid
0.05

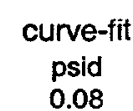

Accepted Tolerance: +/-
fixed
psid
0.00

$\%$ RDG $+\quad 0.0001 \quad$ mADC) psid

\begin{tabular}{|c|c|c|}
\hline$\underset{\text { psid }}{\text { Sxx }}$ & $\begin{array}{c}\text { SEE } \\
\text { mADC }\end{array}$ & $\begin{array}{l}\text { MSE } \\
\text { MADC }\end{array}$ \\
\hline 33771.99 & 0.0008 & 0.0000 \\
\hline
\end{tabular}

\section{PASS CALIBRATION? YES}

TRANSFER EQUATION: $\quad$ PSIG $=\quad 6.293 \quad{ }^{*} \mathrm{~mA} \cdot-35.524$

Figure F9. Pre-test Calibration Data of Gauge Pressure Transducer P2 
UNCERTAINTY ANALYSIS

REF. WSRC-TR-91-106, REV. 0

\begin{tabular}{|c|c|c|}
\hline \multicolumn{3}{|c|}{ Calibration Data } \\
\hline Nominal & Applied & Gage \\
\hline $\begin{array}{l}\text { Pressure } \\
\text { (psig) }\end{array}$ & $\begin{array}{c}\text { Pressure } \\
\text { (psig) }\end{array}$ & $\begin{array}{l}\text { Reading } \\
\text { (mADC) }\end{array}$ \\
\hline 0.00 & 0.00 & 4.01 \\
\hline 31.00 & 31.00 & 7.28 \\
\hline 61.00 & 61.00 & 10.44 \\
\hline 91.00 & 91.00 & 13.61 \\
\hline 121.00 & .121 .00 & 16.80 \\
\hline 151.00 & 151.00 & 20.01 \\
\hline 0.00 & 0.00 & 4.01 \\
\hline 31.00 & 31.00 & 7.28 \\
\hline 61.00 & 61.00 & 10.44 \\
\hline 91.00 & 91.00 & 13.61 \\
\hline 121.00 & 121.00 & 16.80 \\
\hline 151.00 & 151.00 & 20.01 \\
\hline 0.00 & 0.00 & 4.01 \\
\hline 31.00 & 31.00 & 7.28 \\
\hline 61.00 & 61.00 & 10.44 \\
\hline 91.00 & 91.00 & 13.61 \\
\hline 121.00 & 121.00 & 16.80 \\
\hline 151.00 & 151.00 & 20.01 \\
\hline 0.00 & 0.00 & 4.01 \\
\hline 31.00 & 31.00 & 7.28 \\
\hline 61.00 & 61.00 & 10.44 \\
\hline 91.00 & 91.00 & 13.61 \\
\hline 121.00 & 121.00 & 16.80 \\
\hline 151.00 & 151.00 & 20.01 \\
\hline
\end{tabular}

TR-2145

$\begin{array}{ccc}\begin{array}{c}\text { Curve } \\ \text { Fit } \\ \text { (mADC) }\end{array} & \begin{array}{c}\text { Error } \\ \text { (mADC) }\end{array} & \begin{array}{c}\text { Error } \\ \text { (psig) }\end{array} \\ 3.99 & -0.016 & -0.15 \\ 7.28 & -0.003 & -0.03 \\ 10.45 & 0.014 & 0.13 \\ 13.63 & 0.021 & 0.20 \\ 16.81 & 0.008 & 0.08 \\ 19.99 & -0.025 & -0.23 \\ 3.99 & -0.016 & -0.15 \\ 7.28 & -0.003 & -0.03 \\ 10.45 & 0.014 & 0.13 \\ 13.63 & 0.021 & 0.20 \\ 16.81 & 0.008 & 0.08 \\ 19.99 & -0.025 & -0.23 \\ 3.99 & -0.016 & -0.15 \\ 7.28 & -0.003 & -0.03 \\ 10.45 & 0.014 & 0.13 \\ 13.63 & 0.021 & 0.20 \\ 16.81 & 0.008 & 0.08 \\ 19.99 & -0.025 & -0.23 \\ 3.99 & -0.016 & -0.15 \\ 7.28 & -0.003 & -0.03 \\ 10.45 & 0.014 & 0.13 \\ 13.63 & 0.021 & 0.20 \\ 16.81 & 0.008 & 0.08 \\ 19.99 & -0.025 & -0.23\end{array}$

\author{
cal. date;
}

page__of
Standard Uncertainties:

\section{Multimeter: $+/-($ Dead Weight Tester: $+/-$}

0.04
0.1

Xbar

psig

75.83

24.00

2.07

3.9939

0.1059

Calculated Uncertainties: standard psig

0.13

curve-fit
psig
0.35

Accepted Tolerance: +/-

3

$$
\% \mathrm{RDG}+\quad 0.0001 \quad \mathrm{mADC})
$$

psig

$\begin{array}{ccc}\text { Sxx } & \text { SEE } & \text { MSE } \\ \text { psig2 } & \text { mADC2 } & \text { mADC2 } \\ 63603.33 & 0.0063 & 0.0003\end{array}$

\section{Total Uncertainty}

psig

0.38

PASS CALIBRATION? YES

$\begin{array}{lllll}\text { TRANSFER EQUATION } & \text { PSIG }= & 9.442 & { }^{*} \mathrm{~mA} & \mathbf{- 3 7 . 7 1 2}\end{array}$

Figure F10. Pre-test Calibration Data of Gauge Pressure Transducer P3 
UNCERTAINTY ANALYSIS

REF. WSRC-TR-91-106, REV. 0

Calibration Data

\begin{tabular}{|c|c|c|}
\hline $\begin{array}{c}\text { Nominal } \\
\text { Pressure } \\
\text { (psid) }\end{array}$ & $\begin{array}{l}\text { Applied } \\
\text { Pressure } \\
\text { (psid) }\end{array}$ & $\begin{array}{l}\text { Gage } \\
\text { Readin } \\
\text { (mADC }\end{array}$ \\
\hline 0.00 & 0.00 & 4.00 \\
\hline 1.00 & 1.00 & 4.61 \\
\hline 6.00 & 6.00 & 7.69 \\
\hline 11.00 & 11.00 & 10.76 \\
\hline 16.00 & 16.00 & 13.84 \\
\hline 21.00 & 21.00 & 16.92 \\
\hline 26.00 & 26.00 & 20.00 \\
\hline 0.00 & 0.00 & 4.00 \\
\hline 1.00 & 1.00 & 4.61 \\
\hline 6.00 & 6.00 & 7.69 \\
\hline 11.00 & 11.00 & 10.76 \\
\hline 16.00 & 16.00 & 13.84 \\
\hline 21.00 & 21.00 & 16.92 \\
\hline 26.00 & 26.00 & 20.00 \\
\hline 0.00 & 0.00 & 4.00 \\
\hline 1.00 & 1.00 & 4.61 \\
\hline 6.00 & 6.00 & 7.69 \\
\hline 11.00 & 11.00 & 10.76 \\
\hline 16.00 & 16.00 & 13.84 \\
\hline 21.00 & 21.00 & 16.92 \\
\hline 26.00 & 26.00 & 20.00 \\
\hline 0.00 & 0.00 & 4.00 \\
\hline $1: 00$ & 1.00 & 4.61 \\
\hline 6.00 & 6.00 & 7.69 \\
\hline 11.00 & 11.00 & 10.76 \\
\hline $\begin{array}{l}16.00 \\
21.00\end{array}$ & $\begin{array}{l}16.00 \\
21.00\end{array}$ & $\begin{array}{l}13.84 \\
16.92\end{array}$ \\
\hline & & (6) \\
\hline
\end{tabular}

TR-3495

$\begin{array}{ccc}\begin{array}{c}\text { Curve } \\ \text { Fit } \\ \text { (mADC) }\end{array} & \begin{array}{c}\text { Error } \\ \text { (mADC) }\end{array} & \begin{array}{c}\text { Error } \\ \text { (psid) }\end{array} \\ 4.00 & -0.004 & -0.01 \\ 4.61 & 0.001 & 0.00 \\ 7.69 & -0.002 & 0.00 \\ 10.77 & 0.005 & 0.01 \\ 13.84 & 0.003 & 0.00 \\ 16.92 & 0.000 & 0.00 \\ 20.00 & -0.003 & -0.01 \\ 4.00 & -0.004 & -0.01 \\ 4.61 & 0.001 & 0.00 \\ 7.69 & -0.002 & 0.00 \\ 10.77 & 0.005 & 0.01 \\ 13.84 & 0.003 & 0.00 \\ 16.92 & 0.000 & 0.00 \\ 20.00 & -0.003 & -0.01 \\ 4.00 & -0.004 & -0.01 \\ 4.61 & 0.001 & 0.00 \\ 7.69 & -0.002 & 0.00 \\ 10.77 & 0.005 & 0.01 \\ 13.84 & 0.003 & 0.00 \\ 16.92 & 0.000 & 0.00 \\ 20.00 & -0.003 & -0.01 \\ 4.00 & -0.004 & -0.01 \\ 4.61 & 0.001 & 0.00 \\ 7.69 & -0.002 & 0.00 \\ 10.77 & 0.005 & 0.01 \\ 13.84 & 0.003 & 0.00 \\ 16.92 & 0.000 & 0.00 \\ 20.00 & -0.003 & -0.01\end{array}$

cal. date:<smiles>[R6][18O][GeH2]</smiles>

Standard Uncertainties:

Multimeter: $+1-($

0.04 Dead Weight Tester: $+/$ -

0.01

$\%$ RDG +

psid

$\begin{array}{cccc}\text { Xbar } & \text { Sxx } & \text { SEE } & \text { MSE } \\ \text { psid } & \text { psid }^{c} & \text { mADC } & \text { mADC }\end{array}$

Statistical Info:

$a$
3.9959

Calculated Uncertainties: standard

psid

0.017

6154

$\stackrel{n}{n}$

$\stackrel{T}{2.06}$

11.57

2374.86

curve-fit
psid
0.011

fixed

psid

0.000

0.500 psid

Accepted Tolerance: $+/-$

YES

PASS CALIBRATION? TRANSFER EQUATION: PSID =

$1.6249 \quad{ }^{*} \mathrm{~mA}$

$-6.4930$

Figure F11. Pre-test Calibration Data of Differential Pressure Transducer dP1 
Pilot scale X-flow: EnvA+ES Page 221 of 226

BNF-003-98-0221

Revision 0

UNCERTAINTY ANALYSIS

TR-532

REF. WSRC-TR-91-106, REV. 0

cal. date:

page__of ___

\begin{tabular}{|c|c|c|}
\hline \multicolumn{3}{|l|}{ Curve } \\
\hline Fit & Error & Error \\
\hline$(\mathrm{mADC})$ & $(m A D C)$ & (psid) \\
\hline 4.00 & -0.004 & -0.03 \\
\hline 7.32 & 0.002 & 0.01 \\
\hline 10.49 & -0.001 & 0.00 \\
\hline 13.66 & 0.007 & 0.04 \\
\hline 16.82 & 0.005 & 0.03 \\
\hline 19.99 & -0.008 & -0.05 \\
\hline 4.00 & -0.004 & -0.03 \\
\hline 7.32 & 0.002 & 0.01 \\
\hline 10.49 & -0.001 & 0.00 \\
\hline 13.66 & 0.007 & 0.04 \\
\hline 16.82 & 0.005 & 0.03 \\
\hline 19.99 & -0.008 & -0.05 \\
\hline 4.00 & -0.004 & -0.03 \\
\hline 7.32 & 0.002 & 0.01 \\
\hline 10.49 & -0.001 & 0.00 \\
\hline 13.66 & 0.007 & 0.04 \\
\hline 16.82 & 0.005 & 0.03 \\
\hline 19.99 & -0.008 & -0.05 \\
\hline 4.00 & -0.004 & -0.03 \\
\hline 7.32 & 0.002 & 0.01 \\
\hline 10.49 & -0.001 & 0.00 \\
\hline 13.66 & 0.007 & 0.04 \\
\hline 16.82 & 0.005 & 0.03 \\
\hline 19.99 & -0.008 & -0.05 \\
\hline
\end{tabular}

Calibration Data

$\begin{array}{ccc}\begin{array}{c}\text { Nominal } \\ \text { Pressure } \\ \text { (psid) }\end{array} & \begin{array}{c}\text { Applied } \\ \text { Pressure } \\ \text { (psid) }\end{array} & \begin{array}{c}\text { Gage } \\ \text { Reading } \\ \text { (mADC) }\end{array} \\ 0.00 & 0.00 & 4.00 \\ 21.00 & 21.00 & 7.32 \\ 41.00 & 41.00 & 10.49 \\ 61.00 & 61.00 & 13.65 \\ 81.00 & 81.00 & 16.82 \\ 101.00 & 101.00 & 20.00 \\ 0.00 & 0.00 & 4.00 \\ 21.00 & 21.00 & 7.32 \\ 41.00 & 41.00 & 10.49 \\ 61.00 & 61.00 & 13.65 \\ 81.00 & 81.00 & 16.82 \\ 101.00 & 101.00 & 20.00 \\ 0.00 & 0.00 & 4.00 \\ 21.00 & 21.00 & 7.32 \\ 41.00 & 41.00 & 10.49 \\ 61.00 & 61.00 & 13.65 \\ 81.00 & 81.00 & 16.82 \\ 101.00 & 101.00 & 20.00 \\ 0.00 & 0.00 & 4.00 \\ 21.00 & 21.00 & 7.32 \\ 41.00 & 41.00 & 10.49 \\ 61.00 & 61.00 & 13.65 \\ 81.00 & 81.00 & 16.82 \\ 101.00 & 101.00 & 20.00\end{array}$

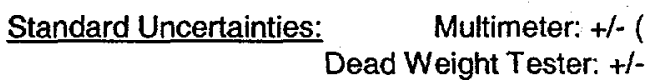

$0.04 \quad \% R D G+\quad 0.0001 \quad$ mADC)

$0.1 \quad$ psig

Statistical info:

\begin{tabular}{ccc}
$a$ & $b$ & $n$ \\
3.9956 & 0.1584 & 24.00 \\
& \\
Calculated & \\
\hline standard & \\
psid & curve-fit \\
0.11 & psid \\
& & 0.07
\end{tabular}

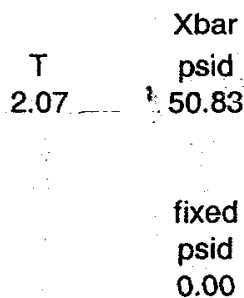

Sxx

psid $^{2}$

28403.33

SEE

$\mathrm{MADC}^{2}$

0.0006

MSE

$\mathrm{MADC}^{2}$

0.0000

Accepted Tolerance: $+/-$

2 psid

PASS CALIBRATION? YES

TRANSFER EQUATION: PSID =

$6.314 \quad{ }^{*} \mathrm{~mA} \quad-25.227$

Figure F12. Pre-test Calibration Data of Differential Pressure Transducer dP2 
UNCERTAINTY ANALYSIS

REF. WSRC-TR-91-106, REV. 0

Calibration Data

\begin{tabular}{|c|c|}
\hline \multicolumn{2}{|l|}{ Nominal } \\
\hline $\begin{array}{c}\text { Pressure } \\
\text { (psid) }\end{array}$ & $\begin{array}{c}\text { Correction } \\
\text { (psid) }\end{array}$ \\
\hline-11.00 & 0.71 \\
\hline 0.00 & 0 \\
\hline 21.00 & -0.71 \\
\hline 41.00 & -0.71 \\
\hline 61.00 & -0.71 \\
\hline 81.00 & -0.71 \\
\hline 101.00 & -0.71 \\
\hline-11.00 & 0.71 \\
\hline 0.00 & 0 \\
\hline 21.00 & -0.71 \\
\hline 41.00 & -0.71 \\
\hline 61.00 & -0.71 \\
\hline 81.00 & -0.71 \\
\hline 101.00 & -0.71 \\
\hline-11.00 & 0.71 \\
\hline 0.00 & $\mathbf{0}$ \\
\hline 21.00 & -0.71 . \\
\hline 41.00 & -0.71 \\
\hline 61.00 & -0.71 \\
\hline 81.00 & -0.71 \\
\hline 101.00 & -0.71 \\
\hline-11.00 & 0.71 \\
\hline 0.00 & 0 \\
\hline 21.00 & -0.71 \\
\hline 41.00 & -0.71 \\
\hline 61.00 & -0.71 \\
\hline 81.00 & -0.71 \\
\hline 101.00 & -0.71 \\
\hline
\end{tabular}

Applied

Pressure Reading

(psid) (mADC)

$-10.29$

0.00

20.29

40.29

60.29

80.29

100.29

$-10.29$

0.00

20.29

40.29

60.29

80.29

100.29

$-10.29$

0.00

20.29

40.29

60.29

80.29

100.29

$-10.29$

0.00

20.29

40.29

60.29

80.29

100.29

3.99

5.48

8.43

11.34

14.24

17.13

20.01

3.99

5.48

8.43

11.34

14.24

17.13

20.01

3.99

5.48

8.43

11.34

14.24

17.13

20.01

3.99

5.48

8.43

11.34

14.24

17.13

20.01
TR-3115

pagl. date:
cal

page__of
Standard Uncertainties:

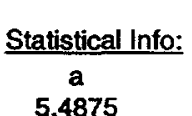

$b$
0.1450
Calculated Uncertainties: standard

psid

0.11

Accepted Tolerance: +/-
Multimeter: $+/-($ Dead Weight Tester: $+f-$

\begin{tabular}{|c|c|c|c|c|c|}
\hline \multicolumn{2}{|c|}{$\begin{array}{r}\text { Multimeter: }+/-( \\
\text { Dead Weight Tester: }+\delta \text { - }\end{array}$} & $\begin{array}{c}0.04 \\
0.1\end{array}$ & $\begin{array}{l}\text { \% RDG + } \\
\text { psid }\end{array}$ & 0.0001 & $\mathrm{mADC})$ \\
\hline $\begin{array}{c}n \\
28.00\end{array}$ & $\begin{array}{c}\mathrm{T} \\
2.12\end{array}$ & $\begin{array}{c}\text { Xbar } \\
\text { psid } \\
41.59\end{array}$ & $\begin{array}{c}\text { Sxx } \\
\text { psid } \\
40678.85\end{array}$ & $\begin{array}{c}\text { SEE } \\
\text { mADC } \\
0.0026\end{array}$ & $\begin{array}{c}\text { MSE } \\
\text { mADC } \\
0.0001\end{array}$ \\
\hline $\begin{array}{l}\text { curve-fit } \\
\text { psid } \\
0.16\end{array}$ & & $\begin{array}{l}\text { fixed } \\
\text { psid } \\
0.00\end{array}$ & & $\begin{array}{c}\text { Total Uncert } \\
\text { psid } \\
0.19\end{array}$ & \\
\hline
\end{tabular}

PASS CALIBRATION? 2 psid

YES

$$
\text { PSID = }
$$

6.898

*mA

Figure F13. Pre-test Calibration Data of Differential Pressure Transducer dP3 
UNCERTAINTY ANALYSIS

REF. WSRC-TR-91-106

\begin{tabular}{|c|c|c|c|}
\hline \multirow{3}{*}{$\begin{array}{l}\text { Meter } \\
\text { Output } \\
\text { (mA) }\end{array}$} & \multicolumn{3}{|c|}{ Calibration Data } \\
\hline & Water & Water & Time \\
\hline & $\begin{array}{l}\text { Temp } \\
\text { (C) }\end{array}$ & $\begin{array}{l}\text { Weight } \\
\text { (lbs) }\end{array}$ & $\begin{array}{l}\text { Duration } \\
\text { (min) }\end{array}$ \\
\hline 3.977 & 21.40 & 0 & 0.50 \\
\hline 7.115 & 21.40 & 1228 & 15.00 \\
\hline 10.434 & 21.80 & 1682 & 10.01 \\
\hline 13.535 & 22.00 & 1246 & 5.00 \\
\hline 16.807 & 22.00 & 1679 & 5.01 \\
\hline 19.889 & 21.50 & 2078 & 5.00 \\
\hline 19.887 & 21.40 & 2079 & 5.00 \\
\hline 16.740 & 21.00 & 1664 & 5.00 \\
\hline 13.594 & 20.90 & 1254 & 5.00 \\
\hline 10.325 & 20.80 & 1652 & 10.00 \\
\hline 7.194 & 20.70 & 1257 & 15.01 \\
\hline 3.978 & 20.70 & 0 & 0.50 \\
\hline 7.216 & 20.80 & 1264 & 15.00 \\
\hline 10.379 & 21.30 & 1669 & 10.01 \\
\hline 13.628 & 21.90 & 1258 & 5.00 \\
\hline 16.724 & 21.70 & 1663 & 5.00 \\
\hline 19.813 & 20.90 & 2070 & 5.00 \\
\hline 3.979 & 20.90 & 0 & 0.50 \\
\hline
\end{tabular}

TR-20350

\begin{tabular}{|c|c|c|c|c|}
\hline & & calibratio & $\begin{array}{l}\text { page } \\
\text { on date }\end{array}$ & - of \\
\hline & Calcu & ated $\mathrm{D}$ & ata & \\
\hline Mass & Water & Volume & Volume & Curve Fit \\
\hline $\begin{array}{l}\text { Flow } \\
\text { (lbs/min) }\end{array}$ & $\begin{array}{l}\text { Density } \\
(\mathrm{lb} / \mathrm{t} \wedge 3)\end{array}$ & $\begin{array}{l}\text { Flow } \\
\left(\mathrm{ft}^{\wedge} 3 / \mathrm{min}\right)\end{array}$ & $\begin{array}{l}\text { Flow } \\
\text { (GPM) }\end{array}$ & $\begin{array}{l}\text { Ouput } \\
(\mathrm{mA})\end{array}$ \\
\hline 0.0 & 62.29 & 0.00 & 0.00 & 3.99 \\
\hline 81.9 & 62.28 & 1.31 & 9.83 & 7.12 \\
\hline 168.1 & 62.28 & 2.70 & 20.19 & 10.42 \\
\hline 249.0 & 62.28 & 4.00 & 29.91 & 13.52 \\
\hline 335.3 & 62.29 & 5.38 & 40.27 & 16.83 \\
\hline 415.5 & 62.29 & 6.67 & 49.90 & 19.90 \\
\hline 415.6 & 62.29 & 6.67 & 49.90 & 19.90 \\
\hline 332.6 & 62.30 & 5.34 & 39.94 & 16.72 \\
\hline 250.6 & 62.30 & 4.02 & 30.09 & 13.58 \\
\hline 165.2 & 62.30 & 2.65 & 19.83 & 10.31 \\
\hline 83.8 & 62.30 & 1.34 & 10.06 & 7.19 \\
\hline 0.0 & 62.30 & 0.00 & 0.00 & 3.99 \\
\hline 84.3 & 62.29 & 1.35 & 10.12 & 7.21 \\
\hline 166.8 & 62.29 & 2.68 & 20.03 & 10.37 \\
\hline 251.5 & 62.28 & 4.04 & 30.21 & 13.62 \\
\hline 332.6 & 62.29 & 5.34 & 39.95 & 16.72 \\
\hline 413.9 & 62.30 & 6.64 & 49.70 & 19.83 \\
\hline 0.0 & 62.30 & 0.00 & 0.00 & 3.99 \\
\hline
\end{tabular}

Density: $\square=62.441-1.374 E-3^{\star} T-271.818 E-6^{\star} T^{\wedge} 2+194.093 E-9^{\star} T^{\wedge} 3$ 7.4805 gallons $=1 \mathrm{ft}^{\wedge} 3$

Uncertainty of the Standards:

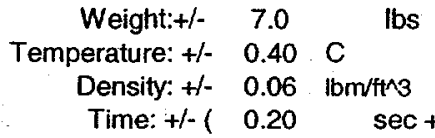

$500.00 \mathrm{nsec} / \mathrm{sec})$

Accepted Tolerance: $+/-\quad 0.50$ GPM

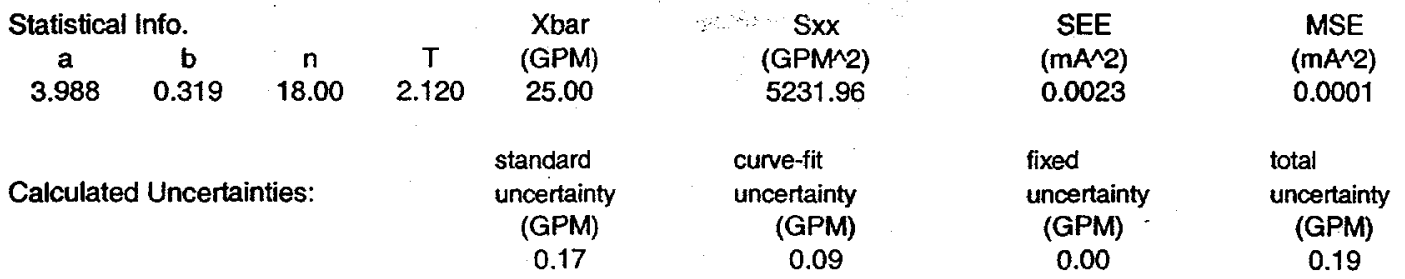

PASS CALIBRATION?

YES

TRANSFER EQUATION GPM $=3.137 \mathrm{~mA} \quad-12.509$

Figure F14. Pre-test Calibration Data of Magnetic Flowmeter Q1 
UNCERTAINTY ANALYSIS

REF. WSRC-TR-91-106

\section{Calibration Data}

\begin{tabular}{|c|c|c|c|}
\hline $\begin{array}{l}\text { Meter } \\
\text { Output } \\
(\mathrm{mA})\end{array}$ & $\begin{array}{l}\text { Water } \\
\text { Temp } \\
\text { (C) }\end{array}$ & $\begin{array}{l}\text { Water } \\
\text { Weight } \\
\text { (lbs) }\end{array}$ & $\begin{array}{l}\text { Time } \\
\text { Duration } \\
\text { (min) }\end{array}$ \\
\hline 4.00 & 15.50 & 0.00 & 0.00 \\
\hline 8.21 & 15.50 & 13.25 & 5.03 \\
\hline 12.18 & 16.30 & 25.48 & 5.00 \\
\hline 16.17 & 19.50 & 37.83 & 5.00 \\
\hline 20.18 & 22.50 & 50.38 & 5.00 \\
\hline 20.18 & 23.00 & 50.44 & 5.00 \\
\hline 16.12 & 23.10 & 37.94 & 5.01 \\
\hline 12.28 & 22.80 & 25.95 & 5.00 \\
\hline 8.09 & 22.90 & 12.83 & 5.00 \\
\hline 4.00 & 22.90 & 0.00 & 0.00 \\
\hline 4.00 & 22.90 & 0.00 & 0.00 \\
\hline 8.15 & 22.90 & 12.95 & 5.00 \\
\hline 12.02 & 23.00 & 25.12 & 5.00 \\
\hline 16.05 & 25.20 & 37.63 & 5.00 \\
\hline 20.05 & 25.20 & 49.98 & 5.00 \\
\hline
\end{tabular}

TR-20353

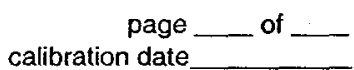

Calculated Data

\begin{tabular}{|c|c|c|c|c|c|c|}
\hline $\begin{array}{l}\text { Mass } \\
\text { Flow } \\
\text { (lbs/min) }\end{array}$ & $\begin{array}{l}\text { Water } \\
\text { Density } \\
\text { (ib/ti^3) }\end{array}$ & $\begin{array}{l}\text { Volume } \\
\text { Flow } \\
\text { (f^^ } 3 / \mathrm{min})\end{array}$ & $\begin{array}{l}\text { Volume } \\
\text { Flow } \\
\text { (GPM) }\end{array}$ & $\begin{array}{l}\text { Curve Fit } \\
\text { Ouput } \\
\text { (mA) }\end{array}$ & $\begin{array}{l}\text { Error } \\
(\mathrm{mA})\end{array}$ & $\begin{array}{l}\text { Error } \\
\text { (GPM }\end{array}$ \\
\hline 0.00 & 62.36 & 0.00 & 0.00 & 3.99 & -0.01 & -0.00 \\
\hline 2.64 & 62.36 & 0.04 & 0.32 & 8.21 & 0.01 & 0.000 \\
\hline 5.09 & 62.35 & 0.08 & 0.61 & 12.16 & -0.03 & -0.00 \\
\hline 7.56 & 62.31 & 0.12 & 0.91 & 16.13 & -0.04 & -0.00 \\
\hline 10.07 & 62.27 & 0.16 & 1.21 & 20.15 & -0.03 & -0.00 \\
\hline 10.08 & 62.27 & 0.16 & 1.21 & 20.18 & 0.00 & 0.000 \\
\hline 7.58 & 62.27 & 0.12 & 0.91 & 16.16 & 0.04 & 0.003 \\
\hline 5.19 & 62.27 & 0.08 & 0.62 & 12.31 & 0.04 & 0.003 \\
\hline 2.56 & 62.27 & 0.04 & 0.31 & 8.10 & 0.01 & 0.001 \\
\hline 0.00 & 62.27 & 0.00 & 0.00 & 3.99 & -0.01 & -0.00 \\
\hline 0.00 & 62.27 & 0.00 & 0.00 & 3.99 & -0.01 & -0.00 \\
\hline 2.59 & 62.27 & 0.04 & 0.31 & 8.14 & -0.01 & -0.00 \\
\hline 5.02 & 62.27 & 0.08 & 0.60 & 12.05 & 0.03 & 0.008 \\
\hline 7.52 & 62.24 & 0.12 & 0.90 & 16.07 & 0.03 & 0.002 \\
\hline 9.99 & 62.24 & 0.16 & 1.20 & 20.03 & -0.01 & -0.0 \\
\hline
\end{tabular}

Density: $\left[=62.441-1.374 E-3^{*} T-271.818 E-6^{*} T^{\wedge} 2+194.093 E-9^{*} T^{\wedge} 3\right.$

7.4805 gallons $=1 \mathrm{ft}^{\wedge} 3$

Uncertainty of the Standards:

$\begin{array}{cc}\text { Weight: }+\delta & 0.1 \\ \text { Temperature: }+/- & 0.40\end{array}$

Density: + - 0.06 ibm/tis

Time: $+1-(0.20 \quad \mathrm{sec}+$ lbs

$\sec +$

$500.00 \square \mathrm{sec} / \mathrm{sec})$

Accepted Tolerance: $+\gamma \quad 0.01$ GPM

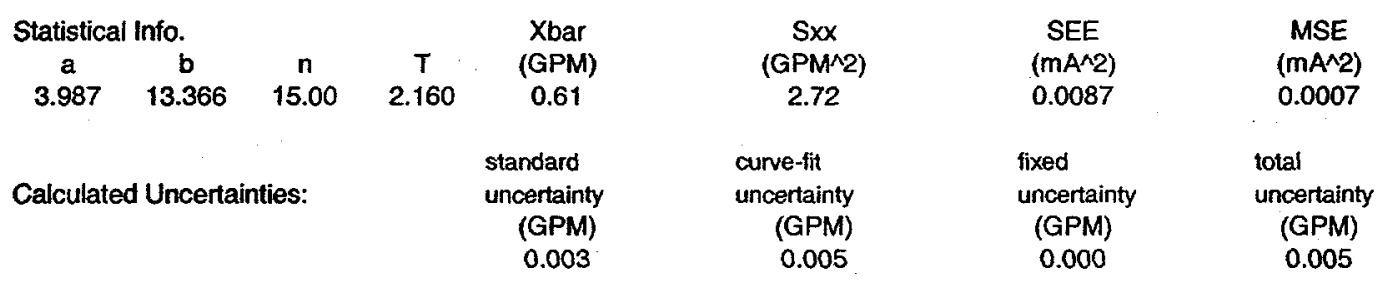

pASS CALIBRATION?

YES

TRANSFER EQUATION: $\quad$ GPM $=\begin{array}{lll}0.075 & \mathrm{~mA} & -0.298\end{array}$

Figure F15. Pre-test Calibration Data of Magnetic Flowmeter Q2 
UNCERTAINTY ANALYSIS REF. WSRC-TR-91-106

\section{Calibration Data}

\begin{tabular}{|c|c|c|c|}
\hline Meter & Water & Water & Time \\
\hline $\begin{array}{l}\text { Output } \\
(\mathrm{mA})\end{array}$ & $\begin{array}{l}\text { Temp } \\
\text { (C) }\end{array}$ & $\begin{array}{l}\text { Weight } \\
\text { (tos) }\end{array}$ & $\begin{array}{l}\text { Duration } \\
\text { (min) }\end{array}$ \\
\hline 3.97 & 24.60 & 0.00 & 0.00 \\
\hline 7.97 & 25.60 & 51.79 & 5.00 \\
\hline 11.96 & 25.20 & 103.40 & 5.00 \\
\hline 16.08 & 25.40 & 125.52 & 4.00 \\
\hline 19.98 & 25.70 & 124.58 & 3.00 \\
\hline 3.98 & 25.90 & 0.00 & 0.00 \\
\hline 8.01 & 25.90 & 52.35 & 5.00 \\
\hline 12.00 & 25.90 & 103.82 & 5.00 \\
\hline 15.97 & 25.90 & 124.28 & 4.00 \\
\hline 20.03 & 25.90 & 124.64 & 3.00 \\
\hline 3.98 & 25.70 & 0.00 & 0.00 \\
\hline 8.11 & 25.70 & 53.48 & 5.00 \\
\hline 12.04 & 25.80 & 1.04 .44 & 5.00 \\
\hline 15.99 & 25.80 & 124.75 & 4.01 \\
\hline 20.05 & 21.70 & 125.64 & 3.00 \\
\hline 3.98 & 23.00 & 0.00 & 0.00 \\
\hline 7.97 & 23.00 & 51.92 & 5.00 \\
\hline 11.96 & 22.90 & 103.69 & 5.00 \\
\hline 15.97 & 22.70 & 124.62 & 4.00 \\
\hline 19.92 & 22.70 & 124.36 & 3.00 \\
\hline
\end{tabular}

TR-3562

page
calibration date

Calculated Data

Mass
Flow
(lbs/min)
0.00
10.36
20.67
31.36
41.48
0.00
10.47
20.75
31.05
41.55
0.00
10.69
20.87
31.13
41.87
0.00
10.37
20.73
31.13
41.43

\begin{tabular}{|c|c|c|c|}
\hline 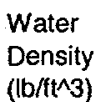 & $\begin{array}{l}\text { Volume } \\
\text { Flow } \\
\left.\text { (t } \mathrm{t}^{\wedge} 3 / \mathrm{min}\right)\end{array}$ & $\begin{array}{l}\text { Volume } \\
\text { Flow } \\
\text { (GPM) }\end{array}$ & $\begin{array}{l}\text { Curve Fit } \\
\text { Ouput } \\
\text { (mA) }\end{array}$ \\
\hline 62.25 & 0.00 & 0.00 & 3.98 \\
\hline 62.23 & 0.17 & 1.25 & 7.98 \\
\hline 62.24 & 0.33 & 2.48 & 11.95 \\
\hline 62.23 & 0.50 & 3.77 & 16.07 \\
\hline 62.23 & 0.67 & 4.99 & 19.98 \\
\hline 62.23 & 0.00 & 0.00 & 3.98 \\
\hline 62.23 & 0.17 & 1.26 & 8.02 \\
\hline 62.23 & 0.33 & 2.49 & 11.99 \\
\hline 62.23 & 0.50 & 3.73 & 15.96 \\
\hline 62.23 & 0.67 & 4.99 & 20.01 \\
\hline 62.23 & 0.00 & 0.00 & 3.98 \\
\hline 62.23 & 0.17 & 1.29 & 8.11 \\
\hline 62.23 & 0.34 & 2.51 & 12.03 \\
\hline 62.23 & 0.50 & 3.74 & 15.98 \\
\hline 62.29 & 0.67 & 5.03 & 20.11 \\
\hline 62.27 & 0.00 & 0.00 & 3.98 \\
\hline 62.27 & 0.17 & 1.25 & 7.98 \\
\hline 62.27 & 0.33 & 2.49 & 11.97 \\
\hline 62.27 & 0.50 & 3.74 & 15.98 \\
\hline 62.27 & 0.67 & 4.98 & 19.95 \\
\hline
\end{tabular}

Error (GPM)

$0.01 \quad 0.004$

$0.01 \quad 0.002$

$-0.01 \quad-0.002$

$\begin{array}{ll}-0.01 & -0.002\end{array}$

$0.00 \quad-0.001$

$0.00 \quad 0.001$

$0.01 \quad 0.003$

$-0.01 \cdot-0.004$

$-0.01 \quad-0.005$

$-0.02 \quad-0.008$

$0.00 \quad 0.001$

$0.00 \quad-0.001$

$-0.01 \quad-0.002$

$-0.01 \quad-0.004$

$0.06 \quad 0.020$

$0.00 \quad 0.001$

$0.01 \quad 0.003$

$0.01 \quad 0.004$

$0.01 \quad 0.003$

$0.03 \quad 0.009$

Density: $\left[=62.441-1.374 E-3^{*} T-271.818 E-6^{*} T \wedge 2+194.093 E-9^{*} T \wedge 3\right.$ 7.4805 galions $=1 \mathrm{f} \wedge$ 3

Uncertainty of the Standards:
Accepted Tolerance: $+/-\quad 0.05$ GPM

\begin{tabular}{|c|c|c|c|c|}
\hline $\mathrm{OA}$ & nfo. & & & Xbar \\
\hline $\begin{array}{c}a \\
3.982\end{array}$ & $\begin{array}{c}b \\
3.208\end{array}$ & $\begin{array}{c}n \\
15.00\end{array}$ & $\begin{array}{c}T \\
2.160\end{array}$ & $\begin{array}{c}\text { (GPM) } \\
2.50\end{array}$ \\
\hline
\end{tabular}

Calculated Uncertainties:

PASS CALIBRATION? TRANSFER EQUATION:

Weight:+t- $0.1 \quad$ lbs perature: $+1-0.40 \mathrm{C}$

Density: $+/-0.06 \quad$ bm/ $/ \mathrm{tt}^{\wedge} 3$

Time: + - $\left(\begin{array}{lll}0.20 \quad \mathrm{sec} \\ \mathrm{s}\end{array}\right.$

$500.00 \mathrm{usec} / \mathrm{sec})$ 


\section{DISTRIBUTION:}

D. B. Burns, 786-5A

J. J. Connelly, 773-41A

M. R. Duignan, 786-5A

M. A. Ebra, 773-42A

H. N. Guerrero, 786-5A

M. E. Johnson, BNFL, Inc., 3000 George Washington Way, Richland, WA 99352

C. A. Nash, 773-42A

L. M. Nelson, 773-43A

T. J. Steeper, 786-5A

J. L. Steimke, 786-5A

H. F. Sturm, 773-A

P. S. Townson, BNFL, Inc., 3000 George Washington Way, Richland, WA 99352

S. T. Wach, 773-42A

EESD Job File No. 22699, 730-A

BNFL File, 773-41A, Room 260

ETF File, 786-5A 